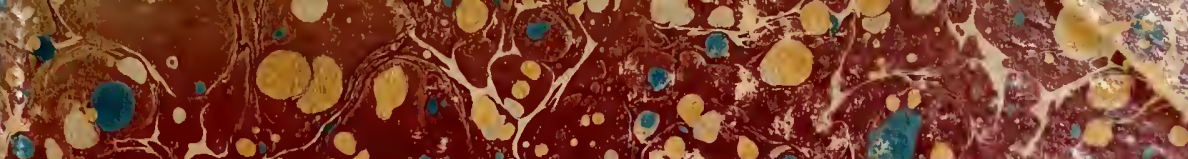

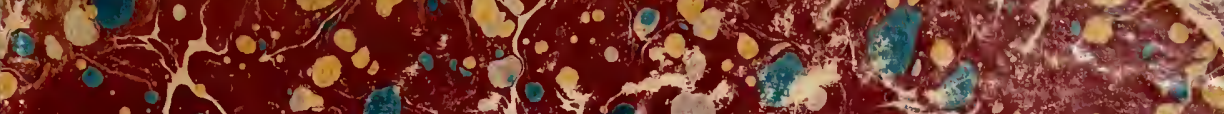
a. $5 \mathrm{x}^{2}$ -

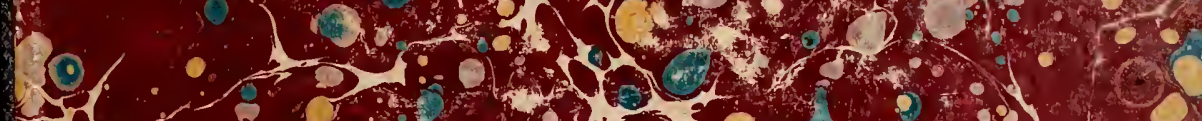

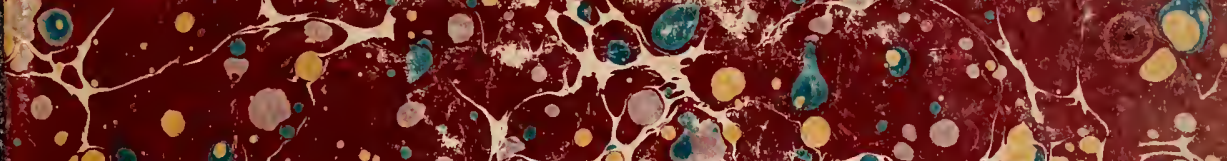

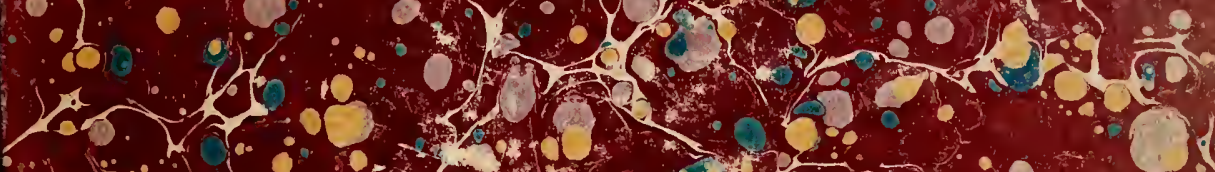

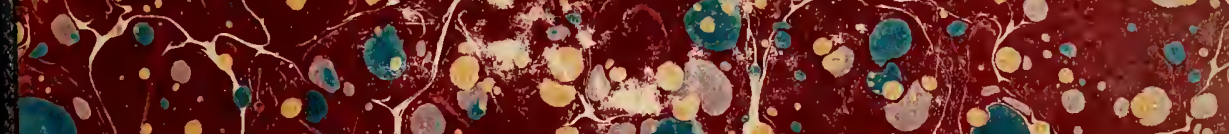
5,10000000 b8. - a. 0.0001000

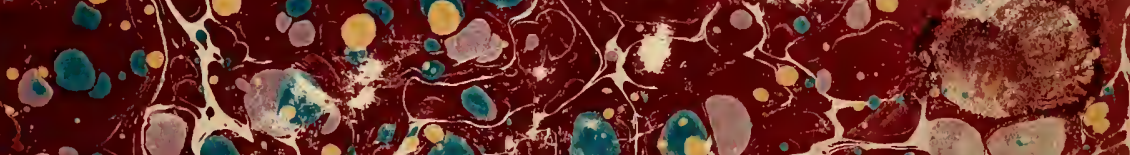

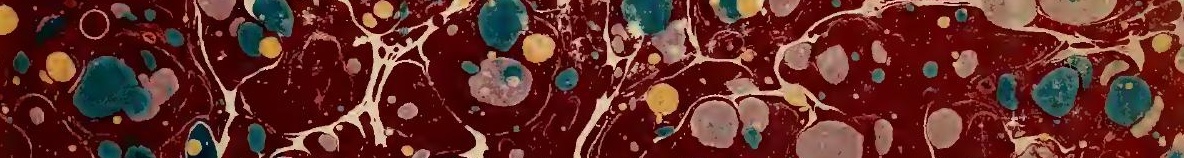
or.

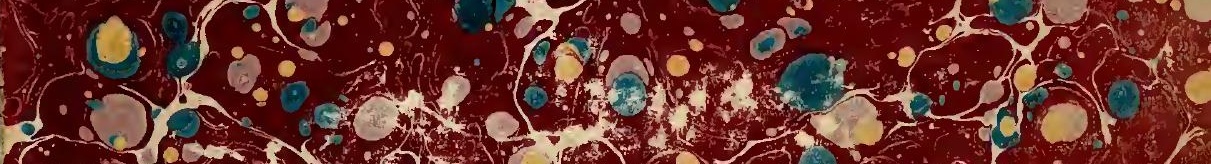

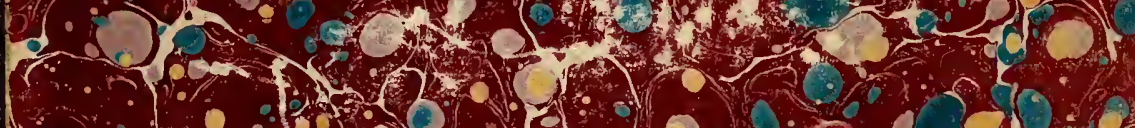

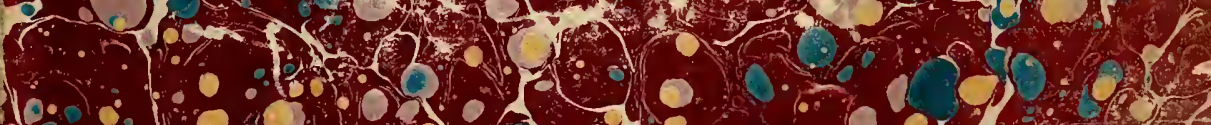

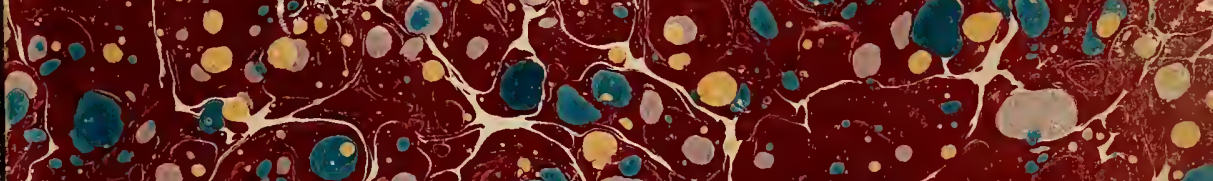

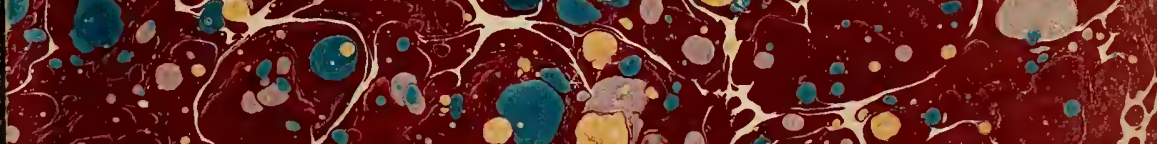

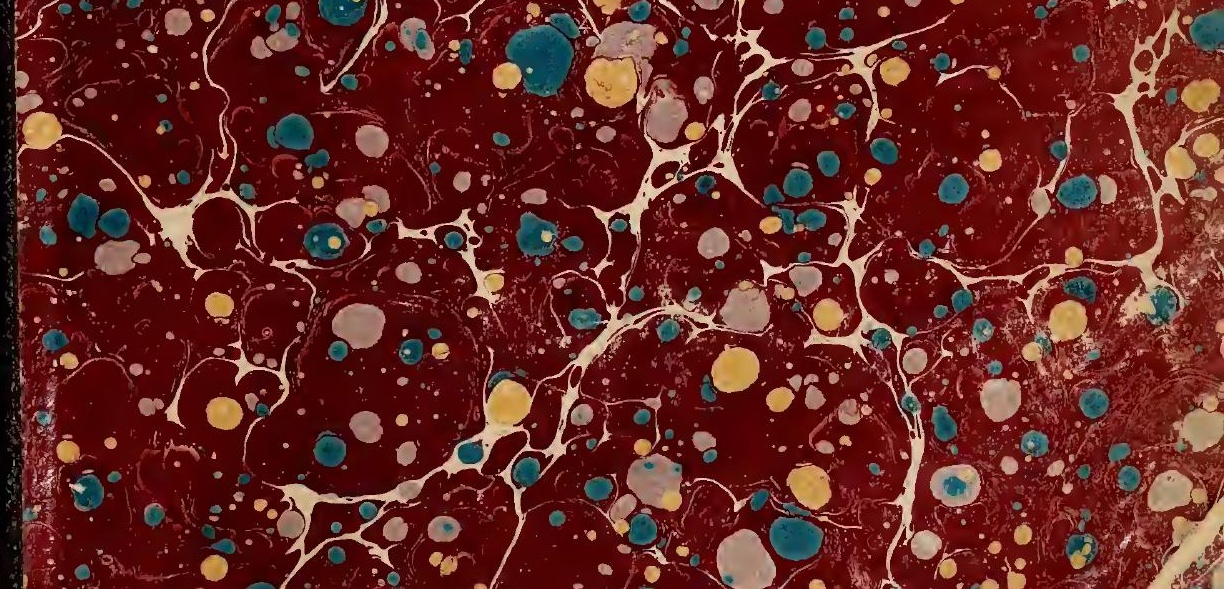




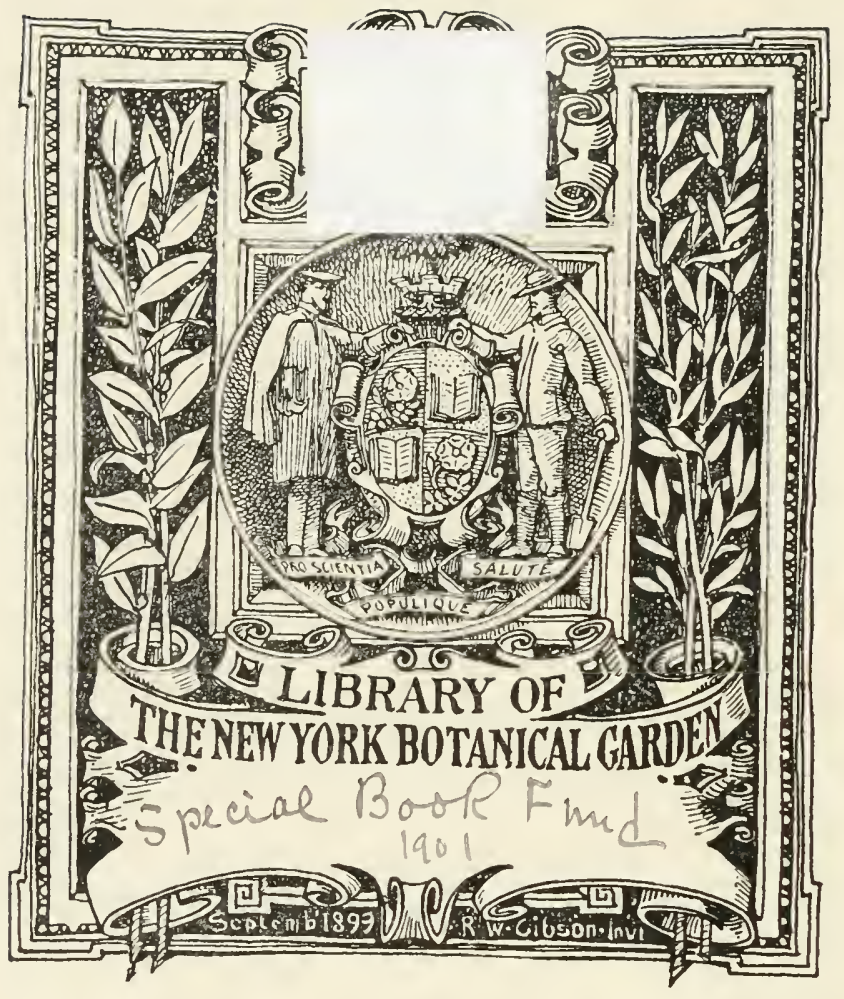









\title{
Botanische Mittheilungen
}

\section{aus den Tropen}

herausgegeben

Von

Dr. A. F. W. Schimper,

\author{
Heft 9. \\ Phycomyceten und Ascomyceten. \\ Von \\ Alfred Möller.
}

Mit 11 Tafeln und 2 Textabbildungen.

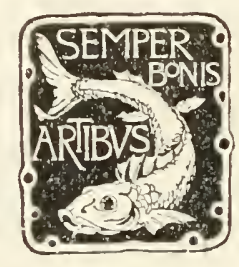

JENA.

VERLAG VON GUSTAY FISCHER. 1901. 


\title{
Phycomyceten und Ascomyceten.
}

\author{
Untersuchungen aus Brasilien
}

von

\section{Alfred Möller.}

Mit 11 Tafeln und 2 Textabbildungen.
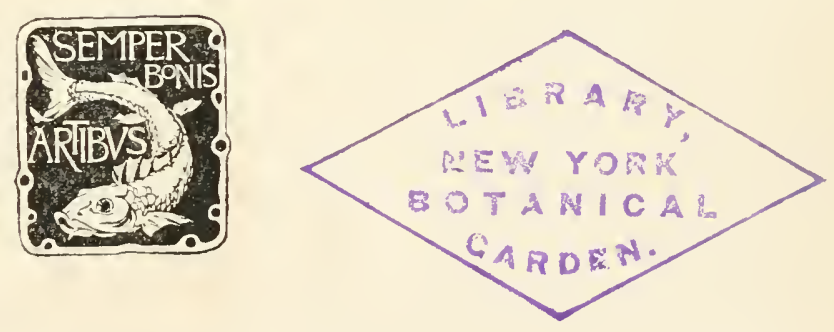

JENA.

VERLAG VON GUSTAV FISCHER.

1901. 



\section{Vorwort.}

Wenn die folgenden Mitheilungen sich von einigem Werthe für die Wissenschaft erweisen sollten, so gebührt der Dank dafür, dass sie überhaupt erscheinen konnten, in erster Linie meiner vorgesetzten Behörde, den Leitern der Preussischen Staats-Forstrerwaltung. Nachdem ich schon für die Jahre der Reise 1890-1893 aus dem Staatsdienste beurlaubt worden war, so wurde dieser Urlaub nach der Rückkelı aus Brasilien noch bis zum 1. April 1895 verlängert, um mir die Möglichkeit zur Veröffentlichung der Ergebnisse zu gewähren. In dieser Zeit konnte ich die beiden vorigen Hefte dieser Mittheilungen, die Pilzblumen und die Protobasidiomyceten, vollenden. Am 1. April 1895 wurde mir die Terwaltung der Oberförsterei Wörsdorf, Regierungsbezirk Wiesbaden. iibertragen, am 1. April 1896 diejenige der Oberförsterei Eberswalde im Regierungsbezirk Potsdam. Gleichzeitig mit der letzteren Stellung erhielt ich den Auftrag, an der hiesigen Forstakademie den I'nterricht in der Forstbenutzung und im Waldwegeban zu ertheilen. Die Arbeiten der Revierverwaltung und der neue Lehrauftrag beschäftigten mich so, dass ich zu weiterer Bearbeitung des noch in reicher Fülle vorliegenden Materials aus Brasilien nur wenig und mit langen Unterbrechungen Zeit gewinnen konnte. Waren auch im Lanfe der Jahre Einzeluntersuchungen, wie z. B. über Choane- 
phora, über Corallomyces Jatrophae und über Ascopolyporus abgeschlossen, so widerstrebte es mir doch, sie einzeln zu veröffentlichen, und sie blieben liegen, bis die günstige Veränderung dęr äusseren Verlältnisse mir ihre zusammenhängende Mittheilung ermöglichte.

In einem ausfühılichen Bericht an den Herrn Minister fïr Landwirthschaft, Domänen und Forsten hatte ich darzulegen versucht, dass die Schaffung einer mykologischen Arbeitsstätte, welche zunächst nicht sowohl dem Unterricht, als vielmehr der Forschung. zu dienen hätte, nach dem gegenwärtigen Stande der Wissenschaft auch für die preussische Forstverwaltung empfehlenswerth sein dürfte, da eine Fülle von Fragen in Bezug auf die Bedeutung der Pilze im Boden des Waldes, auf die mycorhizenbildenden Pilze, auf die Wurzellknöllchen der Akazie, endlich auch auf die den Waldbäumen als Parasiten schädlichen Pilze ein weites Arbeitsgebiet eröffne, an dessen Pflege die Forstverwaltung ein Interesse habe. Meine Darlegımgen fanden eine wohlwollende A ufnalıme. Se.Excellenz der Herr Oberlandforstmeister Donner und der Herr Landforstmeister Waechter nahmen sich des Planes an, und den Bemühungen beider Herren ist es vorzüglich zu danken, dass am 1. Juli 1899 eine mykologische Abtheilung bei der Hauptstation des forstlichen Versuchswesens in Eberswalde eingerichtet und mir übertragen wurde.

War num auch die Finleitung neuer Versuche und Beobachtungen im Rahmen des vorgezeichneten Arbeitsfeldes meine erste Pflicht, so durfte ich doch daneben die Tollendung der in Brasilien begonnenen Arbeiten ins Auge fassen. Das schon über nem Jahre lang zurückgehaltene, mit vielen Mühen und mit materieller Unterstiitzung der Königlichen Akademie der Wissenschatten gewomnene Naterial konnte num noch gerettet und nutzbar gemacht werden.

Ich gebe mich der Hofthumg hin. dass es mir in nicht zu ferner Zeit möglich sein wird, in einem weiteren Hefte dieser Mittheilungen 
über Beobachtungen an Basidiomyceten zu berichten, und damit die Darstellung meiner durch dreijährige Arbeit in Brasilien gewomnenen Ergebnisse zu vollenden.

Yon den 116 Figuren der beigegebenen ersten acht Tafeln verdanke ich nicht weniger als 25 , und wie man sich leicht überzeugen wird, die bei weitem schönsten der Güte und Sorgfalt meines verehrten Freundes, Herrn Rich. Volk zu Hamburg. Seine künstlerische Bethätigung in diesen Bildern verdient nicht weniger Bewunderung. als seine trene Gewissenhaftigkeit in der" Wiedergabe des sachkundig Brobachteten. Ohne seine Hülte wäre die Bearbeitung der so artenreich in meinen Sammlnngen vertretenen Gattung Cordyceps unmöglich gewesen und für diese Gattung ist er mir zum vollberechtigten Mitautor geworden. Ich bin sicher, dass, wie viel auch an dieser Arbeit zu tadeln sein mag und getadelt werden wird, doch für Herrn Volks Mitarbeit nur die Stimme höchster Anerkennung laut werden kann, und es ist mein aufrichtigster Wunsch. dass er aus ihr den Dank höre für die unendliche Miihe. welche er nur im Interesse der Wissenschaft auf sich nahm.

Zn jeder Zeit habe ich die bereitwilligste, liebenswürdigste Hïlfe und Unterstiitzung für meine Arbeiten bei den Herren Hemmings und Dr. Lindau im botanischen Museum in Berlin gefunden. Ohne des ersteren selbstlose Hülfsbereitschaft hätte ich wohl oft vergeblich unter Saccardoschen Diagnosen mich zurecht zu finden gesucht, und ohne des letzteren freundliches Interesse von mancher für mich wichtigen Literaturerscheinung keine Kemntniss erhalten. Anch hat Herr Dr. Lindau, wie beim vorigen Hefte so bei diesem, mir für die Korrekturen seine sorgsame U'nterstiitzung angedeihen lassen. Den Herren Hennings und Lindan sei daher hier der herzlichste Dank ausgesprochen.

Dank endlich gebülırt dem verehrten Herrn Yerleger, der jedem in Bezug auf die Abbildnngen geäusserten Wumsche auf das Bereit willigste entgegenkam. und dem Lithographen Herrn Giltsch, der 
die bestmögliche Wiedergabe der Zeichnungen lind besonders auch der Farben sich angelegen sein liess, manche Zeichnungen z. B. Fig. 43 auf Tafel III selbst noch erheblich verbesserte, die zweckmässige Retouche der Photographien besorgte. und die Tmstände vielfacher mühsamer Korrekturen niemals schente.

Eberswalde. December 1900. 


\section{Inhaltsübersicht.}

I. Phycomyceten

1. Oomyceten . . . . . . . . . . . . . . . . 1

2. Zygonyceten . . . . . . . . . . . . . . . . 15

3. Choanephora mmericana . . . . . . . . . . . . . . 18

4. Bemerkmgen znm natiirlichen System der Pilze . . . . 37

II. Ascomyceten

1. Perisporiaceen (Penicilliopsis) . . . . . . . . . . . . 62

2. Pyrenomyecten

а. Hy pocreaceen . . . . . . . . . . . . . . 73

a. 1. Amerosporae . . . . . . . . . . . . . 75

Melanospora . . . . . . . . . . . . . . 75

а. 2. Didymosporae . . . . . . . . . . . . . . 82

Hyponyces . . . . . . . . . . . . . 83

Hyростеа . . . . . . . . . . . . . . . . . . . . 86

Corallomyeer. . . . . . . . . . . . . . . 92

Nectria . . . . . . . . . . . . (91) 112

Sphaerostilbe. . . . . . . . . . . . 122

Mycocitrus . . . . . . . . . . . . . . . 124

а. 3. Phragmosporae . . . . . . . . . . . . 133

Calonectria . . . . . . . . . . . . (197) 133

Peloronectria . . . . . . . . . . . . 134

a. 4. Dictyosporae . . . . . . . . . . . . . 137

Megalonectria . . . . . . . . . . . . . . 137

Shiraia . . . . . . . . . . . . . . 140

а. 5. Scolecosporae. . . . . . . . . . . . . . . 141

Oomyces . . . . . . . . . . . . . . 149

Hypocrella . . . . . . . . . . . . . 151

Mycomalus . . . . . . . . . . . . . . 160

Ascopolyporus . . . . . . . . . . . . . . . 163

Epichoё . . . . . . . . . . . . . . 184 


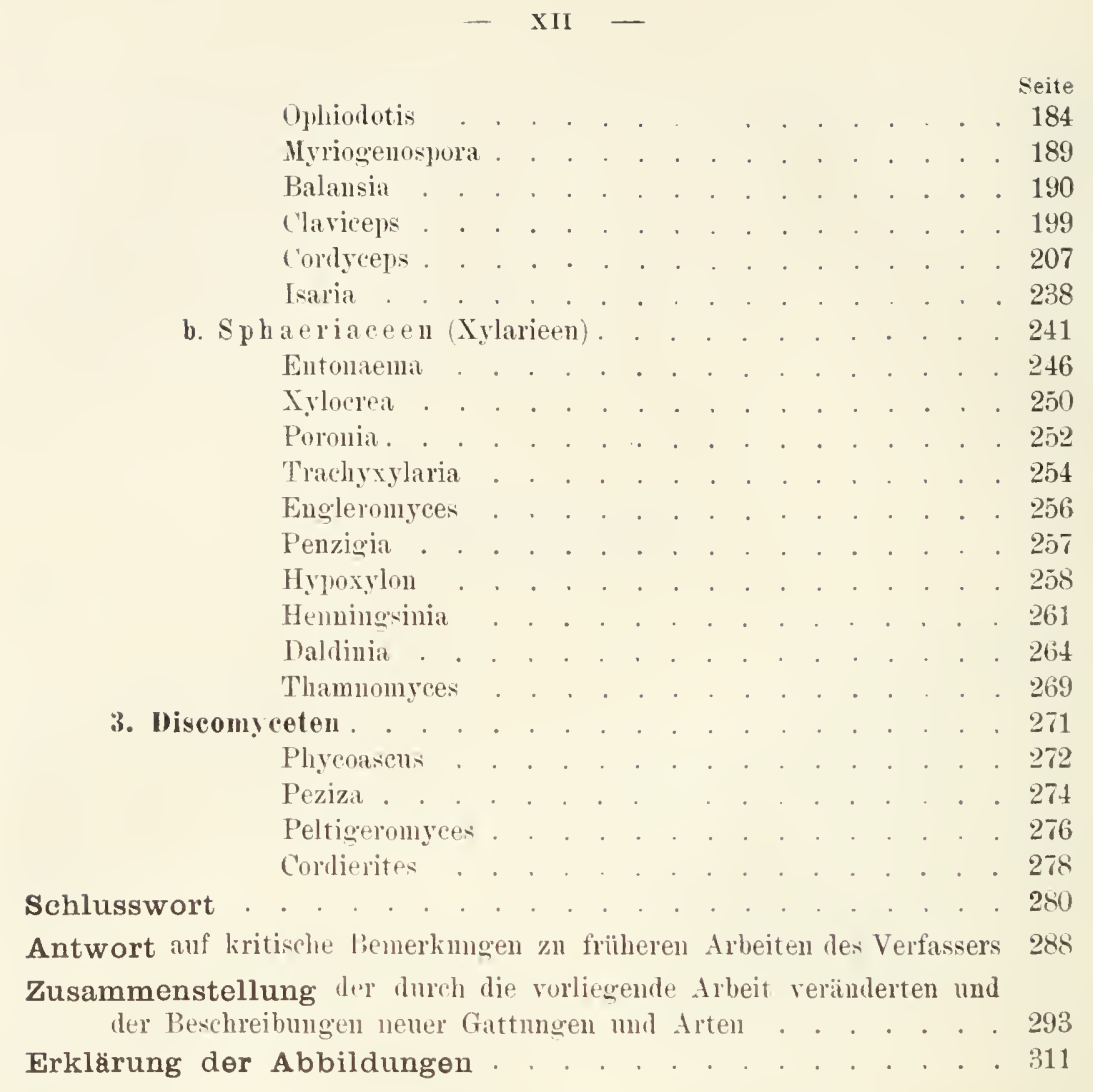

Anf Seite 145 lies viermal "Hypocrea" anstatt .Hipocrea“. Auf Seite 195, Zeile 10 lies: ,Bal. redumdans" anstatt "Bal. ambiens". Anf Seite 205, Zeile 2 lies: " 4 ('m" anstatt ..t mm". 


\section{Phycomyceten im allgemeinen und Choanephora americana nov. spec. im besonderen, nebst Bemerkungen zum natürlichen System der Pilze.}

Während meiner fast dreijährigen mykologischen Arbeitszeit zu Blumenau in Brasilien habe ich den Phycomyceten meist nur nebenher Beachtung geschenkt, und nur zweien ilıer Formen, der Choanephora americana nor. spec. und dem Basidiobolus ranarum Eidam länger fortgesetzte eingehende Untersuchung gewidmet. Ich kannte weder die Arbeiten Cumninghams ïber Choanephora Cunn. noch diejenige Eidams über Basidiobolus, als ich nach Brasilien ging. doch ist diese Unkenntniss für meine Untersuchung der von mir zunächst für ganz neu gehaltenen Formen nicht nachtheilig gewesen. Toh kounte später um so unbefangener die in Brasilien gemachten Befunde mit den in Calcutta und in Breslau gewonnenen vergleichen. Hierbei stellte sich demn heraus, dass die Choanephora in Blumenau zwar grosse Verwandtschaft mit den indischen Formen hatte. demnoch aber bemerkenswerthe Verschiedenheiten im einzelnen darbot, während der am Ufer eines Urwaldbaches aufgefundene Basidiobolus mit dem Breslauer in allen Stiicken so genau ïbereinstimmte, dass meine Arbeit und meine Zeichnungen nur eine Bestätigung der Eidamschen Untersuchung ergaben, der ich irgend etwas wesentliches nicht hinzu- 
zufügen vermochte. Wemn ich meine in Blumenan gefertigten Zeichnungen der Conidienträger und der schnabeltragenden 0osporen, anch der Keimungserscheinungen beider betrachte, Zeichnungen, die ohne jede Kemntniss der Eidamschen Untersuchungen gefertigt waren, und wenn ieh dabei feststelle, dass jeder Unbefangene glauben würde, ich lätte sie von Eidams Tafeln abgezeichnet, so kann ich mich des Stamens nicht erwehren über die weite Verbreitung einer so kleinen Form, die mit all ihren wunderlichen Eigenthümlichkeiten im Breslaner Laboratorium sich darbietet genau bis aufs kleinste wie im Süden Brasiliens, und wie wir ans Thaxters vorzüglicher Arbeit über die Entomophthoreen der Tereinigten Staaten wissen, auch in Nordamerika; und dies Erstamnen ist $1 \mathrm{~m}$ so grösser, wenn ich mir ins Gedächtniss zurückrufe, dass die dortige Phanerogamenflora in ihrer unerschöpften Reichhaltigkeit kaum in einem (Pteris aquilina?) oder allenfalls ganz wenigen Vertretern mit der heimischen Flora Uebereinstimmung zeigt.

Die Zahl der überaus weit auf der ganzen Erde verbreiteten Pilze wächst in demselben Maasse, wie nenerdings ausseremropäische Pilze immer meln bekamnt und untersucht werden. Eine Zusammenstellung der muthmaasslich kosmopolitischen Pilze wäre ein wichtiger Beitrag zur Pflanzengeographie; ihre Zahl dürfte grösser sein, als man glaubt, weil sicher gar viele Pilze durch verschiedene Namen nur deshalb ron einander getrennt sind, weil sie in rerschiedenen Erdtheilen gesammelt wurden. Ganz besonders aber scheinen die Phycomyceten weite Terbreitungsgebiete zu besitzen. Da num diese Pilze sich wenig zn Sammlmngsobjekten eignen, und unsere Kemntnisse ïber aussereuropäische, namentlich tropische Plycomyceten wohl hauptsächlich aus diesem Grunde noch besonders mangelhaft geblieben sind, so mag es dadurch gerechtfertigt sein, dass ich in folgenden eine kurze Nittheilung ron meinen Beobachtungen gebe. obwohl sie wenig umfangreich und meist wenig eingehend sind. 
Auf den aus Europa nach Brasilien eingefïhnten Feigen kommt eine Phytophthora vor, die ich im Garten des von mir bewohnten Hauses oftmals gesehen habe. Der Pilz befällt die reifenden Früchte, an deren Aussenseite seine Conidienträger einen weisslichen Flaum bilden. Ton der Angriffsstelle breitet sich der Conidienrasen radial fortschreitend weiter und in der Regel über reichlich die halbe Oberfläche der Frucht ans. Gleichzeitig wird das Fruchtfleisch nach allen Richtungen von den Fäden des Pilzes durchwuchert. Nach Frau Brockes zuverlässiger Mittheilung hat dieser Pilz schon zu wiederholten Malen die Feigenernte in Blumenau recht erheblich geschädigt. Die mehrfach unregehmässig gabelig rerzweigten Conidienträger erreichen eine Höhe von etwa 100-200 «. Die Enden der Gabelzweige, an denen die Conidien abgegliedert werden, sind stumpf. Unter ihnen sieht man, jedoch nur in geringer Anzahl. die Ansatzstellen früherer Conidien, wie bei Phytophthora infestans. Die citronenförmigen Conidien, von $38-45$ " Länge nnd $20-25 \mu$ Breite haben ein deutliches pafillenartiges Spitzchen am oberen Ende, und wenn sie abgefallen sind, am unteren Ende eine kragenartige Ansatzstelle. Schon auf der Feige selbst findet man lıäufig gekeimte Conidien. Die Keimschläuche treten fast immer entweder dicht neben der Spitzenpapille, oder dicht neben der Ansatzstelle aus. Andere Auskeimungsstellen finden sich selten. In Wasser und Pflaumenabkochung trat nur selı dïrftige Keimung mit einem kurzen Keinschlanche auf. In Nalzextraktlösung wurden die Keimschläuche schon länger und kräftiger und mitunter wurde hier Sekundärconidienbildung in der Art beobachtet, dass der aus der Conidie keimende Faden sich in die Luft bis zur Höhe der gewöhnlichen Conidienträger erhob. und auf seiner Spitze eine Sekundärconidie bildete, welche etwas kleiner blieb, als die primäre, und in die der gesammte Protoplasmainhalt der Keimconidie durch den fadentörniigen 'Träger' hindurch einwanderte, nach linten durch successive auftretende Scheidewände abgegrenzt. Schwärmsporenbildung 
habe ich nie beobaclitet. Als ich zur Kultur eine Abkochung von Feigen verwendete, war die Keimung erheblich kräftiger und es kam zur Bildung verzweigter Mycelien, welche gabelig verzweigte Conidienträger hervorbrachten, genan wie sie auf den befallenen Feigen gefunden waren. Die Beobachtungen stehen in genauester Uebereinstimmung mit dem von Brefeld (Bd. V S. 25) mitgetheilten Verhalten der Ph. infestans, welche ebenfalls in kïnstlichen Nährlösungen sich rollkommen üppig entwickelte. Damals im Jahre 1883 wurde gerade dieses Kulturergebniss von Brefeld zur Darlegung seiner ebenso neuen als bahnbrechenden Ansichten über' den Parasitismus iuberhanpt und ferner zur Erklärung des Auftretens und der Verbreitung der Kartoffelkrankheit verwendet, so dass die Bemerkung A. Fischers ïber Phytophthora infestans. welche sich anf Seite 415 seiner Bearbeitung der Phycomyceten für Rabenhorsts Kryptogamenflora befindet: „seit de Barys zusammenfassender Darstellung ist ein Fortsclıitt nicht gemacht worden" der Berichtigung bedarf. Ebenso ist die Angabe desselben Autors auf Seite 391 a. a. O. unrichtig. wo el sagt: „Ein Versuch, die streng parasitischen Peronosporaceen kïnstlich, olne lebenden Wirth zu kultiviren. ist noch nicht gemacht worden."

Rasen von Saprolegniaceen liabe ich an faulenden Pflanzenresten an den Lfern der Itajalỵ oftmals gesehen. Fliegenleichen. in Flusswasser geworfen, bedeckten sich mit Saprolegnien, wie sie es bei uns thun und die langgestreckten Sporangien, wie sie bei Achlya und Saprolegnia rorkommen, habe ich oftmals gesehen, doch ohne mich mit diesen Formen näher beschäftigen zu kïnnen.

Lurze Zeit, nachdem ich Fruchtkörper von Aureularia auricula Judae ins Laboratorium gebracht. und von ihnen Aussaten gemacht hatte, fand sich auch, jedenfalls mit jenen eingeschleppt, der von Brefeld entileckte Conidiobolus utriculosus ein. den ich einige Wochen in Kultur behiclt, bis ich mich ron der vollkom- 
menen Identität der brasilischen und der dentschen Form überzeugt hatte.

Die Stubenfliegen in Blumenau leiden genau wie unsere deutschen an der Empusa Muscae und in drei anfeinanderfolgenden Jahren beobachtete ich das Auftreten des Pilzes einige Wochen nach dem Beginn der heissen Sommerzeit, nämlich 1891 zuerst Ende September, 1892 im Dezember und 1893 erst am 5. Januar. Das häufige Torkommen des Pilzes dauerte dann bis zum Beginn kïhlerer Witterung im April, wo auch die Fliegen an Zähl bedentend abnahmen. Oosporen in den Fliegenleibern wurden trotz mehrfachen Sucheus auch in Brasilien nicht gefunden. Da dort nun Fliegen das ganze Jahr hindurch, wenn auch zu Zeiten wenig zahlreich rorkommen, so hat es keine Schwierigkeit anzunehmen, dass der Pilz dort ohne Oosporenbildung allein durch die Conidien das ganze Jahr hindurch sich erhalten kann.

In meinen Notizen finde ich noch unterm 1. Tuni 1892 eine im Walde gefundene von einer Empusa befallene Fliege erwähnt. die auch in Alkohol aufbewahrt wurde. Eine andere Entomophthoree, wahrscheinliclı auch eine Empusa mit erheblich kleineren Conidien als Empusa Muscae wurde auf einer Motte ebenfalls im Walde beobachtet.

Von allen Mitgliedern der Oomycetenfamilie hat aber Basidiobolus ranarum Eidam meine Aufmerksamkeit am meisten erregt. Der Pilz trat ohne meine Absicht in verschiedenen Kulturen als Eindringling auf, nachdem ich Material von abgestorbenen Blatt- und Holzresten rom Ufer eines Urwaldbaches heimgebracht hatte. Wenngleich es ja nicht ausgeschlossen ist, dass Reste von Froschexkrementen, auf denen allein bisher der Pilz angetroffen wurde, auch bei den erwähnten Material sich befunden haben, so glaube ich doch bestimmt, dass die schon von Eidam geäusserte, von Raciborski in seiner im 82. Bande der „Flora“ erschienenen Arbeit wiederholte Vermuthung zutrifft, dass nämlich Basidiobolus als Saprophyt an allerlei organischen Resten auch in der Natur zu 
finden sein wird. Hierfür spricht entschieden die Leichtigkeit, mit der er in künstlichen Kulturen verschiedenster Art gezogen und zu üppiger und vollständiger Entwickelung gebracht werden kann. Ich habe ihn monatelang kultivirt und sehr genau beobachtet und mich dadurch von der vollkommenen Identität der Form aus Blumenau mit der in Nordamerika von Thaxter und in Breslan von Eidam beobachteten überzeugt. Was sind aber doch die so regelmässig auftretenden Schnäbel des Basidiobolus für wunderbare Gebilde! Da exheben sich von je zwei benachbarten Hyphenzellen an ihrer Scheidewand die zwei wohl ansgebildeten in der Form ganz bestimmten Fortsätze und legen sich dicht aneinander. Der Beobachter wartet gespannt, was nun werden soll, sicher tritt eine Oeffuung ein; aber nichts geschieht. Die Schnäbel sind ganz unnïtz, unter ihnen an der. Wand, die von Anfang an da war, entsteht ein grosses Loch und der Inhalt der einen Zelle wandert in die andere. welche zur Oospore wird, vollständig ein. Sicherlich liegt in den Schnäbeln ein umnütz gewordenes Gebilde vor, das früher einmal von Bedeutnng gewesen sein mag. Die änssere Aehnlichkeit mit Bildnngen, wie sie von Thaxter in der Botanical Gazette Tol. XX Tafel XXIX (s. 'Taf. 1 Fig. 15 dieses Heftes) für Monoblepharis insignis beschrieben und dargestellt sind. verdient Erwähnung. Dort ist der eine Schnabel das Antheridium. welches schwärmende männliche Zellen entlässt, der andere die Spitze des Oogoniums. Die Vermuthung liegt nahe, dass anch bei Basidiobolus die Verhältnisse früher ähnlich gewesen sind, dass dann die Bildung der Schwïrmer verschwunden ist. in ähnlicher Weise, wie sich diese Rückbildung an den ungeschlechtlichen Sporangien der Peronosporeen noch verfolgen lässt. und dass schliesslich die Terbindung der männlichen Zelle mit der weiblichen auf dem einfacheren Wege grade durch die Zellwand sich vollzog, die Schnäbel aber nun ganz überflüssig geworden waren. Eidam meint, dass seine Beobachtungen ïber die Kerntheilungen „Aufschluss über die charakteristischen Schnabelfortsätze" brächten. Ich kann aber 
nicht einsehen warum so eigenthümlich bestimmt geformte Schnäbel nothwendig waren, nur um den Kernen Platz zu ihrer der Kopulation vorhergehenden Theilung zu gewähren und die Oosporen ron Conidiobolus lelıren doch deutlich, dass für den gleichen Vorgang flort die Schnäbel nicht notwendig sind.

Lie Aehnlichkeit mit den Thaxterschen Figuren von Monoblepharis wird besonders gross und fast iiberzeugend, wenn die beiden Schnabelfortsätze, wie Eidam gelegentlich gesehen und z. B. T'af. XI Fig. 6 ('Taf. I Fig. 16 dieses Heftes) seiner Arbeit gezeichnet hat, sich nicht unmittelbar berühren. Um dem Leser, der vielleicht die angezogenen Arbeiten nicht gerade zur Hand hat, wenigstens eine Andeutung zu geben, gestatte ich mir, eine Kopie sowohl einer Thaxterschen Zeichnung von Monoblepharis wie auch der betreffenden Eidamschen hier beizufügen (Taf. I Fig. 15 u. 16). Ich stehe nicht an, die Schnäbel ron Basidiobohıs als rudimentär gewordene Organe anzusprechen, als die Reste der Differenzirung von Oogonium und Antheridium. In dieser Auffassung erleichtert uns Basidiobolus die Herleitung der Entomophthoreen von Stammformen mit ausgeprägterer Geschlechtlichkeit, die bei den Monoblepharideen ihre Stelle würden gefunden haben. Die Spermatozoiden verschwanden und der gesammte Inhalt des Antheridiums wurde zur Befruchtung rerwendet. Es ist dieselbe Rückbildung, welche anch die Peronosporeen gegeniber den Monoblepharideen aufweisen. Noch weiter in derselben Entwickelungsrichtung geht Conidiobolus, bei dem nur noch die ungleiche Grösse der kopulirenden Fadenenden an die Geschlechtszellen erinnert. Brefeld äussert sich im Anschluss an seine Beobachtungen über Conidiobolus Heft VI S. 65: „Es liegen in den Entomophthoreen Pilzformen vor, welche unter den Oomyceten in der Reduktion der geschlechtlichen Fruchtträger uiber die Peronosporeen hinausgehen, es werden auch die Anlagen der geschlechtlichen Sporangien, der Oogonien und Antheridien nicht melır durch Scheidewände abgegrenzt, es sind nur noch die Anschwellungen an ihren Enden übrig geblieben, welche 
sie andeuten." Diese Anschaumng erhält durch die vergleichende Betrachtung vou Monoblepharis, Basidiobolus und Conidiobolus eine bemerkenswerthe Erläuterung, welche uns eine genane Vorstellung ermöglicht, wie der besprochene Reduktionsvorgang im einzehnen vorzustellen ist. Zur Erleichterung fiir den Leser füge ich nocl eine Wiedergabe einer Brefeldschen Figur des Conidiobolus hinzu (Taf. I Fig. 17).

Im Anschluss an die von Brefeld begründete, bei von Tavel (Vergl. Morphologie, Jena. 1892) in übersichtlicher Kürze zusammengestellte Anordning der Phycomyceten müsste ich jetzt zu den Zygomyceten übergehen. Inzwischen aber, seit von Tavels Buch erschien, hat unsere Kenntniss der Phyconyceten wesentliche Erweiterung durch Thaxter erfahren. Thaxters Arbeiten veranlassen mich, einige Funde von Syncephalis und Coemansia nicht mehr, wie es früher lıätte geschehen müssen, im Anschluss an Piptocephalis, sondern hier schon bei den Oomyceten zı erwähnen, und ich möchte die Gelegenheit benutzen, dies kurz zn begründen. Im Jahre 1875 hat van T'ieghem in den Annales des sciences nat. 6. Série Bd. I zwei neue Gattungen von Pilzen beschrieben, Dimargaris und Dispira; er sagt von ihnen, sie seien Parasiten auf Mucorineen, gehörten aber nicht zu dieser Gruppe, sondern wahrscheinlich zu den Ascomyceten, er vereinigt sie mit der schon früher (1873) ron ilmm beschriebenen Gattung Coemansia und den ron Coemans aufgestellten Gattungen Kickxella und Martensella zu einer besonderen Gruppe. Dafür, dass diese Pilze zu den Ascomyceten gehörten, sprach eigentlich nur eine unsichere Vermuthung. Von Dispira laben wir num durch Thaxter (Botanical Gazette 1895) erfahren, dass sie zu den Phycomyceten gehört, und dort eine sehr eigenthümliche stellung einnimmt, welche ron 'Thaxter selbst meines Erachtens nicht bestimmt genıg bezeichnet ist. Nach Thaxter bilden die regetativen Hyphen des Pilzes kurze Seitenzweige, welche mit ihrem leicht geschwollenen Ende sich dem Sporangienträger des Mucor dicht 
und fest anheften. Hiernach theilt sich der Seitenzweig durch eine Wand in zwei Zellen, von denen die vordere gewöhnlich kleinere dem Mucorfaden dicht aufsitzt. Unmittelbar danach wird die eben gebildete Trennungswand wieder durchbrochen und die rückwärtige, mit dem Mucor nicht in unmittelbarer Verbindung stehende Zelle schwillt an, rundet sich ab und wird zur Oospore, während der Inhalt der vorderen kleineren von dem Mucor num wohl ernährten Zelle in sie übertritt: diese letztere sendet dann nachträglich unregelmässige, nach allen Seiten ausstrahlende Fortsätze aus, welche die reifende Oospore zur Hälfte gleich einer Cupula umschliessen. 'Thaxter sagt am Ende seiner Beschreibung dieser merkwürdigen Bildung, dass der einzige Fall von Conjugation unter den Zygomyceten, welcher mit dem vorliegenden vergleichbar wäre, der von Basidiobolus sei; ich möchte glauben, dass Conidiobolus ein noch besseres Tergleichsobjekt bildet. Aus Thaxter's eigener Arbeit kann man Empusa Grylli auch noch zum Vergleich heranziehen.

Thaxter macht uns nun weiter darauf aufmerksam, dass seme Dispira americana zwar in der Tracht aufs nächste der Dispira cornuta van Tieghem verwandt, aber in der Form ihrer Conidienträger der Dimargaris cristalligena weit näher steht und er macht es aufs Aeusserste wahrscheinlich, dass wir es in Dimargaris und Dispira mit zwei nahe verwandten Formen zu thun haben, die wahrscheinlich in eine Gattung vereinigt werden kömnen. Durch seine Untersuchung der Dispira americana ist ferner dargethan, dass diese Pilze zu den Phycomyceten gehören. Er möchte sie mit den Cephalideen Fischers vereint zu den Mucorineen rechnen. In diesem Punkte kann ich nun nicht beistimmen. Diese Pilze gehören ebenso wie die Entomophthoreen den Oonyceten viel eher an, als den Zygomyceten und werden zweckmässig bei einer systematischen Behandlung am Schluss der Oomyceten behandelt und ror den Zygomyceten, wie es mit den Entomophthoreen bei v. Tavel geschehen ist. 
Und an dieser Stelle werden dam auch am besten die Genera Fickxella und Coemansia, sowie die zweifelhafte Martensella angeschlossen. van Tieghem selbst hat darauf aufmerksam gemacht, dass eine eigenthiimliche linsenartige Verdickung in den Scheidewänden der Conidienträger bei Dimargaris ebenso wie bei Kickxella und Coemansia charakteristisch ist. Die Termuthmng, dass diese Formen zu Ascomyceten gehörten, ist durch gar nichts gestützt, hingegen wird sich Niemand. der sie kultivirt und mit den Knlturen andere Phycomyceten vertraut ist, dem Eindruck verschliessen können, dass sie in dieser Pilzgruppe ihre natürliche Stellmug finden. Nachdem ich schon vor mehr als zehn Jahren in Ratzeburg die Kickxella längere Zeit in Kultur gehabt hatte, fand ich in Blumenau in Brasilien die Coemansia. Tch habe beide ron Anfang an für Phycomyceten gehalten, würde aber kaum gewagt haben, mit dieser Ansicht hervorzutreten, wemn nicht 'Thaxter durch seine Untersuchung der Dispira eine weitere thatsächliche Grundlage geschaffen und seine Abhandlung dann mit den Worten geschlossen hätte: „In the writers opinion the peculiarities of the sporophores, the coherence of the gelatinous sporemass when ripe, together with the peculiarities of the septa just mentioned as well as the general habit of these plants would indicate a connection with the Mucorineae rather than with any other known fungi."

Rechnen wir nun aber Dispira und ihre Yerwandten zu den Oomyceten, weil bei ihnen von zwei benachbarten Zellen nu die eine, von Anfang an grössere, zur Oospore, wird, nachdem der Inbalt der kleineren in sie übergetreten ist, wälırend ron einer Tereinigung zweier gleichwerthiger Zellen, wie bei den Zygomyceten, nicht die Rede sein kann, so müssen wir folgerichtig auch die ron Bainier zuerst (Ann. sc. nat. 6. Série Tome XV Pl. 6) und danu von 'Thaxter genaner untersuchte Syncephalis nodosa hier anschliessen.

Nach der genauen Untersuchmng des genannten Autors (Bo- 
tanical Gazette, Juli 1897) ist kein Zweifel daran, dass bei dieser Form die durch je eine Scheidewand abgegrenzten verschieden grossen und verschieden gestalteten Endzellen zweier spiralig umeinander' gerollten aufrechtstehenden Hyphen (vergl. 'T'af. I Fig. 18 dieses Heftes) in offene Verbindung treten, dass dann der Inhalt der kleineren in die grössere iibertritt, und dass als Folge davon die Oospore gebildet wird. in Form einer Aussackung an der grösseren ler beiden copulirten Zellen. Ausser ron Syncephalis nodosa ist nur noch von einer der vielen beschriebenen Syncephalis" Arten, nämlich von Syncephalis cornu van Tieghem (= S. curvata Bainier) rie Zygosporenbildung bekannt. Der Tergleich dieser mit der eben erwähnten S. nodosa einerseits, nit Piptocephalis andrerseits ist ıun m. E. so ausserordentlich bemerkenswerth, dass ich, da er bisher nicht angestellt worden zu sein scheint, die entsprechenden Figuren von Thaxter, van Tieghem und Brefeld auf der Tafel I Fig. 18-20 zu wiederholen mir erlaube, un eine schnellere Verständigung mit dem Leser zu ermöglichen.

Bei S. nodosa sind, wie ich schon nach Thaxter berichtet habe, die beiden kopulirenden Zellen unglcich, der Inhalt der kleineren tritt in die grössere über und diese lässt an einer der von der Kopulationsöffnnng entfernten Stelle die Oospore aussprossen. Die Beziehung zu dem Vorgange bei S. cornu ist unverkennbar. Auch hier sind die beiden copulirenden Zellen noch stets und ständig ungleich, van Tieghem sagt, dass die eine um ein Drittel bis ein Tiertel, manchmal um die Hälfte kürzer sei, als die andere. Den Vorgang der Oosporenbildung können wir nun, da wir S. nodosa kennen, so beschreiben, dass wir sagen, anch hier tritt der Inhalt der kleineren in die grössere Zelle iiber und diese lässt in Folge davon die Oospore aussprossen; der Unterschied ist nur der, dass der Ort des Aussprossens ganz bestimmt geworden ist, und mit der Kopulationsstelle zusammenfällt. Hierdurch kommt die Erscheinung zu Stande, welche van Tieghems anf Taf. 1 Fig. 19 dieser Arbeit wiedergegebene Figur darstellt 
und die jeder unbefangene, mit S. nodosa nicht bekannte Beobachter dahin auffassen würde, dass beide Kopulationszellen verschmelzen, und gemeinschaftlich an der Stelle ihrer Berühung die Oospore aussprossen lassen.

Die dargestellten Verhältnisse werfen nun aber ein ganz neues Licht auf den längst durch Brefelds Untersuchung bekannten Vorgang der Zygosporenbildmg bei Piptocephalis (Taf. 1 Fig. 20) Dass die Gattungen Syncephalis und Piptocephalis nahe verwandt sind, ist allgemein erkannt und vielfach zum Ausdruck gebracht wordeu. Es wäre wunderbar, wemn sie gar keine Vergleichspunkte in ihrer geschlechtlichen Fruchtform darbieten sollten. Thatsächlich sind diese Beziehungen nahe, unverkenubare und äusserst bemerkenswerthe. Wir brauchen nämlich uur die bei S. cornu noch ungleichen beiden Kopulationszellen gleich werden zu lassen, so haben wir die Zygosporenbildung von Piptocephalis vor uns. Die Reihe Syncephalis nodosa. Syncephalis cornu, Piptocephalis Freseniana ist eine äusserst natürliche, welche uns die Ableitung einer echten Zygospore ron einer echten Oospore handgreifliclı vor Augen führt.

Die Folgerungen aus diesen Thratsachen für die Systematik der Phycomyceten geben sich nun von selbst. Die Piptocephalideen (Fischers Cephalideen) müssen am Ende der Oomyceten, oder wenn man dies lieber will, am Anfang der Zygomyceten, jedenfalls zwischen beiden Ordnungen behandelt werden. Zu ihnen gehören die rorerwähnten Genera Dispira (einschliesslich Dimargaris) Kickxella, Coemansia (wahrscheinlich = Martensella) und als eine zweite Gruppe die vier Gattungen Calrocephalis. Syncephalis, Syncephalastrum und Piptocephalis. Meiner Ansicht nach war nämlich Bainier ron einem sehr richtigen Gefülıl geleitet, als er (Étude sur les Mucorinées 1882 seite 120) trotz der nach Thaxter nicht vollkommen richtigen Beobachtmng der Oosporenbildung vorschlug, die Syncephalis nodosa als Vertreterin einer eigenen Gattung: Calvocephalis anzuerkemnen. Diese Gattung wird durch die oben 
geschilderte Eigenart ihrer Oosporenbildung vorzïglich charakterisirt.

Znl Gattung Syncephalis gelı̈ren dann die Formen. deren Oosporenbildung nach dem Muster von S. cornu sich heransstellen wird. Aus Zweckmässigkeitsgründen wird man vorläufig. ehe die sexuell erzengten Sporen bekannt sind, die zahlreichen beobachteten Formen mit ähnlichen Conidienträgern bei der Gattung Syncephalis belassen. Syncephalastrum, von Schröter aufgestellt, ist wegen der verzweigten Conidienträger' zur Gattmo erhoben, die 'neuen Untersuchungen von Thaxter in der Botanical Gazette 1897 ergeben aber für diese Gattung einen wichtigen Charakter darin, dass sie echte langgestreckte Sporangien trägt, an Stelle der bei den anderen Gattungen auftretenden Conidienreihen. Die Vermuthung; dass diese Conidienreihen als aus sporangien entstanden anzusehen sind, als ein zweiter besonderer Fall von Umbildnng der Sporangien zu Conidien, gewinnt durch Thaxters Mitheilnngen erheblich an Wahrscheinlichkeit. Die Gattung Syncephalastrum ist also wohl begründet, sie steht wegen äusserer Aehnlichkeit vorlänfig am Besten in der Nähe von Syncephalis, bis die Bildmng ihrer geschlechtlichen Sporen bekannt geworden sein und ihre genauere Stellung im Systeme bezeichnet haben wird. Piptocephalis endlich schliesst sich an Syncephalis möglichst natïrlich an. Bei Piptocephalis sind die beiden kopnlirenden Zellen gleich geworden; zwar ist ein geringer Grössemmterschied oftmals vorhanden, doch gestattet er nicht mehr eine kleinere und eine grössere Zelle mit Bestimmtheit zu mnterscheiden; beide betheiligen sich in gleichem Maasse an dem Aufbau der zur Zygospore gewordenen Oospore, welche aber im Gegensatze zir den typischen Zygosporen auch hier bei Piptocephalis wie bei Syncephalis cornu ansserhalb der beiden kopulirenden Zellen als eine Aussprossung angelegt wird.

Wir kennen nun also innerhalb der Oomyceten drei verschiedene, je wohl zusammenhängende Formenreihen, welche alle unter demselben Gesichtspuunkt verständlich sind, nämlich : Reduk- 
tion der Geschlechtlichkeit und der Geschlechtsorgane. Die erste Reihe ist dargestellt durch die Gattungen Pythium, Phytophthora, Peronospora. Diese Reilıe beginnt mit einer Form, welche schon mämnliche Schwärmzellen nicht melır hat, sondern das Protoplasma (Gonoplasma) des Antheridiums zur Befruchtung verwendet, nnd endet mit völligem Verluste der Geschlechtlichkeit. Die zweite oben besprochene Reihe begimnt in Monoblepharis insignis mit volkommener Geschlechtlichkeit, Antheridien mit Spermatozoiden, und führt ïber Basidiobolus zn Conidiobolus mit starker Reduktion der Geschlechtsorgane, ja vielleicht oder wahrscheinlich darüber hinaus noch zu Entomophthora mit rölligem Verluste der Geschlechtlichkeit überhaupt. Die dritte Reihe ist die zuletzt besprochene ron Calvocephalis. Syncephalis und Piptocephalis. Auch sie beginnt, wie die ersterwähnte mit einer Form, welche Spermatozoiden nicht mehr besitzt, wohl aber noch den Unterschied des Antheridiums ron Oogonium erkennen lässt. und sie zeigt das allmähliche Verschwinden dieser Differenzirung der beiden Geschlechtsorgane gegen einander. Dass iibrigens anch innerhalb der Saprolegniaceen sich eine ähnliche rïckschreitende Reihe beobachten lässt. sei nur angedentet (cfr. r. Tavel S. 17). Es verdient Erwälmung. dass, während das erste Auftreten der Geschlechtlichkeit im Organismemreiche sich durch Kopulation zweier gleichgearteter Schwärmer anzeigt, und von diesem Znstande ans ein Fortschreitrn eintritt, in dessen Terlanf die männliche und die weibliche Zelle verschieden werden und sich ron einander entfernen, nun innerhalb der Reihe der Pilze verhältnissmässig früh die Geschlechtlichkeit wieder schwindet und zurückgeht, in manchen Fällen auf einem älnnlichen Vege, wie der war, auf dem sie entstand. Die ungleichen Geschlechtzzellen verlieren ihre besonderen Charaktere und werden einander wieder gleich. Schliesslich unterbleibt ihre Verbindung and die frïher geschlechtlich erzengte Sprore entsteht olne jeden Geschlechtsakt regetatir (Azrgosporen!).

Im Anschlusse an diese Erörterungen habe ich $11 u n$ ansser 
dem schon erwälnten Torkommen der Coemansia in Brasilien zu erwähnen, dass Syncephalisformen vielfach beobachtet wurden. Auffällig: war insbesondere eine, die auf Citronen vorkam, einfache lräger von $1-1^{1} / 2 \mathrm{~mm}$ Länge und rings mit Conidienketten besetzte Kugelköpfe erzengte. Die 'T'räger' hatten etwa 27 " Durchmesser, sehr dicke Wände, die Conidien wurden bei der Reife braun, waren kuglig mit 9 " Durchmesser und besassen ein sehr fein sculpirtes stachliches Epispor. Eine andere auf verschimmeltem Brote gefundene Form mit gelben glatten junden Conidien von 6 " Durchmesser zeigte den Habitus von S. sphaerica. Eine weitere ganz farblose sehr kleine Form mit reich aber' unregelmässig verzweigten 'Trägern, die auf den fanlenden Früchten der Crescentia Cujete gefunden wurde, vertrat den Typus von Syncephalastrum.

Von Piptocephalis Freseniana ist zu berichten, dass sie auf Pferdemistkulturen in Blumenau ebenso leicht zu beobachten ist wie bei uns in Deutschland.

Ich konme nun zur Erwähnung der Funde von echten Zygonyceten.

Bald nach meiner Ankunft in Brasilien verschaffte ich mir Mist der Anta (Tapir) und legte ihn unter einer feuchten Glocke aus. Ich liatte gehofft nie gesehene Mucorineen dort beobachten zn können. Doch mein Erstaunen über solche hätte kaum grösser sein können, als es über die Wirklichkeit war, welche Hucor Ifucedo mit Chaetocladium Jonesii (in der ron Brefeld angewendeten Bezeichnung; nach Schıöter ist dies Chaet. Brefeldii) zur Erscheinung brachte, nichts anderes, als hätte ich in einem dentschen Laboratorium beliebigen Pferdemist ansgelegt. Im Laufe meiner Arbeiten in Brasilien sind mir dann zahlreiche Mucorformen gelegentlich rorgekommen, unter denen ich nur den Chlamydomucor racemosus als sicher identificirt aufführen will. Racemös sowohl als cymös verzweigte Formen finden sich in grosser Mannigfaltigkeit und es ist mir nicht zweifelhaft, dass 
sie wohl alle oder doch weitans die meisten sich mit europäischen Formen decken. Ich werde in dieser Annahme durch Thaxter bestärkt, der von der nordamerikanischen Mucorflora in der Botanical Gazette vom Juli 97 sagt, dass in ihr alle beschriebenen Gattungen der Mucorineen mit zwei oder drei Ausnahmen meist gut vertreten seien. Dies wird nun ebenso für die Umgegend von Blumenau und wahrscheinlich für den grössten Theil Südamerikas zutreffen. Denn wenn ich die Gruppen der Zygomyceten, wie sie auf der von Brefeld geschaffenen Grundlage so übersichtlich und klar in von Tavels Morphologie zusammengestellt sind, übersehe, so kann ich von ihnen sagen, dass sie olme Ausnahme anch in Siidamerika wohl vertreten sind.

Anf Vogelmist beobachtete ich eine zierliche Circinella, welche zwar mit keiner der beschriebenen Arten vollkommen ïbereinstimmt (ihre Sporen haben 10-11 "Durchmesser), aber der Circinella umbellata ausserordentlich nahe steht. Wenigstens zeigt sie keine Eigenthümlichkeiten, die für die Beurtheilung der Verwandtschaftsverhältnisse der Mucorineen oder für die Beurtheilung ihrer Fruchtformen neue Aufschlüsse ergeben kömnten, so dass eine Neubenennumg der Art überflüssig scheint.

Auf der Landstrasse in Blumenan fand ich an kühleren Tagen des Morgens frühı fast regelmässig zahllreiche Pferdeäpfel mit schimmernden Rasen des Pilobolus crystallinus besetzt.

Auf einer Agaricine im Walde beobachtete ich einen melrere Centimeter hohen sehr kräftigen Nucor mit braunen Sporangienträgern, mächtig entwickelter Columella und länglichen etwas gebogenen, an den Enden abgerundeten Sporen ron 50 " Länge. Er dürfte zu der von van Tieghem begründeten Gattung Spinellus gelören; das dornige Luftmycel ist zwar nicht aufgefunden worden, doch ist es ja auch für Incor (Spinellus) macrocarpus nicht bekannt.

Ton den Thamuidieen erscheint Thamnidium clegans auf Mistkulturen wie bei uns. Anf Hühnermist fand ich eine ansser- 
ordentlich reich gegliederte zierliche For'm von Helicostylum, einer Gattung, welche Thamnidium ja nächst verwandt ist.

Dies Helicostylum vereinigt in wunderbarer TVeise die Charaktere mehrerer der bisher beschriebenen Arten. Der Bau der Hauptsporangien ist genau derselbe wie bei dem von Bainier in den Amn. d. sc. 1880 beschriebenen H. piriforme, auch das Aussehen der birnenförmigen Sporangiolen ist dasselbe, so dass die von Bainier gegebene Figur Taf. IV Fig. 6 a. a. O. genau zutrifft. Hingegen sitzen die dicht gabelig-lappigen Verzweigungen, welche die żahlreichen Sporangiolen tragen, ganz dicht am Hauptträger gewöhnlich ringsum, so dass dieser mit mehreren übereinander angeordneten vollständigen Quirlen von Sporangiolen besetzt ist, wie bei H. nigricaus. Endlich hat unsere Form üppig rankende, weit reichende und sich selbständig wieder bewurzelnde Stolonen, wie sie fuir H. repens angegeben sind. Bemerkenswerth ist. dass die Erzeugung ron Hauptsporangien offenbar stark im Rückgange ist, man findet deren nur verhältnissmässig wenige im Tergleich zu der Ueberzahl der massenhaft auftretenden Sporangiolen, deren dichte Quirle zudem häufig auch anstatt eines Endsporangiums die Spitze der Träger krönen. Ich habe dies Helicostylum mehrere Wochen lang in üppigen Kulturen auf Objektträgern gezogen, doch von Zygosporen nichts bemerkt.

Aus der Gruppe der Chaetocladieen ist das Torkommen des Chaetocladium Jonesii schon oben erwähnt worden.

Unter den carposporangischen Zygomyceten war Rhizopus nigricans eine der häufigsten Erscheinungen auf schimmelndem Brot und Frïchten. Eine zweite Rhizopusart beobachtete ich auf aufgeschnittenen schimmelnden Früchten der Crescentia Cujete. Eine Mortierella fand ich im Walde, deren Sporangien in dichten Büscheln wohl zu 100 nnd mehr zusammen standen. Es gelang mir sie zu kultiviren und zur Sporangienfruktifikation zu bringen und ich stellte fest, dass zwischen ihr und Mortierella Rostafinskii kein wesentlicher Unterschied sich findet. 
Auch das stromaartige Geflecht, welchem die unteren 'Theile der' Sporangienträger eingesenkt sind, fand sich kräftig entwickelt.

Aus diesen freilich nur flïchtigen gelegentlichen Aufzeichnungen entrollt sich ein Bild von der Phycomycetenflora von Blumenau, welches fast völlig ïbereinstimmt mit dem irgend einer Gegend Europas; nach 'Thaxters Mittheilungen ist es in Nordamerika nicht anders, und aus Buitenzorg hören wir dasselbe. Es gewinnt die Meinung an Wahrscheinlichkeit, dass die meisten Phycomyceten kosmopolitisch sind. Man künnte das vielleicht mit dem hohen Alter dieser algenähnlichen Pilze und damit zu erklären versuchen, dass sie ihre gewöhnlichen Nährsubstrate in annähernd gleicher Zusammensetzung in der ganzen Welt finden, von den Einfliissen des Klimas aber im ganzen wenig abhängig sind.

Nach unseren bisherigen Kenntnissen macht von der Eigenschaft kosmopolitischer Verbreitung eine entschiedene Ausnahme die Gattung Choanephora. ron der ich einen neuen Tertreter, die

\section{Choanephora americana nov. spec.}

in Blumenau aufgefunden und genau untersucht habe.

Wenn wir die bisher bekannten Pilzformen einmal aus dem Gesichtspmukte betrachten. Welchen Werth jede einzelne durch Aufklärung und Befestigung der Anschauungen fiir das Gesammtbild des Systems der Pilze gelıabt labe, so glaube ich, dass die Choanephora Cunninghamiana, welche im Jahre 1878 rou Cumningham zuerst und grïndlich in den Transactions of the Limnean Society beschrieben mo abgebildet wurde, an eine der allerersten Stellen der Trerthschätzung gerïckt werden muss.

Jm Januar 1891, während ich eifrig mit Objektträgerkulturen beschäftigt war. und kurze \%eit, nachdem ich wieder einmal frisches Material von Pilzen. die anf faulenden Zweigen am Rande eines Ilwaldbaches gesammelt waren, in mein Laboratorium gebracht hatte, trat plützlich in verschiedenen Kulturen ein Eindringling auf. der rom ersten Augenblick an mein Interesse aufs höclıste 
erregte, ein Pilz mit Mucorsporangien und gleichzeitig auftretenden reich verzweigten hochorganisirten Conidienträgern, der ansserdem noch Gemmen oder Chlamydosporen bildete. Ich isolirte ihn alsbald, ïberzeugte mich, dass die verschiedenen Fruchtformen thatsächlich zu ein und demselben Organismms gehörten, und gelangte dann zu der Einsicht, dass ich es mit einem Vertreter der Gattung Choanephora zil thun haben müsste. Anf die alsbald von Berlin verschriebene Cumninghamsche Arbeit musste ich bei der weiten Entfernung ein Vierteljahr warten, und in der Zwischenzeit kultivirte ich die brasilische Form in sehr zahlreichen Knlturen und brachte die Untersuchnng zn dem mir möglichen dbschluss. Es war ein kleines Fest, an dem anch Fritz Müller frendigen Antheil nahm, als das Heft eintraf, welches die im fernen Indien, nahezu bei den Antipoden ansgefülırten so ausserordentlich sorgsamen mud ansführlich geschilderten Untersuchnngen des britischen Antors mittheilte, wir lasen sie zusammen am selben Abend von Anfang bis zu Ende mit wahrem Genuss, und ich verglich Schritt für Schritt meine nun vorliegenden Ergebnisse mit den hier mitgetheilten. In vielen Punkten fand sich eine bei der Entfermmig der Beobachtungsorte unwillkürliches Staunen erregende Uebereinstimmung, in manchen Einzellıeiten wieder wurden scharfe Verschiedenheiten festgestellt. Tnsbesondere hatte die brasilische Ch. anffallende hyaline Haarbüschel an den beiden Enden ihrer Sporangiensporen, welche bei Ch. Conninghamiana nicht vorkamen. Ein Punkt besonders war geeignet, mich etwas niedergeschlagen zn machen. ('nnningham hatte an seinem indischen Pilze Zygosporen beobachtet, die anfznfinden mir in Brasilien nicht gelnngen ist. So blieb meine Arbeit hinter der englischen recht zurück, und auch jetzt da ich sie nach langer Zeit der Oeffentlichkeit übergebe, möchte ich sie nur als eine geringe Ergänzung zu den ausgezeichneten Conninghamschen Mittheilungen aufgefasst wissen, eine Ergänzmng, die mir nebenbei Gelegenheit giebt, meine in manchen Punkten 
von der Cunninghamschen abweichende Auffassung des Beobachteten zur Sprache zu bringen.

Inzwischen erschien eine neue Arbeit von Cumningham im Jahre 1895: „A new and parasitic species of Choanephora" in den Annalen des botanischen Gartens zu Calcutta, und in dieser wurde eine Form besclurieben: Choanephora Simsoni, welche eben jene eigenartigen Haarbüschel an den Sporen besitzt. Wenn ich aber anfänglich geglaubt liatte, dies sei sicher dieselbe ron mir in Brasilien gefundene Choanephora, so lehrte genauerer Vergleich, dass dies nicht zutrifft, dass vielmehr die Brasilianerin in seln eigenartiger Weise Eigenscliaften der beiden indischen Formen in sich vereinigt, von jeder einzelnen aber scharf und deutlich rerschieden ist.

Offenbar war auch Cunningham lebhaft angezogen worden ron diesem eigenthümlichen Pilze. der ein so fabelhaft schnelles Wachsthum in den Kulturen zeigt. so wunderbar reagirt auf die Terschiedenheit der angewendeten Nälnlösungen, abgesehen ron den Besonderheiten seiner Lebensweise. Desshalb widmete er ilm jene lang fortgesetzte Sorgsamkeit der Beobachtung, welche aus jenen beiden gründlichen Arbeiten spricht. Mir war es ähnlich ergangen, ich hatte kaum je ein anziehenderes Kulturobjekt in Händen gehabt, und ich latte die Kulturen variirt in aller erdenklichen Teise und in ungewölnnlich grosser Zahl, so dass ich in der Lage war. und jetzt bin, die Verschiedenheiten und Uebereinstimmnngen der Ergebnisse in Indien und in Brasilien im einzelnen zu verfolgen.

Cumningham hat aber auch, zumal in der letzterwälnten Arbeit. jene hohe Bedeutung des Pilzes erkannt und gewïrdigt. die ich in den Eingangsworten angedentet labe, und die er in folgender Weise ausspricht: „The genus in fact in a sellse appears to form a sort of centre from which rarious groups of both the higher and lower fungi radiate and seems. therefore, to be wortlyy of rery special attention." Ich möchte die Bedentung des Pilzes wohl anders 
ausdriicken und sagen: jene beiden in Indien gefundenen Choanephorae sind die einzigen bekannten Pilze, welche je an einer und derselben Pflanze zusammen alle vier 'Typen der bei Pilzen überhaupt vorkommenden Fruktifikationsorgane besitzen, nämlich die als geschlechtlich betrachtete Zygospore der niederen Pilze, welche ron der Oospore nur graduell rerschieden ist, die Gemmen oder Chlamydosporen, die Sporangien, die Torläufer der Ascen und die Conidien, die Torläufer der Basidien, letztere noch dazu in einer Form, welche unter gewissen Cmständen die Basidienähnlichkeit in hohem Grade zeigt. - (Vgl. Cum. 1895 Fig. 10 Taf. IX, wo die Basidienähnlichkeit sofort in die Angen springt.)

In den Kulturen der Choanephora americana nov. spec., welche zuerst bei mir spontan im Laboratorium auftrat, fanden sich, wie gesagt. neben einander ror Sporangien und Conidienträger (Taf. I Fig 1). Beide erscheinen, wenn sie reif sind, fast schwarz, die Sporangienköpfe sogar tiefschwarz, aber ihle Stiele zeichnen sich aus durch einen dentlich violetten Sichimmer, der an die Farbe angelaufenen Stahls erinnert und den beiden indischen Arten nicht zukommt. Die Stiele der Sporangien sind nach oben schwanenhalsartig gekriimmt, und an der Stelle der stärksten Krï̈mmung ein wenig verdickt, die sporangien hängen. Aehnlich verhält sich C. Cunninghamiana, obwohl hier die Krimmmung schwächer ausgeprägt erscheint, während C. Simsoni in der Form ihrer Sporangien sich genau wie die americana verhält. Die Sporangienmembran ist bei allen dreien durch Kalkabscheidungen fein gekörnelt. Bei allen auch ist ein kuglige Columella vorhanden. Die Grösse der Sporangien ist sehr unbestimmt. Fïr C. Cumninghamiana giebt Cunningham nur $27 \mu$ als Durchmesser an, bei C. Simsoni sagt er, seien die Sporangien grösser, doch ist ein bestimmtes Maass nicht gegeben. Bei C. americana kommen Sporangien von $170 \mu$ Durchmesser nicht selten vor, und solche enthalten nach ungefälnrer Schätzung an 200 Sporen. Die Grösse 
geht aber bei dürftiger Ermährung auf ein sehr kleines Maass zurück, und ich habe Sporangien mit nur einigen wenigen Sporen öfter getroffen, freilich niemals eines mit nur einer Spore, wie es bei C. Simsoni beobachtet worden ist.

Auch ganz reife Sporangien pflegen nicht, wie es bei vielen anderen Mucorineen der Fall ist, sofort zu zerfallen, wenn man sie in Wasser bringt. Es genügt aber ein gelinder Druck, um sie zul sprengen, und man beobachtet dann, dass die einzelnen Sporen durch eine Quellsubstanz etwas anseinandergetrieben werden. Die Sporangiensporen (Fig. 9) haben eine braunröthliche Farbe, spindelförmige Gestalt, eine doppelt konturirte Membran, und an jedem spitzen Ende ein strahlig ausgebreitetes Büschel von je etwa 12-20 feinen hyalinen Fäden, sie gleichen also sehr genan den von C. Simsoni beschriebenen: auch für ihre Farbe gilt dies. Es heisst indess, dass die Sporangiensporen bei C. Simsoni ebenso wie dort die Conidien, und. wie wir gleich hinzusetzen künnen, anch die Conidien unserer Form ein fein gestreiftes Epispor hätten. Dies haben die Sporangiensporen von C. americana nicht und sie unterscheiden sich durch diesen Mangel sehr dentlich ron den Conidien, auch dann, wemn die selm feinen Haarschöpfe nur schwer oder undeutlich zu erkennen sind. So ist hier wieder ein zwar an sich unbedentender aber doch scharfer Unterschied der neuen Form gegeniiber den bekannten festzustellen. Die Haarbiischel entspringen einem sehr feinen knopfförmigen ebenfalls hyalinen Polster an den spitzen Enden der Sporen, und bei gïnstiger Belenchtung und starker Vergrösserung wollte es mir scheinen, als sei die ganze Spore vou einem winzig dümen Mantel solcher hyalinen Substanz umhiillt, der nur an den Polen knopfförmig verstärkt ist. und dort die Haare entsendet.

Bei C. Simsoni heisst es von diesen Haarbüschehn: „a bundle of fine long radiant colourless processes which in some cases originate from a colourless protrusion and in others appear to emerge directly from a point at which the epispore is absent." - 
Ich habe nun oftmals Bilder im Mikroskop gesehen in Uebereinstimmung mit meiner Figur 9, welche ich nur so deuten kann, dass die farblose Masse. aus welcher die Fäden des Büschels ihren Ursprung nehmen, thatsächlich durch die äussere durchbohrte Haut der Spore hindurch mit dem Inneren in Verbindung steht, jedoch nicht durch eine runde, sondern durch eine ringförmige Oeffnung: Nur so kann das oftmals ron mir beobachtete und abgebildete mikroskopische Bild erklärt werden. T'm den Ring selbst zu sehen, müsste man die längliche Spore auf die Spitze stellen und von oben betrachten. Dies ist mir jedoch an meinen Präparaten nicht mehr gelungen und am frischen Material habe ich versäumt, den immerhin schwierigen Versuch zu machen.

Unsere Sporen wechsehn zwar sehr in der Grösse, liaben aber, aus normalen Sporangien entnommen, 27-31 "Länge und 12 15 "/ Breite, auch sind sie unter übrigens gleichen Umständen stets grösser als die Conidien. Für C. Simsoni finden wir das umgekehrte Grössenverhältniss als Regel angegeben. und die Länge von $11 u 17$ ", die Breite von 9 " verzeichnet; auch bei C. Cunninghamiana sollen die Sporen höchstens 20 " Länge und 13 « Breite haben. Wennschon auf die Sporenmaasse ein erhebliches Gewicht nicht zu legen ist, da sie ausserordentlich wechseln - ich habe ansuahmsweise auch bei $\mathrm{C}$. americana Maasse ron $12 \times 6$ " verzeichnet - so dürfte doch soviel sicher sein, dass die grössten und zahlreichsten Sporen und die grössten Sporangien der letztgenannten Form zukommen.

In reinem Wrasser tritt eine Keimmng der Sporen nicht ein. Dagegen kündigt sich eine solche bei Zusatz von Nährlösmngen schon nach einer Stunde durch Anschwellen und Rundung des äusseren Umrisses an. Danach platzt das Epispor, und der Keimschlanch - mit seltenen Ausnahmen nur einer - tritt aus, fast regelmässig seitwärts im Aequator der Spore. Ias Mycel hat sehr dicke Hyphen mit vakuolenreichem grobkörnigen Protoplasma, und wächst unter günstigen Verhältnissen mit ganz ausserordentlicher 
Geschwindigkeit, zeigt dabei alle Eigenthïmlichkeiten der Mucorinenmycelien, die Scheidewandlosigkeit, das Strömen des Protoplasma, das nachträgliche Abgrenzen entleerter Fadenpartien durch Scheidewände u. s. w.

Cunningham meint, es komme den Haarbüscheln eine myceliale Bedeutung zu, demn die Sporen vergrösserten sich vor del Keimung durch Anschwellung, ohne dass Vakuolen aufträten, wie es sonst der Fall ist. Bei Ch. americana habe ich aber mit der Keimung und Anschwellung ein Hellerwerden der braunen Farbe und ein Auftreten von Vakuolen im Innern deutlich beobachtet. glaube demnach nicht, dass es nöthig ist, den Haaren eine solche besondere Bedeutmg zuzuschreiben.

Die Fruktifikation an den in Nährlösungen gezogenen Mycelien tritt sehr bald, oftmals schon nach kaum 24 Stunden ein und zwar entweder wieder in Form ron Sporangien oder aber auch in Conidienköpfen unter jeweils mehr oder weniger genau zu bestimmenden Bedingungen, die wir weiterhin erörtern. Die fruchttragenden Fäden erheben sich in die Luft, und zeichnen sich durch sehr erheblich vermehte Dicke aus gegeniber den Hyphen, von welchen sie entspringen. Träger üppiger Conidienköpfe können bis $50 \mu$ Durchmesser erreichen. In kümstlichen Kulturen ist aber diese Verdickung eine von der Ursprungsstelle nach oben allmählich fortschreitende und eine knollige Terdickung des Fusses der Träger, wie sie für Ch. Simsoni und in minder scharfer Form auch für Ch. Cunninghamiana angegeben wird, kommt hier nicht vor. Wohl aber wurde eine solche dort bemerkt, wo die Conidienträger aus welkenden Blumenblättern von Hibiscus - auf denen unser Pilz auch in Brasilien rorkam - ihren Ursprung herleiteten, und es scheint demnach, wofür anch Cunninghams Beobachtungen sprechen, dass diese knollige Verdickung des Fusspunktes der Conidienträger eine Anpassung an das besondere in den Blumenblättern gegebene Substrat ist; sie füllt die Athemhöhle unter der Spaltöffnung, aus welcher der Fruchtträger austritt. Bei günstigen 
Ernährungsverhältnissen erreichten die Conidienträger eine Länge von $5 \mathrm{~mm}$, bei Ch. Cumninghamiana sollen sie bis $8^{1 / 4} \mathrm{~mm}$ hoch werden, während von Ch. Simsoni nur gesagt wird, dass sie kleiner seien als bei der rorigen Art. In ihrem eigenthümlichen Bau ähneln sich die 'Träger aller drei Arten sehr. Im einfachsten Falle schwillt der Träger am Ende kugelkopfig an und bedeckt sich in seinem oberen Theil auf etwa $\% / 4$ der Oberfläche mit den auf kurzen Sterigmen sitzenden Conidien (Fig. 3 und Fig. 1). Bei besserer Ernährung aber sprossen aus dem runden Kopf sekundäre kurz gestielte hyaline Köpfe (Fig. 6) in wechselnder, in den beobachteten Fällen auf etwa ein Dutzend ansteigender Anzahl. und jeder Kopf trägt nun seinerseits Conidien in derselben Art. wie vorher der einfache Träger. In Fällen noch ïppigeren Wachsthums sind die Träger der sekundären Kïpfe verzweigt. und bringen je 3 oder 4 Conidienköpfe hervor. Bei solchen reich entwickelten Bildungen stehen die Conidienköpfe dicht gedrängt zusammen, und während die Farbe der einzelnen Conidien braunröthlich ist gleich der der Sporangienspore, so sieht ein solcher dichtbesetzter Kopf fast schwarz aus, bisweilen zeigt er auch einen Schimmer von jenem Violett, welches den Stiel so auffällig. färbt, welches aber an der einzeln liegenden Conidie nicht bemerkt werden kann.

Ihren Namen rerdankt die interessante Gattung einer Eigenthümlichkeit, welche nur der zuerst beschriebenen Art, Ch. Cunninghamiana, eigen ist. Bei ihr ist nämlich die untere Hälfte des conidientragenden Kopfes mit stärker widerstandsfähiger Membran versehen, als die obere, auf der die Conidien eingefïgt sind. Fallen nun diese ab, so sinkt die obere Kugelhälfte schlaff zusammen in die übrig bleibende trichterförmige Unterhälfte hinein. und es erscheint der von Conidien freie Träger besetzt mit regelmässig ausgebildeten Trichtern, die Cunningham auch abgebildet hat. Dies ist nun nicht der Fall bei Ch. Simsoni; hier sind die einzelnen Köpfe abgestımpft und älneln der Botrytis einerea. 
Choan. americana steht in diesem Punkte zwischen den beiden indischen Verwandten, sie hat rundliche Köpfe, wie Ch. Cumninghamiana, anch ist die nutere Membranlälfte etwas stärker als die obere ausgebildet, aber ein regelmässiges Zusammensinken in die Trichterform findet doch nicht statt. sondern ein unregelmässiges Welken ist die Regel, nnd die conidienfreien Träger sehen denen der Ch. Simsoni ähnlicher, als den Trichterträgern der Ch. C'unninghamiana. Unter diesen Umständen ist zu bedauern, dass die Gattung nicht auf den Namen C'mninghamia getauft ist, wie Currey wollte (cf. Journal Limn. Soc. 1872), wo dann die zuerst entdeckte Art viel besser Cunninghamia choanephora heissen würde. Die Conidien der Ch. americana sind oval, und zeigen dentlich einen kleinen hyalinen Ansatz an der Stelle, wo sie ron ihrem Sterigma getrennt wurden. Sie sind ron derselben braunröthlichen Farbe, wie die Sporangiensporen, aber ihre Membran lässt deutlich ein regelmässiges Netz von meridian verlaufenden, bisweilen andstomosirenden Streifen erkemnen, die auf Membranrerdickungen zurückzufïhren sind. Hierin stimmen sie mit den Conidien der Ch. Simsoni auf das genaueste iiberein. Ihre Grösse wechselt, beträgt aber an gut entwickelten Köpfen 19-22 "Länge und 9 bis 11 "Breite. Sie sind also ebenso gross, wie diejenigen von Ch. Cunninghamiana, von denen sie durch die Streifung rerschieden sind, und grösser als diejenige ron Ch. Simsoni, mit denen sie die Streifung gemein haben. Uebrigens muss anch hier wieder betont werden, dass auf die stets sehr wechselnden Maasse ein zu grosser Werth nicht gelegt werden darf. In sehr dürftigen Kulturen habe ich auch bei Ch. americana Conidien ron dem Ansmaasse 12-15 $\times 9-10 \mu$ gefunden.

Unmittelbar nach der Aussaat in Nährlösungen schwellen die Conidien an, sie nähern sich der Kugelgestalt, ihre Farbe wird heller, die Streifung der Membran deutlicher, im Inneru werden Vacuolen sichtbar, und nach wenigen Stunden tritt der Keimschlauch aus dem aufplatzenden Epispor (Fig. 8, 10, 11). Sehr 
häufig ist nur ein Keimschlanch vorhanden, wie bei den Sporangiensporen und er tritt auch so ans wie dort, doch finden sich bis zu drei Keimschläuche an einer Conidie, und häufigere Ausnahmen auch in Bezug auf die Austrittsstelle, als bei den Sporen. Demnach stimmt die Keimung iiberein mit derjenigen der Conidien von Ch. Cunninghamiana, aber gar nicht mit Ch. Simsoni, deren Conidien die hier vorliegenden doch sonst so gleichen. Bei dieser Form nämlich platzt nach Cunningham in Folge der Anschwellung das Epispor in unregelmässige Stiicke auseinander. Die Bruchstiicke umgeben die auskeimende angeschwollene Spore wie gebrochene Eierschalen; ein sehr bemerkenswerther und eigenthïmlicher Fall von Conidienkeimung, ein Gegenstück zu Chaetocladium Fresenianum, dessen Keimung bei Brefeld Band IX Taf. II Fig. 23 dargestellt ist. Anch die Sporangiensporen dieser Art keimen in ähnlicher Weise, jedoch spaltet hier das Epispor nur in unregelmässiger Weise auf. Diese Beobachtungen geben Cunuingham Anlass zu folgender Bemerkung: „The occurence of rupture of the epispore of the sporangic spores clearly shows that the occurrence of such a phenomenon in the case of conidia is no just ground for regarding the latter as parallels of unisporic sporangia; for if the conidia are to be regarded as such on this ground, than in a case like the present the sporangic spores must be regarded in the same light and this leares the presence of the mother sporangium unaccounted for. Evell where conidiiferous filaments produce a single conidinm and the sporangia become unisporic. as is not unfrequently the case under the influence of defective nutrition, the difference between the two forms of fructification remains as sharply defined as ever."

Diese Bemerkungen sind sehr fein und bestechend. Es lässt sich aber dagegen einwenden, dass sie von der Voraussetzung ausgehen, es seien die Conidien hervorgegangen aus den Sporangien, wie sie heute neben ihnen rorkommen. Dann allerdings würde man das braune Epispor der Conidien mit dem der Sporangien- 
sporen gleichbedeutend setzen müssen. Wenn wir aber ans anderen Thatsachen, unter denen die Übergänge von Sporangien zu Conidien bei Peronospora, ferner Formen wie Chaetocladiun und Thamnidimm maassgebend sind, schliessen, dass die Conidien als einsporig gewordene Sporangien richtig aufzufassen sind, so können wir als eine Bestätigung für diese Auffassung auch das Zerplatzen des Epispors der Conidien von Ch. Simsoni anffassen. Nur müssen wir annehmen, dass diese Conidien von Sporangien herstammen, die zugleich Stammformen der heutigen Sporangien waren, von diesen aber sehr verschieden gebildet sein konnten. Das braune Epispor der Sporangiensporen kann und wird walnsscheinlich nach jener Spaltung der Fruchtformen erst siclı gebildet haben, und ebenso dasjenige der Conidien. Hierfür spricht die rerschiedene Bildung beider, die bei Ch. americana besonders anffallend hervortritt, wo das Conidienepispor gestreift, das der sporangien aber glatt ist.

Als dritte Fruchtform besitzt Ch. americana gleich ihren Gattungsgenossen Chlamydosporen, die sich im Terlanfe der Fäden dadurel bilden. dass das Protoplasma aus grösseren Fadensystemen sich nach einem Punkte zusammenzielnt; an dieser Stelle verdickt sich der Mycelfaden und nimmt spindelförmige Gestalt an, dieser spindelförmige Ranm füllt sich mit immer mehr concentrirtem Protoplasma und grenzt sich nach beiden Seiten durch eine Scheidewand ab. Die normale Form dieser Gemmen ist in Fig. 13 dargestellt. Sehr viele aber gelangen nicht zu dieser Normalform. sondern zeigen beliebige unregeimässige, semmelförmige oder sogar verzweigte Formen. wenn der Punkt der Zusammenziehung des Protoplasma an der Terzweigungsstelle eines Mycelfadens lag. In diesem Falle wird die Chlamydospore durch drei Scheidewände abgegrenzt. Unter geeigneten Umständen keimen die Chlamydosporen wieder aus, und zwar meist mit einem Keimfaden, der um vieles stärker ist als derjenige Mycelfaden, in dessen Terlauf sie entstanden (Fig. 14).

Zygosporen, welche Cunningham bei seinen beiden Formen, 


\section{- $29-$}

und zwar bei Ch. Cumninghamiana seltener und nur auf dem natürlichen, in den Hibiscusblumen gegebenen Substrate, bei Ch. Simsoni häufig, sogar in künstlichen Kulturen erhielt, traten bei der brasilischen Form niemals auf, obwohl ich sie drei Tahre hinter einander auf rerschiedenen Substraten und in mannigfach geänderten kïustlichen Kulturen untersuchte.

Nachdem wir so die Beschreibung der brasilischen Form vergleichsweise mit den beiden indischen vollendet haben, ist es wohl auch der Mühe wertl, das Torkommen und Terhalten einer âhnlichen vergleichenden Betrachtung zu unterziehen und ich kaun hier überall an die ron Cumningham gemachten Ausführungen und Bemerkungen anschliessen.

Ch. Cunninghamiana ist, wie es scheint, nur und ausschliesslich auf den Blumenblättern ron Hibiscus gefunden worden. Zwar giebt Cumningham in seiner ersten Arbeit auch Blumen der Zinnia als Standort an, sagt aber 1895, dass hier wohl eine Terwechselung mit der erst später entdeckten Ch. Simsoni vorliege. Die Blumenblätter werden vou dem Pilze im ersten Beginne des TVelkens, jedenfalls noch am Strauche befallen, nicht aber, wem sclıon weitere Zersetzung an ihnen eingetreten ist. Das Welken wird durch den Pilz beschleunigt. Ganz genau so verlı̈lt sich auch Cl. americana, die ich ebenfalls im Jahre 1892 auf den Blumenblättern eines weiss blühenden Hibiscus antraf. Der Pilz fand sich auf den moch am Stiele sitzenden, kaum den Anfang des Terwelkens zeigenden Blättern, kam aber zur üppigsten Entwickelung erst an den abgefallenen am Boden liegenden Blumen, und er entwickelte sich am allerbesten, wenn man die Blumen, welche als befallen erkannt waren, sofort abgepfliickt auf fenchten Sand legte und mit einer Glocke iberdeckte. Schon oben labe ich aber erwähnt. dass ich den Pilz in Jahre 1891 zuerst mit faulenden Blatt- und Zweigstïckchen vom Rande eines Urwaldbaches unbeabsichtigt ius Laboratorium rerschleppte. wo ich damn sein natiuliches Substrat nicht mehr genau zu bestimmen vermochte. Doch 
war ein Hibiscus hier ganz ansgeschlossen. Im Jahre 1893 fand ich ihm auf schon weit in der Zersetzung vorgeschrittenem abgeschnittenen und bei seite geworfenen Spargelkraut (herrührend von einem Versuche mit aus Europa eingeführten Spargelpflanzen) und anf diesem Substrat war er üppiger entwickelt als jemals auf den Hibiscusblumen. Hiernach ist nun wohl mit Gewissheit anzunehmein, dass der Pilz als ein Saprophyt im Walde bei Blumenau anch anf anderen verwesenden Pflanzentheilen bei genauem, freilich nicht ganz leichtem Suchen anzutreffen sein würde, und dass er als Saprophyt mit vollem Rechte bezeichnet werden kann. Trotzdem kamn ich nun Cumninglam nicht recht beistimmen, wenn er die (h. Cumninghamiana in seiner zweiten Arbeit am Schlusse als "a purely saproplytic organism" in einen scharfen, meiner Ansicht nach gewaltsamen Gegensatz zu der Choan. Simsoni bringt. die als „Parasitic species“ schon im Titel der Arbeit bezeiclnet wird. Ich meine vielmehr, dass $\mathrm{Ch}$, Cuminghamiana und americana sehr lehrreiche Beispiele von beginnendem Parasitismus sind. So unsicher und schwankend wie die Grenze zwischen einem frischen Blithenblatt und einem anderen ist, welches die ersten Spuren des Terwelkeins aufweist. so msicher ist die Entscheidung darüber, ob jenes Torkommen der beiden Choanephorarten noch als saprophytisch oder schon als parasitisch bezeichnet werden mus.s. Wie leicht ist die Vorstellung; dass die Choanephora, welche msprünglich oder vielleicht anch noch jetzt nur Blätter mit Spuren des Verwelkens befällt. später. rielleicht schon jetzt, auch auf' frischen zu keimen rermag oder lernt. nud sich noch weiterhin rielleicht zu einem Parasiten des Hibiscus entwickelt. der schon die Knospen befällt und an der Fntfiltung hindert! Jil diese Ueberlegungen drängen sich doch wie ron selbst auf, wenn wir hören, dass ('hoan. Simsoni auf gesunde Blüthenblätter ron Zimnia übertragen, dort keint und das Abwelken der Blätter hervorruft. und dass diese Form auf Ipomoea rubro-coerulea zu einem gefähl'lichen Parasiten thatsächlich geworden ist, der Blätter und Achsen 
befällt, und die Kultur der Pflanze zum Stillstand bringt. Da num weiter diese letztere Form sich der künstlichen Kultur sehr wohl zugänglich zeigt, ja in ihr sogar üppig gedeilıt und reichlich Zygosporen bildet, so geräth Cunninglam in ernste Zweifel darüber. ob man sie besser als "fakultativen Parasiten" oder als "fakultativen Saprophyten" zu bezeichnen habe, und er führt aus, dass wenn man die Ueppigkeit des Wachsthums als Maassstab nehme. die zweite Bezeichnung; während wemn man mit de Bary die Erzellgung ron Zygosporen als ausschlaggebend anerkenne, die erste Bezeichnung gewählt werden mïsse.

Nichts kam besser als diese ernsthafte Untersuchung vor Augen führen, wie gründlich verfehlt jene Ausdrücke von fakultativem Parasitismus oder Saprophytismus gewählt sind, Ausdrücke die nur entstanden unter der Nachwirkung des Fundamentalirrtlums, es gäbe geborene Parasiten und Saprophyten unter den Pilzen, zwischen denen eine reinliche Scheidung mögliclı sei. Dass die parasitisch rorkommenden Pilze ron solchen Formen herstammen, die ron Parasitismus noch nichts wussten, dass sie sich allmällich elst, die einen unvollkommener, die anderen bis zu erstamlich holem Grade dem Leben auf ihren Wirtlispflanzen angepasst haben, ist es denn nöthig; das heute noch zu betonen. machdem der Gegenstand schon ror 16 . Tahren (Brefeld IT S. 30 ff.) ron Brefeld klar behandelt und seitdem wiederholt mit immel nenem thatsächlichen Beweismaterial dargestellt worden ist? Und demnoch scheint es nothwendig, darauf zurückzukommen, wemn ein so grïndhicher Mykolog wie Cumingham diese Frage in der Art zu behandeln für nothwendig hält, wie oben angedentet wurde. Fs ist bemerkenswerth. dass die drei rerschiedenen Formen ron Choanephora, welche wir nun kemnen, und die mit einander offenbar sehr nahe rerwandt sind, die Uebergänge ron saprophytischer zu parasitischer Lebensweise in verschiedenen Abstufungen zeigen. Alle drei gedeihen rorzüglich in rerschiedenen künstlich hergestellten Nährlösungen, können also saprophytisch leben, ron 
Ch. americana wissen wir, dass diese Lebensweise anch in der Natur noch nachzuweisen ist, von $\mathrm{Ch}$. Cuminghamiana ist mit Sicherheit dasselbe anzunehmen. Diese beiden Formen kommen nun auch auf Blumenblättern von Hibiscus vor, und zwar während diese Blumenblätter noch an ihrer natürlichen Stelle sich befinden. Ob sie nur solche Blätter befallen, die schon zu welken anfangen, oder auch ganz gesunde, ist nicht über allen Zweifel festgestellt. In den knolligen Terdickungen, welche unter der Epidermis des Blattes und unter der Ursprungsstelle der Fruchthyphe bei Ch. Cumninghamiana beschrieben werden, dürfte schon eine Anpassung an den besonderen Standort, an die Wirthspflanze also zu erblicken sein. Denn nach Cunningham zeigt z. B. Ch. Cmnn. in künsthicher Kultur diese Anschwellung nicht, so wenig wie unsere Ch. americana. Ch. Simsoni befällt dann thatsächlich auch gesunde Pflanzen der Ipomoea rubro-coerulea an Stengeln und Blättern und bringt sie zum Absterben. tritt also in ansgeprägter Parasiteneigenschaft anf. Dementsprechend sind bei ihr jene Anschwellungen am stärksten, und sie werden auch als Anpassungen an die Wirthspflanze erklärt: es sind nämlich einfach nyceliale Ansfüllungen der Athemhöhle unter der Spaltöffnmmg. aus welcher der 'Träger hervortritt. Dass auch diese Choanephora in der Natur' auf totem Substrat anzntreffen sein würde, ist nach den vorzïglichen Resnltaten. die ('mnningham in künstlichen Kulturen erzielte, wahrscheinlich.

Mit dieser Feststellung der 'Thatsachen ist alles W'esentliche gesagt. Die Frage, ob Ch. Simsoni als fakultativer Saprophyt oler Parasit richtig zu bezeichnen sei, kann meiner Ansicht nach ein wissenschaftliches Interesse überhaupt nicht beanspruchen. Uebrigens werde ich weiterhin bei dem Corallomyces Jatrophae nov. spec. noch ein sehr bemerkenswerthes Beispiel von dem Parasitischwerden eines saprophytischen Pilzes rorzuführen in der Lage sein.

In Brasilien habe ich die Ch. americana in drei auf einander- 
folgenden Jahren immer etwa um dieselbe Jahreszeit beobachtet; 1891 im Februar an vermoderten Zweigen im Walde, 1892 Anfang März auf Hibiscusblumen, 1893 im Februar an Hibiscus und im März an faulendem Spargelkraut, wie ich oben schon mitgetheilt habe. Dies Torkommen stimmt mit dem aus Indien über die beiden verwandten Arten mitgetleilten überein. Anch jene treten gegen Ende des Sommers, im September, auf und verschwinden im allgemeinen mit Eintritt trockener und kühler Tage im November, gleichrvie die südamerikanische Form nach meinen Beobachtungen mit den kälteren Tagen des April, spätestens Anfang Mai verschwand. Den Hibiscusstrauch, an welchem der Pilz rorkam, hatte ich das ganze Jahr unter Augen und ron diesem Standorte wenigstens weiss ich, dass er in der Zwischenzeit. also rom Mai bis zum nächsten Februar. frei ron dem Pilze war. Es ist mit Rïcksicht auf die in Kulturen gewonnenen Ergebnisse wahrscheinlich, dass der Pilz anch anderwärts um diese Zeit nicht in Erscheinung trat, obwohl dies nicht zu beweisen ist. Demnach entsteht die Frage, in welcher Form er die lange Zwischenzeit zubringt, und die Termuthung spricht dafür, dass dies in Form der bei den beiden so nalie verwandten Arten vorgefundenen Zygosporen geschieht, obwohl es mir nicht gelungen ist, solche aufzufindell.

Ueber die Zeit und die Bedingungen des Auftretens von Sporangien, Conidien und Chlamydosporen macht Cunningham sehr bemerkenswerthe ausführliche Mitheilungen. Eine der wunderbarsten hierher gehörigen Thatsachen ist jedenfalls die, dass die Conidienträger von Ch. Cunninghamiana "only in the hours of darkness" gebildet werden. Ehe ich die Cunninghamsche Arbeit erhielt, hatte ich viel Zeit vergebens aufgewendet, um Conidienträger während ihrer Bildung anzutreffen und zu beobachten. Ich kam erst nach Verlauf einiger Tage auf die richtige Spur, indem ich feststellte, dass auch diese Träger ausschliesslich in den frühen Morgenstunden gebildet werden. Das Licht spielt liierbei keine Rolle 
mehr, denn auch an den dauernd dunkel gehaltenen Kulturen tritt nur um jene Zeit die Bildung der Conidienköpfe ein. Von Ch. Simsoni ist über diese merkwiirdige, vorläufig wohl unerklärliche Erscheinnng nichts mitgetheilt.

Anch iiber die Bedingungen, unter denen die eine oder die andere der verschiedenen Fruchtformen anftritt, stellte Cunningham Untersuchungen an. Diese Bedingungen sind fïr die Zygosporenbildung nicht bekannt, im übrigen aber auscheinend allein in der grösseren oder geringeren Konzentration der Nährlösungen gegeben. Nur die Ernährungsbedingungen sind nach Cunningham ausschlaggebend, und zwar treten bei Ch. Cumninghamiana, wenn vollkommen ausreichende kräftige Nährlösmng verwendet wird, nur die Conidienträger auf, bei geringerer Nährlösung werden diese 'T'räger schwächer und weniger verzweigt angelegt, und daneben treten Sporangien auf, bei ganz geringer Ernährung erscheinen die Chlamydosporen. Bei Ch. Simsoni werden die Conidienträger allerdings auch nur bei kräftigster Ernährung gebildet. die Sporangien lingegen treten bei allen Frnährungsgraden auf nnd erreichen beträchtlichere Grösse nud üpligere Fntwickelung als bei der ersten Form. Chlamydosporen finden sich auch hier nur bei schlechter Ernährung. Cumningham nimmt hiernach an, dass für Ch. Cumn. die Conilienform, für Ch. Sims. aber die Sporangienform die normale typische sei, und er macht hierzu die anregende Bemerkung, es scheine demmach Ch. c'mm. mehr zu den conidientragenden Stämmen der höheren Pilze, Ch. Sims. hingegen mehr zu den sporangientragenden hinzuneigen.

Bei beiden indischen Pilzen sind auf dem natürlichen Substrat nur die Conidien gefmuden, in Brasilien fand ich dort sowohl Conidien als sporangien. In den kïnstlichen kinlturen traten beide Fruchtformen in wechsender Mischung auf. aber als ein Durchschnitsergebniss ans sehr zahlreichen Kulturen lässt sich auch hier feststellen. dass bei reicher Enährung die Conidien, bei schwacher die sporangien rorzugsweise erschenen. Erwähmmg verdient vielleicht die durch vielfache Versuche festgestellte 'l'hat- 
sache, dass es für die Ergebnisse der Kultur vollkommen gleichgiiltig ist, ob Conidien oder Sporangiensporen oder Chlamydosporen den Ausgangspunkt bilden.

In jedem Falle ist das Wachsthum des Mycels bei genügend vorhandener Nahrung ganz ausserordentlich. Ein dicker Nährlösungstropfen von der Grösse eines Narkstïckes, wird von einer einzigen Spore aus in Zeit von 12 Stunden mit so dichtem Mycelgeflecht durchwuchert, dass kein mikroskopisches Gesichtsfeld ohne Mycelfaden mehr zu finden ist. Ich habe einmal das ans einer Spore in Zeit von 7 Stunden gewachsene Mycel genan gemessen und gefunden, dass es das 24 fache Volumen der Kieimspore besass. Schon nach 24 Stunden können hier wie bei Ch. Cunninghamiana Conidienträger erzeugt werden. Wemn man aber starke Nährlösung anwendet, so ist zunächst nur die Mycelentwickelung gefördert. Saugt man alle 24 Stunden die erschöpfte Nährlösung ab, und ersetzt sie durch frische hochkonzentrirte, so kann man die Fruktifikation bis zu 8 Tagen hinausschieben; sie erscheint dann mit um so grösserer Ueppigkeit, und die Träger der Conidien sind auch in künstlicher Kultur dann eben so reich gegliedert, wie auf dem natïrlichen Standort. Ich stellte in grösseren Krystallisirschalen eine diimme Schicht von Arrowrootkleister her, angerïhrt mit Nährlösung, und durch melrrfaches Erhitzen über dem Wasserbade nothdïrftig sterilisirt. Nachdem die Aussaat der Choanephora anf diesem Substrat vorgenommen war, so danerte es acht Tage, während deren das Mycel die ganze Kleisterschicht durchwucherte; dann erschienen mit einem Male in dem Raume der ganzen schale die üppig entwickelten Conidienträger. Ein in kräftiger Nährlösung wachsendes Mycel brancht man nur in eine dïmne wässrige Lösung zu ïbertragen, so tritt sofort (jedoch immer nur in den frühen Morgenstunden) die Fruktifikation ein.

Da mir daran gelegen war, den Beweis der Zusammengehörigkeit beider Fruchtformen durch die Kultur in ganz zweifelloser 
Weise zu erbringen, so stellte ich viele Kulturen an, indem ich je eine Conidie in dünne Nährlösung aussäete, und auf diesem Wege gelang es auch, das in Fig. 2 abgebildete Mycel zu züchten, welches zeigt, wie aus dem von der Conidie herstammenden Mycel das Sporangium gebildet wird. Die grössere Fig. 1 zeigt einen Conidienkopf und ein Sporangium an ein und demselben Mycel.

Von der Einwirkung der Temperatur auf die Choanephora giebt die folgende Beobachtung ein Beispiel. Ich hatte zahlreiche Kulturen, von denen an jedem Tage einige fruktifizirten. Am 4. Mai war die niedrigste beobachtete Temperatur in der Nacht noch $17^{\circ} \mathrm{C}$., die fälligen Kulturen fruktifizirten; am 5. und 6. Mai hatten wir dagegen Minima von 7 und $8^{\circ} \mathrm{C}$.. alle Kulturen standen still, nicht ein Conidienträger wurde gebildet, auch nicht in solchen Kulturen, die entsprechend kräftig mehrere Tage ernährt und dann mit Wasser versetzt waren, und die sonst mit Sicherheit auf diese Behandlung mit Conidienbildung geantwortet liatten. Mit dem Steigen der Minimaltemperatur in den folgenden 'Tagen des Mai trat auch wieder Fruktifikation ein.

Die Chlamydosporen bilden sich auch bei Ch. americana wie Cunningham für die beiden anderen Arten angiebt, nur unter ungünstigen Ernährungsverhältnissen. Am sichersten erzielte ich sie, wenn ich in den Nährlösungstropfen recht viele Sporen oder Conidien auf eimmal aussäete. Alsdamn traten sie massenweise schon nach wenigen Stunden anf.

Es verdient wohl Erwähnung, dass die Chlamydosporen von Choanephora mit ihrer noch wenig bestimmt ansgeprägten Form durchaus jene Auffassungen bestätigen, welche iiber den morphologischen Werth der Chlamydosporen bei den Zygomyceten Brefeld im VIII. Bande seiner Untersuchungen Seite $211 \mathrm{ff}$. niedergelegt hat. Brefeld sieht in diesen Chlanydosporen individnalisirte, gleich den Sporen der Fortpflanzung dienende Fruchtträgeranlagen, und als sichere Bestätigung dieser a. a. O. eingehend begrïndeten Auffassung finden wir bei Cumningham die Nittheilung. 
dass mehrfach die unmittelbare Auskeimung von Chlamydosporer der Ch. Simsoni zu Sporangien genan in derselben Weise beobachtet wurde, wie sie bei Brefelds Chlamydomncor racemosus vorkommt, und als klassisches Beispiel für die Frläuterung ïber den morphologischen IVerth der Chlamydosporen Verwendung fand.

Die vorliegende Untersuchung über Cloanephora americana und die Betrachtmng der beiden durch Cunningham bekannt gemachten verwandten indischen Formen bietet mir den willkommenen Anlass hier am Schlusse meiner Mittheilung iiber brasilische Plyycomyceten darauf hinzuweisen, wie alle einschlägigen Beobachtungen ïber Pilze. welche veröffentlicht sind, seit Brefeld im X. Bande seines Werkes den Grundplan des natürlichen Systems der Fadenpilze aufstellte, sich diesem Plane auf das natïrlichste anschliessen und unterordnen, so seine Richtigkeit immer mehr und mehr erweisend. Und es bietet sich zn gleicher Zeit die Gelegenheit, die ich als Brefelds Schüler nicht vorbeigehen lassen darf, Stellung zn nehmen auch gegenïber jenen Veröffentlichungen, die in nenerer Zeit ganz besonders gegen den Grundgedanken der Brefeldschen Arbeiten. die Ungeschlechtlichkeit der höheren Pilze gerichtet und am eifrigsten von Dangeard in seiner Zeitschrift „Le Botaniste" gefördert worden sind.

Ich habe schon oben bei Beginn der Nittheilung über Choanephora gesagt, dass diese Gattung für die vergleichende Morphologie der Pilze eine ganz einzigartige Bedentung dadurch hat, dass sie ganz allein von allen die man kennt, an ein und demselben Einzelwesen neben einander rorkommend alle Fruchtformtypen aufweist, die bei Pilzen iiberhaupt bestehen (s. S. 21). Es giebt keine Fruchtform irgend eines bekannten Pilzes, die sich nicht auf eine der bei Choanephora vorkommenden leicht und natiirlich zurückführen liesse. Darum giebt es vielleicht keine andere Gattung im ganzen Reiche der Pilze, welche so geeignet ist zur Einführ'ung in das richtige Verständniss 
des natiurlichen Systems der Pilze, wie wir es Brefelds Lebensarbeit verdanken. Dieses natürliche System, welches uns durch die Mannigfaltigkeit der Formen so sicher führt, welches eine so klare, dabei in den Grundziigen so überaus einfache Uebersicht des ganzen Reiches gestattet, gewinnt zwar von Jahr zu Jahr mehr und mehr verständnissvolle und überzeugte Anhänger. Wenn aber trotzdem die mykologische Literatur anch der neuesten Zeit reich ist an Schriften, die sich nicht auf den Boden der Brefeldschen Anschaumngen stellen, zum 'Theil an solchen, die sie ummittelbar bekämpfen, so liegt der Grund vielleicht in den meisten Fällen darin, dass die betreffenden Autoren nicht griundlich und tief genug in den Geist der Brefeldschen Darlegungen eingedrungen sind, dass sie insbesoudere jene meisterhaften zusammenfassenden Abhandlungen, die am Ende des VIII. Bandes der ,. Untersuchungen aus dem Gesammtgebiete der Mykologie" von Seite 185 an und noch kïrzer, schärfer und schlagender zusammengefasst von Seite 341 des X. Bandes an zu finden sind, nicht mit genügendem Verständnisse gelesen haben. Auch die "vergleichende Morphologie der Pilze" von von Tavel (Jena 1892), in welcher die Brefeldschen Anschaumgen einen möglichst klaren durch zahlreiche Abbildungen erläuterten Ausdruck gefunden haben, hat meinem Gefiille nach bis hente noch nicht in genügendem Grade das klare Verständniss des natürlichen Systems der Fadenpilze zum Gemeingut aller arbeitenden Mykologen werden lassen. Der Grund dieser Erscheinung liegt meines Erachtens darin, dass nur verhältnissmässig wenige Mykologen mit den Vethoden der künstlichen Kinltur der Fadenpilze genügend vertraut sind, nur zu wenige sie ausïben. In den 'Thatsachen der Entwickelungsgeschichte aber, welche allein die künstliche Kultur uns anfgedeckt hat, in ihnen liegt der Schlüssel zum wahren Verständniss des natïrlichen Systems. Diese Thatsachen wirken unmittelbar und völlig überzeugend nur auf den, der sie mit eigenen Augen sieht. Sie können stets nur höchst unvollkommen und mangelhaft durch Wort und Bild einem grösseren Publikum 
mitgetheilt werlen. Wer niemals Kulturen des Heterobasidion annosum selbst gemacht hat, wo auf jedem Objektträger hunderte von mannigfachen Uebergängen ihn den Zusammenhang von Conidienträger und Basidie verstehen lehren, dem kann keine noch so beredte Schilderung die Ueberzeugung verschaffen, welche eine Durchmusterung solcher Kultur mit dem Mikroskop sofort gewährt. Die Menge der Einzelheiten. welche in ihrer Gesamtheit erst zur richtigen Beurtheilung der Thatsachen führen, kann Niemand abbilden; wer nicht selbst in täglich beobachteten Kulturen zugesehen hat, wie Conidien einzeln an Mycelfäden entstehen, wie sie damn in dichterer Zusammenordnung auftreten. wie die Art ihrer Bildung bestimmter wird. wie sie zu fruchtkörperähnlichen Gebilden sich zusammenordnen. dem kann keine Beschreibung den Einblick ersetzen, welchen solche Beobachtmng der wachsenden lebenden Organismen thun lässt in die Werkstätte der Natur: in der die Fruchtkörper der lıöheren Pilze gebildet wurden. Nur allein darin dass es so schwer ist, die Entwickelungszustände der Pilze in künstlicher Kultur schrittweise beobachtend zu verfolgen, dass es unmöglich ist die Kulturen in Präparaten von genïgender Uebersichtlichkeit aufzubewahren. oder in Abbildungen von ausreichender 7ahl einem grösseren Publikum mitzutheilen, dass stets naturgemäss nur wenige Forscher Zeit. Gelegenheit, Lust und Geschich genug haben, solche Beobachtungen anzustellen und aus eigener Anschaumg jene 'Thatsachen der vergleichenden Morplologie der Pilze kennen zu lernen, welche das feste und sichere Fundament des von Brefeld aufgeführten Baues bilden, nur allein darin finde ich den Grund dafür, dass nicht längst das Brefeldsche System der Pilze in noch viel löherem Grade die allgemeine Anerkenung der arbeitenden Mykologen gefunden hat, als es z. Z. schon der Fall ist. Nichts ist nach Brefelds Arbeiten an mykologischen Untersuchungen erschienen, was bei unbefangener Wiirdigung seine Anschaumgen in ihren wesentlichen Punkten zu erschïttern geeignet sein könnte, und Dangeard irrt, wenn er glaubt, durch die 
zahlrenclıen Arbeiten, welche in den nummehr rorliegenden 7 Bänden seiner" Zeitschrift "Le Botaniste" niedergelegt sind, ein Hauptel" gebniss der Arbeit Brefelds umgestossen zu haben.

Es ist dieses Hauptergebniss der Nachweis, dass die Reilue der Pilze sich im Gegensatze zu der der Thiere und Pflanzen ungeschlechtlich entwickelt hat. "Ich glaube mich nicht zu irren", sagt Brefeld (Bd. VIII S. 272), ,wenn ich annehme, dass mit dem Nachweise diesel beiden Reihen, der sexuellen und der asexuellen Reihe einer der wichtigsten und ersten Fortschritte gewonnen ist, welche auf dem Gebiete der Morphologie und der Systematik der Pflanzen und der Gesammtlıeit der Lebewesen ïberlaupt möglich sind."

Brefelds wiederholt und in kürzester Zusammenfassung am Finde des TII. Bandes seines Trerkes niedergelegte Auffassung geht dahin, dass die Sexualität bei den niederen algenälnnlichen Pilzen in derselben Form rorhanden ist, wie bei den rerwandten Algen, dass sie in der Reihe der grïnen Pflanzen bestehen bleibt, sich immer hölıer entwickelt, ja schliesslich die ungeschlechtliche Fortpflanzung ganz in den Hintergrund drängt. Die vergleichende Norphologie der Sexualorgane lıat bei den grimen Pflanzen die höchsten Triumphe der Systematik gezeitigt. Sie ist zur Grundlage des in seinen Hauptzügen sicher begründeten natürlichen Systems der griunen Pflanzen geworden. Anders in der ungeschlechthichen Reihe der Pilze. Die Sexualität, welche bei den niederen Formen noch vorlanden war, geht verhältnissmässig' früh, schrittweise verfolgbar. zurück bis zum Terschwinden; die ungeschlechtlichen Fruchtformen überwiegen mehr und nehr, und das ganze grosse Reich der Fadenuilze entwickelt sich bis zu seinen höchsten stufen ohne Sexualität. Die rergleichende Morplologie der ungeschlechtliclıen Fruclıtformen erwies sicll hier aber als eine ebenso sichere Fülırerin durch das Labyrinth der verschiedenen Gestalten. wie die rergleichende Morphologie der Sexualorgane es in der Parallelıeihe der grüren Pflanzen gethan lıatte; sie führte zu dem durclı Brefeld errungenen 
und wenn anch mit Widerstreben allmählich immer mehr und melır als richtig anerkannten natürlichen System del Fadenpilze, wie wir es lieute haben.

Brefeld kan zu seinen Schlüssen keineswegs auf Grmnd rorgefasster Meinungen. Bei seinen ersten Arbeiten steht er durchans auf dem Boden der damals herrschenden de Baryschen Ansichten. er spricht sich noch $187 t$ im II. Bande seines W'erkes S. 80 dahin aus, dass, bei den höheren Pilzen die ursprüngliche Form ungeschlechtlicher Termehrmng nicht mehr existirt. dass sie von der fortschreitenden Sexualität unterdrückt sei". Nur die zwingende Gewalt der durch lange fortgesetzte. stets weiter ausgedehnte Untersuchungen festgestellten 'Thatsachen brachte Brefeld im Lanfe der Jahre zu der immer klarer, inmer bestimmter gefassten, oben kurz dargelegten Anschaumng.

Ton Anfang an aber begegnete die Lelne ron der Asexualität der höheren Pilze dem Lnglauben und der Anfeindung zahlreicher Mykologen. Es war, als ob dieselben unter der Herrschaft des Dogma ständen: die Sexualität muss vorhanden sein. es handelt sich nur dal'um, sie zu finden. Und sie wurde gefunden, an den verschiedensten Stellen in dem Entwickelungsgange einzehner Pilze. in der rerschiedensten Gestaltung der als sexuell gedeuteten Organe: und bis in die allerneueste Zeit haben die Entdeckungen der Sexualität der lı̈lıeren Pilze nicht aufgelı̈rt. Das Torkommen sehr kleiner. in grosser Zahl gebildeter, anscheinend nicht keimfälıiger Conidien bei Basidiomyceten und Ascomyceten verleitete zuerst dazu, in diesen Organen „Spermatien“" zu sehen. Reess und van Tieghem entdeckten in den $70 \mathrm{er}$ Jahren die sexuelle Bedentung solcher Conidien beim Coprinus stercorarius, die ron Brefeld in seiner klassischen Untersuchnng desselben Pilzes (Bd. III) so schllagend und zweifellos als nicht vorhanden nachgewiesen wurde, dass nachdem Niemand melı darauf zurïckgekommen ist. Die ungeschlechtliche Fortpflanzung der Basidiomyceten blieb nothgedrungen bis in die allerneueste Zeit als nnangreifbare Thatsache mnan- 
gefochten. Nicht so bei den Ascomyceten. Hier latte Stahl 1877 in den sogenannten Spermatien des Collema microphyllum männliche Organe zu finden geglaubt und deren befruchtende Wirkung auf das mit einer Trichogyne versehene Ascogon ausfïhrlich geschildert. Stahls Arbeit fand ausserordentliche Beachtung, man lielt den Nachweis der Sexualität für die Ascomyceten damit für erbracht, in de Barys rergleichender Morphologie von 1884 wurden die Stahlschen Beobachtungen als unumstössliche Thatsachen aufgeführt. Eine Form aus der ungelieuren Zahl der Ascomyceten war anfgefunden, bei der eine geschlechtliche Deutung der Untersuchungsergebnisse möglich schien. Ein Beweis fïr die materielle Vereinigung der männlichen und weiblichen Zelle war nicht erbracht. ja die Möglichkeit einer solchen Vereinigung musste jeden Unbefangenen aufs äusserste unwahrscheinlich bleiben; denn der befruchtende stoff des ,.Spermatiums: hätte durch eine ganze Reihe von Zellwänden der Trichogyne sich durcharbeiten miissen; und labei war nicht einmal sein Eintritt in die oberste freiliegende Spitzenzelle sicher gesehen worden. Die Stahlschen Beobachtungen fanden auch keine Bestätigung in späteren Untersuchungen. Bei Polystigma und bei Gnomonia fand man Bildungen, die der Collemaceentrichogyne ähnlich waren. md gleichzeitig fanden sich nichtkeimende Conidien bei diesen Formen, welche man als Spermatien deutete. Aber auch bei diesen Formen gelang es nicht, die Vereinigung des Spermatieninhalts mit der weiblichen Zelle zu sehen. Brefeld führte den mnangreifbaren Nachweis, dass in all den aufgeführten Fällen falsche Deutungen der ungenügend beobachteten 'T'hatsachen vorlagen, dass ron einer Sexualität bei ihnen nicht die Rede sein könne. Nachdem er schon im Jahre 1881 (Heft IV S. 148 fi.) seine begriundeten Zweifel gegeniiber der Stahlschen Behauptung der Sexualität bei den Flechten klar ausgesprochen hatte, reranlasste er mich in .Jahre 1887, die Kúnlur der sogenannten Flechtenspermatien in Nählösungen zu unternehmen. Ich konnte feststellen, dass in 9 verschiedenen Fällen 
beliebig herausgegriffene Flechtenspermatien keimten und sich entwickelten, wie andere Conidien auch, ja dass auch die als Spermatien ganz besonders verdächtigten Conidien des Collema microphyllum sehr langsam zwar, aber doch sicher in Nährlösungen zur Alskeimung in Fäden zu bringen waren (rgl. Bot. Ztg. 1888 S. $422 \mathrm{ff}$.). Um aber die Spermatien der Ascomyceten überhampt verschwinden zu machen. ihre wahre Natur als Conidien für jeden nubefangen Urtheilenden ganz sicher zu stellen, bedurfte es weiter ausgedehnter umfassenderer Untersuchungen. Brefeld lieferte sie mit ron Tavels Unterstiitzungen im IX. Bande seines Terkes. Er fasste das Ergebniss (TX S. 53) kurz dahin zusammen: „im Ganzen sind mehr als zweihundert verschiedene Formen ans allen Klassen der Ascomyceten zur Untersuchung gelangt, deren Nebenfruchtformen theils direkt bisher als Spermatien angesprochen worden sind, theils nach aller Analogie so gedeutet werden konnten. Si haben alle das Resultat ergeben, dass es Spermatien nicht giebt. Diesen zweilnundert stehen - vier Formen gegenïber, auf welche die sexuelle Dentung der Spermatien sich grïndet, Polystigma, Gnomonia. Collema und Physma, welche ausserdem, wie gezeigt wrurde, der Kritik nicht stand halten, und trotzdem ist diese Dentung generalisirt worden". In der 'That. wenn man sich klar' macht, wie durch die Untersuchungen Brefelds und vieler anderen Forscher für jeden mit morphologischem Verständnisse ausgestatteten Beobachter, der ïber genïgende Formenkemntniss verfügt, die vollkommene Uebereinstimmung der vordem als Spermatien bezeichneten Conidien mit echten zweifellosen Conidien in Rücksicht auf Form, Ort und Art der Bildung handgreiflich deutlich geworden ist, wenn man ferner dazu nimmt, dass das erforderliche weibliche Organ, die 'T'richogyne, nur in ganz wenigen seltenen Fällen ïberhaupt vorhanden ist, dass die Analogie zwischen Collemaceen- und Florideenbefruchtung an den Haaren lierbeigezogen ist und an Unwahrscheinlichkeit ungefähr alles für sich hat, dass in einer sehr grossen und stets sich mehrenden Zahl 
ron Fällen die Entstehıug der Ascusfrucht und der einzehnen Schläuche ohne Ascogon und Trichogyne und ohne Spermatien und ohne irgendwelche jenen entsprechende ähnliche Organe ganz sicher festgestellt ist, so erscheint es fast unglaublich, dass noch im Jahı 1898 in den Berichten der dentschen botanischen Gesellschaft (S. 363) die „Frage nach der Sexualität der Collemaceen“ im alten Simne wieder auftauchen komnte, dass dort die alten. so gründlich widerlegten und ad absurdum geführten Anschaumgen wieder vorgetragen werden, ohne dass der zu ihrer Stütze nun doch wohl sicher nothwendige Beweis in irgend ansreichendem Maasse geliefert wïrde.

Noch viel erstamlicher als jene Arbeit ist num aber eine Aeusserung von Harper; die er in den Amnals of Botany, September 1900, Seite $326 \mathrm{ff}$. vertritt. Er sagt: "the existence of trichogynes and carpogonia in the Lichens, essentially similar to those in the red Algae, must be regarded as established. The most essential phenomena involved in the behaviour of the nuclei are still to be worked ont, but the sexual significance of the apparatus from which the ascocarp arises can hardly be questioned by anyone not already committed to some other view". In Wirklichkeit sind 'T'richogynen ron der bekamnten Gestalt bei ganz wenigen, darunter anch einigen flechtenbildenden Ascomyceten beubachtet; von diesen wenigen Fällen abgesehen. hat man trotz eifrigen Suchens keine Spur dieses Organs entdeckt, die Bedentung. der 'Trichogyne kennt man nicht, für ihre geschlechtliche Bedeutung fehlt jeder Beweis. Alle sogenannten Spermatien, die man untersuchte. haben sich als Conidien erwiesen. Daher zieht Harper Beobachtungen iiber Parthenogenese von seeigeln herbei. um es glaublich zu machen, dass die "Spermatien" nur durch die kiäftigen Nährlösungen veranlasst seien, zu keimen und Mycelien mit neuen „Spermogonien“ und „Spermatien“ zu bilden, während sie sonst ihren sexuellen Funktionen hätten genügen kömnen.

Derartige Versuche. sichere Thatsachen zn Gunsten gänzlich 
in der Luft schwebender Hypothesen in der unwahrscheinlichsten Weise umzudeuten, sind meines Erachtens nur dadurch zu erklären, dass noch immer viele Botaniker an dem vorgefassten Glauben festhalten, die Sexualität der höheren Pilze muss vorhanden sein, muss gefunden werden, und dass ihnen die unwahrscheinlichste Einzelentdeckung in diesem Sinne lieber ist, als das Ergebniss der gross angelegten, gross durchgeführten, ifber alle Formenkreise ausgedehnten Untersuchungen Brefelds, der erklärt, die Sexualität der höheren Pilze ist verschwunden, sie existirt nicht. Es trifft sich nun gut, dass der nenerdings eifrigste und thätigste Gegner der Brefeldschen Arbeiten, der Entdecker und Vertheidiger einer ganz neuen Art von Sexualität bei den Pilzen, Dangeard, mit dessen Arbeiten wir uns noch zu beschäftigen haben werden, dass dieser gerade die Collemaceensexualität verwirft. lass el auf Grund seiner Beobachtungen (Le Botaniste 7. série S. 125) zu dem wohlbegründeten Schlusse kommt, es verlohne sich nicht mehr, sich mit dieser Anschaunng zu beschäftigen. Ich bin durchaus derselben Ansicht, aber gerade wie Dangeard selbst habe ich es nicht unterlassen können, von neuem auf die Unhaltbarkeit dieser Ansicht hinzuweisen, die wieder aufleben zu lassen num schon so oft stets ohne Erfolg versucht worden ist. Als solchen missglückten Versuch betrachte ich mit Dangeard die von Thaxter konstruirte Sexualität der Laboulbeniaceen. Thaxter hat uns durch seine mit so grosser Energie fortgesetzten mühevollen und sorgsamen Untersuchungen in den vor ihm nur wenig bekannten Laboulbeniaceen eine höchst eigenartige, durch ihre parasitische Lebensweise in der Formgestaltung merkwürdig beeinflusste Gruppe der Ascomyceten kennen gelehrt. Er hat eine ungealmte Formenmannigfaltigkeit bei diesen winzigen Organismen aufgedeckt und auf den 26 'Tafeln seines grossen Werkes über die Laboulbeniaceen von 1896 zur Anschauung gebracht. Er schreibt ihnen Trichogynen, Spermatien und geschlechtliche Fortpflanzung zu. Aber einen irgendwie zwingenden Beweis für die sexuelle Bedeutung der von 
ilım als Geschlechtsorgane bezeichneten Bildungen erbringt el nicht. Man kamn 'Thaxters Werk volle Anerkennung, seinen Abbildungen grösste Znverlässigkeit einräumen; aber seine Trichogynen sind nichts als vegetative Bildungen, seine Spermatien sind echte Conidien, genau wie sie auch sonst bei Ascomyceten rorkommen. Bei Pyxidiophora und Patellea unter den Ascomyceten liegen sogar Fälle vor, welche die Bildung unzweifelhafter Conidien in genau ebensolchen büchsenförmigen Behältern zeigen, wie die sind, in denen nach 'Thaxter die "Antherozoiden" der Laboulbenien gebildet werden. Ich kann es unterlassen, näher auf die Frage der Laboulbeniensexualität einzugehen und die Unhaltbarkeit der 'Thaxterschen Deutungen nachzuweisen, indem ich mich auf die durchaus zutreffenden Ausfiilnungen Dangeards berufe, die a. a. 0 . s. 124 niedergelegt sind. Tch nehme Dangeards Zeugniss und seine Unterstiitzung nur zu gerne in Anspruch. Ihm, dem eifrigsten Gegner der Brefeldschen Anschaumugen, für welche ich eintrete, wird man volle Unparteilichkeit gewiss zutranen in den Punkten, wo er Brefelds Ansichten so energisch zu den seinigen Inaclit.

Demn in welch scharfen Gegensatz er sich in der Hauptsache zu Brefeld stellt, geht klar daraus herror, dass er im 4. Bande seiner Zeitschrift, mit Toranstellung seines eigenen Bildnisses, unter der Teberschrift „Conchusions gènérales“ gleichsam das Facit seiner bisherigen Arbeiten in die stolzen Worte zusammenfasst: „Nons sommes arrivé au but que nous nous étions proposé: à l'affirmation de Brefeld qui proclame que l'absence de sexualité chez les champignons supérieurs est un fait acquis, indiscutable, nous pouvons maintenant répondre par une affirmation contraire: Les champignons supérienrs ont une sexualité qui ne diffère rien dans ses traits essentiels de celle des antres plantes et des animaux."

Und trotzlem liefert gerade Dangeard nach meiner Ansicht lediglich erwünschte Bostätigungen füı die Richtigkeit der Brefeld- 
schen Anschaumgen, wie ich gleich noch weitel ausfiihren werde. Zunächst sehe ich ein grosses Verdienst des französischen Forschers darin, dass er alle jene konstruirten Sexualitäten, deren Daseinsberechtigung Brefeld zerstört hatte, die aber immer noch in den Köpfen zahlreicher Mrkologen spukten, ron neuem und von einer nenen Beobachtungsmethode ausgehend beseitigt und in ihrer Haltlosigkeit nacligewiesen hat.

Es gab bekanntlich ausser der 'Trichogynensexualität bei den Ascomyceten noch eine andere, fül welche Sphaerotheca Castagnei zuerst durch de Bary 1863, dam durch Harper 1896, endlich 1897 durch Dangeard das meistbegünstigte Objekt geworden ist. Die Zelle, welche zum Ascus wird, entspringt seitwärts an einem Mycelfaden. De Bary nannte sie Archicarp oder Ascogon. Thr schmiegt sich enge ein dicht daneben aus einem benachbarten Mycelfaden entspringender Mycelzweig an, de Barys Antheridium. De Bary beobachtete richtig, dass zwischen beiden nie eine oftene Velbindung eintritt, aber er wollte sie geschlechtlich deuten, darum gab er ihmen sexuelle Namen und rermuthete, dass der befiuchtende Stoff durch die geschlossene Wand diffundire. Harper wollte de Barys Anschauung bekräftigen, er gab an, die offene T'erbindung beider Zellen gesehen zu haben; auch den Eintritt des Antheridiumkernes in das Ascogon und seine Verschmelzung mit dem Ascogonkerne wollte Harper gesehen haben. Dangeard hat die Wühe nicht gescheut, in einer ausführlichen Abhandlung, die durch zahlreiche Figuren erläutert wird, den sicheren Nachweis zu fïhren, dass Harpers Angaben falsch sind; es kann an der Richtigkeit der Dangeardschen Beobachtungen und ihrer unbedingten Ueberlegenheit ïber die oberflächliche Mittheilung Harpers nicht der geringste Zweifel walten (Le Botaniste 5. S. $245 \mathrm{ff}$ ).

Im Augenblick uun, da ich diese Arbeit der Druckerei zu senden im Begriffe bin, kommt mir Harpers oben (S. 44) schon citirte Abhandlung zu rechter Zeit noch in die Hände. Auf Seite 328 sucht er die Dangeardsche Widerlegung seiner irrthïm- 
lichen Beobachtungen an Sphaerotheca zu bekämpfen, aber nichts Thatsächliches bringt er vor, und Dangeards Darstellung der Ascusbildung bei jenem Pilze behält volle Gültigkeit. Nicht gewarnt aber durch die Niederlage, die er erlitten, bringt Harper gleichzeitig eine neue der früheren parallele Beobachtung über Pyronema confluens. Die sehr auffällig gestalteten Initialfäden der Ascusfrucht dieses Pilzes sind aus Tulasnes und de Barys Untersuchungen hinreichend bekannt. Auf dem Mycelgeflecht erheben sich je zwei keulig bauchige Zellen, die grössere, nach der Sexualitätsauffassung das „Oogonium“, treibt an der Spitze eine fadenförmige Verlängerung, welche sich mit ihrer Spitze der kleineren, dem „Antheridium" anschmiegt. Danach wird sie von dem „Oogonium" durch eine Scheidewand getrennt. Tach den übereinstimmenden Berichten von Tulasne, de Bary und Kihlmann tritt alsdann eine offene Verbindung jenes fadenförmigen Fortsatzes mit dem Innern des "Antheridium" ein. Obwohl nun die genannten Forscher sich sicherlich die grösste Mühe gegeben haben, sahen sie nie eine offene Verbindung zwischen dem "Antheridium" und "Oogonium", und auf Grund ihrer Angaben konnte doch höehstens von dem Inhalt des „Oogonimms“ durch den Verbindungsschlauch etwas zum „Antheridium “ ̈̈bergetreten sein, unmöglich war der umgekehrte Weg. Dennoch wurde hier eine Befruchtung des „Oogoniums" angenommen, und de Bary sagt ausdrücklich: „auf die Kopulation folgt nun Tolumzunahme der Archicarpien" (S. 227 der vergleichenden Morphologie). Das wenig Ueberzeugende dieser Darlegung ist wohl allgemein gefühlt worden, und man wagte kaum mehr bei Pyronema vou einer nachweisbaren Befruchtung zu sprechen. Harper sucht nu mit Hiilfe derselben Methode - Einbettung in Paraffin und Nikrotomschnitte - welche ihn bei Sphaerotheca zu nachweisbarem Irrthum gefiilırt hat, für Pyronema die alte de Barysche Sexualitätslehre zu retten. In Fig. 15 und 15 a seiner Arbeit bildet er zwei Mikrotomschnitte ab, welche eine Auflüsung der kuz zuror gebildeten Trennungswand zwischen 
„Oogonium" und „Verbindungsschlauch" und eine demnach offene Verbindung zwischen "Antheridium“ und „Oogonium" zeigen. Es sollen nun Hunderte von Kernen aus dem "Antheridium" zum „Oogonium" wandern, in dem ebenfalls Hunderte von Kernen vorhanden sind, und in dem nun eine massenhafte wechselseitige Kopulation der Kerne vor sich geht. Aber gerade die Abbildungen Fig. 16, 16a, $16 \mathrm{~b}$ jener Abhandlung, welche diese Massenkopulation im Innern eines „Oogoniums" darstellen, sind die wenigst klaren und wenigst iiberzengenden der ganzen Arbeit.

Erwägt man, mit welchem Eifer hier, wie früher bei Sphaerotheca nach der behaupteten Verbindung zwischen "Antheridium" und „Oogonium" von wahrlich nicht ungeschickten Beobachtern erfolglos gesucht worden ist, erwägt man die Unsicherheit der Methode, welche aus Mikrotomschnitten, die immer nur das Nebeneinander der Zustände, nie das Nacheinander zeigen, die Entwickelung konstruiren muss, erwägt man ferner wie für Sphaerotheca durch Dangeard das Irrthümliche der aus den Hobelschnitten gefolgerten Behauptungen und auch die Veranlassung der Täuschung klar gelegt worden ist, so wird kein Einsichtiger sich der Ueberzeugung verschliessen, dass die zwei von Harper jetzt gegebenen Bilder, welche die vordem vergeblich gesuchte Oeffinung zeigen, nicht genïgen könmen, um die klaren, auf Hunderten von sicheren Beobachtungen aufgebauten Anschaumgen Brefelds irgendwie zu erschüttern.

Man wird vielmehr ruhig abwarten dïrfen, dass vielleicht Dangeard in nicht zu ferner Zeit diese neue mittelst des Mikrotoms gewonnene Entdeckung Harpers als ebenso irrthümlich nachweist, wie die erste an Sphaerotheca. Denn Dangeard muss wohl ein Interesse daran haben. Giebt es doch nun bei Pyronema hinter einander zwei ganz verschiedene Sexualitätsvorgänge, den einen Harperschen, eben beschriebenen, den Dangeard nicht als solchen gelten lassen kann, und einen zweitell, später vor Erzengung jedes einzelnen Ascus eintretenden, den Dangeard für Schimper's Mittheilungen, Heft 9. 
den richtigen hält, den aber Harper als solchen nicht gelten lässt. Man wird auf diesen Kampf der beiden Sexualitäten gespannt sein dürfen.

Inzwischen ist für Sphaerotheca vorläufig durch Dangeard festgestellt, was für Pyronema wahrscheinlich auch noch wird festgestellt werden, dass die Schlauchfrucht im bisherigen Sinne ungeschlechtlich, vegetativ entsteht, dass das sogenannte "Antheridium" nichts als der erste Hüllfaden ist, also genau das, was Brefeld stets behauptet hat. Und mit Dangeards Auffassungen und Ausführungen steht endlich im besten Einklange die von Brefeld stets und zuletzt im XII. Bande Seite 221 klar und bestimmt ausgesprochene Thatsache, dass all jene wirklich nachgewiesenen Zellfusionen, die man sexuell hat deuten wollen, wie bei Endomyces Magnusii, Eremascus, Pyronema und Dipodascus nicht anders aufzufassen sind als andere Zellfusionen, die bei höheren Pilzen aus allen Verwandtschaftsreihen vorkommen, und denen dort Niemand sexuelle Bedeutung beilegt.

Brefeld macht a. a. 0. mit Recht die immer wieder nöthig werdende Bemerkung, dass die Beurtheilung derartiger Erscheinungen richtig nur erfolgen kamn auf der breiten Grundlage vergleichender Betrachtung vieler Formen. Wer in der Mykologie wenig bewandert, nur den Eremasus Eidams und den Dipodascus von Lagerheims kennt, wer nie selbst Fadenfusionen in ihrer mannigfachen Gestaltung lat entstehen sehen. der wird nicht zu überzeugen sein, dass in solchen Fällen nur Sondervorkommnisse einer weit verbreiteten häufigen Erscheinung vorliegen, die mit Sexualität gar nichts zu thun hat.

Dangeard hat also in dankenswerther Weise den Weg gesäubert. den Brefeld durch die Wüstenei der Sexualitäten gelegt hatte, er hat neuerdings das anfschiessende Unkraut ausgerissen und die zur Seite gedrückten Ranken, die den Weg der Erkemntniss sperren wollten, ganz abgeschnitten. Es giebt keine Sexua- 
lität der höheren Pilze melır. Brefelds Anschauungen bewähren und bestätigen sich.

So scheint es mir; das ist aber Dangeards Ansicht gar nicht. 'Er steht in unversöhnlichem Gegensatze zu Brefeld. An die Stelle aller jener fälschlich konstruirten Sexualitäten setzt er eine neue ganz andersartige und er weist sie nach in allen Klassen der Pilze. In der That unterscheidet sich Dangeard von allen, die vordem die Sexualität der höheren Pilze beweisen wollten, aufs vortrefflichste dadurch, dass er nicht von einem Ausnahme-Einzelfall ausgeht und diesen in unberechtigter Weise verallgemeinert. El hat im Verein mit zahlreichen anderen Forschern, unter denen besonders Sappin-Trouffy, Poirault und Raciborski, Rosen, Juel und Wager zu nemnen sind, ein höchst beachtenswerthes Thatsachenmaterial gesammelt, dem gegenüber es gilt Stellung zu nehmen.

Es ist ein unbestreitbares grosses Verdienst der genamnten Forscher, dass sie die bis dahin nur gelegentlich in seltenen Fällen beobachteten Zellkerne der Pilze zum Gegenstande eingehender Vntersuchungen machten, und Dangeards ganz besonderes Verdienst, dass er alle in diesem Simne gemachten Beobachtungen sammelte, sie durch zahlreiche eigene Untersuchungen vervollstäıdigte, und unterstiitzt durch seine Mitarbeiter, auf alle Klassen des Pilzreichs ausdehnte. Die Resultate, welche diese Arbeiten förderten, sind jedenfalls seln werthvoll und beachtenswerth, welche Deutung immer man ihnen geben mag.

Dangeard selbst ist der Meinung, die Sexualität aller Pilze sei nachgewiesen. Sehen wir nun zu, worin sie nach ihm bestelit, und versuchen wir dann, Dangeards Ergebnisse mit dem festbegründeten, von Brefeld aufgeführten Bau des natïrlichen Systems der Pilze in Einklang zu bringen.

Bei den Phycomyceten findet Dangeard die Geschlechtlichkeit da, wo sie allgemein bisher angenommen wurde, bei der Bildung der Zygosporen und Oosporen. Allein gerade hier, bei den Formen, 
deren Sexualität allgemein anerkannt war, habeu ums die vielfachen Untersuchungen der Zellkerne bisher zu keiner Erweiterung unserer Einsicht in die betreffenden Verhältnisse gefülnt. Die Vereinigung zweier Zellkerne bei der Bildung der Zygo- oder Oospore konnte nirgends festgestellt werden. Auch bei dem eineni einzigen von Dangeard viel citirten Fall des Basidiobolus hat Eidam sie, wie er ausdrücklich angiebt (Cohn, Beiträge IV S. 222), trotz sorgsamster Beobachtungen nicht feststellen können, doch soll sie hier von Chmielewsky später gesehen worden sein.

Nimmt man zu den bisherigen negativen Resultaten der Kernbeobachtungen hinzu, was über die sogenannten Azygosporen bekannt ist, und alle die oben bereits berïhrten Thatsachen der vergleichenden Morphologie, welche uns den offensichtlichen Rückgang bis zum allmählichen Verschwinden der Sexualität innerhalb der Phycomyceten deutlich anzeigen, so stehen sämmtliche Beobachtungen im vollkommensten Einklang mit einander und lehren, was wir oben in einer Reihe von Sonderfällen im einzelnen verfolgten: Diese Sexualität, dieselbe, welche bei den nahe verwandten Algen in gleicher Weise vorkommt und bei ihnen zum Ausgangspunkt der inmer bedeutungsvoller werdenden, die ganze grïne Pflanzenreihe beherrschenden Geschlechtlichkeit wird, eben diese geht in der Reihe der Pilze frühzeitig verloren.

Dangeard findet weiter die Sexualität unter den Mesomyceten bei den Brandpilzen. In den von ihm untersuchten Brandsporen sind anfänglich zwei sehr kleine Kerne vorhanden, diese vereinigen sich in einen, der sich alsbald wieder theilt und die Sporenkerne der Hemibasidie liefert; das ist die Sexualität der Hemibasidii. Die Kerne sind ausserordentlich klein, die Beobachtungen, wie Dangeard selbst sagt, sehr schwierig, und die mitgetheilten Abbildungen lassen immer noch manchem Zweifel Raum. Hemiasce Formen sind vorläufig nicht untersucht.

Wir kommen zu den Protobasidiomyceten, rou denen Dangeard immer noch die Uredineen als besondere Klasse abtrennt, obwohl 
gerade seine, bezw. des Herrn Sappin-Trouffy ansgezeichnete Untersuchungen nenerdings die allerbesten Beläge dafür bringen, dass sie thatsächlich nichts als Protobasidiomyceten sind, wie Brefeld zuerst festgestellt hat. In den brasilischen Gattungen Saccoblastia und Jola habe ich (Protobasidiomyceten, Heft VIII dieser Mittheilungen) Formen nachgewiesen, welche durch den Besitz einer der Teleutospore vollkommen entsprechenden, nur der verdickten Membran entbehrenden Bildung die nahen Beziehnngen der Uredineen zu den übrigen Protobasidiomyceten noch unverkennbarer erscheinen liessen. Nun hat Sappin-Trouffy nachgewiesen, dass die bisher sogenamite Teleutospore von Coleosporium in Wirklichkeit eine echte Protobasidie ist, dass dieser bisher einstimmig zı den Uredineen gerechneten Form also die Teleutospore fehlt, das einzige Merkmal, welches nach Dangeard ihre Abtremnung von den Protobasidiomyceten begründet (VII. Série s. 94). Dementsprechend nennt num Dangeard a. a. O. Coleosporium eine Uebergangsform zwischen den beiden rou ihm getrennten Klassen, und die Protobasidiomyceten bezeichnet er als Uredineen, bei denen

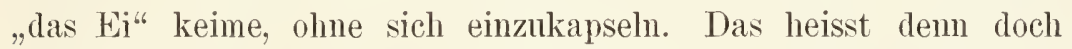
die Thatsachen auf den Kopf stellen und die mïhsam gewonnene Einsicht durch schlecht gewählte Bezeichnungen verdunkehn. Der Besitz der Protobasidie ist das wesentliche Merkmal all der hierher gehörigen Pilze, die Protobasidionyceten umfassen also die durch ihre Anpassung an parasitische Lebensweise eigenthïmlich veränderten Uredineen mter sich und nicht umgekehrt. Durch die Behandlung der Uredineen als Unterabtheilung der Protobasidiomyceten wird unsere Uebersicht des natïrlichen Systems der Pilze vereinfacht und geklärt, und eben deshalb muss an ihr festgehalten werden, nachdem sie durch Brefeld einmal begrïndet ist.

Bei diesen Protobasidiomyceten, also einschliesslich der Uredineen, findet der Geschlechtsakt nach Dangeard vor der Bildung' jeder Basidie statt. Diejenige Zelle, aus welcher die Basidie 
sprosst, also die Teleutospore oder deren Theilzelle, in den anderen Fällen diejenige, welche zur Basidie auswächst, enthält nach Dangeard zwei Kerne. Diese verschmelzen mit einander und unmittelbar darauf oder nach einer Ruhepause theilt sich der "sexuelle" Kern wieder und erzeugt, gewöhnlich nach doppelter Zweitheilung, die Kerne für die vier Sporen der Protobasidie. Die Scheidewände der Protobasidie entstehen unmittelbar, nachdem die Kerntheilung stattgefunden hat.

Ganz ähnlich ist es bei den Autobasidiomyceten. Jede junge Basidie enthält zwei Kerne, die mit einander verschmelzen; dann tritt doppelte Zweitheilung des "sexuellen" Kernes ein und die vier Tochterkerne wandern durch die Sterigmen in die Sporen. Das ist die Sexualität der Basidiomyceten.

Etwas anders liegt es bei den Ascomyceten. Das Fadenende, welches dem Ascus den Ursprung giebt, hat zwei Kerne; jeder von ihnen theilt sich in zwei. Ton den vier entstandenen Kernen werden die beiden äussersten durch je eine Wand abgegegrenzt, es bleibt eine Nittelzelle mit zwei Kernen. Diese beiden verschmelzen mit einander. Darauf wächst diese Zelle zum Ascus ans und in ihm erfolgt durch dreifache Zweitheilung des „sexuellen" Kernes die Bildung der Ascussporen. Das ist die Sexualität der Ascomyceten.

Eben diese selbe Dangeardsche Ascomycetensexualität kommt nun wie Harper in seiner oben citirten Abhandhung ausführlich darlegt, auch Pyronema confluens zu. Aber da Harper schon eine Sexmalität bei jener Massenkopulation der Kerne im "Oogonium" entdeckt hat, so kanı er die vor jeder Ascusbildıng eintretende Kernverschmelzung als Sexualität nicht anerkennen.

Wir wollen nm zunächst im Lichte der auf den Thatsachen der vergleichenden Morphologie ruheuden Anschanungen die Dangeardsche Sexualität der Pilze betrachten, und wir gehen dabei von der Gattung Choanephora aus. Hier giebt es im Entwickelungsgange eines und desselben Pilzes zunächst die ge- 
schlechtlich erzengte Zygospore, als unzweifelhaft von derselben Bedeutung, wie die Zygospore der verwandten Algen, wie die Oospore der Oomyceten und der mit ihnen nächstverwandten Algen. Die vergleichende Morphologie der Pilze lehrt uns, wie diese Sexualorgane der Zygomyceten und Oomyceten, deren geschlechtliche Bedeutung in den allermeisten Fällen an sich schon gering erscheint, schrittweise bis zum völligen Verschwinden sich zurückbilden. Diese Sexualität also, die in der grünen Pflanzenreihe sich unumterbrochen immer weiter und höher differenzirt, geht bei den Pilzen unzweifelhaft verloren, findet keine Fortsetzung.

Weiter finden wir in dem Entwickelungsgange der Choanephora die Sporangien und die Conidienfrüichte. Die vergleichende Morphologie lehrt mit einer gar nicht misszuverstehenden Sicherheit, dass ans den Sporangien die Ascen, aus den Conidien die Basidien sich herleiten. Nun sind die Sporangien ungeschlechtlichen Ursprungs, die Conidien, welche in ihrem ersten Ursprung auf einsporig gewordenen Sporangien zurïckführen, ebenfalls. Ist also der Ascus geschlechtlich, so ist eine neue Sexualität im weiteren Verlauf der plyylogenetischen Entwickelung eingetreten, und an welchem Punkte? Offenbar da, wo das Sporanginm zum Ascus wird, wo, wie Brefeld sagt, das Sporangium in Form und Sporenanzahl bestimmt wird. Und wodurch ist es bestimmt geworden? Durch eigenthümliche Vorgänge der Kernverschmelzung und Kerntheilung, welche Dangeard uns näher kemmen lehrte.

Und wemn die Basidie geschlechtlich ist, so ist abermals im Laufe der phylogenetischen Entwickelung der Conidien eine neue Sexualität aufgetreten, und zwar ebenfalls da, wo der Conidienträger zur Basidie wurde, wo, wie Brefeld sagt, der Conidienträger in Form und Sporenanzahl bestimmt wurde. Und Dangeard zeigt, dass eben dieses "Bestimmtwerden in Form und Sporenanzall1" mit ähnlichen Vorgängen der Kernverschmelzung und Kerntheilung. Hand in Hand gelit. Dass der Ascus nichts als ein besonderes Sporangium ist, lehrt auch Dangeard (VII S. 178). Er bildet 
neben einander eine mit einem Sporangium keimende Mucorzygospore und einen aussprossenden Ascus ab, an dessen Grunde die nach ihm geschlechtliche Kernverschmelzung stattgefunden hat. Will er damit jene dem Ascus den Ursprung gebende zweikernige Zelle, die zum Ascus wird, der Mucorzygospore gleichwerthig setzen? Das wiirde nicht angehen. Denn das Mucorsporangium keimt ebenso wie aus der Zygospore auch ais dem einfachen Mycel und auch aus der Chlamydospore des Chlamydomucor racemosus, in beiden Fällen also ohne jeden vorangegangenen Sexualakt. Leitet er also - und dies mit Recht -- den Ascus ans dem Sporangium ab, so ist seine Ascussexualität der Peziza nicht von der Zygospore niederer Formen her überkommen, sondern sie ist neu entstanden, sie ist später. sie ist etwas ganz anderes. als die überhanpt nie gesehene, nur vermuthete Kernkopulation in der Zygospore.

Und genan so sicher wie die Ableitung des Ascus aus dem Sporangium, ist anch diejenige der Basidie ans dem Conidienträger. Nur ist sie noch anschanlicher und überzeugender nachzuweisen, weil die Entwicklungsgeschichte einzelner Formen uns hente uoch ontogenetisch diese Formsteigerung verfolgen lässt. Ich verweise hier ganz besonders auf die Entstehung der Protobasidie aus dem heute noch vorhandenen Conidienträger bei Pilacrella und der Autobasidie aus dem heute noch vorhandenen Conidienträger bei Matruchotia, über die ich im vorigen Bande dieser Mittheihungen Seite 148 ff. ansführlich mich geäussert habe. Diese Thatsachen der vergleichenden Morphologie sind so einleuchtend, so ganz unbestreitbar, dass man an ilnen nicht vorbeikommen kamn. Ist also die Basidie geschlechtlich, so ist hier eine neue Sexualität unabhängig von der früheren erloschenen der Phycomyceten und unabhängig von der am Grunde des Ascus aufgetauchten in den Entwickelungsgang der Formen eingeschoben. Dangeard bildet freilich die aus den Brandsporen keimenden Hemibasidien von Tilletia und Ustilago anf dem schon oben angeführten Bilde 
(Bd. 4 S. 178) neben dem Ascus und dem aus der Zygospore keimenden Mucorsporangium ab und er findet nahe Beziehungen zwischen dem Ascus und der Basidie, von denen der erstere die Sporen nur endogen, die letztere sie exogen entwickele. Aber er behauptet, soweit ich sehen kann, nirgends eine genetische Ableitung der Basidie aus den Ascus. Hierfür würde auch jeder Anhalt in den Thatsachen fehlen, und Choanephora lelirt uns, dass die Stammformen dieser beiden höchsten Fruchtformen je für sich schon relativ hoch entwickelt bei ein und demselben Pilze noch hente neben einander bestehen, dass also ihr gemeinsamer Ursprung viel weiter zurückliegt.

Endlich nun kommt auch die vierte, die letzte der bisher iiberhaupt bekannten Fruchtformen der Pilze, die Chlamydospore neben den drei anderen bisher besprochenen bei choanephora vor, und sie ist dort, wie iberhaupt bei den Phycomyceten, zweifellos ungeschlechtlichen Ursprunges. Thre morphologische Merthbestimmung hat Brefeld im V'III. Bande seines Werkes erschöpfend gegeben und er hat das Torkommen dieser eigenartigen, von der Conidienfruktifikation durchaus verschiedenen Fruchtform bei allen Stämmen des Pilzreichs nachgewiesen. Die vergleichende Morphologie lehrt, dass die Brandsporen Chlamydosporen sind. Sind nun die Brandsporen geschlechtlich, so ist auch bei ihnen wiederum an einem anderen Punkte der Entwickelungsreihe eine neue Geschlechtlichkeit, eine nicht von den Torfalnen überkommene, in die Erscheinung getreten.

Wir sehen also, dass mit den Thatsachen der vergleichenden Morphologie die Dangeardschen Auffassungen ron der das ganze Pilzreich beherrschenden Sexualität rollkommen unvereinbar sind, man mïsste denn annehmen, dass die Sexualität znerst vorhanden, dann geschwunden sei, um später bei höheren Formen an verschiedenen Stellen der Entwickelungsreihen unvermittelt in nener Form wieder aufzutauchen. Dies aber widerspricht durchaus auch den Dangeardschen Auffassungen. Der französische Forscher geht 
nämlich ebenso wie die meisten Entdecker einer Pilzsexualität an seine Aufgabe mit der vorher gefassten bestimmten Ueberzeugung; die Sexualität muss da sein, es handelt sich nur darum, sie znl finden. Dies verräth er durch den Beginn seiner Abhandlung im 3. Bande des „Botaniste“ Seite 222, wo er mit den Eingangsworten: „la sexualité se présente dans l'ensemble des êtres vivants, comme un phénomène générale d'une importance capitale" eben das vorweg behauptet, was bewiesen werden soll; er lässt denselben Gedanken in den Worten erkennen (Band III S. 233): „Puisque tous les efforts des observateurs en vue de découvrir dans ces champignons une reproduction sexuelle caractérisée morphologiquement sont restés vains, il faut (sic!) changer les méthodes d'investigation"; endlich schreibt er im vierten Bande in einer Art Schlusswort die schon oben angeführten Worte: .nous sommes arrivé au but que nous nous étions proposé".

Hätte er sich einfach an die Darstellung der beobachteten Thatsachen gehalten und versucht, sie mit dem derzeitigen Besitzstande der Wissenschaft in Einklang zu bringen, so wäre meines Erachtens sein Terdienst - an dem ich iibrigens gewiss nicht mäkeln will - ein grösseres gewesen. Zu dem gesicherten Besitzstande der Wissenschaft gehören aber die Thatsachen der vergleichenden Morphologie, die uns eine so wundervoll klare Uebersicht ïber das ganze vielgestaltige Formemreich der Pilze vermittelt haben. Diese Thatsachen sind aus den zuverlässigsten Beobachtungen gewonnen und sie kömnen nicht ohne weiteres durch eine vorgefasste Deinung umgestossen werden, welcher die Deutung neuer Beobachtungen zwangsweise angepasst wird. All die von Dangeard beobachteten gesammelten und zusammengestellten Thatsachen über Kerntheilungen und Kernverschmelzungen sind auf das natürlichste verständlich, wenn man sie von dem festgefügten. mit dem Mörtel der vergleichenden Morphologie aufgeführten Gebäude des natiirlichen Systems der Pilze aus betrachtet, dessen Baumeister Brefeld ist. Denn wo ist die Sexualität nach Dangeard? 
Immer da, wo Brefeld uns die charakteristische höchste Fruchtform der Pilze erkemmen lehrte; bei der Bildnng der Protobasidie, der Antobasidie, des Ascus. Dangeard hat eine höchst bemerkenswerthe weitere Erläutermng geliefert zu dem Ansdrncke Brefelds: der Conidienträger, das Sporangimm werden nach Form und Sporenzahl bestimmt; er hat gezeigt, dass dieses Bestimmtwerden mit besonderen Torgäugen der Kernverschmelzung und Kerntheilung zisammenfällt. Aber die Idee der Geschlechtlichkeit ist allen diesen Torgängen, von einer vorgefassten Meimming ausgehend, anfgezwungen.

Dangeard sagt: .,la sexualité assure la perpétnité de l'espèce; elle est en même temps la source des variations qni s'y produisent." Nin sehe man sich eimmal die vermeintliche Geschlechtlichkeit z. B. von Sphaerotheca Castagnei nach der vorzüglichen, durch zahlreiche Fignren erlänterten Untersuchung Dangeards im 5. Bande des Botaniste Seite $268 \mathrm{ff}$. an. Die Zelle, welche dem Ascus den Ursprumg giebt, hat einen Kern, dieser theilt sich in zwei, die zwei theilen sich in vier; zwei von den vieren verschmelzen mit einander und bilden den sogenannten sexuellen Kern, der durch seine abermalige wiederholte Zweitheilung die Ascosporenkerne erzengt. Mir ist merfindlich, wie Dangeard hier und in vielen anderen Fällen von einer ,origine différente" der kopulirenden Kerne reden kann, sie sind ja eben erst ans einem einzigen Kerue hervorgegangen, und unerfindlich bleibt, wie man es sich vorzustelleu habe, dass dnurch diese Vorgänge im Innern einer Zelle la perpétuité de l'espèce oder gar „la source des variations“ solle gewährleistet werden. Wenn dies Sexualität sein soll, so ist es jedenfalls ganz etwas anderes, als was man bei dem Worte sich zu denken gewohnt ist. Und warum soll es Sexualität sein? Offenbar nur damit der zu Anfang aufgestellte unbewiesene Satz eine Stïtze finde: „la sexualité se présente dans l'ensemble des êtres vivants, comme un phénomène générale."

Gegen den oben erhobenen Einwand der zu nahen Verwandtschaft 
der kopulirenden Kerme beruft sich Dangeard (7. Band S. 102) auf das Beispiel von Basidiobolus, wo zwei benachbarte Zellen fusioniren und wo die „reproduction sexuelle est admise par tout le monde." Da die Berufung auf „alle Welt" eine Beweiskraft nicht hat, so scheint mir die richtigere Folgerung zu sein, dass eben auch bei Basidiobolus die Geschlechtlichkeit in einem Zustande der Rückbildung ist, dass ilır anch hier eine Bedeutung in dem Sinne wie bei den höheren Pflanzen nur noch in geringem Naasse zukommen kann, und dies steht in vollständigem Einklang mit unserer Anschauung von der Rückbildung und dem schliesslichen Verschwinden der Sexualität unter den Phycomyceten, wie ich oben bereits gezeigt habe.

Herr Professor R. Hertwig hat am 7. November 1899 in der Gesellschaft für Morphologie und Physiologie in Mïnchen einen Vortrag gehalten, der in den dortigen Sitzungsberichten veröffentlicht wurde, und den er die Güte hatte mir zu senden gerade als ich mit Abfassung des vorliegenden Kapitels beschäftigt war. Er behandelte die Frage: Mit welchem Rechte unterscheidet man geschlechtliche und ungeschlechtliche Fortpflanzung? und er geht von der Betrachtung aus, dass sich „auf dem Gebiete der Biologie der grösste Theil unserer allgemeinen Vorstellungen und der damit zusammenhängenden Bezeichnungen, welche ihrerseits wieder unsere Vorstellungsweise in hohem Haasse beeinflussen, beim studium der höher entwickelten Lebewesen ansgebildet hat, in der Botanik beim Studium der phanerogamen Pflanzen, in der Zoologie beim Studium des Menschen, der Sängethiere und der iibrigen Wirbelthiere." Dies, so führt er weiter aus, verführe uns oft, und ganz besonder's bei der Frage nach der geschlechtlichen oder ungeschlechtlichen Fortpflanzung dazu, umberechtigter Weise unser Urtlıeil über die Terhältnisse der niederen Wesen dem Standpunkte anzupassen, den wir vermöge unseres Erfahrungen an höheren Organismen einnelımen. Dies trifft meines Erachtens in dem uns beschäftigenden Falle ausgezeichmet zu. Von Sexulität 
$-61-$

bei den Pilzen zu sprechen, in dem Sinne wie Dangeard es thut, heisst einem zuerst von den höheren grümen Pflanzen hergeleiteten Begriffe zu Liebe den bei den Pilzen beobachteten Thatsachen eine Deutung aufzwingen, die sie bei unbefangener Würdigung niemals haben kömnen. 
II.

\section{Ascomyceten.}

\section{Perisporiaceen.}

In der Anordnung der Mittheilungen, welche ich während meines Blumenauer Aufenthaltes über Ascomyceten gesammelt habe, schliesse ich mich der klaren, übersichtlichen und den Stand der gegenwärtigen Kenntnisse am besten rerwerthenden Eintheilung an, welche von T'avel in seiner vergleichenden Morphologie der Pilze zu Grunde legt.

Formen der Hemiasci sind mir nicht zu Gesicht gekommen; ebensowenig habe ich Vertreter der Exoasci aufgefunden. Ton den beobachteten und untersuchten Carpoasci gehört die ganz überwiegende Mehrzahl den Pyrenomyceten an. Gymnoasci kamen mir iiberhaupt nicht vor. Von den Perisporiaceen beobachtete ich eine Form, welche für mich ron hohem Interesse war, Penicilliopsis brasiliensis n. sp. Mit der Beschreibung dieses Pilzes und der Ergebnisse, welche seine künstliche Kultur zeitigte, will ich daher meine Nittheilungen begimnen. Bezüglich der vorher erwähnten, in meiner reichen Sammlung brasilischer Pilze überhaupt nicht vertretenen Gruppen niederer Schlauchpilze glaube ich mit der Vermuthung nicht felıl zu gehen, dass sie jedenfalls iu dem durchforschten Gebiete nicht lıäufig sein dürften. Während fast dreier Jahre ist wohl kaum eine Woche rergangen, in der 
ich nicht eine oder mehrere Exkursionen ausfïhrte, und in den letzten zwei Jahren hat Herr Gärtner zeitweise täglich eifrig für mich gesammelt. Wir sammelten alle Pilze, die wir finden konnten, und jedesmal sah ich die Ausbeute wenigstens soweit soînt in frischem Zustande an, als nöthig war, um über den allgemeinen Charakter der Form ins Klare zu kommen. Wennschon ich num durch diejenigen Formgruppen, welche in den jetzt vorliegenden vier letzten Heften dieser Mitheilungen behandelt sind, vornehmlich in Anspruch genommen war, und auf niedere Ascomyceten nicht mit besonderem Nachdruck mein Augemmerk richtete, so wäre es doch, einige Häufigkeit jener Formen vorausgesetzt, wunderbar, dass sie mir unter dem überreichen Material, welches neben den zu besonderen Untersuchungen ausgewählten Formen durch meine Hände ging, niemals sollten begegnet sein.

Penicilliopsis brasiliensis nor. spec. ist mit der bisher einzigen durch des Grafen H. zu Solms-Laubach Untersuchung (Ann. du Jard. Bot. de Buitenzorg Vol. VI S. 53-72) bekannt gewordenen Art dieser Gattung: Penicilliopsis clavariaeformis Solms-Laubach sehr nahe verwandt. Es wiederholte sich hier für mich die lehrreiche und wunderbare Eıfahrung, die ich schon bei Choanephora gemacht hatte, dass ich nämlich nach Auffindıng und genauer Untersuchung eines mir bis dahin ganz unbekannten höchst auffälligen und systematisch bemerkenswerthen Pilzes in Brasilien erst viel später erfuhr, eine ganz ähnliche Form sei schon aus Indien, und nur von da bekannt und bearbeitet, dass ich beim ersten flïchtigen Durchsehen der betreffenden Arbeit mit höchstem Erstaunen glaubte, das müsse genau derselbe Pilz sein, in Brasilien und in Indien, und erst durch schrittweise sorgsam durchgeführte Vergleichung mich davon überzeugte, wie auch hier wieder ein so eigenartiger Organismus von ganz bestimmter Lebensgewohnheit und ganz bestimmter Formausbildung an zwei so weit von einander entfernten Punkten der Erde auftritt, an beiden Punkten so genau uibereinstimmend in allen wesentlichen Eigenschaften, 
dass an der nahen Blutsverwandtschaft nicht der leiseste Zweifel gehegt werden kamn, dennoch im Einzelnen mit fest ansgeprägten Verschiedenheiten, die eine Artentrennung nothwendig machen.

Ich fand den fraglichen Pilz nur zweimal, zuerst im Mai 1891 auf einem ausgefallenen am Boden liegenden Samen von Mucuna, sodann im November 1892 auf einer Frucht von Strychnos triplinervia; beide Vorkommnisse sind durch die photographischen Bilder (Taf. IX Fig. 1 u. 2) dargestellt. Der ostindische Verwandte wurde bekanntlich auf Früchten von Diospyros macrophylla entdeckt.

Man sielit anf der Fig. 1 Taf. IX, dass die Conidienfruchtkörper unserer Form bei völliger Entwickelung bis $5 \mathrm{~cm}$ Höhe, und besonders im oberen Theile eine grosse Anzahl von ringsum fast seukrecht abstehenden bis $8 \mathrm{~mm}$ langen Seitenzweigen haben, und sich hierdurch wesentlich von den einfach glatt pfriemenförmigen oder mur wenig unregelmässig verzweigten Conidienträgern der P. clavariaeformis (die von dieser Fruchtform ihren Namen erhielt) unterscheiden. Die Untersuchung unserer gelbgrünlich gefärbten Fruchtkörper ergiebt, dass der Hauptstamm nur hie und da, die einzelnen Seitenzweige jedoch hỵmeniumartig in dichter Schicht mit den conidientragenden Hyphenenden besetzt sind. In rechtem Winkel biegen diese Hyphen von dem parallel gerichteten Fadenbündel der Axe nach aussen ab. und verdicken sich in den pallisadenartig gestellten Endigungen keulenförmig (T'af. II Fig. 40 d). Aus jeder Keule sprossen mehrere (ich zählte bis zu 8) Einzelträger, welche sich zuspitzen, und je eine Kette von Conidien heryorsprossen lassen. Höchst auffallend ist num der Umstand, dass fast auf jeder Keule zweierlei dentlich verschiedene Conidien, runde und lange gebildet werden (Fig. $40 \mathrm{~d}$ ). Die runden sind in der Mehrzahl, die langen werden in der Regel nur von einem Sterigma jeder Keule gebildet. Sie haben etwa 15 " Länge bei $5 \mu$ grösster Breite und fast glatte Membran, während die runden einen Durchmesser von $6-7 \mu$ und eine selır fein stachlich punktirte Membran besitzen. Die Bildungsweise aber ist bei beiden 
die gleiche. Nachdem die erste Conidie ausgesprosst ist, wird sie durch eine scheidewand abgegrenzt, und unter ilı sprosst die zweite. Beide stehen in Verbindnng durch ein kurzes mycelfadenartiges Zwischenstück, gegen welches sich die zweite Conidie ihrerseits durch eine scheidewand abgrenzt. Beim \%erfallen der Kette bleibt das dann völlig entleerte Zwischenstiick als ein kragenartiger welker Ansatz stets an dem unteren Ende der oberen, also früher gebildeten Conidie sitzen, während an der entgegengesetzten, der Ursprungsstelle abgewendeten Seite jede Conidie damn glatt erscheint.

Bei der geringsten Erschütterung' der Conidienf'uchtkörper' zerstäuben die Conidien wolkenartig, und man kann daher sehr leicht Aussaaten erhalten. Beide, lange sowohl wie runde Conidien sind schon wenige Stunden nath der Aussaat in Nährlösung etwas angeschwollen nnd entlassen einen ditken von vakuolenreichem Plasma erfüllten Keimschlanch, der an unbestimmter Stelle, bei den langen Conidien hänfig in der Nitte seitwärts austritt. Auch mehrere Keimschläuche kommen vor. Ist die Nährlösung sehr dünn, oder liegen die Sporen in stärkerer Nährlösung sehr zahlreich bei einander, so geht der Keimschlanch nach kurzem Wachsthum unmittelbar an seinem Ende zur Conidienbildung über (Fig. 40 c). Bei besserer Ernährung bilden sich entsprechend grössere und reicher verzweigte Mycelien, die an beliebigen Endund Seitenfäden unter der Flüssigkeit Conidien in Reihen abgliedern (Fig. 40a b k e f). Wennschon die Bildung dieser Conidien derjenigen auf den hochentwickelten Fruchtkörpern im Grundplane entspricht, so machen sich doch erhebliche Verschiedenheiten geltend, die alle klar und zweifellos in dem simne zu deuten sind, dass die Fruktifikation zunächst in weniger scharf ausgebildeter, unbestimmterer also niederer, älterer Form ror sich geht. Der hoch entwickelte verzweigte, in dem photographischen Bilde (Taf. IX, Fig. 1) dargestellte Conidienfruchtkörper mit seinen in Pallisadenreihen stehenden gleichmässig keulig geschwollenen Trägern, mit Schimper's Mittheilungen, Heft 9. 
den bestimmt geformten Sterigmen, mit den in zwei bestimmt velschiedene Formen differenzirten gelblich gefärbten mit stachlicher Membran versehenen Conidien, steht zu den einfachen in den Abbildungen dargestellten Conidienbildungen an kleinen Mycelien in ganz genau demselben Verhältniss, wie der im vorigen Bande dieser Mittheilungen (S. 48 ff. Fig. 28. 29. 30. 31. 32 Taf. V) dargestellte Basidienfruchtkörper von Pilacrella delectans zu den ebenda abgebildeten Conidiensprossungen an losen Mycelien. Und wie es dort möglich war unter Benutzung der Hülfsmittel der künstlichen Kultur die Entstehungsgeschichte des Basidienfruchtkörpers lückenlos von dem conidienbildenden Mycel her zu verfolgen, also die Stammesgeschichte der Art zu einem grossen Theile noch heute vollständig zu rekonstruiren, genau so gelang diese höchst bemerkenswerthe Rekonstruktion auch bei Penieilliopsis brasiliensis für deren Conidienfruchtkörper.

Bei solchen Bildungen z. B. wie Fig. 40 c Taf. II in armer Nährlösung ist von dem bestimmten Sterigma, welches die Conidien erzeugt, noch nichts zu sehen, geschweige demn von der keuligen Anschwellung. welche die Sterigmen trägt. Werden aber die Mycelien kräftiger ernährt, so tritt die Conidienbildung etwas später, dann aber schon in etwas bestimmterer, höhlerer Formausbildung ein. Wir sehen (Fig. $40 \mathrm{k}$ ), dass die Fadenspitze etwas anschwillt, und sich nach hinten zu durch eine Wand abgrenzt, so dass eine sterigmaartige Endzelle des Fadens zu Stande kommt; diese hat aber noch seln unbestimmte und ron Fall zu Fall wechsehnde Länge. Man hat es nun in der Hand durch kräftigere Ermährung der Mycelien die Conidienbildung noch etwas weiter hinauszuschieben und sie dann in der Form der Fig. 40 a erscheinen zı sehen. Die Sterigmen werden allmählich immer gleichmässiger in Länge und Form, und in der anschwellenden Gabelzelle der Fig. 40 a haben wir schon den Ursurmg der später gleichmässig keulig ausgebildeten und mehrere Sterigmen erzengenden basidienähnlichen \%ellen der rollkommenen Form vor uns. Die unter 
Flüssigkeit zunächst gebildeten Conidien zeigen noch keine gekörnelte Membran, sie sind glatt, noch keine gelbe Farbe, sie sind farblos, noch keine bestimmte Form, oder gar Differenzirung in zweierlei Formen, sie schwanken zwischen den beiden Formen der höchsten Fruchtkörper und zeigen unregelmässige Abmessungen, die Zwischenstiicke sind noch wenig ausgebildet, und nur bei sehr starker Vergrösserung mit einer guten Immersionslinse zu erkemnen.

Durch Aussaat einer oder ganz weniger Conidien in hochkonzentrirte Nährlösungen lässt sich die früher schon an Tage der Aussaat eintretende Conidienbildung um mehrere Tage verzögern zu Gunsten einer zunächst üppigen Entwickelung steriler Mycelien. Dann aber treten die Conidien an Luftfä̀len auf und mit diesem Inomente nehmen sie auch die charakteristische gelbgriine Farbe an, und lassen zu einem Theile wenigstens die skulpirte Membran erkemnen; anch das Zwischenstiick prägt sich deutlicher aus. Noch aber ist die Form ausserordentlich variabel. Insbesondere werden die Ketten hier oftmals sehr lang (s. Fig. 40 f.), die Form der einzelnen Conidien ist noch nicht bestimmt, wie die Figur das ebenfalls erkemnen lässt. In Objektträgerkulturen und noch besser in den Brefeldschen Kulturfläschchen (rgl. Heft VII dieser Mittlı. S. 104) erzielte ich thalergrosse dichte Mycelgeflechte, welche von einem grünlich gelben Filz der Conidienketten dicht bedeckt waren. Die weitere Steigerung zur eigentlichen Fruchtkörperbildung kam aber bei dieser Ernährung nicht zu Stande. Ich musste dazu auf das natürliche Substrat, insbesondere die Strychnosfrüchte. die mir am leichtesten zur Hand waren, zurückgreifen.

Am 26. November 1892 brach ich von einer gesunden, fast reifen Strychnosfrucht ein Stiick der Schale ab, legte einen Samen ganz frei und bestrente ihn dicht mit Conidien. Hier entwickelte sich das Mycel im Innern des Samens, nach aussen brachen die fadenförmig auftretenden Conidienfruchtkörper hervor, von denen der erste am 15. Dezember schon $3 \mathrm{~cm}$ Höhe erreicht hatte. Diese 
zuerst auftretenden Fruchtkörper waren unverzweigt, vollständig denen von Penicilliopsis clavariaeformis ähnlich. Wie jene waren sie an ihrer ganzen Aussenfläche mit Conidien besetzt, zunächst aber war auch jetzt noch nicht die Bestimmtheit in der Form der Conidienbildung erreicht, wie sie dem vollkommenen Fruchtkörper eignet.

Sehr lehrreich erwies sich die genauere Untersuchung eines jüngeren etwa $2 \mathrm{~cm}$ hohen noch nicht verzweigten Stückes. An $\checkmark$ seiner Spitze stehen die conidienbildenden Sterigmen dicht gedrängt, noch ganz unregelmässig angeordnet, und wenig bestimmt in der Länge, genau wie in Objektträgerkulturen; die keulenförmigen Sterigmenträger treten erst weiter unten, an der Mitte des Fruchtkörpers deutlich auf, wo sie dicht gedrängt dessen ganze Oberfläche bekleiden. Noch weiter abwärts ist die Conidienbildung schon lokalisirt, der centrale Hauptträger ist streckenweise frei von Conidien, wie an den höchstentwickelten verzweigten Fruchtkörpern. Die Trennmng in zweierlei Conidienformen ist an diesem Entwickelungszustande noch nicht deutliclı. Erst nach Verlauf eines Monats, etwa Ende Dezember 1892, traten auch auf der künstlich infizierten Frucht die höchstentwickelten rel'zweigten Conidienfrüchte anf, wie ich sie rom natürlichen Standorte oben beschrieben und abgelildet habe; sie sind deutlich lichtwendig und die Bildung der Seitenzweige schreitet ron oben nach unten fort.

Wir kïnnen diese relzweigten Conidienfruchtkörper der Penicilliopsis brasiliensis nach der Höhe und Bestimmtheit ihrer Formausbildung mit gutem Rechte neben die Fruchtkörper mancher Proto- und Autobasidionyceten stellen. Sie haben sicher dieselbe wo nicht grössere Höhe der Organisation erreicht, wie z. B. die Frnchtiörper von Pilacrella delectans oder 'T'remella damaecornis. die ich im vorigen Hefte dieser Mittleilungen beschrieben habe. oder wie nuter den Autobasidiomyceten viele Formen von Pterula oder Clavaria. Sie sind anch wie diese nichts anderes als in der Bildungsart bestimnt gewordene und zum Zwecke besserer Keim- 
verbreitung auf Fruchtkörpern von bestimmiter Gestalt angeordnete Conidien. Die Basidie der Basidiomyceten ist. wie die Untersuchungen ron Heterobasidion annosum Bref. und den MatruchotiaArten unter den Autobasidiomyceten, von Pilacrella delectans unter den Protobasidiomyceten für jeden, der vergleichend morphologisches Terständuiss hat, handgreiflich beweisen, nichts als ein zur Bestimmtheit der Form und Sporenzalıl. und in der ïberwiegenden Mehrzahl der Formen zur Tierzahl fortgeschrittener Conidienträger. Die Basidie ist zweifellos nicht einerlei Trsprungs. sondern sehr verschiedene Conidienformen laben sich gerade zu viersporigen Basidien entwickelt.

Conidienbildung ron der bestimmten Form, wie bei Penicilliopsis giebt es gegenüber der unendlichen Zahl der Basidien nur verhältnissmässig wenige. Die Conidienträger von Aspergillus und Penicillium sind ja offenbar nahe verwandt. Gäbe es derartige Conidienformen in grösserer Zahl und von etwas gleichmässiger ausgeprägter, typischerer Form, so würden sie in ihrer Gesammtheit eine Gruppe darstellen, die man den Basidiomyceten an die seite setzen dürfte. Sie würden sich von ihnen dann rorzïglich dadurch unterscheiden, dass bei ihnen neben der Conidienfruktifikation noch diejenige in Ascusfrüchten existirt. Soweit unsere bisherige Kenntniss reicht, scheint diese bei keiner Form erhalten zu sein, deren Conidien bis zur Höhe der viersporigen Basidie sich entwickelt haben. Es ist aber einleuchtend und zweifellos und wird durch die gegenwärtige Darstellung dem Verständniss näher gebracht, dass die Existenz echter Basidiomyceten, welche auch noch Ascusfrïchte besitzen, durchaus nicht ausser dem Bereiche der Möglichkeit liegt, wie das Brefeld Bd. TIII S. 264 Anm. 2 schon ausgesprochen hat.

Man findet auch einen ähnlichen Fall von Conidienbildung, die aus unregelmässigen Bildungen bis nahe zur Basidienähnlichkeit fortschreitend sich heute noch verfolgen lässt bei Brefeld Band X S. 264 von Xylaria polymorpha beschrieben. wo es zum Schlusse heisst: 
"So lässt sich denn sagen, dass die freien Conidienbildungen der Xylaria polymorpha einmal eine Steigerung zu Stromata, zu Fruchtkörpern erfahren, zum Andern aber, dass damit eine morphologische Vervollkommnung Hand in Hand geht, indem sie in den letzteren basidienähnlich werden."

Ein weiterer hierher gehöriger Fall ist aus neueren Untersuchungen vermuthungsweise zu folgerm und näherer Priifung werth. Juel hat (K. Svenska Tet.-Akad. Handlingar. Band 24 Afd. III Nr. 9) in einer Abhandlung über Stilbum vulgare Tode nachgewiesen, dass dieser bis dahin nur als fungus imperfectus betrachtete Conidienfruchtkörper sich bei genaner Untersuchung als ein Protobasidiomycet erweist. Angeregt durch Juels Arbeit hat Nassee (Journ. Linn. Soc. XXXIV 1900 Nr. 240) eine Reihe ähnlicher Conidienpilze untersucht, und bildet für mehrere derselben z. B. auch für die zu Nectria cinnabarina gehörige Tuberenlaria vulgaris protobasidienähnliche Conidienträger ab. Nassee hat nirgends nachgewiesen, dass in den Entwickelungsgang eines Ascomyceten ein wirklicher Protobasidiomycet gehöre, lat auch den Charakter der Protobasidie ganz falselı anfgefasst. nnd seine weitgehenden Betrachtungen über den Ursprung der Basidionyceten kümnen wohl von Niemand, der mit dem natïrlichen System der Pilze bekannt ist, gebilligt werden. Immerhin erscheint es nach seinen Mittheilungen nicht ganz unmöglich, dass die Steigermng einer neben der Ascusfrucht bestehenden Conidienform bis zur Protobasidienbildung noch einmal kömnte anfgefunden werden. Ein solcher Fall, wenn er nachgewiesen wäre, würde die Brefeldschen Anschaunngen vortrefflich erläntern und bestätigen.

Doch kehren wir nach dieser Abschweifung zu Penicilliopsis zurüick.

Wie bei den Friichten von Diospyros macrophylla Bl. der Pilz stets einen Samen befällt, sich in dessen Innern ernährt, und danı rhizomorphenartige Stränge aussendet, welche in unregehnässigen Windungen die Frucht durchwachsen und an geeigneter Stelle 
nach anssen treten, genau so ist es mit Penicilliopsis brasiliensis auf den Früchten von Strychnos triplinervia der Fall. Die aus dem Samen tretenden Stränge haben bis $2 \mathrm{~mm}$ Dicke; sie sind kastanienbraun und glatt. Aus ihnen gehen an der Oberfläche der Frucht die beschriebenen Conidienträger von gelbgrünlicher Farbe hervor. An denselben Strängen entstehen aber auch die kleinen runden knolligen Ascusfrüclite von honiggelber Farbe, welche an dem abgebildeten Hucunasamen (Taf. IX Fig. 2) in grösserer Zahl angelegt zu sehen sind; auf der Strychnosfrucht war nur eine solche Ascusfrucht entwickelt, die zur Untersuchung schon vor der Abbildnng abgenommen worden ist. Sie hatte $3 \frac{1}{2} \mathrm{~mm}$ Durchmesser und ist im Längsschnitt in doppelter Crösse in Fig. $40 \mathrm{~g}$ abgebildet. Sie besitzt eine dicke Rindenschicht ans plectenchymatischem Gewebe, welches in allmählichem Uebergang in das aus parallelen kurzgliedrigen Fäden bestehende Gewebe des tragenden Fadens überfülırt. Das Innere des Fruchthörpers erscheint weiss, doch lassen sich darin mattweisse schwache mregelmässig verlaufende Adern erkennen, welche ihn durchziehen. Die dazwischen liegenden Felder haben ein glasiges Ansehen. In diesen Feldern entstehen zuerst in dichtem Fadengewirre, als die anfgeschwollenen Enden der Hyphenverzweigungen die r'mden kurzgestielten Asci von 12 "Durchmesser, welche je 8 ovale Sporen (cf. Fig. $40 \mathrm{~h}$ ) von $9 "$ Lünge und $5 \mu$ Breite enthalten (gegen 6 " zи $2 \mu$ bei Pelı. clav.). Sie besitzen eine skulpierte Membran mit hohen Netzleisten (Fig. 40 i) genau, wie die Sporen von P. clavariaeformis. Die Netzleistenskulptur; welche von Fall zu Fall kleine Verschiedenheiten aufweist, ist aus den Figuren 40 i besser als aus einer Beschreibung zn entnehmen. Sie stimmt mit der gleichen Bildung bei der javanischen Form röllig iiberein. Dagegen ist zn bemerken, dass dort nach der Angabe des Grafen Solms die Asci und die Sporen etwas kleiner sind, dass die Sporen in wechselnder Zahl im Ascus liegen, während ich in den Fällen, wo ein sicheres Zählen möglich war, stets deren acht rorfand, und 
dass abweichend gebildete Sporen, welche anstatt der Netzleisten mit Stacheln besetzt sind, bei meinen brasilischen Funden nicht beobachtet wurden. Tch habe keinen einzigen Frıchtkörper zur Verfügung gehabt, der als röllig reif liätte angesprochen werden kömnen. Ueberall, wo im Ascus die Anlage ron Sporen schon sichtbar ist, findet man die zunächst liegenden Hyplentheile, die Tragfäden, ron Protoplasma entleert. In allen Fruchtkörpern aber, die ich untersuchen konnte. waren noch sehr viele protoplasmaerfüllte dicht verschlungene Hyphenmassen vorhanden von wechselnder (von 12 " abwärts) Stärke, welche zum grössten Theile die Anlage der Ascusfrïchte schon andentungsweise erkennen liessen. Es erscheint mir nacl meinen Befunden zweifellos, dass bei vollkommener Reifung alle Hyphen im Innern des Fruchthörpers zur Ascusbildung werden entleert werden, und dass im Reifezustand der ganze Innenraum rou reifen Schläuchen, oder vielleicht auch nach Zerfall der Schlauchwand ron reifen sporen pulverig erfüllt sein wird.

Um auch durch die Kultur den manfechtbaren Beweis der Zusammengehörigkeit der Ascus- und Conidienfriichte zu erbringen. brachte ich kleine zerzupfte Mycelfückchen mit den ansitzenden Schläuchen aus dem Tnuern des Fruchtkörpers in Nährlösung. Die noch unreifen Sporen keimten nicht. Wohl aber wuchsen die noch protoplasmagefüllten Fadenpartien ausnahmslos sofort zu velzweigten Mycelien aus. und an ihnen trat alsbald die Conidienfruktifikation in höchster Ueppigkeit genau so auf, wie an den Kulturen, welche ron Conidien hergeleitet waren, und die ich friilser beschrieben habe.

Ton der ausserordentlich nahen Telwandschaft der brasilischen mnd jaranischen Form endlich giebt auch der T'mstand Zengniss, dass wenn man die grünlichgelben Conidienfrüchte von P'enicilliopsis brasiliensis in Alkohol bringt, dieser sofort jene schöne tiefrothe Farbe annimmt. Welche bei Pen. clavariaeformis beobachtet und ron Reinke in einer besonderen Abhandlung (Ann. du. Jard. Bot, de Buitenzog Tol. TI 1886) chemisch und spek- 
troskopisch untersucht worden ist. Dieselbe Farbe erhält man, wemn man die kastanienbraunen rhizomorplaartigen Stränge in Alkolıol bringt. Dies erscheint dem mbefangenen Beobachter nicht so merkwïrdig, weil man das tiefe Roth in dem Kastanienbraun sich wohl vorstellen kann. Dagegen ist es eine höchst wunderbare Wahrnehmung, wenn man beim Eintauchen der gelbgrïnen Conidienfrüichte, an denen von Roth gar nichts zu bemerken ist. sofort die intensiv rothe Farbe im Alkohol erscheinen sieht.

\section{Pyrenomyceten.}

a. Hyрocreaceen.

Zu den Hypocreaceen gehört bei weitem die grösste Zahll der ron mir in Brasilien untersnchten Ascomyceten. und die Darstellung der an ilmen gewonnenen Ergebnisse wird demmach auch den Haupttheil dieses Heftes in Anspruch nelımen. Bei der Anordnung des Stoffes im Einzelnen folge ich imnerhalb der Hypocreaceenfamilie in den Hauptzügen Saccardo. Sein sogenamntes sporologisches System, wie es am Anfang des XIT. Bandes der Sylloge zusammengestellt ist, kann in meiner Auffassmng selbstrerständlich nur den Werth eines nach willkürlichen Prinzipien anfgestellten Registers laben, und in der Bezeichnung der „preredibili funghi futuri" mit Nummern kamn ich natürlich, wie dies anch von anderer Seite schon geschehen ist, nur eine geistreiche Spielerei sehen, die wie Lindau sehr richtig bemerkt (Bot. Ctbl. Beihefte. Bd. IX S. 335) unwillkürlich zu der Frage leitet, warum Saccardo nicht gleich alle noch mentdeckten Pilze anstatt mit Nummern, mit Namen rersehen habe, wo denn für die künftigen Mykologen die unselige Synonymie von rornlıerein ausgeschlossen sein würde.

Allein wie Limné bei seinem künstlichen System lie und da z. B. in den Klassen Didynamia, Tetradynamia und Gynandria natürliche Einheiten durch die kïnstlichen Charaktere fasste, wobei gutes Glück und natïrlicher Formensim in gleichem Naasse 


\section{$-74-$}

ihn mögen begiinstigt haben, so hat auch Saccardo imnerhalb mancher Formenkreise und im besonderel nach meiner Ueberzengung bei den Hypocreaceen, die natürliche Blutsverwandtschaft zutreffend durch seine Zusammenstellung ausgedriickt, welche auf der Beschaffenheit der Ascussporen beruht. Und wenn er die durch ihre Sporengestalt rerschiedenen Formen je nach der Höhe ihrer sonstigen Organisation in Parallele zu einander setzt, so bringt er dadurch oftmals jenes richtige Prinzip zu zwecknässigem Ausdruck, welches ich in meinen Protobasidiomyceten wiederholt und insbesondere Seite 153 ff. erörtert habe, dass nämlich die Steigerung: der Formen zu immer höher organisirten Fruchtkörpern sich bei allen Klassen der Pilze, in Folge des überall gleichen Baumaterials - der einfachen Hyphen - und des iiberall gleichen Zweckes Erhebung der sporen- oder conidientragenden Theile über das Substrat zu leichterer Terbreitung - in ähnlicher oder gleicher Weise vollzogen hat.

In den Protobasidiomyceten (S. 15̃4) hatte ich gezeigt, dass bei Tremellaceen. Anriculariaceen und Autobasidiomyceten sich eine gradezu erstamliche Uebereinstimmung der Fruchtkörperausbildung in parallelen Reilen nachweisen lässt, welche keineswegss auf die Blutsverwandtschaft der in der äusseren Form ihrer Fruchtkörper sich gleichenden Gattungen, sondern auf die Wirksamkeit des oben dargelegten Prinzips zurïckzuführen ist.

Ich hatte dort in Aussicht gestellt, die zahlreichen oft schon herrorgehobenen Formübereinstimmungen bei Basidiomyceten und Ascomyceten, welche durch dieselbe Erklär'nngsweise verständlich werden, noch durch nene und bemerkenswertle Nittheilungen über brasilische Ascomyceten zn ergänzen, wie dies im Folgenden nuı geschehen soll. Als das erstannlichste Beispiel in dieser Hinsicht ist del auf 'Taf. III Fig. 52 n. 53 dargestellte Ascopolyporus zn nennen, ein Pilz der ganz besonders eindringlich daran erimnert, dass Formenähnlichkeit oder Gleichleeit hochentwickelter Fruchtkörper bei den Pilzen niemals einen Beweis der nahen 
Verwandtschaft liefert. Diese Erkenntniss müssen wir auch bei Betrachtung der Hypocreaceen im einzehnen zn Grunde legen, und uns klar machen, dass anch hier das Stroma und seine Ausbildung uns fast nie einen sicheren Anhalt für die richtige systematische Anordnung der Gattungen bieten kann. Innerhalb einer Reihe von Formen, die wie z. B. Saccardos Scolecosporae mnter den Hypocreaceen durch die Eigenart ihrer Schläuche und Sporen ihre Blutsverwandtschaft sicher bekundet, kann die jeweilige Höhe und Art der Stromabildung zur praktischen Abgrenzung der Gattungen vortreffliche Dienste leisten. wohingegen der Versuch, auf Grund gleicher oder ähnlicher Stromata Verwandtschaften zwischen Pilzen mit ganz verschiedener Sporenbildung zu konstruiren,keine Aussicht auf Erfolg verspricht. Dies werden die folgenden Untersuchungen klarer erweisen.

\section{a. 1. Amerosporae Hypocreacerum.}

Ich beginne num mit der Beschreibung eines Pilzes, welcher die erste Unteroruppe der Hypocreaceen, mit ungetheilten Ascussporen, vertritt, der Melanospora erythraea nov. spec. Zweimal im Jahre 1891 fand sich in meinen Kulturen ein Mycel ein, welches sehr schnell den ganzen Kulturtropfen durchwucherte, und mit der Bildung von Perithecien auf dem Objektträger endete. Das Mycel war reich verzweigt, mit vielen Anastomosen versehen, seine Fäden waren von sehr ungleicher bis zu $10 \mu$ ansteigender Stärke und mit einem vakuolenreichen Protoplasma erfüllt. Die Bildung der Perithecien erfolgte in grosser Zahl und komnte von Anfang an beobachtet werden. Da wo nicht allzuviel Mycelgeflecht die Beobachtung erschwert, sieht man einen Mycelzweig sich zur Perithecienbildung entweder schraubig, oder auch unregelmässig knäuelig eimrollen (T'af. II Fig. 34 e, f). Der Knäuel vergrössert sich schnell durch weitere Verzweigungen des Ursprungfadens, die sich den früheren Windungen eng anlegen und bald einen kugligen undurchsichtigen Körper von hellgelb- 
licher damı röthlicher Farbe bilden. In manchen Fällen gelang es festzustellen, dass die ganze Perithecienanlage nur von dem einen Mycelfaden, dem sie ihren Ursprung verdankte, wie von einem Stiele getragen wurde, so dass es ausgeschlossen war, dass andere benachbarte Fäden bei ihrer Bildung betheiligt sein kounten. Vom unteren Theile der reifenden Perithecienanlage strahlen nun nach allen Richtungen Hyphen aus, welche den Fruchtkörper auf seiner Unterlage befestigen und halten. Die Farbe wird bei der Reife immer dunkler, das Roth verschwindet bald und gelıt in Schwarz über. Das reife Perithecium ist fast kuglig; mit einer kurzen, stumpf kegelförmigen Mündung versehen und hat etwa 1. mm Durchmesser. Aus der Mïndung tritt bei der Reife die Sporenmasse wursttörmig oder anch in Gestalt eines dunkelschwarzgrïnen Tropfens ans. Die Schlänche (Fig. 34 a) sind etwa $250 ~ u$ lang und am oberen Ende in charakteristischer Weise stumpf abgestutzt. sie enthalten vier ovale Sporen, die anfangs wasserhell, dann hellgrünlich. in völlig reifem Zustande dunkelschwarzgriün gefürbt sind, und in der Grösse nicht immer gleich. doch im Nittel $36 "$ " Länge bei 16 " Breite in der Mitte zeigen. An den in den Präparaten längere Zeit autbewahtrten sporen bemerkt man eine Längsstreifung der Membran, welche mir bei den frisch zur Beobachtung gekommenen nicht aufgefallen, daher auch in den Zeicllnungen nicht wiedergegehen ist.

Die Sporen keimten in der Xälnlïsung. in weleher sie gebildet waren, auf keine Weise, trotz vielfältiger Tersuche, indessen genïgte es, ein beliebiges abgerissenes Mycelstiickchen ans der Kúultur in einen nenen Nährlüsungstropfen zn übertragen. um eine nene Kultur zu gewinnen, die dann wieder mit Perithecien der beschriebenen Art endete. Die Früchte branchten zu ihrer Reifung 14 Tage bis 3 Wochen. Fis lag hier also der seln seltene Fall vor, dass in der kiinstlichen Kultur die höchste Fruchtform sehr leicht gewonnen werden kounte, wälnend die Conidien zunächst nicht rorkamen. Und doch mussten Conidien rorhanden sein. 
demn wenn eine Spore den Ausgangspunkt der Kulturen gebildet lätte, so hätte ich sie bei ihrer Grösse und dunklen Farbe leicht noch auffinden müssen.

Eines Tages nun brachte mir ein gefälliger Bewohner des Stadtplatzes Blumenau (der alte Herr Merck) ein Stïck rerschimmeltes Maisbrot, das einen sehr auffallenden Anblick bot. Von dem Brote war nichts melır zu sehen. Es war eingehïllt in eine hellorangerothe, lockere, nach aussen staubig zerfallende Pilzmasse, welche auf der Oberfläche ein ïber $10 \mathrm{~cm}$ starkes Polster bildete. Ich nalım nur wenige der zerstäubenden Conidien, die, wie wir gleich sehen werden, besser noch als Oidien bezeichnet werden, und machte davon Anssaaten in Nährlösungen, und ich erhielt davon Kulturen, welche in gleicher Weise, wie die frülıer beschriebenen. Perithecien mit viersporigem Ascus erzeugten. Dieser auffallende leuchtend rothe Schimmelpilz stellte demnach eine Nebenfruchtform unserer Melanospora dar.

Ich habe schon früher (Heft VI dieser Mitth. Seite 65) hervorgehoben, dass ich im allgemeinen von den so überaus zahlreich und mannigfacl vorkommenden Conidienformen keine Kulturen anzusetzen pflegte. da ja nur in den seltensten Fällen etwas anderes, als immer dieselben Conidien dabei herauskommt. Nach den oben beschriebenen Erfahrungen aber erschien es mir num doch der Mühe werth, auch mit einer Conidienform Versuche anzustellen, die mir in den Rogas der Colonien sehr oft aufgefallen war und mit dem beschriebenen Brotschimmel übereinzustimmen schien. Bekanntermaassen erfolgt die Kultur des Urwaldes in den südbrasilischen Kolonien in der Weise, dass zunächst alle Stämme umgeschlagen werden. Sie bilden nun ein wirres Durcheinander von Stämmen, Aesten, Schlingpflanzen u. s. w. Man wartet num einige Wochen oder Monate und zündet an einem möglichst trockenen Tage das Ganze an. Aucl wenn der Brand noch so gut und nach Wunsch verläuft, so bleiben immer zahllose verkohlte Aeste und Baumstümpfe auf der Brandfäche zurück, und wenn 
jetzt Regenwetter eintritt, so kann man sicher darauf rechnen, an zahlreichen Stellen und immer auf verkohltem Holze einen leuchtend rothen Schimmel hervorbrechen zu sehen, der bisweilen faustgrosse Knollen bildet und bald in ein staubiges Pulver zerfällt, das vom nächsten Regen rertwaschen wird. Dieser Pilz schien mir mit dem auf Brot rorkommenden vollständig übereinzustimmen, und ich überzeugte mich nun durch eine Aussaat desselben auf Brotscheiben, dass er hier in derselben ohen beschriebenen höchst iippigen Weise wucherte Eine dicke Brotschnitte war in vier T'agen von dem Pilze durchwuchert, und ringsum mit den rothen oidienartig zerfallenden Fäden bedeckt. Tn Januar 1893 wiederholte ich den Versuch, indem ich zwei solche durchwachsene Brotschnitten anfeinanderlegte, und sie mit einer Glasglocke bedeckte. Schon am nächsten Norgen war von dem Brote nichts mehr zu sehen, und in den folgenden Tagen entwickelte sich der Pilz mit erstamnlicher Schnelligkeit und Uepuigkeit. An verschiedenen Stellen erhoben sich dicke, mehrere Centimeter im Durchmesser haltende Wüiste und Knollen, solche brachen sogar seitwärts miter dem Rande der Glocke herror. Sie rerschmolzen mit einander und bildeten auf dem Brote ein mehrere Centimeter dickes Kissen, das ganz und gar ans dicht gedrängtelı, radial ausstrahlenden Hyphen des Pilzes bestand. Anfänglich sind die rorbrechenden Kinollen zart weiss-gelblich. bald nelmen sie einen röthlichen schimmer an, und im Verlauf weniger Stunden geht die Farbe in wundervoll zart abgestuften Farbentönen über zum leuchtenden Orangeroth (Saceardo Chromotaxia Nr. 21).

Die dumklere Farbe ist das Zeichen des Verfalles der äusseren Fäden in Oidien. Am festesten gebildet waren jene vorbrechenden Massen. die unter dem Glockenrantie hervor ins Freie traten. Im Innern der Glocke war die Bildung lockerer. Hier ist am dritten Tage stellenweise schon rother. pulvriger staub rorhanden, wie wir ihn auf der Rogsa fanden, an anderen Stellen erhebt sich noch hellrosa gefïrbter duftig lockerer Irycelfilz mehrere Centimeter 
loch, und lier sind erst die äussersten Enden der Fäden im Zerfalle. Die Fäden sind reich septirt und reich rerzweigt, ron 4-16 $\mu$ Durchmesser schwankend. und ron vakuolenreichem Plasma strotzend gefüllt. Die Glocke stand in der Nälıe des Fensters, und es war zu beobachten, dass die dem Liclıte zugekehrte Seite in der Entwickelung und Färbung der anderen weit vorauseilte. Nachdem die Glocke damn mmgedreht worden war, entwickelte sich auch die zurückgebliebene Hälfte im Laufe des folgenden 'Tages zn gleicher Iächtigkeit, und es traten nun anch an dieser Seite dicke Wülste unter dem Rande der Glocke hervor. Die Temperatur im Innern des Brotes war wälnend der Entwickelung des Pilzes mm etwa 10" höher als die im umgebenden Raume (nämlich $37^{\circ} \mathrm{C}$. gegen $28.5^{\circ}$ und bei einer zweiten Messung $35^{\circ} \mathrm{C}$. gegen $25^{\circ}$ ).

Beliebige Mycelföckchen aus den noch nicht zerfallenen Mycelmassen wurden nun zn zalılreichen Objektträgerknlturen verwendet. Ich erhielt eine grosse Anzahl von Kulturen, welche, wie in frülheren Fällen, den ganzen Objektträger bedeckten und in grosser Anzahl zur Perithecienbildung schritten, ohne dass rorher Oidien aufgetreten wären. Die Perithecien waren dieselben oben beschriebenen dunklen Frnchtkörper mit viersporigen Schlänclıen, die im Zeitraum von 14 Tagen etra reiften. Wunderbarer Weise aber erhielt ich jetzt auch ebenso zahlreich solche Knlturen, in denen die Oidien anftraten und keine einzige Perithecienanlage; und doch waren Zeit und Stunde der Aussiat, das Anssaatmaterial und die angewendete Näln'lösung für uiclı ununterscheilbar in allen Fällen dieselben. Es ist dies wieder ein bemerkenswerthes Beispiel für die nun schion oft festgestellte Thatsache, dass die Entscheidung darüber, ob von einem Pilze die eine oder andere seiner Fruchtformen gebildet wird, oftmals von Umständen der allergeringfügigsten Art abhängt, so geringfügiger, dass ihre Bemtheilung und Feststellung sich unserer W'ahrnehnung. völliø entzieht. Aehnliche nnd sehr auffällige Erscheinmugen bei der Kultur der Rozites gongyloplkora, des Ameisenpilzes, habe iclı im VI. Hefte dieser Mitth. ansfuilnlich beschrieben. 
Ueber die Oidienbildung selbst sind nun noch einige Einzellıeiten nachizuholen. Sei es, dass die Masse des Pilzes auf dem künstlichen Substrate, dem Brote, oder auf dem natïrlichen, den kohlenden Holzresten, sich entwickelt, so ist sie stets zunächst in derselben Weise zusammengesetzt aus parallel gerichteten pallisadenartig eng zusammengedrängten und senkrecht von der Unterlage wegstrebenden Hyphen von verschiedener bis 16 " ansteigender Stärke, mit vakuolenreichem Plasma erfüllt. Sparrige Verzweigmng der Füden beobachtet man an dem änsseren Umfange des Polsters, wo die Zusammensetzung lockerer wird. Tährend das Polster sich mit ungemeiner Schnelligkeit üppig entwickelt, ist die Farbe, wie oben beschrieben wurde, noch hell und vom Zerfall der Fäden nichts zu bennerken. Dieser tritt ein, wemn die verfügbaren Nährstoffe erschöpft sind, auf ärmeren Substraten frïher an kleinen Polstern, auf reicheren wie den Brotscheiben, später, an sehr grossen höchsst auffallenden Bildungen. Die Endzellen der Fäden und zwar mehrere, vier bis fünf etwa gleichzeitig schwellen dann mehr oder weniger bauchig oder tomenförmig an. Znuächst ist nur je eine Zellwand zu erkennen, bald aber tritt eine deutlich sichtbare Spaltung derselben ein. der die Tremnng der beiden Lamellen anf dem Fusse folgt. Bisweilen auch sieht man die schon in selbständige je für sich mit eigener Membran versehene Zellen zergliederten Fäden noch in losem Zusammenhange, der durch die Reste der gemeinschaftlichen Membran des Mycelfadens zwischen den einzelnen Gliedern noch aufrecht erhalten wird. Die Lamellen, in welche die Trennungswand sich spaltet, bleihen zunächst gerade, die einzelnen Oidien sind, wie die Figuren (Fig. 34 c, d) zeigen auf einer dem Querschnitte des ursprünglichen Fadens gleichen Fläche abgeplattet, und erst weiterhin runden sie sich meist ab, so dass man die Abtremnmgsfläche nicht mehr erkennt. Sie sind der Art ilırer Entstehung entsprechend von selır verschiedener Gestalt und Grösse (Fig. 34 d). Die Zergliederung der Fäden greift allmällich immer weiter zurück, 
und verwandelt endlich das ganze Polster des Pilzes in ein stäubendes Pulver der rothen Oidien. In Nährlösung gesäet keimen die Oidien (Fig. 34 g) schon nach zwei Stunden und erzengen in 24 Stunden ein Mycel, das den ganzen Tropfen durchwuchert. Wo es zur Bildung von neuen Oidien auf den Glasplatten der künstlichen Kultur kommt, entstehen diese g*wöhnlich in der Luft am Rande des Kulturtropfens, viel seltener in der Flüssigkeit, wo sie der Darstellung leichter zugänglich werden, wie in Fig. 34 c, die nach einer 24 Stunden alten Kultur gezeichnet wurde.

In Garten des ron mir bewohnten Hanses war ein Orangenstamm umgeschlagen worden, die Aeste waren am Grunde des Stumpfes zusammengehäuft und verbrannt, wobei anch der Stumpf selbst angekohlt war. Trotz recht trockenen Wetters in jener Zeit brachen nun im Dezember 1892 ans der rom Fener beschädigten Rinde dieses W'urzelstockes eben jene rothen Oidienpolster herror, die mir ron den Roças her so wohl bekannt waren. Aussaaten auf Brot und Aussaaten in Nälırlösung; die ich alsbald rornalım, ergaben genau dasselbe Resultat, wie früher. Als aber die Perithecien in meinen Kulturen diesmal reiften, ersah ich mit Erstaunen, dass sie ausnahmslos Schläuche mit 8 Sporen erzengten (Fig. 34 b). Die Schläuche hatten dieselbe oben charakteristisch stumpf abgeschnittene Form, wie die friiher beobachteten, auch die Sporen waren an Form und Farbe den früheren gleich, jedoch an Grösse erheblich geringer, nämlich nur etwa $25 \mu$ lang und $14 \mu$ breit (gegen 36 und 16 wie oben). Mitte Januar beobachtete ich reife Perithecien anch im Freien an dem Orangenstanm und auch diese hatten ausnahmslos achtsporige Schläuche, während vordem stets nur viersporige, und unter Hunderten nur eimmal ein sechssporiger Schlauch beobachtet worden war. Ich nehme nach diesen Befunden an, dass die Melanospora erythraea in zwei verschiedenen zu relativer Beständigkeit vorgeschrittenen Formen, einer viersporigen und einer achtsporigen, rorkommt, und möchte den Werth eines Artunterschiedes der rer- 
schiedenen Sporenanzahl nicht zuschreiben, zumal das Vorkommen vier- und achtsporiger Schläuche auch von anderen Melanosporaarten angegeben wird (vgl. auch Lindau in Engler u. Prantl. Nat. Pflanzenfam. I, 1. S. 352). Erwähnung verdient endlich noch die Thatsache, dass die immerhin seltene Bildung der Perithecien in künstlichen Kulturen auf dem Objektträger auch bei der von Brefeld Band X Seite 163 beschriebenen Melanospora nectrioides beobachtet wurde.

\section{a. 2. Didymosporae Hypocreacearum.}

An zweiter Stelle kommen wir jetzt zu der überans formenreichen Gruppe, deren Ascussporen durch eine Querwand zweizellig sind. Saccardos weitere Theilung dieser Formen in Hyalodidymae und Phaeodidymae bleibt zweckmässig ganz ausser Berïcksichtigung. Denn die ersteren sollen „sporidia hyalina vel olivascentia" und die anderen "sporidia fuscescentia" haben. aber schon in der Gattung Nectria finden sich die verschiedensten Farbenabstufungen. Neben den Perithecien kommen bei den hierher gehörigen Pilzen Conidien mannigfacher Form und Bildungsart vor, und ausserdem Chlamydosporen. Durch den Besitz besonders charakteristischer Nebenformen können einige Gattmingen, wie Hypomyces und Pyxidiophora zweckmässig begrenzt werden. Sodann ist vielfach eine Steigerung der Conidienbildung von einfachen Lagern zu Fruchtkörperbildungen zu verfolgen, und wemn diese Steigerung eine charakteristische Höhe der Ausbildung erreicht, so giebt sie ebenfalls ein brauchbares Gattungsmerkmal ab, wie es für Sphaerostilbe vorliegt. Hypocrea wiederum ist durch die scharf ausgeprägte Eigenart der Sporenbildung vorzüglich charakterisirt. Im ïbrigen kamn die jeweils erreichte Höhe der stromatischen Entwickelung, also die Form der Fruchtkörper, zur Ungrenzung von Gattungen oder Untergattungen hier vortrefflich verwendet werden; denn von einzeln stehenden Perithecien 
ansgehend finden sich alle denkbaren Uebergänge bis zu der clavariaähnlichen Hypocrea alutacea oder dem erstaunlichen Fruchtkörper von Mycocitrus ('Taf. III Fig. 45).

Wir beginnen mit der Gattung Hypomyces, welche durch den Besitz eines stromaähnlichen Hyphenfilzes, sowie durch das gleichzeitige Vorkommen von Conidien und Chlamydosporen, endlich dadurch höchst natürlich zusammengehalten wird, dass fast alle ihre Angehörigen auf anderen Pilzen parasitiren.

Die Gattung dïrfte in dem Gebiete, welchem diese Arbeit entstammt, in zahlreichen Arten vertreten sein. Wenigstens sind mir zu wiederholten Malen Chlamydosporenformen vorgekommen und auch in die Kulturen gerathen, welche auf Zugehörigkeit zu Hypomyces schliessen liessen. Ton nur zwei Formen indessen habe ich die Perithecienfrüchte kennen gelernt, und diese seien hier kurz besprochen. zumal die eine von ihnen durch Bresadola bereits unter dem Namen Hypomyces Möllerianus in der Hedwigia 1896 Seite 299 veröffentlicht. jedoch nicht genïgend beschrieben ist.

Bresadolas Beschreibung lautet: Stromate late effuso spongioso-gossypino $1^{1} / 2-2 \mathrm{~mm}$ crasso, albido-stramineo; peritheciis subsuperficialibus, basi tantum stromati nidulantibus, albis, obovatis, fusco-papillatis $200-250 \mu$, ascis cylindraceo-subfusoideis, $80-90=$ $5-6 \mu$; sporidiis subdistichis. elongatis, utrinque attenuatis, 1 septatis, interdum 3 septatis, $16=4 \mu$. Hab. . . ? Blumenau Brasiliae.

Der fragliche Pilz ist am 15. Februar 1892 gefunden worden. Das auffallend stark entwickelte Stroma sass auf der unteren hymenialen Seite eines Löcherpilzes, den Herr Bresadola unter dem Namen Fomes fulvo-umbrinus n. sp. (Hedwigia 1896 S. 280) bekannt gemacht hat. Das grösste Exemplar unseres Hypomyces hatte $5 \mathrm{~cm}$ Durchmesser in der einen und $2 \mathrm{~cm}$ in der anderen Richtung und war dem Fomes nur lose aufgeheftet. Es bildete eine Art Kissen, das in der Mitte am dicksten, in frischem Znstande ïber $5 \mathrm{~mm}$ stark war, und nach dem Rande allmählich in einen spinnewebfeinen Flaum überging. Sehr auffallend ist die 
Struktur dieses Kissens, welche ïbereinander in vielmaliger Wiederholung deutlich dichter und dïnner verflochtene Schichten zeigt, ähnlich wie sie in den Fruchtkörpern der Stereumarten zu beobachten sind. Die ganze untere Fläche ist mit Perithecien bedeckt, die in fast regelmässiger Vertheilung mit etwa $1 / 4 \mathrm{~mm}$ Abstand von einander angeordnet sind. Was die Sporen angeht, so habe ich solche mit mehr als einer Theilwand nie gesehen. Die Sporen (Bresadolas und der Systematiker Sporidien) sind nicht ganz gleichmässig und messen z. Th. bis $21 \mu$ in der Länge. Zur Keimung schwillt jede Theilzelle in der Mitte auf und dann sehen die Sporen ganz aus, wie die von Tulasne für Hypomyces ochraceus abgebildeten. Die dem Fomeshymenium zugekehrte obere Seite des Stroma ist, soweit sie nicht in unmittelbarer Verbindung damit steht, und dies ist nur an einzelnen wenigen Stellen der Fall, zottig haarig von unregelmässig aufragenden Hyphenbüscheln, und an den Fäden dieser Hyphenbüschel werden in ungehener grosser Zahl eigenartig geformte farblose Conidien abgegliedert. Sie sind eiförmig, doch an der Ursprungsstelle mit gerader W'and versehen und tragen dort einen kragenartigen Ansatz, der bei ihrer Ablösung von der tragenden Hyphe abreisst. Thre Länge beträgt $6 \mu$. Diese Conidienform ist sonst bei Hypomycesarten wohl noch nicht beobachtet, und rermehrt die auffallende Zahl der verschieden gestalteten Nebenfruchtformen dieser merkwürdigen Gattung.

Eine zweite Hypomycesform, die ich in dankbarer Anerkennung der von Herrn Bresadola meinen Pilzen gewidmeten Aufmerksamkeit als Hypomyces Bresadolianus nor. spec. einführe, fand ich zu wiederholten Malen auf einer von dem Parasiten vollständig verunstalteten Agaricine, die ihrerseits auf morschen Rindenstïcken am Boden des Waldes angesiedelt war. Die zahlreich beobachteten Gebilde ('Taf. IX Fig. 3) machen den Eindruck, als hand̄le es sich um eine stiellose weich fleischige Agaricine, welche vielleicht erst unter dem Einflusse des Parasiten resupinat geworden ist, derart 
dass die verhältnissmässig kleine Oberseite sich dem Substrat zugeneigt hat, und die üppig entwickelten dichtstehenden oftmals verzweigten Lamellen nun aufrecht neben einander stehen und ein System von faltigen Wänden bilden, wie die Figur es darstellt. In allen beobachteten Fällen sind nun diese Lamellen, an denen von Basidienbildung in keinem Falle trotz sorgsamster Untersuchung etwas festzustellen war, dicht punktirt von den einzeln stehenden aber ïber ihre ganze Fläche gleichmässig dicht vertheilten weissgelblichen Perithecien. Diese sind halb eingesenkt, von der Form einer Kürbisflasche mit kugligem Bauche von ca. 200 "Durchmesser und einem Halse von 100 „ Länge. Die cylindrischen achtsporigen Schläuche sind $120 \mu$ lang, 4-5 $\mu$ breit, die hyalinen zweizelligen Sporen, deren Theilzellen meist nicht ganz gleich gross sind, messen $10-13 \mu$ Länge bei $3,5-4 \mu$ Breite, sie sind nur sehr wenig nach den Enden zu verschmälert. Sie keimen leicht in Nährlösungen, erzengen ein reich verzweigtes Nycel das sich alsbald mit einem dichten Schimmelrasen aufragender wirtelig verzweigter Conidienträger bedeckt. Diese Träger sehen den für Hypomyces ochraceus ron 'T'ulasne abgebildeten sehr ähnlich, doch sind die Seitenzweige meist einfach, nicht wieder verzweigt, und die Conidien bilden sich an ihren Enden in grösserer Zahl, zu kleinen Köpfchen verklebend. Die Conidien sind oval, hyalin, und messen $6 \mu$. Sie schwellen zur Keimung erheblich an und erzengen wieder Mycelien mit derselben Schimmelbildung. Eben dieselbe trat auch in grosser Ueppigkeit auf, wenn ich Stücke der befallenen Agaricine, an denen Perithecien noch nicht sichtbar entwickelt waren, unter einer Glocke feucht hielt. An diesen Stücken beobachtete ich weiterhin auch die Bildung der Perithecien, welche im Laufe weniger Tage reiften, und dann reichlich Sporen entleerten.

Mit allergrösster Wahrscheinlichkeit gehören zı dieser Form endlich runde selı kleine, nur $6 \mu$ im Durchmesser haltende gelbbrame Chlamydosporen, welche an vielen Stellen der befallenen 
Fruchtkörper in nächster Nachbarschaft der Perithecien und in grossen Mengen gefunden wurden. Ihre Membran erweist sich bei sehr starker Vergrösserung als stachlich rauh. Da diese Chlamydosporen aber in meinen Kulturen nicht auftraten, und auch von ihnen keine reinen Aussaaten gewonnen werden komnten. so ist die unbedingte Sicherheit für ihre Zugehörigkeit zu Нypomyces Bresadolianus noch nicht gegeben und Vorsicht dürfte hier mehr als sonst wo am Platze sein, nachdem selbst ein Tulasne sich durch die Chlamydosporen der Nyctalis täuschen liess, die er dem Hypomyces asterophorus zuschrieb.

Die formenreiche Gattung Hypocrea (einschliesslich der später abgezweigten Podocrea), von der schon weit über 100 Arten beschrieben sind, ist durch ihre Schläuche und Sporen höchst eigenartig und bestimmt charakterisirt. Die acht Sporen des Schlauches nämlich zerfallen sehr früh, noch im Schlauche, in je zwei oft etwas ungleiche Theilsporen, so dass der reife Schlauch stets 16 sporig erscheint. Schon Tulasne hat diese sporenbildung richtig beobachtet und ansführlich beschrieben, ebenso beschreibt sie Schröter und ebenso Brefeld, in dessen X. Bande auf Tafel V Fig. 56 sich von Hypocrea rufa ein Schlauch abgebildet findet, der ïber die Eintstehung der 16 Sporen gar keinen Zweifel lässt. Diesen Angaben gegenïber muss es mindestens als unrorsichtig. bezeichnet werden. wenn IV. Ruhland in einer Arbeit über Hypocrea (Verhandl. bot. Ver. Prov. Brandenburg 1900, S. 64) angiebt „In den Ascen werden durch freie Zellbildmng 16 besondere Sporen angelegt, wie durch Jodreaktion leicht nachzuweisen. Es steht diese Angabe im Gegensatz zu den irrthümlichen der systematischen Werke, anch der Tulasnes und Brefelds" u. s. w. Wenn man in einem Athem die beiden Grössten unserer Wissenschaft des Irrtlıums zeiht, damm bedarf es doch eines gründlicheren Gegenbeweises, als der Bemerkung: ..wie durch Jodreaktion leicht nachzuweisen." In der That, wenn man viele Hypocreaarten in frischem Zustande untersucht, so überzengt man sich leicht, dass T'ulasne 
und Brefeld sehr richtig beobachtet haben. Die Behauptung einer „freien Zellbildung“ im Ascus würde heutzutage zu ihrer Stütze ebenfalls sehr grïndlichen und überzengenden Beweismaterials bedürfen. Denn alle sicheren Beobachtungen der Neuzeit erweisen klar, dass der Ascus urspriinglich einen Kern enthält, der durch wiederholte Zweitheilung vier, acht, oder bei Hypocrea endlich sechszehn Sporenkerne erzeugt. Dass man in manchen Fällen bei den fadensporigen Hypocreaceen noch ganz genau 32 und 64 Theilzellen der einzelnen Sporen nachweisen kann. werden wir später sehen.

Wenn man, wozu ich reichlich Gelegenheit hatte, eine grosse Anzahl verschiedener Arten von Hypocrea vergleichend untersucht. so wird man sich der Ueberzeugung nicht rerschliessen können, dass diese eigenartige Sporenbildung. welche beim ersten Blick ins Mikroskop dem Beobachter sagt: dies ist eine Hypocrea, nur durch die nahe Blutsverwandschaft der betreffenden Formen befriedigend erkläıt werden kann. Es erscheint dann ganz selbstverständlich, dass man die sämmtlichen Pilze, welche unter allen Hypocreaceen durch diese schliesslich 16sporigen Schläuche sich auszeichnen, in eine Reihe ordnet, sie systematisch zusammenfasst, wie auch bisher stets geschehen ist.

Da Hypocreaarten mit freistehenden Einzelperithecien bisher nicht bekannt geworden sind, so setzen wir an den Anfang der Reihe ganz naturgemäss Formen, wie die von Tulasne in den herrlichen Bildern 7 und 8 Tafel IV Band III der Carpologie dargestellte Hyp. delicatula, bei der die Perithecien noch ziemlich regellos ạuf und in dem wenig entwickelten Stroma stehen. Das Blumenaner Gebiet, welches ich durchforschte, war sehr reich an Hypocreaarten, von denen nemn durch die Herren Bresadola (Hedwigia 1896, S. 300) und Hennings (Hedwigia 1897, S. 220) bereits beschrieben sind. Darunter sind einige, die durch ein unregelmässig begrenztes weit ausgebreitetes, dem Substrat eng anliegendes Stroma sich der Hyp. delicatula anschliessen; andere bilden mehr oder 
weniger regehmässig rundlich umschriebene kissenförmige bisweilen nur mit der Nitte ihrer Unterseite, gleichsam mit einem Stiel angeheftete Polsterchen. Aehnliche Formen beherbergt meine Sammlung noch mehrere, sie fanden sich sehr häufig. doch unterlasse ich ein näheres Eingehen darauf, weil ich, abgesehen von der durch Bresadola a. a. O. beschriebenen Hypocrea succinea, Kulturversuche nicht mit ihnen angestellt habe, und weil sie alle grosse Aehulichkeit mit einander aufweisen, so dass die Artabgrenzung nur auf Grund sehr geringfügiger Unterschiede in Farbe und Dicke der Stromata, Länge und Grösse der Schläuche und Sporen erfolgen kamn.

Hypocrea succinea Bres., die ich gleich zu Anfang meines Blumenauer Aufenthaltes, vom 15. Oktober bis 8. November 1890, in Kultur nalım, bildete im Nährlösungstropfen reich verzweigte Mycelien, die an anfragenden farblosen Luftfäden Conidien von ovaler Form, $9 \mu$ Länge und $4 \mu$ Breite hervorbrachten. Da dieselbe Fadenspitze hinter einander zahlreiche Conidien bildet, so entstehen durch Verkleben derselben die bekannten Köpfchen, welche bei flüchtiger Betrachtung bisweilen ein Sporangium vortäuschen. Die conidientragenden Fäden waren häufig reich verzweigt und ähmelten den durch 'Tulasne und Brefeld für Hypocrea rufa und Terwandte bekannt gemachten Conidienträger'n.

Gegenüber den Arten mit unregelmässig dïmnkustig ausgebreitetem Stroma wie z. B. Hyp. flavidula P. Henn., membranacea P. Henn., glancescens Bres.. sind offenbar jene höher organisirt, die den Beginn individualisirter Fruchthörper durch annähernd regelmässig umschriebene (Hyp, atrofusca P. Henn.), weiterhin sogar durch einen kleinen Stiel über das Substrat erhobene Stromapolster anzeigen. Wiederum höher entwickelt ist die Hypocrea lufa, wie ein Blick auf 'Tulasnes Abbildung (Carpol. III Taf. III Fig. 6) ohne weiteres dentlich macht. Hier ist ein gut entwickelter Stiel vorlanden, das Stroma hat eine sterile dem Substrat zugerendete Unterseite ausgebildet, doch ist seine Form noch 
ziemlich unbestimmt. Auf ganz ähnlicher Höhe der Fruchtkörperbildıng steht die neue, in Blumenau auf morschem Holze am Waldboden gefundene Hypocrea pezizoidea nov. spec, welche auf Taf. II Fig. 37 c in zweimal vergrössertem Längsschnitt skizzirt ist. Sie bildet bis thalergrosse pezizaähnliche Fruchtkörper von unregelnässiger Umgrenzung. Sie sind in der Mitte kurz gestielt, ledergelbbraun gefärbt, und feinpunktirt durch die Perithecienmündungen. Ober'- und Tnterseite sind an dem scheibenförmigen bis $5 \mathrm{~mm}$ dicken Fruchtkörper dentlich ausgebildet. Der Durchmesser der Perithecien beträgt etwa 200-250 $\mu$, die Länge der Schläuche $75 \mu$, der Durchmesser der Sporentheilzellen $4 \mu$. Wiederum einen Schritt weiter in der Fruchtkörperbildung' geht eine in Jahre 1890 im Journal de botanique Seite 64 von Patouillard aus 'Tonkin beschriebene Art, Hyp. cornea, welche schon eine fast kreisförmige central gestielte Fruchtscheibe besitzt. Thr schliesst sich die auf nassen faulenden Holzstückchen am Rande eines Urwaldbaches im Blumenauer Gebiet im Oktober 1891 gesammelte Hypocrea sphaeroidea nor. spec. an. Sie zeigt annähernd regelmässig; kuglig gebildete, kurze gestielte Stromata, die kaum $1 \mathrm{~cm}$ Durchmesser besitzen, von ziegelrother Farbe (Saccardo Chromotaxia Nr. 19). Das ganze kuglige Köpfclren ist ringsum bis auf den nach unten zu gerichteten Theil der Kugelfläche mit den eingesenkten dicht gedrängten Perithecien besetzt (Taf. II Fig. 37 b). Die Maasse der Perithecien, Schläuche und Sporen sind dieselben, wie bei Hyp. pezizoidea.

Durch ihre Fruchtkörperform von Interesse ist ferner die im Februar 1892 auf morschem Holze im Velhathale bei Blumenau gesammelte Hypocrea poronioidea nov. spec. (T'af. II Fig. 37 a). Auf einem verlältnissmässig langen bis $1 \mathrm{~cm}$ hohen Stiel trägt sie einen runden flachen in der Mitte etwas eingedrückten scheibenförmigen Hut. Die Perithecien bedecken die Oberseite desselben in gleichmässiger Schicht. Das ganze sieht einem kleinen Hutpilze recht ähnlich und weist nicht minder eine gewisse Aehn- 
lichkeit mit der Gattung Poronia auf. In reifem Zustande ist der Stiel und untere Theil des Hutes umbrabraun (Sacc. 9) mit einem Stich ins oljvfarbene (39), die Scheibe hellederbraun. Jngendexemplare sind kegelförmig (s. Fig.) und an der fortwachsenden Spitze weiss. Der Durchmessel der Perithecien ist etwa $180 \mu$, die Länge der Schläuche ca. $70 \mu$, der Durchmesser der Theilsporen 2,8 $\mu$.

Angesichts der eben beschriebenen Arten erscheint num die längst bekamte Hypocrea aI utacea Pers. mit ilırer clavariaähnlichen Keule nicht mehr so wunderbar und anschlusslos, wie sie noch Tulasue vorkommen musste, welcher sie für eine von einer Hypocreacee befallene Clavaria Ligula hielt, ein damals leicht verzeihlicher Irrthum, den indess Schröter schon berichtigt hat. Ich fand bei Blumenau auf norschen Rinden 1891 im Oktober eine Hypocrea, welche mit der Schröterschen Beschreibung des Pilzes (Kryptogamen-Flora v. Schlesien Bd. II S. 272), und nuit Tulasnes Abbildungen in allen Theilen so rollständig ïbereinstimmt, dass ich nicht Anstand nehme, den Pilz, der uns schon aus Europa und Nord-Amerika bekannt ist. auch als einen Bewohner Süd-Amerikas bekannt zu machen. In der Richtung der Fruchtkörperbildung, welche Hyp. alntacea einschlägt. geht noch weit über diese Form linaus die durch Patouillard aus 'Tibet bekanut gemachte Hypocrea cornu damae, welche reich geweihartig verästelte Keulen besitzt, die stromatisch am reichsten entwickelte Hypocrea, welche wir bisher kennen.

Ueberblicken wir nun die mannigfachen Formen der duch ilure Sporenbildung geeinten Gattung Hypocrea. so ist sofort einlenchtend, dass sie sich wesentlich durch die relative Höhe ihrer Fruchtkörperbildnug unterscheiden, und in eine Reihe natïrlich ordnen lassen. Will man die höchst natürliche Gattung regen ihrer grossen Artenzahl aus praktischen Gründen in mehrere zerspalten, so muss man die Stromaausbildung zum Eintleilungsgrunde machen. In Ausfülırung dieses Gedankens ist die Gattung Podocrea voll Hypocrea abgespalten worden. Sie soll die Formen mit aufrechtem. keuligem oder sogar rerästeltem Stroma begreifen. 
Geht man mit der Gattungstheilung indessen nicht weiter, so schafft man nur zwei sehr ungleichwerthige Abtheilungen der ganzen zusammengehörigen Gruppe. Genau mit demselben Rechte, wie man Podocrea abspaltet, müsste man mindestens am unteren Ende der Reihe die krustenförmig ergossenen Formen als Gattung zusammenfassen, und auch der Rest der zwischen diesen beiden Grenzen liegenden Uebergangsformen würde auf mindestens noch zwei weitere Gattungen zu vertheilen sein. Nöthig ist eine solche Theilung wohl nicht, und so lange sie nicht mit gründlicher Berücksichtigung aller bekannten Formen durchgeführt ist, empfielılt es sich zweifellos, Podocrea fallen zu lassen. oder höchstens als Untergattung ron Hypoclea aufzufülıren.

Auf die Beziehungen zwischen Hypocrea und Hypomyces, die sich z. B. dadurch andeuten, dass bei beiden Gattungen die sporen je zwei etwas ungleiche Theilzellen aufweisen, hat schon Tulasne hingewiesen. Auch macht er auf die Aehnlichkeit der Stromabildung bei Hypocrea und Hypoxylon aufmerksam. Ich werde weiterhin zeigen, dass wir für fast alle die rerschiedenen Stromaformen. wie sie bei Hypocrea vorkommen, unter den Xylarieen Analoga finden, und wir erklären diese Form-Anklänge durch dieselben in diesen Blättern mehrfach erörterten und durch die Untersuchungen belegten Betrachtungen, welche uns die äussere Aehnlichkeit hoch entwickelter Fruchtkörper bei Pilzen aus sehr rerschiedenen Terwandtschaftsreihen natiullich verstehen lassen.

Die Gattung Nectria bildet den Stamm einer dritten natürlichen Untergruppe der Hypocreaceen mit zweizelligen Sporen. Innerhalb dieser Gruppe begegnen wir Formen mit frei und einzeln stehenden Perithecien, und wir beobachten das Auftreten eines Stroma, welches unter den bekannten Gattungen in Corallomyces seine lıöchste Ausbildung erreicht. Die Nectrien sind durch reiche Conidienfruktifikation neben den Ascusfrüchten ausgezeichnet, und auch diese Conidienbildungen steigen zu Conidienfruchtkörpern an. Auf den Besitz bestimmt geformter Conidienfruchtkörper ist z. B. 
die mit Nectria sonst nächstverwandte Gattung Sphaerostilbe gegrüudet. Die nahe Beziehung von Corallomyces, wenigstens in der von mir näher untersuchten Form, mit Nectria wird im Folgenden nachgewiesen werden. Aus Gründen der Darstellnng beginne ich die Besprechung der Nectriaceen im engeren Sinne mit der Unter suchung über Corallomyces Jatrophat nor. spec., und lasse dam erst die einfacher gebanten Nectriafor'men folgen, denen sich zum Schlusse eine Sphaerostilbe anreiht.

Die erste Bekanntschaft machte ich mit dem vorbenannten Pilze durch freundliche Vermittelung meines Onkels, des Herrn August Müller in Blumenau, der mich (im Oktober 1890) daranf aufmerksam machte, dass in seiner Aipim-Pflanzung eine grosse Anzalıl von Stöcken im Absterben wäre, und dass auf deren Wrurzeln sich reichlich Pilze fänden. Der Aipim (Jatropha Aipi) wird nur durch stecklinge rermehrt. Man setzt etwa daumenstarke verholzte stengeltheile ron Spannenlänge und darïber. Ton diesem Steckling gehen später strahlenförmig die bis armstarken ziemlich flach unter dem Borlen verlaufenden Wrurzeln aus, welche ein so werthrolles Nahrumgsmittel bilden. Wir gruben eine Anzahl kranker Pflanzen aus. Ihre Wurzeln waren an verschiedenen Stellen rerjancht, und liessen sich nicht mehr ganz aus dem Boden nelmen, an anderen Stellen, wo sie schon krank unt weich aber noch in natürlicher Form waren, fanden wir sie besetzt mit zahlreich aus der Rinde herrorbrechenden Fruchtkürperu. Diese Fruchtkürper von selten mehr als 3 mm Höhe besitzen eine rein weisse flache Scheibe. welche auf einem schön und kräftig roth gefärbten Stiele sitzt. Bisweilen ist die Scheibe flach. fest, olne Rand (Fig. 21 b), bei anderen ist ein deutlicher nach imnen etwas eingebogener Rand rorhanden (Fig. 21 c, d). Solche Becher wachsen aber randwärts weiter, und es kommen dann Faltungen in der oberen Fläche zu stande (Fig: 21 a, längs durchschnitten). Immer ist der Stiel dentlich roth, nach oben abblassend und in den rein weissen Rand iibergehend. Die Scheibe 
selbst zeigt etwas gelblichen T'on (Fig. 22 b rechts). Indem num die Ränder weiter und weiter wachsen und sich dabei mehr und mehr in Falten legen, entstehen gekröseartige Bildungen, wie sie Fig. 23 zeigt, welche ihre Stiele ganz zudecken. Oftmals lässt sich ein ganzes solches Köpfchen, welches bis zu $1 \mathrm{~cm}$ Fläche bedecken kann, auf einen einzigen Stiel zuriick verfolgen. Es kommt vor, dass die von den gegenüberliegenden Seiten her eingebogenen Lappen sich in der Mitte berühren und ganz eng zusammenlegen, so den Raum der Scheibe gleichsam in zwei Theile trennend. Die beschriebenen Fruchtkörper waren unterirdisch gewachsen; sie mussten zum Zwecke genauerer Beobachtung mit Hülfe der Pincette und Spritzflasche erst mühsam gereinigt werden. Die mikroskopische Betrachtung zeigt, dass wir es mit einem hochentwickelten Conidienfruchtkörper zu thun haben, dessen ganze Masse aus einem weitmaschigen Plectenchym besteht, in dem keine Fadenstruktur mehr erkemnbar ist. Alle Membranen zeigen röthliche Färbung, welche indessen nach der Aussenwand zu am tiefsten auftritt. Das Conidienlager, auf dessen besondere Beschaffenlıeit wir noch zurïckzukommen haben, bedeckt die ganze obere scheibenartige Fläche der Fruchtkörper.

Hält man nun von dem Pilze befallene Wrurzelstïcke der AipimPflanze im feuchten Raume einer bedeckten Schale, etwa auf feuchtem Sande liegend, im Zimmer, so entwickeln sich die Conidienfrüchte in reicher Menge im Laufe weniger 'Tage, nehmen aber vielfach ganz andere Gestait an, wie vordem, weil sie nun nicht mehr durch die auflagernde Erdschicht an freier Entfaltung gehindert sind. Die Stielclen der einzelnen Fruchtkörper erreichen jetzt grössere Höhe, nämlich bis zu $3 \mathrm{~mm}$, ihre schön leuchtend rothe Farbe wird deutlich sichtbar, alle sind nun ziemlich gleichmässig an der Spitze ein wenig verdickt und flach schïsselartig ausgehöhlt. Die pezizaähnliche Scheibe ist hellgelblich gefärbt, sie trägt das Conidienlager. Die Conidien werden in ungeheurer Zahl gebildet, und da gleichzeitig eine wässerige Flüssigkeit abge- 
sondert wird, so bildet sich anf jedem Becher ein runder schneeweisser Tropfen, der die Conidienmasse, durch die Flüssigkeit zusammengehalten, trägt (Fig. 22). Diese weissen Tröpfchen auf den rothen Stielen gewähren einen sehr schönen auffallenden Anblick. Bei der geringsten Erschïtterung oder Berülırung, z. B. wenn ein Insekt in die Nähe kommt, fliesst der Tropfen ab, es genügt dann aber der Zeitranm einiger Stunden, ım einen nenen wiederum erstehen zu lassen. Sind mun schon die eben geschilderten mehr regelmässigen Conidienfruchtkörper nach Möglichkeit verschieden von den durch die Figur 23 dargestellten, unregelmässigen gekröseartigen Bildungen, so ist die Mannigfaltigkeit der Formgestaltung doch noch lange nicht erschöpft. An Stellen üppigen Wachsthums bilden sich unter der Rinde der befallenen Wurzel dichte fast sclerotienartige Mycelmassen aus Plectenchym, welche an der Oberfläche iiberall da, wo sie mit Luft in Berührung kommen, alsbald die rothe Farbe amnehmen. Aus solchen Mycelmassen kommen nun wolıl die gewölmlichen Conidienfrüchte anch hervor, doch bisweilen treten statt dieser dïnne korallenförmige, weit höhere, verzweigte Bildungen auf (s. Tafel I Fig. 22 a). Diese bleiben bisweilen ganz steril, enden aber anch häufig mit der Erzengung ron Conidienlagern an einzelnen ilırer Spitzen. Gerade durch diese letzterwälmten Bildungen rechtfertigt unser Pilz den Namen Corallomyces.

Die zuerst zur Beobachtung gebrachten, ron dem Pilze befallenen Wurzelstücke waren am 31. Oktober 1890 ansgelegt worden. Bis zum 10. November waren sie mit Conidienfrüchtchen dicht bedeckt. An diesem Tage bemerkte ich an den rothen Stielchen dicht nnter dem schon beschriebenen weissschleimigen Tropfen, welcher den Gipfel krönte, kleine dunkelroth gefärbte Wärzchen (Fig. 22 b rechts) in grösserer Zahl und mmregelmässiger Anordnung. In den nächsten Tagen nalmen diese an Zahl und Grösse zu, und es wurde bald deutlich, dass hier an demselben Stiele, welcher die Conidien erzeugt hatte, Perithecien sich bildeten 
(Fig. 22 b links 11. Mitte). Diese reiften nun ans in der Zeit bis zum 26. November. Sie erreichten etwa $1 \mathrm{~mm}$ Länge und hatten eiförmige Gestalt. Sie waren an der Spitze mit einem deckelartigen kegelförmigen Ansatz versehen, der bei Betrachtung mit der Lupe eine feine Oeffnung an seiner Spitze erkennen liess. Am 26. November sah ich zuerst an der Mündung einiger dieser Perithecien ein dunkel gefärbtes Tröpfchen, welches sich als eine Ansammlung ron ausgestossenen Ascussporen erwies. Von der ersten änsserlich merkbaren Anlage bis zu der Reife der Perithecien waren also 16 Tage verflossen. Die Sporen waren (Fig. 26) eilänglich bis spindelförmig, häufig ein klein wenig sichelförmig gebogen, gelbbräunlich gefärbt, nach den Enden stumpf zugespitzt und mit einer Querwand in der Mitte rersehen, 30-40 $\mu$ lang und $7-9 \mu$ breit. Ihre Keinung in Nährlösung (Fig. 24) erfolgt unter geringer Anschwellung fast sofort nach der Aussaat und schon nach 12 Stunden sieht man ein rerzweigtes Mycel daraus entstanden.

Ist nun in der offenen Objektträgerkultur die Errählırung der raschwachsenden Mycelien einigermaassen dürftig, so sehen wir schon am zweiten oder dritten Tage die Conidienfruktifikation in der durch die Figur 27 dargestellten Weise auftreten. Die langen wurstförmigen Conidien, dieselben, welche in den schon erwähnten hochentwickelten Becherfiüchten anzutreffen sind, werden zunächst von beliebigen Mycelendigungen abgeschnïrt. Schnell ninmt die Conidienerzengung zul, und man bemerkt nun, dass auch die abschnïrenden Mycelenden allmählich eine bestimmte nach der Spitze zu gleichmässig verdiinnte Form annehmen, und sich nach hinten gegen das übrige Mycel in annähernd gleicher Länge als Sterigmen abgrenzen.

Gleichzeitig nun nimmt man wahr, dass die Conidienbildung sich auf bestimmte Zweigsysteme des Mycels allein beschränkt, und dort um so üppiger auftritt. Anfänglich werden die Conidien 
in der Flïssigkeit gebildet, später, wenn sie einander, bïschelweise erzeugt, gegenseitig drängen, richten sich die Bündel auf, nnd die Conidien ragen ïber die Flüssigkeit linaus in die Luft. Weiterhin sehen wir nun, wie die hinter den Sterigmen liegenden Mycelfäden sich in immer kürzere, schliesslich fast isodiametrische Zellen durch Scheidewände theilen (Fig. 30), auch etwas aufschwellen, und bei gleichzeitiger reicher Erzengung von Verzweigungen ein plectenchymatisches Gewebe darstellen, welches mit "Sterigmen" dicht bedeckt ist, und strahlenartig nach allen Seiten hin die Conidien erzeugt. Sorgt man durch Anwendung grösserer Objektträger, reichere Nährlösungszufuhr, oder durclı Anlage der Kulturen in kleinen Erlenmeyerschen Kölbchen, wo eine dickere nicht so schnell zu erschöpfende Flüssigkeitsschicht von vornherein geboten werden kann, für kräftige Ernähırung der Mycelien, so treten jene rudimentären Anfänge der Conidienfruchtkörperbildung gar nicht auf. Es erfolgt vielmehr eine ungemein üppige Mýcelentwickelung durch die ganze Flüssigkeit und alsbald entstehen in dem Fadengewirre Centren engerer Verflechtung, in denen die Fäden dicker und kürzer septirt sind, plectenchymatisch zusammenschliessen, und eine gelbliche bis endlich braunröthliche Farbe zeigen. Erst wemn solch ein kleiner Hyphenballen von kompakter Masse gebildet ist, tritt an seiner oberen mit der Luft in Berührung kommenden Seite eine Art ron Pallisadenbildnng anf, es werden in dichter Schicht die Sterigmen gebildet, welche wir schon kemnen lernten, und Conidien in grosser Zahl erzeugt. Zunächst ist das Conidienlager einfach das runde polsterförmige Ende eines säulenartigen Gebildes, welches die Fortsetzung jener erst gebildeten Mycelknolle darstellt, und im Gegensatz zu jener rein weiss gefärbt ist (Taf. II Fig. 32). Während die rorhandenen, Sterigmen bildenden Endzellen nun fortwährend durch zwischengeschobene neue rermehrt werden und der Kopf unseres Gebildes dadurch verdickt wird, wäclıst gleichzeitig das unter der Conidienschicht angelegte Säulchen zu einem 
längeren Stiele aus, am Rand des Conidienlagers tritt ein steriler Wulst hervor, welcher das Lager als Schüsselrand umgiebt (Fig. 31). Im Anfange dieser Vorgänge kann man in dem Stiele des Fruchtkörpers die Hyphenstränge in ihrer Hauptrichtumg noch wohl unterscheiden, in dem Maasse aber wie das Wachsthum fortschreitet, und die Zusammendrängung enger wird, entsteht ein festeres Plectenchym. dass schliesslich den ganzen Fruchtkörper zusammensetzt.

Plectenchym dieser Art findet sich in ähnlicher Ausbildung in vielen Nectriaceenstromaten und ist, um ein Beispiel unter vielen herauszugreifen von Tulasne (Carpol. III Taf. XII Fig. 14) für Nectria cinnabarina abgebildet. Die Conidienabschnürung geht ununterbrochen weiter; zil den abgeschnürten kommen stetsfort nene. welche die früheren in die Höhe drängen. Gleichzeitig. erfolgt auf der Scheibe des Bechers eine Absonderung geringer Mengen wässeriger Flïssigkeit, in der die Conidien schwimmen, und da, wie wir gesehen haben, jetzt der sterile Rand sich über die Scheibe erhebt, kam der entstehende milchige Tropfen nicht hermuterlaufen, sondern steht, den Durchmesser der Scheibe iibertreffend, wie eine balancirte Kugel auf dem becherformigen Fruchtkörper. Das zierliche Bild des Pilzes in dieser normalen Entfaltungin künstlicher Kultur (Taf. I Fig. 22b) gewimnt an Schönheit erheblich durch die lebhafte Färbung. Der Fuss des Fruchtkörpers, hervorgegangen aus der ursprünglichen Knolle, ist lebhaft roth, dies Roth geht nach oben ganz allmählich abblassend in das reine Weiss des äussersten Scheibenrandes iiber, und auf dem rein weissen Rande steht num die ebenfalls weisse, glänzende Flüssigkeitskugel. Die geringste Berührung reicht natürlich hin, diese Kugel zum Abfliessen zu bringen. es bleibt dann der pezizaförmige Becher übrig, dessen Grund gelblich ist; doch genügt eine Nacht, um auf denselben eine neue Kugel entstehen zu sehen, in gleicher Weise wie wir es früher an den auf Aipimwurzeln wachsenden Fruchtkörpern beobachteten. Die über den beschriehenen Entwickelungs- 
zustand hinausgehenden korallenartigen Stromabildungen traten dagegen nur auf dem natürlichen Substrat, in künstlichen Kulturen niemals auf.

Die beschriebenen Conidienfruchtkörper des Corallonyces Jatrophae bilden ein bemerkenswerthes Gegenstïck zu den oben (Seite $65 \mathrm{ff}$.) geschilderten und in der Entwickelung verfolgten ron Penicilliopsis brasiliensis. So wie dort, könmen wir auch hier in einem besonders günstigen Falle in der Entwickelungsgeschichte eines und desselben Pilzes alle Uebergänge von der frei und einzeln erzeugten Conidie bis zum hochorganisirten Fruchtkörper verfolgen, ja wir können durch entsprechend angeordnete Kulturversuche jeden Zwischenzustand einzeln noch hente in die $\mathrm{Er}$ scheinung rufen. Die Ansbildung dieses Fruchtkörpers unterliegt nun aber denselben Gesetzen, welche in allen Reihen der höheren Pilze gelegentlich wirksam werden, und Aehnlichkeit der Fruchtkörper- oder Stromabildungen erzengen, worauf i،h oben (S. 68, 74, 91) mit Beziehung auf die im vorigen Hefte dieser Mittheilungen gemachten Darlegungen wiederholt lingewiesen habe. Wenn wir uns die dort betrachteten Thatsachen rergegenwärtigen. so erscheint es nun nicht mehr wunderbar. wenn unter den Conidienfruchtkörpern von Ascompceten gleiche oder ähnliche Formen gefunden worden. wie sie bei Basidiomyceten auftreten. Conidien und Basidien sind, wie win nun wissen. wesensgleiche Gebilde, bei ihrer Ansteigerung rom freien Torkommen an den Fäden zur Fruchtkörperbildung treten dieselben treibenden líäfte in Wirksamkeit. Ob Conidienträger oder Basidien. in jeden Falle muss ein Hymenium gebildet werden, eine dichte Schicht Coniclien-bezw. Sporen-abschnïrender Zellen. Das Hymenium muss dann zu besserer T'erbreitung der Sporen in die Höhe gelıben werden.

Diesen Gedankengang zu stützen scheint es mir zweckmässig. hier in nnmittelbarer Geg*enüberstellung zu len Conidienfrüichten von Corallomyces Knlturergebnisse eines Basidionyceten, nämlich des bekannten Schizophyllum commune. mitzutheilen, welche. auf 
den ersten Blick gar nicht hierher gehörig, dennoch gerade an dieser Stelle in allervortheilhaftester Belenchtung erscheinen.

Schizophyllum commune ist in der Ungebung von Blumenau neben Polyporus sanguineus und Auricularia auricula Judae der gemeinste, gradezu uiberall vorkommende Pilz. Schon Brefeld hat ein aus Java stammendes Schizophyllum in künstlichen Kulturen mit Erfolg gezogen (Bd. VIII S. 68), und es schien mir darum der Miihe werth, zuzusehen, wie dem die brasilische Form sich verhalten würde. Die Sporen keimten leicht und bildeten reich rerzweigte mit Schnallen rersehene Mycelien. Nach Brefelds Beschreibung treten an den in die Luft ragenden Mycelfäden dieser Kulturen sehr eigenthümliche, fast an Conidien erimnernde kuglige Sekrettropfen auf, gebildet von kurzen Mycelseitenzweigen, welche als sekretabsondernde Organe anzusehen sind. Es war mir nun in der That merkwürdig zu beobachten, dass diese selben eigenthümlichen Bildungen, die in Münster von einem aus Java stammenden Schizophyllum gezogen waren, bis ins kleinste genau jetzt in Blumenau in Brasilien in meinen Kulturen wieder erschienen. Welch wunderbares unerschütterliches Festhalten scheinbar so unbedeutender winzigster Einzelheiten im Entwickelungsgange einer Art über unermessliche Zeiten und riesige Räume hinweg! Brefeld hatte mitgetheilt, dass es in seinen künstlichen Kulturen zur Anlage ron Fruchtkörpern gekommen wäre und ich war begierig zu erfahren, ob auch dies in Brasilien ebenso eintreffen wïrde. Ich hatte nicht lange zu warten. Schon am 13. Tage bemerkte ich Anlagen von Fruchtkörpern aus dicht verknäuelten Hyphen, und diese entwickelten sich so schnell weiter, dass ich schon am 16. Tage nach Beginn der Kultur sporenreife Basidien in Menge fand. Thie aber sahen die auf den $\mathrm{Ob}$ jektträgern angelegten Fruchtkörper aus? Die Figur 33 Tafel II giebt einen Längsschnitt durch die Mitte. Ein pezizaartiger Fruchtkörper, gebaut genau wie eine Solenia oder Cyphella oder aber wie unsere Conidienfruchtkörper von Corallomyces. Genau 
wie bei diesen verläuft auch seine Entwickelungsgeschichte, die ich deswegen nicht im einzelnen zu schildern brauche. Wir sehen vor uns einen Schizophyllumfruchtkörper mit horizontalem nach oben gerichteten, vollständig lamellenlosen, ron einem etwas vorstehenden Ringwalle aus sterilen Hyphen umgebenen Hymenium, ein Schizophyllum also im Thelephoreenzustande. Und in diesem Zustande gleicht das Schizophyllum äusserlich vollständig dem Conidienfruchtkörper von Corallomyces. In dem einen Fall sollen Conidien, im anderen Basidiensporen in grösster Nenge beisammen gebildet, zur Verbreitung ausgestellt werden; für beide sind gleiche Mittel zur Erreichung des Zweckes angebracht. Das Baumaterial der Fruchtkörper ist in beiden Fällen dasselbe, so kommt die gleiche Bildung zu Stande.

Als ich im rorigen Hefte dieser Vittheilungen über den Protomerulius berichtete, einen Pilz, der unter den Protobasidiomyceten genau die Gestalt des Nerulius nachahmut, habe ich darauf lingewiesen, dass diese Formübereinstimmung genau in derselben Weise zu erklären sei, wie die eben besprochene, dass sie keinesfalls dazu nöthige, ejne unmittelbare verwandtschaftliche Terbindung zwischen jenen beiden Formen anzunehmen. Dort lag eine solche Ammahme nicht ausserhalb des Bereichs der möglichen Spekulation; die beiden in Betracht kommenden Formen gehören wenigstens beide der grossen Klasse der Basidiomyceten an. Man lıätte es wohl rerstehen kömnen, wemn Jemand die Meinung rertreten wollte, der Merulius sei ans dem Protomerulius durch Verlust der Scheidewände in den Basidien hervorgegangen; wie demn neuerdings Juel in dem XXXII. Bande der Jahrbücher tür wissenschaftliche Botanik thatsächlich die Abstammung der Antobasidiomyceten ron den Protobasidiomyceten annehmbar zu machen sucht.

Ich selbst, wie erwähnt, kam auf Grund meiner Untersuchungen zu entgegengesetzter Ansicht, die ich ansführlich erläuterte, and die weiter durch ein einlenchtendes Beispiel zu belegen ich 
beim Corallomyces nm Gelegenheit finde. Herr Massee jedoch, der meiner Arbeit iiber die Protobasidiomyceten eine in wohlwollend ïberlegenem 'Tone gehaltene Besprechnng in der Zeitschrift Nature (6. Febrnar 1896) widmete, stellt an öffentlicher Stelle jene von mir bekämpfte Ansicht, dass Protomerulins nämlich eine Stammform fïr Mernlins sei, als die von mir vertretene seinen Lesern dar, und - bekämpft sie darauf mit der Wendmng, ob dies sich so verhalte, sei „more a matter of faith, than of conviction". Und dies Verfahren wiederholt Massee zu verschiedenen Malen, er zeigt einen vollständigen Mangel an Verständniss fïr das voll mir ausführlich dargelegte, er stellt das Gegentheil ron dem, was ich behanptete, als meine Ansicht hin, um sie damn zu bezweifeln odor anzugreifen. Hat er das von ihm kritisirte Buch gar nicht gelesen? Oder habe ich mich undentlich ausgedrïckt? Das letztere nelıme ich nicht an, demn meine anderen Tritiker haben mich ganz richtig verstanden. Indessen es kam kein besseres Beispiel geben, meine Meinung. daran ganz unzweifellhaft darznlegen, wie das hier besprochene von Corallomyces und Schizophyllum, zwischen denen eine ummittelbare Blutsverwandtschaft zn behaupten auch der Herr Massee mir wohl nicht zumuthen wird.*)

*) Nenerdings lat Massee nun allerdings in dem Jomlnal of the Limnean Society $1900 \mathrm{Nr}$. 240 seine Ansicht etwas geändert, er hat mein von ihm kritisirtes Buch offenbar einer ernenten Durchicht gewiirdigt, und einiges richtiger verstanden. Hätte er es, ehe er es kritisirte, nur wirklich gelesen, so wärde ihm nicht begegnet sein, was ich ihm nun rorrücken muss. Er citirt nämlich a. a. O. eine treff liche Bemerkmng Tulasnes ïber die Aelmlichkeit der Basidien bei Uredineen und bei Stypinella purpurea (damals noch Hypochnus genamnt) ans den Ann. d. sc. Bot. V Série Tome IV. Diese selbe Stelle hatte ich Seite $\mathbf{1 5}$ meines von Massee kritisirten Buches vollständig anfgeführt und in ihrer Bedentung gewïrdigt. Massee aber schreibt, er zöge sie ans Licht zum ersten Iale, seit ihrer Veröffentlichung und schliesst seine vermeintliche literarische Ehrenrettung Tulasnes mit den stolzen Worten: „palman qui mernit, ferat." Wer so eifrig ist zur Vertheidigme der Palme Tulasnes, welche dem grossen Forscher ohnehin Niemand entreissen will, noch wird, der sollte doch wenigstens so gerecht sein, dass er eines kleinen neneren Autors Arbeit nicht kritisirte, ohne sie gelesen zu haben. 
Haben nun diese beiden mit einander gar nicht näher verwandten Pilze in dem abgebildeten (Fig. 33 ı. 31) Fruchtkörperzustand eine vollständige Uebereinstimmung aufgewiesen, so vermögen sie beide darüber hinaus noch höher entwickelte Zustände zu erreichen, und schlagen dazu wiederum verschiedene Wege ein. Ich habe früher ausgeführt (Protobasidiomyceten S. 15̃4), dass das weitere Ziel solcher Basidiomycetenfruchtkörper, wie der von Schizophyllum beschriebene es ist, num dahin gehe, ohne zu viel Stoff auf den sterilen Theil des Aufbanes zu verwenden, die Oberffäche nach Möglichkeit zu vergrössern. um immer mehr Sporen zur Erzeugung und Verbreitung bringen zu können. Die Erreichung dieses Zieles ist nur möglich durch Wellen, Falten, Lappen. Blätter, regelmässig grubige V'ertiefungen. Röhren oder Stacheln in der hymenialen Fläche, und alle diese Möglichkeiten finden wir verwirklicht. Der Conidienfruchtkürper von Corallomyces vergrössert seine hymeniale Fläche, wie wir oben schon gesehen haben, zul einer Scheibe mitt lappigen Falten und Windungen. er schlägt denselben Weg ein, wie z. B. Dacryomitra unter den Basidiomyceten, Morchella unter den Ascomyceten; Schizophyllum hingegen geht aus dem 'Thelephorazustande in den der Agaricinen ïber. Auf der runden glatten Hymenialfäche erheben sich rom äusseren Rande beginnend radial gerichtete Leisten steriler Hyphenbüschel, und an ilmen wachsen von beiden Seiten die basidienbildenden Hyphen in die Höhe, so die Wände jener Leisten zur Hymenialfläche umwandelnd. Ich will auf diese Einzelheiten an dieser Stelle nicht weiter eingehen, da sie für das, was ich hier auszuführen habe, nicht von Bedentung sind, behalte mir viehmehr die Entwickelungsgeschichte der Schizophyllumfruchtkörper. welche ich in künstlichen Kulturen bis zur völlig normalen Ausgestaltung verfolgte, für das nächste Heft vor, wo ich hoffentlich ïber meine Untersuchungen brasilischer Basidiomyceten berichten darf.

Wir kehren jetzt zu den Conidien des rorallomyces zuriick. Jhre Entstehung und Bildung an den sterigmaartigen Zellen des 
Lager's ist aus der Fig. 30 Taf. I ohne weiteres ersichtlich. Die Länge der bananenförmigen, an beiden Enden abgerundeten schwach gekrümmten Conidien ist ausserordentlich wechselnd, sie schwankt ron 40-100 "/ in der Länge, während ilı'e grösste Breite 8-10 " beträgt. Sobald die Conidie ilne volle Länge erreicht hat, wird sie ron dem alsdann ganz entleerten Sterigma durch eine Scheidewand abgegrenzt, und fällt gewöhmlich sofort ab. In der frei gewordenen Conidie bemerkt man alsbald, schon mit starken Trockensystemen den Zellkern in der Mitte, und man nimmt wahr. wie dieser in weiter vorgeschrittenem Zustande eine längliche Form zeigt (Fig. 28). Danach tritt in der Spore die Querwand genau in der Mitte auf, und man sieht in jeder Zelle einen runden Kern. Teder der Kerne sielıt bald daranf wieder länglich aus, und es treten zwei nene 'Theilwände auf. die Conidie ist vierzellig, in jeder Zelle sieht man den Kern. Die meisten Conidien bleiben vierzellig: in ïppigen Lagern fundet man aber zahlreich solche mit fünf, ja in selteneren Fällen auch solche mit noch mehr Querwänden. Die Auskeimung der Conidien in Nährlösungen erfolgt leicht nnd schnell, immer zuerst an den beiden Enden begimnend. hernach auch aus den mittleren Zellen. Sehr hänfig wurde der in Fig. 24 dargestellte Fall beobachtet, dass der austretende Keimschlauch nämlich zuerst eine schneckenförmige Windung macht, ehe er in der gewöhnlichen Weise sich verlängert und verzweigt. In der Zeit ron kaum 24 Stunden kommen reichrerzweigte Mycelien zu Stande und schon rom zweiten Tage nach der Anssat ab beginnt die Erzengung nener Conidien zuerst an einzelnen Fäden, dann ansteigend bis zur Erzeugung der Conidienfruchtkörper, alles in derselben Treise wie oben bei der Auskeimung: der Ascosporen beschrieben worden ist.

Die Mycelien unseres Pilzes sind nun ausgezeichnet durch ein so häufiges und allgemeines Torkommen ron Fadenbrücken, wie es selten beobachtet wird. Die ron einem Mycel radial dicht beieinander ausstrahlenden Fäden bilden gowölnnlich einen fast 
$1 \mathrm{~mm}$ breiten schön regelmässigen Rand der Kultur, von seidenglänzender Beschaffenheit. Mustert man diesen genauer, so sieht man Faden für Faden mit dem Nachbar nicht nur durch eine. sonderı durch zahlreiche Fadenbrïcken verbunden. Die aus ein und derselben Spore oder Conidie austretenden Fäden anastomosiren alsbald nach dem Austritt mannigfach mit einander (Fig. 25). Aber auch die aus verschiedenen Conidien stammenden Mycelien treten mit. einander in Verbindung. Den genetischen Zusammenlang zwischen den Ascosporen und Conidien kamn man aufs schmellste beweisen. indem man eine Spore und eine Conidie neben einander aussäet (Fig. 24). Es danert nicht lange, unter Umständen kaum 12 Stunden, so wird man sie in natïrlichem Zusammenlange mit einander durch Fadenbrïcken verbunden finden (vgl. auch lierzu Tulasne Carpol. III Taf. XI Fig. 16, Nectria Stilbosporae). Ein so auffällig massenhaftes Auftreten von Fadenbrücken regt ganz unwillkürlich zu Betrachtungen ïber die Bedeutung dieser Eimrichtung an. Hierüber lat zuerst Brefeld sich eingelıend geäussert. Es geht aus seinen Mittheilungen hervor, dass durch die Fusionen eine innere Stärkung und Kräftigung des Nycels gewonnen wird und er sagt, man lï̈me sich vorstellen, dass in der Fusion eine Differenz der Zellen zum Austrag komme. Die thatsächlichen Befunde bei unserem Corallonyces lehren nun in Tebereinstimmung nit vielen anderen in gleichem simne angestellten Untersuchungen bei anderen Pilzen folgendes. Säet man in einen Kulturtropfen nur eine einzige Conidie, so entwickelt sich je nach der Stärke der Nährlösung und nach der herrschenden 'Temperatur schmeller oder langsamer daraus ein Nycel, welches an Grösse melır und mehr zunimmt, und endlich. sagen wir im besonderen Falle, am 10. Tage nach der Aussaat einen neuen kleinen Conidienfruchtkïrper erzengt hat. Säen wir zur gleicher Zeit in einen gleich grossen T'ropfen der Nälurlösung zehn Conidien aus, so treten die daraus entstelenden zehn Mycelien alsbald in Verbindung durch Fadenbricken, die Mycelentwickelung ist, soweit die Schätzung 
folgen kann, eine weit mehr als zehnfach so üppige wie vorher, und junge Fruchtkörper sind schon am dritten Tage erzeugt. Aus diesem Tersuche, den man mit gleichem oder entsprechendem Erfolge bei anderen Fusionen bildenden Pilzen wiederholen kann, ergiebt sich klar und zweifellos, dass die Fusionen für die Entwickelung des Oroanismus rortheilhaft sind; dem wenn dies nicht zuträfe. so würden auch in der aus zehn Sporen hergeleiteten Kultur die Fruchtkörper bei übrigens gleichen Umständen nicht eher als bei der aus einer Spore stammenden auftreten.

Den bisher mitgetheilten morphologischen Untersuchungen ïber Corallomyces Jatrophae schliesse ich jetzt einige Beobachtungen und Betrachtungen übel sein parasitisches Torkommen an.

Bald nach der 1850 erfolğten Grïndung der Kóonie Blumenau wurde atus dem nördlichen Brasilien der Aipim als Kulturpflanze in das vollkommen abgeschlossen liegende Itajahythal, eben das Gebiet der genannten Kolonie, eingeführt. Weiterhin ist diese Pflanze nur durch Stecklinge rermehrt worden, und die zahlreichen Aipimptlanzungen. welche am ganzen Itajahý und seinen Nebenflïssen einer Berölkerung von weit mehr als 30000 Seelen ein wichtiges Nahrungsmittel liefern. dürften fast ausschliesslich durch vegetative Termehrung jener zuerst eingefülırten Stecklinge entstanden sein. Krankheiten der Pflanzen wurden fast 30 Jahre lang nicht beobachtet. Ende der achtziger Jahre trat zuerst die durch unseren Corallomyces rerursachte Wurzelfäule auf, und zwar an verschiedenen von einander durch weite Entfernungen getreunten Stellen. Aus diesem Grunde sprach Dr. Fritz Müller mir gegenüber wiederholt die Termuthung aus, der Pilz müsse ein einheimischer Wraldbewohner sein. der seine Parasitenlaufbahn auf dem Aipim erst in Blumenau begonnen habe, und nicht etwa an und mit der Aipimstaude eingeschleppt sei. Diese Termuthung zur grössten Wahrscheinlichkeit zu steigern glückte mir dadurch, dass ich am 25. Februar 1891 an der Rinde eines faulenden Baumstammes am Ufer des Telhabaches mitten im Walde den Corallo- 
myces Jatrophae als wilden Waldbewohner auffand. Sein Aussehen war nicht bemerkenswerth verschieden von demjenigen, welches er an den Aipimpflanzen zeigte, und das ich vorher beschrieben habe. Conidienfrüchte und Ascusfrüchte fanden sich im Zusammenhange, wie sonst anch, nur waren die Stromata nie so reich ansgebildet, so hoch und korallenartig weit verzweigt, wie z. B. in der Fig. 22 a, und jene üppig entwickelten lappig faltigen Conidienlager, wie sie in Fig. 23 abgebildet sind, fand ich bei dem saprophytisch vorkommenden Pilze nicht. Im ïbrigen wurden Aussaaten mit seinen Ascussporen und seinen Conidien angestellt, und parallel mit den aus Aipimpflanzungen fortgefiihrt, bis die rollständige Tdentität der Pilze in allen Einzelheiten ganz sicher gestellt war. Der so aufgedeckte Fall von plötzlicher Entstehung einer Pflanzenpilzkrankheit, rom plötzlichen parasitischen Auftreten eines frïher nur saprophytisch lebenden Pilzes ist jedenfalls sehr bemerkenswerth. Er zeigt uns recht dentlich, wie wir uns die Entstehnng von pilzlichen Pflanzenkrankheiten an Kulturgewächsen vorzustellen haben. Es erscheint ganz sicher, dass durch die Massenkultur anf weiten Flächen, bisweilen auch auf der Pflanze weniger zusagenden Böden eine für uns allerdings nicht unmittelbar sichthare Schwächnng der Lebensenergie eingetreten ist, welche $n$ m dem früher olmmächtigen Pilze eine Entwickelnng auf der noch lebenden Pflanze ermöglicht. Oder will man annelmen, dass es im Itajahýthale 30 Jahre gedanert habe, bis zum ersten Male der Zufall eine Aipimpflanze mit einer Spore oder Conidie des im Walde in nächster Nachbarschaft rorkommenden Pilzes in Beruihrung gebracht labe, dass damn aber dieser Zufall gleichzeitig an verschiedenen Stellen der Kolonie eingetreten sei? Auf frischen Roçen, gerodeten Wraldgebieten, die zum ersten Male bebant wurden, ist der Pilz noch nicht beobachtet worden; anch dies spricht dafür, dass irgend eine ungünstige Beeinflussung der Aipimpflanzen den Pilzangriff einleiten muss, nnd der freilich nicht beweisbare Gedanke, dass die durch mehr als 


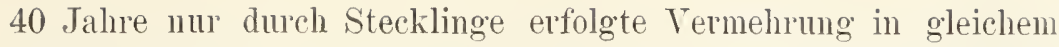
Sinne ungïnstig gewirkt haben könnte, drängt sich auf. Dass aber auch heute noch nicht die blosse Beriihrung mit den Keimen des Pilzes, ja nicht einmal jede beliebige Infektion mit denselben ein Erkranken der Aipimwurzeln herbeizuführen vermag, lehten mich zahlreiche Infektionsrersuche, denen ich viel Zeit gewidmet habe.

Sofort, nachdem ich den Pilz kemnen gelernt, und mich davon iiberzengt hatte, wie leicht er der künstlichen Kultur sich zugänglich erwies, dass es mir also an Infektionsmaterial zu keiner Jahreszeit mangehn wïrde, pflanzte ich mir im Garten einige kräftige Aipimpflanzen, die in dem gut bearbeiteten Boden üppig gediehen. An ihnen, ebenso auch an anderen im Freien in den Pflanzungen stehenden Stauden stellte ich nun zu rerschiedenen Zeiten des Jahres Infektionsversuche an. Es wurden die Wurzeln freigelegt, und mit den Sporen und Conidien reichlich bespritzt, oder auch bestrichen, an anderen Stellen entfernte ich die Pinde, und brachte dann die Pilzkeime an die Pflanze, in wieder anderen Fällen wurde die Wurzel angebohrt, und in das Loch hinein wurden die Infektionskeime gebracht. ja ich schnitt sogar Stïcke aus der Wurzel aus, und setzte dafür gleich grosse Stücke erkiankter ron Pilzmycel durchwucherter Wurzeln ein. Es wurde Sorge dafür getragen, dass ein zu schnelles Austrocknen der inficirten Stellen verhindert wurde. Der an allen Wrundstellen alsbald austretende Milchsaft schien der Pflanze als Schutrmittel zu dienen. Ich wartete daher in einigen Fällen, bis die Wundstelle vollkommen trocken geworden war und inficirte erst dann. Aber alle Versuche ohme Ausuahme misslangen. Nie ist es mir gelungen, eine gesunde, am Stocke sitzende Wurzel pilzkrank zu machen. Kaum 1 , Stunde von meinem Garten entferut ging einem Kolonisten der Ertrag seiner ganzen Pflanzung zu Grunde, wreil Stock für Stock an den Wurzeln von dem Pilze befallen war, und meine im Garten so mühsam inficirten Pflanzen 
heilten ilıre Wunden aus und blieben ganz gesund. Dagegen gelang der Versuch stets, wenn ich Wurzeln der Aipimstande abschnitt, Stücke davon auf feuchtem Sande unter einer Glocke auslegte, und diese in irgend welcher Art mit Sporen oder Conidien bestrich oder impfte. Hier danerte es nur 8-14 Tage etwa, so erschienen mit Sicherheit die Conidienfrüchte des Pilzes und ich will hier gleich bemerken, dass diese Versuche ebensowohl mit dem saprophytisch im Walde aufgefundenen Material gelangen, wie mit dem von kranken Aipimstauden hergenommenen. In diesem Falle also, gerade wie in so vielen anderen Fällen von Pflanzenkrankheiten wissen wir nichts über die besonderen die Pflanze in ihrer Lebensenergie beeinträchtigenden Torbedingungen, welche allein einen erfolgreichen Pilzangriff ermöglichen. Wir können nur sagen, dass im besonderen Falle bei dem Aipim in der Kolonie Blumenan im Laufe der 40 jährigen Kultur durch Stecklingsvermehrung derartige Beeinträchtigungen eingetreten sein müssen. Tom praktischen Standpunkte aus, der die Bekämpfung der Krankheit als seine Aufgabe betrachtet, wäre die Frage nach diesen Bedingungen die wichtigste, der wir aber längst nicht immer die nöthige Aufmerksankeit der Pflanzenpathologen gewidmet sehen. Tene Torbedingungen kann man doch hoffen änderu oder besserln zu kömen, in unserm besonderen Falle sind sie ja 40 Jalıre lang nicht vorhanden gewesen; die Infektion durch die Pilzkeime zu hindern. wird wohl meist numöglich bleiben. Wie leicht sie stattfindet. ersielıt man ans dem schnellen Lmsichgreifen der Kranklıeit in einer befallenen Pflanzung. Und dabei steckt nicht etwa eine Pflanze die andere unmittelbar durch Beriihrming an, sondern jede ist selbständig inficirt, und zwar fast ausnahmslos an melıreren Stellen auf einmal. Wenn man eine kranke Aipimstaude ausgräbt, so findet man in der Nitte des Wurzelsystems den in die Erde gelegten Steckling, und von ihm gehen strahlenförmig die starken Wurzeln ans. Gewöhnlich sind mehrere derselben gleichzeitig erkrankt, aber die erkrankten Stellen sind von einander getrennt 
durch vollkommen gesunde Wurzeltheile, in denen auch durch mikroskopische Untersuchung keine Spur des Pilzmycels zu entdecken ist. Diese Beobachtung habe ich wiederholt bestätigt gefunden.

An dieser Stelle sei es gestattet, zur weiteren Erläuterung: nnd Bestätigung des Gesagten in aller Kürze von jahrelang fortgesetzten Untersuchungen zu berichten, die ich $1886 \mathrm{im}$ heimischen dentschen Walde begann, um festzustellen, wie der Kiefernwurzelschwamm (Heterobasidion annosum), der in unseren Forsten so grosse Verheerungen anrichtet, in die Bäume eindringt. In einem Reviertheile der Oberförsterei Münster, in dessen nächster Nähe der Pilz häufig vorkam. suchte ich mir meine Versuchspflanzen aus und inficirte sie mit dem Pilze in der verschiedensten Art und Weise an den verschiedensten Stellen, wie ich es nur immer ansdenken konnte. Im Ganzen inficirte ich 163 Bäume, meist Kiefern, doch auch Fichten und Birken und zwei Juniperussträucher, nachdem an allen diesen Holzarten dort in der Gegend der Pilz von mir gefunden worden war. Die meisten Versnchspflanzen waren Stangen (d. h. bei $1 \mathrm{~m}$ Höhe bis etwa $14 \mathrm{~cm}$ Durchmesser), doch nahm ich auch einzelne jüngere und einzelne ältere Bäume mit hinzu.

Ich liatte das denkbar beste Infektionsmaterial. Von sehr üppigen über tellergrossen Fruchtkörpern, wie ich sie damals öfter sammelte (an Weymouthskiefern im Schlossgarten zu Münster) fing ich auf untergelegten Glasplatten die Sporen auf, die dort nach kurzer Zeit in ihrer Masse dichte, graue Niederschläge bildeten. sie wurden alsdann mit einer geeigneten Nährlösung; in welcher sie nachweislich gut und bald auskeimten, abgespiilt, in einen Glaskolben gebracht, der mit einem Zerstäuber versehen war, und ich überzeugte mich, dass in jedem kleinsten Tropfen, der aus dieser Flasche verspritzt wurde, eine grosse Menge von Sporen sich befand. Mit dieser Flüssigkeit inficirte ich einen 'Theil der Pflanzen. Aber ich hatte auch anderes Material. Brefeld hatte nachgewiesen (Bd. VIII der Untersuchungen aus d. Gesammtgebiet 
d. Mykologie), dass der Kiefernwurzelpilz sich bei genïgender Vorsicht rein kultiviren lässt, und dass er damn eine Fruchtform erzeugt in Gestalt eines sehr kleinen, rasenartig auftretenden Schimmelpilzes, der ungeheure Mengen winziger Conidien bildet, welche den aus den grossen Fruchtkörpern stammenden Sporen selır ähnlich sind und wie jene leicht und sicher auskeimen. Reinkulturen des Pilzes zog ich damals in grosser Menge, auf ausgekocliten Sägespähnen besonders entwickelte er sich sehr gut und ich hatte von den Conidien geradezu unbegrenzte Mengen zur Verfiigung. Anch diese brachte ich in Flïssigkeit, wie ich es für die Sporen beschrieben liabe, und inficirte wieder andere Versuchspflanzen damit. Endlich war auch fanles Wurzelholz zur Verfügung, ganz und gar von den Fäden unseres Pilzes durchzogen. Legte man es einige Zeit in feuchtem Raume, etwa der Botanisirtrommel, aus, so entwickelten sich daran jene oben erwähnten Conidienträger, unverkembar in ilırer Gestalt, und es konnte so der Nachweis stets erbracht werden, dass der Kiefernwurzelpilz und nicht etwa ein anderer Fänhissbewohner vorlaanden war. Nun anch nit solchem, von Pilzfäden durchwnchertem Holze, endlich auch mit Stïcken der Fruchtkörper wurde inficirt. Ich legte Wurzeln der betreffenden Bäume frei, starke und schwache, oder anch den Wurzellals, an dem der Pilz ja meist gefunden wird, ich spritzte die Sporen auf die unverletzte Rinde oder in anderen Fällen entfernte ich die Rinde. In anderen wurde die W'urzel angebohrt und bis ins Herz hinein mit den Sporen oder anch mit dem rom Pilze befallenen faulen Holze gefüllt. Letzteres wurde dann wieder an andere Wurzeln nur angelegt nud festgebunden n. s. w. Icì versuchte alle Möglichkeiten, die ich nur ersimnen komnte. Stets wurde anch die Infektionsstelle mit einem Terband aus frischem Moos versehen, um ein Austrocknen der Sporen oder Conidien zu vermeiden. W'Tar der Bodenüberzug rorher entfernt, so wurde er nachler wieder iibergedeckt.

Die Infektionsstelle aber wurde für jeden Stamm in dem 
Notizbuche genau beschrieben, die Bäume selbst danerhaft bezeichnet und nun der Erfolg abgewartet. 163 V'ersuchspflanzen, wie gesagt, waren so im Sommer und Herbste 1886 behandelt. Nachdem ich Münster verlassen hatte, hat der Herr Forstmeister Limnenbrink dort die Freundlichkeit gehabt, die Stämme weiter zu beobachten und ich habe sie später bei gelegentlichen Besuchen noch mehrmals untersucht.

Und das Resultat aller Bemühungen, aller dieser sorgsam ausgeführten Versuche, die mich ein halbes Jahr lang vorzugsweise beschäftigten? - Nicht ein Stamm ist pilzkrank geworden, nicht einer ron 163 dem Wurzelpilze zum Opfer gefallen.

Wenn wir mit Entsetzen sehen, wie ganze grosse Kiefernbestände, scheinbar gesund und frohwüchsig, auf einmal von dem Pilze befallen und völlig durchlöchert werden, so möchten wir glauben, es genüge, dass der feindliche Pilz mit den W'urzeln der Bäume in Berührung kommt, um seine Entwickelung. und das Absterben der Bäume herbeizuführen. Das oben mitgetheilte Ergebniss zeigt uns, dass dies nicht der Fall ist. Es schliesst sich ergänzend und erläuternd vortrefflich an das rorher erörterte ebenso negatire Ergebniss der Versuche mit dem Pilze der Aipimpflanze an. Diese Beobachtungen bestärken mich in der Ansicht, dass wahrscheinlich kein Pilz im Stande ist, ohne weiteres eine gesunde normal wachsende höhere Pflanze anzugreifen und zu töten. Wahrscheinlich immer müssen besondere Bedingungen erfüllt sein, wenn ein Pilzangriff gelingen soll, entweder geschwächte Lebensthätigkeit der ganzen Pflanze in Folge ungünstigen Standortes und anderer nicht kontrolirbarer ungünstiger Einwirkungen, oder Zusammentreffen der Infektionskeime mit ganz besonderen empfindlichen Entwickelungszuständen der Pflanze, wie es z. B. in völliger Klarheit und Sicherheit für die Angriffe der Brandpilze Brefeld festgestellt hat, oder bestimmte Verwundungen und dergleichen mehr. Gerade ïber diese Bedingungen (Prädisposition!) aber erfahren wir durch die zahlreichen Lehrbücher der Pflanzenkrankheiten meist sehr 
wenig oder nichts, obwohl für die Praxis, in deren Dienst diese Bücher in erster Linie gestellt werden, diese Fragen die wichtigsten sein dürften.

Meine Aufgabe in Brasilien komnte es nicht sein, die Aetiologie der Wurzeltäule des Aipim weiter zu verfolgen; ich wäre dadurch von meinem eigentlichen Arbeitsfelde wahrscheinlich auf lange Zeit und mit unsicherer Aussicht des Gelingens allzuweit abgezogen worden. Die Feststellung der Thatsache aber, dass hier ein saprophytisch im Walde lebender Pilz, Corallomyces Jatrophae, mit einem Male seit wenigen Jahren sich zum gefährlichen Parasiten einer Kulturpflanze herausgebildet hat, war sicherlich selır bemerkenswerth und trug wesentlich dazu bei, mein schon rom rein morphologischen Standpunkt aus grosses Interesse für diesen Corallomyces noch zu erhöhen.

Nectria capitata Bres. ist ron Bresadola in der Hedwigia 1896 Seite 299 nach dem ron mir gesammelten und seiner Zeit an Herrn Hennings eingesandten Material als neue Art erkannt und folgendermaassen charakterisirt worden:

„Peritheciis in caespitulis $2-4 \mathrm{~mm}$ latis collectis, raro solitariis, superficialibus, glabris, ovoideo-capitatis, 250-300 "l latis, $1 / 2$ - $3 / 4 \mathrm{~mm}$ longis, basi connatis, purpureo-rubris, capitulo miniato, membranaceis. contextu indistincte celluloso, flammeo, ostiolo vix prominulo. subnigricante; ascis jam esorptis;" (sic!) „sporidiis hyalinis elongato-ellipticis, medio 1 septatis, subconstrictis $28-32=10-13$ " episporio longitudinaliter tenuissime striato."

„Hab.: ad cortices Blumenau Brasiliae (n. 25 b et c).“ „Obs.: Notis micrologicis Nectriae Balansae Speg. accedit. sed modus crescendi, habitus etc. diversi. Perithecia ovoideo-elongata. prope apicem constricta ita ut capitata videantur, et bene statum juniorem, diminutum Agarici cujusdam repraesentent."

Dieser Pilz. den ich zu wiederholten Malen auf morschen Aesten 
und Rindenstïckchen im Walde fand, eimmal sogar in nächster Nachbarschaft ron Corallomyces Jatrophae auf demselben Rindenstiick. ist diesem letzteren ganz ausserordentlich nahe rerwandt. Die Perithecien beider Formen sind in frischem Zustande kaum zu unterscheiden, sie stimmen überein in der Grösse, der lenchtend rothen Farbe und der Form, und erst an dem konservirten Material wird die ron Bresadola in seinen Observationes treffend hervorgehobene besondere Eigenthümlichkeit der Perithecienform ron Nectria capitata recht dentlich. Anch die Ascussporen der letzteren sind wie die friiheren ron derselben hellgelbgrünlich bräunlichen Färbung und sehr ähnlicher Form (Fig. 29 'Taf. I), nur ein wenig dicker und an der Wrand etwas mehr eingeschnürt, ein Unterschied. der völlig verschwindet, wenn diese Sporen noch nicht ganz reif, oder die auderen zur Keimung schon etwas angeschwollen sind. Obwohl die Sporen auch bei dieser Nectria häufig in dunklem Tröpfchen auf dem Ostiolum der Perithecien sich sammeln. von wo man sie mit einer Nadel abnehmen kann, so werden sie unter geeigneten Umständen auch ausgeschleudert, woron ich mich durch deu Versuch überzeugte. Ich legte in der feuchten Kammer einen reinen Objektträger etwa $1 \mathrm{~cm}$ hoch iber einem mit delı Perithecien besetzten Rindenstïcke aus und fand llach einigen Stunden auf diesem Glase enporgeschleuderte Ascussporen, die zur Aussaat benutzt wurden. Die Keimung und Mycelbildung erfolgt in Nährlösung leicht und schnell, die Theilzellen der Sporen schwellen dabei noch ein wenig mehr in der Breite an, die Einschniirung an der Theilungswand wird noch deutlicher. Die Mycelien sind in der Stärke ihrer Fäden, in der Art ihrer Ausbreitung und Verzweigung rou denen des Corallomyces nicht zu unterscheiden und gleichen ihnen vollständig besonders anch dadurch, dass die Fadenbrücken ron Anfang an in derselben Massenhaftigkeit und Allgemeinheit auftreten, wie dort.

Schon am zweiten 'Tage nach der Aussaat beginnt an beliebigen und verschiedenen Stellen des Mycels an einzelnen Faden- 
enden die Conidienbildung in der durch die Fig. 39 b Taf. II dargestellten Weise. Man sieht, wie sehr anch die Conidien denen des Aipim-Pilzes gleichen. Sie fallen, wenn sie ihre volle Grösse erreicht lıaben, ab, und theilen sich nachträglich durch Querwände in eine grosse Anzahl von Einzelzellen. Thre Grösse schwankt ausserordentlich, bewegt sich aber meist zwischen 70 und $90 \mu$. Die Anzahl der Theilzellen steigt bis zu 12 und bisweilen noch dariiber.

Bei weiterer Kultur treten gewöhnlich in ummittelbarer Nähe des zuerst Conidien bildenden Hyphenendes noch andere solche auf, und es bilden sich die Conidien nun in Büscheln (Fig. 39 a). Gleichzeitig ist zu bemerken, wie in den Mycelfäden selbst die Scheidewände zahlreicher werden, und die nun kïrzeren Zellen besonders nach dem vorderen Ende zu sich allmählich verdicken, und dann gerade an diesem vorderen Ende nene Seitenzweige bilden, welche sich den frïheren eng anschmiegen, und ebenfalls Conidien erzengen. Fusionen benachbarter Fäden komnen auch noch hinzu; so entstehen dicke, schliesslich nicht mehr im Einzehnen zu ïbersehende Conidienbüschel, die Fäden aber verwandeln ihren Charakter allmällich nnd es entstelit jenes plectenchymatische Gewebe, welches die Stromata dieses, wie des vorhergehenden Pilzes und so vieler anderen Nectriaceen zusanmensetzt.

Es gelang mir in weiteren Verlaufe der finlturen anch von Nectria capitata ziemlich grosse zusammenhängende Conidienlager mit pallisadenartig angeordneten Sterigmen auf einer Art ron Stroma zu erziehen. Niemals aber kamen bestimmt geformte, mit einem stiel versehene oder gar mit jenem eigenartigen sterilen Rande einer runden Scheibe ansgestattete Fruchtlkörper zn stande. Anch an natiirlichen standorte wurden keine solchen eigentlichen ('onidienfruchtkörper' beobachtet.

Wem die Conidien ihre volle Reife erlangt laben, so zeigen sie gegen diejenigen des Aipim-Pilzes einige erlıebliche Verschiedenheiten, die mich znerst davon iiberzengten. dass ich es hier sicher mit einem von jenem rerschiedenen Pilze zu thun hatte. Die Zahl 
der Theilzellen nämlich, welche freilich bei beiden Formen schwankend ist, bleibt doch bei Corallomyces fast immer unter acht, während sie bei $\mathrm{N}$. capitata meist mindestens acht beträgt, häufig bis zwölf und darüber (Fig. 39 c). Die einzelnen Theilzellen selbst zeigen eine deutliche, bei der vorigen For'm nicht vorhandene Neigung zur Anschwellung und Abrundung. Wenn diese sich vollzieht, so entsteht natuirlich an der Stelle der Scheidewand eine Einschnürung und häufig brechen die Conidien damn an diesen Stellen von einander. Bisweilen werden einzelne Theilzellen vom Inhalt entleert, schrumpfen zusammen, während die benachbarten sich verdicken, abrunden und scheinbar auch eine stärkere Membran ausbilden, also durchaus gemmenartige Bildungen erzeugen (Fig. $39 \mathrm{~d}$ und e).

Wegen der ausserordentlichen Aehnlichkeit der beiden besprochenen offenbar sehr nahe verwandten Pilze, deren Mycelien ununterscheidbar sind und in gleicher Weise die Neigung zu überall auftretenden Fadenbrücken zeigen, habe ich viele Beobachtungen darüber angestellt, ob nicht auch solche Fadenbrücken zwischen beiden Formen eine Verbindung herzustellen im Stande wären. Ich säete also je eine oder ganz wenige Sporen der einen Form mit solchen oder Conidien der anderen zusammen aus, oder auch Conidien der einen mit Conidien der anderen. Schon nach kaum 24 Stunden waren dann reichlich Fadenbrïcken zu finden, und jeder Mycelfaden liess sich noch auf die Keimstelle zurück verfolgen. Auch am zweiten Tage setzte ich die Beobachtungen noch fort. Es waren jetzt in jedem Gesichtsfelde des Mikroskops mindestens ein Dutzend Fadenbrücken zu finden, aber stets liess sich feststellen, dass solche nur zwischen Fäden der Individuen einer und derselben Art vorkamen, hier aber ebenso häufig als Verbindung der Mycelien zweier Individuen, wie zwischen den Fäden eines und desselben Myceliums. Das negative Resultat der durch mehrere Tage fortgesetzten Beobachtungen war ja wohl zu erwarten, und steht im Einklange mit dem Ergebniss älnnlicher 
Versuche, ïber die van Tieghem in den Ann. d. sc. nat. VI Série Tome I p. 7 berichtet. Auf jeden Fall ist es ein wunderbarer und erstaunlicher Anblick, wenn man Mycelfäden dicht neben einander herlaufen sieht, die man mit dem Mikroskop in keiner Weise unterscheiden kann, und nun beobachtet, wie von dem einen nach dem rechts liegenden, aus einer anderen Spore derselben Art herstammenden Faden zahlreiche Briicken gebildet werden, während nach dem anderen links ebenso nahe anliegenden, ja ihn beriihrenden Faden der anderen Art auch nicht eine Verzweigung sich hinneigt. Die Bilder, welche man in derartigen Präparaten zu sehen bekommt, sind nicht verständlich, wenn es nicht eine geheimnissvolle Fernwirkung von einem Mycelfaden zum anderen der gleichen Art giebt, eine Fernwirkung; welche das Vortreiben von zu Brïcken bestimmten Verzweigungen der Fäden bewirkt. Um so sicherer erscheint unter diesen Umständen der Beweis der specifischen Identität, welchen die Fig. 24 Taf. I fïr die Ascusspore aus einem auf Rinden im Walde gewachsenen Perithecium und die Conidie aus dem parasitisch anf Aipim- ITurzeln gewachsenen Conidienfruchtkörper des Corallomyces Jatrophae erbringt.

Die rergleichende Betrachtung der beiden eben behandeiten Pilze lässt ganz von selbst Zweifel an der Berechtigung der Gattung Corallomyces auftauchen. Dass unser Corallomyces Jatrophae eben dieser Gattung muss zugerechnet werden. daran dürfte kein Zweifel sein, wemn wir ihn z. B. mit dem von Hennings in Englers Jahrbüchem 1898 Seite 506 beschriebenen C. novopommeranus oder dem in denselben Jahrbüchern 1897 Seite 538 verzeichneten C. Heinseni vergleichen. Bei beiden findet sich dieselbe Bildung der Conidienfruchtkörper, welche die Gattung in genan demselben Sinne rechtfertigen würde, wie Sphaerostilbe durch ihre Conidienfriichte gekennzeichnet wird. Die Perithecienstromata sind freilich bei unserer Form wie bei C. berolinensis P. Henn. oder C. noro-pommeranus P. Hemn. nicht so hochentwickelt. wie bei dem a. a. O. abgebildeten C. Heinseni oder dem in Engler- 
Prantl Seite 366 abgebildeten Corallomyces elegans Berk, et Curt., welcher zur Grïndung der Gattung Veranlassung gab. Es dïrfte also nothwendig sein, die Gattung Corallomyces mit Rücksicht auf die seit ihrer Grïndung neu hinzugekommenen Formen nicht nur wie bisher durch die Gestalt der Perithecienstromata, sondern auch durch diejenige ihrer Conidienfrüchte zu charakterisiren. Wenn unser Corallomyces an seinem natürlichen Standorte im Walde zufällig ohne Conidienfrüchte angetroffen wird, so bildet er, wie ich oben schon erwähnte, oftmals nur sehr wenig vorragende Stromata mit wenigen Perithecien, und seine Erscheinumg ist in nichts verschieden von der der Nectria capitata. Dass man alsdamn in solchem Zustande die beiden Gattungen nicht würde tremmen können, hindert nach meiner Auffassung nicht im mindesten die Berechtigung der Gattung Corallomyces. Denn wir trennen aus praktischen Gründen der Uebersichtlichkeit vielfach die Gattungen je nach der Gestaltung der höchsten Fruchtkörperbildung; welche sie unter günstigen Verhältnissen zu erreichen im Stande sind, und Schizophyllum bleibt bei den Agaricinen, obwohl es, wie wir oben gesehen haben - und zwar nicht nur in kïnstlichen Kulturen, sondern auch im Freien - oftmals in einem niederen thelephoreenartigen Entwickelungszustande vorkommt. *)

*) Mit dieser Bemerkung möclite ich zugleich die ausserordentlich oberflächlichen Bemängelungen abthun, welche Holtermanu in seinen mykologischen Untersnchungeu aus den Tropen, Berlin 1898 Seite 73 und 87 gegen die ron mir aufgestellten und scharf charakterisirten Gattungen Stypella und Exidiopsis vorbringt. Näher aut die Holtermaunschen Auslassungen einzugehen verlohnt sich kaum, da sie sich durch mangelndes Verständniss mo grosse Flïchtigkeit des Autors für jeden Einsichtigen sofort erledigen. Ich will nur darauf hinweisen, dass zwischen Nectria uud Corallomyces ein ganz ähnliches Verhältniss besteht, wie zwischen Stypella und Exidiopsis oder zwischen Exidiopsis und Exidia. So wie manche Agaricinen und Polyporeen gelegentlich noch im Telephorazustande vorkommen kömneu, so kann eine Exidiopsis sehr wohl einen Stypellazustand durchmachen, obwohl dies bisher nicht beobachtet wurde, und eine Exidia kam einen Exidiopsiszustand zeigen, wie es z. B. fiur die ron mir in den Protobasidionyceten Seite $95 \mathrm{ff}$. beschriebene Exidia sucina thatsächlich 
Nectria Euterpes nov, spec. - Auf einer abgefallenen Frucht der Euterpe oleracea fand ich im Dezember 1892 eine lenchtend rothe Nectria (nach Saccardos Chromotoxia zwisclien ruber (14) und miniatns (15)), deren Perithecien frei, einzeln. nicht eingesenkt in grosser Zahl rerstreut, stellenweise auch so enge beieinander standen, dass sie sich gegenseitig berïlnten. Sie sind fast kugelig, haben $1 / 2 \mathrm{~mm}$ Durchmesser und eine kurze stumpfe Miindung. Die ganz reifen Perithecien zeigen eine etwas dunklere braunrothe Färbung. Die Sporen treten in Gestalt eines weissen schleimigen 'l'röpfchens aus der Mündung' des Peritheciums und sitzen als weisses Knöpfchen oft von derselben Grösse, wie das Perithecium selbst, auf dessen Spitze. Zwischen den Perithecien erscheinen die Conidienlager als kleine Schleimpolster ron unregelmässiger Umgrenzung nnd keinem grösseren Unfange, als er den Perithecien zukommt, es sei denn, dass hie mo da benachbarte Conidienlager zusammenfliessen. Im Anfange ihrer Bildnng zeigen die Conidienlager einen röthlichen Anflug, ältere sind rein weiss.

Die Ascussporen sind farblos, oval, $14 \mu$ lang, $5 \mu$ breit, mit einer schon im Schlanche deutlich erkennbaren Scheidewand (Fig. 35 Taf. II) und oftmals ron der einen Seite her ein wenig zusammengedrïckt, die Keimumg beginnt durch Anschwellung der Sporen schon in dem anf der Spitze des Peritheciums sitzenden Tröpfchen. Tn Nährlösung tritt sie allgemein auf. naclıdem die Sporen semmelförmig angeschwollen sind; in wenigen Stunden erfolgt die Bildmng eines reich verzweigten Mycels mit ausserordentlich zahlreichen Fadenbriicken. aber erst nach einigen 'Tagen tritt die Conidienbildung an den aus Ascussporen elzogenen My-

zutrifft. Man charakterisirt aber die Gattung durch den höchsten Fruchthörperznstand, welchen die betreffenden Pilze unter günstigen Wachsthumsverhältnissen zu erreichen fähig sind. - Leider bin ich genöthigt, weg'en der unmotivirt ausfallenden Ausdrucksweise des Herru Holtermann, an Schlusse dieser Mittheilungen noch ein weiteres Beispiel der grossen Fliichtigkeit und Unzuverlässigkeit seiner Beobachtungen darzulegen. 
celien, zuerst untergetaucht in der Flïssigkeit, auf. Zunächst sind es ganz beliebige Fadenenden, welche je eine sichelförmige Conidie abschnüren (s. Fig. 35), genau wie es für die beiden vorigen Arten beschrieben ist, deren Kulturen die hier geschilderten sehr älnlich sind. Weiterhin treten die conidienbildenden Fäden und Verzweigungssysteme enger zusammen, bilden die Conidien in grösseren Massen, und nun sieht man anch einzelne Conidien in die Luft ragen. In den Mycelien grenzen sich stellenweise einzelne Fadenstiicke scharf ron den Nachbarzellen ab und füllen sich mit einem schmutzig dunkelrothen Inhalt; ebenda finden sich dann rundlich gestaltete morganische Abscheidungen neben den Mycelien, welche ebenfalls eine der Nährlösung nicht eigenthümliche röthliche Farbe haben, dieselbe, welche auch an den ganz jungen Conidienlagern im Freien beobachtet wurde. Zuletzt, nach etwa 14 Tagen, ist kein Unterschied zwischen den in der Nährlösung gebildeten und den auf dem Palmenkern beobachteten Conidienpolsterchen. Bei beiden kommt es nicht zur Bildung eines stromatischen Gewebes, wohl aber zeigen die Fäden hinter den conidienbildenden Enden kurze Zellen, die nach rorn zu anschwellen, wie ich sie für Nectria capitata abgebildet habe. Dort bedeuten diese Veränderungen der Fäden den Beginn der Plectenchymbildung; bei der N. Euterpes kommt ein Plectenchym in den beobachteten Fällen indessen nicht zu Stande. Die Conidien sind lang, sichelförmig, $60-70 \mu \times 10-12 \mu$, gestaltet wie die von Corallomyces Jatrophae, jedoch durch die Art ihrer Theilung von jenen etwas verschieden. Meist nämlich beobachtet man eine mittlere und zwei äussere Theilwände, durch welche die Conidie in zwei mittlere grössere und zwei kleinere Endzellen getheilt wird. Auch die Conidien keimen in Nährlösung leicht und erzengen dieselben Mycelien, wie die Ascussporen, jedoch verdient es wohl Erwähnung, dass an diesen aus Conidien gezogenen Kulturen die Bildung von neuen Conidien schon nach 24 Stunden eintritt, während sie an den in der gleichen Nährlösung wachsenden, unter 
derselben Glasglocke befindlichen Kulturen aus Ascussporen im besten Falle doch mehrere Tage auf sich warten lässt.

Die Nectria Euterpes schliesst sich den beiden vorher besprochenen Formen durch den Besitz gleichgestalteter nnd gleichgebildeter Conidien offenbar nahe an. Sie bleibt in der Fruchtkörperbildung hinter Nectria capitata weit zurück, wie jene hinter Corallomyces Jatrophae. Doch gehören alle drei zweifellos einer natïrlichen zusanmenhängenden Formenreihe an. Für die Zerlegung der übergrossen Gattung Nectria in natürliche Untergruppen ist die genaue Kenntniss der betreffenden Conidienformen unerlässlich. Diese sind aber erst für relativ wenige Formen gut bekannt. Unter ihnen dürften N. Stilbosporae, episphaeria, sanguinea, Leptosphaeriae, ferner auch noch ditissima und coccinea sich den besprochenen brasilischen Formen anschliessen, da bei ihnen allen durch Tulasnes und Brefelds Lntersuchungen die Fusariumartigen Conidien nachgewiesen sind. Dass alle diese unter einander jedenfalls nähere Beziehungen haben. als jede von ilnen zu Formen, wie N. inaurata oder cinnabarina, die in der Art der Conidienbildung so weit abweichen (Bref. X Taf. IV) dürfte zweifellos sein.

Lie Nectriaformen waren in dem Blumenaner Arbeitsgebiet ausserordentlich zahllreich vertreten, doch ist es mir nicht möglich gewesen, ansser den genannten noch andere entwickelungsgeschichtlich zu untersuchen. Von den Herren Hennings und Bresadola sind in der Hedwigia 1896 seite 299 und 1897 s. 219: 9 Arten aus meinen Sammlungen beschrieben. Nehrere andere sind mit dem iibrigen Material, welches in diesem Hefte bearbeitet worden ist. den Sammlungen des botanischen Museums in Berlin iibergeben.

Zu der von Bresadola a. a. O. aufgefülnten N. Epichloë Speg. var. rosea Bres. muss ich noch bemerken, dass nach Spegazzinis Amnahme dies eine Nectria sein soll. welche auf einem Andropogon ein epichloëartiges ïber mehrere $\mathrm{cm}$ sicl erstreckendes 
schwarzes Stroma erzeugt, auf dem truppweise die kleinen Perithecien sitzen. Wenn dem so wäre, so hätte wahrlich Spegazzini mit seiner dieser Art gewidmeten Bemerkung recht: „facile novum genus constituens." In Wirklichkeit dürfte es sich um eine Nectria handelı, die auf einer noch nicht fruktifizirenden Epichloë oder Ophiodotis parasitirt.

Die ron Herrn Hennings a. a. O. unter der Gattung Nectriella aufgeführten drei Arten: miniata. Mölleri und farinosa haben sehr kleine Sporen, an denen, zumal weun sie nicht ganz reif sind, die Theilwände schwer zu erkennen sind. In Wirklichkeit sind sie bei allen vorhanden; die drei Arten gehören also zur Gattung Nectria, wie ich im Einvernelnmen mit Herrn Hennings hierdurch feststelle.

An vierter Stelle erwähnt Herr Hennings als ron mir gefunden die Nectria episphaeria (Tode) Fries. (S. Y. Sc. 1. 388). Sie kam auf einer Nummularia und auf Kretzschmaria Clavus vor. Nectria episphaeria würde ein errähnenswerthes Beispiel eines anscheinend kosmopolitischen Pilzes sein, da sie bereits aus allen Welttheilen den Sammlungen des botanischen Mnseums in Berlin zugegangen ist. Nachdem ich aber durch Herru Hennings Liebenswürdigkeit in den Stand gesetzt worden bin, das Friessche Originalmaterial zu vergleichen, und nicht minder auch Originalmaterial von Rehm (1585 Ascomyceten) so trage ich doch Bedenken, die unbedingte Identität der Formen anzunehmen. Bei den ron mir gefundenen nänılich haben die Sporen ein deutlich warzig. rauhes Epispor (wie bei Winters Nectria asperula), was für die Friessche und Rehmsche Form nicht zutrifft. Ich lialte es desshalb für sicher, dass die von mir auf den südamerikanischen Sphaeriaceen gefundene Nectria nicht mit der N. episphaeria (Tode) Fries identisch ist, wennschon sie ilır sehr nalıe stehen mag; und hierdurch wird allerdings eine gründliche und sorgsame vergleichende Untersuchung der aus den verschiedenen Erdtheilen bekannten „Nectria episphaeria“"formen dringend wünschens- 
werth, ehe man diesen Pilz als Kosmopoliten linzustellen berechtigt ist.

Sphaerostibe longiascus nov. spec. - Die Gattung Sphaerostilbe ist ebenso wie Corallomyces mit Nectria aufs allernächste verwandt. Man vergleiche die Conidien auf dem prachtvollen Bilde von Sphaerostilbe flammea bei 'Tulasue (Carp. III Taf. XIII Fig. 10. 11) mit den für unseren Corallomyces Jatrophae abgebildeten und gleicherweise die Ausbildung des Stroma, der darauf sitzenden Perithecien und Conidienträger, wie sie besonders für Sphaerostilbe gracilipes Carp. Bd. UI Taf. XIT Fig. 15 und 16 gegeben sind, mit den Abbildungen unseres Corallomyces, so springt die nahe Verwandschaft so sehr in die Augen, dass man versucht sein könnte, beide Gattungen zusammenzuziehen. Lediglich. weil diese Beziehungen der Formen zu einander dadurch von einer nenen Seite aufgezeigt und in wïnschenswerther Weise ergänzt werden, thue ich hier einer neuen Sphaerostilbe Erwähnung. welche ich im Dezember 1892 auf morschen Rindenstückchen am Rande eines Baches (im sogenamnten "Traurigen Jammer") bei Blumenau reichlich fruchtend mit kräftigen Perithecien auffand, nachdem die Conidienfruchtform für sich schon früher viederholt beobachtet war. Für die allgemeine Erscheinumg des Pilzes kann die Abbildung Tafel II Fig. 36 a zur Erläuterung dienen. Das polsterförmige Stroma, welchem die Perithecien und die Conidienträger entspringen, zeigt die bekannte Struktur und ebenso wie die Frïchte selbst durchweg eine lebhaft rothe Farbe; diese kommt auch den bis zu $7 \mathrm{~mm}$ langen Conidienträgern im unteren Theile zu, geht dann aber nach oben in helhroth und gelb über. Die Perithecien sind länglich tonnenförmig und ebenso wie die langen Stiele der Conidienköpfe schwach behaart. Nur die obere kappentörmige Spitze der Perithecien, welche ron dem Mündungskanal durchbolnt ist, erscheint glatt olme Haare ron fast braunrother Farbe. Die reifen achtsporigen Schläuche (Fig. 36c) sind enorm lang gestielt, sie elreichen bis ïber 300 "Läng’e. Die Sporen 
sind gelbbraun, spindelförmig mit stumpf abgerundeten Enden, 28 bis $38 \mu$ lang, $10 \mu$ breit, ein wenig gekrümmt. und an der einen mittleren Querwand, welche sie besitzen, ein wenig eingeschnürt. Bei starker Tergrösserung lässt die Spore eine schwache Längsstreifung und ringsum einen dümnen Mantel hyaliner Substanz erkennen. Die Conidien bilden an der Spitze der Träger knglige schleimige 'Tröpfchen von $1 \frac{1}{2} \mathrm{~mm}$ Durchmesser und von rothbrauner Farbe. Sie entstehen, wie die Figur $36 \mathrm{~b}$ zeigt, auf der Spitze der 'Träger' in einem dichten Gewirre steriler Fäden, welches die Massen der abgelösten Conidien zusammenhält. Sie sind eiförmig gestaltet, ron 44-50 $\mu$ Länge und etwa 15 « Breite in der Mitte. Zmnächst theilen sie sich durch eine Querwand in der Mitte, danach grenzt sich oben und unten noch je eine Kappenzelle ab. Nur die grösseren beiden mittleren Zellen sind gelbbraun gefärbt, die Kappen sind weiss und scheinbar leer. Dass sie in Wirklichkeit nicht leer sind, geht schon daraus hervor, dass aus ihnen allein, nie ans den mittleren Zellen, die ersten Keimschläuche austreten. Anch die in Nährlösung anfgefangenen Sporen keimen leicht und schnell und entsenden die Keimschlänche ans beliebigen Stellen ihres Umfanges. Die aus Sporen und die aus Conidien erzogenen Mycelien gleichen sich vollkommen, verbreiten sich schnell in der Kultur, bilden gegen einander zahlreiche Anastomosen und liefern so noch einen unanfechtbaren Beweis der Zusammengehörigkeit beider Fruchtformen, dessen es allerdings nach dem sonstigen Untersuchungsbefunde im Terein mit den über andere Sphaerostilben bekannten Thatsachen kanm bedurft hätte. Ton der vorzüglichen von Tulasne gegebenen Gattungsdiagnose der Sphaerostilbe weicht die neue Form in manchen Stïcken ab. Demn es heisst bei Tulasne III S. 99. "Perithecia" - „minute verrucosa, nuda" wälnrend sie hier behaart sind; ferner: "Thecae quasi sessiles“, während hier die Schläuche ausserordentlich langgestielt sind; die Sporen endlich sind gelbbratm gegeniiber der Charakteristik "sporae" - "pallidae". Nichts 
destoweniger diirfte es keinen Zweifel unterliegen, dass unsere Form der Sphaerostilbe einzuverleiben ist, und dass deren Gattungsdiagnose für die Aufuahme der neuen Form passend zu erweitern ist. Diese Sphaerostilbe giebt durch die Farbe ihrer Sporen einen nenen Anhalt für die Termuthung der nahen Terwandtschaft nuit Nectria, bei der vielfach dieselbe Färbung, anch die Streifung des Sporenmembran vorkommt. Sie ist uns ausserdem werthvoll dnrch die neue Conidienform, welche zu den vielen verschiedenen schon bekannten Conidienformen inıerhalb der Gattung hinzutritt. Die Conidienfruchtkörper endlich sind bemerkenswerth durch die Bildumg der sterilen Fäden, welche zwischen sich die Conidien festhalten. Sie erimern daran, dass gleiche Bildungen bei den Protobasidiomycetenfruchtkörperı von Pilacrella und Hyaloria und noch lïher entwickelt bei Pilacre rorkommen und wir stellen diese Formanklänge bei Conidien- und Basidienfruchtkörpern dem für Corallomyces und Schizophyllum oben (Seite $99 \mathrm{ff}$.) ausführlich erläuterten Beispiel als eine bemerkenswerthe Ergäuzung zur S'eite.

\section{Mycocitrus amantium nov. gen. et nov. spec.}

Den wunderbaren Pilz, welchen die Tafel III Fig. 45 in natürlicher Grösse und Farbe zur Anschaumng bringt, mache ich zum Vertreter einer neule Gattung der Didymosporae Hypocreacearum. Die vorherrschende Kugelform des riesigen leuchtend rothen Fruchtkörpers, der; wie das noch ron keiner Hypocreacee bekanut ist, an der ganzen Oberfläche ringsum Perithecien trägt, begrïndet die nene Gattung nicht ninder sicher, wie der Umstand, dass bei ihr die entleerten Perithecien ïberwachsen, und den Stroma tief eingesenkt werden, welches ïber ilnten eine neue Perithecienschicht hervorzubringen vermag. *)

*) Wemn mein verehrter Freund Möbins einen Blick auf die Figuren 38a b, c der Tafel II geworfen haben wird, so wird er mir rerzeihen, dass ich seinen Ausführungen in dem Aufsatze über Parasitismu: und Sexnalität im biologischen C'entralblatte Br. XX Seite 566 nicht beiptlichten kams. wo er 
Ich habe diesen Pilz in etwa 15 Stücken gesammelt, deren kleinste $1 \mathrm{~cm}$ Durchmesser besassen. Der grösste (24. Sept. 1891) hatte $11 \%$ cm Durchmesser, war ziemlich regelmässig kuglig, schön orangeroth, (Saccardo 21/22) und wog in frischem Zustande $320 \mathrm{~g}$. Der abgebildete (rom 10. Juni 1891) ist ron mittlerer Grösse. Er umfasst, wie man sieht, den tragenden, dünnen abgestorbenen Bambuszweig rollständig, so dass dieser etwa die Axe der Pilzkugel bildet, und dies verhielt sich in den meisten Fällen so. Der Pilz wurde nur auf lebenden oder abgestorbenen Bambuszweigen melnere Leter über dem Boden angetroffen, und die tragenden Zweige waren in allen Fällen sehr düm, meist kaum bleistiftstark; nur jenes grösste erwälnte Stiick sass auf einem Zweig von $1^{1 / 2} \mathrm{~cm}$ Durchmesser. So weit ich in zahlreichen Längsund Querschnitten feststellen konnte, dringen die Hyphen des Pilzes in das Gewebe der Bambusstengel niemals ein.

Es giebt 5 verschiedene Arten von Bambusen. die im Walde bei Blumenau häufiger vorkommen. und auf allen olne Unterschied ist unser Pilz angetroffen worden. Seine leuchtend orangerothe Farbe, seine Grösse und der Umstand, dass er so hoch ïber dem Boden wächst, machen ihn weithin sichtbar und auffällig. Man glaubt eine Orange zu sehen. Wir nannten ihn in Blumenau den Orangenpilz oder in der dortigen Ausdrucksweise Laranschenpilz ( rom portugiesischen laranja=Orange) und danach mag er nun auch seinen wissenschaftlichen Namen erhalten.

Wenn ich bedenke, wie viel von eifrigen Pilz-Sammlern gerade im letzten Jahrzehnt auch in den Tropen zusammengebracht

schreibt: „Den Unterschied zwischen Asco- und Basidiomyceten in der Keimbildung sehen wir schon daran, dass bei ersteren der Fruchthörper zu Grunde geht, wenn alle in demselben zur Entwickelung kommenden Asci entleert sind, dass bei letzteren aber der Fruchtkörper auf der früheren Hymenialschicht eine neue, sogar auf dieser wieder eine nene u. s. w. erzeugen, und so z. B. bei holzigen Baumschwämmen jahrelang fortwachsen kann." Die mehrfache Perithecienbildung in über einander liegenden Schichten kommt anch dem merkwürdigen Engleromyces P. Henn. zu, den ich im weiteren Verlanfe dieser Arbeit unter dell Spliaeriaceen zu erwähnen habe. 
worden ist, so muss ich mich immer aufs neue wundern, dass dieses anffallende Gebilde, das ich seit nunmehr 10 Jahren kenne, noch nicht von anderer Seite beschrieben worden ist. Und dasselbe trifft zu für die anderen demnächst zu beschreibenden Riesenbambusascomyceten aus Bhmenau, die Ascopolyporus-Arten besonders, dann auch Mycomalns und Peloronectria. Fast möchte man zu der Vermuthung kommen, dass diese Formen doch relativ selten und in ihrem Vorkommen vielleicht auf wenige Gebiete beschränkt seien. Und hiermit würde im Einklange stehen, dass ich bei meinen vielen Ausfliigen und bei der Unterstiitzung, die mir durch Herrn Gärtner mnd viele andere zu Theil wurde, von diesem Pilze. den so leicht Niemand übersehen kann, in drei Jahren nur 15 Stück zu Gesicht bekam. Die Funde vertheilten sich ïbrigens auf alle Jahreszeiten. In einem einzigen Falle habe ich ein und denselben Pilz am Standort längere Zeit beobachten können, vom 20. Juli bis 9. Oktober, und da er, als ich ihn bemerkte, schon über Nnssgrösse hatte, mnd als ich ihn am 9. Oktober zur Untersuchung zog, noch vollständig frisch und wuchskräftig war, so ist jedenfalls die individuelle Lebensdauer eine beträchtliche, mindestens mehrere Monate umfassende.

Junge Fruchtkörper sind von weisshicher Farbe, das eben erwähnte am standorte beobachtete Stück reigte, als es bemerkt wurde, im Juli, nur erst einen schwachröthlichen Anfug. dabei noch keine Perithecienanlagen. Am 10. August komnten solche mit einer guten Lupe wahrgenommen werden, und um diese Zeit war anch die rothe Farbe schon recht deutlich. Ich schnitt an diesem Trage von dem am standorte befindlichen Pilze eine sulheibe ab, so dass das weisse Fleisch freigelegt wurde. Die Schnittstelle färbte sich in der Zeit bis zum 16 . Sept. wiederum röthlich und anch anf ihr fand die Anlage ron Perithecien statt. In der Zeit vom 15. Sept. bis 9. Oktober hatte der Pilz seinen Durchmesser von 34 auf $36 \mathrm{~mm}$ vergrössert, die Perithecien reiften und entleerten sporen und gleichzeitig war die Farbe erheblich inten- 
siver und lenchtkräftiger geworden. Die ganze Masse des reifen Pilzes besteht aus einem vollkommen gleichartigen weissen festen zähelastischen, im Aussehen an Marzipan erinnernden Fleische. Die mikrokospische Untersuchung zeigt ein sehr dichtes unregelmässiges Gewirre starkwandiger Fäden von etwa 3-4 4 Dicke. Nur an einem der beiden kleinsten aufgefundenen Fruchtkörper, die wenig über $1 \mathrm{~cm}$ Durchmesser, und noch weisse Farbe besassen, wechselten im Innern heller glasige Partien mit dunkleren Adern, und hier ergab die Untersuchung noch ein Geflecht feinfädiger 1, $2 \mu$ starker Hyphen, die in den dunkleren Adern dicht zusammengeschlossen, in den helleren Partien selır weitläufig und locker in einer Gallerte verliefen. Nur erst stellenweise wurden hier die stärkeren dickwandigen Hyphen angetroffen, welche in sämmtlichen untersuchten reifen Fruchtkörpern ganz allein in dichtem Zusammenschhnss das Fruchtfleisch bilden. Dies Fleisch hat einen schwach bitteren Geschmack. Ich zerschnitt einen Fruchtkörper in dümne Scheiben, reihte diese auf Fäden und trocknete sie. An der dem Lichte zugewendeten Seite nahmen sie in wenigen Tagen eine schwach röthliche Färbung an; iiberhaupt übt das Licht auf die rothe Farbe unseres Pilzes einen zweifellosen Einfluss. Bei einem sehr schön und regehmässig rund geformten am 10. Sept. 1891 gesammelten Exemplar von $200 \mathrm{~g}$ Gewicht war die dem Lichte ausgesetzte Seite, wie bei einem Apfel durch lenchtende Farbe vor der Schattenseite deutlich ausgezeichnet, und man konnte den äussersten Farbenunterschied der dunkelsten von der hellsten Stelle nach Saccardos Farbentafe! etwa so ansdrücken, dass man die erstere durch eine Farbenmischung $\frac{(2 \times 21)+22}{3}$ und die letztere durch $\frac{22+(2 \times 30)}{3}$ bezeichnete. Zwischen diesen beiden Grenzen waren alle Farbenabstufungen vorhanden.

Wahrhaft erstaunlich ist die Menge der Sporen, welche ein solcher Pilz hervorbringt. Legt man einen reifen Fruchtkörper 
in einer fenchten Kammer ïber einer Glasplatte aus, so sammeln sich die Sporen im Laufe weniger Stunden auf dieser Platte in Form eines weissen Pulvers. Will man Aussaaten gewimnen, in denen die einzelne Spore verfolgt werden kann, so darf man die mit Nährlösung beschickten Objektträger nur wenige Augenblicke unter dem Fruchtkörper liegen lassen. Fängt man die Sporen auf einer trockenen Platte auf, so sieht man sie häufig zu 8 beisammen liegen, ein Beweis, dass der Ascus seinen Inhalt auf einmal ausschleudert (Fig. 38 f.). Die Sporen sind farblos, oval, $6-9 \mu$ lang, kaum 3-4 $\mu$ breit und mit einer Querscheidewand rersehen. Die Schläuche bieten keinerlei Besonderheiten, sie sind 48 "lang, $4 \mu$ breit und die Sporen liegen in ilmen in einer Reilı. Der Durchmesser der kugelrunden nur mit einem winzigen nabelartigen, von dem Mïndungskanal durchsetzten Spitzchen versehenen.Perithecien schwankt von ${ }_{6}^{1 /}-{ }_{4}^{1} \mathrm{~mm}$ etwa. Die ganze Oberfläche des Pilzes erscheint von ihnen unter der Lupe fein gekörnelt. Ich ermittelte ungefähr 2500 Perithecien auf einen Quadratcentimeter der Fläche. Der grösste gefundene kuglige Fruchtkörner hatte, wie oben erwähnt $11^{1 / 2} \mathrm{~cm}$ Durchmesser, seine Oberfläche liatte demnach rund 370 Quadratcentimeter mit rund 900000 Perithecien. Auf Grund einiger Probezählungen hat jedes Perithecimm erheblich mehr als 50 Schläuche, aber nur bei Ammahme von 50 Schlänchen zn 8 Sporen ergiebt sich eine Sporen-Produktion von 360 Millionen. Nun aber liegen bei diesem Pilze die Perithecien in drei bis vierfacher Schicht über einander, so dass wir ron diesem einen Fruchtkörper schlecht gerechnet eine Milliarde Sporen erhalten.

Die Anlage der Perithecien erfolgt an und dicht unter der Oberfläche des Fruchtkörpers, nicht vollkommen in gleicher Höhe und oftmals anch in ungleichmässiger Vertheilung. Die jungen Perithecien werden als kuglige dicht rerflochtene Fadenknäuel in der gewöhnlichen Weise zuerst sichtbar. Im reifen Zustande sitzen sie, bisweilen sich berülırend, bisweilen auch durch kleine Zwischenräume getrennt, auf dem Fruchtkörper, mehr oder 
weniger eingesenkt in der Weise, wie die Figur 38 a es darstellt. So war es z. B. der Fall bei dem auf Taf. III Fig. 45 abgebildeten Stücke. Die Untersuchung anderer Fruchtkörper zeigt aber gelegentlich andere und sehr fremdartige Bilder; zwei Fälle sind in den weiteren Fig. 38b und c zur Darstellung gebracht. In dem eimen sieht man die Perithecien in doppelter Schicht angelegt vollkommen in das Stroma versenkt, welches sich ïber sie hinaus vergrössert hat, und uun wieder eine sterile Oberseite zeigt, in dem zweiten Fall, der von dem erwähnnten grössten gefundenen Fruchtkïrper stammt, lassen sich sogar drei bis vier Schichten von Perithecien erkennen, von denen die oberste reife die Fruchtkörperoberfläche bedeckt. Nur diese enthält Schläuche und Sporen. Die eingesenkten Perithecien sind mit einem Hyphengeflecht in unregelmässiger Weise erfüllt, und zeigen keine Spuren von Schläuchen melrr; dagegen ist ihre Wandung und wo der Schnitt sie getroffen hat, auch ihre Mündung noch deutlich erkembar. Die richtige Deutung dieser Bilder kann nur diese sein, dass das Wachsthum des Stroma bei günstigen Bedingungen nicht mit der Erzengung einer Perithecienschichte abgeschlossen ist, sondern dass es, wenn diese ihre Sporen entleert hat, sie überwächst, sich wiederum schliesst, und abermals eine neue Perithecienschicht bildet. Andere Befunde, die des Raumes wegeu nicht alle abgebildet werden konnten, zeigen, dass bisweilen Schichten von Perithecienanlagen in dieser Weise in das Stroma versenkt werden, ehe sie noch zur Reife kommen und Sporen bilden.

Ob unter der tiefsten Schicht noch erkemnbarer Perithecien welche in Fig. 38c dargestellt ist, früher weitere Schichten vorhanden gewesen sind, die mit dem Stroma so vollkommen verwachsen sein mïssten, dass man von ihnen keine Spur mehr erkennt, vermag ich natürlich nicht zu sagen. Es erscheint mir aber unwahrscheinlich. Meine sämmtlichen Beobachtungen bestärken mich lediglich in der Annahme, dass das Stroma in sterilem Zustande grössere oder geringere Ausdehnung erreicht, in diesem Zustande 
meist noch wenig gefärbt und darum leichter zu ïbersehen ist, dass es damn erst, wenn es amähernd die definitive Grösse erreicht hat, zur Perithecienbildung auf der ganzen Fläche übergeht, und nur unter besonders günstigen Verhältnissen nachträglich noch so viel weiter wächst, dass verschiedene Lagen von Perithecien über einander angelegt werden können. Künftige Beobachtungen am Standorte mögen diese bemerkenswerthen Vorgänge näher feststellen und aufklären. Säet man die Sporen in Nährlösung, so schwellen die beiden Theilzellen erheblich, bis fast zur Kngelform auf, und es tritt aus jeder ein Keimschlanch, der sich bald verzweigt. In meinen Kulturen trat die Keimung am zweiten Tage nach der Aussaat ein. Die schnell heranwachsenden und Terzweigungen bildenden Mycelien bestehen aus relativ kurzen etwas angeschwollenen Theilzellen und gehen schon am dritten Tage zu reichlicher Conidienbildung iiber. Zahlreiche Seitenzweige lanfen in eine ziemlich scharfe Spitze aus, und ans dieser Spitze sprosst eine Conidie von ovaler Form hervor, die ungefähr dieselbe Grösse wie die Ascospore erreicht (Fig. 38d). Tramm ist sie gebildet, so treibt die Fadenspitze eine zweite Conidie, welche die erste zur Seite drängt, oder abstösst. und so fort mit zahlreicher Wiederholung. Die conidienbildmng erfolgt gleicher Weise an untergetauchten und an Luftfäden. Im ersten Falle sieht man die abgestossenen Conidien neben der wieder austreibenden spitze in der Fliissigkeit liegen (Fig. 38d), im anderen Falle verkleben sie zu kugligen Köppfchen auf der Spitze des Trägers, wie es bei anderen Hypocreaceen so vielfach vorkommt (Fig. 38 e). Die Conidien keimen leicht wieder ans und erzengen nene conidienbildende Mycelien. Conidienträger derselben Art wurden auch auf der Oberfläche des jüngsten anfoefundenen noch weissen Fruchtkörpers nachgewiesen. Die älteren Mycelfäden in den Kulturen umhülleı sich il höchst charakteristischer Weise mit einer gelhröthlichen Gallerthiille (in der Figur 38d durch Schattirung angedeutet), welche aber niemals auf die Conidienträger übergreift. Diese 
Gallerthülle wird besonders deutlich bei Zusatz von etwas Kalilauge, wo sie um mehr als $1 / 2$ ihres Durchmessers aufschwillt.

Für die genaue Bestimmung der systematischen Stellung des Mycocitrus lassen sich sichere Anhaltspunkte vorläufig nicht gewinnen. Es ist anzunehmen, dass er von allen bekannten Gattungen der Hypocreopsis Karst. am nächsten steht. Doch ist iiber diese Gattung selbst noch zu wenig Genaues bekannt.

Jedenfalls erreichen in Mycocitrus die didymosporischen Hypocreaceen ihre nach den derzeitigen Kenntnissen lö̈chste und in der That erstaunlich mächtige Fruchtkörperausbildung. Angesichts der erheblichen Masse festen Fleisches, welche ein solcher Fruchtkörper von melı als 1/2 Pfund Frischgewicht erzeugt, und angesichts der Thatsache, dass seine Hyphen in das Substrat, den abgestorbenen Bambusstengel, gar nicht eindringen, drängt sich unwillkïrlich die Frage auf: woher bezieht der Pilz seine Baustoffe, woher die Energie, welche seine organische Masse schafft? Um einer Lösung dieser Frage vielleicht doch näher zu kommen, hatte ich, wie oben erwähnt, einen grösseren Fruchtkörper in Scheiben zerlegt und an der Luft, später auf dem Backofen getrocknet. Das so getrocknete Material hat mein Freund, Herr Professor Dr. Ramam, auf meine Bitte zu analysiren die Freundlichkeit gehabt, und er theilt über das Ergebniss seiner Untersuchung Folgendes mit:

..Die Aschenanalyse von Mycocitrus aurantium wurde unter Einhalten der sichersten Bestimmungsmethoden durchgeführt (Phosphorsäure mit Molybdänlösung; Alkalien durch Ausfällen mit Ammon, oxalsaurem und phosphorsaurem Ammon, essigsaurem Blei und Ammoncarbonat; Schwefelsäure in einer besonderen Menge der Substanz unter Zusatz von Natriumcarbonat und Teraschen über Spiritus).

Die trockenen Stücke des Pilzes enthalten (abzüglich $7,19 \%$ 
Feuchtigkeit) 4,88\% Reinasche; es ist dies ein für Pilze geringer Gehalt, da sich sonst durchschnittlich $8-10 \%$ vorfinden.

Ergebuisse:

$$
\begin{array}{cc}
\begin{array}{c}
\text { Zusammensetzung } \\
\text { der Reinasche }
\end{array} & \begin{array}{c}
\text { Thl. Trockensubstanz } \\
\text { enthalten }
\end{array}
\end{array}
$$

$\begin{array}{lrl}\text { Kali . . . . . . } & 76,50 \% & 3,745 \% \\ \text { Kalk . . . . . . } & 0,67 \% & 0,033 \% \\ \text { Magnesia . . . . . } & 2,13 \% & 0,103 \% \\ \text { Eisenoxyd . . . . } & 0,62 \% & 0,031 \% \\ \text { Phosphorsäure . . } & 8,15 \% & 0,398 \% \\ \text { Schwefelsäure . . } & 10,85 \% & 0,529 \% \\ \text { Kieselsäture . . . } & 1,07 \% & 0,053 \%\end{array}$

Mangan und Natrium waren nicht nachweisbar.

Die Analysen ergeben das normale Bild einer Pilzasche, welche sich durch hohen Gehalt an Kali, Phosphorsäure und Schwefelsäure von anderen Pflanzenaschen unterscheidet.

Wieviel Kieselsäure an dem Aufbau des Pilzkörpers thatsächlich theihnimmt, ist schwer zu beurtheilen, da der Methode der Bestimmung dieses Stoffes immier kleine Unsicherheiten anlaften. In der Rohasche fanden sich kleine Mengen anorganischer Beimischungen, die wahrscheinlich dem wachsenden Pilze als Staub zugefiihrt und in das Mycel eingeschlossen wurden; es ist daher immmerhin möglich, dass die Kieselsäure nicht der Pflanzenasche angehörte, sondern aus jenen Beimengungen stammt.

Geringer Gehalt an Kalk scheint den meisten Pilzen eigenthïmlich zn sein, ebenso dass die Menge der Magnesia die des Kalkes ïbersteigt.

Die aufgenommenen Mineralstoffe müssen dem Pilz von aussen zugefiilırt sein: als einzige Quelle kann nur Auslaugen absterbender Pflanzentheile in Betracht kommen. Die bisher rorliegenden Untersuchungen zeigen. dass tote Pflanzenteile, insbesondere die Blattorgane, grosse Mengen löslicher Mineralstofte algeben. Es 
lässt sich dies aus der Zusammensetzung der an manchen Bäumen längere 'Zeit verbleibenden abgestorbenen Blätter' schliessen und ist auch durch besondere Versuche erwiesen worden.*)

Uebereinstimmend hat sich ergeben, dass Kalium am stärksten ausgewaschen wird, daun folgen Schwefelsäure, Magnesia und Phosphorsäure, in relativ sehr kleiner Menge Kalk und Eisenoxyd (v. Schröder a. a. O. S. 97). Hiernach werden namentlich jene Stoffe leicht ausgezogen und mit dem abfliessenden Wasser weggefiihrt, welche in den Pilzaschen reichlich vorhanden sind. Es ist daher anzunehmen und mit den bisher bekannten 'Tluatsachen in Uebereinstimmung, dass die untersuchten Pilze ilıren Mineralstoffgehalt aus Wässern anfgenommen habell, deren Salzgelialt abgestorbenen Pflanzenstoffen entstammt."

Die vorstehende dankenswerthe Untersuchung macht zwar die Herkunft der in dem Pilze enthaltenen Mineralstoffe begreiflich; demnoch bleibt die Frage nach der nothwendigen organischen Nalıung eines so mächtigen Pilzkörpers ein ungelöstes Räthsel.

\section{a. 3. Phragmosporae Hypocreacearum.}

Die Gattung Calonectria de Not. ist die artenreichste Vertreterin der pluagmosporischen Hypocreaceen, derjenigen Formen also, welche durch längliche bis spindelförmige, quer in vier oder mehr Zellen getheilte sporen ausgezeichnet sind. Wine neue Art dieser Gattung: C. cimnabarina P. Hemn. wurde aus dem von mir gesammelten Material in der Hedwigia 1897 Seite 220 von Herru Hennings beschrieben. Wenig von den schon beschriebenen Arten abweichende andere Calonectriaarten fanden sich noch mehrach in dem durchforschten Gebiet; doch konnten sie zu genauer Untersnchung ans Zeitmangel nicht gelangen. Es lässt sich ein bemerkens-

*) v 0 u Schröder, Forstchemische und ptlanzenphysiolog. Untersuchungen. Dresden 1878. Kitman n, Zeitschr. f. Forst- und Jagdwesen 1888 S. 1. 
werther Parallelismus in der stromatischen Ausbildung der phragmosporischen und der diymosporischen Gattungen feststellen, ein Parallelismus, auf den Saccardo in seiner tabellarischen Zusammenstellung (Sylloge XIV S. 20-23) schon hingewiesen hat. Die Gattung Berkelella Sacc., welche nur mit einer Art aus Neucaledonien bekannt ist, bildet ein Seitenstück zu Hyponyces, die Gattung Stilbonectria zu Sphaerostilbe, während Calonectria selbst der Nectria entspricht. Unter dem Namen Broomella endlich sind Formen beschrieben, welche den Beginn einer höheren Ausbildung des Perithecien tragenden Stromas in derselben Weise zeigen, wie er bei den niederen Hypocreaformen vorkommt. Dass aber auch diese Formenreihe zu einer Fruchthörperbildung fortgeschritten ist, welche weit über das bisher bekannte Maass hinausgeht, und zu Mycocitrus sich in Parallele stellt, beweist die Auffindung des auf Taf. IX Fig. 4 in natïrlicher Grösse nach einer photographischen Aufnahme dargestellten Pilzes:

\section{Peloronectria rinosa nor. gen. et nor. spec.}

Nur dies eine Exemplar des auffälligen grossen Pilzes ist mir bei der dreijährigen Arbeit im Blumenaner Waldgebiete zu Gesicht gekommen. Es wurde ron Hellnut Brockes, einem Enkel Fritz Muillers, am 7. September 1892 auf einem abgestorbenen gespaltenen Bambusstengel unweit rom Orte im Walde gefunden. Es stellt, wie man sieht, eine unregelmässig geschwollene keulenartige Ḱnolle dar, die den tragenden Bambuszweig rollkommen umschliesst, und die Betrachtung mit der Lupe lässt erkennen, dass das ganze Gebilde ringsum mit Perithecien feinwarzig besetzt ist. Die Farbe im frischen Zustande war schmutzig fleckig, zwischen hellederbraun, r'ussbraun und braungelb (Saccardo 8, 32 und etwas 11). Die Perithecien erschienen etwas heller als der Untergr'und. Der Fruchtkörper hat ein zähes festes Fleisch von hellchokoladenbrauner Färbung; die je weiter nach innen zu, um so mehr verblasst. Wrunderbar ist num, dass dieser an sich so unscheinbar und unschön gefärbte Pilz dem Alkohol, in dem er 
alsbald aufbewahrt wurde, eine ganz prachtvolle leuchtkräftige weinrothe Farbe verleiht, die sich bis lente intensiv erhalten hat, und von der der Artname hergenommen ist. Das ganze knollige Stroma ist aufgebaut aus dümwandigen weitlumigen Hyphen ron 5-10 „ Durchmesser, die reich verzweigt, und überall dicht verwirlt sind, trotzdem aber im wesentlichen radiale Richtung elkennen lassen. Nirgends aber schliessen diese Hyphen. wie wir es bei Mycocitrus kennen lernten, gewebeartig lïckenlos zusammen, sonder'l es ergiebt hier jeder Schnitt ein mehr oder weniger deutliches Netzbild, in dem immer die einzelnen Fäden durch Zwischenräume getrennt erkembar bleiben. Nur nach dem Rande zu, erst ganz dicht unter demselben bildet sich ein Plectenchym, die Rinde des Stromas. Auf dieser erheben sich kuglige Warzen von der dunklen Farbe des Stromas, welche ganz aus isodiametrischen Zellen bestehen und den Eindruck von Perithecienanlagen machen. In Wirklichkeit werden sie nie zu Perithecien, sondern diese entwickeln sich erst auf ilnen, entweder einzelı oder zu zweien, in der Art, wie die Figur ('Taf. IV Fig. 54 a) es darstellt. Diese Bildung der kleinen Perithecien ron kugliger Gestalt auf einem äusserlich gleichgestalteten kugligen Fusse ist eine sehr eigenartige und fïr die neue Gattung charakteristische. Die reifen Perithecien messen löchstens ${ }^{1 / 4} \mathrm{~mm}$ im Durchmesser, und haben eine winzige, gar nicht hervorragende, mit der Lupe kaum erkemnbare Oeffnung. Die Länge der Schläuche beträgt etwa $60 \mu$ (Fig. 54b). Sie beherbergen je 8 Sporen, die im reifen Zustande gelbbräunlich gefärbt, länglich spindelförmig gestaltet und durch drei scheidewände in vier Theilzellen zerlegt sind. Thre Länge beträgt 16, die Breite $5 \mu$. Reife Sporen sind immer viertheilig, wie mit Sicherheit daraus hervorgeht, dass man, wemn man einen Objektträger im feuchten Raume unter den Fruchtkörper legt, nur solche Sporen und zwar in grossen Massen darauf entleert findet. In mreifen Perithecien sind die Sporen hyalin, und die Scheidewände manchmal noch nicht erkemnbar. Die reifen 
Perithecien sind etwas heller gefärbt, als die kugligen Träger, anf denen sie ruhen. Es gelang mir bei der Massenhaftigkeit der Sporenentleerung unschwer reine Aussaaten in Nährlösungen in grosser Zahl zu gewinnen. Bei der Keimung der Sporen schwellen die Theilzellen erheblich an (Fig. 5tc). Aus den geschwollenen Zellen treten sprossartig ähnlich geschwollene Keimschläıche aus, die dann schrittweise allmählich in gewöhnliche glatte Mycelfüden überführen, sich reich verzweigen und mir im Laufe weniger Tage Mycelien lieferten. die den ganzen Nährlösungstropfen durchwucherten und reichlich in Conidien fruktificirten. Fadenbrücken wurden trotz wiederholten Suchens bei dieser Form nie beobachtet. Beliebige Mycelenden spitzen sich zu und schnüren, auch in del Nährflüssigkeit, eine eiförmige Conidie ab (Fig. 5 4 f), die sofort abfällt, und nachträglich noch sich erheblich vergrössert, ehe sie wieder keimt. Dasselbe Fadenende lässt dann nach und nach zahlreiche Conidien hervorsprossen. Tiel seltener und spärlicher als au den untergetanchten, erfolgt die Conidienbildung an Luftfäden, wo dann anch wieder, wie in so vielen anderen Fällen, mehrere Conidien unregelmässig zu Köpfchen verklebt an der Spitze des 'Trägers eine Zeit lang festluaften. Die am T'age nach der Aussaat an den kleinen Mycelien noch spärliche Conidienbildung nimmt mit dem Heranwachsen der Kulturen immer mehr zu, und schliesslich wird der ganze Kulturtropfen. soweit die Mycelien Raum lassen, mit Conidien erfüllt. Sie schwanken in der Grösse sehr erheblich. weil sie nach dem Abfallen noch Wachsen; man findet solche ron 6-18 $\mu$ in del Länge wechselnd (Fig. 5 te). Nach kuzer Zeit theilen sie sich durch Qnerwände, die Theilzellen schwellen an, und die Keimung erfolgt ganz älnnlich wie die der Sporen, so dass in diesem Zustande eine gekeimte Conidie von einer gekeimten Spore kaum zu mterscheiden ist (rgl. Fig. j4 c und Fig. 5 4 d). Es kommt aber auch ror, dass zumächst aus den Conidien hefeartig neue Conidien sprossen (Fig. 5๋e). Wir haben hier einen der Uebergangsfälle vor uns, welche einen handgreif- 
lichen Beweis dafür liefern, dass die Hefesprossung nichts als eine besondere Art ron Conidiensprossung ist; in unserem Falle kommt sie nur in beschränkter Ansdehmung vor, bald überwiegt die Mycelkeimung. Icl erinnere hier an die Protobasidiomyceten, bei denen wir alle Abstufungen finden von dieser eben erwälnten Besonderheit bis zu dem Falle, wo die Hefen in kïnstlichen Kulturen jahrelang nichts als wieder Hefen erzengen, olne je auszukeimen. Die vollkommensten und lehrreichsten Beispiele in dieser Hinsicht liefern bekanntermaassen die Brandpilze.

Es könnte vielleiclıt ein Kritiker auf die Vermuthung kommen, die Peloronectria bestehe aus irgend einem rubekannten Stroma, ant dem eine Calonectria sich angesiedelt hatte. Diese Annalnme trifft nicht zu. Erstens ist das ganze grosse Stroma ringsum gleichmässig mit Perithecien besetzt, sodann lässt sich an dïnnen schnitten, deren ich zahlreiche aufbewahre, aufs klarste der umittelbare Cebergang der Stroma bildenden Fäden in das Plectenchym der Rinde und des Perithecienpolsters verfolgen. Den sichersten Beweis aber für die Einheitlichkeit des ganzen Gebildes liefert der Umstand, dass auch in den aus Sporen künstlich elzogenen Mycelien senr bald Farbstoffabsonderungen auftreten, welche die für die grossen Fruchtkörper so charakteristische weinrothe Farbe zeigen.

\section{a. 4. Dictyosporae Hypocreacearum.}

Auch unter den netzsporigen Hypocreaceen begegnen wir denselben oder älnnlichen Formtypen, wie in den vorhergehenden und in der folgenden Gruppe: die Gattung Pleonectria steht zu Nectria und Calonectria in ähnlichem Verhältniss, wie Negalonectria zu Sphaerostilbe und Stilbonectria. Unter meinen brasilischen Pilzen habe ich eine Megalonectria genauer untersucht welche als Megalonectria rerucosa nov. spec. bezeichnet werden mag.

Diese der M. pseudotrichia (Schwein.) Speg. nahestehende Art wurde auf trockenen Zweigen im Velhathal bei Blumenau im 
Juni 1892 gefunden. Die Perithecien von leuchtend rother Farbe brechen gr'uppenweise dicht zusammengedrängt aus der Rinde helvor, je für sich haben sie kaum 1/2 mm Durchmesser. Ihre Aussenwand ist warzig rauh, indem kleine Pyramiden melı oder weniger loser Zellen darauf sich erheben. Diese losen Zellen sind nach der Spitze der Pyramide zu etwas heller gefärbt. Die Perithecienmündung tritt kaum hervor. Die Schläuche sind ungefähr $70 \mu$ lang und achtsporig; die reifenden Sporen drängen sich im Schlauche und dehnen dessen Wand in unregelmässiger Weise aus. Die reifen Sporen (Fig. 55) sind 28-38 $\mu$ lang und 10-12 $\mu$ breit, und zerfallen durch Längs- und Querwände in zahlreiche Theilzellen. Schon die auf der Mindung der Perithecien anzutreffenden reifen freien Sporen zeigen die in der Figur dargestellte Aussprossung von kleinen länglich runden Sprossconidien. die abgefallen ihrerseits weiter sprossen. Diese Conidien haben etwa 3 "Durchmesser. Zwischen den Schläuchen bemerkt man zahlreiche Paraphysen; durch diese letzteren, dann durch die rauhe Oberfläche der Perithecien und die Hefesprossung ans den 'Theilzellen der reifen Sporen ist die Art gegen die iibrigen bisher bekannt gewordenen gut abgegrenzt. In der Mitte zwischen den dichtgedrängten Perithecien und mit ihnen aus dem gleichen flach polsterförmigen wenig entwickelten stroma entspringend, erheben sich die Conidienträger, welche wenig iiber $1 \mathrm{~mm}$ Länge erreichen. Es sind feine Stielchen, die unten dasselbe lenchtende Roth aufweisen wie die Perithecien, nach oben werden sie heller: an der Spitze, wo die Conidien abgeschniurt werden, sind sie weiss. Das ganze kaum verdickte Ende des Stielchens ist bedeckt mit conidienabschnürenden Sterigmen, zwischen denen sich zahlreiche steril endende Fäden über die Zone der Conilienbildung hinaus erheben (Fig 55). Es entsteht so am Fnde des Conidienträgers ein Haarbüschel. der eine grössere Anzahl von Conidien für längere Zeit auf der Spitze des Säulchens festzuhalten geeignet ist. Die conidien sind länglich eiförmig 5-6 " lang, 2-3 "“ breit, und man findet sie häufig mit Fäden aus- 
gekeimt schon auf der Spitze des Träger's. Hefesprossung ist an ihmen nicht bemerkt worden.

Die Gattung Megalonectria, durch ihre mauerförmig getheilten Sporen und ilre stilbumartigen Conidienträger charakterisirt, bietet auf den ersten Blick nahe Beziehungen durch das erste Merkmal zu Pleonectria, durch das zweite zu Sphaerostilbe und Stilbonectria. und es ist gewiss der Erwägung werth. welcher vou beiden Beziehungen man für die systematische Gruppirung der Gattungen höheren Trerth beilegen muss. Ich glaube, dass je zwischen Sphaerostilbe und Nectria, zwischen Stilbonectria und Calonectria, zwischen Megalonectria und Pleonectria die blutsverwandtschaftlichen Bande engere sind, als zwischen den drei Gattungen Sphaerostilbe, Stilbonectria und Megalonectria, dass also die älnnlichen stilbumartigen Conidienträger bei allen diesen drei Gattungen unabhängig ron einander entstanden sind. Die Schläuche und Sporen der Ascomyceten stellen einen Endpunkt del Entwickelung dar, iiber den hinaus in dieser Richtung eine Steigerung nicht eingetreten ist. Die einmal erreichte Form der Schläuche und Sporen wird mit seltener Ausuahme festgehalten, kein Merkmal ist so fest und untrïglich, so wenig Variationen unterworfen, wie das von den Schläuchen und Sporen hergenommene. Viel schwankender heute noch finden wir die Conidienbildung: Sie zeigt inmerhalb der Grenzen ein und derselben Art oftmals beträchtliche Formschwankungen, und umgekehrt finden wir älıliche oder fast gleiche Conidienbildungen bei offenbar weit von einander abstehenden Gruppen. Innerhalb einer durch Sporengleichheit geeinten Reihe kann die Art und Form der Conidienbildung und ganz gewiss auch die Formsteigerung zu Conidienfrïchten ein vortreffliches systematisches Hülfsmittel sein. So ist die Gattung Pyxidiophora unter den didymosporischen Hypocreaceen durch ihre Büchsenkonidien sicher gekennzeichnet. Ueber die didymosporischen Hypocreaceen hinaus aber reicht die Bedeutung dieser eigenartigen Büchsenconidien nicht, wir können sie 
nicht verwerthen, um etwa für Pyxidiophora eine nähere verwandtschaftliche Bezeichnung zu Patellea oder den Laboulbenien zn konstruiren, bei denen die gleiche eigenartige Conidienbildung anzutreffen ist. So dürfen wir in unserem Falle den ähnlichen Conidienfrïchten der drei Gattungen Sphaerostilbe, Stilbonectria und Megalonectria auch keinen systematischen Werth beilegen, der jene Trenumg der drei Gattungen iiberbrückt, welche durch ilıre verschiedene Sporenform angezeigt ist.

Dass eben so wenig wie die jeweilige Beschatfenheit der Conidienfruktifikation, die Stromanasbildung oder die Fruchtkörpergestalt ïber die durch charakteristische Schlanch- und Sporenform getrennten Reihen hinweg verwandtschaftliche Brïcken schlagen kamm, habe ich schon oben ansgetührt (Seite 74. 75). So habe ich in Mycocitrus eine Form rorgeführt, welche unter den Didymosporae zur Bildung eines knolligen mächtigen ringsum mit Perithecien besetzten Fruchtkörpers fortgeschritten ist, unter den Phragmosporae trifft das gleiche fiir Peloronectria zu. Das gleiche Gesetz der Fruchtkörperbildung hat für zwei verschiedene Reilıen gewaltet; aber die Aehnlichkeit der Fruchtkörper begrïndet keine nähere Terwandtschaft dieser Pilze. Es trifft sich nun in del' 'That wnuderbar'. dass anch für die dictyosporische Reihe der' Hypocreaceen kurz ror Abschluss diesel Arbeit noch eine analoge Pilzform durch Herrn Hennings aus Japan bekannt gemacht worden ist. Es ist dies die in Englers botanischen Tahnbïchlern Band 28 1900 Seite 274 beschriebene Shiraia bambusicola P. Henn. Sie bildet Knollen ron 2-3 cm Durchmesser, welche rings mit eingesenkten Perithecien besetzt sind, genan, wie diejenige des Mycocitrus. Aber ilne netzförmigen Sporen lassen sie als ein Glied, nach der stromatischen Ausbildung als das höchste bekannte (ilied einer parallelen Entwickelungsreihe erkennen. und rerweisen sie, wie Herr Hennings mit Recht hervorhebt, in die Verwandtschaft ron Mattirolia, einer Gattung, welche den Beginn höherer selbst- 
ständiger stromatischer Bildungen unter den dictyosporischen Hypocreaceen aufweist.

\section{a. 5. Scolecosporae Hypocreacearum.}

Eine ausserordentlich natiirliche Verwandtschaftsgruppe innerhalb der Hypocreaceen bilden die Formen mit fadenförmigen langen Ascussporen. In der That ist der iiberaus lange hyaline zarte Schlanch mit den Fadensporen ein gar nicht zu verkennendes Merkmal aller hierher gehörigen Formen. Der Schlauch weist fast ausnahmslos an der Spitze eine charakteristische hyaline Kappe auf, die von einem wie ein dunkler Faden erscheinenden Kanal durchzogen wird. Die langen Fadensporen zerfallen, soweit die Beobachtungen reichen, stets in 'Theilzellen, bisweilen erst bei der Keimung ausserhalb des Ascus, bisweilen schou im Schlauch, ja es können die 'Theilzellen schon im Schlauche die beginnende Keimung durch Anschwellung erkemmen lassen, sich auch im Schlauche schon von einander trennen. Diese Variationen kümen zur Tnterscheidung von Arten bisweilen mit Tortheil benutzt werden. Eine vergleichsweise hohe Entwickelung der Stromata oder Fruchtkörper ist fast allen Formen dieser Gruppe eigen. Frei und einzeln stehende Perithecien besitzt nur die von Fuckel aufgestellte Gattung Barya, die einzige, welche uns in dieser Gruppe den Typus von Nectria wiederholt. Auf die Herleitung der typischen feinen Fadensporen aus dickeren länglichen mehrzelligen Sporen, wie sie Calonectria besitzt, werden einige neuere Gattungen wie Ophionectria Sacc. und 'T'ubeufia Penz. et Sace. bei genauer' Untersuchung vielleicht ein Licht werfen. Torläufig bleibt die Zugehörigkeit der Letztgenannten zu unserer Gruppe zweifelhaft.

Die sicher hierher gehörigen ausserordentlich zahlreichen Pilze sind bisher unter zwölf verschiedenen Gattungsnamen beschrieben worden, nämlich; Oomyces Berk. et Br., Hypocrella Sacc., Mölleriella Bres., Echinodothis Atk., Dussiella Pat., Epichloë Fries, 
Dothichloë Atk., Balansia Speg., Claviceps Tul., Ustilaginoidea Bref., Torrubiella Boud., Cordyceps Fries.

Dass alle diese Formen unter einander nahe verwandt sind, kamn nicht bezweifelt werden, Saccardo ordnet sie in seinem Sporensystem unter dem Namen Scolecosporae zusammen. Atkinson findet für sie die noch viel besser passende gemeinsame Bezeichnnng „linosporous" Hypocreaceae. Es hat die Vermuthung alle Wahrscheinlichkeit für sich, dass dieser so eigenthümlich gestaltete, dabei so wenig variirende, all diesen zahllreichen Formen gemeinsame Ascus viel älter ist, als die sonstigen Eigenschaften, welche diese überans vielgestaltigen Pilze von einander mterscheiden. Ist dem aber so, damn gelören in diese Verwandtschaftsreihe noch zwei weitere Gattungen, die man nach Saccardos Vorgang unter die Dotlideaceen gestellt, also ziemlich weit von ihren nächsten Verwandten getrennt hat, nämlich Ophiodotis Sacc. und Myriogenospora Atk. Diese beiden, ausgeriistet mit den nämlichen charakteristischen Schlänchen, wie die genannten alle, sollen deslaalb nicht mit ilmen nächst verwandt sein, weil das angebliche Fehlen einer eigenen Peritlecienwandung sie in eine ganz andere Reihe der Pyrenomyceten, die der Dothideaceen rerweist. Abgesehen davon, dass ron einer sehr dentlich ausgebildeten bis zur fast fehlenden Perithecienwandung immerhalb der bekannten Formen alle Cebergänge sich finten, so kam ich gerade lier Saccardos eigenes Zengniss für die Richtigkeit meiner Anschaunng anrufen. In der Grevillea XT. 1882_83 nämlich sagt er bei der Vertheidigung seines Systems gegenuiber Cooke (S. 63): ..In ny opinion and in that of many other mycologists, the characteristics of the spores are more constant, than the others. This being admitted, I think that in any classification we ought to prefer, for the primary division, those characteristics which are the most constant, and in our case these are the spores." .Te meln ich geneigt bin, das Zutreffende dieses Satzes anzuerkemnen. unsomehr muss ich mich darüber wundern. dass ein so musicheres und schwankendes 
Merkmal, wie die Stärke der Perithecienwand, die Abtrennung der letztgenannten beiden Formen von ihren nächsten Verwandten hat bewirken können, mit denen sie durch das viel beständigere Merkmal der fadensporigen Schläuche so enge verbuuden sind. Wir laben es demnach mit 14 verwandten Gattungen der fadensporigen Hypocreaceen zu thun, an deren Aufstellung zehn verschiedene Autoren betleiligt sind.

Versucht man uun aber, wie ich es thum musste, nene Funde unter die bekannten eimzureihen, die Gattungscliaraktere gegen einander abzugrenzen, oder den Terwandtschaftsbeziehungen der 14 Gattungen naclizuspuiren, so stösst man auf unüberwindliche Schwierigkeiteu. Will man nicht jede neue Form zum Range einer eigenen Gattung erheben — und liermit ist für das Terständniss der ganzen Gruppe, und besonders für die Erleichterung der Arbeit kommender Forscher nichts erreicht - so bleibt nur übrig, die Gattungscharaktere der eimmal aufgestellten Gattungen besser und schärfer und nach möglichst einheitlichen Grundsätzen zu fassen, und gegen einander abzugrenzen. Dies will ich im Folgen den rersuchen, um die Mehrzahl der neuen ron mir beobachteten Formen den benannten Gattungen eimreilıen zu können, und nur zwei neue Gattungen muss ich hinzufïgen: Ifycomalus und Ascopolyportis.

Wir kömnen nicht erwarten. dass es gelingen werde, die pliylogenetischen Beziehungen aller unserer hierher gehörigen Pilze der 14 Gattungen im einzelnen anfzuklären, dies um so weniger, als die grosse Mrehrzahl sich parasitischer Lebensweise oder wenigstens einem ganz bestimmten Wohnort auf bestimmten anderen Pflanzen angepasst hat, ein Torgang, durch den die Erkenntniss der Terwandtschaftsbezielinngeu stets erschwert wird. Aber indem wir als Haupteintheilungsgrund die Höle der jeweils erreichten stromatischen also Fruchtkörperausbildung zu Grunde legen, so können wir in einzelnen Fällen die Gattungen in Reilıen ordnen. welche olme Zwang ein Fortschreiten in dieser 
Hinsicht erkennen lasseu, und unserem Bediirfniss der Uebersicht und des Verständnisses der Formgestaltungen in wïnschenswerther Weise entgegenkommen. Wo dies nicht möglich ist, muss der praktische Gesichtspunkt der Ordnung und Uebersichtliclıeit den Ausschlag geben.

Zunächst ist die grosse an Formen überreiclıe Gattung Cordyceps, von der ich zahlreiche nente Vertreter vorzufüluren liabe, fast allein dadurch sicher charakterisirt, dass sie anf Insekten oder unterirdischen Pilzen parasitirt. Boudier hat 1885 unter dem Namen Tortubiella solche Formen ron ilı abtremnen wollen, welche ausserhalb des befallenen Insekts keinen Stromakörper, sondern nur einen lockeren Hyphenfilz oder nur die Perithecien erzengen. Praktisch ist damit nichts Wesentliches erreicht, weil diese Formen wenig zahlreich sind gegenüber der Mehrzahl der anderen, und wissenschaftlich auch nichts. wie ich im einzelnen zeigen werde. Massee hat die auf Pilzen parasitirenden als eigene Gattung abzweigen wollen, was ebenfalls zwecklos ist; denn es sind nur zwei Formen, und diese sind entsprechenden Insektenbewohnern offenbar aufs allernächste remwandt. Man thut daher vorläufig an besten daran, alle auf Insekten, und die wenigen auf mnterirdischen Pilzen schmarotzenden Hypocreaceen nit fadensporigen Schläuchen in der Gattung Cordyceps zu vereinen. und diese Gattung aus weiter noch darzulegenden Gründen am Schlusse der ganzen Gruppe aufzuführen. Die allermeisten anderen hierher gehörigen Pilze nun parasitiren oder leben wenigstens auf Gräsern. nur verhältnissmässị wenige auf den Stengeln und Blättern anderer Pflanzen.

Ton allen den einfachsten Ban zeigt Oonyces. Die Gattung ist gut dadurch charakterisirt. dass sie stets nur wenige, soweit bekannt. bis sieben Perithecien anfweist, die von dem wenig ansgebildeten Stronta wie ron einem gemeinsanen Sack muschlossen sind. An Oomyces kann man zwanglos Hypocrella anschliessen. man braucht sich nur vorzustellen, dass das ursprünglich sehr einfache 
auf eine sackartige Umlü̈llung der Perithecien beschränkte Stroma stärker und mächtiger wird, so kommt man zn den flach scheibenförmigen, polsterförnigen, dann auch kugligen, knolligen oder lıöckerigen Bildungen der Hypocrellaarten. Mölleriella Bres. gehört zu Hypocrella und lat keinen selbstständigen Gattungswerth. Die Gattung Dussiella Pat. ist eius der glorreichsten Beispiele von solcher Gattungsmacherei, welche lediglich den Fortschritt der Wissenschaft hemmt, und jedem ernsthaften Arbeiter auf diesem Gebiete ımüitze lı̈̈chst zeitraubende Schwierigkeiten bereitet. Es bestand cine Hipocrea tuberiformis, von Berkeley und Ravenel in der Grevillea IV Seite 13 aufgestellt. Das war ein auf Arundinaria in Südcarolina aufgefundenes knolliges Stroma olne jede Fruktifikation. Wozu es überhaupt benannt wurde und mit welchem Rechte es damals Hipocrea benannt werden komnte, ist mnerfindlich. 1890 nun untersucht Patoullard eine im Berliner botanischen Musenm befindliche, auf einer Arundinaria in Caracas gesammelte Hipocreacee, mi erklärt sie schlankweg für den reifen Zustand jener Hipocrea tuberiformis, eine Behauptung; die natiiılich ganz willkürlich war, aber in ihrer Unrichtigkeit erst nachgewiesen werden komte, nachdem man die Fruktifikation jener Hipocrea tuberiformis aufgefunden hatte. Dies geschah durch Atkinson 1891 in der Botanical Gazette Seite 282. Ausserdem untersucht Patouillard ein von Duss in Martinique gesammeltes äusserlich ähnliches Stroma, welches im Lmmern Höhlungen besitzt. deren Wände mit Conidienlagem ausgekleiriet sind, und wiederum hehauptet er ohne jede Spur eines Beweises, dies sei der Conidienzustand desselben bis dahin Hipocrea tuberiformis genamnten Pilzes. Und seine ganz willkürliche \%usammenstellung dreier an ganz verschiedenen stellen in Nord- Mittel- und südamerika gesammelten Pilze krönt er damit, dass er für sie einen neuen Gattungsnamen: Dussiella schafft. Dussiella ist also eine lediglich in Patoullards Phantasie bestehende Gattung, die gänzlich zu streichen ist. Natürlich steht sie aber längst im Saccardo, 
und wer nicht die unendliche Mïhe und Zeit aufwenden kamn, um aus der Zusammenstellung der vielfachen in der Literatur verstreuten Mittheilungen sich endlich die Ueberzeugung vou der Nichtexistenz der Dussiella zu erwerben, steht einer räthsellıaften Form gegeniiber, die ihn lediglich an richtiger Beurtheilung der wirklich bekannten Dinge hindert. Es scheint, als lıätte Tulasne vorahnend die Dussiella im Auge gehabt, wenn er auf Seite 186 seiner Prolegomena zur Carpologie also warnt: "Neque enim nos fugit quanta prudentia et sagacitate uti debeant observatores quibus in eo cura sit utrum scientia studiis recentiorum parta aliquo modo mycologiae proficiat, an contra illi in detrimentum vertat. Quemadmodum varia ejusdem typi membra nunc ab invicem, praeter naturae leges, imprudenter direpta quotidie vidimus, sic etiam profecto erunt inter posteros nostros quibus typum e partibus undique quaesitis et sibi invicem alienis struere hybridumque seu heterogeneum et fictitinm suis in scriptis promere fungum incautis acciderit.

Ueber Hypocrella linaus in der Stromadifferenzirung gehen dann die beiden neuen Gattungen Ascopolyporus und Mycomalus (Taf. III Fig. 47, 50, 52, 53). Bei ersterer tritt die strenge Trennung der sterilen und fertilen stromaoberfläche auf, welche zu polyporusartigen dem tragenden Bambus seitlich angehefteten Fruchtkörpern führt, bei letzterer ist eine ebensolche Tremmung zu bemerken, doch bildet die fertile Fläche eine Ringzone $1 \mathrm{~m}$ den kugligen Fruchtkörper, welcher den tragenden Bambuszweig rings umschliesst. Von Oomyces und noch mehr von Hypocrella ist der Schritt zu Epichloë nicht weit. Diese Gattung ist vou Hypocrella eigentlich nur dadurch verschieden, dass ihr Stroma scheidenförmig die Grasstengel umschliesst, während Hypocrella selbststäudig geformte Stromata besitzt. In die nächste Nähe von Epichloë gehöreu nun auch Ophiodotis und Myriogenospora, nicht minder Dothichloë; auch giebt es von Epichloë nach Balansia höchst natürliche Uebergänge. 
Die Abgrenzung dieser Gattungen aber ist ganz unbestimmt, und es herrscht da eine grosse Verwirrung, wie man schon daraus entnehmen kann, dass z. B. ein und derselbe Pilz unter den Namen Epichloë Hypoxylon Pk., Hypocrella Hypoxylon Sacc., Ophiodotis vorax (Berk. et Curt.) Sacc. und Dothichloë Hypoxylon (Pk.) Atk. beschrieben worden ist. Auch hat Atkinson schom die hier bestehende Verwirrung gefühlt und in dem Bulletin Torrey Botan. Club Vol. XXI 1894 auf Seite 222 einen Aufsatz veröffentlicht: „Steps toward a Revision of the linosporous Species of North American graminicolous Hypocreaceae." Doch kann man nicht sagen. dass damit eine Verbesserung erreicht worden wäre. Zunächst gründet Atkinson in diesem Aufsatz die neue Gattung Echinodothis für die ron ihm selbst schon 1891 in der Botanical Gazette Seite 282 ausführlich beschriebene nnd abgebildete Hypocrella tuberiformis Berk. et Rav. Alle seine Nittheilungen bestätigen aber lediglich, dass man es mit einer typischen Hypocrella zu thun hat, die zur besonderen Gattung zu erheben nicht der leiseste Grund vorliegt. Diese ganz unnïtz und willkïrlich aufgestellte Gattung ist also zu streichen. Schon ihr Name musste als eine recht verfehlte Bildung bezeichnet werden. Offenbar war er nach dem Muster von Ophiodotis gebildet. Mit diesem Namen wollte Saccardo eine Dothideacee mit schlangenförmigen Sporen bezeichnen; denn der Hauptcharakter dieser neuen Gattung sollte darin liegen, dass sie ein dothideaceenartiges Stroma besass. In diesem Sinne war der Name Ophiodothis recht gut gewählt, der Pilz aber, den Atkinson Echinodothis nemen wollte, hat vollständige Hypocreaceenstruktur, so dass schon der Name an sich Verwirrung zu stiften geeignet schien. - Ophiodotis also soll ein dothideaceenartiges, d. h. aussen schwarzes Stroma bilden, in dem die Perithecien nicht durch scharf erkennbare eigene Wandung abgesetzt sind; ausserdem ist die Gattungsdiagnose möglichst kurz und unbestimmt: „Stroma breve vel late effusum. subplanum, granulosum, nigricans. Asci elongati. octospori; sporidia filiformia continua subinde pluri- 
guttulata, hyalina." Wir werden weiterhin sehen, dass die Gattung Ophiodotis nur bestehen bleiben kann, wenn für sie ein neuer Charakter bestimmt wird, der in höherer Stromadifferenzirung gegenïber Epichloë gegeben ist.

Dothichloë ist von Atkinson a. a. O. unbegründeterweise aufgestellt; denn seine Charakteristik dieser neuen Gattung passt ganz und gar für die schon früher bestehende Ophiodotis. Dothichloë ist in Folge dessen glïcklicherweise auch nicht als selbstständige Gattung in den XIV. Band der Sylloge aufgenommen. Sie ist zu streichen.

Myriogenospora ist 1894 von Atkinson gegründet, und generisch von Ophiodotis nur dadurch verschieden, dass der lange Schlauch von zahllosen Einzelsporen erfïllt ist, deren muthmaassliche Entstehung aus ursprünglich wohl acht fadenförmigen sporen. die sich im Schlanche theilen, nur vorläufig noch nicht nachgewiesen werden komnte.

Die vier Gattungen Epichloë, Opliodotis, Balansia und Claviceps, deren Grenzen bisher vollkommen unsicher und schwankend waren, bilden eine sehr bemerkenswerthe natïrlich zusammenlä̈ngende und dennoch für das praktische Bedürfniss leicht in ihre einzelnen Abschnitte zerlegbare Reihe. wenn wir sie folgendermassen charakterisiren. Alle haben ein Stroma, welches sich den Grasstengeln, Blättern oder Bliithentheilen scheidenartịg anlegt oder anch parasitirend in die Gräser eindringt: dies Stroma kann entweder gleichmässig fertil ausgebildet sein: Epichloë, oder aber es treten unregelmässig umgrenzt und rertheilt auf der sterilen Stromaoberfläche einzelne Partien besonders herror. und diese allein tragen Perithecien: Ophiodotis. Weiterhin rerden diese allein fertilen stromatheile in ilner For'm bestimmt und gleichmässig geformte, rielfach sogar gestielte Scheiben, Kuneln oder Köpfchen: Balansia. Endlich kann der sterile in oder an der Wrirtlispflanze ausgebildete Stromatheil ebenfalls eine bestimmte 
selbstständig geformte Gestalt annehmen, ein Sclerotium werden, welches bis zur Erzengung des fertilen Theiles einen Ruhezustand durchmacht, so haben wir die Gattung Claviceps.

Mit Clavicep's aufs nächste verwandt ist die anch in Blumenau vertretene, von Brefeld begründete Gattung Tstilaginoidea: durch den Besitz ihrer Chlamydosporen ist sie von Claviceps charakteristisch abgegrenzt. Brefelds Untersuchungen dieser löchst interessanten Gattung im XII. Bande seines Werkes Seite 194 und die ergänzende Untersuchung dazu im botanischen Centralblatt Band LXV legten den Charakter der Form nach allen Richtungen so klar, wie nu möglich. Es ist geradezu nubegreiflich, wie in dem XTY. Bande der Sylloge Saccardos. Wo selbst die schlechteste und die flüchtigste sogenannte Diagnose jedes beliebigen Autors Aufnahme findet, die Resultate einer Meisterarbeit des ersten lebenden Mykologen geradezu mit Nichtachtung oder sollen wir sagen mit dem vollständigsten Mangel an jeglichem morphologischen Verständniss behandelt werden. Man findet nämlich die Gattung Ustilaginoidea, deren Zugehörigkeit zu den Hypocreaceen sonnenklar lewiesen ist, unter den Ustilagineen aufgefiihrt, und als etymologische Erklärung des Namens die Worte: ..ab Ustilago. cui affinis." Wahrlich, wenn so verständnisslos verfahren wird, so wäre es besser, die Gattungen erschienen in der Sylloge dem Alphabet nach geordnet; dann wüsste man von vornherein, dass man es nur mit einem mechanisch zusammengestellten Register der neu beschriebenen Arten zu thum hat. - Die nun folgenden Einzeluntersuchungen werden die oben in kurzen Zügen gegebene Tebersiclit einer Gruppirung der Hypocreaceen näher begründen und die Berechtigung meiner Anschaumgen nachzuweisen versuchen.

Oomyces monocarpus nov. spec. wurde auf einer Bambuse gefunden, die rings auf den Höhen um Blumenau häufig bestandbildend auftritt. Sie heisst dort Taguara mansa und Herr Pro- 
fessor Schumann hatte die Freundlichkeit, sie mir als Microstachys speciosa Spr. zu bestimmen.

An den diunnen kaum bleistiftstarken Verzweigungen des lebenden Rohres stehen in dichten Trupps die länglichen, nach oben wenig verdümnten und mit stumpfer Kappe abgeschlossenen Stromata von etwa $1,5 \mathrm{~mm}$ Höhe, deren jedes nur ein einziges Perithecium beherbergt (Fig. 56 Taf. IV). Die Stromata sind von weichfleischiger Beschaffenheit und bald hellgelblicher; bald etwas mehr röthlicher Färbung. Sie stehen selten ganz einzeln, meist zn mehreren am Grunde büschelig verwachsen, wie die Figur zeigt; an anderen Stellen überziehen sie den ganzen Stengel wie ein Rasen. Ein Querschnitt (Fig. 56 b) zeigt. dass das Plectenchym des stromas dentlich von der sehr zarten Wand des ganz eingesenkten Peritheciums unterschieden ist.

Die gelegentliche Beobachtung einer anderen kleineren Oomycesform, von der nicht genügend Naterial gesammelt wurde, um eine genanere Beschreibung und Benennmng zu ermöglichen, zeigte mir, dass dort die ebenfalls einfruichtigen Stromata noch weiter, auf einen ganz zarten Ueberzug der Perithecienwand reducirt waren. so dass es keme Schwierigkeit bietet, sich die Entstehung dieses Hypocreaceenstromas derart vorzustellen, dass an ursprünglich freistehenden Perithecien von den Hyphen des sie erzeugenden Fadengeflechtes aus gleichsam eine Verstärkung der Perithecienwand angelegt wird, die allmählich bestimmtere Form und grössere Dicke annimmt. Wie dem auch sei, so ist der Oomyces monocarpus immerhin bemerkenswerth als diejenige Form der fadensporigen Hypocreaceen. welche von allen Bekannten das Stroma in der denkbar niedersten Form der Ausbildung uns zeigt.

Die Schläuche des Pilzes sind etwa $500 "$ lang. $7-8 \mu$ breit; ilıre blasen- oder knopfförmige hỵaline Kappe zeigt eine geringe mabelartige Vertiefnng an der Stelle, wo der fadendümne sie dnrchsetzende Kanal ausmindet. Ueberall wo mir die sichere Feststellung gelang, fand ich nur zwei oder vier spiralig um einander 


\section{$-151-$}

gedrehte Sporen (Fig. 56d), welche schon im Schlauche durch Querwände in etwa $9 \mu$ lange und $2 \mu$ breite Theilzellen zerlegt erscheinen. Ein Zerfall der' Sporen in ihre 'Theilzellen im Schlauche wurde nicht beobachtet.

Hypocrella ochracea Mass. ( $=$ Hyp. Edwalliana P. Henn. $=$ Mölleriella sulphurea Bres.). - Dieser Pilz wurde von mir im Jahre 1890 an Herrn Hennings geschickt, und von ihm dem Herrn Bresadola mitgetheilt, der ihn zum Vertreter einer freundlicherweise mir gewidmeten Gattung machte (Hedwigia 1896 S. 298). Die Diagnose der Gattmg lautete: „Stroma subcarnosum, verruciforme, parenchymati foliorum immatum; perithecia plus minusve immersa; asci polyspori; spoidia subfusoidea, continua hyalina." Die Gattung wurde darauf begründet, dass die Schläuche von Anfang an vielsporig seien. Als ich von dieser Benennung hörte, bedanerte ich sehr, dass mir eine Gattung gewidmet wäre, die, wie ich mich deutlich erimnerte, kein Recht zum Bestehen hatte; ich latte gesehen, dass die Sporen fadenförmig sind. und sehr früh im Schlauch in ihre Theilzellen zerfallen; in diesem Simne sprach ich mich gelegentlich gegen Herrn Dr. Lindau aus, der in Folge dessen bei seiner Bearbeitung der Hypocreaceen fiir Engler und Prantl die Mölleria Bres. als zwreifelhafte Gattung aufnahm. Als ich später Herrn Henning's einmal besuchte, zeigte er mir einen neuen Pilz, den er unter dem Namen Hypocrella Edwalliana in Hedwigia 1897 Seite 223 beschrieben hatte; ich erklärte sofort, dies sei derselbe, den Bresadola Mölleria sulphurea getauft hätte. Als ich mit den Herren Hennings und Lindau mich ïber diesen Pilz unterhielt, hatte ich mein Material und meine Aufzeichnungen nicht zur Hand, konnte sie auch, da ich anderweit sehr beschäftigt war, nicht so schnell herausfinden und urtheilte nur nach dem Gedächtniss. Erst später kam ich bei langsamem Fortschritt der Bearbeitung meiner brasilischen Untersuchungen und Sammlungen auch an diese Form, und überzeugte mich alsbald, dass ich mit beiden Behauptumgen, dass näm- 
lich der Pilz fadenförmige, früh zerfallende Sporen hat, und dass Mölleria sulphurea Bres. $=$ Hypocrella Edwalliana P. Henn. ist, vollständig Recht hatte. Inzwischen aber widmete Herr Bresadola dem unglücklichen Objekt eine besondere Mittheilung im Bulletino della Societí botanica italiana unter der Ueberschrift: „Genus Mölleria Bres. critice disquisitum". Hier wird der Name in Mölleriella umgewandelt, weil Mölleria bereits eine Algengattung heisst. Sodann wird Saccardo als Zeuge dafïr angeführt, dass die Sclıläuche wirklich von Anfang an vielsporig sind und anch dafiir, dass die Ascussporen, welche von den Herren Systematikern unbegreiflicherweise immer den Namen Sporidia erhalten, an den Enden stumpf und nicht spitz seien, wie Herr Hennings angegeben hatte. Und trotz der Autorität der Herren Bresadola und Saceardo hat der Pilz dennoch fadenförmige Sporen; seine Theilsporen sind allerdings an den Enden abgerundet stmmpf, aber seine mit jenen leicht zin verwechselnden Conidien sind an beiden Enden nadelspitzig. Ausserdem ist die Bemerkung: „parenchymati foliorum innatum." mindestens irrefülırend. denn die Stromata sitzen auf der Epidermis der befallenen Blätter, und die Fäden des Pilzes dringen in das Gewebe der Blätter nicht ein. Dass etwa verschiedenes Material den Grund der rerschiedenen Ansichten bilde, ist ausgeschlossen, denn ich habe das Material selbst gesammelt, und das von Herm Hemnings benutzte, von Edwall in Capivary gesammelte habe ich auch selbst untersucht. In der Hedwigia 1898 Seite (44) veröffentlichte alsdann Lindau einen weiteren Aufsatz über die Gattung Mölleria Bres., in dem er seine Untersuchungen des im Berliner Museum befindlichen Materiales der Hypocrella Edwalliana mitheilt, welche den Sachverhalt klarlegten, und die Zugehörigkeit der Mölleriella zu Hypocrella erwiesen. Nachträglich num finde ich im Journal of Botany 1896 eine Abhandlung von Massee: „New or critical fungi“" mit der durch Abbildung erlänterten Beschreibung einer in Brasilien von Glaziou gesammelten Hypocrella ochracea Mass., welche soweit die Beschreibung reicht 
ganz zweifellos mit der vielgeprüften Mölleriella gleichbedentend ist. Dieser Name wïrde also vor Hyp. Edwalliana P. Henn. den Vorrang haben. Der Vollständigkeit halber sei erwähnt, dass die Conidienform unseres Pilzes ebenfalls schon als selbstständige Gattung Aschersonia Mont. beschrieben worden ist.

Auf der Ober- und Unterseite sehr verschiedener und soweit meine Befunde reichen nur Dikotyledonenblätter findet man im Walde bei Blumenau sehr häufig kleine gelbrothe halbkuglige glatte Stromata, die am Rande von einem ganz flachen ringförmigen bis $1 \mathrm{~nm}$ breiten, der Epidermis der Blätter eng aufliegenden hellen Hypothallus umgeben sind. An Querschnitten sieht man, dass sie ans dicht verflochtenen Hyphen bestehen, die in der Mitte, der Ursprungsstelle, am dichtesten zusammenschliessen und daher dunkler erscheinen (Fig. 64a). Die jüngsten Zustände, welche man beobaclitet sind rein weiss, ältere zeigen gelbliche Farbe. Bei etwas vorgeschrittener Entwickelung bemerkt man am unteren Rande der Kugelkappe ringsum getrennt auftretende hellgelbrothe Flecke, zuerst gewöhnlich $6-8$ in unregelmässiger Anordnung. Dies sind die Conidienlager. Sie sind anfänglich flach, später bei weiterem Wachsthum des Stroma vertiefen sie sich und bilden unregelmässige (iruben mit mannigfachen Falten, die alle mit conidienabschnürenden Fäden dicht ausgekleidet sind (Fig. 64 c). Nanche nehmen eine Gestalt an, die an Perithecien erinnert. Die nun immer intensiver werdende zinnoberrothe Farbe rïhrt von den Conidien her, die in ungeheuren Mengen gebildet werden, und zu einer schleimigen Nasse vereint, bald die Grenzen der anfänglich gesonderten Conidienlager verwischen. Die Conidien sind spindelförmig, an beiden Enden scharf zugespitzt, 16-18 " lang, 2-3 $\mu$ breit. Aeltere Stromata zeigen eine rauhe, unregelmässige r'unzelige Oberfläche, erreichen bis $8 \mathrm{~mm}$ (in den beobachteten Fällen) Basisdurchmesser, und sind bisweilen von kurzen borstenartig auftretenden Hyphenbündeh zottig rauh auf der Oberfläche. In älteren Fruchtkörpern findet man die Perithecien. Sie stehen 
einzeln, zerstrent, tief eingesenkt, und ragen mur mit der Nündung wenig hervor (Fig. 64b). Sie enthalten die langen schmalen Schlänche, deren Länge schon Bresadola auf 250-300 $\mu$ bei 10 bis $16 \mu$ Breite feststellte.

Mustert man in sorgsamen Schnitten, nicht in zerdrückten Präparaten, zahlreiche Schläuche, so sieht man allerdings die meisten von unregelmässig wirr gelagerten unzählbaren Sporen erfiillt (Fig. 64e unten), man findet dann aber auch zahlreiche jüngere Schläuche, welche die fadenförmige Anlage voll acht Sporen erkennen lassen, und man findet auch solche, wie den in Fig. 64e abgebildeten, an dem man sieht, wie die fadenförmigen Sporen in eine grosse Anzahl von 'Theilzellen zerfallen. die alsdam anschwellen, und da der Platz im Schlauche nun nicht mehi ausreicht, sich gegenseitig driicken und rerschieben, so dass ihre Entstehungsart nicht mehr erkemnbar bleibt. Im oberen Theile der abgebildeten Schlauchhälfte ist die Anordnung der sporen in Fäden noch erhalten, im unteren Theile ist sie bereits zerstört. Die bei stärkerer Vergrösserung gezeichnete Fig. $6 \pm f$ zeigt endlich auch ein 'Theilstïck einer' fadenförmigen Spore, dessen Glieder noch zusammenhängen. Die reif'en 'Theilsporen $(6 \pm d)$ haben mit den Conidien (6tc) dadurch Aelmlichkeit. dass sie in der Mitte angeschwollen, nach den Enden verschmälert sind, sie unterscheiden sich von jenen dadurch, dass sie an den Enden nicht zugespitzt, sondern abgerundet stumpf sind: sie messen 11-14 $\mu$ in der Länge und $3 \mu$ in der Breite (in der Mitte).

Ich habe den fraglichen Pilz nicht kultivirt, und ich labe niemals Stromata gefunden. die gleichzeitig Conidien und Perithecien trugen, wohl aber Blätter, auf denen dicht neben einander die offenbar gleichartigen conidien- und die perithecientragenden Stromata rorkamen. Es blieb deshalb immerhin noch der Rest eines Zweifels an der Zusammengehörigkeit beider bestelıen. und dies habe ich s. \%. Herrn Dr. Lindau gegenüber betont, der in Folge dessen schrieb (Engler und Prantl s. 372), es sei nach 
meiner Angabe nicht sicher, ob die von Bresadola gefundenen Perithecien und Conidien zusammengehörten. Nachdem indessen Lindau bei seiner oben angefiihnten Untersuchnng des berliner Materiales die Conilienlager und die Perithecien an ein und demselben Stroma angetıoffen hat, zweifle ich an der Zusammengehörigkeit beider jetzt $\mathrm{um}$ so weniger, als ich dasselbe gemeinsame Vorkommen bei einer der vorigen ausserordentlich ähnlichen Нypocrella beobachtet habe, die im August 1892 auf Bambusblättern gefunden winde. Sie bildet sehr ähnliche grangelbliche Stromata von 3-5 mm Durchmesser. Die Fig. $64 \mathrm{~g}$ stellt einen Schnitt dar, an dem man die vereinzelt angelegten noch nicht sporenreifen Perithecien, und zugleich die in Bnchten und Falten des Stroma angelegten reichlich fruktifizirenden Conidienlager erkennen kann. Diese Hypocrella hat stumpfere Conidien, die für Hypocrella ochracea charakteristische Znspitzung fehlt hier. Die Schlänche sind noch nicht ganz reif. Doch ist mit Sicherheit schon zu sehen, dass sie Fadensporen enthalten, die sich im Schlanche in Theilzellen zergliedern. Ich unterlasse wegen der mangehnden Kemntniss der ganz reifen Sporen die Benemnung der Art, welche der vorigen jedenfalls ausserordentlich nahe steht, wollte sie aber nicht ganz mit Stillschweigen iibergehen, weil sie gerade in dem anfgefundenen Entwickelnngszustande eine willkommene Ergänzung and Erlänterung anch für die Entwickelungsgeschichte der Hypocrella ochracea bietet.

Vortrefflich ergänzend schliesst sich ferner hier die nene Hypocrella cavernosa nov. spec. an, die in Fig. 63 der Tafel IV abgebildet worden ist. Iclr fand sie im April 1893 auf den absterbenden Zweigen der oben erwähnten Microstachyys speciosa Spr. (S. 149,150), welche gerade seit 11 Jahren zum ersten Male wieder auf den Bergen um Blumenau gebliilt hatte. Sie bildet hier annähernd kuglige glatte Kinollen von hellbraunröthlicher Farbe (Saccardo Chromotaxia 18, hell), die in den beobachteten Stücken nur wenig ïber $1 \mathrm{~cm}$ Durchmesser besassen, und dem tragenden 
Bambusziveige in der Weise an- und aufgeheftet waren, wie das Querschnittsbild Fig. 63b es andeutet. Das Fleisch ist fest, weiss, marcipanartig; und wird gebildet von sehr dicht, liickenlos, fast gewebeartig verflochtenen dickwandigen Hyphen von 4-5 $\mu$ Durchmesser. Die Perithecien stehen sehr vereinzelt, vollkommen eingesenkt, verstreut iiber die Oberfläche, an der ihre Mündungen uur als winzige Pünktchen erscheinen. Sie sind lang flaschenförmig, ihre banchige Höhlung hat etwa 225 "Länge, 125 " Breite, der lualsartige Ausführungskanal ist $200 \mu$ lang. Auf dem Querschnitt der Fig. 63b ist nur em einziges Perithecium oben links durch den Schnitt getroffen. Die Schläuche messen $170 \mu$ in der Tänge, und ihre Fadensporen zerfallen, wie Fig. 63 d darstellt schon im Schlauche in Theilzellen von 10-12 « Länge, die an den Enden abgestutzt sind, in der Mitte bis zum Durchmesser von 4 " aufschwellen. Wird del Fruchthörper angefeuchtet. so treten an verschiedenen Stellen massenhafte Conidien in röthlich gefärbten wurmförmigen strängen ins Freie. Es finden sich nämlich in dem Fruchtkörper zahlreiche labyrinthartig verzweigte und mit einander in Verbindung stehende sackartige Höhlungen, deren Wände mit kurzen Sterigmen gleichmässig tapezirt sind. Auf diesen sterigmen werden die länglich spindelförmigen Conidien (Fig: 63c) in grossen Massen abgeschnürt. Sie sind im Mittel $20 \mu$ lang, 6 „ breit, nach den Enden verschmälert und zeigen in frischem Zustande mehrere grosse Oeltropfen, doch keine Scheidewände. In den Präparaten verschwinden die Oeltropfen. und es gewinnt den Anschein, als hätten die Conidien ein bis mehrere undentliche scheidewände, doch ist dies nur auf Teränderungen ihres protoplasmatischen Inhalts zurïckzufülıren. Wirkliche Wände sind nicht vorhanden. Einzeln ansgesäet erscheinen sie farblos, in grossen Massen zeigen sie die erwähnte röthliche Färbung. Ein Querschnitt, wie Fig. 63 b. erweckt den Anschein. als wiirden die Conidien in inneren vollständig abgeschlossenen Höhlıngen des Strona gebildet. In Wirklichkeit hat jede Höhlung Terbindung 
mit der Aussenseite. Fin ähnliches conidienführendes Stroma wie das unsere hat offenbar Patouillard vorgelegen, als er seine oben (S. 145) kritisirte unlaltbare Gattung Dussiella zusammensetzte. Der Tergleich unserer Hypocrella cavernosa mit den vorher besprochenen Formen deckt die nahe Verwandtschaft beider zweifellos auf.

Durch den Besitz sehr älmlicher, im Schlanche zerfallender Fadensporen ist nun auch die in Fig. 61 dargestellte Hypocrella rerruculosa nov. spec. ausgezeichnet. An den von mir aufgefundenen Exemplaren fehlten Conidienlager, die muthmaasslich an jüngeren Zuständen ebenfalls vorkonmen. Der Pilz bildet auf Stengeln von Bambus und einer Olyra kleine halbkugliche Polster von wenigen Millimeter Durclmesser, deren Oberfläche warzig körnelig erscheint (Fig. 61a). Das doppelt vergrösserte Querschnittbild eines solchen Polsterchens (Fig. 61 b) lässt erkennen, wie die warzig rauhe Oberfläche zu Stande gekommen ist, nämlich durch lokalisirtes Wachsthum des Stromas, welches von einem gewissen Zeitpunkt ab nicht melr gleichmässig auf der ganzen Fläche zuwächst, sondern nur auf rundlich umschriebenen Stellen, zwischen denen in Folge dessen ein netzförmiges System von Rimnen sich ausbildet. Bei dieser Form sitzen die Perithecien sehr zerstreut vollkommen eingesenkt, sie sind langflaschenförmig mit langem Halse. messen vom Grunde bis zur Mündung $600 \mu$. Die Schläuche sind 270-300 "lang, die fadenförmigen sporen werden zu je vier in einem Schlauch (Fig. $61 \mathrm{c}$ ) angelegt. Thre zahlreichen Theilzellen verdicken sich aber genan wie bei Hyp. cavernosa noch im schlauche und nehmen ovale Gestalt an. wie die Fig. 61d zeigt; sie bleiben in diesem Zustande lange in Kietten zusammen, zerfallen endlich aber noch im Schlanche, den sie dann in unregelmässiger Lager'ung füllen. Sie haben 12-15 $\mu$ Länge und 3--5 $\mu$ Breite. Ich hätte der Hypocr. verruculosa vielleicht gar nicht Erwähnung gethan. wemn nicht das bei ihr nur erst in den Anfängen ausge- 
bildete lokalisirte Flächenwachsthum ein besseres Verständniss ermöglichte für die wunderbare Hypocrella Gürtneriana nov. spec., welche auf Taf. III Fig. 51 durch Herrn Volk meisterhaft dargestellt ist. Ich erhielt den Pilz erst nach meiner Rückkehr aus Brasilien durch meinen getreuen Gehülfen bei der Arbeit, Herrn Erich Gärtner nachgesandt, der iln im März 1894 am Cederfluss, einem oberen Nebenfluss des Itajahý auf einer Bambuse (Cará genannt) fand. Die Perithecien sitzen in nicht eben grosser Zahl einzehn, halb bis ganz eingesenkt, nur auf den einzehnen Vorragungen des Stromas, wie man an dem farbigen Bilde Taf. III Fig. 51 und auch auf dem kleineren Querschnittbilde Fig. 62 Taf. IV erkennen kann. Sie heben sich durch dunklere Fürbung von dem blassgelblichen Stroma sehr deutlich ab. Sie sind rundlich, kurzhalsig und messen rom Grunde bis zur Mündung $350 \mu$. Die Schlänche mit der charakteristischen hyalinen Kappe am Ende sind $190 \mu$ lang und enthalten, soweit ich zählen komnte, vier Fadensporen, die schon im Schlauche dentlich in stäbchenförmige Theilzellen ron $4-6 \mu$ Länge und 1,5 $\mu$ Breite zerlegt erscheinen. Jedoch tritt hier im Schlanche selbst keine Anschwellung oder Trennung und in Folge dessen auch keine Terschiebung der Lagerung ein.

Ueberblicken wir die besprochenen Arten ron Hypocrella im Verein mit den älteren schon beschriebenen derselben Gattung, so finden wir, dass Hypocrella durch die bei Engler und Prantl Seite 366 ron Lindau zusammengefasste Charakteristik gnt getroffen ist. Es heisst dort: „Stroma scheiben- oder polsterförmig, flach, nicht scheidenförmig, lebhaft gefärbt oder dunkel. Fruchtkörper mehr oder weniger tief eingesenkt. Schläuche cylindrisch, achtsporig. Sporen fädig, von Schlanchlänge, meist in einzelne Glieder zerfallend. Ton Epichloë nur durch das nicht scheidenförmig die Pflanzentheile umschliessende, sondern flach in einer Ebene ausgedehnte Stroma verschieden." Immerhin sind dieser Diagnose einige Ergänzungen nud Abänderungen nothwendig. 
Zunächst muss man das Stroma nicht nur polsterförmig, sondern auch kuglig knollenförmig nemnen. Die Achtsporigkeit der Schläuche darf nicht als Gattungscharakter aufgeführt werden, weil auch viersporige Schlänche vorkommen. Die Anzahl der feinen Fadensporen genau zu bestimmen ist meist ausserordentlich mühsam, und ich bin überzeugt, dass oftmals „asci octospori“ geschrieben worden ist, ohne dass eine genane Prüfung der Zahl stattgefunden hat. Das häufige Vorkommen von Conidienlagern auf dem gleichzeitig oder später Perithecien führenden Stroma dürfte hingegen der Gattungsdiagnose zugefügt werden. Wir sehen, dass in dem vorliegenden Formenkreise die Stromabildung höhere Differenzirung erreicht, als nach den bisher bekannt gewordenen Funden anzunehmen war. Es giebt aber auch über die num dargelegte Stromabildung hinaus noch eine Steigerung, welche wir bei den nun im Anschluss an Hypocrella zu besprechenden Gattungen Mycomalus und Ascopolyporus antreffen. Hier ist eine Scheidung. der Stromaoberfläche in sterile und fertile Partien eingetreten. welche bei den niederen Formen noch nicht vorkommt. Nur Hypocrella Gärtneriana zeigt einen Anlauf in der nenen Richtung, insofern hier die Perithecien auf die warzigen Vorragungen des Stroma beschränkt sind. Die von Hennings in der Hedwigia 1897 Seite 222 aus meiner Sammlung beschriebene auf Taf. III Fig. 48 11. 49 dieses Heftes abgebildete Hypocrella Mölleriana hingegen zeigt die Tremung einer sterilen Ober- und fertilen Unterseite des Stroma so deutlich, dass ich sie zu der neuen Gattung Ascopolyporus ziehen muss.

Die Eigenthïmlichkeit, dass manche Hypocrellen ihre Fadensporen im Schlanche schon nicht nur durch Querwände gliedern. sondern dass sogar die Theilzellen im Schlauche für sich wachsen, und sich von einander trennen, so dass der reife Schlauch vielsporig erscheint, bildet ein Merkmal der betreffenden Arten. welches nach den bisherigen Beobachtungen durchaus konstant ist; er unterscheidet diese Arten charakteristisch von jenen anderen, 
deren Sporen als lange Fäden den Schlauch verlassen. Es wïrde nicht ohne Berechtigung sein, wenn man die Formen mit in reifem Zustande wirklich vielsporigen Schläuchen als eine Untergattung von Hypocrella ausschiede; und diese Erwägung findet eine besondere Bestätigung dadurch, dass von den beiden nun zu beschreibenden Gattungen. Nycomalus und Ascopolyporus, welche beide von hypocrellaartigen Almen zweifellos abstammen, die erstere den vielsporigen Typus fortsetzt, während die andere ihre Sporen als Färlen entlässt, die sich erst bei der Keimung in Theilzellen gliedern.

Mycomalus bambusinus nov. gen. et nov. spec. Der wunderbare Pilz ist auf Traf. III Fig. 47 und 50 von Hel'rn Tolk nach Alkoholmaterial mit Zugrundelegung meiner an den frischen Fruchtkörpern gemachten Messungen und Farbebestimmungen höchst naturgetreu abgebildet. $\mathrm{Fr}$ ist bei Blumenan nicht eben häufig. Ein laalbes Dutzend Fruchtkïrper rerschiedener Grösse, doch stets von ziemlich gleicher Gestaltung wurden im Oktober 1891 und 1892 gesammelt. Sie kamen alle nur auf đer mächtigsten der Blumenauer Bambusen, Guadua 'Taguara Kth. vor. Ein abgestorbenes dümmes \%weiglein von nur 2 mm Durchmesser trägt den apfelfürmigen Pil\%, der es rings umschliesst, und wird durch die Last abwärts gezogen. Der grösste Fruclitkörper (den die Fig. 47 u. 50 rorstellen) hatte $6 \mathrm{~cm}$ IJurchnesser und ein Gewicht von $65 \mathrm{~g}$. Oben rings um den tragenden Bambusstengel zeigt der Pilz eine etwas vertiefte. liastanienbraune. unregelmässig kreisruntle, sterile Fläche, eine ebensolche findet sich unten rings um den dort austretenden Bambusstiel. In breitem Giurtel zieht sich rings um die Kugel die polsterförmig erhobene heller und dunkler lonigfarbene fertile Zone. Wo die Lichteinwirkung am stärksten, ist wie beim Apfel die Farbe an dunkelsten. Die Perithecienmindungen erscheinen als dunkle Pïnktchen, wie Nadelstiche auf dem helleren Glunde. Sie sind ziemlich reitläufig reltheilt, nur etwa 9 im Durchschnitt auf dem Quadratcentimeter. 
und hie und da sieltt man die Sporenmasse in Gestalt eines weissen T'röpfchens auf ilırer Spitze. In feuchter Kammer auf untergelegten Objektträgern wurden die Sporen in Massen aufgefangeu. Man findet, dass sie länglich spindelförmig sind. von 30-50 Länge, und unmittelbar nach ihrem Anstritt aus dem Perithecium werden in ilmen drei, zunächst sehr dünne feine Querwände siclıtbar, die vordem, so lange sie im Schlauche sich befanden, nicht erkennbar waren. Die Keimung erfolgt schon 24 Stunden nach der Aussaat in Nährlösung. Bevor wir aber auf diese eingehen, und auf die höchst eigenthümliche von allen bisher bekannten abweichende Conidienfruktifikation dieses Pilzes, soll uns ein Schnitt über den Bau der Perithecien und Schläuche unterrichten.

Die Perithecien sind ausserordentlich gross, von der Mündungsspitze bis zum Grunde bisweilen über $2 \mathrm{~mm}$ lang, flaschenförmig und völlig in dem Stroma versenkt. Dieses besteht aus einem sehr dichten lückenlosen Geflecht ziemlich starkwandiger Fäden von 4-6 $\mu$ Durchmesser. Ja auf dümnen Schnitten erhält man meist das Bild eines an Sklerotien erinnernden Gewebes. Makroskopisch ist das Fleisch dieses Pilzapfels weiss. Der grossen Länge der Perithecien entspricht die bis zu $1 \mathrm{~mm}$ ansteigende Länge der Schlïuche. Nimmt man, was in diesem Falle sehr leicht ist, den ganzen Ascusapparat aus dem seitlich angeschnittenen Perithecium heraus und betrachtet nun die in Wasser liegenden schläuche. so sieht man, dass ein jeder von einer hyalinen dicken Hülle 1mkleidet wird, welche oben an der Spitze bis auf die innere Schlauchwand eingedriickt ist (Fig. 60 a).

Betrachtet man möglichıst junge schlänche. so sieht man die Sporen darin in Gestalt langer ununterbrochener Fïden (Fig. 60a), ans deren Theilung offenbar die oben beschriebenen reifen Theilsporen hervorgehen, und soweit die äusserst mülıseligen zahlreichen Untersuchungen, die ich zu verschiedenen Malen vorgenommen habe, einen Schluss gestatten. glaube ich, dass mrsprünglich acht lange fadenförmige Sporen im Schlauche vorhanden sind. Ein Schimpex's Mittheilungen, Heft 9. 
klein wenig später, wenn nämlich die Spindelform der einzelneı Theilsporen erkennbar ist, findet man den Schlauch gleichsam vollgepfropft mit Sporen, und an Stellen, wo er zerbrach oder abriss (Fig. 60 b), kann man sich leicht überzeugen, dass jetzt jedenfalls viel mehr als acht Sporen auf dem Querschnitt vorhanden sind. Unzweifelhaft wachsen die einzelnen von einander getrennten Theilsporen schon im Schlanche nach Länge und Dicke, und füllen auf diese Weise den Schlauch schliesslich zum Platzen. Zur Keimung schwellen die Theilzellen der ausgeworfenen Theilsporen wenig an und es tritt zunächst aus den Endzellen an ihren Spitzen, dann aus den mittleren Zellen je ein winzig dünner Faden, der alsbald zum Träger einer kugelrunden Conidie wird (Fig. 60c. f. g). Unter dieser bildet der dünne Stiel alsbald einen seitwärts winklig abstehenden, eben so dünnen kurzen Seitenzweig (Fig. $60 \mathrm{f}$ ). und auch dieser erzengt eine Conidie. Wiederum vom letztgebildeten Stiel zweigt ein nener ab und so weiter, wie die Figuren es darstellen. Ilie Conidien fallen meist nicht leicht ab, die erstgebildeten sind die grössten, nach den Enden dieser sympodialen Conidientraube zu werden sie kleiner. Nun kommt es häufig vor, dass eine noch ansitzende Conidie mit einem feinen Stiel auskeimt (Fig. $60 \mathrm{~h}$ ), und in gleicher Art wie beschrieben, eine sekundäre Traube bildet. Dies kann sich mehrfach wiederholen, und so wird schliesslich die Keimspore mit dichten Conidienhaufen bedeckt: doch nie sah ich an ihr einen eigentlichen mycelialen Keimschlanch austreten. Ein solcher wird nur von den einzelnen schliesslich doch abgefallenen Conidien gebildet, und giebt einem kleinen ver"aweigten Mycel den Ursprung (Fig. 60 d). Sehr bald jedoch, und ehe das Mycel noch erhebliche Dimensionen erreicht, werden wieder alle seine Endigungen zu Conidienträgern der bezeichneten Art. Endlich im Verlanf von etwa 14 Tagen hatten sich doch Mycelflückchen gebildet, die für das blosse Auge eben siclıtbar waren. Sie kommen so zu Stande, dass immer hinter den conidientragenden Fadenenden seitliche Terzweigungen anftreten, die 
nach kurzem Wachsthum mit Conidienbildung enden. Auch an den glössten Mycelien, die ich in Kultur erzog, waren stets sämmtliche äussere Fadenenden zu Conidienträgern geworden.

Die besondere Art der Conidienerzeugung, wie wir sie bei Mycomalus beobachten, steht vollkommen einzig da. Sie zeigt entschiedene Aehnlichkeit mit der für Tstilaginoidea von Brefeld Band XII Taf. XII Fig. 22-26 abgebildeten und auch mit der für Pilacre bekannten. Doch wächst bei jenen der Conidienträger nach Abschnürung der ersten Conidie an der Spitze weiter und drïckt jene Conidie zur Seite, während er hier bei Mycomalus einen Seitenzweig erzeugt.

\section{Ascopolyporus nor. geell.}

Die neue Gattung Ascopolyporus ist unter allen bekannten Hypocreaceen am weitesten zu einer bestimmten Formausbildung ilıres kräftig entwickelten Stromas vorgeschritten. Sie bildet Fruchtkörper, welche eine deutliche 'T'rennung' in eine sterile obere und eine fertile untere Hälfte der Oberfläclıe erkennen lassen, und in einem ihrer Vertreter bis zu täuschender Aelnllichkeit mit der Basidiomycetengattung Polyporus gelangt sind. Ton den vier Arten dieser Gattung, welche ich auffand, ist Ascopolyporus polychrous nov. spec., die bei Blumenau nach meinen Beobachtungen häufigste. Die Bilder Taf. III Fig. 41, 42, 44 stellen den Pilz in natürlicher Grösse und Farbe dar. Er lebt, wie seine nächstrerwandten und einige andere noch zu besprechende neue Hypocreaceen auf den Stengeln verschiedener Bambusarten, vorzugsweise aber auf derjenigen, welche man bei Blumenau Taguara assí d. h. grosse Taguara nennt (Guadna Taguara Kth.). Sie hat die stärksten Stämme aller dort vorkommenden Bambusen, die unter Umständen Schenkeldicke erreichen, sehr rauhe Blattscheiden, und spitze Dornen; ihr Inmeres ist hohl. Schenck erwähnt sie Seite 85 Bd. 4 dieser Mittheilungen. An den jüngeren 'T'rieben und an Seitenzweigen dieses Bambus bietet unser Pilz einen sehr auffallenden und eigenthümlichen Anblick. In ganz verschiedener 
Höhe über dem Erdboden und wie es scheint regellos in Bezug auf die Himmelsrichtung sitzen seine bisweilen hellrosa, dann wieder ganz weissen, hellgelblichen oder rostrothen knolligen Fruclitkörper dem Stengel an, oft am Grunde umgeben von einem strahlig ausgebreiteten dünnen kreisrunden Mycelgeflecht (vergl. Fig. 42 Taf. III), das ich - nur um eine kurze Bezeichnung dafür zu haben - einfach den Hypothallus nennen will. Mit seiner Bildung beginnt die Ansiedelung des Pilzes auf dem Bambusstengel. Er schmiegt sich der Unterlage auf das engste lückenlos an und bildet auf diese Art für den später entstehenden schwereren Fruchtkörper ein Art Haftscheibe. Niemals aber dringt der Pilz mit seinen Hyphen in den Bambusstengel ein; wenigstens haben mich sehr zahlreich ausgefülırte Untersuchungen ausuahmslos in dieser Ansicht bestärlit. Damit stelıt im Einklang, dass die von dem Pilze bewohnten Bambusstengel in keiner Weise in ilırer Gesundheit und Lebensfähigkeit beeinträchtigt werden, und die weitere Thatsache, dass der Pilz zwar meist an den lebenden, oftmals aber auch in eben so guter Entwickelung an absterbenden z. B. abgeknickten Bambusstengeln angetroften wird. Der Hypothallus besteht ans sehr dümnen, kamm 1 " starken, dicht verfilzten, im Wesentlichen radial ausstrahlenden Hyphen und er bedeckt sich oftmals, aber niclit immer mit einem Rasen feiner sehr kleiner ('onidienträger (Fig. $57 \mathrm{f}$ Taf. IV), die an ihrer Spitze winzige weisse (onidien in grosser Zahl bilden. Ilıre Zugehörigkeit zu dem Ascopolyporus wird durch die Kultur erwiesen. Der winzige Conidienträger ist nichts als ein aufrechtstehender Mycelfaden, der an seiner spitze nach einander mehrere rundlich ovale 7-12 $\mu$ lange und $4-6$ !" breite Conidien abschnïrt. welche in der bekamnten Art häufig zu Käpfchen rerkleben. Anch können die Conidien ron zwei oder drei benachbarten Trägern zu einem winzigen T'röptchen zusammenfliessen. Welches dann auf zwei oder drei Füssen steht.

Die Conidie theilt sich unmittelbar. nachdem sie gebildet ist. 
oft noch während sie dem Träger anhaftet, durch eine Scheidewand (Fig. $57 \mathrm{~g}$ ), ja sie kann sogar die Anfänge der Keimung in dieser Stellung zeigen. Ueber ihr Verhalten in künstlicher Kultur wird weiter unten berichtet. Aus der Mitte des Hypothallus erhebt sich der knollige Fruchtkörper in Gestalt einer zunächst weissen weichen gallertig durchschimmernden Warze. Diese vergrössert sich sehr schnell in Laufe weniger Tage bis zu etwa $1 \mathrm{~cm}$ Durchmesser und zeigt in diesem. Jugendzustande eine mehr oder weniger helle rosaröthlich durchscheinende Färbung (Fig. 42 Taf. III). Bei weiterem Wachsthum geht diese Färbung zu Gunsten eines matten Weiss verloren. Die jungen Fruchtkörper sind oftmals, jedoch nicht immer: dicht bedeckt ron einem Lager derselben Conidien, die vordem auf dem Hypothallus beobachtet wurden. Bei gutem d. h. feuchtem Wetter und zur warmen Talı'szeit wachsen die Fruchtkörper sehr schnell (vergl. die weiterhin mitgetheilten genaueren Angaben) zu ihrer endgïltigen Grösse heran, die nach meinen Beobachtungen höchstenfalls $4 \mathrm{~cm}$ im Durchmesser beträgt. Sie sind prall bei nassem Wetter. an trockenen Tagen manchmal etwas runzelig eingefallen. Junge neu entstandene Fruchtkörper sind wohl immer von dem Hypothallus umgeben; dieser verschwindet während der Ausbildung des Fruchtkörpers d. h. er wird für das blosse Auge fast unsichtbar. Wem ein Fruchtkörper abfällt, was sehr leicht geschieht, da die runde Anheftungsstelle nur klein ist, so erscheint an derselben Stelle auf dem alten Hypothallus ein neuer Fruchtkörper, der dann aussieht, als habe er gar keinen Hypothallus, zumal, wenn er so gross wird, dass er den ursprünglichen Hypothallus gänzlich überdeckt.

schneiden wir einen Fruchtköryer längs durch. so sehen wir im Inneren von der Anheftungsstelle ausstrahlend einen dunkel gefärbten Centralstrang, der sich nach aussen verbreitert und büschelartig ausstrahlt, ohne irgend wo bis zum Umkreise zu reichen (Taf. IV Fig. 57 c). Er besteht aus denselben sehr feinen, eng 
verfilzten Mycelfäden, wie der Hypothallıs. Die Hauptmasse des Fruchtkörpers nimmt eine wässerig durchscheinende Gallerte ein, welche unter den Mikroskop keinerlei Struktur zeigt, aber durchweg von einem sehr losen Geflecht feiner kaum $1 \mu$ starker Hyphen durchzogen ist. Nach aussen gehen diese Fäden ïber in eine Rindenzone, die aus sehr abweichenden Elementen zusammengesetzt ist, nämlich aus etwa $5 \mu$ starken, sehr dickwandigen und ausserordentliclı stark lichtbrechenden, ganz enge, wirr und unregelmässig verflochtenen Hyphen. In ihrer Gesammtheit sieht diese Rindenzone auf dem - Schnitte milchglasartig oder opalisirend aus.

Kurz bevor der Fruchtkörper seine endgültige Grösse erreicht hat, oder auch erst nachdem dies geschehen, beginnt die Anlage der Perithecien. Diese ist in den meisten Fällen auf die Unterseite des Fruchtkörpers beschränkt, jedoch finden sich zahlreiche Ausnahmen von dieser Regel. Ich labe Fruchtkörper gefunden, die fast ringsum in ununterbrochener Schicht von Perithecien bekleidet waren, andere, bei denen die Perithecien auf einen kleinen kreisförmigen Fleck auf der Unterseite beschränkt waren; oft bedecken sie die untere Hälfte des Fruchtkörpers, jedoch ohne dass eine regelmässige Begrenzungslinie den fertilen von dem sterilen 'Theile schiede und nur unter giünstigen Terhältnissen erreicht der Pilz seine typische Ausbildung mit scharf begrenztem Hymenium, wie es z. B. auf' 'Taf. III Fig. 44 deutlich zu sehen ist. Die Perithecien bilden sich in der alleräussersten Schichte des Fruchtkölpers und zwar mehr auf als in ihr. Diese alleräusserste Schicht liegt der vorher beschriebenen Rindenzone unmittelbar auf und besteht aus wieder radial und riemlich parallel geoudneten, weniger als die nnteren vergallerteten Hyphen. Ueberall nun wo Perithecien nicht angelegt werden, bilden diese Hyphen, oftmals bïschelig zusammengeordnet, eine Art Haarbekleidung des Fruchtkörpers, die aber für das blosse Aıge nur durch mattrauhe Oberflächenbeschaffenheit kenntlich wird. Wo hiugegen die Frïchte entstehen, bilden sich eng verfilzte Faden- 
knäuel in der durch die Fig. 57 a dargestellten Wreise, welche schnell zu den lang flaschenförmigen Perithecien heranreifen. Die Anlagen stehen so dicht bei einander, dass schon die reifenden Perithecien sich gegenseitig dicht berühren und zusammenpressen. Auf dem Querschnitt (Schä]schnitt) erscheint daher ein Maschennetz von 5-6 eckigen Maschen, den Querschnitten der einzelnen Perithecien.

Während der Reifung nimmt der Fruchtkörper auf der perithecientragenden Lnterseite eine mehr oder weniger deutliche gelbliche Färbung, auf der sterilen Oberseite eine ebenso mehr oder weniger bräunliche Färbung an; bisweilen bleibt auch das Weiss ziemlich rein erhalten. Eine grosse Anzahl von Fruchtkörpern aber findet sich, die sofort durch inre rostrothe leuchtende Farbe ron allen anderen sich unterscheiden und zunächst den Eindruck machen, als gehörten sie einer ganz anderen Art an. Dies ist aber nicht der Fall. Sie kommen überall untermischt mit den weissen vor, ilıre Sporen, ilne Conidien, iln Hypothallus, alles ist unverändert dasselbe, ja ich habe sogar beobachtet, dass aus einem anfänglich weissen später ein solcher rother Fruchtkörper wurde. Diese rothen Fruchtkörper sind von den weissen dadurch unterschieden, dass sie von zahlreichen, meist sternförmig verlaufenden Madengängen im Tnnern durchsetzt sind. Unter dem Einflusse irgend eines Insekts, welches seine Eier jedenfalls in den noch sehr jugendlichen Fruchtkörper ablegt, kommt in dessen Tnnern die sonst stets vorhandene wasserhelle Gallerte gar nicht zur Ausbildung, vielmehr erzengt ein solcher Fruchtkörper durchweg ein festeres, undurchsichtig weisses Fleisch, das aus jenen dickwandigen Hyphen allein besteht, die bei den nicht befallenen normalen Pilzen nur in der Rindenzone in stärkerer oder geringerer Mächtigkeit angetroffen werden. Unter demselben Einflusse nimmt der Pilz die rostrothe Farbe an, sein Wachsthum, die Bildung der Perithecien und Sporen leidet aber hierunter nicht im Geringsten. Hunderte von Beobachtungen brachten mich zur Auf- 
klärung dieser sehr merkwürdigen Erscheinung. Da ich das betreffende Insekt selbst nicht genauer beobachtet habe, so ist wohl zu erwarten, dass meine Angabe wird bezweifelt werden. Ich stelle deshalb die meines Erachtens zwingenden Gründe für dieselbe zusammen. Ich habe Hunderte von Fruchtkörpern des Pilzes beobachtet und durchgeschnitten, ich fand stets die rothen untermischt mit den weissen vorkommend, die wasserhelle Gallerte fehlte den ersteren stets, den letzteren niemals, ich beobachtete einmal, dass ein ursprïnglich weisser Fruchtkörper allmählich roth wurde, ich fand eimmal eine innige Verwachsung zweier Fruchtkörper, von deneu der eine weiss, der andere rostroth war. ich fand olme jede Ausnahme in jedem rothen Fruclitkörper dieselben Frassgänge, welche in den weissen nie rorkamen. und stellte fest, dass im Uebrigen zwischen den beiden Formen auch in der Sporenkeimung und Conidienerzengung nicht der leiseste Unterschied sich findet.

Freilich werden auch die weissen Fruchtkörper ron verschiedenen 'T'hieren begehrt, und finden sich oft angefressen und ansgehöhlt, aber die Beschädigungen sind stets anderer Art, als die ganz charakteristischen Frassgänge in dem festen Fleische der rothen Fruchtkörper. Einen kleinen Käfer fand ich besonders oft in den weissen, und seine aushöhlende Thätigkeit bringt manchen Fruchtkörper zı verfü̈htem Abfallen.

Der reife Fruchtkürper entleert seine Sporen in geradezu erstaunlichen Massen. Bringt man ihn zur Beobachtung im oberen Theile eines hohen Cylinderglases an. so kann man den Fall der Sporen in grauen Wolken deutlich sehen. Auf dem Boden des Gefässes sammeln sich die Sporen zu einer graugelblichen Haut. und diese ist bei der Länge der nun verfilzten Sporen so zusammenhängend, dass man Fetzen von einem Quadratcentimeter Grösse mit der Nadel aufheben kann. Liegt der Fruchtkörper ruhig, mit der Perithecienseite nach oben im feuchten Raume, so 
bedeckt er sich selbst mit einem solchen festrerwebten Filze der ausgestossenen Sporen.

Einen Fruchtkörper liess ich im feuchten Raume über acht 'Tage lang' liegen. Der untergelegte Objektträger bedeckte sich mit einer über $1 / 2 \mathrm{~mm}$ dicken gelblichen schicht der Sporen. Diese Schicht erschien unter der Lupe ron regelmässig angeordneten punktförmigen Erhebungen gekörnelt. .Jeder dieser erhabenen Punkte entsprach offenbar einer Perithecienmiindung: Auf einem anderen Objektträger hatte die feuchte Luft der Kammer genügt, um ein reiches Conidienlager anf den abgefallenen Sporen entstehen zu lassen.

Nach der Sporenentleerung wird der Fruchtkörper gewöhnlich runzlig faltig und sinkt merklich zusammen.

Die Perithecien erreichen 750 „ Länge, die Schläuche über 500 " bei nur 4 " Dicke; sie tragen die typische hyaline Kapye und enthalten 8 Sporell, welche etwa $300 \mu$ lang, kaum 1 " dick und wasserhell sind. Untersucht man frisches Material, so erscheinen die Sporen ungetheilt, und nur bei Anwendung starker Vergrösserung gelingt es festzustellen, dass eine grosse Anzahl von sehr feinen Querwänden die Spore in melı als 50 'Theilzellen von je etwa 6 " Länge zerlegt. Fängt man aber die Sporen in Nährlösungen einzeln auf, so sind schon nach 48 Stunden die Theilwände sehr deutlich geworden (Fig. 57 e). Es schwillt nämlich jede Theilzelle für sich auf etwa $4 \mu$ Stärke an. während an den Scheidewänden der Durchmesser nicht wächst. so dass die nun im Beginn der Keimung befindliche Spore einer Schnur von länglichen Perlen gleicht. Später treten noch neue Querwände hinzu. Selır leicht bricht bei dieser Anschwellung der einzelnen Glieder die Spore in ungleich lange Stïcke aus einander. Auf trockenen Glasplatten aufgefangen erscheinen die Sporen wellig oder korkzieherartig hin und her gebogen (cf. Fig. 57 d). Fast gleichzeitig mit der Anschwellung beginnt auch die Keimung, und zwar treten die ersten Keimschläuche stets an den Enden der 
Theilzellen dicht neben der Scheidewand aus (Fig. 57 h). Hierdurch entsteht ein Druck auf die Wand, in Folge dessen die Spore nun noch häufiger in Stücke zerbrochen wird. Zu einem Theile treten die Keimschlänche unmittelbar aufwärts strebend in die Lufft und werden zu Conidienträgern (Fig. 57 h) von der früher schon beschriebenen Art. Zum anderen Theile verbreiten sie sich in der Flüssigkeit, verzweigen sich, bilden Fadenbrücken nnd erzengen im Lanfe weniger Tage ein dichtes diimnes Mycelgeflecht durch den ganzen Kulturtropfen, welches dem Hypothallus auf den Bambusstengeln vollkommen entspricht und mit ihm auch darin übereinstimmt, dass es sich alsbald mit dem dichten Rasen der zarten ('onidienträger bedeckt. der im Sommer nach 2, im Winter nach 3 Tagen entwickelt war. Natürlich wurden zahlreiche Kúulturen mit den Conidien angestellt, welche ebenso wie die von Conidien des natiirlichen Standortes stammenden dieselben Iycelgeflechte und Conidienrasen auf dem Objektträger wieder erzeugten. wie sie von Sporenaussaaten hergeleitet wurden.

Der Ascopolyporus polychrous ist in den Wäldern bei Blmmenan eine häıfige Erscheinung. Die reichlichsten Funde machte ich in den Nonaten Norember bis Janıar 189091. doch kommt der Pilz auch in den kalten Monaten. ja zu allen Zeiten des Jahres vor. Dahingegen war in den einzelnen Jahren wohl ein Unterschied in der Hänfigkeit zu rerzeichnen. An denselben Standorten. wo ich ihn 189091 in Massen sammelte, konnte ich 189192 nur wenige Pilze sammehn mnd im nächsten .Tahre war er beinahe noch seltener anzutreffen.

Um die Daner nnd die Art der Entwickelnng zu studiren, machte ich zu rerschiedenen Malen genane Anfzeichnnngen über einzelne bestimmt bezeiclnete und leicht wiederzufindende Fruchtkörper und beobachtete diese in regelmässigen Zwischenrämmen. Hierbei stellte sich heraus, dass nur wenige Stücke ihren Lebenslauf ungestört vollenden und zur grösstmöglichen Ausbildmng und Reife gelangen, Sehr leicht fallen die Knollen bei Erschüttermng 
der 'Träger ab. Insekten aller Art befressen sie und höhlen sie aus. wie oben schon angegeben ist, und es scheint mir nicht unwahrscheinlich, dass anch höhere Thiere, vielleicht Vögel, gelegentlich diese Pilzspeise nicht verschmähen. Wenigstens ist das plötzliche, oftmals bemerkte völlige T'erschwinden ausgebildeter Fruchtkörper nicht wohl anders zı erkläıen. Der Pilz hat einen schwach süsslichen Geschmack.

Ton den zahlreichen Aufzeichnungen über die Wachsthumsdaner will ich nur einige anführen:

Fruchthörper $\quad$ 10. Nov. $\quad$ 14. Nov. $\quad$ 21. Nor. $\quad$ 27. Nov. $\quad$ 3. Dezbr.

Durchmesser Durchmesser Durchmesser Durchmesser Durchmesser

\begin{tabular}{|c|c|c|c|c|c|}
\hline Nr. 1 & $13 \mathrm{~mm}$ & $15 \mathrm{~mm}$ & $\begin{array}{l}\text { verschwun- } \\
\text { den }\end{array}$ & - & - \\
\hline Nr. 2 & $12 \mathrm{~mm}$ & $15 \mathrm{~mm}$ & $18 \mathrm{~mm}$ & $18 \mathrm{~mm}$ & $\begin{array}{l}\text { verschwum- } \\
\quad \text { den }\end{array}$ \\
\hline Nr. 3 & $18 \mathrm{~mm}$ & $22 \mathrm{~mm}$ & $25 \mathrm{~mm}$ & $\begin{array}{l}\text { verschwm- } \\
\quad \text { den }\end{array}$ & - \\
\hline Nr. 4 & f; $\mathrm{mm}$ & $9 \mathrm{~mm}$ & $\begin{array}{l}\text { rerschwim- } \\
\text { den }\end{array}$ & - & - \\
\hline Nr. $\delta$ & $\begin{array}{l}\text { war an diesem } \\
\text { Tage sicher } \\
\text { noch nicht } \\
\text { vorhanden. }\end{array}$ & $10 \mathrm{~mm}$ & $15 \mathrm{~mm}$ & $\begin{array}{l}\text { verschwum- } \\
\text { den }\end{array}$ & - \\
\hline Nr. 6 & desgl. & $4.5 \mathrm{~mm}$ & $6 \mathrm{~mm}$ & $6 \mathrm{~mm}$ & $\begin{array}{l}\text { verschwun- } \\
\quad \text { den }\end{array}$ \\
\hline Nr. 7 & $15 \mathrm{~mm}$ & $18 \mathrm{~mm}$ & $19 \mathrm{~mm}$ & $\begin{array}{l}\text { war ange- } \\
\text { fressen }\end{array}$ & $\begin{array}{l}30 \mathrm{~mm} \\
\text { aber ausge- } \\
\text { höhlt nnd } \\
\text { abgefallen. }\end{array}$ \\
\hline
\end{tabular}

Die Entwickelungs- und höchste Lebensdauter wird daher wohl selten ïber einen Monat betragen. Bei sehr trockener Witterung tritt Stillstand des Wachsthums ein. Die Ansiedelung: und erste Entwickelung geht bei günstigem TVetter jedenfalls selır schnell vor sich. Dem ich fand einmal fast ausgereifte frische Fluchtkörper an jungen Bambustrieben, die noch kaum einen Monat alt sein konnten.

Als ich im November 1891 von Blumenau aus eine Reise nach dem Hochlande des Staates Sa. Catharina unternahm, führte mich der Weg allmählich aufwärts bis zur Ersteigung der dort soge- 
namnten "Serra", des parallel mit der Küste sich hinziehenden Gebirgszuges. Schon von der Subida an, bei einer Meereshöhe von ungefähr $400 \mathrm{~m}$, fiel mir recht häufig ein Ascopolyporus anf, der von dem vorher beschriebenen für den Anblick mit dem blossen Auge sich recht dentlich unterscheidet. Die fast stets deutlich begrenzte sterile Oberseite dieser Form, die ich Ascopolyporus villosus nov. spec. (Taf. III Fig. 46) nenıen will, ist nämlich mit einem dichten, oftmals mehrere Millimeter starken wolligen Haarfilze bekleidet, der vorzüglich geeignet ist, Wasser zu speichern und zu halten. Dieselben haarig abstehenden Hyphenbündel, welche bei der rorigen Form die sterile Oberseite als ein feiner für das blosse Auge kaum kenntlicher Flaum ïberziehen, erheben sich hier büschelweise zu beträchtlicher Höhe, die Büschel erweitern sich nach oben, fliessen zusammen und bilden eine locker gewebte Hüllschicht über der eigentlichen Oberfläche. Von dieser ersten Hüllschicht streben in noch loserem Verbande neue Hỵphenbündel nach aussen, die in einigem Abstand wiederum mit einander verschmelzen. und so fort in mehrmaliger Wiederholung, wie die Figur $58 \mathrm{~b}$ Taf. IV in 50 facher Vergrösser'ung es darstellt. Während bei der Küstenform die Perithecienschicht. wie wir gesehen haben, sich über die glatte sterile schicht erhebt, ist es hier ungekehrt, die Haarzotten stehen viel weiter vor, als die Perithecien. Die Farbe dieses Pilzes ist bestimmter. die harige Oberseite zeigt ein deutliches Hellisabellbraun, das bei älteren Exemplaren oft in Kastanienbraun (Saccardo 8-10) übergeht. Die Perithecienschicht ist lehmgelb oder honigfarben (Saccardo 30). Wenn ferner bei Ascopolyporus polychrous im allgemeinen die Fruchtkörpergestalt kugelig ist, und die Perithecien auf einem grösseren oder kleineren unteren Theile der Kugelfläche auftreten, so finden sich hier vielfach schon hufförmige Bildungen (Fig. 58a), bei denen das Hymenium eine ziemlich ebene horizontale untere Fläche bekleidet. Hierdurch kommt die charakteristische Polyporusform in die Erscheinung, welche für den demnächst zu besprechenden Ascop. 
polyporoides so sehr charakteristisch ist. Das abgebildete Stiick ('Taf. III Fig. 46) ist das grösste am 5. November 1891 am Pombasflusse gesammelte, welches durch die Verwachsung dreier benachbarter Pilze zu Stande gekommen ist. Es ist in seiner eigenartigen Form nicht gerade typisch zu nennen. Eine ungelieure Mannigfaltigkeit beherrscht die Form dieser Pilze, die durch Zeichnung zum Ausdruck zu bringen nicht möglich ist. Ton den vielen in Alkohol bewahrten Fruchtkörper'n meiner Sammlnng gleicht keiner genau dem anderen. Finem mittleren Typus würde vielleicht der Querschnitt ('Taf. IV Fig. 58 a) entsprechen.

Ich fand diese zottige Form auf der ganzen Reise bis zur Stadt Lages (etwa $1000 \mathrm{~m}$ ïber dem Meer) recht häufig und zwar immer an demselben unten bei Blumenau nicht oder jedenfalls nur selten vorkommenden Bambusiohr. Welches auf der Serra iiberall häufig und jedem Reisenden wohl bekannt ist. Die Seitenzweige dieses Rohres, mit langen schmalen Blättern, stehen nänlich dicht büschelweise an den Knoten und lassen sich mit einem Griffe anf eimmal leicht abreissen. An jedem Lagerplatze werden sie eingesammelt und dienen zur bequemeren Herrichtung des Nachtlagers. Dies Rohr ist hohl, schlank und seine stämme werden im allgemeinen nicht ïber 4 cm stark.

Ob nun dieser Ascopolyporus villosus im Gegensatze zu der erst beschriebenen Form „polychrous" eine sogenannte gute Art darstellt, ist mir manchmal zweifelhaft erschienen, trotzdem bei typischer Ausbildung jedes Find die beiden unterscheiden kann. Zunächst ist aber zu betonen. dass er in der ersten Anlage, in dem Hypothallus und dem Bau der jungen, ebenfalls weissen Fruchtkörper dem vorigen so völlig gleich ist, dass in diesem Zustande einen Tnterschied zu machen durchaus ummöglich ist. Die Fig. 43 auf Taf. III stammt ron A. villosus, kann aber ebenso gut den Asc. polychrous darstellen. Erst wem der Fruchthürper seine endgïltige Grösse ziemlich erreicht hat, beginnt die Haarbildung und damit der Unterschied. Dieser für das blosse Ange 
so sehr charakteristische Haarfilz ist aber auch nichts weiter, als eine ïppigere Entwickelung des Oberhautfilzes, der an Asc. polychrous beobachtet wurde. Und hierzu kommt, dass er nicht immer gleichmässig stark entwickelt ist. Auch habe ich später einmal unweit Blumenau in Velhathal einen vereinzelten Fruchtkörper von Ascopolyporus auf der grossen Taguara gefunden, der durch einen mässigen Haarfilz durchaus an die Hochlandsform erinnerte. Der imnere Ban des Fruchtkörpers und die Perithecienschicht endlich ergeben nicht den allergeringsten Unterschied der beiden fraglichen Arten. Derselbe büschelig verzweigte Centralstrang, dieselbe wässerige Gallerte von wenigen dümnen Hyphen durchzogen, und in der Rindenzone die milchige Gallerte aus dicken stark lichtbrechenden Fäden, begegnen uns hier wie früher. Kulturen konnte ich leider nicht anstellen, da ich den Pilz nur auf der Reise sammelte.

Wie dem nun sei, und die Frage ist ja sehr mwesentlich, ob wir in dem Asc. villosus nur eine Standortsform oder eine selbstständige Art sehen, in jedem Falle ist er ms ron grossem Werthe, denn er bildet ein verbindendes Glied zwischen dem Ascopolyporus polychrous und der nun zu besprechenden merkwürdigsten Art der nenen Gattung.

Wir haben gesehen, dass bei den Hypocrellaarten die Perithecien verstreut in unregelmässiger Anordnung an den verschiedensten Stellen der Stromaberfläche rorkommen, beim Ascopolyporus polychrous dagegen tritt zum ersten Nale eine schärfere, jedoch noch nicht überall gleichmässig bestimmt auftretende Differenzirung der Oberfläche auf; diese wird damn noch dentlicher bei Asc. villosus, indem durch starke Haarbildumg die sterile Oberseite schon für das blosse Ange sich dentlich abhebt, während der scharf abgegrenzte nach unten gerichtete fertile 'Theil eine mehr oder weniger ebene, Fläche bildet, und der ganze Fruchtkörper eine Hufform aufweist, wie in Fig. 58 a Taf. IT. Noch viel bestimmter 
in der eigenartigen Fruchtkörperform ist aber Ascopolyporus polyporoides nov. spec.

Jeder Mykolog, der unbefangen die Bilder (Taf. III Fig. 52 u. 53) betrachtet, wird sicher glauben Polyporeenfruchtkörper vor sich zu haben. Die huftörmige Gestalt des massigen fleischig. gallertigen Fruchtkörpers, welche bei Asc. villosus nur in einzelnen Fällen annähernd erreicht wird, ist hier zur Regel geworden. Die gewölbte Oberseite ist in reifem Zustande schön kastanienbraun gefärbt, unregelmässig runzlig, nach dem Rande zu tönt sich die Farbe etwas heller ab. Der Rand ist ein wenig vorgewölbt und etwas faltig, rings um die scharf abgegrenzte gelbliche, nach unten annähernd horizontal ausgebreitete hymeniale Scheibe zusammengezogen. Wennschon auch hier die individuellen Terschiedenheiten der Fruchtkörper beträchtich sind, wie auch aus den abgebildeten Stücken herrorgeht. so ist doch der beschriebene Formtypus stets deutlich erkennbar. Dabei erreiclit dieser Pilz eine Grösse, wie sie bei den rorigen niemals beobachtet wurde. Das grösste gefundene Stück hatte nicht weniger als $7 \mathrm{~cm}$ grössten Durchmesser bei $4 \mathrm{~cm}$ Dicke und ein Gewicht ron $120 \mathrm{~g}$. Mit sehr wenigen Ausnahmen kam dieser Pilz, der zwar erheblich seltener als der Asc. polychrous zu sein scheint, immerhin in mehr als 20 Stücken gesammelt und in noch mehr Fällen beobachtet wurde, auf einer Guaduaart vor, die man als Taguari oder kleine Taguare in Blumenau bezeichnet. Es ist ein rankendes nicht hohles Rohr mit sehr langen Trieben, die selten mehr als $2 \mathrm{~cm}$, gewöhnlich nicht über $1-1^{1} / 2 \mathrm{~cm}$ Dicke erreichen. Jener grösste Fruchtkörper von $120 \mathrm{~g}$ Gewicht sass einem Rohrstengel ron nur $7 \mathrm{~mm}$ Dicke an, und seine Anheftungsstelle war nicht grösser als ein Fünfpfennigstück. In das Gewebe des Rohres dringen die Hyphen, soweit meine Beobachtungen reichen, niemals ein, und es ist hiernach wicht zu verwundern, dass diese grossen Fruchtkörper schon bei geringen Erschütterungen ron dem glatten Rohrstengel sehr leicht abbrechen, ja dass es besonderer Torsicht 
bedarf, um das tragende Rohr mit dem ansitzenden Fruchtkörper abzuschneiden, ohme dass letzterer abfällt.

Lebhafter aber als bei den früheren kleineren Formen drängt sich hier diesem wunderbaren Gebilde gegenüber die räthselhafte Frage auf: woher nimmt dieser 120 g schwere Fruchtkörper, der melnere Meter iiber dem Erdboden an einem bleistiftstarken Rohrstengel sich gebildet hat, diesen nur als Anhalt benutzte, ohne in ihn einzudringen, ohne von ihm etwas zu nehmen, woher nimmt er die Baustoffe, welche seinen Körper zusammensetzen, woher die Energie, diese Masse organischer Substanzen zu erzeugen? Ich sehe vorläufig keine Möglichkeit der Antwort auf diese schon oben bei Mycocitrus angeregte Frage.

Der Fruchtkörper fühlt sich weich knorpelig gallertig an, und ein Querschnitt belehrt uns, dass seine ganze immere Masse zusammengesetzt ist aus genan den gleichen Elementen, die wir bei den relwandten Formen schon kennen lernten und in genau gleicher Anordnung. Der Centralstrang ist der erheblicheren Grösse entsprechend reicher rerzweigt. Die glasige nnd die milchige Gallerte ist reicher entwickelt, aber unter dem Mikroskop zeigt sich kein Lnterschied in der Beschaffenheit dieser Elemente ron den frïher geschilderten. Auch die Anlage der Perithecien geschieht in gleicher Treise, ihr Ban und ihre schläuche und Sporen sind genau dieselben, nur ist die Iänge der Perithecien dem grösseren Fruchtköruer entsprechend auch etwas gesteigert. Die reife Perithecienschicht kann eine Dicke von $1^{1}$ a $\mathrm{mm}$ erreichen. Die mikroskopische Untersuchung beweist zweifellos. dass wir es mit einer den rorigen aufs engste rerwandten Form zu thun lıaben. ja man kömnte hiernach wohl auf den Gedanken kommen, dass del Asc polyporoides nur als eine besonders entwickelte Form des Asc. polychrous aufzufassen sei. Dagegen spricht, dass er fast stets auf' einer anderen 'T'ragpflanze vorkommt - nur einmal wurde er (Taf. III Fig. 53) anf der Tagnara mansa (Microstarhys sjeciosa spr.) und nur eimmal auf Taguara assí (Gua- 
dua Taguara Kth.) gefunden, auf welch letzterer der Asc. polyclirous fast ausschliesslicl rorkam - ror allem aber beweist die Conidienfruktifikation unzweifelhaft seine selbstständige ,eigenartige": Stellung.

Die Perithecien können einschliesshich des Halses, wie erwähnt, iiber $1 \mathrm{~mm}$ Länge erreichen. Die Schläuche sind im Durchschnitt wohl 500-600 $\mu$ lang bei $4 \mu$ Breite, die Sporen nahezu $500^{\star} \mu$ bei kaum 1 " Dicke. Sie werden als Fäden in geradezu fabelhaften Massen entleert und es gilt für sie alles oben beim Asc. polychrous Mitgetheilte. Sie gliedern sich 24 Stunden nach der Aussaat in Nähılösung in eine grosse Zahl ron oftmals über 60 Theilzellen, deren Länge mbestimmt zwischen 8 und 15 $\mu$ etwa schwankt. Die Theilzellen schwellen an und gleichzeitig beginnt die Keimung, wiederum zunächst dicht an den 'Theilwänden, und die Spore wird.in Folge dessen geknickt und gebrochen. Eim Theil der Keimfäden erhebt sich in die Luft und wird zu Conidienträgern, die Conidienabschnürung aber ist lier, wie gesagt, durchaus eigenartig. Das Ende des in die Luft ragenden Fadens wird durch eine geringe Terdickung, auf etwa $2 \mu$, unmittelbar zu einer fadenförmigen Conidie von sehr verschiedener $9-20 \mu$ betragender Länge. Diese Conidie kamn der Richtung nach die unmittelbare Fortsetzung des Fadens darstellen (Fig. 59c) oder aucll gegen den Faden bis zu $90^{\prime \prime}$ geneigt sein (Fig. 59 b). Untel' dem Ende dieser Conidie entsteht alsbald ein neuer Tegetationspunkt (in Fig. 59 b links bereits angedeutet) und dieser erzeugt eine zreite, der vorigen gleiche Conidie. Diese nimmt von vornherein eine zum 'Träger' mehr oder' weniger' geneigte Richtung an, sie geht unmittelbar aus dessen Spitze herror, so dass nun die zuerst gebildete Conidie mit dem Träger nicht mehr in unmittelbarer Terbindung ist. Wohl aber bleibt sie mit ihrem unteren Ende der zweiten Conidie noch längere Zeit angeheftet. Die Bildung geht nun in der Weise weiter fort, dass immer das ganze Ende des Trägers unter der letztgebildeten Conidie zu einer neuen Schimper's Mittheilungen, Heft 9. 
Conidie aussprosst. Da die oberen Conidien aber zunächst nicht abfallen, so entsteht eine durchaus eigenartige Zusammenhäufung der länglichen Gebilde. welche auf ilırem Träger über einander sitzen, wie die Stufen einer steinernen Wendeltreppe, und mit den Enden, die wie bei jenen Stufen eines aufs andere gesetzt sind, selbst die Axe der 'Treppe bilden. Komplikationen dieser einfachsten Form der Conidienbildung können in mannigfacher Art auftreten. Zunächst kann der in die Luft ragende Faden von Anfang an verzweigt sein, und an verschiedenen Zweigenden die Conidienhaufen tragen (Fig. $59 \mathrm{c}$, d). Sehr hänfig bemerkt man ferner, dass die letztangelegte Conidie ihrerseits fadenartig auswäclist, und an ihrer Spitze einen neuen Conidienhaufen erzengt. Endlich beobachtete ich zu verschiedenen Malen am Rande des Kulturtropfens, wo die Nälnlösung fast eingetrocknet war, dass aufsitzende Conidien an ihrer Spitze mit einem verlıältnissmässig dïmnen Faden auskeimten und an demselben in geringer Entfernung eine zweite Conidie (Sekundärconidie) bildeten, welche der ursprünglichen gleich wurde (Fig. 59 e).

Die Conidien werden nur in Luft, nie unter Flïssigkeit gebildet, und ihre Bildung ist desshalb schwer zu beobachten. weil man mit genngsam vergrössernden Linsen nur unter Anwendung allergrösster Torsicht an sie herankommen kamn. Beim Bedecken mit dem Deckglase zerfallen sie sofort; auch nicht zwei bleiben an einander haften. Nur die 'Träger zeigen z. Th. die letztgebildete Conidie noch ansitzend und sie erscheint in allen Entwickelungszuständen. oft noch ohne. sonst mit einer ausserordentlich zarten Abgrenzmgswand. Man ist nun in der Lage die einzehnen Conidien mit stärkeren Linsensystemen näher betrachten zu kömen. An den meisten sieht man am einen Ende eine Art seitlich umgebogenen mitunter fast knollig verdickten Fusses (Fig. $59 \mathrm{~g}$ ), dies ist das Ende, an welchem der Tragfaden nuter dem Drucke der aufliegenden Conidie seitlich ausbog. nm die nächste Conidie zu bilden. Anch erkennt man jetzt mit starken Vergrössermngen, 
dass die Conidien schon während sie auf dem Träger sassen, durch ein bis vier ansserordentlich zarte Querwände getheilt werden (Fig. $59 \mathrm{~g}$ ). Diese sind an den in Luft befindlichen Conidien mit den für diese allein verwendbaren Trockensystemen nicht zu erkennen.

Die Keimung der so gebildeten Conidien in Nährlösung entspricht in allen Stücken der Sporenkeimung. Die Gliederzellen schwellen bedeutend an und nehmen fast rundliche Gestalt an (Fig: 59f); dann treten die Keimschläuche aus, erst einzehn, später zu mehreren ans jeder Zelle und schon am dritten 'Tage nach der Aussaat zeigen die in die Luft ragenden Fäden wieder dieselbe Conidienfruktifikation, die wir eben beschrieben haben. In den Objektträgerkulturen erhielt ich ein dichtes weisses radial ausstrahlendes und die ganze Glasplatte schliesslich bedeckendes Mycelgeflecht, aut dem sich der Rasen der Conidienträger erhob, einen Entwickelungszustand. wie er dem Hypothallus entsprechen würde. Ob ein solcher in der Natur vorkommt, kanm ich nicht sagen, vermuthe es aber. Der Pilz war, wie schon erwälnt, viel weniger häufig als Ascopolyporus polychrons und nicht alle Entwickelungszustände kamen mir zu Gesicht. Der jüngste Fruchtkörper, den ich gesehen habe. hatte etwa $1 \mathrm{~cm}$ Durchmesser, war kugelig und rein weiss. die Gallerte im unteren Theile zart röthlich angehaucht, in keinem stiicke ron jungen Fruchtkörpern des Asc. polychrous verschieden. Späterhin erst bildet sich die Hufform heraus. Sehr bemerkenswerth aber ist es, dass auch bei diesem Pilze gelegentlich Fruchtkörper vorkamen, welche rostroth gefärbt, und von Madengängen durchsetzt waren, und deren Fleisch fester. ohne die wässerige Gallerte, nur aus den dicht verflochtenen dickeren englumigen stark lichtbrechenden Hyphen zusammengesetzt war.

An älteren Fruchtkörpern, wie solche angefressen oder ausgehöhlt gelegentlich noch lose ansitzend oder schon abgefallen, gefunden wurden, erhält sich die festere Rindenschicht und die 
lıymeniale Perithecienschicht am längsten. Man findet an solchen Stücken, dass der hohle Raum der entleerten Perithecien einschliesslich des Halses nachträglich von einer lockeren Masse bräunlicher Hyphen ausgefüllt worden ist. Das Perithecienhymenium stellt jetzt eine $1 \frac{1}{1} \mathrm{~g}$ mm dicke Röhrenschicht dar, deren einzelıe Röhren, die frülıeren Perithecieı, sich leicht von einander lösen lassen, wie es bei manchen Boleten der Fall ist. Es kommt dies daher, dass in den Begrenzungshinien der einzelnen Röhren, also an den Berührungsflächen der benachbarten Perithecien der Zusammenlang nur locker ist. Da in den Röhren in diesem Zustande von Schläuchen keine Spur mehr erkennbar ist, würde man einen solchen alten Fruchtkörper von Ascopolyporus auch bei näherer Besichtigung wohl sicher für einen überreifen Polyporus oder Boletus lialten.

Ascopolyporus Mölerianus (P. Henn.) wurde ron Hemnings in der Hedwigia 1897 Seite 222 unter dem Namen Hypocrella Mölleriana beschrieben. Im Gegensatz zu seinen eben beschriebenen Verwandten lebt dieser Pilz, der durch Herru Tolk in den Figuren 48 und 49 der Tafel III in natürlicher Grösse und Farbe abgebildet ist, nicht auf Bambusen, sondern auf einer rankenden Aracee (Philodendron spec.), die bei Blumenau häufig ist. Aber auch er dringt in das Gewebe der nur zur Anheftung der Fruchtkörper benutzten Tragpflanze niemals ein, soweit meine Beobachtmigen und rielfachen Schnitte einen Schluss erlauben. Seine Ansiedelung auf der Ranke beginnt mit einem unscheinbaren, flach ausgebreiteten Mycel, aus dessen Mitte sich ein kleines weisses Hyphenknötchen erhebt, das aus dicht zusammengewirten Hyphen besteht, und sich allmählich zu dem im Wesentlichen kugeligen, lıäufig unregelmässig gestalteten Fruchtkörper auswächst. In der Jugend ist dieser Fruchtkörper weiss, seine Aussenseite fein wollig und ziemlich dicht besetzt mit Conidienträgern, die denen des Ascopolyporus polychrous sehr ähnlich sind. Fin Unterschied macht sich un dahin geltend, dass hier die an 
der Spitze des einfachen fädigen T'Tägers gebildeten ovalen 11 r etwa $4 \mu$ langen Conidien in noch grösserer Zahl und fester zu einem Kügelchen verklebt sind, und dass die conidien keine Scheidewand in ihrer Nitte besitzen. Zur Keimmng, die schon auf dem 'Träger zu begimmen pflegt. nelımen sie an Länge und Umfang erheblich zu, so dass man sie stets in allen möglichen Grössenabstufungen neben einander findet (Taf. IT Fig. 65 b).

Die Fruchtkörper bleiben meist nur klein und erreichen höchstens Haselnussgrösse, der grösste einmal gefindene hatte wenig über 2 cm Dnrchmesser. Sie sind oftmals von unregelmässiger Gestalt, umgeben den tragenden Faden bisweilen so, dass sie ihn völlig einschliessen, was bei den anderen Ascopolypornsarten nicht rorkam; länfiger anch als bei jenen sind sie dicht neben einander in grosser Zahl angesetzt und benachbarte rermachsen mit einander (s. d. Fig. 48 und 49 'Taf. III). Stets aber', auch an den kleinsten ist die Oberseite in dunkler brauner Farbe von der hymenialen gelbweissen Unterseite deutlich verschieden. Die Abgrenzungslinie beider hat oft unregelmässigen Verlauf. wie bei Asc. polychrous. Die Perithecien werden ebenfalls auf der Fruchtkörperoberfläclie angelegt, und treten alsbald in nahe Berührung mit einander, so dass sie eine ununterbrochene Schicht bilden (Fig. 65̃a), ein wesentlicher Unterschied gegen die früher beschriebenen Arten kommt aber darin zum Ausdruck, dass die Perithecien in ihrem oberen Drittel sich erheblich zusammenziehen derart. dass sie mit diesem Theile frei und ron einander getrennt dastehen, und darin, dass sie auf ihrer Spitze eine dentlich dunkler gefärbte. ron dem Mündungskanal dnrchbohrte Kappe tragen, wie die Fig. 65a es darstellt. Die Höhe der reifen Perithecienschicht beträgt kaum ${ }^{1 / 2} \mathrm{~mm}$. Die fadenförmigen kaum $1 \mu$ dicken Sporen erreichen bis 360 " Länge und werden in ungeheuren Massen, aber immer als ungetheilte Fäden ansgeworfen. Scheidewände sind in ihnen erst mühsam als feinste Linien zu erkennen, wenn sie einen 'Tag' in Wasser oder Nälırlösung gelegen 
haben. Alsdann beginnt auch die Keimung und schon am zweiten Tage nach der Aussaat sind im Nährlösungstropfen ziemlich reich verzweigte Mycelien gebildet. Die Sporentheilzellen schwellen zur Keimung verhältnissmässig nur wenig an, und ein weiterer Unterschied gegen die iilrrigen Ascopolyporusarten liegt darin. dass die Keimschläuche an beliebiger Stelle der Theilzellen, nicht stets wie bei jenen, zunächst dicht an der Trennungswand austreten. Dieser Unterschied findet sich mit grosser Bestimmtheit ansgebildet, und er erweist im Zusammenhange mit den anderen schou geschilderten Eigenthümlichkeiten zweifellos, dass diese Form in dem Grade der Blutsverwandtschaft von den drei vorigen weiter absteht, als jene drei nächstrerwandten von einander. Am dritten Tage traten die oben beschriebenen Conidienträger (Fig. 65́c) anch in den Kulturen aus Ascussporen auf, bisweilen unmittelbar von einem Theilstiicke der Ascusspore aus in die Luft ragend. Auf dem Objektträger entstanden grosse lockerwollige Mycelrasen, so gross wie der Kulturtropfen und zahlreiche Conidienträger, die nur in Luft gebildet werden, aber nicht rasenartig zusammen, sondern in ziemlich lockerer weitständiger Anordnung auftreten. Das Fleisch des Fruchtkörpers ist ziemlich fest, knorpelig, die wässerige Gallerte fehlt ganz darin, auch ist der Centralstrang: der für die übrigen Arten von Ascopolyporus so charakteristisch war. hier nicht zu erkennen. Dagegen zeigen normale Fruchtkörper dieser Form eine ziemlich genau radial fortschreitende zonenartige Ausbildung und diese kommt durch eine ähnliche Verflechtung der dickwandigen und in Folge der rergallerteten Wände stark lichtbrechenden Hyphen zn Stande, wie sie für den Haarfilz des Ascopolyp. villosus in Fig. 58b Taf. IV abgebildet worden ist. nur dass die Zwischemrämme zwischen den Hyphenbündehn einen riel geringeren Raum eimnelmen.

Ich fand den Pilz im September 1891 in nur wenigen Exemplaren, im Oktober 1892 sammelte dann Herr Gärtner selı' zahlreiche Fruchtkörper, von denen indessen keiner über Hasehnuss- 
grösse hatte. In diesem Jahre trat der Pilz so zahlreich auf. dass an manchen Stellen im Walde dicht bei Blumenau kaum eine Philodendronranke ohne iln angetroffen wurde.

IVie aus meiner Beschreibung und der Zeichnung 'Taf. IT Fig. 65 hervorgeht. kann man die Perithecien als eingesenkt nicht wohl bezeichnen. Wenn demnach für die Gattungsbeschreibung von Hypocrella die im Stroma versenkten Perithecien massgebend sein sollen, so wiirde schon die Perithecienbildung die rorliegende Art von Hypocrella entfernen. Ich bin indessen nicht der Ansicht, dass man dem Umstand, ob die Perithecien eingesenkt sind oder nicht, einen so grossen Werth beilegen sollte, sehen wir doch z. B. bei Mycocitrus, dass in dieser Beziehung Sclwankungen bei ein und derselben Art rorkommen. Ich lege viel mehr Gewicht anf die scharfe Trennung der sterilen und fertilen Stromaoberfläche, welche diese Art der neuen Gattung Ascopolyporus zilweist.

Herr Hennings macht in seiner a. a. O. gegebenen Diagnose iiber unseren Pilz noch die Bemerkung: ,sporidiis in articulos dilabentibus": während ich oben angegeben habe, dass die Sporen durchaus ungetheilt sind, ungetheilt ausgestossen werden, und erst an dem auf die Aussaat folgenden Tage feine Querwände erkemmen lassen. Dieser Widerspruch klärt sich leicht auf durch eine Beobachtung; welche für die Beurtheilung der nach totem oder besonders nach Alkoholmaterial angefertigten Beschreibungen von Wichtigkeit ist. Ich habe s. Z. die frisch in Wasser aufgefangenen Sporen mit der sehr guten Seibertschen Immersion ${ }_{12}^{1}$ untersucht und fand sie vollkommen scheidewandlos. In den Präparaten aber, die ron Alkoholmaterial angefertigt wurden, sind Veränderungen in dem Inhalt der zarten Schläuche und Sporen eingetreten, welche den Eindruck erwecken, als zerfielen die Sporen in viele kurze Theilstücke. Der gleiche Unterschied macht sich bei vielen fadensporigen Hypocreaceen geltend und wenn er nicht beobachtet wird, kamn er zu vielen Verwirrungen 
Anlass geben, wie ich besonders bei Untersuchung der Cordycepsarten festznstellen Gelegenheit fand. Sodamn muss bei all diesen Hypocreaceen viel schärfer als bisher geschehen ist unterschieden werden, ob die Fadensporen wirklich im Schlanche in Theilzellen zerfallen, die sich im Schlanche von einander trennen, oder ob nur Theilwände in ihnen sichtbar werden; der Ausdruck "sporidiis in articulos secedentibus" oder "dilabentibus" sollte nur angewendet werden, wemn das erstere sicher erwiesen ist. Meine Untersuchungen überzengen mich davon, dass der wirkliche Zerfall der Fadensporen im Innern des Schlauches ein durchaus konstantes Merkmal der Arten ist, bei denen er vorkommt. --

Wenn wir in den eben behandelten Gattungen Mycomalus und Ascopolyporis Formen erkannten, die auf Hypocrella umzweifelhaft sich zurückführen lassen, jener Gattung gegenïber aber eine hohe Steigerung nach Richtung der stromatischen Ausbildung hin anfweisen, so ist die Gattung Epichlö̈ vielmelur als eine Nachbar- oder Schwestergattung zu Hypocrella aufzufassen. Wir kömnen sagen, dass wir unter Epichloë solche Hypocrellen zusammenfassen, welche ein flach ausgebreitetes, scheidenförmig die befallenen Pflanzentheile umkleidendes fleischiges. znerst Conidien, dann aber Perithecien anf der ganzen Oberfläche in gleichmässiger Vertheilung tragendes Stroma besitzen. In diesem Sinne ist die Gattung anch von Saccardo (Sylloge II Seite 578) definirt. Es gelı̈̈rt zu Epichloë in dieser zweckmässig festzıhaltenden Begrenzung die von Magnus beschriebene Epichloë Warburgiana ans Celebes. Anch die von Hemnings aus Ostafrika mitgetheilten nenen Arten der Gattung: E. Schumanniana und Volkensii und Oplismeni dürften hier ihre richtige Stellung gefunden haben.

Nahe mit Epichloë verwandt ist die bisher weit von ihr getrennte Gattmng Ophiodotis Sace. Ich mutersuchte die von Rehm in der Hedwigia 1897 S. 380 beschriebene Ophiodotis rhaphidospora 
Rehm. Das Originalmaterial zu dieser Beschreibung ist von Ule in Sa. Catharina gesanmelt; ich konnte es durch Herrn Hennings Freundlichkeit erhalten und mich von der vollkommenen Uebereinstimmung mit dem von mir mehrfach auf Blättern einer (olyra und anch der Bambuse Microstachys speciosa Spr. angetroffenen Pilze überzengen. Die Rehmsche Beschreibung, die ich in vielen Punkten nicht bestätigen kann, jedenfalls für äusserst ergänzungsbedïrftig lralte, lantet: „Stromata linearia, foliis involutis imnata, elongata, $1-3 \mathrm{~cm} \mathrm{lg.,} 0,1-0,15 \mathrm{~cm}$ lat., albofarinacea, fusce" (sic!?) "contexta, loculis multis immersis, poro minimo apertis. Asci cylindracei $3006-7$. Sporidia filiformia multicellularia, in cellulas singulas 101,5 secedentia liyalina, quaque cellula biguttulata. Paraphyses filiformes?:"

(„Die langen schmalen Stromata und die in einzelne Zellen zerfallenden Sporen kennzeichnen die Art."

Der Pilz erscheint auf den durch ihn völlig zusammengerollten und an der Entfaltung gehinderten Blättern änsserlich in der Gestalt mehrere Centimeter langer schmaler schwarzer Streifen (Fig. 69 a Taf. V). Macht man einen Querschnitt durch ein solches Blatt, so findet man (Fig. 69 b), dass das diclit gewebeartige Hyphengeflecht des Pilzes, sein Stroma also, die Zwischenräıme des spiralig eingerollten Blattes liickenlos ausfiillt. Unter der äısseren einhüllenden Blattschicht verdickt sich dies Stroma in geringer Breiten- nnd erheblicher, doch unbestimmter Längenansdehnıng; sprengt die bedeckende Blatthülle der Länge nach auf und tritt streifen- oder striemenförmig zu Tage. Soweit es num frei liegt, färbt es seine Oberfläche schwarz, und erzengt unter ihr in dem verdickten Stromatheile und nur in diesem die Perithecien, stets, soviel ich sehen komte, in zwei parallelen Reihen, wie der Querschnitt Fig. 69 b erkennen lässt. Pilzhyphen dringen anch in das Blattgewebe ein, dessen Zellenstruktur wird aber nirgends zerstört, wir haben wie bei Epichloë ein aufgelagertes Stroma, nicht eine Art von Pilzpseudomorphose, wie wir sie bei 
Balansia und noch ausgebildeter bei Claviceps antreffen werden. Es lenchtet ein, dass die eigenartige hier vorliegende Stromaform durch die Rehmsche Beschreibung nicht wiedergegeben wird, und dass es unrichtig ist, die Länge und Breite der vorbrechenden schwarzen Streifen als die Länge und Breite der Stromata zu bezeichnen, während doch, wie unser Querschnittsbild dentlich zeigt, das Stroma selbst ganz anders gestaltet ist, und zwei oder mehr solcher perithecienführenden Streifen erzengen kamn. Das ganze Stroma ist ungefärbt und weich. Die schwarze Farbe und ein wenig kohlige Beschaffenheit beschränkt sich ausschliesslich auf die der Luft ausgesetzte streifenförmige Rinde der perithecientragenden Stromatheile. Diese Rinde ist von den Mündungen der Perithecien überaus fein punktirt. Die Form der Perithecien erkennt man am besten auf dem Längsschnitt durch eine der beiden parallelen Perithecienreihen (Fig. 69c). Sie erscheinen dort mehr oder weniger rechteckig mit abgerundeten Ecken. Die Schläuche sind 200-250 " lang, und etwa 6 " breit. Sie tragen die typische hyaline Kappe, welche hier auffallend eckig. nicht wie sonst meistens abgerundet ist (Fig. 69d, e). Die sporen, welche annähernd Schlauchlänge haben, lassen freilich auch in frischem Zustande im Schlauche schon zahlreiche Theilwände erkennen, zerfallen aber nie im Schlauche, wie man nach der Rehmschen Benerkung ,in cellulas singulas secedentibus" annelmmen könnte. Ausserhalb des Schlauches zerfallen sie in stäbchenförmige Theilzellen, die aber nicht. wie Rehm angiebt $10 \mu$, sonderu 20-27 "lang sind, wie ich auf frund selır vieler Messungen versicher'n kann.

Fragen wir num, warum die beschriebene fadensporige Hylocreacee auf den Namen Ophiodotis getauft ist, und worin iiberhaupt der Charakter ron Ophiodotis liegt, so erfahren wir, dass er in der schwarzen kohligen Beschaffenheit der die Perithecienmündungen überlagernden Rinde, nnd in dem Fehlen einer eigenen Perithecienwandung gefunden worden ist. Diese Eigenschaften 
sollen Ophiodotis zur Angehörigen einer ganz anderen Gruppe, der Dothideaceen, machen. In Wirklichkeit nun finden sich alle $\mathrm{Ab}$ stufungen von einer stark ausgebildeten Perithecienwand, besonders bei frei auf dem Stroma gebildeten Perithecien, bis zn einer selır dïmnen Wrand der ins Stroma versenkten, welche eines besonderen Schntzes nicht bedïrfen. Die Wandmng ist schon bei Epichloë mnd bei Claviceps selı dïnn und kanm kenntlich, bei Ophiodotis ist sie noch ein wenig mehr redncirt. Aber sie ist auch hier vorhanden. Tem man geniigend zahlreiche und feine schnitte macht, so erkennt man sie zweifellos, wenn sie anch zart mnd von Stroma wenig abgesetzt erscheint. Wohin man kommt, wenn man einem so willkürlich gewählten Merkmal Einfluss anf die systematische Anordnumg einrämnt, sieht man an Jaczewskis Eintheilung der Pyrenomyceten, die er im Bull. de la soc. mycol. de France 1894 Seite 13 entwirft, nnd in der er sogar Cordyceps, Epichloë nnd Oomyces ans ihrem natürlichen Verwandtschaftskreise der Hypocreaceen heransreissen und zn den Dothideaceen stellen will, ein Verfahren dem glïcklicherweise ebenso wie den anderen ganz verfehlten Jaczewskischen Eintheilnngsversnchen der Pyrenomyceten niemand gefolgt ist. Vielmehr ist das Umgekehrte richtig, die Dothideaceen bilden gar keine natürliche Grmppe und mïssen allmählich mit besserer Kenntniss der Formen aufgelöst werden, wie Lindan selı richtig in seiner Bearbeitmmg für die natïrlichen Pflanzenfamilien betont (S. 374 a. a. O.). Und mit dieser Anflösmng machen wir zmnächst mal einen Anfang, indem wir Ophiodotis mnd Myriogenospora in die nächste Nähe ron Epichloë versetzen, wohin sie gehören.

Sobald wir aber diese nothwendige Anordmmmg rollzielıen, so lat die Gattmo Ophiodotis gegen Epichloë nur den Unterschied, dass bei ihr die Perithecienwandnngen noch ein wenig mehr, wie dort redncirt sind und dies kam offenbar ilıren Bestand nicht mehr rechtfertigen. Soll sie bestehen bleiben, was ich für sehr zreckmässig erachte, so müssen wir ihr einen Charakter geben. 
Während bei Epichloë das ganze Stroma an der Oberfläche in gleichmässiger Vertheilung die Perithecien trägt, so differenzirt sich bei Ophioditis das Stroma in einen flachen dem Substrat anliegenden sterilen Stromatheil, und auf diesem erheben sich einzelne in der Form noch nicht bestimmt gestaltete Partien, welche allein die Perithecien erzeugen (vergl. Seite 147-148). Begrenzen wir Ophiodotis in dieser Weise, so bleibt die Gattung zwar nicht, was sie gewesen ist, aber sie umfasst mehrere der ihr bisher zugeschriebenen Arten, so z. B. die vorliegende, ferner auch die Ophiodotis Aristidae (Atk.) Sacc., für welche Atkinson den ganz unnöthigen neten Gattungsnamen Dothichloë einsetzte, des sogar bei Saccardo keine Aufnahme sondern nur Erwähnnng gefunden hat (Sacc. XIV S. 686). 'Zu der Gattung Ophiodotis in unserem Sinne gehört als ein typisches Beispiel Ophiodotis Hemningsiana nov. spec, welche die Blattscheiden einer Andropogonart auf viele Centimeter Länge mit einem glatten schwarzen Ueberzug von $1 / 10 \mathrm{~mm}$ Dicke umkleidet. Diesen Ueberzug habe ich oftmals völlig steril angetroffen. und in diesem Zustande mag er dann wohl das Substrat der oben (S. 120) erwähnten Nectria Epichloë Speg. bilden. Wenigstens ist jenes' ebenfalls auf Andropogon gefundene, von der Nectria besetzte Stroma von demjenigen unserer Ophiodotis nicht zu unterscheiden. Zur Perithecienbildung verdickt sich das Stroma beträchtlich, bis zu 1 mm, und in der rerdickten Partie finden wir dann die dicht bei einander tief eingesenkten Perithecien, welche mit der Miindung. kaum als winzige Pünktchen hervorragen.

Wichtig ist es nun, dass jene fertilen stromaverdickungen sich nicht gleichmässig auf der ganzen Fläche des sterilen Stromas bilden, sondern dass sie in vollkommen unregelmässiger Anordnung, manchmal auf längere Strecken ununterbrochen, dann wieder fleckweise unregelmässig rundlich umgrenzt auftreten, so dass der Pilz in reifem Zustande nicht eine glatte gleichmässig dicke, sonder'n eine uneben höckerige Hülle um die befallene Blattscheide bildet, wie dies auch das Qnerschnittsbild Fig. 70 Taf. V erkennen lässt. 
Die Perithecien sind flaschenförmig, etwa 300 "lang; ihre Wandung* ist nur um ein wenig deutlicher als bei der vorigen Form ausgebildet, die Schläuche messen $200 \mu$ in der Länge bei $6 \mu$ Breite. Ein Zerfallen der Sporen im Schlauche tritt nicht ein. Die hyaline Kappe der Schläuche ist gleichmässig gerundet. In vielen Fällen fand ich, was auch Herr Hennings bestätigte, nur vier fadenförmige Sporen von ammähernd Schlauchlänge im Ascus, in anderen Fällen waren es sicher mehr, genau acht zu zählen ist mir bei dem zarten Objekt nie gelungen, wie denn iberhaupt die Feststellung der Sporenzahl in all diesen fadenförmigen Schlänchen meist überaus mühselig und unsicher ist. Ganz gewiss ist die Achtzahl in sehr vielen Fällen, wo in den Diagnosen , ascis octosporis" steht, mehr vermuthet, als wirklich gezählt.

Die Mycelfäden der Ophiodotis Henningsiana dringen in das Innere der befallenen Blattscheide zweifellos ein, ohne jedoch deren Zellgewebe zu zerstören; denn man bemerkt häufig auch an der Innenseite der gefalteten Scheide die dort wieder in reicherer Ausbildung auftretenden, immer aber viel lockerer, als in dem äusseren Stroma gefügten Hyphen, die manchmal sogar die Andeutung einer schwärzlichen Rinde erkennen lassen (rgl. die Fig. 70).

Zu der ron Atkinson aufgestellten Gattumg Myriogenospora Atkins. gehört ein Pilz, den ich im Januar 1891 auf Paspalumpflanzen fand. Ein schwarzes Stroma von wenigen Centimeterı Länge und wenig über ein $1 \mathrm{~mm}$ Breite lag der Mittelrippe der Oberseite des Blattes auf und hielt die beiden Blatthälften in spitzem Winkel so zusammen, dass sie sich nicht, wie die gesunden Blätter entfalteten. Herrn Bresadola lat das von mir s. Z. an Herrn Hennings geschickte Material in der Hedwigia 1896 Seite 301 beschrieben, und nennt es Myriogenospora Paspali Atkins.; giebt aber an, es mnterscheide sich von der durch Atkinson mitgetheilten Form. Ganz sicher ist der brasilische nicht derselbe Pilz, wie der nordamerikanische; dies ergiebt eine Vergleichung mit 
Atkinsons Beschreibung. Doch kann eine Neubeneunung der noch nicht genügend untersuchten Art fïglich unterbleiben. Der Pilz müsste seinem Aeusseren nach zu Epichloë gehören, demn seine ganze Oberfläche trägt Perithecien. Diese Perithecien ähneln sehr denen der Ophiodotis rhaphidospora in Form und Anorduung. Die Sclıläuche aber von 150-200 « Länge mit kleiner abgerundeter liyaliner Kappe enthalten unzähllbare länglich spindelförmige Sporen und haben die grösste Aelnlichkeit mit denen des Mycomalus. Und wie dor't ist es mir auch hier trotz vieler Bemühungen nicht gelungen, die Entstehung dieser zahllosen Sporen aus etwa acht Fadensporen sicher nachzuweisen. Die Anuahme, dass diese Sporen selbstständig im Schlauche entstanden seien, ist freilich ebenso wenig bewiesen. Nach den oben mitgetheilten Untersuchungen iiber Hypocrella ochracea, cavernosa und rugulosa hat jedenfalls die erste Annahme der Entstelıug aus Fadensporen riel mehr Wahrscheinlichkeit als die letzte. Immerhin bis die Entstehungsgeschichte dieser zahlllosen sporen einmal aufgeklärt sein wird, kann man der Myriogenospora mit einem gewissen Rechte Selbstständigkeit einuäumen: dass sie in die nächste Nähe von Epichloï gehört, unterliegt keinem "zweifel. Sobald fïr eine hierher gehörige Form die Entstehung der zahlreichen Theilsporen aus wenigen Fadensporen nachgewiesen wäre, mïsste man sich klar machen, dass die Gattung Myriogenospora neben Epichlö̈ für eine solche Form genau so wenig und so viel Berechtigung haben wïnde, wie Mölleriella neben Hypocrella lat.

Die Gattung Balansia ist von Spegazzini mit der Art Balansia Claviceps speg. begründet worden. Der vortrefflich gewählte Name deutet auf die Verwandtschaft der Form mit Claviceps hin. Der l'ilz lat nämlich gestielte perithecientragende Köpfchen, ganz älnlich. wie sie das Mutterkorn hervorbringt, sie entspringen aber ans einem sclerotienartigen Gebilde, welches in langer Frstreckung die Rispe eines Grases epichloëartig einschliesst und 
sind von schwarzer Farbe. Eine der vorigen, ersten Art der Gattung sehr ähnliche wurde unter dem Namen Balansia trinitensis von Cooke und Massee in den Annals of botany Vol. III 1889 -90 beschrieben und abgebildet. Wir erfahren aus dieser Abhandlung; dass die Balansia die Aehren des Grases (eines Panicum) umschliesst und alle ihre Theile in ihr Stroma einschliesst, ohne sie jedoch zu verzehren. Anf Querschmitten sind die eingeschlossenen Theile der Aehre noch als solche zu erkennen. Es handelt sich also um ein Stroma, welches gleich demjenigen von Épichloë oder Ophiodotis rhaphidospora sich den befallenen Pflanzentheilen eng anschmiegt, und ihrer Form folgt. Auf diesem Stroma erheben sich die perithecientragenden gestielten Köpfchen. Bei Balansia trinitensis wird eine pezizafürmige Conidienform als zugehörig angegeben, die unter dem Namen Ephelis beschrieben worden ist, deren Zugehörigkeit zn der Balansia jedoch durch die CookeMasseesche Arbeit keineswegs sicher bewiesen ist. Jenen beiden Balansiaarten schliesst sich offenbar nahe verwandt unsere auf Taf. I Fig. 67 a und b abgebildete Balansia redundans nov. spec. an, und alle drei im Verein machen die Beziehungen der Gattung zu Claviceps zweifellos. Nach einer anderen Richtıng aber wird der Anschluss der Gattung Balansia vortrefflich durch die beiden in Fig. 66 und 68 unserer Tafel dargestellten Formen vermittelt. Der Stiel des Köufchens ist dort nur kürzer (Fig. 66b), ja fast ganz unausgebildet (Fig. 68b), und wir sehen die perithecientragenden Köpfehen fast unmittelbar auf dem sterilen Theile des Stromas aufsitzen in genau derselben Weise, wie die perithecientragenden nicht köpfchenförmigen Theile des Stromas von Ophiodotis Henningsiana Fig. 70. Der Unterschied gegeniïber dieser Form liegt nur darin, dass die perithecientragenden Partien bestimmt in ihrer Form geworden sind, und eben in diesem Umstande finden wir den einzig stichhaltigen Charakter, welcher Balansia von Ophiodotis abgrenzt.

Balansia ambiens nov. spec. An den Stengeln einer bei Blumenau häufigen Olyraart habe ich in grossen Mengen einen Pilz gefun- 
(len, der auf die Länge von melıreren Centimetern die Blattscheiden auseinandersprengt und zwischen ihnen in Gestalt eines wenig über $1 \mathrm{~mm}$ breiten schwarzen Streifens sichtbar wird (Fig. 66a). Unregelmässig auf diesem Stroma vertheilt sitzen ziemlich gleichmässig rundlich kopfig ansgebildete, mit dem Stroma gleichartige schwarze Köpfchen von geringem etwa $2 \mathrm{~mm}$ betragenden Durchmesser anf einem kaum sichtbaren Stiele und in diese Köpfchen sind die Perithecien eingesenkt (s. Fig. 66 a und b). Die genaue Untersuchung ergiebt, dass das Stroma des Pilzes den ganzen Grasstengel in geschlossenel Scheide von ungefähr 100 "Stärke umgiebt. Diese Scheide ist sclerotienartig aus ganz dicht und lückenlos verwebten Mycelfäden gebildet und geht ohne scharfe Grenze, wie es die Fig. 66b andentet, in den sehr kurzen Stiel und in das Köpfchen über. Die tiefschwarze Farbe hat die sclerotienartige Scheide an ihrer Aussenseite nur, soweit sie nicht von der Blattscheide der Olyra bedeckt ist. Wenngleich die Hyphen des Pilzes sicher in das Gewebe des Wirthes eindringen - die Blattscheide scheint ganz voln ihnen frei zu bleiben - so rufen sie doch in dem Olyrastengel keine benerkbaren Zerstörungen hervor und sind dort überliaupt nur vereinzelt bei sehr dimnen Schnitten and genanestem Nachsuchen nachweishar. Die flaschenförmigen Perithecien sind, wie die Zeichnung erkennen lässt, völlig eingesenkt; ilıre dünne Wandung geht allmählich in das Plectenchym des Köpfchens ïber. Die Länge der Schläuche beträgt im Mittel $225 \mu$; sie zeigen die vielfach besprochene, hier abgerundete hyaline Kappe am oberen Ende. Die hyalineu fadenförmigen Sporen sind wohl zu 8, manchmal nur zı 4 im Schlauche vorhanden. In frischem Zustande erkennt man die 'Theilwände. solange sie im Schlauche eingeschlossen sind, kaum. Ich fing die Sporen in Nährlösung auf, wo dann jede Spore in eine orosse Anzahl vou etwa $18 \mu$ langen Theilstiicken durch Scheidewände zerlegt erscheint. Die Kieimung begimnt sehr bald, stets znerst dicht neben einer Scheidewand. Die Spore wird dabei unregelmässig an den Stellen der Wände hin und her geknickt. 
Mit der Balansia ambiens nahe verwandt ist die von Hennings in der Hedwigia 1900 Seite 77 beschriebene B. discoidea P. Henn., welche an Halmen von Chloris distichophylla Lag. von E. Ule ebenfalls bei Blumenau gesammelt worden ist. Während aber bei Bal. ambiens die Köpfchen nur in einer Reihe am Halme auftreten, weil die Blattscheide nur streifenweise durch das Stroma aufgerissen wird, kommen sie bei B. discoidea ringsum rertheilt am Stengel vor, was auf eine etwas andere Art der Stromabildung schliessen lässt.

Nur auf der Eigenart ilırer Stromabildung beruht num auch der Charakter der Balansia regularis nov. spec, welche an der Guadua Taguara Kth. höchst merkwürdige hexenbesenartige Bildungen erzeugt. Ein Theil solchen Hexenbesens ist durch die Photographie Taf. X Fig. 2, ein noch kleinerer Theil in natürlicher Grösse durch die Zeichnung Fig. 68a Taf. $\mathrm{V}$ dargestellt.

Anstatt der langen Internodien, welche sonst diesem Bambus eigen, bilden sich an bestimmten Stellen zahlreich zusammengedrängt kurze Seitenzweige mit ganz kurzen Internodien. An jedem Knoten ohne Auswahme und zwar immer an der Seite, wo die Blattscheide des Knotens geöffnet ist, daher vollständig regelmässig alternirend rechts und links des Stengels auftretend, findet sich ein tiefschwarzer Fruchthörper unseres Pilzes ron 1 bis höchsten Falles etwa $3 \mathrm{~mm}$ Durchmesser und abgeflacht kugeliger Form. Die grössten Fruchtkörper sitzen unten an den ältesten Verzweignngen des Hexenbesens, nach oben werden sie allmählich kleiner, bis sie an den alleräussersten feinen Terzweigungen fast ganz verschwinden. Der ganze Hexenbesen ist so regelmässig lückenlos von ihnen besetzt, dass man den Eindruck gewinnt, es gehörten diese schwarzen Pünktchen als normale Bildungen der grünen Pflanze, dem Bambus, all, während sie doch ron ihr nur ihren Platz genau angewiesen erhalten, wie oben angegeben wurde. Die einzelnen Stengelglieder krümmen sich unter dem Einflusse des parasitischen Pilzes in charakteristischer Weise hin Schimper's Mit theilungen, Heft 9. 
und her, wie die Zeichnnng Fig. 68 a erkennen lässt. Ein Querschnitt, schematisch in Fig. $68 \mathrm{~b}$ dargestellt, zeigt uns, dass das sclerotiumartige, völlig liickenlose Stroma des Pilzes ziemlich tief in den Stengel des Grases eindringt, und dessen Gewebe theilweise zerstört. Der iibrig bleibende, nicht angegriffene 'Theil scheint völlig gesund zu bleiben und auch die Blattscheide wird von dem Pilzmycel nicht angegriffen. Nach oben und unten lässt sich das Pilzstroma auf Längsschnitten ebenfalls eine Strecke weit verfolgen, es führt allmählich mo unmerklich in das anscheinend gesunde Stengelgewebe ïber. Einzelne Fäden des Pilzes jedoch wachsen mit dem wachsenden Grase weiter nach oben. und elzeugen am nächsten Knoten dann einen neuen Fruchtkörper. Vereinzelte Hyphen wurden bis dicht unter der Vegetationsspitze des Grases nachgewiesen. Das Stroma zeigt auf dem Querschnitt weisse Farbe. seine Aussenrinde ist tiefschwarz. Die Krimmung der Internodien kommt offenbar dadurch zu Stande, dass der wie ein Fremdkörper in den Grasstengel lineingetriebene Stromatheil von der nicht angegriffenen stärker wachsenden Seite des Stengels aus iiber- und mnwachsen wird.

Die Perithecien zeigen eine sehr dünne, wenig scharf abgesetzte, schwärzlich gefärbte Wandung. Sie sind lang flaschenförmig, ganz eingesenkt und messen 350-400 $\mu$ rom Grunde bis zur Mündnng. Die mit der hyalinen Kappe versehenen Schlänche sind $200 \mu$ und darüber lang. Sie enthalten in den beobachteten Fällen vier fadenförmige sporen, welche schon im Schlanche eine Gliedermng in stäbchenfürmige Theilzellen von im Mittel $25 \mu$ Länge erkennen lassen. Ein Zerfall der Sporen im Schlauche findet nicht statt. Finen wesentlichen Tnterschied von den vorher besprochenen Arten zeigt B. regularis dadurch, dass ihre Stromata nicht der befallenen Pflanze nur anf- und umgelagert sind, von ihr die Form entlehnend, sondern dass sie echt parasitisch in das Gewebe des Grases eindringen. und sich an stelle mnd auf Kosten des Gewebes der Wirthspflanze ausbilden. anch in Folge dessen 
recht erheblich auf deren Formbildung einwirken; dass aber durch diesen physiologischen Unterschied eine generische Abtrennung der Art nicht nothwendig wird, scheint mir angesichts ihrer sonstigen rollkommenen Uebereinstimmung mit Balansia zweifellos.

Balansia redundans nov. spec. ist durch die Figuren 67 a und b auf Tafel $\mathrm{V}$ wiedergegeben. Wenn wir den Querschnitt $67 \mathrm{~b}$ mit dem Querschmitt $66 \mathrm{~b}$ ron Bal. ambiens vergleichen, so finden wir eine ganz vollkommene Uebereinstimmung der Stromaausbildung. Bal. ambiens kommt auf einem stark behaarten, nicht näher bestimmbaren Grase bei Blumenau vor, und umschliesst dessen Stengel nnter der einhüllenden Blattscheide mit einem cylinderförmig ausgebildeten etwa 100 " starken Plectenchymmantel. In einem Längsrisse wird dann die Blattscheide aufgesprengt, und das stroma bildet eine schwarze sclerotienartige Rinde aus, soweit es nun frei liegt. Auch hier ist die mit den langen Haaren besetzte Blattscheide anscheinend ron dem Mycel ganz unberïhrt. Der Unterschied gegen Bal. ambiens liegt hauptsächlich in der bis zı $5 \mathrm{~mm}$ ansteigenden Länge des schwarzen schuppig rauhen Stieles. Das Köpfchen ist hier (vgl. die Figur) rom Stiele durch eine dunkler gefärbte Schicht scharf abgesetzt, greift auch rings um den Stiel sich verbreiternd ïber, so dass der Stiel einer muldenförmigen Aushöhlıng auf der unteren Seite des Köpfchens eingefügt scheint, eine Bildung, die in ganz ähnlicher Weise bei Claviceps (Fig. 73c) angetroffen wird. Die Perithecien ragen mit ihren Mündungen etwas vor und geben dem Köpfchen ein rauhes Ansehen. Wie sich Balansia ambiens von Bal. discoidea durch die Anordnung der Köpfchen unterscheidet, genaı so unsere Balansia ron den durch Spegazzini, Massee und Cooke beschriebenen schon erwähnten Arten. Bei jenen stehen die Köpfchen rings um die befallene Aehre, hier stehen sie in einer Reihe, weil die schiitzende Blattscheide nur in einem Längsrisse durch das unter ihr verborgene Stroma aufgespalten wird. 
Ich fand an den mir zur Terfügung stehenden Stïcken, die im Nai 1892 gesammelt wurden, nur noch in wenigen der etwa $400 \mu$ langen flaschenförmigen Perithecien Schlänche der typischen Form vor. Diese Schläuche latten etwa $200 \mu$ Länge, eine hyaline runde Kappe, und enthielten acht fadenförmige Sporen mit vielen Querwänden. Die allermeisten Perithecien waren entleert. Die heransgeworfenen Sporen sassen in gekeimtem Zustande unregelmässig zu losen Flocken durch einander verflochten auf der Nü̈ndung der Perithecien, waren aber von da aus anch ïber die ganze Rinde des Küpfchens und des rauhen Stieles verbreitet, gleichsam iibergeflossen (redundare). Sie waren gekeimt in genau derselben Weise, wie ich es für Ascopolyporus polychrous beschrieben habe, mid bildeten sehr zahllreiche Einzelconidien und verklebte Conidienköpfe auf der ganzen Aussenfläche des Fruchtkörpers und auch des Stromas. Die hyalinen kileinen Conidien sind länglich, $4 \mu$ lang und unter 1 " breit und verkleben in Köpfchen von mehr als ein Dutzend. Nit den von Cooke und Massee a. a. O. für Bal. trinitensis abgebildeten langen Ephelisconidien haben sie keine Aelunlichkeit.

Einer höchst merkwürdigen Beobachtung aber muss ich hier noch Erwähnıng thmur. Ich fand längst nicht regehmässig, aber zu wiederholten Nalen in entleerten Perithecien unserer Balansia eine fiemde Nectriacee parasitirend. Diese bildete rundliche Perithecien von höchstens 150 "u Länge, welche ganz genau dem oberen Drittel des entleerten Balansiaperitheciums eingebant waren, so zwar, dass sie denselben Ausführungskanal fïr ihre Sporen benutzten, durch den vorher die Fadensporen ausgestossen waren. Diese fremden Perithecien, welche bei flüchtiger Betrachtung zu grossen Irrthïmern Anlass werden künnen, hatten eine eigene an die Struktur der Nectriaceen erinnernde Wandung, welche seitwärts mit der ursprïnglichen Wandung des Balansiaperitheciums rerschmilzt, nach unten aber, wo sie das viel kleinere parasitirende Gebilde gegen den nun leeren Raum des grossen Peritlecimms der 
Balansia abschliessen muss, zu vollkommener Ausbildung gelangt. Dieser Parasit lat $65 \mu$ lange, 4 " breite achtsporige Schläuche, braune, viertlleilige, längliche, wenig gekrïmmte Sporen von $13 \mu$ Länge und 3-4 3 Breite, welche ihm bei Calonectria seinen Platz anweisen. Er mag als Calonectria Balansiae nor. spec. wegen seines eigenartigen Parasitismus weiterer Aufmerksamkeit empfohlen sein.

Balansia diadema nov. spec. In der kleinen mykologischen Gemeinde am Itajahý, welche aus Fritz Mïller und seinen Enkeln, Frau Brockes, Herrn Erich Gärtner und mir bestand, nannte man den "Krönchenpilz", jene zierliche Form, welche die Aehrchen eines locker rispigen Panicum in der durch die Photographie Taf. $\mathrm{X}$ Fig. 1 und die Zeichnung Fig. 74 Taf. T dargestellten Weise schmückte. Ein oder auch zwei benachbarte Aehrchen waren von Pilzmycel umsponnen und durchwuchert, doch so, dass sie in ihrer Gestalt deutlich erhalten und sichtbar, dass insbesondere auch ihre einhüllenden Spelzen zwar durch Pilzfäden den Aehrchen fest aufgeheftet, aber nicht unkenntlich geworden waren. Zwischen den breit einander gegenüber stehenden Spelzen des obersten fertilen Blüthchens war an Stelle des Frnchtknotens ein reines dicht verflochtenes Pilzgewebe vorhanden und dies erweiterte sich nach oben über die Grenzen des Aehrchens in ein parallel zur Fläche der Spelzen vorquellendes Polster, aus dem unmittelbar an dem Grase selbst die perithecientragenden Küpfchen hervorsprossten. Oftmals waren es fïnf in gleichmässiger Anordnung, eins auf der Spitze, zwei an jeder Seite, oder sechs, drei auf jeder Seite, wo denn das befallene Aehrchen eine kleine Krone darstellte. In anderen Fällen, z. B. in dem abgebildeten (Fig. 74), war die Anordnuug der Köpfchen weniger reg'elmässig.

Der Pilz wurde in Fritz Mïllers Garten und Pflanzung im April 1892 und in sehr reicher Verbreitung im März 1893 gefunden. Jüngere Aehrchen waren von eineru Mycel aus feinen 
kaum 2 " starken Fäden locker durch- und umwuchert. Wie schon erwälınt, waren öfter auch zwei benachbarte Aehrchen durch das Mycel fest mit einander vereinigt, und in dieses war auch wohl die Aehrenspindel so fest mit eingeschlossen, dass man sie ohne Zerreissung des Pilzgewebes nicht lösen konnte. Untersucht man ein Aehrchen, an dem die Perithecienträger völlig entwickelt sind, so findet man, dass sie ans einem ganz dicht verflochtenen, kaum liart zı nennenden Stroma entspringen, welches nach oben und aussen. also iiber dem Aehrchen, eine Art dunkelgelb gefärbter Rindenschicht ausgebildet hat, keineswegs aber eine so ausgeprägte Rinde, wie etwa ein echtes Mutterkorn. Dies Stroma findet nach unten zu seine Fortsetzung zunächst in dem Fruchtknoten der oberen fertilen Blïthe des Aelrrehens, sodann in lückenlosem Pilzgewebe zwischen den Spelzen des ganzen Aehrchens und führt dann allmählich in das lockere feinfädige Hyphengeflecht ïber, welches die Bliithentheile und auch die Spindel umhïllt und durchflechtet. ron einem in sich abgeschlossenen Sclerotium ist keine Rede. Tielmehr ist das Verhältniss hier genan dasselbe wie z. B. bei Balansia clariceps und trinitensis. welche die Aelırchen rom Panicum und anderen Gräseru vollständig. einhüllen, und damn Perithecienköpfe treiben. nur mit dem C'nterschiede, dass die Farbe unserer Balansia diadema hellgelblich, und nirgends schwar" ist. Die Stiele der Perithecienköpfe sind etwa 2-4 mm lang, die Köpfchen haben meist nur ${ }^{1}{ }_{2}-1 \mathrm{~mm}$ Durchmesser, ihre Form ist aus dem Längsschnittbilde Fig. 74 ersichtlich. Die Perithecien ragen nur mit der Mlündung wenig über die Oberfläche des Köpfchens hervor. Sie sind etwa 250 "l lang. die Länge der selır feinen schläuche ist ca. $130 \mu$.

Die in Nährlösung aufgefangenen Fadensporen zeigen viele Theilzellen, welche etwas anschwellen und sofort Keimschläuche treiben. Es bilden sich sehr schnell reich rerzweigte Mycelien von 3 " starken Fäden, welche nach drei Tagen sowohl in der Flüssigkeit, als anch uiber iln in Luft an kleinen zugespitzten seiten- 
zweigen ovale $7-9 \mu$ lange, am unteren Ende zugespitzte Conidien abschnïren. Diese theilen sich meist durch eine Querwand in zwei Zellen, ehe sie auskeimen und wieder gleiche conidientragende Mycelien erzeugen. Die Zweitheilnug mo die Auskeimung; letztere auch ohne Zweitheilung, kömnen schon eintreten, während die Conidie noch am Träger sitzt, und ich habe Fälle gefunden, wie Fig. 74, wo die ansitzende Conidie keimt. der kurze Keimschlauch eine nene Conidie erzengt. die ihrerseits an einem Keimschlanch noch eine dritte Conidie bildete. Dieselbe Spitze schnürt nach und nach mehrere Conidien ab, doch kam ein Zusammenkleben derselben zu Köpfehen nicht vor. An den $\mathbf{M y}$ celien sind Fadenbrücken selır häufig.

Unser Pilz ist der ron Winter in der Hedwigia 1887 Seite 32 reröffentlichten Balansia pallida Wint. offenbar aufs nächste rerwandt. Das Naterial zu jener Beschreibung hat Ule bei São Francisco gesammelt. Winter giebt aber an. dass jüngere Stromata seiner Form mit langen (4t-62 "') gekrümmten, die ganze Oberfläche bedeckenden Conidien besetzt waren. Da solche Conidien, welche in diesem Verwandtschaftskreise eine sehr auffällige Erscheinung wären, dem von mir beobachteten Pilze nicht zukommen, dessen Conidien vielmehr, wie wir gesehen haben, ganz ander's gestaltet sind, so ist es unmöglich ihn mit der Balausia pallida Wint. zu identifiziren.

Dass aber unser Pilz ebensowohl wie der Wintersche bei der' Gattung Balansia seine richtige Stelle findet, scheint mir nach Unitersuchung seines Stromas zweifellos zu sein. Wenn wir Verwirrung vermeiden wollen, können wir ihn nicht zu Claviceps stellen, denn diese Gattung ist nach dem Typus der klassischen Clar. purpurea durch den Besitz eines echten festrindigen, für einen längeren Ruhezustand augepassten Sclerotiums charakterisirt.

Claviceps balansioüdes nor. spec. Auf einem locker rispigen Panicum (Echinochloa) mit breiten Blättern, das bei Blumenau 
lıäufig ist, fand ich in den Jahren 1891 und 1892 in den Monaten Mai und Juni eine sclerotiumartige Bildung, die meine Aufmerksamkeit erregte. Die kleinen Aehrchen dieses Grases bestehen aus zwei Deckspelzen, welche ein unteres steriles und ein oberes fertiles Blüthchen einschliessen. Bei den von dem Pilze befallenen Aehrchen ist zunächst entweder nur die obere fertile Blüthe oder aber auch das ganze Aehrchen, ja bisweilen sind zwei dicht bei einander stehende Aehrchen zusammen ron dem Mycel durch- und mmzogen. Auf den Spelzen bildet sich ein weissflaumiger Ueberzug, an dem auch farblose längliche Conidien von 9-12 " Länge entstehen. Bei weiterem Fortschritt der Entwickelung des Pilzes werden allmählich alle Zwischenräume zwischen den Spelzen vollkommen mit einem sich immer dichter ver'flechtenden Mycelium ausgefüllt, das ganze Aehrchen. oder auch wenn zwei benachbarte zusammen befallen sind, diese beiden werden in ein sclerotimmartiges Gebilde verwandelt, welches jedoch die Blüthentheile nicht verzehrt, sondern sie umschliesst, in ganz gleicher Weise. wie wir es bei Balansia fanden. Auch im vorliegenden Falle schliesst sich die fertige sclerotiale Bildung der Form des befallenen eingeschlossenen A ehrchens an. Den Spitzen der Spelzen entsprechen stumpfeckige Herrorragungen und die Form ist in allgemeinen eine umgekehrt trichterförmige. enge unten an der Ansatzstelle des Aehrchens und nach oben sich rerbreiternd. Dies ist in noch höherem Grale der Fall, wenn. wie in der Abbildung Fig. $73 \mathrm{a}$, zwei tehrchen von einem Sclerotium umwachsen sind. Die unteren Hüllspelzen bleiben meist ausserhalb des sclerotiums, aber auch die äussere Spitze des unteren sterilen Blüthchens ist in dem reifen Sclerotium oft der Struktur nach noch erkembar, weil sie nur durch eine dicht auflagernde dïnne Schichte von Pilzmycel überdeckt wird. An Stelle des im Anfang rorhandenen lockeren weissen conidientragenden Ueberzugs tritt mit der Ausreifung eine tiefblauschwarze Sclerotiumrinde. Die Sclerotien sind von ungleicher Grösse. Bei ïppiger 
Ernährung wachsen sie auch ïber die befallenen tehrchen nach oben hin etwas weiter ans mo bilden dort einen nur aus Pilzmasse bestehenden von Einschlüssen freien oberen Theil.

Die znerst aufgefundenen wenigen kleinen sclerotien legte ich im Mai 1891 auf feuchten Sand in eine Glasschale. Sie keimten Mitte September ans. Eines derselben ist in Fig. $73 \mathrm{~b}$ in doppelter natïrlicher Grösse abgebildet. Ungleich kräftigere und zahlreichere Sclerotien sammelte ich im nächsten Jahre, im .I uni 1892. Ich legte sie am 19. Juni aus. Die ersten Keimungen erschienen Ende September desselben Jahres, und im Oktober keimten dann die meisten, aber bei vielen verzögerte sich die Keimung länger, und trat erst während des November, Dezember und Januar nach und nach ein. Im Januar keimten die letzten der zahlreich ausgelegten Bildungen. Die Keimung erfolgt an beliebiger stelle, und es wird die schwarze Rinde dabei durch eine winzige Oeffnung durchbrochen. Das austretende Hyphenbündel verbreitert sich alsbald und es wird sofort, noch ehe die Streckung des Stieles beginnt, das rundliche Köpfchen angelegt. Sobald eine geringe Verdickung des anstretenden Fruchtkörpers an seiner Spitze bemerkbar ist, sieht man auch schon darin die Anlage der Perithecien in Gestalt heller Fadenknäuel dicht unter der Oberfläche. Im Terlaufe weniger Tage wird dann der zarte Stiel, der ebenso wie das Köpfchen von hellgelber Farbe ist und bleibt (Saccardo Chrom. zwischen 24 und 28), bis zu beträchtlicher Höhẹ gestreckt. Kleinere Sclerotien erzeugen nur eiren Fruclitkörper, grössere deren mehrere; einer der kräftigsten mit fünf Fruchtkörpern ist in der Figur 73 a in natïrlicher Grösse dargestellt. Nan sieht, dass die Stiele bis zu $8 \mathrm{~cm}$ Länge, die Köpfchen einen Durchmesser von $1^{1 / 2} \mathrm{~mm}$ erreichen. Die Stiele sind dentlich lichtwendig. Das Köpfchen ist vom Stiel deutlich abgesetzt, wie der Längsschnitt (Fig. 73 c) andeutet, es reicht nach unten kragenartig ein wenig über den Stiel, was in gleicher Weise für Clav. purpurea zutrifft. Die Perithecien haben etwa 300 « ganze Länge 
und ragen mit 1/4 oder etwas mehr dieser Länge frei lıerans, so dass sie dem Köpfchen ein morgensternartiges Anselıen geben. Die Schläuche (Fig. $73 \mathrm{~d}$ ) sind selır zart, 150-180 " lang, 3 " dick, an der Spitze mit kleiner hyaliner Kappe. Die fadenförmigen Sporen, welche nur 1/g " Durchmesser haben, und im Schlanche im frischen Znstande noch keine Theilwände erkennen lassen, werden in grossen Mengen ausgeschleudert und können auf Objektträgern leicht rein aufgefangen werden. Sie schwellen da znnächst stark an auf 3-4, 4 Dicke und theilen sich durch zahlreiche Qnerwände (s. Fig. 73e). Kurze Seitenverzweigungen erzengen alsbald reichlich ovale hyaline Conidien von 12 " Länge und 5 " Breite. Die 'Träger der Conidien sind anffallend dimmer' als die ibbrigen Hyphen, welche kurze dicke Theilzellen lıaben. Sie schnüren nach und nach mehrere Conidien ab, aber diese verkleben nur selten zu zweien, nie zu Köpfchen, meist sitzt nur eine Conidie anf dem 'Träger. Abgefallen keimen die Conidien sofort (Fig. 73f) und erzengen neue conidientragende Mycelien. Im Laufe der Keit erzog ich anf den Objektträger und auch in Brefeldschen Kulturfläschchen (s. Heft 6 dieser Mittl. s. 55) bis thalergrosse dicht verflochtene Mycelrasen mit reichlichem Luftmycel; sie waren mit Conidienträgern ïberall, aber immerlnim spärlich. nicht in dichter schicht bedeckt.

Die Claviceps balansioüdes ist eine höchst benterkenswerthe Zwischenform zwischen Balansia und Claviceps. Bei ihr ist noch kein echtes sclerotium rorhanden, das wie beim Mntterkorn eine eigene typische Gestalt anfwiese, und nur ans reinem Pilzgewebe bestände. Hier werden nur, genan wie bei Balansia, Blïtlren und Blüthentheile mmsponnen und eingesclılossen, und schliesslich mit sammt den dazwischen liegenden sclerotienartigen Pilzbildungen von einer schwarzen einheitlichen Aussenrinde umlïllt. Aber die eingeschlossenen Blüthentheile bleiben grösstentheils erlualten. und die Form des Sclerotiuns ist nur eine plumpere, in den Contouren abgermulete Nachahmung der mmsponnenen Bliithen und Bliithentheile, 
keine Psendomorphose und auch kein selbstständig geformtes Gebilde in dem Simne, wie das Mutterkorn. Nur insofern zeigt dies Sclerotium eine viel grössere Selbstständigkeit, als es nicht unmittelbar in den perithecientragenden gestielten Kopf überführt. sonderu zu einer mehrmonatlichen Ruhezeit ausgeruistet ist. Erst nach deren Ablauf erscheinen die Perithecienköpfe, sie sind aber jetzt ron ganz anderer Beschaffenheit und Farbe, als diejenigen der Balansia, welche nur als Ausläufer des sclerotialen Stromas aufgefasst werden kömnen. Mit anderen Trorten, die 'T'rennung' des Stromas in einen sterilen und einen fertilen Theil. welche bei Epichloë noch fehlt, bei Ophiodotis sich andeutet, bei Balansia zu bestimmter Form der fertilen Theile fülıt. wird bei Claviceps eine ganz scharfe. Jeder der beiden Theile verfolgt nun eine eigene seinen besondereu Aufgaben entsprechende Entwickelungsrichtung. Das sclerotiale Stroma umgiebt sich mit fester. meist wohl schwarzer Rinde für die Ruheperiode, das sporentragende Köpfchen wächst schnell auf zartem hellgefärbten Stielchen zn relativ bedeutender Höhe, und sinkt nach der Sporenentleerung mit dem Stiele zusammen.

Man wird vielleicht die Abgrenzung der Gattung Claviceps gegen Balansia durch den physiologischen Unterschied der Ruheperiode des Sclerotiums beanstanden. Aber auch wemn hiermit Hand in Hand nicht die oben näher geschilderten Unterschiede sich nachweisen liessen, so ist doch nicht abzusehen, warum für die praktische Frage der Gattungsbildung nicht ein so scharf hervortretendes, wenn auch physiologisches Merkmal sollte verwendet werden. Ist doch, wenn wir genau zusehen, die vielgestaltige Gattung Cordyceps nur durch einen physiologischen Charakter, den Parasitismus auf Insekten oder unterirdischen Pilzen zusammengehalten.

Die phylogenetische Entstehungsgeschichte der wunderbaren Bildung der Claviceps purpurea, welche dem Verständniss vollständig unzugänglich war, so lange man nur die europäischen 
Formen kannte, wird durch die num bekannten Uebergangsformen anfs deutlichste klargelegt.

Gegenüber dem balansiaartigen Sclerotium der eben beschriebenen Form zeigt nun Claviceps lutea nor. spec. zunächst einen weiteren bemerkenswerthen Fortschritt durch die Bildung eines schon viel selbstständiger, in bestimmter ron der Wirthspflanze weniger beeinflusster Form auftretenden Sclerotiums. Der Pilz wurde auf einem lockerrispigen Paspalum im Mai 1891, dann im Mai 1892 gesammelt. Reichliches Material sammelte Frau Brockes auf demselben Grase im Jahre 1895. Ausserdem fand ich auf Panicum zizanioides im Juni 1892 Sclerotien, die denen der Claviceps lutea äusserlich ganz ähnlich, nur entsprechend den etwas grösseren Aehrchen dieses Grases auch etwas stärker waren; doch habe ich bei den letzterwälnten die Keimung nicht beobachtet.

Ehe die Sclerotien zur Ausbildung kommen, sind die Bliithchen von einem lockeren wolligen Geflechte sehr feiner weisser Hyphen durch- und umsponnen, an dem auch Conidien ron derselben Form und Grösse gefunden wurden, wie sie später an den Kulturen der Ascussporen auftraten. Das Sclerotium bildet sich aber hier ïber dem Aehrchen aus, in Form einer kappenartigen gekrümmten Wulst (s. Fig. 71 Taf. V). Die grössten Sclerotien hatten etwa $3 \mathrm{~mm}$ Dnrchmesser. Sie sitzen dem Aehrchen fest auf, und ragen mit Wnrzeln aus fest rerflochtenem Mycel in dessen Fruchtknoten und zwischen seine Spelzen hinein; sie fallen mit dem Aehrchen zusammen ab, und dieses sitzt wie ein kurzer kegelförmiger Stiel dem Sclerotium fest an. Wenn das letztere aber völlig ansgereift ist, so lässt es sich leicht von dem an Nährstofłen nun ganz erschöpften Aehrchen tremnen (Fig. 71 rechts). Die Sclerotien sind im Innern weiss, sie bilden eine deutliche scharf abgesetzte Rindenschicht aus ziemlich isodiametrischen Zellen mit schwach verstärkten Wänden ans. Diese Rinde ist von ansgesprochen gelber Farbe (Sacc. luteus 22) und schwach körneligraulh. Die Sclerotien lagen vom Mai bis Dezember auf feuchtem 
Sande und keimten dann je mit einem oder auch zwei langen feinen hellgelbeu (Sacc. sulphurens 25) Stielen aus, die bis zu $4 \mathrm{~mm}$ Länge erreichten und an ihrem Ende ein mit Perithecien dicht besetztes honiggelbes (mellens 30 ) rundes Köpfchen von 11/2 $\mathrm{mm}$ Durchmesser trugen. Die im Imnern angelegten Perithecien erscheineu zunächst als helle Pünktchen auf der Oberfläche des Köpfchens, dann aber wachsen sie nach oben zu einer länglich kegelförmigen Spitze aus. Diese Perithecienköpfchen haben nach Farbe, Grösse und Gestalt vollkommenste Aehnlichkeit mit den aus den Halbsclerotien der Clariceps balansioides erzogenen. Die Schlauchlänge beträgt etwa 250 !, die charakteristische etwas verdickte hyaline Kappe fehlt auch bei ilmen nicht, die Sporen messen etwa $180 \mu$. Die Keimung erfolgt in Nähriösung sofort, indem die Spore etwas anschwillt, sich durch Querwände theilt, Seitenverzweigungen treibt, und schon nach 24 Stunden an diesen 9 " lange und etwa 2 " breite Conidien in grossen Mengen hervorbringt. Im Kulturtropfen entstehen Mycelflocken von beschränktem Umfange mit reichlichem Luftmycel und üppiger Conidienfruktifikation.

Claviceps ranunculoides nov. spec. (Taf. V Fig. 72) zeigt ein Sclerotium ron der typischen Form des Mutterkorns. Hornartig gekrïmmt standen die Sclerotien deutlich schon von weitem sichtbar auf den bürstenförmigen Aehren einer Setaria, die am 3. Mai 1892 nahe bei Fritz Miillers Wohnung gefundeu wurde. An denselben Aehren beobachtete ich auch jüngere noch mausgebildete sclerotienanlagen und dabei typische Sphacelialager von orangerother Färbung. Die hier in grossen Massen gebildeten Conidien waren oval und latten $7-8 \mu$ Länge bei 3 bis 4 « Breite. Die Sclerotien wurden auf feuchtem Sande ausgelegt, es dauerte aber beinahe neun Monate, bis zum 22. Januar 1893, ehe die Keimung an einzelnen eintrat. Die Perithecienfrüchte sind hellgelb, am Fusse, wie bei Clav. purpurea etwas verdickt und mit Hyphenfilz auch wohl haarartig umgeben.' Sehr be- 
merkenswerth ist die Bildung der Perithecienköpfe, welche mit Rammkelfrïchten eine auffallende Aelınlichkeit haben, wie das ein Blick auf die prächtigen von Herrn Volk vorzüglich hergestellten Zeichnungen der Fig. 72b und c darthut. Man kann sich nach der Zeichnumg leicht vorstellen, dass nur die obersten mittleren Perithecien symmetrisch ausgebildet sind, die iibrigen sind seitlich angefügt und angebogen und dementsprechend anch in ihrem Hohlraume einseitig ansgebaucht. Ganz ähnlichen Bildungen begegnen wir bei einigen Cordycepsarten und iclı verweise vorläufig unr auf die Fig. 90 ı. 92 der Taf. VI. Trotzdem sind diese Perithecien als eingesenkt zu bezeichnen. Deun auch die äussersten sind nicht nur von ihrer eigenen Wand eingeschlossen, sondern das Stromagewebe, welches man ron den diumen Perithecienwandungen auf jedem schnitt deutlich unterscheiden kamn umhïllt auch alle Perithecien bis auf die flach lialbkuglige Spitze, welche frei herausragt. Die Perithecien haben rom Grunde bis zur Spitze 400-500 " Länge. die fadenförmigen Schläuche mit sehr flacher Kappe erreichen 300 " und dariiber bei 4 " Breite. Die Fadensporen fing ich in Wasser und Nährlösmng auf, und fand ihre Läıge zu 160 ". Sie zeigen bald je einige 30 etwa 5 " lange Theilzellen, welche in der Nitte etwas anschwellen. Schon einen Tag nach der Aussaat brechen die Sporen in die Theilzellen ans einander, und die letzteren keimen einzeln ans. Die ersten Keimschlänche treten je aus den Enden der Theilsporen in deren grader Terlängerung ans. und eben anf diesen Umstand ist es zurïickzufïlıren, dass die Sporen vollständig zerbrochen werden. Die Mycelien erreichten in den nächsten vier T'agen ziemlich reiche Entwickelung mit Luftmycel, ele Conidienbildung an den in die Luft ragenden Fadenenden beginnt. Es werden hier längliche hyaline Conidien von 8-12 "Länge nnd 2 "Breite, melırere linter einander von derselben Fadenspitze abgeschniint. Sie rerkleben lıäufig anf der Spitze zı runden Köpfchen. Aus ihnen konnten leicht im Terlauf weniger Tage gleiche conidienbildende Mycelien 
wieder erzogen werden. Auffallend ist, dass die Form dieser Conidien von derjenigen der oben beschriebenen Sphaceliaconidien nicht unerheblich abweicht.

Cordyceps Fries. Die Artenanzahl der Gattung Cordyceps ist allmählich und mit immer steigender Geschwindigkeit zu beträchtlicher Höhe gewachsen. Tulasne behandelte im III. Bande der Carpologie ein Dntzend Arten. Cooke zählt deren in seinem 1892 erschienenem Buche: „Vegetable Wasps and Plant Worms“ schon gegen 50 auf, während Massee 1895 in den Annals of Botany eine „Rerision of the Genus Cordyceps“ lieferte, welche 62 Arten enthält. Mit den seither noch beschriebenen und den im Folgenden bekannt gemachten Arten wird die Zahl 100 nahezu erreicht. Ueberblicken wir sie in der Gesammtheit, so begegnen wir einer solchen Mannigfaltigkeit und Verschiedenheit der Gestaltungen, dass an gemeinsamen Charakteren aller. also an Gattungscharakteren schliesslich nur der Besitz der langen fadensporigen Schläuche und die biologische Eigenthümlichkeit übrig bleibt, derzufolge alle diese Pilze auf Insekten (nur zwei auf unterirdischen Pilzen) schmarotzen.

Ein ungewöhnlich grosses Maass individueller Formverschiedenheiten zusammen mit dem Umstande, dass viele, besonders ausländische Arten nur auf Grund eines oder weniger Fundstücke beschrieben werden mussten, macht die Bestimmung ron Cordycepsformen durch kure Beschreibungen ausserordentlich schwierig. Es verhält sich in dieser Beziehung mit ihnen ganz ähnlich wie mit den Phalloideen (rgl. Einleitung zu Heft VII dieser Mittheil.); grade wie dort, so sind anch hier gute Abbildungen ein fast unumgängliches Erforderniss. Ich bin deshalb meinem verehrten Freunde, Herrn Richard Volk in Hamburg zu ganz besonderem Danke verpflichtet, dass er seine hervorragende künstlerische Fähigkeit in den Dienst der Sache stellte, und der Abbildung meiner Cordycepsfunde aus Blumenau sich mit wahrer Hingebung vidmete, wodurch allein eine so trene und dabei so schöne Samm- 
hung ron Bildern dieser wunderbaren Pilze geschaffen werden konnte, wie die Tafeln VI und VII nun darbieten.

Eine besondere Scliwierigkeit für die Bestimmung ausländischer Cordycepsarten liegt in dem Umstande, dass die bisherigen besseren Diagnosen fast immer die Länge der Schläuche und Sporen und den Zerfall der letateren in Theilsporen, sowie deren Länge angeben. Wenn diese Maasse, wie es fast ausnahmslos geschieht, nach trocknem oder in Alkohol aufbewahrtem Material festgestellt werden, so sind sie immer unzuverlässig. Ich habe mich oft davon überzengt, dass bei Alkohohmaterial scheinbare Querwände in den Sporen auftreten und eine Bildung ron Theilzellen, welche der Wirklichkeit in frischem Zustande gar nicht entspricht. Dass die Länge der Schläuche und Sporen fast nie sicher festzustellen ist, wird jeder zugestehen, der derartige Messungen gewissenhaft zu machen oftmals versucht hat. Die Sporenlänge ganz sicher zu ermitteln gelingt nur, wenn man die Sporen in frischem Zustande auf Glasplatten auffängt. Wo dies nicht möglich ist, möchte ich für die Beschreibung konservirten Materiales empfehlen, möglichst mediane Schnitte durclı die Perithecien anzufertigen. und die Gestalt und Grösse der Perithecienlängsschnitte genau anzugeben. Diese Angabe wird im allgemeinen sicherer ınd zuverlässiger ausfallen können, als die bisher berorzugten ron der Länge der Sporen und deren angeblichen Theilzellen.

Dass ich eine Zerleg'ung der Gattung Cordyceps vorläufig nicht für zweckmässig halte. insbesondere also weder Torrubiella Boudier, noch Cordylia Tul. als selbstständige Gattungen behandelt sehen möchte, habe ich schon oben (S. 144) ausgeführt; bei Betrachtung der einzehen Formen wird sich Gelegenheit bieten, anf die Frage zurückzukommen.

Cordyceps flaro-riridis nor. spec. (Taf. VTI Fig. 97 a, b, c, d). Die von Herrn Volk in natïrlicher Grösse und Farbe abgebildete Form fand sich auf Blättern einer Calathea, wo sie ein dicht anliegendes lockerfilziges Fadengewirr bildete, welches einige win- 
zigee braun gefärbte Puppen zum Ausgangspunkt hatte. Diese Puppen, welche ron dem filzigen Hycel dicht eingehïllt waren, sind zum Zwecke der Abbildung freigelegt worden.

Von dem Gewirr der Fäden strahlen nach verschiedenen Richtungeu dichter verflochtene grauweisse Stränge ron etwa $1 \mathrm{~mm}$ Stärke aus, und auf diesen sitzen frei. einzehn oder in Gruppen, die lang flaschenförmigen gelbgrünen Perithecien. Thre Länge beträgt ${ }^{1 / 2}$ mm. Die Schläuche mit der schwach verdickten hyalinen Kappe und die Fadensporen zeigen keine Besonderheiten. Letztere lassen sich leicht einzeln in Nährlösungen anffangen, und keimen sofort, wobei sie etwas aufschwellen und an den nun erst deutlich werdenden Scheidewänden etras eingeschnürt erscheinen (Fig. 97d). Die Keimschläuche treten zwar häufig, allein durchans nicht immer dicht an den Querwänden der Spore aus. Alsbald werden rundlich orale Conidien ron 2-3 ", Durchmesser in grossen Mengen sowohl unmittelbar an der Spore, als auch hauptsächlich auf kurzen sterigmaartigen zugespitzten Seitenzweigen in der Weise gebildet, wie die Figur erkennen lässt. Zunächst in der Flüssigkeit gebildet, lösen sich die Conidien rom Träger leicht $a b$ und liegen oft in grosser Zahl um ilm herum. Später werden sie an dem reichlich sich bildenden Luftmycel (Fig. 97 c) abgeschnïrt; es entstanden auf den Kulturen dichte Rasen von verzweigten Conidienträgerm, die an der Spitze und auch seitwärts oft in wirteliger Anordnung Conidien erzengten (Fig. $97 \mathrm{~d}$ ). Dass noch am Tragfaden ansitzende Conidien auskeimten, und Sekundärconidien bildeten, wurde hänfig beobachtet. Die Kulturen wurden rom 18. Februar bis 4. März 1891 fortgesetzt, und dann abgebrochen. da weitere Entwickelung nicht zu erwarten war.

Man sieht leicht ein, dass die vorliegende Form zu Torrubiella Boudier zu ziehen sein würde, weil diese Gattung durch den Mangel eines ausserhalb des Insektenkörpers selbstständig aufstrebenden, irgendwie gestalteten Stromas charakterisirt wird. Ebenso ist aber einleuchtend, dass die hier rorkommenden wenig Schimper's Mittheilungen, Heft 9 . 
festen, dem Blatte anliegenden Mycelstränge, welche die Perithecien tragen uur ein wenig fester verflochten zu sein brauchten, um aufrecht zu stehen und den Unterschied von Torrubiella und Cordyceps in ein Nichts aufzulösen.

Cordyceps gonylepticida nor. spec. (Taf. VI Fig. 89). Am 5. November 1892 fand ich im Telhathale zwischen am Boden liegenden Rindenstïckchen eine kleine Spinne, deren ganzer Körper einschliessliclı der Beine dicht, doch in unregelmässiger Anordnung mit orangerothen frei aufsitzenden flaschenförmigen Perithecien besetzt war (Fig. 89 Taf. VI). Die Spinne war, als ich sie auffand, vollkommen unverletzt, wie die Abbildung in doppelter natürlicher Grösse sie darstellt. Mit Herrn Dr. von Brunns güitiger Hülfewurde sie in Hamburg als Gonyleptus nahe verwandt festgestellt. Auf dem Transport waren die Beine z. Th. zerbrochen, die Hinterbeine beide ganz abgebrochen. Herr Volk hat der Abbildung die grösste Sorgfalt gewidmet, nur entstand die Frage, ob die Hinterbeine richtiger als Obeine oder als Xbeine angeheftet werden müssten. Nach Vergleich mit dem Sammlungsmaterial des Hamburger Naturhistorischen Museums wurde das letztere schliesslich für richtig erachtet.

Die flaschenförmigen Perithecien sind 300-400 " lang und haben eine verhältnissmässig dicke plectenchymatische Wandung. Die gewölbten Zellwände der ziemlich isodiametrischen Aussenzellen lassen die Perithecienwand unterm Mikroskop uneben, stumpf gebuckelt erscheinen. Die Schlauchlänge beträgt etwa $170 ~ "$ bei nur 3 " Stärke. Die fadenförmigen Sporen lassen am Alkoholmaterial schon im Schlauche Theilzellen ron etwa $7 \mu$ Länge sichtbar werden. Doch möchte ich, wie oben erwähnt, diesen Maassangaben nicht eine zu grosse Bedeutung einräumen.

Es ist bei dieser Cordyceps gonylepticida von einem Stroma ausserhalb des Spinnenleibes nicht das geringste zu bemerken. Wir können aber olme Zwang jedes Spinnenbein. das ja von dem Mycel des Pilzes ganz durchwuchert ist, als ein Stroma ansehen. 
Ind der morphologische Werthunterschied zwischen einem solchen in dem Bein, gewissermaassen in einer "Lehre", gebildeten Stroma und den freien Mycelsträngen der vorigen Form oder den aufrecht stehenden schlanken zugespitzten Stromaten, wie sie Tulasne für Cordyceps Sphingum abbildet (Carpol. III Taf. I Fig. 2), ist in der That nicht gross.

Mit Boudiers Torrubiella aranicida kann unsere Cordyceps nicht vereinigt werden, denn dort sitzen die Perithecien auf einem byssoiden Mycelfilz.

Cordyceps rhynchoticola nov. spec. (Taf. VI Fig. 87) wurde nur in einem Stïck, doch in prachtroller Entrickelung auf einer Blattwanze an einem Serjaniastamme in der Nähe des Telhaflüsschens bei Blumenau gefunden. Der eigenartige Fund ist in Fig. 87 Taf. VI in dreifacher linearer Vergrösserung dargestellt. Das ganze Thier ist ron einem lockeren anliegenden Hyphenfilz bedeckt und eingehiillt, ind dieser heftet es an die Unterlage fest, und breitet sich auch auf derselben noch etwas aus. Die Perithecien stehen einzeln und in Gruppen in grosser Zahl auf dem ganzen Körper des Insekts. Sie sind ron braungrünlicher Färbung, 600-700 « lang, 250 " dick, flaschenförmig und zum grössten Theil von demselben lockeren Hyphenfilz gleichartiger locker verwirrter 1,5 "u dicker Fäden, aus welchem sie sich erheben, wie von einem äusseren Mantel eingehüllt. Nur ihre Spitze ragt mit etwa 250 " Länge frei hervor, wie das Herr Volk aucl in der Zeichnung sehr schön zum Ausdruck gebracht hat. Einzelne Perithecien finden sich auch ausserhalb der Insektenleiche auf den Hyphengeflecht, welches das Rindensubstrat iiberzieht (Fig. 87 rechts). An zwei Stellen auf dem Rücken des Insektes erheben sich Hyphenbündel in Form aufrechtstehender Stromata ganz genau denen der später zu besprechenden, weit höher organisirten Cord. Mölleri entsprechend. Diese tragen im rorliegenden Falle nach keine Peritlecien. So gut aber solche, wie wir auch in dem Bilde erkennen, auf dem flachen filzigen Stroma seitwärts 
der Wauze rorkommen, ebenso gut mögen sie bei üppiger Entwickelung auch auf diesen senkrecht sich erhebenden Hyphensäulchen entstehen können. Wenn eine Form, so ist diese geeignet, die Grenze von Torrubiella zu Cordyceps zu ïberbrïcken. Die Perithecien enthalten sehr feine Schläuche von 380 " Länge mit fadenförmigen Sporen. Ich lıabe von diesen Sporen sofort nach dem Auffinden des Objekts Aussaaten in Nährlösung gemacht, und in der Zeit vom 25. Februar bis 9. März reich verzweigte Mycelien daraus erzogen, an denen keinerlei Conidienbildung auftrat. Die sporen zeigten bei der Keimung fast keine Anschwellung. Die Länge ihrer Theilzellen liabe ich leider nicht gemessen, nach dem Alkoholmaterial ist sie mit Sicherheit nicht melır festzustellen.

Cordyceps cristata nov. spec. (Taf. TI Fig. 81). Das einzige im Nai 1892 auf der „scharfen Ecke“ bei Blumenau gefundene Exemplar erscheint in Herrn Tolks meisterhafter Darstellung in doppelter natürlicher Grösse. Eine düster gefärbte Motte, wohl eine Noctuine, ist von dem Pilze befallen. Der Pilz tritt an den Beinen des Schmetterlings ins Freie, die Torderbeine sind durch Pilzgeflecht unnatiurlich verdickt, und alle Beine sind durch die Hyphen dem Blatte fest angeheftet. Die hellgelben Perithecien stehen auf einem lockeren wenig entwickelten äusseren Stroma. halb eingehïllt, am Kopf, an den Leibsegmenten nnd der Länge nach zwischen den Flügeln, auch auf den Flïgeladern und Beinen zu kleineren und grösseren Kämmen reihenweise geordnet. Sie sind 300-500 "lang, eiförmig, mit fester Wandung versehen. Die Schlauchlänge beträgt bis $300 \mu$ und das Alkoholmaterial lässt Theilzellen von $4 \mu$ Länge an den Fadensporen erkemnen.

Cordyceps cristata schliesst sich den bisher besprochenen durch die geringe Entwickelung eines ausserhalb des Insektenkörpers auftretenden Stromas an. Bei allen folgenden Arten werden die Perithecien über den Insektenkörper linausgehoben, und in der Bildung ihrer 'Träger, also der' äusseren Stromata finden wir ähn- 
liche Abstufungen, wie solche in den verschiedenen Reihen der Hypocreaceen rerfolgt werden konnten.

Wir besprechen zunächst zwei Formen mit ganz oder fast ganz freistehenden Perithecien.

Cordyceps polyarthra nor. spec. ('Taf. VI Fig. 83). Aus einer zwischen moderndem Laub am Boden liegenden im Telhathale am 18. Februar 1892 gefundenen grossen sphingiden-Puppe erheben sich über ein Dutzend perithecientragende Keulen ron rerschiedener bis zu $5^{1}, \mathrm{~cm}$ ansteigender Länge und kaum $1 \mathrm{~mm}$ Stärke, ron honiggelber Farbe (Sacc. 30 melleus). Sie sind ron weicher hinfälliger Beschaffenheit. Die Keulen, unter denen sich anch eine gabelästig getheilte befand (s. d. Figur), tragen nur in ihrer oberen Hälfte Perithecien. welche dicht gedrängt der Keule frei aufsitzen, aber mit einer Nadel leicht abgenommen werden und sich dann ron einander olme Mühe tremen. Der peritlecientragende Theil des Trägers ist kaum dicker; als der untere, er erscheint als Keule nur durch die aufsitzenden Früchte. Nicht an allen Stiicken ungeben die Perithecien den 'Träger' gleichmässig ringsum, sondern an vielen bleibt an der einen Seite ein Längsstreifen frei, wodurch die Keule das Ansehen einer langgestielten nur zu ${ }^{3}{ }_{4}$ ihres Umfangs mit Borsten besetzten Bürste bekommt, wie solche zur Reinigung ron Flaschen und Cylindern benutzt zu werden pflegen. Die Puppe ron beinahe $2 \mathrm{~cm}$ Dicke und mit einer harten Spitze am einen Ende ist nur zu einem Theile erhalten, aber vollständig leer und hohl, also nur eine Hülle, welche zum grössten Theil aussen von einem seidenpapierdümmen Mycelhäutchen bedeckt wird, ans dem die bïrstenförmigen Träger ihren Ursprung nelmen. Diese selbst zeigen im Innern ein lïckenloses grosszelliges Gewebe, entstanden aus den ursprïnglich parallelen Fäden, welche als solche nicht melır erkennbar' sind. Die Perithecien sind birnenförmig, 300-400 "lang und etwa halb so breit. Sie laben eine doppelte Wandung, eine innere dunkler gefärbte dichtere, und darüber eine lockere aus 
grossmaschigem Hyphengewebe bestehende einfache Zellschicht. Die Länge der Schläuche beträgt etwa 150 \%. Vor allen anderen untersuchten sind sie dadurch ausgezeichnet, dass die hyaline Kappe bei ihnen fast fehlt. sie erscheint nur als ein winziges kaum wahrnehmbares helles knö̈pfchen. Die Fadensporen sind durch Qnerwände in 'Theilzellen zerlegt, deren Länge in frischem Znstande nicht gemessen wurde, und nach dem Alkoholmaterial mit voller Sicherheit nicht zu bestimmen ist.

Die Auskeimung in Nährlösung erfolgt fast unmittelbar nach der Aussaat. Es bilden sich üppig wachsende Mycelien, die alsbald an zugespitzten Luftfäden ovale Conidien von 3-6!" Länge nnd 2-4 " Breite in langen Fetten von eigenthïmlicher Bildungsweise erzengen (Taf. TI Fig. 82).

Unter der znerst abgeschniirten Conidie bildet sich eime nene am Tragfaden, welche die erste in die Höhe hebt und so weiter. Die später aussprossenden Conidien richten ihre Längsachse quer zum Träger, und nach verschiedenen Richtungen. Die Conidien bleiben in grosser Zahl zusammenlı̈ngend und bilden sehr lange Ketten ans weit melı wie 20 Conidien, welche in ihrem Aussehen an jene aus unregelmässigen Stïcken zusammengesetzten Korallenketten erimnern, wie man sie in Italien so häufig sielıt. Die Bildungsart ist ihrem Wesen nach dieselbe, wie wir sie für Ascopolyporus polyporoides kemnen lernten, nur dass bei jener Form niemals annähernd so viele Conidien wie hier zu einer Kette verklebt bleiben. Untergetaucht zerfallen die Ketten leicht in ihre einzelnen Glieder, deren jedes sofort anskeimt und Mycelien mit derselben Kettenfruktifikation er'zengt.

Ich fand dieselbe Form nocl eimmal am 11. Dezember 1892 auf einer sehr kleinen Puppe von noch nicht $1 \mathrm{~cm}$ Länge, die ebenfalls hohl nnd von Pilzmycel eingehiillt war. Hier stand unmittelbar neben dem Perithecienträger auf derselben Unterlage eine Isaria, ein 1,2 cm hoher an der Spitze pinselförmig in einzelne Aestchen aufgelöster 'Träger' mit stäubenden weissen Conidien 
ron der Form und Grösse der vorher beschriebenen, in künstlicher Kultur erzogenell. Bei der Untersuchung fielen alle Conidien ab, so dass ihre Bildungsweise am 'Träger nicht mehr sicher festgestellt werden konnte. Soweit die erhaltenen Reste indessen einen Schluss gestatten, bilden sich die eigenthümlichen vielgliedrigen Conikienketten auf dent Isariaträger genau so, wie in künstlicher Krultur.

In: Ellis \& Everhart "North American Pyrenonycetes“ findet sich auf Taf. XV Fig. 4 eine als Cord. Sphingum bezeichnete Form abgebildet, welche nit der unserigen Aehnlichkeit besitzt. Allein abgesehen davon, dass die beigegebene Beschreibung sehr erhebliche Unterschiede andeutet, so kann die C. polyarthra mit der von T'ulasne vortrefflich abgebildeten und geschilderten Cord. Sphingum unmöglich vereinigt werden, wie ein Blick auf die Fig. 1 und 2 der I. Tafel III. Bandes der Carpologie lehrt. Doch ist C. Sphingum Tul. zweifellos nahe verwandt.

Cordyceps Mölleri P. Henn. (Taf. VI Fig. 79, 80, 84. Taf. XI Fig. 3 b n c). Die Art ist ron Herru Hennings nach einem voll mir im Dezember 1890 aus Blumenau eingesandten Exemplar in der Naturwissenschaftlichen Wochenschrift (1896 S. 318 Fig. 5) ind in der Hedwigia 1897 S. 221, an letzterer Stelle mit der folgenden Beschreibung begründet worden:

„Stromatibus sparsis, erectis, pallide flavis, $1 \frac{1}{2} \mathrm{~cm}$ longis; pedicello basi discoideo-radiato, $3-5 \mathrm{~mm}$ longo, $1 \frac{1}{2} \mathrm{~mm}$ crasso; clavula spicata, asperata, apice subulata, sessili usque ad $5 \mathrm{~mm}$ elongata; peritheciis superficialibus omnino liberis conico-ovoideis; ascis cylindraceo-clavatis, octosporis $250-300 \times 4-5 \mu$, apice rotundatis; sporis filiformibus in articulos secedentibus $0,5 \mu$ crassis hyalinis."

„Die Art ist mit C. isariö̈des Schwein. und Cord. Engleriana P. Henn. verwandt, durch völlig freie Perithecien, die ährenförmig stehen, ausgezeichnet. Oberhalb der Perithecien verlängert sich die Kenle in eine pfriemliche sterile Spitze." 
Ich habe denselben Pilz viermal gefunden, das schönste Exemplar hat Herr Volk (Fig. 79), um die Hälfte etwa vergrössert, dargestellt, zwei andere erscheinen in der Photographie Taf. XI Fig. 3. Der unscheinbare Schmetterling, eine Noctuine, ist ron dem Pilze durchwuchert, dessen Mycel anch hie und da auf dem Leib des Insekts einen gelblichen Ueberzing bildet und auf das Blatt ïbergehend den Körper darauf befestigt. '/unächst brechen die Keulen dann hervor, wie ich an einem unreifen Exemplar beobachten konnte, in Gestalt von parallel verflochtenen Hyphenbündeln mit pinselförmigen Enden. Die pfriemliche Znspitzung. erreichen sie erst später, wenn an ihnen seitwärts die Perithecien angelegt sind.

Der ganze Pilz ist hellgelblich, die Perithecien haben einen schwachgrünlichen Schimmer. Sie sind eiförmig und erreichen die beträchtliche Länge von $700 \mu$. Anch bei ihnen kann man eine innere dichtere zarte und eine äussere lockere mehrschichtige Wandung unterscheiden, wie bei Cord. polyarthra. Sie stehen nicht ganz frei, sondern sind dem an den frnktifizirenden Stellen etwas verdickten Strona mehr oder weniger, manchmal bis zn ${ }^{1 / 3}$ eingesenkt. Die Schlanchlänge ist ïberall beträchtlich grösser. als Herr Hennings angiebt, nämlich 400-500 «: doch zerbrechen die Schlänche sehr leicht. Fenchtet man den Pilz in frischem Znstande etwas an, so sieht man unter der Lupe die Schlänche in dichtem Büschel hervorquellen, später werden sie einzeln mit erheblicher Kraft vorgetrieben. Legt man aber den Pilz im fenchten Raume ïber einer Glasplatte aus, so füngt man nur einzelne, manchmal spiralig um einander gewrndene Fadensporen anf, welche durch Qnerwände in 5-6 "“ lange Theilzellen zerlegt erscheinen. In einem Falle gelang es mir, genan $6+$ solche Theilzellen an einer frisch aufgefangenen Spore zn zählen. Ail den Scheidewänden knicken sich die anfgefangenen sporen leicht hin und her, brechen anch hänfig anseinander. Schon nach 6 Stunden waren auf den mntergelegten Objektträger'n die Sporen in lockeren 


\section{$217-$}

Flocken bis zll ${ }_{\text {a }}^{1} \mathrm{~cm}$ hoch angehäuft. An so gewonnenen Präparaten kann man anch die sporenlänge genan, im rorliegenden Falle zll 450-480 "/ bestimmen.

In Nährlösung keimen die Sporen sofort und erzeugen reich verzweigte äusserst feinfädige Mrycelien mit reichlichem Luftmycel. An diesem tritt fïnf Tage nach der Anssaat die Conidienbildung auf, genan nach dem 'Typus der Cord. polyarthra, nur mit dem Unterschied, dass die Ketten kaum mehr als acht Conidien im Zusammenhange zeigen, und dann zerfallen (Fig. 8t). Die Art ist der vorigen und der Cord. Sphingum 'T'ul. zweifellos nahe verwandt. Sie ist inzwischen durch Herm Hennings anch ans NenPommern bekannt gemacht worden (Englers Jahrbïcher Bd. XXV 1898 S. 507).

Cordyceps corallomyces nor. spec. (Taf. TI Fig. 85 1. 86). Am Ufer eines Trwaldbaches fand ich im Dezember 1892 einen diinmen morschen Zweig, der fast im Wasser, also sehr fencht lag. Auf ihm erhoben sich zahlieich kräftig braunroth gefärbte kleine nur etwa $5 \mathrm{~mm}$ hohe dümne feste Stielchen, die an ihrer Spitze ein Häufchen von wenigen, bis höchstens 20 anscheinend frei nebeneinander stehenden Perithecien trugen. Ans diesem Köpfchen ging bei den kräftigsten Stïcken in stumpfem Winkel (s. Fig. 85) eine Verlängerung des rothen Stieles ab, die wieder etwa $5 \mathrm{~mm}$ lang wurde, und damn ein ebensolches kleineres Perithecienhäufchen trug. Tn einigen Fällen setzte sich der dann steril endende Stiel auch ïber das zweite Köpfchen hinaus in stumpfem Wrinkel noch fort. Diese zierlichen durch ihre fast lenchtendrothe Farbe anffallenden Fruchtkörper standen auf der sehr dïmnen stark in Terwesung iibergegangenen leicht ablösbaren Rinde des Zweiges. Es war 1 m leicht festzustellen, dass unter dieser Rinde sich $6 \mathrm{~mm}$ lange glatte kellerasselartige Insektenleichen fanden, aus denen je zu mehreren unsere Cordycepsstiele entsprangen.

Die Perithecien erscheinen bei Betrachtung mit der Lıpe zu $1 / 3$ bis $1 / 2$ ihrer Tänge frei zll stehen. In Wirklichkeit sind sie, 
wie Fig. 86 zeigt vollkommen eingesenkt, und im oberen Theile von der dort dicht anliegenden gemeinsamen Stromarinde umschlossen. Sie sind gedrungen eiförmig, $380 \mu$ lang und $270 "$ etwa breit. Ihre eigene Wandung ist sehr zart. Die Schläuche haben eine eichelförmige lyyaline Kappe, sind etwa 200 "lang und 7-8 ". breit. An frisch aufgefangenen Sporen gelang es mir melırmals, genau je 32 Theilzellen von $6-8$ « Länge zu zählen, die einzelnen Theilzellen zeigten leichte Anschwellung; so dass die Spore einer Oidienkette glich. Im Gegensatz zu fast allen anderen Cordycepssporen, mit welchen Versuche angestellt wurden, waren diese weder in Wasser noch in Nährlösungen zur Keimmng zu bringen.

Die Art ist mit Cord. memorabilis Cesati aus Italien nächstverwandt, von der sie sich vorzugsweise durch ihre im Stroma völlig rersenkten Perithecien unterscheidet (vergl. Cooke: Tegetable Wasps S. 84 ff.).

Cordyceps australis Speg. (Taf. VI Fig. 92-93). Spegazzini hat unter obigem Namen in den „Fungi Argentini“ IT p. 80 eine auf einer grossen schwarzen Ameise (Pachycondyla striata Smith) parasitirende Cordyceps reröffentlicht, und erwähnt dieselbe ferner in seinen Fungi Puiggariani I Seite 536, wo er ausführliche „Observationes" beifügt. Ich nelıme an, dass die Cordyceps, welche ich zu drei rerschiedenen Malen bei Blumenan auf eben derselben, durch Herrn Professor Forels Güte als solche bestimmten Pachycondyla, und zwar aus deren Thorax herrorbrechend antraf, wohl dieselbe sein wird, wie die von Dr. Puiggari in Apiahý (São Paulo) für Spegazzini gesammelte, obwohl die Maasse der Sporen und Theilzellen mit den von Spegazzini angegebenen nicht ïbereinstimmen. Der Pilz ist in natürlicher Grösse in Fig. 93 von Herrn Volk dargestellt, mnd ich will seine Beschreibung an der Hand der Spegazzinischen „Observationes" geben, indem ich meine abweichenden Beobachtungen jedesmal einschiebe.

„Stromata subcarnea filiformia erecta, quandoque breviuscula 
rigidula recta ( $5-10^{\prime \prime \prime} \mathrm{lg}$.), quandoque elongata flexuosa subflaccidula (30-60" lg.). semper gracilia $\left(0,2-0,4^{\prime \prime \prime}\right.$ crs.)."

Ich fand die rhizomorphaartigen Stiele der Köpfchen stets lang, am Boden zwischen dem Abfall umherkriechend, und nur mit dem äussersten Ende gerade anfstrebend. Ich habe bis zu $14 \mathrm{~cm}$ Länge gemessen.

.fusco-atra r. atro-subpurpurascentia, longitudinaliter rugosostriata glabra opaca apicem versus attenuata ac flarescenticarnosa, abrupte in capitulo globoso v. ovato $\left(0.5-2^{\prime \prime \prime} \mathrm{dm}\right.$. $)$ expansa."

Hierzu ist zu bemerken, dass der dicht nnter dem Köppfchen auf etwa $1 \mathrm{~cm}$ Länge ganz hell gefärbte Theil des Stieles sehr auffällig von der im iibrigen dunklen Farbe absticht und ein recht auffälliges Nerkmal bildet. wie auch Spegazzini am Schlnss seiner Bemerkungen herrorhebt mit den Worten: „species variabilis pulcherrima stipite marasmioideo nigro apice pallescente mox dignoscenda". Then dies ist der Grund, weshalb ich meine Funde der Cord. australis Speg. zurechne, obwohl die folgenden Bemerkungen auf sie nicht unbedingt zutreffen. Es heisst nämlich weiter: "capitula laevia carnoso-subceracea aurantia glabra acrogena solitaria, rarius pleurogena; perithecia cylindracea $(300-600 \times 100 \mu)$ non v. vix ostiolato-papillata; asci cylindracei $(250-300$ rarius $--450 \times 5-8 \mu$ apice glandiformes aparaphysati; sporidia filiformia ascorum longitudine, in articulis cylindraceo-fusoideis utrinque rotundato-subtruncatis $(5-15 \times 1-1.5$ " $)$ hyalinis secedentia“.

Die Farbe der in feuchtem Zustande rom Waldboden leuchtend sich abhebenden Köpfchen wird unter Zugrumdelegung von Saccardos Chromotaxia zutreffend mit miniatus anstatt mit aurantius bezeichnet.

Die Köpfchen zeigen auf einem Längsschnitt einen auffallend lockeren Hyphenfilz mit vielen Zwischenräumen, die Perithecien sind rollkommen eingesenkt und genau so bouquetartig angeordnet, wie ich es für Clavicepss ranunculoides beschrieben habe 
(S. 206). Nur die mittleren oberen sind symmetrisch gebaut, die anderen der centralen Spindel des Köpfchens angesetzt, und damm nach aussen und oben jedes dem nächsthöheren angeschmiegt. Das ganze Köpfchen zeigt eine gemeinsame Rindenschicht, welche sich der Form der einzehen Perithecien anschmiegt, so dass diese unter der Lupe gleich wie Zapfenschuppen einzeln zn erkennen sind. Die Fig. 92, welche diese Verhältnisse sehn schön zur Anschanung bringt, ist nach Alkoholmaterial gezeichmet; in frischem Zustande ist der zapfenartige Bau weniger dentlich, weil damn das lockere Stromageflecht zwischen den Perithecien mehr aufschwillt und deren Einzelform undentlicher macht. Immerhin sind auch dann die Spegazzinischen Ausdrücke "laevia" nnd „glabra“ nicht recht treffend. Die Perithecien sind nach meinen Messungen 650-750 " lang, am Grunde banchig, 250 " dick mol dam lang. flaschenförmig ansgezogen, die meisten gebogen in ähnlicher Weise, wie es ron Thlasne (Carp. III Taf. I Fig. 8) für Cord. sphecocephala dargestellt ist. Die Schlänche, deren Kaple ron Syegazzini sehr treffend als eichelfürmig bezeichnet wird, messen bis $700 "$ ", nnd an den frisch aufgefangenen Sporen stellte ich deren Länge zn 600 " etwa fest. In vier Fällen hinter einander gelang es mir, an ihnen jedesmal genau 64 Theilzellen von je 9-10 " Länge zu zählen, so dass in dieser wiederholt und auch bei anderen Formen festgestellten Zahl wohl nicht mehr ein Zufall, sondern die Folge der wiederholten Zweitheilung gesehen werden muss.

Die Keimung in Nährlösung erfolgte ummittelbar nach der Aussaat. Im Gegensatz zu den meisten anderen Formen trat. aber eine Conidienfruktifikation überhanpt nicht ein, obwohl i*h reich rerzweigte Mycelien in der Zeit rom 27. April bis 11. Mai 1892 knltivirte. Dagegen rerdickten die Hyphen der älteren Kulturen ihre Membranen in charakteristischer Treise und nahmen eine brame Farbe an, die sonst nie beobachtet wurde, und die genan der Farbe der braunen Köpfchenstiele unseres Pilzes entsprach. 
Bemerkenswerth ist endlich noch der kurze sterile Seitenzweig des Stieles dicht unter dem Köpfchen (Fig. 93), der Spegazzinis Bemerkung „capitula rarius pleurogena“ zu bestätigen scheint. Eine der beschriebenen in allen Theilen gleiche Form, nur mit hellbraunem Stiele fand ich im April 1892 auf einer Puppe unbekannter Herkunft, wonach die Annahme gerechtfertigt ist, dass cord. anstralis nicht allein anf die Pachycondyla striata als Wirthin ancewiesen ist.

Cordyceps thyrsoilles nov. spec. (Fig. 90, 91). Diese von Herrn Gärtner am 23. September 1891 anf einer Hummel (Xylocopa spec.) aufgefundene Cordycepsform zeigte vier langgestielte gelbbram gefürbte längliche Köpfchen von je etwa $5 \mathrm{~mm}$ Länge und 2-3 mm Dicke. Der Bau dieser Köpfchen (Fig. 90), welche an den stilisirten Pinienzapfen der Thyrsusstäbe erinnern, ist durchaus ähnlich dem eben besprochenen bei Cord. australis, so dass ich nicht näher darauf einzugehen brauche. Nur sind die vortretenden Mündungen der Perithecien mit kräftigeren Papillen versehen. Die Perithecien selbst erreichen die beträchtliche Länge von fast $1 \mathrm{~mm}$. Die Schlauchlänge beträgt bis $800 \mu$. Die hyaline Kappe ist sehr gross und dentlich, fast kugelig, an der Spitze etwas abgestumpft. Die frisch anfgefangenen Sporen liessen sehr regelmässige spindelförmige, in einem genan gezählten Falle 64 Theilzellen von .je etwa 13 "Länge erkennen. Dem gegenüber zeigt die Untersuchung des Alkoholmaterials meist kürzere (2 bis 10 u) schon im Schlanche kenntliche Theilzellen, die an den frisch aufgefangenen Sporen nie rorkamen.

In Nährlösung schwellen die Theilsporen an, die Keimschlänche treten, an ihren Enden zuerst, seitwärts aus. In den ersten drei Tagen trat an den verzweigten Mycelien keine Conidienbildung auf. Die Kulturen sind danach leider über anderen Arbeiten vernachlässigt und zu Grunde gegangen.

Cordyceps muscicola nov. spec. (Taf. VI Fig. 88). Das in zweimaliger Vergrösserung von Herrn Volk abgebildete Stück 
wurde im Dezember 1892 auf einer von dem Pilze ganz durchwucherten und durch Mycel der Unterlage fest angehefteten Fliegenleiche gefunden. Aus dem Körper der Fliege erheben sich in ziemlich regelmässiger Anordnung, wie das Bild zeigt, sechs faserige locker gebaute, etwa $1 \mathrm{~cm}$ lange Träger, deren jeder an seinem Ende ein flachkugelförmiges Köpfchen trägt. Die Farbe der Stiele in frischem Zustande war isabellbraun (Sacc. Nr. 8), die Farbe der Köpfchen gelbweiss (Sacc. Nr. 28). Die Stiele bestehen aus einem sehr lockeren Bündel einander nicht durchweg berührender Hyphen, nur ihre Rinde ist fester gewebt, der Körper des Köpfchens zeigt ebenfalls einen überaus lockeren Bau aus lose zusammengewirten Fäden. Die lang flaschenförmigen, $700 \mu$ langen Perithecien ragen nur mit der Mündungsspitze hervor und sind im übrigen dem lockeren Stroma völlig eingesenkt. Auf der Mündung findet man Haufen ausgetretener verwirrter Fadensporen, welche in Schläuchen von etwa 500 " Länge und $6 \mu$ Dicke gebildet werden. Sie zeigen im Alkoholmaterial eine Gliederung in etwa $5-7$ " lange Theilsporen. Oftmals sind die Sporen schon im Schlauche an den Theilwänden hin und her geknickt, so dass man Bilder erhält, die durchaus an Hypocrella ochracea (Taf. IT Fig. 64e) erinnern.

Die Perithecien haben gegenüber dem losen Gewebe, in welches sie eingebettet sind, eine ziemlich feste, aus dichtaneindergeschlossenen sehr feinen Hyphen gebildete Wandung. Daher kommt es, dass bei Aufbewahrung in Alkohol in Folge der Schrumpfung des Köpfchens die festere Form der einzelnen Perithecien sich deutlich ausprägt, so dass das Köpfchen nun einen aus einzelnen Perithecien zapfenartig zusanmengesetzten Eindruck macht und grosse Aehnlichkeit mit demjenigen ron Claviceps ranunculoides (Taf. V Fig. $72 \mathrm{c}$ ) gewinnt. In frischem Zustande ist dies weniger dentlich. Das Mycel, welches jedenfalls den ganzen Leib der Fliege durchwuchert und in eine Pilzmasse verwandelt hat, tritt am Hinterleibe, wie man im Bilde sieht, auch 
noch in Form einer Ringwulst nach aussen. Auch die beiden merkwürdigen spitzen Fortsätze am Hinterleib der Fliege, welche man etwa für Organe des Insekts ansehen könnte, sind Stromabildungen des Pilzes, möglicherweise unentwickelte Anlagen von Perithecienköpfen.

Cordyceps rubra nor. spec. (Taf. VII Fig. 102, 103) ist in nur einem Stück am 21. Januar 1892 bei Blumenau auf einer im Boden verborgenen Elateridenlarve gefunden worden. Wie aus Herrn Volks schöner Abbildung zu ersehen ist, nimmt der $3{ }^{1}{ }_{2} \mathrm{~cm}$ hohe keulenartige Träger seinen Crsprung ans einem verbreiterten, stellenweise in lose Stränge aufgelösten Mycelgeflecht, welches die Larve theilweise eimhüllt und an verschiedenen Stellen, am Kopf und an den Leibesringehn, mit den vollständig in Pilzmasse verwandelten Imern in Terbindung steht. Der Stiel ist glatt, etwas flach gedrückt, etwa $3 \mathrm{~mm}$ stark, er erweitert sich nach oben in einen unregelmässig keuligen Theil, welcher von den vorragenden Mündungen der eingesenkten Perithecien punktirt ist. Die Keule ist hellroth gefürbt, nach unten zu dunkker, nach der Spitze zu heller abschattirt. Die eingesenkten Perithecien haben $500 \mu$ Länge bei 200-250 « grösster Breite, sie verschmälern sich ohne scharfen Absatz allmählich bis zur Iründung. Sie stehen nicht senkrecht zur Oberfläche, sondern in schräger Richtung nach oben. Die gemeinsame Stromarinde ist sehr locker und dünn, so dass, wenn der Fruchtkörper nur etwas eintrocknet, die Perithecien als solche in ähnlicher Weise sichthar werden, wie bei C. australis und thyrsoides. Mit diesen beiden zeigt die Form auch durch die sehr lockere Beschaffenheit des Stromainnern Aehnlichkeit. Die Länge der Schläuche und Sporen beträgt 300-400 $\mu$. Die Sporen fing ich in frischem Zustande in grossen Mengen auf, eine Gliederung in Theilzellen war nicht wahrnehmbar, und da auch zur Keimung nur eine kaum merkliche Anschwellung der äusserst zarten, noch nicht 1 " dicken Sporen erfolgte, so gelang es mir nicht, Scheidewände in der Spore überhaupt mit Sicherheit wahr- 
zumehmen. Seitlich an der Spore (Fig. 102a) treten sofort auf kuren pfriementörmigen Spitzchen ovale Conidien von 3 ॥ Durchmesser auf, die nacheinander abgeschnürt werden und auch in der bekannten Art zu Köpfchen verkleben. Die Conidien ihrerseits keimen sehr unregelmässig; indem sie zuerst anschwellen bis zum doppelten Durchmesser und dam einen Keimschlanch austreiben, der an seitlichen Fortsätzen wieder Conidien erzengt gerade wie die Spore. Allmählich in der Zeit vom 21. Januar bis 15. Februar 1892 erzog ich verzweigte Mycelien mit immer zunehmender Conidienfruktifikation. Anch bildeten sich Luftäden wie der in Fig. 102 b dargestellte mit reichen Conidienköpfchen. In Ausnahmefällen beobachtete ich auch, wie die Conidien reihenweise zusammenklebten, ähnlich wie es bei C. Mölleri und polyarthra die Regel war. Meist aber fallen diese Ketten sehr bald in lockere Köpfchen zusammen. Ton den untersuchten Conidienformen hat die von Cord. flavoviridis mit der vorliegenden die meiste Aehnlichkeit.

Condyceps submilitaris P. Hemn. (Taf. TII Fig. 95 und 96) Die in der Ungegend Blumenaus weitaus häufigste, vielleicht auch nur die wegen ihrer alle anderen beobachteten Arten übertreffenden Grösse und auffallenden Farbe am meisten bemerkte Cordyceps hat Herr Hennings nach einem im Jahre 1891 von mir eingesandten Exemplar unter dem Namen Cordyceps submilitaris in der Hedwigia 1897 Seite 222 und in der Naturwissenschaftlichen Wochenschrift 1896 Seite 319 veröffentlicht, und an der letztgenamnten Stelle auch abbilden lassen. Tm Laufe der Zeit sammelte ich zahlreiche stïcke, darunter auch solche von recht erheblicher Grösse, und ich fand die Formgestaltung dieser Art ausserordentlich mannigfaltig; Herrn Tolks prächtige Zeichmmngen stellen zwei typische Exemplare dar. Herrn Hemnings Diagnose in der Hedwigia a a. O. lautet: „Cordyceps submilitaris P. Henn.“ in Naturw. Wochensehr. 1896 Nr. 17 p. 319 f. 4:

„Stromatibus sparsis vel gregariis, longe stipitatis, clavatis e mycelio membranaceo, effuso, superficiali pallido oriuntibus, $6-7 \mathrm{~cm}$ 
longis, aurantiacis, apice clavato-incrassatis, obtusis $4-5 \mathrm{~mm}$ crassis; peritheciis subliberis, gregariis, conicis; ascis cylindraceis clavatis $250-340 \times 3{ }^{1}{ }_{2}-4$ " , apice rotundatis, 8 sporis; sporidiis longitudinaliter parallelis, filiformibus, inmmeris articulis hyalinis vix 0.5 " crassis, secedentibus."

Hierzı habe ich ergänzend zn bemerken, dass die Grösse je nach der Grösse der befallenen Käferlarve und auch nach der grösseren oder geringeren Anzahl der vorhandenen Keulen erheblich schwankt; ich habe Stiicke von noch nicht $1 \mathrm{~cm}$ Höhe gefunden mit völlig reifen Perithecien und die Fig. 96 zeigt eine Kenle in natïrlicher Grösse, welche $7 \mathrm{~cm}$ Höhe erreicht. Meist kam der Pilz ans einer in morschem Holze liegenden Elateridenlarve hervor. Doch die kleinsten beobachteten Exemplare, von kaım $1 \mathrm{~cm}$ Höhe, welche offenbar derselben Art angehören, fand ich zu verschiedenen Nalen an ein und derselben Stelle auf einenı andersartigen. nicht mehr deutlich erkennbaren, wejt kleineren Insekt. Auch die Länge der schlankbirnenförmigen Perithecien schwankt von 500-700 ", die grösste Breite ron 250-300 "l. Aber darin stimmen alle von mir beobachteten Stïcke ïberein, dass diese Perithecien nicht senkrecht zur Oberfläche der Keule stehen. sondern in ähnlicher Weise, wie bei c. thyrsoides nnd besonder's Cord. rubra, nach oben, nach der Spitze der Kenle gerichtet, und mit den Mïndungen. welche allein vorragen, schwach nach anssen gebogen sind derart, dass man anf einem Querschnitt der Kenle niemals, wohl aber auf jedem Längsschnitt Perithecien antrifft, welche von der Spitze bis zum Grunde zu iibersehen sind. Der Ausdruck ,peritheciis subliberis“ muss also dahin verstanden werden, dass die Perithecien immer bis auf die kurz vorragenden Mïndungen im Stroma ganz eingesenkt sind, dass sie aber mit ihrer Längsseite zum Theil nach aussen weisen, und dort nur von der sich ihrer Form anschmiegenden diimnen Stromarinde bedeckt sind, so dass sie zumal an getrockneten oder in Alkohol bewahrten Stiicken theilweise frei zu stehen scheinen. 
Man kann die Sporen, welche in Massen entleert werden. leicht auffangen. Frische Sporen zeigen weder im Schlauche. noch in Wasser aufgefangen, auch nicht bei 1200 facher Vergrösserung mit einem guten Immersionssystem eine Spur ron scheidewänden. Solche traten aber wenige Stunden nach dem Liegen in Wasser oder Nährlösung deutlich auf. Die entstehenden Gliederzellen, deren ich in einzelnen Fällen genau 32 ron je 8--9 "Länge zählte. schwellen dabei ein wenig an und hald treten Keimschlänche zunächst immer dicht neben einer Scheidewand aus. Bereits 24 Stunden nach der Aussaat beobachtete ich im Nährlösungstropfen reich rerzweigte Mycelien, welche an wirtelig verzweigten Seitenfäden reihenweise rundliche Conidien ron $4-5 \mu$ Durchmesser in Ketten erzengten ganz genau, wie ich solche für die in Fig. 106 Taf. VII abgebildete Isariaform dargestellt habe. Die Conidien keimen leicht und erzengen Mycelien 'mit der gleichen Conidienform. Es ist demnach wohl sehr wahrscheinlich, dass auch zu dieser Cordycepsform eine Isaria gehört, deren Aussehen wohl ähnlich, wie das der beiden in den Photographieen (Taf. XI Fig. 1 und 2) dargestellten Isarien sein dïrfte: zwischen diesen Isarien und den für Cord. militaris ron Tulasne dargestellten dürfte ein Unterschied kaum zn finden sein. während aus der vortrefflichen Beschreibung und Abbildung der Theilsporen und ihrer Keimung bei C. militaris die Terschiedenheit dieser Form ron unserer submilitaris klar hervorgeht. Auch stehen nach Tulasne die Perithecien bei Cord. militaris, zumal im nnteren Theile der Kenle, wirklich frei auf dem Stroma.

Cordyceps ainictos nov. spec. Vor eine Reihe ungelöster Rätlısel stellt uns die in Fig. 105 in ziemlich natïrlicher Grïsse abgebildete Cordycepsform. Ans einer kaum noch als solche erkemnbaren, in Holzmulm und Wurzelwerk rerborgenen Insektenleiche, die am ersten eine grosse Raupe oder Puppe gewesen sein mag, erheben sich in grösserer Anzahl schlanke braune zähe bisweilen verzweigte Fäden bis zu $6 \mathrm{~cm}$ Länge, welche mit nicht 
allzu dicht gedrängten eifömigen braumen bis schwärzlichen Perithecien fast der ganzen Länge nach besetzt sind. Alle diese Perithecien in dem mir zur Verfügung stehenden Material waren vollkommen leer. so dass ïber die Natur des Pilzes hieraus nichts zu entnehmen war. An selu vielen stellen nun entspringen aus diesen braunen Fäden andere feine lellisabellfarbene, welche meist steril enden, in zwei sicher beobachteten Fällen aber (s. die Figur) an ilnem oberen Theile dicht unter der Spitze ein halbseitig ausgebildetes Cordycepsköpfchen ron $2 \mathrm{~mm}$ Dicke trugen, das ron den Mündungen der eingesenkten Perithecien punktirt erschien. Ganz gleiche, nur grösser und liräftiger ausgebildete Fruchtkörper, die in ihrer Gestaltung aufs lebhafteste an die ron Tnlasne abgebildete Cordyceps unilateralis erinnern. nahmen nun aber neben den braunen Fäden, unabhängig von diesen aus dem gemeinsamen Substrate ihren Ursprung. Die Grösse kann aus der Zeichnung entnommen werden; die Farbe ist in allen Theilen hellisabell (Sace. Chrom. 8). Die Perithecien sind bis auf ein kurzes rorragendes Spitzchen völlig. und zwar ziemlich senkrecht zur Stromaoberfläche eingesenkt, langflaschenförmig und mit deutlich ansgebildeter eigener Wandung rersehen. Die sehr zarten Schläuche sind mindestens 500 " lang. manchmal wahlscheinlich noch länger, dabei nur 3 " stark, die hyaline Kappe ist seln klein, halbkugelfürmig. Im Alkoholmaterial erscheinen die Fadensporen in 3 " lange Stäbchen abgetheilt. Das Tnnere des Köpfchens besteht aus lückenlosem Fadengeflecht, in dem die Fadenstruktur noch gut erkennbar ist.

Es giebt nun zwei Möglichkeiten, den vorliegenden und abgebildeten Befund zu erklären. Entweder gehören die braunen perithecientragenden Fäden einer andern Art an, als die isabellfarbenen halbseitigen Köpfchen; der letzteren ausg*eschleuderte sporen hätten damn auf dem andern dicht daneben stehenden vielleicht verwandten Pilz, der nach vollkommener sporenentleerung: kurz vor dem Zerfall war, gekeimt und in den Resten desselben 
noch so viel Banstoffe gefmnden, um zu fruktifiziren; oder aber die bramen Fäden und die hellen Köpfchen gehören ein und demselben Pilze an; in diesem Falle hätten wir bei einem Pilz zwei in Grösse, Anordnung und Farbe ganz verschiedene Ascnsfrüchte. ein ohne Beispiel dastehender Fall, der deshalb vorläufig wohl als zu unwahrscheinlich zu betrachten und auszuscheiden ist. Eine dritte Erklärmug giebt es meines Erachtens nicht. Doch scheint mir jede der beiden erwähnten Deutungen der Beachtung wertl. Mit Cord. ainictos, wenigstens mit dessen hellgefärbten, halbseitig ansgebildeten Köpfchen begimnt nun eine Reihe von Formen. welche im Gegensatz zu den frïheren die Perithecien senkrecht zur Stromaoberfläche eingesenkt tragen, so dass auch von einem scheinbar freien Auftreten derselben nicht mehr die Rede sein kamn. Im allgemeinen lässt sich bemerken, dass je fester das Gefüge des Stronakörpers und der Stromarinde wird, $1 \mathrm{~m}$ so zarter die eigene Wand der Perithecien erscheint, offenbar weil der Schntz der Perithecien gegen Druck mnd Verletzmmg durch das festere Stroma geniigend gewährleistet wird.

Cordyceps incarnata nov. spec. ('Taf. VI Fig. 94). Auf einer nicht mehr bestimmbaren Insektenleiche, wahrscheinlich dem Bruchstiick einer Raupe, habe ich diese Form an 10. März 1892. nur eimmal, im Velhathale gefunden. Aus dem Insektenkörper erheben sich drei je $1 \%$ mm starke, $3 \mathrm{~cm}$ lohlı, hellfleischröthliche, längsstreifige, faserige, wenig feste stiele, welche je ein kugeliges hellbraunrothes Köpfchen ron etwa $5 \mathrm{~mm}$ Durchmesser tragen. Die Perithecien sind länglich eiförmig; etwa 800 "“ lang und 350 " breit und senkrecht zur Oberfläche des Stromas eingesenkt. Ihre spitze mit der Miindmng ragt etwa $170 "$ "hervor und ist ron der Stromarinde, welche sich der dentlich ansgebildeten. dunkel gefärbten Perithecienwandnng hier eng anschliesst, überlagert, das Köpfchen erscheint daher fein gebuckelt, nud bei oberflächlicher Betrachtung würde man vielleicht die Perithecien als zn $3 / 4$ eingesenkt und $1 / 4$ frei bezeichnen, was den Thatbestand 
indessen nu schlecht bezeichnen hiesse. Die Länge der frisch aufgefangenen Sporen. Welche eine Gliederung in viele, je 12 bis 15 " lange 'Theilzellen aufweisen. wurde zu 500-600 " bestimmt.

Cordyceps entomorrhiza (Dicks) Fries. (Taf. VII Fig. 101 a bc). Auf im Waldboden versteckten mumifizirten Käferlarven fand ich zu vier verschiedenen Malen (Juli 1891, Februar, Mär\% und .Tuli 1892) eine Cordyceps, welche ich nicht durch einen neuen Namen auszeichmen möchte, obwohl ihre Vergleichung mit der von T'ulasne gegebenen schilderung der Cord. entomorrhiza immerhin einige bemerkenswerte Differenzen aufweist. Zwei der Fundstiicke sind in Fig. 101 bc abgebildet. Die Grösse des Fruchtkörpers. welche je nach der Lage und Grösse des befallenen Insekts sehr wechselt, ging in den beobachteten Fällen bis zn $6 \mathrm{~cm}$ Länge des glatten Stieles, welcher ein kugeliges oder rundlich eiförmiges Köpfchelı von höchstens $1 \mathrm{~cm}$ Durchmesser trug. Der stiel entspringt der Käferlarve in derselben Dicke, welche er im weiteren Verlante beibehält, und an keinem meiner vier Stücke fand sich jene wurzelartige, die Käferlarve zum 'Theil einhüllende Mycelbildung am Fusse des Stieles, welche sonst für diese Form angegeben wird. Der Stiel ist glatt und fest, fleischig voll. Die Farbe des ganzen Pilzes war lehmbraun. nur bei einem stück zeigte das Köpfchen schwach röthlichen Schimmer. Die langen schlanken flaschenförmigen Perithecien sind ins Stroma ganz rersenkt, im Gegensatz z. B. zur vorigen Art; sie erreichen 900 " Länge. Der Habitus des längsdurchschnittenen Köpfchens entspricht genau dem Bilde der Cord. entomorrhiza bei 'J'ulasne Carpol. III 'Taf. I Fig. 13. Doch sind die Perithecienwandungen, welche Tulasne als ,.tenuissimos pallidosque• bezeichnet, bei dem brasilischen Pilze selı deuthich und dunkler gefärbt, als das umliegende Stromageflecht. Die Schläuche laben eine etwas kissenförmig flach gedrückte Kappe. Wenn man die fadenförmigen Sporen des frischen Pilzes auf einer Glasplatte auffängt, so sieht man, dass sie ungemein leicht in Bruchstïcke zerfallen. Es ist daher schwer, die Länge einer un- 
rerletzten Spore festzustellen. Eine genau genessene frische Spore hatte 660 „ Länge, bei einer anderen zählte ich genan 64 Theilzellen (s. Fig. 101 a) von je 12 "Länge (nach Tulasne nur 6 bis 8 ،). Untersucht man Alkoholmaterial, so sieht es oft aus, als wäre der Schlauch mit weit kürzeren cylindrischen Theilsporeu in unendicher Menge erfüllt. Dies ist aber in frischem Znstande nie der Fall. Ich erzog in kïnstlicher Kultur nur diirftige Mycelien. welche an den Luftfäden mit oralen farblosen 4-5 $\mu$ dicken Conidien fruktifizirten. Die Conidien werden an kurzen sterigmaartigen scharf zugespitzten Seitentrieben der Fäden nach einandel abgescluiurt.

Cordyceps hormospora nor. spec. (Taf. VII Fig. 100). Diese wegen der in den Grenzen der Gattmog verhältnissmässig seltenen sporenausbildung mit dem Artnamen hormospor'a belegte Cordyceps wurde zweinal. jedesmal in mehreren Exemplaren auf Lamellicornierlarven. die im Tnnern morschen Holzes in einer mit Holzmulnı gefüllten Höhluug lagen. aufgefunden. Die ganze befallene Käferlarve ist von den l'ilze in emen lockeren weissen Mantel ron Hyphengeffecht eingehiillt; ron diesem gehen lose rertheilte Hypheustränge ans und durchziehen den Holzmulm in derselben Weise, wie es bei cordyceps submilitaris der Fall ist. und erst aus diesen Hyphensträngen und Bändern erhebt sich die festere Kenle. welche die deckenden Schichten von Holz- und Rindenresten durchbricht und fiei in die Luft ragt. Die Kienlen erreichen nach meinen Beobachtungen höchstens $4 \mathrm{~cm}$ Höhe bei $2-3 \mathrm{~mm}$ Dicke ilnres stieles. sie sind in der Jugend liellgran bereift, bei der Reite deutlich weinroth (vinosus sace. Nr. 50 hell). Alle Keulen sind nach oben rerdickt. und zeigen Neigung zu unregelmässiger, oftmals (Fig. 100 links) typisch geweihartiger Verzweigung. Die dicksten Kenlenspitzen sind bisweilen holn. Die Perithecien, deren Anlage ron oben nach mnten fortzuschreiten scheint, und die am Stiel entlang neln oder weniger weit nach unten vordringen, im Wesentlichen jedorh auf den verdickten 'Theil der Kenle beschränkt 
bleiben. sind ganz eingesenkt, rundlich mit kurz ansgezogener spitze, von der Form eines Luftballons; nur die Spitze ragt ein wenig vor. Thre volle Länge ist 330 ", die grösste Breite 220 ". doch sehr wechsehnd. In einem Falle maass ich ein besonders grosses Perithecium ron 500 "/ Länge und 300 "" grösster Breite. Lässt man den reifen Fruchtkörper fencht liegen, so treten an der spitze der Perithecien lelle Tröpfchen aus; diese bestehen ans einer Tnzahl kleiner fast runder Zellen von 1,5 "“ Durchmesser. Die reifen Schlänche sind 300 " lang und 6 " breit und enthalten fadenförmige annähernd gleich lange Sporen, welche einer Perlenkette gleichen (hormospora) (s. d. Fig. 100 'Taf. VII). Die Figur stellt ein Stückchen einer frisch ejakulirten, im Wassertropfen aufgefangenen spore dar. Bisweilen sieht man die Sporen schon in dem dam vielsporig erscheinenden schlauche in die Gliederzellen zertaflen. Eine Keimung der Sporen trat auch nach mehreren 'Tagen weder in Nasser noch in Nährlösung ein.

Dieser Form sehr nahe verwandt ist jedenfalls Cord. palustris Berk. u. Br. Die Beschreibung bei Cooke, Veget. Trasps and Plant Worms Seite 219 passt fast völlig anf unsere Form. Dagegen ist Gestalt und Anordnung der Perithecien bei Cord. hor'mospora von der durch Massee a. a. O. Seite 12 gegebenen Beschreibung der Cord. palustris ganz zweifellos weit abweichend.

Cordyceps rhizomorpha nov. spec. Durch einen Stiel ähnlich dem ron C. australis ist die Form ausgezeichnet, welche in Fig. 104 dargestellt wird. Aus einer völlig unkenntlichen Insektenleiche erhebt sich ein in seinem Aussehen an die Rhizomorphen des Hallimasch erinnernder fast schwarzer unregelmässig am Boden ınd zwischen den absterbenden Blättern nmherkriechender Stiel von im ganzen fast $15 \mathrm{~cm}$ Iänge bei etwa $1 \mathrm{~mm}$ Stärke. Er ist holzig zähe, glatt, längsgefurcht und tritt an verschiedenen Stellen mit den Blattresten des Waldbodens und mit Bodentheilchen in so feste Berïhrung, dass man ihn nicht ohne Gewalt daron tremnen kann. Solche Anlıängsel zeigt anch die Abbildung. 


\section{$-232-$}

Dadurch erscheint er ranh. Im obersten 'Theil auf etwa $1^{1 / 2}$ chr Länge verdümnt er sich wenig, ist dabei weicher und hell gefärbt und geht dann in die längliche völlig cylindrische Keule von lehmbrauner Farbe, in dem vorliegenden Stiick von etwas iiber $10 \mathrm{~mm}$ Länge und $2 \mathrm{~mm}$ Durchmesser ïber. In diese Keule sind die parallel und senkrecht zur Oberfläche angeordneten Perithecien fast völlig eingesenkt, die Oberfläche der Keule erscheint punktirt ron den winzigen hervorragenden Mündungsspitzen. Die einzelnen Perithecien stehen nicht sehr gedrängt, sie berïhren sich kaum mit ihren Wänden an der dicksten Stelle, sie sind unten fast stielartig znsammengezogen, was ich sonst bei keiner anderen Form gesehen habe, dann erweitern sie sich bauchig und laufen endlich stmmıfkegelförmig aus. Ihr Längsschnitt zeigt die Form des Blattes rou Rnscus aculeatus. Sie messen $800 "$ in der Länge, 250-300 " in der grössten Breite. Die Perithecienwandung ist in dem übrigens ziemlich lockeren Hyphengeflecht der Keule dentlich abgezeichnet mil besteht aus gewebeartig an einander geschlossenen Zellen dunklerer Färbung, während iiberall sonst die Fadenstruktur noch dentlich erkembar ist, auch vielfache Zwischenräume zwischen den lockeren Fäden bleiben. Die änssere Stromarinde ist ähnlich den Perithecienwandungen gebildet. Die Maasse der Schläuche und Sporen sind nur nach dem Alkoholmaterial festgestellt worden. Es sind die Schlänche 400-500 $\mu$ lang. 3-4 $\mu$ breit, mit länglich eiförmiger Kappe. Die Theilzellen der Sporen scheinen 3 " lang zn sein.

Ich habe bei Cooke. Massee und Saccardo alle etwa ähnlichen Formen verglichen, aber den vorliegenden Pilz mit keiner der schon beschriebenen sicher rereinigen können. Insbesondere ist die eigenthümlich gestielte Form der Perithecien wohl für ihn charakteristisch. Nahe verwandt dürfte Cord. obtusa Penz. et Sace. sein (Sace. Sylloge XIT n. 2504). Doch sollen da die Perithecien "lense aggregata" sein, und ihre Grösse bleibt um mehr als die Hälfte hinter derjenigen nuserer Cord. rhizomorphra zurïck. 
Cordyceps Volkiana nor. spec. (Taf. VII Fig. 98, 99 b und c und 'Taf. XI Fig. 4). Unter' allen von mir beobachteten Insektensclmmarotzern ist diese Forn wohl die eigenartigste. Ich benemne sie zu Ehren des um die gewissenhaft trene und gleichzeitig schöne Abbildung der Insektenpilze so lochverdienten Herrn Tolk. Herr Gärtner fand ein Exemplar im Dezember 1891, ich selbst ein anderes im Januar 1892 und vier weitere Stücke am 31. Oktober 1892. Schon die aufgefundenen sechs Stücke zeigen in ihrer Form eine ungewöhnlich grosse Verschiedenheit der Gestaltung. Alle wurden auf verwesender Rinde gefallener morscher Stänme gefunden, und der obere keulige $1-1 \frac{1}{2} \mathrm{~cm}$ dicke und breite hellgelbliche Theil des Stroma lag frei und fiel anf durch die an und diclıt unter ihm in höchst unregelmässiger Anordnung auftretenden stumpfen Stachelfortsätze ron einigen mm Länge (Fig. 99 b, c). Der so zu 'Tage tretende 'T'heil des Pilzes hatte in allen Fällen eine gewisse, nanchmal aber eine so anfallend merkwiurdige Aehnlichkeit mit einer dort rorkommenden ähnlich gefärbten und am Hinterleib mit ähnlichen Fortsätzen verzierten Spinne, dass ich es mir nicht versagen kann, die Abbildungen der beiden Objekte, welche mein Freund Tolk auf meine Bitte farbig auszuführen die Gïte hatte, den Leserı vorzuführen. In Fig. 99 a sieht man die sipinne einmal seitlich, eimmal ron oben und hinten, in $99 \mathrm{~b}$ und $\mathrm{c}$ dagegen den Pilz auf gleicher Unterlage. Ebenfalls durch Herrn Tolks Freundlichkeit erfuhr ich dann, dass die fragliche Spinne Eripus heterogaster Latr. sei, und dass über sie schon Herr Göldi in den Zoologischen .Jahrbüchern von Spengel Bd. I S. 414 Mittheilungen gemacht habe. Herr Göldi beschreibt a. a. O. eine jedenfalls der unseren sehr älnnliche, aber wohl kaum mit ihr völlig. übereinstimmende Spinne, die. wie durch eine beigefügte farbige Tafel weiter erläutert wird, mit einer Orangenblïthe täuschende Aehnlichkeit haben soll. Die Aehnlichkeit wird dadurch hervorgerufen, dass das Abdomen der Göldischen Spinne porzellanweiss ist, während die Fortsätze gelb, nach der Spitze zu intensiver ge- 
färbt sind, und die Stanbfäden der Orangenblïthe nachahmen. Während die sonstige von Göldi gegebene Besclneibung der Spinne auch für die ron mir gefundene zutrifft, so ist diese letztere doch so gefürbt, wie Herrn Tolks Bild es darstellt nnd sie könnte mit einer Orangenblüthe wohl nicht so leicht rerwechselt werden.*)

Möglich ist ja immerhin, dass in denı von mir zur Sprache gebrachten Falle nur ein Zufallspiel der Natur vorliegt, indessen angesichts der wnuderbaren Mimikrytälle ans der Insektenwelt, angesichts insbesondere jener von Forbes ans Sumatra berichteten Tänschung, durch welche Thomiscus decipiens mit ihrem Gespinste anf Pflanzenblättern ausgebreiteten Vogelkoth nachahnt, ein Fall von Spinnemmimikry, auf den Herr Dr. Erust Kranse nuich anfmerksam machte, erscheint es mir nicht ansgeschlossen. dass doch

*) Die Verschiedenheit der Färbung klärt sich noch besser anf durch die folgende Bemerkung ans der Hist. nat. des insectes. Aptères I von Baron de Walckenaer, pag. 562 :

- - Denx individus de l'Eripus heterogaster, renant de Rio Janéino, ont été reçu an Muséum depuis celui que nous avons décrit, et nous montrent dans cette espèce denx variétés.

Var. 1. Tachée de brun. - Longne de 8 lignes, d'un beau jaune uniforme, ayant senlement les extrémités des palpes et celles des pattes brunes, et lextrémité des tubercules de l'abdomen très allongée, cylindrique, brune; puis un tubercule très-pointu sur le corselet, proche l'abdomen.

Var. 2. Tachée de rose, - 6 lignes de long. Jambe et tarses dun rose pâle. Labdomen a les tubercules roses rês leur extrémité, arec une raie rose qui lie de claque coté les six tubercules latéranx, et me antre ligne rose qui part du sommet du tubercule postérieur et se prolonge sur le milieu du dos, en figurant près dn corselet un fer de tlèche. Le côté a aussi deux bandes rose pâle, très larges, qui se prolongent entre lespace des deux tubercules postérieurs, ne litissant qu une bande jaune assez étroite sons le ventre, entre l'anus et la partie sexnelle. Elle est marquée par une suite de points parallèles an nombre de 12. Les tubercules comme le corselet sont rugnenx, et revêtus de petits points noirs chagrinés.

Herr Volk bemerkt zu vorstehendem Citat, welches ich ebenfalls seiner Giite verdanke, dass die von ilnm anf meerer Taf. TH dargestellte spinne sich offenbar mit der Var. I von Walckenaer, die Güldiscle aber mit der Var. II decke, wemn sie nicht etwa besser als eine dritte Tarietät anfzufassen sei, und dass Eripus heterogaster offenbar eine sehr variable Species mit growem Anpassungsvermögen sei. 
vielleicht biologische Bezielıngen auch zwischen den beiden hier geschilderten Organismen bestehen und ein Fall von wirklicher Mimikry hierin durch spätere Beobachtungen festgestellt werden könnte.

Bröckelt man die morsche Rinde, auf der die beschliebenen Pilzgebilde erscheinen, vorsichtig ab, so findet man, dass ilıre gelblichen bedornten Keulen auf einem Stiel ron $1-2 \mathrm{~cm}$ Länge und $\bar{\jmath}-7 \mathrm{~mm}$ Dnrchmesser sitzen, der aus dem Teibe einer dicken Lamellicornierlarve, die offenbar in dem Holze lebte, seinen $\mathrm{Ur}^{\mathrm{r}}$ sprung nimmt ('Taf. XI Fig. 4). Jie ganze Käferlarve ist in eine Pilzpsendomorphose verwandelt, und nur die harten Mundtheile sind unversehrt erlalten. Da an den im Oktober 189.2 gefundenen Stïcken Perithecien noch ebensowenig erkenmbar waren, wie an den früher gefundenen, so setzte ich sie, eingebettet in denselben Holzunlm, in dem sie gefunden wuden. in eine feucht gehaltene Schale, in der sie sich rorzüglich weiter entwickelten und beobachtete, wie schon nach 14 Tagen an den obersten Theilen der vordem ziemlich glatten Hauptkeule an verschiedenen stellen kleinere und grössere polsterförmig vorragende Lager von Ascusfrüchtchen sicl bildeten. Fs dauerte aber bis zum 24. November, ehe der in der Photograplie festgehaltene Reifezustand erreicht war, und nun die aus den Perithecien ausgeschlenderten Sporen aufgefangen werden konnten.

Die reifen Peritlecien sind etwa ${ }_{12}^{1}$ mn lang. Anfänglich sind sie völlig eingesenkt, bei zunelmender Grösse und Reife abel treten sie mehr und melı hervor und scheinen schliesslich zu mehr als der Hälfte ihrer Länge frei zu stehen. In Wirkliclıeit sind sie auch jetzt noch ïberdeckt von dem überaus lockeren Stromageffecht, unter dem sie entstanden, und welches ron den sich entwickelnden Perithecien nicht gesprengt, sondern nur nit der Spitze in die Höhe gehoben und zwischen den einzehnen Perithecien etwas zusanmengedrückt wurde. Sie körmen als frei ebensowenig richtig bezeichnet werden, wie die Perithecien vou 
(. corallomyces, australis, thyrsoides, muscicola, rubra und submilitaris.

Wie fast alle jene, in ein sehr locker gebautes Stroma eingesenkten Perithecien, so besitzen auch diese eine verhältnissmässig feste plectenchymatische, dunkler gefärbte Wandung. Die Perithecienpolster erscheinen stumpf gran gegenüber der hellgelben Farbe der iibrigen Theile. Die Schlanchlänge beträgt etwa $250 \mu$, die Länge der Sporen etwas weniger. Stäbchenförmige Theilzellen von 6-7 " Länge sind schon im Schlanche erkemnbar. An frisch aufgefangenen Sporen gelang es in mehreren Fällen. deren je 32 sicher zı zählen. In einem Flüssigkeitstropfen knickt sich die aufgefangene Spore an den Theilwänden leicht hin und her und ähnelt dann, wie so viele andere der Gattung. einer Oidienkette.

Höchst bemerkenswerth ist num bei der vorliegenden Form ler meines Wissens noch bei keiner anderen Cordyceps beobachtete Umstand, dass die perithecientragenden stromata zu gleicher /eit 'Träger einer' selı' reichlichen Conidienfruktifikation durchaus eigener Art sind. Torzugsweise nämlich an den spitzen jener erwähnten stumpf dornigen Fortsätze des stroma ordnen sich die Mycelfäden pallisadenartig nach aussen in dichtem Zusammenschluss, und zwischen solchen, die stumpf enden, stehen in griisserer Ueberzahl andere. welche sich in charakteristisch bestimmter Art lang zuspitzen (Fig. 98). Die Zuspitzung erfolgt plötzlich, derart, dass ummittelbar muter der spitze eine schwache Verdickung (ein Bulbus) entsteht, aus dem die Spitze meist nicht ganz gerade, sondern schräg seitlich. mitunter fast bajonettartig herausragt. (ob eine solche Spitze im Stande ist. mehrere Conidien nach einander abzuschniiren, ist nicht festzustellen; dem beim schneiden mo Bedecken des Präparates fallen alle conidien ab, die nur einigermaassen ausgebildet sind. und nur ganz junge Conidienanfänge sieht man ansitzen. wie die Figur zeigt. Zwischen den haarartig vorragenden Spitzen und ummittelbar auf der festen 
Pallisadenschicht sieht man in grosser Zahl die abgefallenen Conidien, welche oval sind und $5 \mu$ Länge bei etwa $2,5 \mu$ Breite haben. Gleiche Conidienbildung trifft man, aber in weniger bestimmter Anordnung der Pallisadenschicht, anch zwischen den jungen Anlagen der Perithecien und auf den Seitenwänden der Dornfortsätze, auch auf mebenen höckerigen oder runzlicheu Erhebungen des Stromas, nicht aber auf dessen glatten Theilen, und anch nicht an dem Stiel, welcher von senkrecht nach aussen gerichteten, stumpf endigenden, etwa 4-5 " starken Hyphen unter der Lupe schwach behaart erscheint. und in Folge dessen anch von den ansitzenden Theilen des von ihm durchwachsenen Holzmulm nie ganz zu sänbern ist. Keule und Stiel sind solide, nirgeuds hohl, und sie bilden zusammen mit dem vollständig verwandelten Leib der Larve eine einzige butterweich schneidbare Pilzmasse. Eine eigentliche Rinde ist nirgends dentlich ausgebildet. In dem verwandelten Insektenkörper findet man Pilzfäden mit zahlreichen kugelig aufgetriebenen blasenartigen Zellen, die sich gegenseitig berülnen und stellenweise ein Gewebe aus Masclien von ca. 15 « Durchmesser darstellen. Nach dem Stiel des stroma hin verschwinden diese Blasenzellen allmählich und die Hyphen verlaufen ammähernd parallel. Der Stiel hat fädige Struktur. Die Hyphen haben 5-6 " Durchmesser.

Iclı habe die Cord. Tolkiana am Ende der Cordycepsreihe belandelt; demn durch die Conidienbildung auf den pfriemförmigen Stromaspitzen nimmt sie eine besondere Stellung ein, welche sogar ihre Abtrennung als besondere Gattung in dem Augenblick rechtfertigen wïrde, wo man die Gattung Cordyceps in mehrere Gattungen zu zerlegen gewillt ist.

Welchen Schwierigkeiten eine solche Theilung begegnet, leuchtet jetzt nach Betrachtung der 18 bei Blumenau aufgefundenen Arten noch deutlicher ein, als vorher. Ueberall finden sich Cebergänge. Immerhin lassen sich zur besseren Uebersicht Gruppeu muthmaasslich näher verwandter Formen zusammenstellen. Zu 
einer Gruppe kamn man zunächst alle die Arten zusammenfassen, welche ansserhalb des befallenen Insekts kein anfrecht stehendes stroma besitzen. Hierher wïrden von den von mir beschriebenen Arten die ersten vier (C. flavoviridis, gonylepticida, rhynchoticola und cristata) gehören. Die übrigen mit aufrecht stehendem stroma hat man schon in solche mit freien und solche mit eingesenkten Perithecien eintheilen wollen. Unsere Beobachtung hat gezeigt, dass es zahlreiche Formen mit scheinbar freien Perithecien giebt, welche jedenfalls dann auch für sich betrachtet werden müssen. In den bisher vorhiegenden Beschreibungen ist anf diesen Unterschied nie geachtet worden, so dass num eine erneute Untersuchumg nöthig wäre, um die bisher als freifrüchtig beschriebenen Arten richtig beurtheilen zu können. Ton den in dieser Arbeit behandelten Arten haben wirklich freie Perithecien nur zwei, nämlich polyarthra und Mölleri. Scheinbar frei sind sie bei C. corallomyces, australis, thyrsoides, muscicola. rubra und submilitaris, eingesenkt wenigstens zum grössten Theile und senkrecht zur Oberfläche des Stromas bei C. incarnata, entomorrhiza, hormospora und rhizomorpha. C. Tolkiana wiirde den 'T'ypus einer besonderen Gruppe bilden mïssen, während die Stellung ron C. ainictos so lange zweifelhaft bleibt, bis nähere Aufschlïsse über diese Räthselform gewonnen werden.

Isaria Pers. Seit 'Tulasnes Mittheilungen im 3. Bande der rarpologie ist kein /weifel mehr daran, dass der unter dem Namen Isaria farinosa beschriebene, auf toten Insekten sich entwickelnde Conidienpilz in den Entwicklungskreis von Cordyceps militaris gehört. Die Isaria-Conidienform lässt, wie wir wissen, in Kultmren noch alle Stadien der Entwickelungshöhe erkennen. Die keimende Conidie treibt einen Fader, dessen Seitenverzweigungen sich direkt zuspitzen und hinter einander eine Reilıe kettenförnigg im Zusammenhang bleibender Conidien erzeugen. Bei reicherer Ernährung bilden sich verzweigte Mycelien, die sich nit einem lockeren Filz ron aufstrebenden, wirtelig verzweigten 
nnd mit Conidienketten endenden Hrphen bedecken. Bei natürlicher Entwickelung auf den Insektenkörper bilden sich endlich die bis zu mehreren cm Höhe ansteigenden verzweigten 'Träger, die aber wiederum mit derselben Conidienbildung in ungeheuren Massen abschliessen. Wir sehen hier ror uns die allmählich fortschreitende Steigerung eines Conidienfruchtkörpers zu immer höherer und grösserer Formgestaltung in genau derselben Art und Teise, wie dies für den basidientragenden Fruchtkörper der Pilacrella delectans im rorigen Hefte dieser Mittheilungen gezeigt werden konnte.

Dass es auch in künstlicher Kultur möglich ist, Isariaentwickelung bis zur vollen Höhe der rerzweigten Träger zu erzielen, hat R. H. Pettit in seiner sorgsamen Arbeit: .. Studies in Artificial cultures of Entomogenous Fungi" (Bull. 97 July 1895 Corluell T'nirersity Experiment Station. Botanical and Entomological Division) gezeigt.

Für mich war bei der rerhältnissmässig sehr geringen Zeit, die ich in Anbetracht des iiberreichen zu bearbeitenden sonstigen Materiales den Cordycepskulturen zugestehen komnte, nur die Frage nach dem Typus der etwa rorhandenen Conidienbildung der einzelnen Formen lösbar. Kulturversuche konnten mit 11 von den aufgefundenen 18 Arten gemacht werden. Bei zwei ron diesen (C. corallomyces und hormospora) war eine Keimung in Wasser oder Nährlösung überhaupt nicht zu erzielen, bei zwei anderen (C. rhynchoticola und australis) trat reiche Mycelbildung ohne Conidienbildung ein, bei $C$. thyrsoides wurden renigstens in den ersten drei Tagen nach der Aussat an den entstandenen Mycelien Conidien nicht beobachtet; sechs andere (flavoriridis, polyarthra, Völleri, rubra, subnilitaris und entomorrhiza) bildeten Conidien, in wesentlichen alle nach demselben wenig modifizirten 'Typus, wie er für Isaria farinosa bekannt ist. Die jeweiligen Abweichungen der Bildung sind bei den einzelnen Formen besprochen. 
Ton den wiederholt bei meinen Exkursionen im Walde bei Blumenau beobachteten Isarien, die sich nur sehr schlecht konserviren lassen. bringe ich nur des allgemeinen Interesses halber drei Bilder. Taf. XI Fig. 2 stellt einen Isariawald auf einer grossen haarigen Raupe in geringer Verkleinerung dar. Tch knltivirte die conidien dieser Isaria und erhielt conidientragende Mycelien, von denen ein kleines Exemplar anf 'Taf. TII Fig. $106 \mathrm{~b}$ abgebildet ist. Man sieht, es stimmt mit Isaria farinosa in der Bildungsweise der Conidien völlig überein; ebenso aber auch mit den Conidien, welche ich in den oben erwähnten Ḱulturen aus Ascussporen del Cordyceps submilitaris erzog, und es ist wohl wahrscheinlich, dass diese Isariaform in den Entrickelungskreis von C. submilitaris gehört. Ganz genan dieselben Resultate erzielte ich durch Aussaaten der Conidien einer Isariaveg'etation, welche den Körper einer der grossen Morphopuppen in der durch die Photographie Taf. XI Fig. 1 dargestellten Weise, an den Nähten der Leibesringe reihenweise hervorbrechend, ganz wundersam schmückte. Nach dem Kulturbefunde darf man amnehmen. dass ein und dieselbe Form die Raupe und die l'uppe befällt und nur je nach der Verschiedenheit der durch das Substrat bedingten Ernährung in rerschiedener Teise in die Erscheinung tritt. Bei der grossen Einförmigkeit der Conidienbildnng in der formenreichen Cordyceps. gattung ist natürlich ehensowenig ansgeschlossen, dass liöchst verschiedene Arten Tsarien erzeugen, welche man nicht von einander unterscheiden kann.

I) dritte Isariaphotographie ('T'af'. II Fig.3a) illustrirt recht deutlich eine oftmals bemerkte merkwiurdige Thatsache. Man sieht auf eine Nadel gespiesst die befallene haarige Raupe, uiber ilı liegt ein welkes Blatt, und die hervorbrechenden Isariafruchtkörper durchbohren dies an verschiedenen Stellen. Genan gleiches Durchbohren ïberliegender: z. 'T'h. noch ziemlich zäher Blätter habe ich auch bei perithecientragenden Cordycepskeulen mehrfach beobachtet. Man sollte meinell, wenn eine solche Gruppe von Isaria- 
fruchtkörpern, wie die abgebildete, oder eine kräftige, mehrere Millimeter starke Cordycepskęule in die Höhe wäclıst, so müsste sie ein loses Blatt leicht mit aufheben. Damit wiirde aber der Sporenverbreitung des Pilzes wenig gedient sein. Man findet daher das Blatt regelrecht durchbohrt und zwar so lıäufig und so regelmässig durch Isarien und Cordyceps, dass mir zur Erklärung dieser 'Thatsache nur die Annahme übrig bleibt, die aufstrebenden Fruchtkörper des Pilzes wirken in irgend welcher Weise chemisch lösend auf die ïberliegenden Blatt- und Holzreste ein, um ihre Sporenträger ins Freie zu bringen. Aus demselben Bilde (Taf. XI Fig. 3a) ist anch schön ersichtlich, wie die Isaria unter Unständen mit langem Strange unterhalb eines Blattes entlang kriecht, um am Rande zu fruktifiziren, womit damn für die Sporenverbreitung dasselbe erreicht wird, als wenn das deckende Blatt durchbohrt worden wäre.

\section{b. Spliaeriaceen.}

Von den Sphaeriaceen, welche anch in meinem Blumenauer Arbeitsgebiete iberreich vertreten waren, habe ich nur denen mit hoch entwickeltem, über las substrat hinausragenden stroma, also den auffallendsten Formen, und auch diesen nu' beschränkte '/eit und Aufmerksamkeit widmen können. Nan kann nach den bisherigen Anschaumgen sagen, dass alle derartige sphaeriaceen zur Gruppe der Xylarieen gerechnet werden. Diese sind eben dadurch, sowie durch den Besitz dunkel gefärbter, einzelliger, oft einseitig abgeflachter Sporen und durch die schwarze Farbe, dit entweder auf und in dem Stroma, oder wenigstens in den Peritheciengehäusen auftritt, und meist mit kohliger Beschaffenheit Hand in Hand geht, gekenmzeichnet und bilden anscheinend eine natiurliche Gruppe. Erwägt man aber, dass neben den einzelligen. nach den bisherigen Kenntnissen allerdings ausnahmsweise, doch auch zweizellige Sporen vorkommen, und berücksichtigt man die ausserordentlichen Verschiedenheiten in dem Bau und der Be- 
schaffenheit der Stromata, so wird es mehr als zweifelhaft. ob nicht bei genanerer Kenntnis besonders der zahlreichen ausseremropäischen Formen die Xylarieen in verschiedene Verwandtschaftskreise zerfallen werden, die je für sich auf niedere Sphaeriaceen mit weniger éntwickeltem Stroma zurückführbar sein dürften. Dass der Besitz der hochentwickelten Stromata kein Beweis der Blutsverwandtschaft ist, geht aus dem bisherigen Inhalt dieser Arbeit wohl sicher herror. Bei den Hypocreaceen sahen wir die verschiedenen Verwandtschaftsreihen von stromalosen zu stromatischen Formen ansteigen. Bei der geringerer Anzahl der noch dazu im ganzen besser bekannten Formen war es dort möglich, eine verhältnissmässig klare Uebersicht der einzehnen Verwandtschaftsreihen zu gewinnen. Bei den sphaeriaceen mit ihrem ungeheuren Formenreichthum ist eine einigermaassen befriedigende systematische Uebersicht bis hente noch nicht erreicht. Die z. Z. übliche Klassifizirung kann nur als ein Nothbehelf angesehen werden, wie schon Brefeld (Band X S. 194) ansführt. Unter diesen Umständen ist demnach nicht zu erwarten, dass es heute schon gelingen köme, die muthmaasslichen stammformen der lröchst entwickelten Xylarieen unter der Schaar der niederen Formen mit einiger Sicherheit heranszufinden. Dies um so weniger, wenn sich sogar Zwreifel regen, ob jene Stammformen sämmtlich unter den sphaeriaceen zu finden sein werden, und ob nicht für manche Xylarieen der natïrliche Anschluss in Hypocreaceenstämmen zu suchen ist. Diese Vermuthung wird durch nene Formen, die aus den Tropen bekannt werden, bis zu gewissem Grade unterstützt. Ich denke dabei vornelnmlich an die ron Saccardo Bd. XIT Seite 628 aufgeführte Thuemenella jaranica Penz. et Sace. und an die ron Raciborski im 2. Hefte seiner "parasitischen Algen und Pilze Javas". 1900. Seite 15 beschriebene Konradia Bambusina Rac.

Wie dem num anch sei. so war es mir ron hohem Werthe, feststellen zu könmen, dass unter den Xylarieen in Bezug auf 
Conidien- und Ascusfrucht dieselben Steigerungen in der Stromaausbildung sich wiederfinden, welche wir bei den frïher behandelten Hypocreaceen, und zwar bei den verschiedenen Unterabtheilung*en unabhängig von einander entstehen sahen. Bisher galten die Xylarieen als die in Bezug auf stromatische Ausbildung am weitesten vorgeschrittenen Pyrenomyceten. Formen wie Xylaria. Daldinia, Thamnomyces hatten ihresgleichen kaum moter den übrigen Familien. Jetzt nach dèn vorliegenden Untersuchungen stehen sie den Hypocreaceen in dieser Beziehung nur gleich. und allein etwa Thamnomyces und die wenig bekannte Camillea stellen noch 'Typen dar, welche die Xylarieen vor den iubrigen Verwandten voraus haben. Man kennt auch schon hochentwickelte Conidienfrüchte dieser Familie. Allein es sind das eigentlich nur die Ascusfrüchte, welche sich, ehe die Perithecien angelegt werden, mit einem Lager von Conidien bedecken, so bei Hypoxylon, Xylaria, Daldinia u. a. Unter den Nectriaceen bot uns Sphaerostilbe ein Beispiel, dass die Conidienfruktifikation uıabhängig von der Hauptfruchtform zu eigenartiger höher entwickelter Fruchtkörperbildung ansteigt, unter den Perisporiaceen, wo diese Eigenthümlichkeit weiter verbreitet ist, lernten wir in Penicilliopsis brasiliensis einen Fall kennen, der in gleichem Sime durch die weitgehende Differenzierung der Conidienfruchtkörper erhöhte Aufmerksamkeit beanspruchte.

Die beiden eben erwähnten Formen nuı haben unter den Xylarieen bisher nicht bekannt gewordene bemerkenswerthe Analoga. In der Fig. 107 a Taf. VIII ist die äussere Erscheinung eines im August 1892 bei Blumenau auf totem Holze gefundenen Pilzes skizzirt, der als eine Sphaerostilbe unter den Xylarieen betrachtet werden kann. Neben und auf den schwarzen, harten, kolılig brïchigen Ascusfrüchten erheben sich wenig über $1 \mathrm{~mm}$ holie. gleichfalls schwarze Säulchen, die auf ihrer Spitze mit einer Kappe vou pallisadenartig angeordneten, Conidien in ungeheurer Zahl abschnïrenden helleren Hyphen bekleidet sind. Die hyalinen läng- 
lichen Conidien messen nur $3 \mu$ in der Länge, die Fruchtkörper enthalten je 1 oder meist 2 Perithecien von rein weisser Farbe. Die Schläuche sind schon angelegt, aber noch nirgends reif, so dass ïber die Sporen nichts mitgetheilt werden kann. Ich unterlasse deshalb auch eine Benemnung dieses Pilzes; ich möchte aber darauf aufmerksam machen, dass hier ein neuer, nach aller Wahrscheinlichkeit ein Xylarieentypus vorliegt, der, sobald die Sporen beobachtet sind, zur Aufstellung einer selbstständigen Gattung der Xylarieen begründeten Anlass giebt.

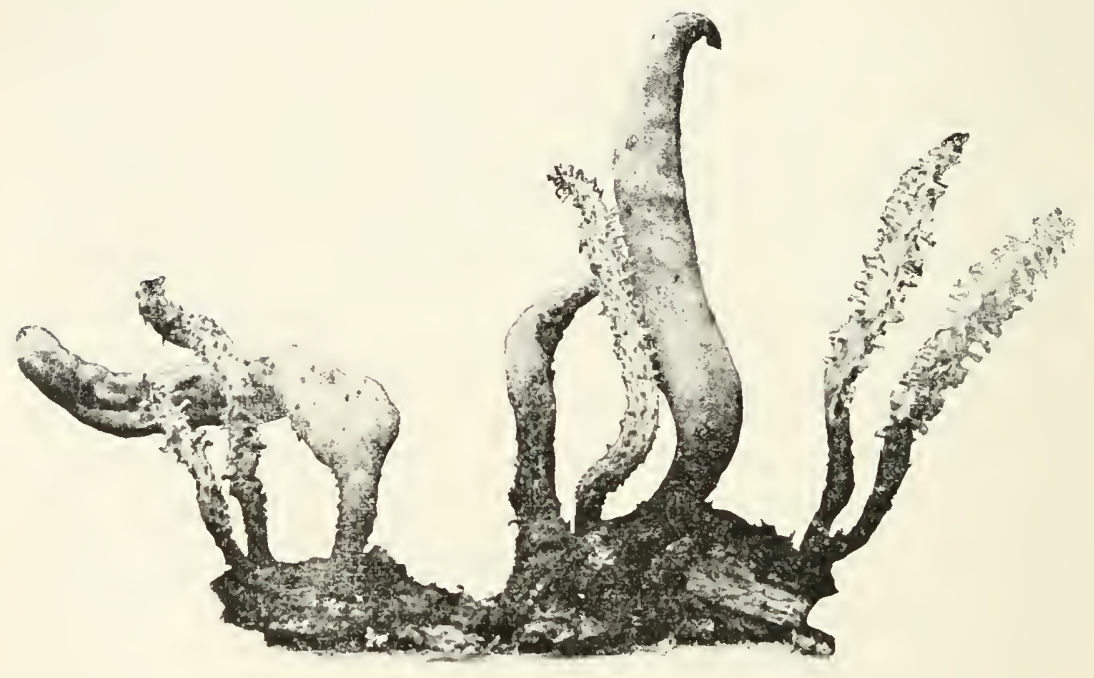

Und dasselbe trifft zu für die merkwïrdige Xylarieenform, welche durch die hier wiedergegebene Photographie in $5 / 6$ der natïrlichen Grösse dargestellt ist. Bereits zu verschiedenen Malen hatte ich die charakteristischen Conidienfruchtkörper im Walde bei Bhumenau auf morschen, am Boden liegenden Stämmen für sich allein gefunden, bis durch den im November 1892 erfolgten, hier abgebildeten Fund ihre Zugehörigkeit zu einem Xylarieenfruchtkörper sicher erwiesen wurde. Aus dem trockenen Holze bricht eine Spindel hervor, welche im unteren Theile 
schwarz, im oberen grauweiss ist. Sie ist unregelmässig kantig und erreicht $6 \mathrm{~cm}$ Höhe in den abgebildeten Stücken, doch entsinne ich mich auch noch etwas grössere früher gesehen zu haben, ehe ich iltre Bedeutung kannte. Die Spindel ist in ilırem grauweiss gefärbten Theile ringsum bcsetzt mit unregelmässig rertheilten. etwa $2 \mathrm{~mm}$ langen Seitenzweigen ron gleicher Farbe, welche an ihrer Spitze ein dunkelmausgraues Polster, das Conidienlager, tragen. Auf dicht gleichmässig basidienartig angeordneten zugespitzten Sterigmen werden dort die ovalen hyalinen Conidien von $9 \mu$ Länge, 4 « Breite abgeschnïrt; ihre Keimung zu beobachten gelang nicht. An dem genannten Tage fand ich nun im Velhathale diese Conidienfrïchte in grosser Anzahl über einen morschen Stamm verbreitet und nicht nur untermischt, sondern, wie auch die Abbildung zeigt, im engsten organischen Zusammenhange mit einer Xylaria von noch weichfleischiger Beschaffenheit; die Keulen waren z. Th. nach der Spitze zu noch gelbweiss, im übrigen schmutzig aschgrau, nach unten ganz schwarz gefärbt; sie sind hohl, wie übrigens auch die Conidienträger, etwas flach zusammengedruickt, und alle zeigten die mehr oder weniger ausgeprägte S-Form, wie sie auch auf dem Bilde erscheint. Die grösste Keule, welche gefunden wurde, hatte $11^{1}{ }_{2} \mathrm{~cm}$ Höhe, der Stiel unten $8 \mathrm{~mm}$ Durchmesser, die Keule an der dicksten Stelle $25 \mathrm{~mm}$ Durchmesser. Eine genaue Untersuchung der F undstelle ergab, dass offenbar die Conidienfrüchte im Abwelken waren, keine einzige war mehr ganz frisch, und viele lagen schon um und waren rerwelkt; dagegen waren alle Keulen ganz frisch, und nur erst mit der Anlage der Perithecien unter der Rinde versehen. reife Ascusfrüchte wurden auch in der grössten noch nicht gefunden. Jedenfalls erscheinen die Conidien vor den Perithecienfrüchten, und oftmals mag zwischen dem Auftreten beider ein längerer Zwischenraum liegen, der es damn unmöglich macht, die Zusammengehörigkeit zu entdecken.

Die Aehnlichkeit dieser Conidienfrüchte mit denjenigen von Penicilliopsis brasiliensis geht aus der Vergleichung der betreffenden 
Abbildungen zweifellos hervor. Auch in dieser Form liegt ein neuer Xylarieentypus vor, der die Begründung einer nenen Gattung erfordert, sobald die Schläuche und Sporen aufgefunden sein werden.

Während derartig entwickelte Conidienfrüchte bisher für die Xylarieen nicht bekannt waren, so weiss man längst, dass die Ausbildung der perithecientragenden Stromata in dieser Familie sehr hoch entwickelt ist. Den bekannten Richtungen, welche diese Stromabildung einschlng, füge ich noch eine nene hinzu, welche hohle Fruchtkürper von weichfleischiger, innen gallertiger Beschaffenheit bildet.

Entonaena mesenterica nov. gen. et nov. spec. bildet gallertig weiche, hohle, kuglige oder unregelnässig blasig gestaltete, fast ungestielte, in reifem Zustande matt schwarz gefärbte Fruchtkörper von bis zu $8 \mathrm{~cm}$ Durchmesser in den beobachteten Fällen. Unsere Fig. $109 \mathrm{~b}$ auf Taf. VIII stellt einen solchen Fruchtköryer in natürlicher Grösse dar. Seine Oberfläche ist mit selır zierlichen gleichmässig vertheilten gekröseartig verschlumgenen vertieften Linien höchst charakteristisch geziert. Dies Merkmal. dem der Artname Rechnung trägt, ist wahrscheinlich erst durch die Aufbewahrung in Alkohol recht deutlich geworden. Ich kann nicht mehr allgeben, ob es auch in frischem /ustande so deutlich war. Die Wand dieser Fruchtkörper hat nur 4 mm Dicke (s. Fig. 109a). Betrachten wir diese Wand bei stärkerer, etwa achtmaliger Vergrösserung im Querschnitt Fig. 109 c. so sehen wir unter einer dünıen äusseren schwarzen Rindenschicht, auf welcher auch mit der Lupe die überaus feinen Perithecienmündungen kaum zu erkennen sind, die rundlichen Perithecien von ' ${ }_{10}^{\prime} \mathrm{mm}$ Durchmesser einzeln vertheilt. Sie haben eine dunkle Wandung und liegen in einer heller gefärbten Mycelschicht. Unter dieser zeigt die Wand eine Zusammensetzung aus zum Fruchtkörper radial gerichteten parallelen Hyphen, welche zu einer Art von prosoplectenchymatischem Ge- 
webe verbunden sind, das durchaus an den Bau der Fruchtkörper von Daldinia erinnert. Dies Pilzgewebe besteht nämlich aus Zellen von etwa 6-12 "Breite nnd 33-40" Länge, welche ziemlich genau reihenweise angeordnet sind. wie sie ans der Hyphe entstanden. Die benachbarten regelmässig parallel gelagerten Zellreilıen schliessen lückenlos dicht zusammen. die Zellwände sind dunkelbraun inkrustirt, vom Zellinlualt sind nur noch spuren vorhanden. Die dunkle Inkrustation der Zellwände ist am schärfsten dicht unter der Perithecienschicht ansgebildet, und verliert sich nach unten und innen zu mehr und melı bis zum gänzlichen Terschwinlen. Die in der Skizze angedeuteten wurzelartigen stränge. welche durchweg aus demselben beschriebenen Gewebe mit längsrestreckten parallel geordneten Zellen bestehen, werden almälılich dïmner und lösen sich in nnregelmässig locker in einer nicht organisirten Gallerte verlaufende Hyphen auf. Die innere Fleischschichte der Fruchthörperwand ist schleimig gallertig und zerfliesst alluällich. Einige Reste auf der Anssenseite einzelner Fruchtkïrper machen es wahrscheinlich, dass in Jugendzuständen ein ('onidienüberzug' vorhanden ist, der anch möglicherweise dem jungen Fruchthörper eine lellere gelbliche Farbe verleiht. Die Schläuche sind typische Xylarienschläuche mit ansserordentlich feiner kaum sichtbarer Wandung und je acht in einer Reihe liegenden ovalen, vou der einen Seite ein klein wenig flachgedrückten schwarzbraunen 10-11 " langen, 5 " breiten Sporen, an denen man häufig einen helleren Längsspalt angedentet sieht, wie dies bei vielen anderen verwandten Formen auch der Fall ist.

Zn weit erstaunlicheren Fruchtkörperbildungen als die beschriebene bringt es eine andere Entonaemaform, welche ich als Entonaena liquescens n. sp. bezeichnen will. Unser Bild (S. 248) griebt nur in ${ }^{1} / 6$, natürlicher Grösse die wunderbare Erscheinung eines hellg̣elb gefärbten blasigen an Tremellaformen erinnernden Fruchtlagers wieder, das ich lange Zeit hindurch in der Nähe meiner W'olmumg auf einem starken alten gefallenen Baumstamm zu be- 
obachten Gelegenheit hatte. Ich bemerkte diese Bildung zuerst am 13. April 1892, wo sie schon recht auffallende Grösse hatte. Die hohlen blasigen Körper bestanden in ihrer Wandung ans weich

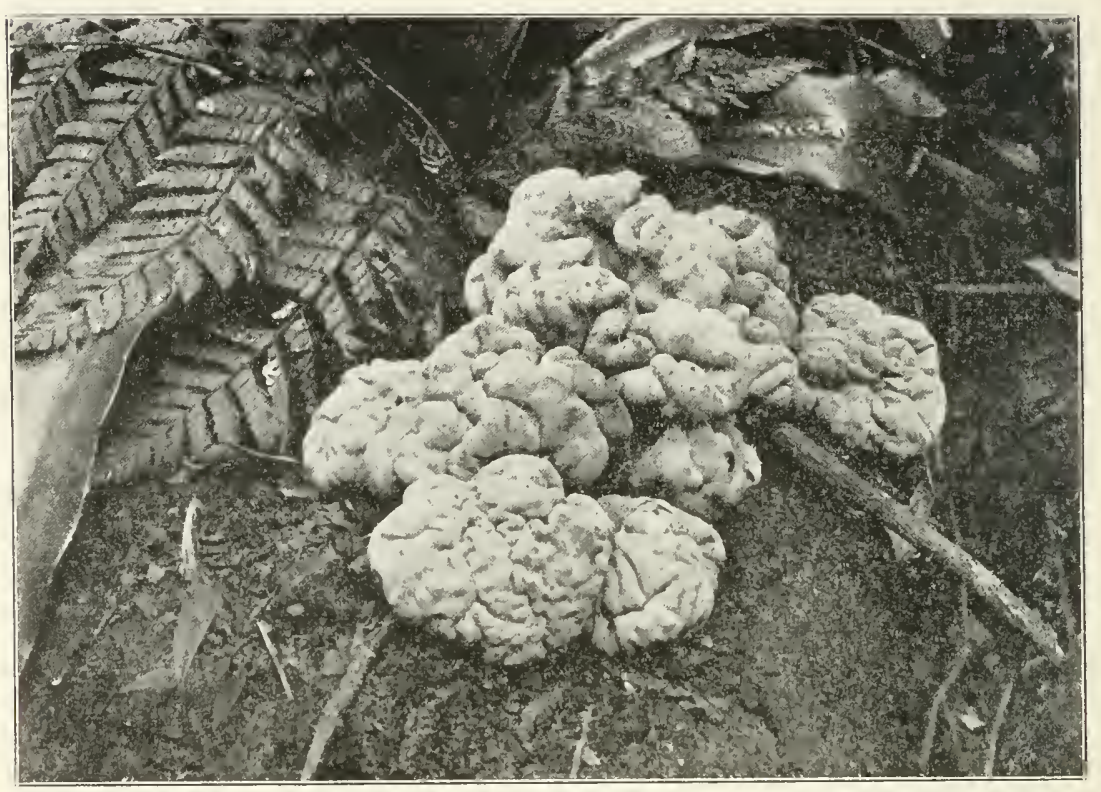

gallertigem Fleische mit einer etwas festeren hellgelb gefärbten Rindenschicht. Vom 1:3. April bis Ende September beobachtete ich den allmählich immer grösser werdenden Fruchtkörper; das Bild wurde im Juni gemacht. Zn dieser Zeit hatte der, wie man sieht, aus zahlreichen mit einander mregelmässig verwachsenen Blasen bestehende Fruchtkürper an den dicksten Stellen eine Höhe ïber dem Substrat ron $15 \mathrm{~cm}$, und seine grösste horizontale Ausdehnung betrug fast $40 \mathrm{~cm}$. Ich wartete gespannt auf das Erscheinen der Früchte, doch immer vergebens; in den ersten Tagen des Oktober zerfielen und zerflossen die ältesten mittleren Partien, und bald griff damm die Zersetzung weiter um sich, ohne dass an irgend einer Stelle eine Spur einer Fruktifikation aufgetreten wäre. Glïcklicherweise hatte ich an einer anderen nicht allzu entfernten 
Stelle im Walde noch einen zweiten weit kleineren Fruchtkörper derselben Art dauernd in Beobachtung, ind diesen fand Herr Gärtner endlich am 17. December 1892 bedeckt mit den in Form einer schwärzlichen Schmiere ans den punktförmigen Perithecienmündungen ausgetretenen reifen Ascussporen. Diese sind denen der Ent. mesenterica fast gleich, nur etwas gedrungener, 9-10 $\mu$ lang, 5-6 « breit, an beiden Enden gleichmässig abgerundet, und die einseitige Abplattung ist nicht erkembar. Auch im Bau der tiefschwarzen Fruchtschicht (Taf. VIII Fig. 108), welche sich mnter der primären hellgelben Rinde bildet, und diese dann abstösst, machen sich grosse Aehnlichkeiten bei dentlichen U'nterschieden gegen die vorige Form geltend. Der schwarzen Oberfläche des reifen Fruchtkörpers fehlt jene mäandrische Skulytur, welche für Ent. mesenterica charakteristisch ist, dagegen sind die Peritheciemmündungen etwas deuthicher. Die Perithecien von annähernd derselben Grösse liegen dicht gedrängt lückenlos an einander und erhalten hierdurch eine etwas mehr längliche anstatt der runden Form. sie liegen auf einem tiefschwarz gefärbten Plektenchym, welches die parallele Lagerung der Zellen nicht so dentlich zeigt, wie bei der vorigen Form; die einzehnen Zellen sind mehr isodiametrisch und untereinander sehr ungleich (von 10-50 $\mu$ Durchmesser). Diese unter den Perithecien liegende ${ }^{3}{ }_{10} \mathrm{~mm}$ starke Schicht mit den dunkel inkrustirten Zellwänden setzt sich nach unten und innen gleichartig in Gestalt von spitz auslaufenden Wurzeln fort, wie die Figur 108 zeigt, doch sind diese Wurzeln weit kürzer, und lösen sich viel früher in lockere in Gallerte eingebettete Fäden auf, als bei Ent. mesenterica. Wir haben zwei offenbar nahe verwandte, doch durch charakteristische Merkmale getrennte Arten der zu den Xylarieen zu rechnenden neuen Gattung Entonaema vor uns.

Es dürfte die Vermuthung nahe liegen, dass die verschiedenen unter dem Namen Glaziella beschriebenen Pilze in die Verwandtschaft unserer Entonaema gehören. Glaziella gehört zu jenen die 
Terzweiflung jedes arbeitenden Mykologen erregenden Gattungen. welche anfgestellt sind, olme dass man jemals ihre Fruktifikationsorgane genau untersucht lıätte*). Lindau sagt daher sehr richtig Seite 372.2 seiner Bearbeitung für Engler und Prantl Nat. Pflnzfam.. man thäte am besten diese Gattung ganz zu streichen. Ich kann dem nur beistimmen. Da aber die Habitusschilderung der Glaziellaformen mir auf eine Verwandtschaft mit meiner Entonaema hinzuweisen schien, so wollte ich doch den Versuch machen, die Gattung Glaziella durch Einreihung meiner sporemreifen Entonaemaformen zu retten. Allein, was ich durch Herrn Hemnings Güte als Glaziella aus dem berliner botanischen Museum erhielt, zeigte einen so weit von Entonaema abweichenden Bau des übrigens mehr knorpeligen, als gallertigen Stromas, dass meine Absicht dadurch vereitelt werden musste. Ich schliesse mich demnach bezüglich der Gattung Glaziella ganz dem Lindauschen Vorschlage an, und laalte dafür, dass sie zu streichen ist.

Bei den beiden untersuchten Entonaemaformen erstreckt sich die Perithecienbildung ïber die ganze Oberfläche des Fruclıtkörpers mit Ausnahme der Anheftungsstelle, der dem Snbstrat aufliegenden Unterseite und mmregelmässig umgrenzter Stellen in den eingefalteten Buchten zwischen den einzelnen Blasen. Zu einer bestimmten Lokalisirung des Hymeniums dagegen, einer Sclieidung der Stromaberfläche in einen sterilen und einen fertilen Theil, in derselben Art, wie wir diese Formsteigerung bei Ascopolyporus polyporoides in höchster Vollkommenheit kennen lernten. ist die neue Gattung Xylocrea vorgeschritten, deren einer

*) Sollte man nicht ebenso wie man sich über Nomenklaturregehn einigt, auch fiir die Aufstellung nener Gattungen und Arten von Pilzen wenigstens einige Grundsätze zu allgemeiner Anerkennung bringen kömnen? Wenn Jemand eine Ascomycetengattung aufstellt, ohne je einen Ascus derselben gesehen zu laben, so miisste Niemand verpflichtet sein, auf derartige Literaturbeschwermg. Rücksicht zn nehmen. Was würde man sagen, wenn Jemand eine nene Phanerogamengattung mur durch die Blïtter charakterisirte und künftigen Forschern die Mühe überliesse, die zngehörigen Blüthen nnd Früchte zn suchen? 
bei Blnmenau nicht eben seltener Vertreter in typischer Form durch die Figur 112 Tafel VIII dargestellt ist.

Xylocrea piriformis nov. gen. et nov. spec. wächst auf abgestorbenen Holztheilen, insbesondere habe ich den Pilz mehrmals im Walde an den Stäben gefunden, welche zum Bau der Wildfallen ver'wendet waren, und einmal fand ich ihn in voller Entwicklung an einem solchen Stabe, der nachweislich nicht länger als ein lıalbes Jahr an seiner Stelle stand. Der Pilz hat nicht inmer die typisch ausgelrägte Birnenform, wie anf der Zeichnung, stellt aber in allen von mir beobachteten Fällen eine kur\% stielartig am Grunde zusammengezogene, nach vorn dicker werdende weichfleischige Kenle dar, welche das Hymenium nur an ihrem Kopfe anf einem ringsum schart abgegrenzten kappenartigen 'Theil der Oberfläche erzengt. Im wesentlichen ist der Pilz von gelber Farbe, die mannigfach wechselt.

Insbesondere verzeichnete ich für das abgebildete Stück am Grunde bis auf ein Tiertel der Tänge eine blasse Lederfarbe (Saccardo 7 : avellaneus - 8: isabellinus). Diese ging dann allmällich in kräftiges Citronengelb (Sacc. 2t) über und wurde noch weiter nach rorll, nach dem Hymenium zu, etwas heller. Das Hymenium hob sich durch eine aschgraue (Sacc. 2: grisens - 43: caesius) Farbe deutlich ab, und auf ihm waren die rein schwarzen Perithecienmündungen schon für das blosse Auge dentlich erkennbar. Bis auf das Hymenimm var die Oberfläche von einem melligsammtigen Ueberzuge lockerer Hyphen bedeckt, doch wurden Conidien nicht daran gefunden. Der Fruchtkörper besteht aus einer soliden, nicht festen, durchweg gleichartig höchst charakteristisch zusammengesetzten Masse eines gelben weichen Fleisches. Auf dümnen Sclmitten erkennt man einen Bau desselben, wie er mir bei Pilzen noch nie vorgekommen ist. El erinnert ausserordentlich an Gewebsformen lö̈lerer Pflanzen. Grosse gefässartige Kellen ron ca $80 \mu$ Durchmesser und sehr dünner Wandung sind darin gleiclmässig vertheilt, und zwischen ihnen befindet sich ein Netzwerk kleinerer, ebenso dünnwandiger Zellen von im Mittel 
$15 \mu$ Durchmesser. Die Fig. 112 erläutert in etwa 50 facher Vergrösserung diese eigenartige Zusammensetzung eines Pilzgewebes, dessen Entstehung aus Hyphen nur stellenweise noch in Andentungen verfolgt werden kamn. Ton der kohligen Beschaffenheit welche für alle Sphaeriaceen einen Hauptcharakter ansmacht und die bekanntlich durch dunkle Ausscheidıngen in den Zellwänden zu Stande kommt, ist bei dieser Form, deren Stroma durchaus an die Hypocreaceen erinnert, ganz besonder's wenig zu merken. Nur eine 1/1" mm starke deckende Schicht über den Perithecien, sowie die Wandungen der Perithecien zeigen diese dunkle Farbe. Die länglich ovalen Perithecien von fast $1 \mathrm{~mm}$ Höhe und "10 $\mathrm{mm}$ Breite liegen in einer Schicht, so dass sie sich an vielen Stellen berühren, läufig aber durch ein dazwischen liegendes plektenchymatisches Gewebe getrennt sind; dies letztere zeigt radialen Bau und lässt seine Hyphenstruktur noch erkemnen, es geht nach unten zu allmählich über in eine etwas dichtere Schicht aus zienlich isodiametrischen, gleichartigen, dïnwandigen Zellen, welche nnter den Perithecien liegt, und ihrerseits in unmerklichem Uebergange zu dem grobporigen, oben beschriebenen Plektenchym des Fruchtkörperfleisches iiberfïhrt. Die zu acht einreihig im Schlauche liegenden schwarzbramen Sporen sind länglich oval, nicht einseitig abgeplattet, 10-13 "lang. 6 " breit. Weder diese noch die der vorerwähnten Entonaemaformen konnten in den damit angestellten Aussatversuchen zur Keimung gebracht werden.

Der Erwähnung werth halte ich ferner eine Form, die ich bei keiner anderen Gattnng besser als bei Poronia unter dem Namen Poronia fornicata n. sp. unterzubringen weiss. Die Fig. 115 zeigt den Pilz im Längsschnitt in doppelter natïrlicher Grösse. Tch fand iln in März 1892 anf den durch Feuer angegriffenen Wurzeln einer Roça, einer abgebramnten Waldschlagfläche. Er bildet kleine flachgewölbte, kuchenförmige Knöpfchen bis $1 \mathrm{~cm}$ Durchmesser; welche nach unten in einen mehr oder weniger langen Stiel zusammengezogen sind. Lang ist der Stiel wie in 
Fig. 115 links, da, wo der Pilz eine Schicht von Wurzelresten und Bodentheilchen zu durchdringen hat, ehe er an die Oberfläche gelangt, und hier finden wir gerade wie bei Poronia die verschiedensten Fremdtheilcheu mit und in den Stiel verwachsen. Auf der flachgewölbten Oberseite sind die Perithecien einzeln verstreut, sie beriihren einander nicht. Die Oberfläche ist von sehr heller Rostfarbe und zierlich punktirt durch die sich scharf abhehenden tiefschwarzen klirzen Perithecienmiindungen, auf deneu sich Häufchen der reifen schwarzbrannen Sporen ansammeln. Hierdurch erinnert das Aussehen lebhaft an Poronia, die Gattung, die ja, wie Tulasne sagt, gerade nach diesem Aussehen ihren Namen erhalten hat („stromatis disco propterea elegantissime nigro-punctato, inde fungilli nomen"). Auch in der weichkorkigen Beschaffenheit der Stromamasse, die ron weisser Farbe ist und aus rerfilzten Hyphen von $4-7 \mu$ Dicke mit vergallerteten Membranen olme geschlossene Gewebebildung besteht, ist eine Vebereinstimmung mit Poronia vorhanden, so dass ich auf das Fehlen der becherförmigen Ausbildung der Fruchtscheibe um so weniger Werth legen möchte, als wir ja gesehen haben, wie innerlalb der durch ihre eigenthïmliche Sporenbildung geeinten Gattung Hypocrea ganz älmliche, ja fast gleiche Stromabildungen zu Stande kommen, wie wir sie bei Poronia punctata einerseits und der hier behandelten Poronia fornicata andererseits finden. Der Durchmesser der reifen kugligen Perithecien beträgt $600 \mu$. Ihre Wandıng ist schwarz, aufs schärfste von dem weissen Fleische des Stromas abgesetzt, die kure kegelförmige Mündung ragt nur eben über die schwachgefärbte, durch etwas dichtere Hyphenverflechtung gebildete Stromarinde hervor. Die Sporen zu acht im Schlauche sind 16 " lang, 7-8 " breit, länglich oval, bisweilen ein wenig citronenfürmig, einseitig sehr schwach gedrückt und im reifen Zustande mit einer hellen Längslinie, der Keimspalte, versehen.

Durch die korkig zähe Substanz des Stroma, an welchem die brüchig kohlige Beschaffenheit fast nirgends deutlich wird, ist nun 
auch eine Xylariee, Trachyxylaria phaeodidyma nov. gen. et nov. spec., ausgezeichnet, welche unter den in dieser Arbeit vorzugsweise betonten Gesichtspunkten ganz besondere Beachtung verdient. Ich labe sie zweimal im Juli 1891 und im December 189:2, beidemal mit reifen Sporen auf morschem Holze angetroffen. An der Zugehörigkeit der in Fig. 114 abgebildeten Form von rein schwarzer Farbe mit einem kurzen Stiel und einer bis zu $7 \mathrm{~cm}$ langen schlanken Keule zur Gattung Xylaria wïrde auf deı ersten Blick wohl niemand zweifeln. Bei genauem Zusehen aber finden wir, dass die Keule durchweg gleichmässig rauh erscheint von den auf ihrer Oberfläche in gleichmässiger Vertheilung, aber frei aufsitzenden Perithecien. Durch ihre freistehenden Perithecien unterscheidet sich diese Form allerdings ron den meisten anderen Xylarien. Wenn wir aber beriicksichtigen, wie imnerhalb der Gattung Cordyceps alle Uebergänge zwischen völlig freien und völlig eingesenkten Perithecien sich finden, so wiirde das erwähnte Merkmal fïr sich allein nicht bedentsam genug sein, um eine neue Gattung zu begrïnden. Es kommt num aber eine weitere Eigenthümlichkeit hinzu, der ich allerdings generischen Werth zusprechen möchte. das ist nämlich der Besitz zweizelliger schwarz brauner Sporen (Fig. 114), wie solche mnter den Xylarieen bisher nur ganz ausnahmsweise bei Camarops Karst. und Xylobotryum Pat. angegeben worden sind.

Für denjenigen, der an die ernsthafte Bedeutung der Saccardoschen Gattungstafeln glaubt, muss die Auffindung der neueu Gattung Trachyxylaria eine erfreuliche Bestätigung sein. Sie ist wirklich eine Parallelgattung zn Xylaria unter den "Plaeodidymae" Saccardos, und wïrde in der beriihmten Tabelle in Anfang des XIV. Bandes Seite 20 an der Stelle, wo jetzt Xylobotryum Pat. steht, ihren vorherbestimmten Platz finden.

Ich kann nun freilich mit wohl den meisten Mykologen zu dem Glauben an die durch Nummern vorgezeichneten „prevedibili funghi futuri" mich nicht bekemnen, aber aus den schon früher 
dargelegten Gründen (vergl. S. 73-74) halte ich allerdings die Beschaffenheit der Ascussporen fiur ein sehr altes und bei der Beurtheilung der Terwandtschaftsverhältnisse an erster Stelle zu berücksichtigendes Merkmal, und es ist mir deshalb nicht zweifelhaft, dass die abweichende Sporenform nnserer 'Trachyxylaria gegenüber den zahlreichen bekannt gewordenen Xylarien mit einzelligen Sporen einen weiten Abstand eröffnet, der durch die Aelnlichkeit der Stromaform nicht überbrïckt werden kann.

Unsere Trachyxylaria ist ron rein schwarzer Farbe. Diese wird zunächst der dïnnen Rindenschicht verdankt, welche, wie die obere Figur andeutet, den Fruchtkörper umschliesst und sich um jedes Perithecium herum kapselartig aufwölbt. Im Innern dieser Kapsel hat jedes Perithecium noch eine eigene geschlossene, deutlich abgesetzte und dunkel gefärbte Wandung. Das Fleisch der Keule wird von einem geschlossenen Gewebe aus Hyphen mit überaus stark vergallerteten Membranen gebildet. Auf dem Querschnitt erscheinen die Zellhumina als rundliche Poren von 6-15 Weite, eingebettet in eine scheinbar strukturlose Gallerte, so zwar, dass die Gallertwände ebenso starken Durchmesser wie die Zelllumina aufweisen. Auf dem Längsschnitte können wir nun feststellen, dass dies Plectenclym aus langgestreckten, im wesentlichen parallel gelagerten, doch häufig mit einander verflochtenen und auch anastomosirenden Hyphen gebildet ist, Ihre benachbarten Wandungen verschmelzen zu Gallertscheiden, in denen eine Trennungslinie meist nicht mehr kenntlich ist. Die einzelnen Zellwandungen scheinen unter dem Mikroskop in diunnen Schnitten nur hellbraun, in ilhrer Gesammtheit hingegen verleihen sie auch dem Stromainnern für das blosse Auge eine fast schwarze Farbe. Nach innen zu, nach der Axe der Keule wird das beschriebene dichte Gewebe immer lockerer, die Wände der Zellen werden immer weniger gallertig, und schliesslich löst es sich in einer Art Markcylinder auf zu eimem losen lockeren Geflecht von braunen verzweigten und anastomosirenden Fäden, die etwa $6-7$ " Dicke 
haben. Solch lockeres Geflecht erfüllt im Innern der Keule einen langgestreckten Markcylinder, der in ganz reifen und besonders starken Stücken stellenweise auch vollkommen hohl ist. Die Höle der Perithecien, deren Fornı die Figur anzeigt, beträgt $0,6 \mathrm{~mm}$, ilıre Breite 0,5 mur. Die Sporen liegen, wie gezeichnet, zweireihig unregelmässig im Schlauch, sie sind schwarzbraun gefärbt, 8-11 " lang, 3-4 " breit und je durch eine Querwand getlieilt.

Icl kamn an dieser Stelle und bei dieser Betraclitung der Xylarieen, welche wesentlich auf neue, bisher nicht beobachtete Typen der stromatischen Ausbildung unter den Sphaeriaceen aufmerksam maclien und uns überzeugen soll, dass fast alle die wunderbaren Formen, die wir bei den Hypocreaceen kennen, auch unter den Xylarieen vorkommen, nicht unterlassen, auf einen der merkwürdigsten und auffallendsten Pilze hinzuweisen, den Herr Hennings muter dem Namen Engleronyces Goetzei im 28. Bande 3. Heft (1900) von Englers botanischen Jahrbüchern beschrieben hat. Engleromyces bildet auf abgestorbenem Bambus im Nyassagebiete bis kopfgrosse kuglige schwarzberindete Stromata, welche ein weiches weisses Fleisch haben, und deren Perithecien bisweilen in mehrfacher Lage ïber einander angetroffen wurden. Die Aualogie dieser Xylariee mit schwarzen Sporen zu unserem friher behandelten Mycocitrus aurantimm, der ebenfalls ja auf Bambus lebt, ist so gross und in die dugen springend, dass ein Hinweis darauf genügt, ın sie jeden einleuchtend zı machen (vergl. auch die Anm. S. 124).

Der Engleronyces soll nach Hennings der Gattung Penzigia sacc. nahestehen, die Lindan vorsichtig noch unter die zweifelhaften Gattungen der Xylarieen rechnet. Und in der That, wenn wir sehen, wie unendlich innerhalb der eigentlichen Gattung Xylaria die typische Keulenform variirt, wie die Feule bald holıl, bald fest, bald breitgedriickt und verzweigt, dann wieder flammiggebogen oder lang, gerade, cylindrisch ist, so könnte man wohl versucht werden, die nur durcl ihre halbkuglige oder fast kug- 
lige oder umgekehrt birnenförmige Gestalt, und faserige Struktur ansgezeichneten Penzigiaarten, soweit sie gestielt sind, bei Xylaria, soreit sie ungestielt sind, bei Hypoxylon unterzubringen. Die in Fig. $110 \mathrm{im}$ Längsschnitte abgebildete Penzigia actinomorpha nor. spec., welche zu rerschiedenen Malen (im Juni und Oktober) in der Nähe von Blumenan auf morschem Holze angetroffen wurde, steht manchen Xylarien jedenfalls sehr nahe. Ihre schwarzen Fruchtkörper sind fast kuglig oder birnenförmig und in einen relhältnissmässig diimnen ebenfalls schwarzen Stiel nach unten zusammengezogen. Die lerithecienfülırende Schicht, welche fast die ganze Oberfläche der Kenle bedeckt, ist von kohlig brüchiger Beschaffenheit, ebenso wie auch die Trandungen der fast $1 \mathrm{~mm}$ I) urchmesser zeigenden Perithecien, welche dicht, doch nicht gedrängt, in gleichmässiger Vertheilung stehen. Tas Innere des Fruchthörpers ist gelblichweiss und zeigt schon für das blosse Ange deutlich einen höchst charakteristischen strahligen faserigen Bau, der in dem Längsschnitt (Fig. 110) anch angedentet ist. Es besteht aus parallel geordneten, nicht plectenchymatisch vereinigten dümmandigen kurzzelligen. etwa $10 \mu$ starken Mycelfäden. Die finzelligen sporen dieser Form sind tiefschwarzbram. $26 \mu$ lang. $6-7 \mu$ breit, an einer seite abgeflacht und bisweilen sogar ein wenig sicheltörmig gebogen.

Man lat bisher dem anatomischen Aufbau der Stromakürper wenig Aufmerksamkeit zugewendet. In den überaus zahlreichen Beschreibungen der Xylarieen, welche eine Orientirung recht erschweren, findet sich hierïber meist kein Wort. Wenn schon ich natiurlich auf die Struktur des Stromas nicht einen ersten und entscheidenden Werth legen möchte. so bin ich doch überzengt, dass seine genauere Beaclitung uns oftmals recht werthvolle Hülfen zur Beurtheilung der näheren oder ferıeren Verwandtschaft äusserlich einander ähnlicher Formen geben wiurde. Man beachte nur die auffallende Uebereinstimmung im Bau der beiden oben beschriebenen Entonaemaformen, die 
höchst charakteristische Zusammensetzung des Stromas ron Xylocrea, und nun wieder diese strangartigen, gar nicht plectenchymatisch verbundenen Hyphen, welche das Stroma der neuen Penzigia zusammensetzen, so kamn man über die Bedeutung dieser jeweils ganz bestimmt ausgeprägten Terschiedenheiten nicht im Zweifel bleiben. Tch bin also wohl geneigt anzunehmen, dass ein ähnlicher strahliger Bau der Kenlensubstanz, zumal wenn er etwa mit der länglichen Form der Sporen Hand in Hand gehen sollte. die Gattmng Penzigia ganz zweckmässig begründen könnte. Dass man iibrigens auch bisher schon in Fällen, wo die Stromasubstanz makroskopisch erkennbare Eigenthïmlichkeiten aufweist, darauf Rücksicht genommen hat, zeigt das Beispiel von Daldinia, welche gegen Hypoxylon nur durch den eigenthümlich geschichteten Bau ihrer Stromata abgegrenzt ist.

Von zweifellosen Arten der formenreichen Gattung Xylaria labe ich eine ganze Reihe gesammelt; doch ïbergehe ich sie hier, da sie wesentlich Neues nicht bieten mo Kulturversuche damit nicht angestellt wurden. Nach Herru Bresadolas und Herrn Hennings Bestimmungen in der Hedwigia 1896 und 1897 befanden sich die Xylaria Portoricensis Klotzsch und X. involuta (Klotzsch) Cooke darunter. An sonstigen zu den Xylarieen gehörigen Formen sind aus meinen Sammlnngen an denselben Stellen noch beschrieben worden: Ustulina vulgaris Tul., Nummularia cinnabarina P. Henn., Nummularia ustulinoides P. Henn., N. Mölleriana P. Henn., N. Glycylurrizae (B. et C.) Sacc., N. placentiform is (B. et C.) Sacc., Hypoxylon ochracemm P. Henn., Hyp. fusco-purpureum (Schw.) Berk., Kretzschmaria Clavus Fr.

Anch von allen diesen habe ich Näheres nicht zu berichten. Dagegen will ich wegen ihrer grossen stromata ron eigenartigem Bau eine neue Hypoxylonform nicht unerwähnt lassen, die als Hypoxylon magnum nov. spec. (Taf. IX Fig. 111) bezeichnet werden mag. Sie bildet auf abgestorbenen Rinden unregelmässig gestaltete, doch im wesentlichen kuglige, ungestielte, aber nach 
der Ansatzstelle hin zusammengezogene Knollen. Ich fand sie nur eimmal anf einer Reise ron Blumenan nach dem Hochlande der Serra Geral am Pombasflusse in einer Höhe von etwa $450 \mathrm{~m} \mathrm{iiber}^{\circ}$ dem Meere. Im frischen Zustande waren die Pilze fast schwarz mit einem röthlichen Anflug. ihre verhältnissnässig dünne Rinde und die Perithecienschicht zeigen kohlig bröcklige Beschaffenheit, das ganze Innere aber ist ein gelb gefärbtes weiches gleichartiges Fleisch. Die Perithecien sind nur an der Oberseite der Knollen in gleichmässiger Schicht angeordnet, wie die Zeichnnng erkennen lässt. Sie sind länglich oval und messen einschliesslich des diinnen Mündungskanales bis $1,7 \mathrm{~mm}$ bei einer grössten Breite von $0,7 \mathrm{~mm}$. Die Schläuche streben vom Grunde und von den Seiten aus schräg nach oben und enthalten je acht in einer Reihe liegende eiförmige tiefbrame Sporen von 13-16 " Länge und $6-7$ " Breite. Die äussere Rinde des Fruchtkörpers erscheint fein rissig gefeldert, und dazwischen schwach punktirt ron den Perithecienmündmngen, in ganz ähnlicher Weise, wie dies Tulasne in seinem allerdings elfmal vergrösserten Bilde des Hypoxylon coccineum (Carpol. IT. Taf. IV Fig. 4) darstellt. Ta man könnte ganz wohl dieses elfmal vergrösserte Bild des Hypoxylon coccineum für die nicht vergrösserte Abbildung eines kleinen Exemplars von Hypoxylon magnum ansgeben. Kwischen und dicht unter den schwarzen kohligen Perithecienwänden befindet sich ein ebenfalls fast schwarz gefärbtes engmaschiges Gewebe, das ganze iibrige Stroma zeigt hingegen bei mikroskopischer Betrachtung einen Bau, der an den für Xylocrea oben beschriebenen und abgebildeten gar sehr erinnert. Es ist ein locker maschiges Gewebe aus kugligen dïmnwandigen Zellen von sehr verschiedenem 25-50 $\mu$ betragenden Durchmesser. Dazwischen finden sich anch grössere Hohlräume und in diesen erkennt man verzweigte Hyphen, während im Uebrigen die Entstehung dieses an höhere Pflanzen erimnernden Plectenchyms aus Fäden gar nicht mehr kenntlich ist.

Noch viel bemerkenswerther als die vorige scheint mir die in 
den Figmren 113 dargestellte Form zu sein, welche ich als Hypoxylon symphyon nor. spec. bezeichnen will. Sie ist ausgezeichnet durch die scharfe Trennmg einer sterilen Ober- ind einer fertilen Unterseite des deutlich gestielten, kreiselförmigen flachen Stromas. Ich fand den Pilz anf demselben Banmstamme, an dem Entonaema liquescens vorkam, und beobachtete seine Entrickelung dort über 3 Monate lang. Er trat gesellig auf. Einzeln stehende Stücke zeigten. wie Fig. 113 oben, eine ganz regelmässige Kreiselfor'm ron bis zu $2 \mathrm{~cm}$ Durelmesser der flach gewölbten dunkel röthlichen Scheibe. Sie sind genlau central kurz gestielt. Die dem Substrate. dem morschen Holze zugewandte Seite des Stromas ist deutlich gezont und von kastanienbranner Farbe. Die Perithecienminnduugen erscheinen anf der oherfläche bei Betrachtung mit der Line als kleine Wölbungen mit punktfürmigem Lüchehchen in der Mitte. Auf dem Längsschnitte sieht man, dass die Perithecien längliche Gestalt haben, $1,3 \mathrm{~mm}$ lang und 0.3 bis $0.4 \mathrm{~mm}$ breit sind und dass sie dicht gedrängt die ganze hỵmeniale Fläche bedecken. Die Sporen liegen zu acht im Schlauch einreihig schräg ïbereinander, sie sind tief brann, oral, 10 "lang; 4.5 " breit. Sie waren nicht zum fieimen zu bringen. Das ganze Innere lieser Fruchtkörper ist rou tief dunkelbraune bis schwarzer Farbe, und zeigt schon für das blosse Ange einen deutlich radialen Ban. Tiefschwarze Linien verlaufen von der Anheftungsstelle nach der Oberfläche. Die consistenz nuld Beschaffeuheit ist genan dieselbe, an Holzkohle erimernde, wie bei Daldinia concentrica, und wie dort findet man auch hier auf mikroskopischen schnitten ein dicht geschlossenes prosoplectenchymatisches Gewebe, aus durchweg parallel geordneten dïmnwandigen, dunkelbraun gefürbten Fäden vou 8 „ Weite. die durch reichliche Querwände getheilt sind. Wenn aber bei Daldinia die dunklen Streifen quer zur Faserrichtung verlaufen, so ist es hier ungekehrt. Zwischen den Fadenreihen mit weitlumigen Zellen finden sich bündelweise solche mit viel engerem Durchmesser nud tiefschwarzen Membranen, und diese sind es, 
welche die schon makroskopisch sichtbaren Radialstreifen hervorrufen. Die Fruchtkörper entstehen, wie gesagt, gesellig, und in der Mehrzahl der beobachteten Fälle treten benachbarte in Berïhrung und verwachsen mit ihren Scheiben miteinander (Fig. 113. Die mittlere Figur zeigt den Fruchtkörper von unten, die untere denselben von oben gesehen). Die einzehnen Stiele bleiben dabei getremnt, und es resultirt ein grosser flachscheibenartig ansgebreiteter Fruchtkörper, der bis zu 5, wahrscheinlich unter Umständen noch melı cm im Durchmesser aufweisen kann, und mit den einzelnen Stielen der ihn zusammensetzenden Einzelstromata an der Unterlage befestigt ist. Es erinnert diese Fruchtkörperbildung an diejenige mancher Thelephoreen und Polyporeen. Ich halte es nach der leider sehr mrvollständigen nnd aller Naassangaben entbehrenden Beschreibung bei Saccardo I p. 323 nicht für ausgeschlossen, dass unser Pilz mit Xylaria cerebrina (Fée), die an abgestorbenen Stämmen bei Rio de Janeiro gefunden ist, gleichbedentend sein könnte. Ist er erst genauer, besonder's auch hinsichtlich seiner doch wahrscheinlich bestehenden Conidienbildung. bekannt, so dürfte er zweckmässig zum Range einer Gattung erhoben werden.

Ich finde keine passendere Stelle als die gegenwärtige. um eines höchst merkwürdigen Pilzes Erwähnung zu thum, den icls glaube zn den Xylarieen stellen zu mïssen, obwohl er in einem ganz wesentlichen Merkmale von allen bekannten Formen abweicht. Seine Perithecien haben nämlich gar keine Mündungen, die in ihnen gebildeten Sporen werden durch Verwitterung des Fruchtkörpers frei. Ich sammelte den Pilz auf einer Reise nach dem Hochlande. am Pombasfluss ganz in der Nähe der Stelle, wo Hypoxylon magnum gefunden wurde. Ich fand ihn in grösserer Anzahl gesellig auf morschem Holze, aber nur in röHlig reifem Zustande, so dass iiber die Entwickelung der Fruchtkörper nichts festgestellt, auch keine Aussaatversuche mit den Sporen gemacht werden konnten. Ich nenne den Pilz Hemningsinia durissima nor. gen. et nor. spec. Er 
bildet iiberaus harte feste knopf-oder kreiselförmige Gebilde ron der in der Fig. 116 abgebildeten Gestalt. Der grösste beobachtete Durchmesser betrug $1,7 \mathrm{~cm}$, die grösste Höhe $1,5 \mathrm{~cm}$.

Die ziemlich regehmässig kreisrunden Fruchtkörper sind von mattschwarzer Farbe mit röthlichem Anflug. Sie sind ganz ungewöhnlich hart. N'ur mit grosser Kraftanstrengung kann man sie zwischen den Fingern zerbröckeln. mit dem Messer gelingt es nicht. sie zu zerschmeiden. Die Festigkeit kommt besonders durch eine Rindenschicht zu Stande, wekche den ganzen Fruchtkörper, den kegelförmigen Stiel sowohl, wie den kuchenartigen Anfsatz rings mmhïllt. Sie ist bis 1 mm stark, und besteht ans einer mattschwarzen im Bruche fast glasig ausselienden Masse. Es gelingt nicht, Schnitte davon herystellen. doch wird diese Masse zweifellos aus sehr englunigen. dicht zusammengelagerten parallelen Hyphen gebildet. deren Wände stark schwarz inkrustirt sind. Denn in diesel Weise ist das ganze Innere des Kegels zusammengesetzt. Die Masse ist auch hier noch ziemlich hart, docli schneidbar, tief clokoladebram. Man erkennt ladial gerichtete, parallel ganz dicht zusammengeordnete Hyphen von etwa 4 " Dicke mit dunklen Wänden. An allen 'Theilen des Fruchthörpers bilden sich leicht rein weisse, aus Vadeln bestehende Krystallsterne, die in Wasser und Alkohol unlöslich, in vordünnter Salzsänle sich langsam ohne Aufbrausen lösen. Der obere kuchenförmige 'Theil des Fruchtkörpers, dessen Deckel ein wenig nach der Mitte zu eingedrïckt ist, umschliesst einen kreisrunden, nach oben verengerten, lurch die glasige VTandschicht scharf begrenzten Hohhranm (s. d. Längsschnitt Fig. 116), mnd in diesem findet man senkrecht bei einander stehende $3 \mathrm{~mm}$ hohe. ${ }^{1 / 3}$ nn weite lange Röhren, die Perithecien. Diese haben keine Minndungen, die obere Deckelscheibe des Fruchtkörpers ist nirgends durchbohrt. Sie bricht aher verhältnissmässig leicht kreisförmig ab und macht dann den Innenraum fiei. Ich fand auch am Fundort einige Fruchtkörper, deren Deckel velwittert war, und im Innern des L'rnenraumes sah man einen tief grïnlich schwarzen, schmierigen 
Brei, bestehend aus den Resten der Perithecienwandnugen nud ungehenren Mengen der ovalen Sporen von 12 ! Länge und 5 « Breite. Einzeln erscheinen sie dnnkelbram gefärbt. Alle zahlreich gesanmelten Exemplare waren in demselben Znstand der Reife, so dass iiber den Ban dieser Perithecien nichts mehr festzustellen war, anch die Asci waren fast iiberall zerfallen, mnd nur die losen Sporen in geradezu erstaunlichen Mengen wurden gefunden. Tur in den Randparthien eines kleinen Fruchtkörpers komnte ich die Asci wenigstens noch beobachten. Sie sind (Fig. 116 rechts länglich elliptisch, 35 « lang, 12 « breit, mud enthalten je acht sporen, die nuregelmässig. nicht in einer Reihe gelagert sind. Ganz ähnlich gebante, röhrenfömig dicht bei einander stehende Perithecien wie hier und von annähernd denselben Dinensionen finden sich iibrigens bei der von Herrn Hemnings beschriebenen oben erwähnten Nummularia nstulinoides. Dort sind es wirklich lange Röhren nit fester kohliger Wand, die im Innern ringsum nit einem hellen zarten Plectenchym ansoekleidet sind, aus welchem die schläuche hervorsprossen. Wenn ich diese Uebereinstimmung der Perithecienschicht mit der einer echten Xylariee in Betracht ziehe, den Bau des strontas, der mit demjenigen ron Hypoxylon magnum, symphyon und Daldinia unverkemnbare Aehnlichkeit zeigt, endlich anch die äussere Formälnlichkeit dieser Henningsinia mit dem vorher beschriebenen Hypoxylon symphyon, so kann ich kaum daran zweifelı. dass dieser Pilz in die Terwandtschaft der Xylarieen gehört, nnd es ist eine weitere Folge die Amnahme, dass bei stärkerer Ausbildung der die Perithecien überlagernden Rindenschichte die Poren und die Perithecienmündungen hier verschwnnden sind. Zur Zeit wenigstens scheint mir keine andere Erklärung dieser ganz eigenartigen und einzig dastehenden Struktureigenthümlichkeit der Henningsinia erlaubt.

Hinweisen muss ich noch darauf, dass wahrscheinlich eine ähnliche Form wie die musrige als Hypoxylon turbinatum Berk. Fungi Challeng. Expedit. II p. 4 Nr. 72 aus Brasilien beschrieben 
ist. Doch stehen in der Diagnose jener Art soviel Einzelheiten. die für meine Hemningsinia nicht zutreffen, dass ich sie nicht für identisch halten kann. Insbesondere lässt die Einreihnng nuter die Gattung Hypoxylon darauf schliessen, dass bei jenem H. tur= binatum Perithecienöfinungen rorhanden sind. Ferner ist auch die Form der sporen von 12-14 $\mu$ Länge bei $8-10 "$ "Breite allzu abweichend ron der unsrigen.

Zu den in der Blumenauer Gegend allerhäufigsten Pilzen. die man auf jeder Exkmsion antrifft, gehört die anscheinend über die ganze Erde verbreitete Daldinia concentrica (Bolt.) ('es. et de Not. Der vorzüglichen Beschreibung der Fruchtkörper, welche 'Tulasne auf Seite 31 ff. des II. Bandes del Carpologie gegeben hat, ist nichts hinzuzusetzen.

Die Keimung der Sporen ist von Tulasne und Brefeld beobachtet. sie trat in Brasilien bei Aussaaten in Nälılösung fast ummittelbà ein, die reich verzweigten und mit Fadenbricken versehenen Mycelien gingen an fünften 'Tage zur Conidienerzengung über. Einzelne Fäden erheben sich in die Luft. rerzweigen sich, das Wachsthum der Seitenzweige lässt bald nach. und am Ende jeder Verzweigung sprosst oftmals genau central. oft anch seiträrts eine Conidie auf dümmen ganz kurzen sterigma. Die fertige Conidie von etwa $6 \mu$ Iänge bleibt zunächst sitzen und es tritt leben ihr eine zweite, eine dritte u. s. w. anf. Ich habe bis zu 12 im Köpfrhen gesehen (Taf. Y Fig. 75a). Beim Bedecken mit dem Deckglase fallen sie sehr leicht ab. und man erkemnt nun mit starker Vergrösserung die Sterigmen recht deutlich. Anch sieht man, wje bei Anlage vieler Conidien die spitze des Fadens basidienartig verbreitert wird. um die Menge der sterigmen tragen zu können (Fig. 75b). Die Conidien bedeckten schliesslich die Kulturen in dichten Massen, nud zeigten dieselbe röthliche Färbung: welche den Fruchtkörpern zukommt. Nach Brefeld Bd. X \&. 260 stimmt diese s. \%. auch in Münster künstlich erzogene Conidien- 
fruchtform mit derjenigen von Hypoxylon fuscum anf das genaueste iibereill.

Säet man Conidien, die von jungen Fruchtkörper'n mit einer Nadel abgenommen sind, in Nährlösung aus, so beobachtet man genau wie bei Aussaat der in Krnlturen gebildeten Conidien eine unregelmässige Keimung. Nur ein geringer Theil der Conidien ptlegt auszukeimen. Die jungen Mycelien erzengen schon am dritten Tage nach der Aussaat wieder Conidienträger.

Da der Pilz in nächster Nähe meiner Wohnung im Talde ïberall häufig zu finden war, stellte ich an ilım vielfache Beobachtungen iiber die Schnelligkeit seines Wachsthums, sowie iiber die Bedingungen und die Dauer seiner sporenerzengung an. Fin Fruchtkörper Nr. I wuchs von einem Durchmesser von $27 \mathrm{~mm}$ am 18. Oktober 1891 auf $34 \mathrm{~mm}$ am 7. Norember. Er begann dann seine Sporenbildung und diese lielt an bis zum 17. Dezember, wo die Beobachtung abgebrochen wurde. Die Grösse des Durchmessers änderte sich aber nicht mehr. Genau ebenso verhielt sich $\mathrm{Nr}$. II, der von 23 mm Durchmesser am 20. Oktober, auf $30 \mathrm{~mm}$ am 7. November gewachsell war.

Nr. III wuchs ron $11 \mathrm{~mm}$ am 27 . Oktober bis auf $22 \mathrm{~mm}$ am 20. November. Er wurde dann abgebrochen und produzirte im 'zimmer reichliche Sporenmassen bis zum 18. Tezember, wo er erschöpft schien.

Welche erstaunlichen Sporenmengen von einem Fruchthörper gebildet werden können, zeigte mir der folgende Tersuch. Ein Fruchtkörper von der Grösse einer kleinen Kartoffel, der reif zu sein schien, doch am Standort offenbar noch keine Sporen ausgeschieden hatte, wurde am 13. November abgebrochen und im 'zimmer unter einer Glocke weiter beobachtet. Schon am nächsten 'Tage bedeckte er sich mit einer blauschwarzen russartigen Schicht der ausgetretenen Sporen, die abgewischt wurden. Ton jetzt an bis zum 9. Dezember wurde fast jeden 'Tag, manchmal nur jeden zweiten 'Tag, die Schicht der nen- 
gebildeten Sporen abgewischt, und immer ernenerte sie sich anscheinend in ungeschwächter Menge. Erst am 7. Dezember liess die Sporenerzengung nach, und vom 9. Dezember ab wurden nene Sporen nicht mehr gebildet. Der Fruchtkörper war erschöpft.

Herr Gärtner ergänzte und bestätigte diese Beobachtungen. indem er einen Fruchtkörper an Ort und Stelle rom 28. Januar bis zum 18. April beobachtete, und fast täglich, längstens mit einem Zwischenraum von 2 Tagen seine Wahrnehmungen verzeichnete. Die Ansmaasse dieses Fruchtkörpers von urspringlich, am 28. Januar, 19 $1 / 2 \mathrm{~mm}$ Länge, $11 \mathrm{~mm}$ Breite und $7 \mathrm{~mm}$ Höhe wuchsen, fast von 'Tag zu Tag messbar, bis zum 14. Februar an auf $23 \mathrm{~mm}$ Länge, $26 \mathrm{~mm}$ Breite und $11.5 \mathrm{~mm}$ Höhe; von da ab bildeten sich an dem ursprünglich rundlichen Fruchtkörper seitliche Ausbuchtungen, wie sie anch sonst angetroffen wurden. Die Maasse, immer in derselben Richtung wie ron Anfang an gemessen, stiegen num bis zum 27. Februar anf $30 \mathrm{~mm}$ Tänge, $33 \mathrm{~mm}$ Breite und $15 \mathrm{~mm}$ Höhe. Conidienlager worden auf dem ältesten Theile rom 17. bis 27. Februar beobachtet, gleichzeitig traten an den jüngeren kugligen Aussackungen schon Sporen aus. Ton dem Augenblick an war aber eine Tergrösserung dieser seitlichen Knollen nicht mehr wahrzunehmen. Indessen vergrösserte sich das ganze Gebilde noch durch Zunahme des mittleren Theils. an dem Sporenruss erst später am 16. März auftrat. Bis dahin waren die ohen angegebenen Maasse des ganzen Gebildes auf $36,5 \mathrm{~mm}, 36 \mathrm{~mm}$ und $15 \mathrm{~mm}$ angewachsen und veränderten sich nun nicht mehr. Dagegen wurde mun weiter Sporenabscheidung in wechselnder Stärke, besonders nach Regentagen festgestellt bis zum 18. April, wo endlich die Fruchtkörper erschöjft waren.

Es ist wohl der Miihe wertl, aus Herrn Gärtners sorgsamen Aufzeichnungen im Vergleich mit den Witterungsangaben del betreffenden 'Tage die Sporenabsonderung der Daldinia zu verfolgenl.

Am 11. und 12. bei liegen und Gewitter sind nur wenige 
Sporenpünktchen. danach am 13. bei heiterem Wetter starke russartige Sporenbedeckung der Fruchtkörper rerzeichnet; am 14. und 15. war heiteres Wetter, die ausgetretenen Sporenmassen waren am 15. ziemlich verschwunden. Am 15. Nachmittags gab es ein Gewitter: ebenso an 16. Nachmittags; an diesem Tage traten neue sporen in dunklen Pünktchen auf, aber am 17. bei leiterem Wetter war der Fruchtkörper wieder russartig bedeckt. Am 18. 19. und 20. war jeden Nachmittag Gewitter oder Regenfall, es wurden nur sporen in Pünktchen angetroffen. aber am 21., der olme Regen war, wieder in Russform. 22. und 23. Regentage: Pünktchen. 24. ohne Regen: Russform. 25. und 26. Regentage: Piinktchen. 27. olne Regen: Russform. Tom 26. Мärz bis zum 8. April gab es nur einen Tag mit wenig Regen. Die russartig austretenden Sporen bedeckten den Fruchtkörper bis zum 30. und verschwanden dann allmählich. Erst nachdem es am 8. und 9. April wieder stark geregnet hatte, trat am 10. bei heiterem Wetter reichliche sporenerzeng'ung in Russform ein.

Noch über einen anderen Fruchthörver besitze ich durch Herrn Gärtner fast tägliche oder einen Tag um den andern gemachte genaue dufzeichnungen, die rom 11. Februar bis 19. April reichen. Am 11. Februar war der Durchmesser $8 \mathrm{~mm}$ und er stieg bis zum 17. März allmählich auf 26,5 mm. Da ich auch hier die täglichen Messungen mit den Witterungsangaben der Tage vergleichen kann, so lässt sich feststellen, dass in dem sonst ziemlich stetig fortschreitenden Wachsthum ein aussergewöhnlich grosser Sprung, um fast $4 \mathrm{~mm}$ in 24 Stunden, vom 27. bis 28. Februar sich verzeiclmet findet. Es war nämlich der 26. ein voller Regentag. gewesell. Dann steht das Wachsthum still rom 28. Februar bis 6. Närz. In dieser Zeit fiel nur einmal am Nachmittag ein wenig Regen. Nachdem es dann am 6. den ganzen Tag geregnet hatte, steigt auch die Grösse der Daldinia rom 6. bis zum 7. $10 \mathrm{~m} 2 \mathrm{~mm}$ Durchmesser.

Am 17. März wurden die ersten Sporen beobachtet und von 
da an keine Grössenzunahme des Fruchtkörper's mehr. Die Sporenelzeugung wurde weiter bis zum 19. April verfolgt und erwies sich in gleicher Weise abhängig rom Wetter, wie ich das vorher mittheilte.

Diese Beobachtungen lehren uts also die 'Thatsache, dass diese Fruchtkörper der Daldinia ihr volles Grössenwachsthım beenden, ehe sie Sporen erzeugen, dass dann die Sporenerzengung sehr lange und sehr reichlich, über einen Nonat lang; ron einem Fruchtkörper aus erfolgt, und besonders nach Regentagen gefördert wird. Die Sporen werden nicht weit weggeschlendert, sondern sammelı sıch in Russform auf dem Fruchtkörper, voul dem sie entweder durch den Regen abgewaschen oder durch Wind weggerveht werden. Im Zimmer unter der Glocke faud ich indessen Sporen auch im Umkreise der ausgelegten Fruchtkörper bis zu einer Entfernung, welche ten Fruchtkörperdurchmesser etwa gleiclı kam.

Während die Daldinia für gewöhnlich von mmegelmässig kugligel Gestalt und an der ganzen freiliegenden Oberfläche mit Perithecien bedeckt ist, habe ich eimnal an einem Stamm eine ganze Reihe ron typisch kenlig ansgebildeten Fruchtkörpern gefunden, bei denen eine dentliche Difterenzirung in einen sterilen Stiel nud perithecientragenden Kopt festzustellen war. Die Keulen hatten bis $5 \mathrm{~cm}$ Höhe. bei nur $1^{1}{ }_{2} \mathrm{~cm}$ Dicke, der Stiel hatte 1 bis $1 \%$ cm Tänge. Fine Keule war sogar gegabelt. Schon 'T'ulasne er* wähnt (S. 33 Bd. II Carpologie) kenlentörmige Daldinien und bemerkt sehr richtig, dass diese Formabweichung zur Bildung einer neuen Art nicht Anlass geben könne, so lange wie in den ilım rorliegenden Stücken die Sporengrösse mit der der gewöhnlichen Form rollkommen iibereinstimmte. Dies ist num bei meinen Fundstïcken nicht der Fall. Die Sporen sind durchweg kleiner (10 "lang; 5 " breit) als bei der typischen Form, doch ist der charakteristische Zonenbau genau der gleiche. Ich trage Bedenken und halte es auch 
fuir ganz mnnöthig, hier einen nenen Artnamen einzuführen, dagegen scheint es mir von grossem Interesse festzustellen, dass auch hier bei Daldinia eine Steigermo der Stammform rorkommt, welche mit minderem Aufwand an Banstoffen durch die 'Trennung' des unteren sterilen vom oberen fertilen Kenlentheil eine Erhöhnng der sporenbildenden Theile über den Erdboden als biologisclien Zweck offenbar anstrebt und erreicht.

In Rücksicht anf die Stromaform nnd -Bildnng, die ich bei den vorliegenden Untersuchmmen in den Tordergrund der Betrachtung gerückt habe, nimmt unter allen bekannten Xylarieen zweifellos der in Fig. 3 Tafel X photographisch abgebildete Thamnomyces Chamissonis Ehrenbg. die eigenartigste Stellung ein. Aus sehr hartem trockenen, am Traldboden liegenden Holze entspringen dicht bei einander zahlreiche tief schwarz gefärbte, ein bis zwei Millimeter dicke aufstrebende Stiele, welche sich bis zu etwa $7 \mathrm{~cm}$ Höhe ohne Terzweigung erheben. Dam aber verzweigen sie sich regelmässig dichotom etwa 5-6 mal hinter einander, und bei jeder folgenden Zweitheilung werden die Stengelglieder entsprechend dïnner und kïrzer. Die Ebene der beiden jeweils in spitzem bis rechtem Winkel dirergirenden Aestchen steht immer ammähernd senkrecht zu der Ebene der vorhergehenden Dichotomie. So kommt eine starre Regelmässigkeit der Form zum Ausdruck. Die Gesammthöhe der reich verzweigten Bäumchen betrug in den beobachteten Fällen bis zu 11 cm. Die letzten kuren dichotomen Terzweigungen sind etwas banchig geschwollen; es sind einzelne Perithecien mit kohlig fester Wand und einem feinen Mündnngskanal an der Spitze. An ihrer Imnenwand entspringen die hyalinen achtsporigen lang gestielten Schlänche zwischen zahlreichen feinen Paraphysen. Die Schlänche messen in ihrem oberen, die Sporen enthaltenden Theile 40-50 $\mu$ in der Länge, 6-7 " in der Breite. Die Sporen liegen in ein bis zwei Reihen, die untersten gewöhnlich einreihig angeordnet, die oberen quer verschoben und oftmals zu zweien neben einander. Sind die 
Perithecien reif, so treten die Sporen aus der Spitze in Form eines feinen aufrecht stehenden Stäbchens, Telches mit einer Nadel leicht abgehoben werden kann. In Wasser lösen sich die einzelnen Sporen leicht von einander. Sie sind gelbbram, oral (Taf. T Fig. 76), an den Enden stumpf abgerundet. in der Mitte sehr schwacl eingeschnürt, 7,7-8,4 " lang, 4,2 " breit. Meist bemerkt man zwei Oeltröpfchen. Zur Keimung. die in Nälulösungen leicht, jedoch immer nur an einer beschränkten Zahl der ansgesäeten Sporen zu beobachten ist, werden sie gesprengt. da das Endospor stark anfschwillt, sie klappen der Länge nach wie eine Dose anf und es erscheinen zunächst zwei Keimschläıche in der Verlängerııg der Sporenachse.

Die Keimschläuche haben 3.5 "“ Stärke. Sie verzweigen sich bald und bilden ïppige weisse lockerflockige, den ganzen Kulturtropfen duchwuchernde Mycelien mit reichlichem Luftmycel. Ich pflegte die Kulturen rom 30. Jannar bis 21. Februar 1893, doch trat keinerlei Conidienfruktifikation dabei auf.

Im Wralde beobachtete ich den Pilz zweimal, im August 1891 und 1892. Tn diese Jahreszeit waren die Stromata weich, grau. Erst ganz allmählich werden sie schwarz und starr. Ich beobachtete den Pilz am Standort mit regelmässigen Zwischenräumen von Anfang August bis Eude Dezember. Während dieser Zeit vollzog sich ganz allmählich die Schwarzfärbung. Aber während schon im Angust die Anlagen der Perithecien dentlich sichtbar waren, konnten die ersten reifen Sporen doch erst an 11. Januar in durchschnittenen Perithecien gefunden werden. Das freiwillige Austreten der sporen aus den Perithecien in der oben geschilderten Form wurde erst an 30. Tanuar beobachtet. Ton Conidien wurde während der ganzen langen Beobachtungszeit nichts bemerkt. Dem Alkohol theilt der Pilz eine schmutzig dunkle violettschwarze Farbe mit.

Zu erwähnen ist noch, dass schon Brefeld (Bd. I S. 265) aus Stromastïcken eines aus Brasilien stammenden Thammonyces, 
muthmaasslich desselben ron mir hier untersuchten, ,gewaltige sterile Mycelien rom Aussehen der aus Xylariasporen gezogenen" kultivirt hat.

Eine rerwandtschaftliche Beziehung des 'Thamnomyces Chamissonis zu den Xylarieen wird übrigens auch durch die lange Keinspalte der Sporen angedentet, die in ganz ähnlicher Weise fuir Nummularia lataniaecola und Hypoxylon fuscum bei Brefeld (Bd. I Taf. IX Fig. 1 und 6), für Xylaria und Poronia bei Tulasne (Carpol. II Taf. II und III) abgebildet ist. Auch das starke Emporwölben des Endospors nach dem Platzen der äusseren sporenhïlle macht die Keimung ron 'Thamnomyces (Fig. T6 'Taf. V) derjenigen ron Xylaria ('Tul. Carp. II Taf. II Fig. 27) ausserordentlich ähnlich. Weun sonach an der Blutsverwandtschaft des 'l'hamnomyces Chamissonis mit den Xylarieen kein Zweifel walten kann, nocl je gewaltet hat, so deutet doch die Eigenart der starren, regelmässig dichotom verzweigten Stromata auf einen sehr langen selbstständigen Entwickelungsweg hin, den diese Form durchlaufen hat und für dessen Aufklärung im einzelnen uns in den bisher bekannt gewordenen noch lebenden Typen vorläufig kaum ein Anhaltspunkt geboten ist.

\section{Discomyceten.}

Discomyceten sind von mir in grosser Zahl bei Blumenau gesammelt und in Alkohol konservirt worden. Fast das gesammte Material habe ich Herrn Hennings übergeben, welcher die Güte haben wird. die Formen zu untersuchen und die Befunde mitzuzatheilen. Im Wege der künstlichen Kultur habe ich nur sehr wenige Discomyceten untersucht, da ich nach sonstigen Erfahrungen dabei viele Schwierigkeit und relativ wenig Erfolg vermuthete, und wegen des ibberreichen Materials, das durch meine Hände ging; mit der Zeit haushalten musste. Meine Mitheilungen über Kulturen von Discomyceten beschränken sich deshalb auf 
wenige Notizen, und neue Formen in geringer Zahl werde ich nur in so weit berücksichtigen, als sie für die bisher noch wenig bekannte stromatische Entwickelung der Discomyceten Beiträge liefern.

An erster Stelle muss ich eines Pilzes Erwähnung thun, den ich unter dem Namen Phycoascus tremellosus nov. gen. et nov. spec. zum Tertreter einer nenen Gattung mache.

Auf feuchten Rindenstiicken findet sich ein lockerfilziges grauweisses Fadengeflecht, welches bei $1 \mathrm{~mm}$ Dicke etwa, anf mehrere Centimeter weit ausgebreitet ist. Es besteht aus sehr locker verflochtenen Fäden von auffallend starkem Durchmesser (10 ‘), die mit schaumigem Protoplasma erfüllt, oft kurzzellig gegliedert und stellenweise angeschwollen, dabei sparrig, recht- und stumpfwinkelig reich rerzweigt sind. Zerstrent auf diesem Hypothallus stehen die Apothecien von wachsartig weicher Beschaffenheit und unregelmässiger Form. Während sie in der Jugend ein wenig konkar und mit einem angedenteten Rande versehen sind. werden sie später konvex, lassen keine Spur eines Randes mehr erkennen, ja die Fruchtschicht wölbt sich soweit vor, dass sie in der Mitte hohl über dem Substrat liegt, am Rande nach anssen und unten sich umliegt, so dass am äussersten Rande die Schlanchschicht sogar dem Substrat zugewendet ist. Die Apothecien erreichen $2 \mathrm{~cm}$ und darïber im Durchmesser und sind unregelmässig rundlich, anch lappig faltig im Umriss. Ihre Oberfläche erhebt sich im reifen Zustand bis $6 \mathrm{~mm}$ iiber den Hypothallus. Die Schläuche sind 200 " lang, 10 " breit, die ovalen farblosen sporen liegen in einer Reihe in ilırem obersten Theile, sie messen $17 \times 8$ !. Im Hypothecium findet man dieselben sparrig verzweigten Hyphen wie im Hypothallus; nur sind sie hier etwas fester verflochten, noch dicker (15 !') und noch kürzer septirt. Selır auffallend ist die Keimung der sporen. welche in Nährlösung sehr bald nach der Aussaat eintritt. Die Spore schwillt auf das Doppelte ihres Durchmessers an und ans dem platzenden Epispor. welches als solches sichtbar bleibt (in ganz ähnlicher Weise wie 
es für Choanephora abgebildet ist), stülpt sich das Endospor als $7 \mu$ dicker Keimschlanch heraus. Die dickfädigen Mycelien, welche daraus entstehen, haben die grösste Aehnlichkeit mit dem Hyphengeflecht des Hypothallus. Die sparrige Verzweigung und das schaumige Protoplasma sind ihnen ebenfalls zu eigen. Tielfach kamen ganz unregelmässige knollenförmige Anschwellungen einzelner Myceltheile ror, welche an die bei Rozites gongylophora beobachteten, Bd. VI Taf. VI Fig. 20 dieser Mittheihungen abgebildeten erimnern. Während 14 tägiger Pflege blieben die Kulturen steril, litten aber unter Bakterieninfektion, wodurch ihre weitere Beobachtung leider verhindert wurde.

Plıycoascus ist zunächst durch den stark entwickelten, weit ausgebreiteten Hypothallus ausgezeichnet, der in ähnlicher Weise von keinem Discomyceten bisher bekannt geworden ist. Sein Torhandensein dürfte die Gattung in die nächste Nähe ron Pyronema verweisen. Mit dem Namen habe ich darauf hindenten wollen. dass der Pilz durch seine ungewöhnlich dicken Hyphen, durch deren vakuolenreichen Protoplasmainhalt, durch das Aufschwellen der Sporen und die Art, wie das Endospor bei der Keimung sich herausstiilpt, unverkennbar an niedere Formen, an Phycomyceten erinnert.

Die Systematik der Discomyceten liegt noch sehr im Argen. Man leitet sie nenerdings sämmtlich von den Pyrenomyceten her, weil sie, soweit die Untersuchungen reichen, angiokarpe oder' wenigstens hemiangiokarpe Fruchtkörperentwickelung erkennen lassen. Doch ist es schwer sich vorzustellen, dass Formen wie unser Phycoascus oder wie Pyronema den Umweg über pyrenomycetenartige Vorfahren sollten durchlaufen haben. Immer wieder drängt sich die Vermuthung auf, ob nicht ron Exoascus über Ascocorticium zu Psilopeziza und Rhizina und vielleicht darïber hinaus durch Lokalisirung der Fruktifikationsorgane auch zu Phycoascus und Pyronema, ja zu manchen Pezizen eine natürliche Entwickelungsreihe führe, die weiter z. B. dur'ch Formen, wie 
Spragueola Mass. sogar zu den Helvellineen verfolgbar sein dürfte. Schon Schröter, dessen feines Formgefühl sich oftmals bewährt hat, ist von ähnlichen Ueberlegungen geleitet worden und hat sie in der von ihm begonnenem Bearbeitung der Ascomyceten für Engler und Prantl Nat. Pflanzenfam. I. 1 Seite 162 u. 175 zum Ausdruck gebracht. Es wird noch vieler Arbeit bedürfen, ehe wir über diese Frage endguiltig urtheilen können; doch giebt mir die Phycomycetenähnlichkeit des Phycoascus erneuten Anlass darauf linzuweisen, ob nicht für manche der mit freien Ascen versehenen Pilze ein kürzerer Anschluss an die niederen Pilze gesucht werden müsse an Stelle des weiten über die Pyrenomyceten führenden Unwegs.

Zu den bemerkenswerthesten Nebenfruchtformen, welche bei Ascomyceten überhaupt vorkommen, gehören die von Brefeld entdeckten basidienähnlichen Conidienträger der Peziza vesiculosa Bull. und cerea Sow. (Band X S. 333 ff. Taf. XIII Fig. 17-28); sowie P. repanda Wahlb. und ampliata Pers. (Band IX Taf. III B Fig. 32 fr.). Die künstliche Kultur der grösseren Pezizen begegnet, wie schon Brefeld a. a. O. hervorhebt, sehr grossen Schwierigkeiten, weil die ausgeschlenderten Ascussporen von der Scheibe her fast immer Bakterien mit sich reissen und in den Kulturtropfen überführen. Wegen dieser Schwierigkeit, die zu ïberwinden ich nicht Zeit genug aufwenden konnte, blieben meine Kulturversuche mit grösseren Pezizaformen, an denen das durchforschte Gebiet übrigens reich ist, sehr dürftig.

Peziza catharinensis nov. spec. wird bei Blumenau auf morschen Holzstückchen am Waldboden häufig angetroffen. Die Apothecien stehen meist einzeln oder anch in Gruppen, sind in den jugendlichsten beobachteten Zuständen halb becherförmig, seitwärts in einert kurzen Stiel zusammengezogen, dann breitet sich die Scheibe vollkommen flach ans; sie ist meist oval im Umriss, excentrisch kurz gestielt mol erreichte bis zu $7 \mathrm{~cm}$ Durchmesser. Besonders auffallend ist sie durch ihre kräftige weimrothe Farbe (Sacc. 50), 
welche an den jüngsten Exemplaren am intensivstell auftritt. Die Fruchtkörper sind stark fleischig, in der Mitte einschliesslich des kurzen Stieles bis zu $1 \mathrm{~cm}$ dick, naclı dem Rande allmählich sich verdünnend. Der ganze Fruchtkörper wird von einem dichten Geflecht $4 \mu$ starker Hyphen gebildet, welche nirgends plectenchymatisch zusammenschliessen. Die Schläuche sind im oberen Theile cylindrisch, am Ende einfach abgerundet, $270 \mu$ lang, 12 « breit; sie stehen dicht eingekeilt zwischen zahlreichen fädigen Paraphysen von gleicher Länge. An dem Alkoholmaterial war durch Anwendung von Jod keinerlei Bläuung melır zu erzielen. Die grossen hyalinen in einer Reilhe liegenden Sporen sind bis $31 \mu$ lang, $12 \mu$ breit und schwach längsgestreift. Frisch aufgefangen zeigen sie zwei grosse und mehrere kleine Oeltropfen (Taf. V Fig. 77). Die Keimung trat bei mehrmals wiederholten Versuchen unregelmässig, d. h. nie bei allen ausgesäeten Sporen ein und die Entwickelung konnte nur wenig über das in Fig. 77 abgebildete Stadium hinaus verfolgt werden. Die Spore theilt sich durch eine Querwand in zwei Zellen, deren jede eiuen Keimschlauch entsendet. Dieser erzengt alsbald Conidien an seinem Ende sowohl, als auch seitwärts. Die Conidien sind oval, $8 \mu$ lang und $4 \mu$ breit, und grenzen sich von dem tragenden Faden durch eine Querwand $a b$, olne dass ein eigentliches Sterigma ausgebildet würde. In anderen Fällen unterblieb die Quertheilung der Spore, es trat nur ein Keimschlauch aus, in den sich der Inhalt der Spore entleerte.

In Fig. 78 habe ich weiterhin die Keimung der Sporen einer anderen im Gebiete läufigen auffallenden grossen Peziza darstellt, welche nach Herrn Hennings gütiger Mittheilung wohl zur Untergattung Plicaria gehören dürfte. Sie bildet hellgelbe kurz gestielte, meist regelmässig runde, glatte schüsselförmige Scheiben, deren Durclimesser $2 \mathrm{~cm}$ und mehr betragen kanı. Illre grossen einzelligen hyalinen Sporen sind oval, $31 \mu$ lang, $11-12 \mu$ breit, und zeigen in frischem Zustande vier Oeltropfen, von denen 2 grössere in der Mitte einander genähert sind. Die in Fig. 78 dargestellte Keimung 
der'Sporen wurde mehrfach erreicht, doch war darüber nicht hinauszukommen, weil die Kulturen stets durch Bakterien gestört wurden.

Tergleichen wir die Figuren 77 n. 78 mit den oben angeführten Brefeldschen Keimungsergebnissen von Pezizaarten, so finden wir sie vor jenen hauptsächlich durch den Mangel der Sterigmen ausgezeichnet, welche dort die Basidienähnlichkeit der Conidienträger in erster Linie bestimmen. Dagegen kommt die so höchst bemerkenswerthe Neigung zur Köpfchenbildung durch Verschiebung der Conidien nach der Spitze des Trägers auch in der Fig. 78 schon zum Ausdruck.

Das von mir gesammelte Material und meine Beobachtungen reichten bei weitem nicht aus, mir ein Eingehen auf die noch ganz unklare Systematik der Discomyceten nutzbringend erscheinen zu lassen. Indessen lag mir nach dem Ergebniss der Pyrenomycetenuntersuchungen natürlich die Frage nahe, ob nicht auch im Reiche der Discomyceten Formen vorkommen, welche einen Fortschritt der stromatischen Entwickelıng über die einfache Scheibe hinaus bekunden. Solche waren um so eher zu erwarten, als sie ja unter den laub- und strauchflechtenbildenden Discomyceten thatsächlich schon vorliegen. Eine in diesem Sime recht bemerkenswerthe Erscheinung beschreibt Rehm in der Hedwigia 1900 Seite 216 unter dem Namen Physmatomyces. Es ist dies nach Rehm ein Pilz mit gelatinösem Stroma, welches zahlreiche Apothecien hervorbringt, ein Pilz, der die Flechtengattung Physma ohne Algen darstellt. Er wurde durch Ule bei Blumenau gesaminielt.

Eine eigenartige Ausbildung des Apotheciums durch lappige Auswïchse oder Verzweigungen zeigt uns Peltigeromyces microsporus nov. gen. et spec, ein Pilz, den ich auf faulem Holze am Waldboden auffand. Die Fruchtscheiben erreichen bis $3 \mathrm{~cm}$ Durchmesser. Sie sind mannigfach gelappt, die einzelnen Lappen haben meist längliche, nach rorn abgerundete Gestalt und zeigen 
starke Neigung zum Einrollen ihrer Ränder. Sie sind stiellos, nur mit einem Punkte der Unterlage angeheftet, von knorpelig fester Beschaffenheit und wenig ïber $1 \mathrm{~mm}$ Dicke. Die Farbe der sterilen Unterseite ist schwarz. Der Pilz bildet hier eine deutliche Rindenschicht aus paraplectenchymatischem Gewebe, dessen Zellen etwa $10 \mu$ Durchmesser und stark gebrämnte Wände besitzen. Der eigentliche Körper ist ans lose verflochtenen, 1-2 ! starken, scheinbar in einer zähen Gallerte eingebetteten Fäden gebildet. Unter der Schlanchschicht befindet sich eine $60 \iota$ starke Hypothecienschicht, in der die dickwandigeren Fäden horizontale Richtung zeigen und fast lückenlos verflochten sind. Die Schlänche von $60 "$ Länge nund 4 " Breite stehen zwischen Paraphysen, welche nicht ïber die Schlauchschicht hinansiagen. Sie sind achtsporig, die Sporen oval, fast kuglig, hyalin, von kanm 2 "Durchmesser. Die Farbe der Fruchtschicht ist matt blangrau (Sacc. 44 mit wenig 45 und 37 Beimischung). Die Lappen der Scheibe mit ilıren eingerollten Rändern erinnern lebhaft an Peltigera.

Wenn man die Scheibe der Discomyceten mit vollem Rechte als ein Analogon des Peritheciums der Pyrenomyceten auffasst, so darf man erwarten, dass in ähnlicher Weise, wie es bei den letzteren in mannigfaltigster Form geschieht. alch bei den Discomyceten Stromata rorkommen werden, welche mehreren Apothecien zur Basis dienen, dam anch solche, welche die Apothecien zur besseren Terbreitung der Sporen hölıer iiber das Substrat hinauszuheben bestimmt sind. Zahlreich sind indessen derartige Vorkommnisse noch nicht, wenn wir von den Laub- und Stranchflechten absehen. Der oben erwähnte Physmatomyces Rehm ist hier anzuführen. In 'T'nlasnes Carpologie III Taf. XIX Fig. 4, 5, 14 finden wir ferner ron Cenanginm Ribis und Dermatea Cerasi Stromata abgebildet, welche gleichzeitig mehrere Apothecien und daneben noch Pycniden tragen in ganz gleicher Art, wie Perithecien und Conidienlager auf manchen Nectriastromaten rorkommen. 
Eine Dermateaform meiner Blumenauer Sammlung (Nr. 598) schliesst sich hier an, welche auf morschem Holze vorkam und ein stielförmiges Stroma ausbildete, an dem mehrere grosse bis $\mathbf{1}^{1 / 4} \mathrm{~cm}$ Durchmesser zeigende Fruchtscheiben, wie Blumen an einem Bouquet zusammen sassen, sich gegenseitig drängend und ihre Rinde gegen einander aufwölbend.

Aelnnliche Fruchtrörperausbildungen sind durch T'ulasnes Zeichnungen auch von Coryne bekannt gemacht, welche systematisch ja von Dermatea weit getrennt wird; auch aus diesem Verwandtschaftskreise kamen ähnlich loch entwickelte Stromata wie die beschriebenen, mit je melneren gallertigen, hellgefärbten, in Alkohol aber schwarz werdenden Apothecien im Blumenaner Valde vor (Nr. 560 meiner Sammlung).

Geradezu charakterisirt durch ihre Stromagestaltung sind aber unter den bisher bekannt gewordenen Discomycetengattungen nur zwei: Cordierites Mont. und Cyttaria Berk. Beide sind für unsere Art der Betrachtung ron hohem Interesse, beide erfüllen die oben ausğesprochene Erwartung, dass nämlich die Ergebnisse derselben Gesetze der Fruchtkörperbildung; welche unter den Pyrenomyceten die auffallendsten Gestaltungen hervorbrachten, anch unter den Discomyceten wirksam sind. Cordierites ist gewissermaassen ein Thamnomyces, Cyttaria aber ein Mycocitrus unter den Scheibenpilzen. Während Cyttarien in meinem Arbeitsgebiete nicht rertreten waren, so fand ich zwei bemerkenswerthe Pilze, auf welche die Diagnose ron Cordierites Mont. anzıwenden sein dürfte; diese Diagnose lautet nach Saccardo VIII Seite 810: „Stipes seu stroma corneo-carbonaceum, ramosissimum fragilissimmmque. Ascomata terminalia, tandem cupulari-aperta, marginata. Discns superus, asciger, sporidiis pruinosis. Asci breviter claraeformes $6-8$ spori. Sporidia oblonga, continua, hyalina, uniserialia."

Cordierites fasciculata nor. spec. tritt biischelweise auf trocknem morschen Holze auf. Die kohlig schwarzen, leicht zerbrechlichen flachgedrückten 1 mm starken Stiele verzweigen sich 
unregelmässig wiederholt, erreichen eine Gesammthöhe von 2 bis $3 \mathrm{~cm}$ und tragen an jedem Ende ein trichterförmiges rundes Apothecinm von verschiedenem bis $7 \mathrm{~mm}$ betragenden Durchmesser. Seine nach oben gerichtete Schlanchschicht ist nur wenig lieller gefïrbt, als der ganze Pilz und sieht wie bereift ans. Das Fleisch des Apothecienkörpers bestelit ans prosoplectenchymatischem braunwandigen lockeren Gewebe, und die Längsrichtung seiner Zellen ist parallel der Scheibenflïche; eine Rindenschicht der sterilen Unterseite ist nur durch dunklere Färbung der Zellwände angedentet. Ein Hypothecium ist nicht dentlich ansgebildet. Die Länge der Schlänche beträgt $60 \mu$, ilıre Breite 4 ॥. Die ovalen hyalinen Sporen liegen in einer Reihe und sind 4-5 " lang. Der Pilz scheint Cordierites gonyanensis Mont. nahe zu stehen; er färbt den Alkohol, in dem er aufbewahrt winde, gelbbraun.

Eine bemerkenswerthe Fol'msteigerung ihm gegenüber weist Condierites umbilicarioides nov. spec. anf, der an gleichen Oertlichkeiten mit dem vorigen vorkam. Ueber sein Stroma und dessen Beschaffenheit gilt in jeder Hinsicht dasselbe, wie bei Cord. fasciculata, die Scheiben aber erreichen bis $2 \mathrm{~cm}$ Durchmesser und sind höchst mnregelmässig zerschlitzt und gelappt; ziemlich flach ansgebreitet bei fenchtem Wetter, falten sie sich beim Eintrocknen in mannigfacher Weise blumenartig nach oben zusammen. Ueber den Ban der Apothecien, Schlänche nnd Sporen gilt alles bei der vorigen Form Gesagte. Die Schläıche sind wenig länger, die Sporen etwas grösser, 5-6 " $"$ lang. Die Sclieibe ist violettschwarz, die sterile Seite kohlschwarz, fein rauh gekörnelt. Im trocknen Zustand erinnert der Pilz ansserordentlich an Gyrophora oder Umbilicaria, weshalb ich anf Herrn Hennings Vorschlag. den Artnamen „umbilicarioides“ wählte. Er ertheilt dem Alkolıol eine rothbranne Färbnng. 


\section{Schlusswort.}

Ich kamn den Schluss dieser Arbeit nicht, wie im vorigen Hefte dieser Mittheilungen geschehen, als „Uebersicht der Ergehnisse" bezeichnen. Denn die Ergebnisse dieser Arbeit sind mannigfaltig, sie liegen nach selı verschiedenen Richtungen hin, ant morphologischem, biologischem, physiologischem und speziell systematischem Gebiete, sie sind in den Gang der Darstellung an gehöriger Stelle eingeflochten, und ich würde bei ilırer Zusammenstellung lange Wiederholungen nicht vermeiden können. Nach der Entstehungsgeschichte meiner Arbeit kann dies nicht Wunder nehmen. Ich beabsichtigte in zusammenhängender Darstellung iiber' alle während meines dreijährigen Aufenthaltes in Blumenan, Brasilien, gemachten Beobachtungen zu berichten, welche sich auf Phycomyceten und Ascomyceten beziehen. Diese Pilzgruppen waren für mich nicht in demselben Sinne Arbeits- und Sammlnngscentren, wie es die Ameisenpilze, die Phalloiden, die Protobasidiomyceten gewesen sind. Während ich auf jene, nachdem ich sie eimmal als besonders geeignete Arbeitsangriffspunkte erkannt hatte. die Hauptaufmerksamkeit richtete, ilırer Kuntur die grösste Sorgfalt angedeihen liess und bei dem Sammelı mnd Suchen im Walde ror allen Dingen nichts zu übersehen trachtete, was jenen Formenkreisen anzugehören schien, blieb natürlich für die Angehörigen der übrigen Pilzklassen bei der Kürze der Zeit nicht die Möglich- 
keit gleich ausgedehnter Beobachtung. Hier war es mehr dem Zufall überlassen, welche Formen mir zu genanerer Untersuchung in die Hände fallen sollten, und zur künstlichen Kultur konnte ich sie nur damn heranziehen, wemn die jeweils in Betrieb befindlichen Kulturen jener ron mir für wichtiger erachteten Formen gerade Zeit dazu liessen. So wurden vorzugsweise solche Formen gesammelt, die ron den mir bekannten Typen möglichst rerschieden zu sein schienell, und dadurch meine Aufmerksamkeit erregten, dann wieder solche, die durch Grösse und Farbe besonder's auffielen oder auch durch Eigenart der Formgestaltung, wie sie besonders die mannichfachen Vertreter der Gattung Cordyceps auszeichnet. Grundsätzlich liess ich alles bei Seite, was nur den „fungis imperfectis" hätte eingereiht werden kömnen, vor allem jene zahllosen Conidienformen, deren Einreihung in das natiilliche Systen wegen mangehnder Kenntniss der charakteristischen Fruchtform unmöglich ist; wie ich denn überhaupt, so lange noch in der Mykologie an den „perfekten“ Pilzen so viel zil thun ist, wie bis heute, die Beschäftigung mit den „imperfekten" für wenig erspriesslich halte, es sei dem, dass der eine oder andere von ilnnen ein besonderes praktisches Interesse als Schädling wichtiger Kulturpflanzen beansprucht; und stets hielt ich mir jene beherzigenswerthe Bemerkung ror Augen, mit welcher Fritz Mïller in Jahre 1861 eine Abhandlung über Polypen und Quallen ron Santa Catharina einleitete:

„Beschreibungen rereinzelter nener Thiere" (man kamn hinzusetzen: und Pflanzen), „die nur die Zahl der schon verzeichneten Arten anschwellen, ohne einen tieferen Einblick in ihren Bau, einen freieren Ueberblick über ihre verwandtschaftlichen Beziehungen zu gewähren, sind im allgemeinen mehr geeignet, den Fortschritt der Wissenschaft zu erschweren, als zu förderı, indem sie nur den zu bewältigenden Stoff und nicht auch entsprechend die zur Bewältigung nöthige Kraft mehren."

So also kam gerade jene Auswahl von Phycomyceten und 
Ascomyceten zur Beobachtung, Untersuchung und Darstellung, welche ich dem geneigten Leser in dem gegenwärtigen Hefte vorgeführt habe.

Wenngleich num, entsprechend der geschilderten Entstehmngsgeschichte der Arbeit, die einzelnen Gruppen und Familien der genannten grossen Kilassen sehr ungleichmässig in meinen Aufzeichnumgen vertreten waren, so that sich doch bald eine von ihnen, die der Hypocreaceen, durch verhältnissmässig grosse Formenzahl und merkwürdige Gestalten vor allen anderen hervor. Die Riesenbambuspilze hatten mich schon in den ersten Monaten meiner Arbeitszeit gefesselt, sie gehörten alle der genannten Gruppe an; ebendahin zählten die wunderbaren Insektenpilze, deren Zahl ganz allmählich im Laufe der drei Jahre sich mehrte, und die Grasbewohner Ophiodotis, Balansia, Claviceps erschienen als nicht minder anziehende Gegenstände der Untersuchung. Da nun auch Angehörige der Gattung Hypocrea selbst in dem durchforschten Gebiete ausserordentlich liäufig waren, so richtete ich zumal gegen das Ende meiner Arbeitszeit immer melı Aufmerksamkeit auf die Hypocreaceen und brachte ein Material zusammen, welches wenigstens für diese Familie eine über den engeren Rahmen der beobachteten Formen hinausgehende systematische Bearbeitung ermöglichte. Das Ergebniss ist in den vorliegenden Blättern niedergelegt. Möchte es sich als ein brauchbarer Beitrag zur Systematik der Carpoasci, zunächst der Pyrenomyceten, erweisen. Bei der grossen Fülle der Einzelheiten. welche in Betracht kommen, würde es ohne lange Wiederholungen auch hier nicht möglich sein, im Schlusswort eine Uebersicht zu geben, welche den Leser der Hühe überlı̈̈be, die einzelnen Ablıandlungen zu lesen. Doch möchte ich einige der leitenden Gedanken in Kürze hervorheben.

Man betrachte die Fignren 52 und 53 auf Tafel III: ein Ascomycet von täuschender Polyporusgestalt. Diese Bilder lehren unzweifelhaft, dass die äussere Gestalt der Fruchtkörper der Pilze uns keinen Aufschluss über ihre verwandtschaftlichen 
Terhältnisse giebt ans Gründen, die ich wiederholt dargelegt habe (vergl. Heft VIII dieser Mitth. S. $154 \mathrm{ff}$. u. S. 74, 75 dieses Heftes). Es ist nun vou Werth, hierzn eine Anmerkung Tulasnes anführen zu können, welche der feinsimnige Forscher schon im Jahre 1853 in den Ann. d. sc. nat. III Série 19. Bd. Seite 225 niedergelegt hat:

„Les Trémellinées composent, dit II. Fries, un groupe très distinct, qui clôt la ğrande série des Hyménomycètes et sert à l'unir aux Discomycètes. On aperçoit effectivement quelques analogies de forme générale entre les Trémelles ondulées plissées et foliiformes, telles que les Tremella mesenterica Retz., T. foliacea Pers. et autres semblables, et le chapean tantôt gonfié lacuneux. taintôt membraneux et sinué des Morilles et des Elvelles, entre les Exidia recisa Fr. et E. spiculosa Sommerf. et les Pézizes etc. Mais il ne faudrait pas ponsser plus loin de telles comparaisons; ce sont lả des analogies pareilles à celles que les Clavaires offrent arec les Xylaria, les Géoglosses ou les Spathulaires, les Crphella avec les Pézizes, certaines Théléphores avec les Rhizina etc. c'est à dire qu'elles sont plus apparentes que réelles, et témoignent senlement de l'admirable harmonie par laquelle il a plus à l'anteur de la nature d'enchâner entre enx tous les êtres, malgré leurs dissemblances."

Aus diesen Betrachtungen, zu deren Stütze die vorliegende Arbeit reiches Beweismaterial erbringt, ergiebt sich zweifellos. dass es durchaus verfehlt ist, einer Neueintheilnng der gesammten Pyrenomyceten die stromatische Ausbildung der Formen als erstes Eintheilnngsprinzip zn Grunde zu legen, wie Jaczewski wollte (Bull. soc. mycol. de France 1894, S. 13). Der genannte Forscher fühlte die vorlänfig noch bestehende Mangelhaftigkeit der systematischen Eintheilnng der Pyrenomyceten und wollte ihr durch ein möglichst natürliches System abhelfen. Er übersal aber, dass dies ein anssichtsloses Beginnen ist, so lange wir über die Entwickelungsgeschichte der einzelnen Formen, ja bei sehr vielen sogar über ihre 
reifen Zustände nur ungenügende Kenntnisse besitzen. Indem er die Pyrenomyceten in die zwei möglichst unnatïrlichen Gruppen der einfachen, stromalosen und der zusammengesetzten, mit Stroma versehenen theilte, rerkannte er vollständig die in diesen Blättern wiederholt nachgewiesene Thatsaclie, dass die Stromaausbildung sich in den allerverschiedensten Reihen der Pilze, oftmals bei sehr weit in der Verwandtschaft getrennten Formen in ganz ähnlicher Weise vollzieht, und übereinstimmende Gestalten hervorbringt. Die Perithecien und Ascen waren offenbar in ihrer Form längst bestimmt und fest geworden, ehe stromatische Weiterbildung begann. Das Ansteigen von stromalosen zu Formen mit immer höher entwickeltem Stroma lässt sich in vielen offenbar und sicher blutsverwandten Reihen schrittweise noch heut verfolgen, so z. B. innerhalb der einen grossen Gattung Hypocrea (vergl. S. 90/91). Für die Trenumg der Hauptgruppen darf man die Stromaform nicht verwenden.

Während der Bau des natürlichen Systems der Fadenpilze durch Brefeld in seinen Hauptziigen klar nnd einfach erwiesen und festgestellt ist, bleibt die engere systematische Anordnung innerhalb der grossen Gruppen der Carpoasci wie der Autobasidiomyceten noch eine Aufgabe der Zukunft, deren Lösung nicht eher vollendet sein wird, als bis alle dorthin gehörigen Pilzformen genau erforscht, entwickelungsgeschichtlich untersucht und bekannt sein werden Bis dahin kann ein stetiger Fortschritt nur erreicht werden, indem man sich zunächst an die Eintheilungen hält, wie sie durch den natïrlichen Takt der Systematiker geschaffen und vorläufig festgelegt sind, und an dieser Anordnung im Einzelnen Korrekturen anbringt in dem Maasse, wie solche durch die vermelnten entwickelungsgeschichtlichen und rergleichend morphologischen Untersuchungem sich als nothwendig herausstellen.

Dass der gleiche Bau der Schläuche und Sporen uns als ein Hinweis auf nähere Blutsverwandtschaft gilt, ist sicherlich berechtigt. Zumal wenn es sich un so eigenartig bestimmte Schläuche 
und Sporenformen handelt, wie bei der Gattung Hypocrea oder den "linosporous Hypocreaceae" und wenn die entwickelungsgeschichtliche Untersuchung bestätigend hinzukommt, dürfen wir getrost annehmen, dass die auf Sporengestalt begründete Saccardosche Eintheilung im besonderen Falle das Richtige getroffen hat. Die nach Sporenzahl und -form bestimmten Schläuche scheinen ebenso wie die Basidien einen Endpunkt der Entwickelungsrichtung zu bezeichnen, ler weiteren Variationen nicht mehr unterworfen war, während die stromatische Fortbildung nun erst einsetzte und, wie unsere Beobachtungen zeigen, vielfach noch hente im Fluss ist. Darum kann nur innerhalb der als blutsverwandt festgestellten Formenreihen die Höhe der stromatischen Ausbildung mit Tortheil als Eintheilungsgrund verwendet werden.

Sekundär nur, wie die Stromabildung kömnen die Nebenfruchtformen, die Chlamydosporen und Conidien, dem Systematiker als allerdings werthvolles Hülfsmittel dienen; dem ähnliche, ja gleiche Conidienformen finden wir bei den allerverschiedensten Gruppen der Fadenpilze, und auch die Ansteigerung von Einzelconidien zu Conidienlagern und Conidienfiuchtkörpern vollzieht sich unabhängig von der Verwandtschaft bei den verschiedensten Formen nach den nämlichen Gesetzen, welche die Ascusfruchtkörper und die Basidienfruchtkörper beherrschen. Ein bemerkenswerthes Beispiel hierfür habe ich durch die vergleichende Betrachtung des Conidienfruchtkörpers von Corallomyces Jatrophae und des Basidienfruchtkörpers von Schizophyllum beigebracht (S. 99 ff.). Fïr die richtige Beurtheilung und Bewerthung der Conidien und Chlamydosporen muss Brefelds Abhandlıng "Vergleichende Betrachtung. der Fruchtformen der Ascomyceten" Seite 341 des X. Bandes zu Girunde gelegt werden.

Als ein erläuterudes Beispiel dafür, wie innerhalb der Hypocreaceen der nächste verwandtschaftliche Zusammenhang durch die Sporenform bezeichnet wird, wie innerhalb der durch die gleiche Sporenform zusammengehaltenen Entwickelungsreihen se- 
kundär einmal die Höhe der stromatischen Ausbildung, daun auch die Entwickelung der Conidienfruchtkörper zur Gattungsabgrenzung zweckmässig benutzt wird, füge ich zum Schlusse die folgende tabellarische Zusammenstellung bei:

\begin{tabular}{|c|c|c|c|}
\hline & $\begin{array}{c}\text { Sporen } \\
\text { zweizellig }\end{array}$ & $\begin{array}{c}\text { Sporen } \\
\text { mehrzellig }\end{array}$ & $\begin{array}{l}\text { Sporen maner- } \\
\text { förmig getheilt. }\end{array}$ \\
\hline $\begin{array}{l}\text { Stroma fehlend, Conidien } \\
\text { nicht auf bestimmt geform- } \\
\text { ten Fruchthörpern. }\end{array}$ & Nectria Fries. & $\begin{array}{l}\text { Calonectria } \\
\text { de Not. }\end{array}$ & Pleonectria Sacc. \\
\hline $\begin{array}{l}\text { Stroma wenig, polsterför- } \\
\text { mig entwickelt; Conidien- } \\
\text { fruchtkörper bestimint ge- } \\
\text { formt, stilbumartig. }\end{array}$ & $\begin{array}{c}\text { Sphaerostilbe } \\
\text { Tul. }\end{array}$ & $\begin{array}{c}\text { Stilbonectria } \\
\text { Karst. }\end{array}$ & $\begin{array}{l}\text { Megalonectria } \\
\text { Sacc. }\end{array}$ \\
\hline $\begin{array}{l}\text { Stroma massig, kuglig } \\
\text { knollig, rings mit Perithe- } \\
\text { cien besetzt. }\end{array}$ & $\begin{array}{l}\text { Mycocitrus } \\
\text { nov. gen. }\end{array}$ & $\begin{array}{l}\text { Peloronectria } \\
\text { nov. gen. }\end{array}$ & Shiraia P. Hemn. \\
\hline
\end{tabular}

Ich habe in meiner Arbeit dargelegt, dass die äussere Aelmliclıkeit, welche zwischen den je drei lıorizontal neben einauder stehenden Gattungen zweifellos lierrscht, für die Nälıe ilırer Blutsverwandtschaft nicht so viel bedeutet, wie die Gleichheit der Sporenform, welche die je drei vertikal unter einander stelıenden Gattungen verbindet.

Es wïrde nicht schwer sein, alle in den vorstehenden Blättern beliandelten Pilze in eine grosse tabellarische Uebersicht nach ähnlichen Prinzipien zusammenzustellen, und eine solclie $\mathrm{Zu}$ sammenstellung wïrde im grossen Ganzen viele Uebereinstimmung mit der melıfacl erwähnten Saccardoschen Tabelle der Hypocreaceen auf Seite 23/24 des XIV. Bandes der Sylloge laben. Ein solches Schema bringt aber die grosse Gefahr mit sich, dass den Thatsachen Gewalt geschieht; die 'Tabellenform ist viel zu roh, als dass die mannigfachen und rel'wickelten Bezielıungen der Organismen zu einander darin zu wirklich treffendem Ausdruck gebracht werden könnten. Auch ist die Zeit dafür noch nicht gekommell. Ist docl nicht einmal die grosse Gruppe der Hypocreaceen selbst endgültig und natürlich begrenzt. Ton den Dothideaceen mussten wir zwei Gattungen zu jenen hinüberzielıen, anf Uebergänge zı den Xyla- 
rieen deuten manche nenere Funde hin. So kann vorläufig nur sorgsame gewissenhafte Einzeluntersuchung uns dem fernen Ziele eines natürlichen Systems aller Pyrenomyceten näher führen. Erst wenn sie alle genau erforscht, entwickelungsgeschichtlich untersucht und bekannt sein werden, dürfen wir hoffen, lass sachkundige Prüfung und Würdigung der erworbenen Kemntnisse späteren Generationen einen befriedigenden Einblick in die verwandtschaftlichen Beziehungen aller zu einander eröffnen wird. Daun wird man klar entscheiden, in welcher Weise wir uns am leichtesten, unserem Verstandesbedürfnisse am besten entsprechend die Entwickelungsreilien innerhalb der artenreichen grossen k̉lassen der Fadenpilze so vorzustellen haben, dass alle beobachteten Thatsachen sich unserer Vorstellung bestätigend anschliessen lassen. 


\section{Antwort}

\section{anf kritische Bemerkungen zu friiheren Arbeiten des Verfassers.}

Herr Privatdocent Dr. Holtermann in Berlin hat im Jahre 1898 ein Buch erscheinen lassen "Hykologische Untersuchungen ans den Tropen". Als Motto künnte man diesem Buche die Wrorte des Verfassers von Seite 1 seiner Arbeit rordrucken: "Wir sind in der Pilzsystematik seit de Bary im Grunde nicht weiter gekommen, obwohl das Mlaterial inzwischen gewaltig gewachsen ist." In diesem Buche findet sich anf Seite 41 über Auricularia Auricnla Judae die Bemerkung: "Die Zahl der Theilzellen" (sc. der Basidien) „ist nicht, wie ron Brefeld und Möller angegeben, vier, sondern sie ist, wie anch Saccardo und Patonillard u. A. behaupten, schwankend" und weiter:

„Für die Brefeldsche Hypothese, nach welcher die Zahl der Sterigmen bei den Basidiomyceten ron dem Unregehnässigen zu dem Typischen und Regelmässigen sich entwickelt haben soll, ist es allerdings von Wichtigkeit, dass bei den höchst entwickelten Fornen Schwankingen in der Zahl der Theilzellen nicht vorkommen. I ie Annahme stimmt aber, wie wir gesehen haben, mit der Wirklichkeit nicht ïberein."

"Im Uebrigen habe ich den Untersuchungen ron Yöller und Brefeld" (soll wohl heissen Brefeld und Möller), „über die Basidien der Anricula" (soll wohl heissen Auricularia) „nichts hinzuzufügen. Dass ilne Angaben über die Zahl" (soll wohl heissen Zahl der Basidientheilzellen) ,unbedingt murichtig sind, habe ich sowohl an frischem Material, als anch an eingebettetem durch Mikrotomschnitte konstatiren können."

Da nun anch weiterhin die von Brefeld gewomnenen, von mir in Brasilien seiner Zeit bestätigten Kulturergebnisse von Anrienlaria durch denselben Herm Holtermann in Jara nicht bestätigt werden konnten, ein Umstand, der meiner Meinung nach lediglich auf mangelhafte Beobachtung zurïckznführen ist, so erschien es mir wünschenswerth, mich an denselben Material, welches Herrn Holtermann vorgelegen hat, von der Unrichtigkeit seiner Angaben überzeugen zı künnen. Ich erhielt durch die Güte des Herm Raciborski aus Java im Februar 1900 an der Luft getrocknete gut erhaltene Fruchtkörper der dortigen 
Auricularia. Die Basidien sind nicht leicht zn untersuchen, wie wiederlıolt betont worden ist. Macht man jedoch mässig dünne Längsschnitte durch das Hymenium, und legt sie 24 Stunden in gewöhnliche Tinte, zerdriickt sie danach leicht mit dem Deckglase, so kann man sich sicher von der Genauigkeit der Brefeldschen Zeichmmgen und Angaben überzengen. Die Basidie zeigt stets rier Theilzellen, die aber nicht zugleich die Sterigmen und Sporen bilden und sich danach entleeren, sondern nach einander; die entleerten Theilzellen und Sterigmen fallen zusammen und werden undentlich. Dass ganz vereinzelte Unregelmässigkeiten rorkommen kömen, wie sie sich schliessich bei allen Basidien gelegentlich finden, soll nicht bestritten werden; mir sind indessen bei Anricularia noch keine solche zu Gesicht gekommen. Holtermann würde sich vielleicht gescheut haben, seine ïberaus leichtfertigen nnd oberflächlichen Bemerkungen über Auricnlaria drucken zu lassen, wemn er die Arbeit ron Sappin-Trouffy (Le Botaniste 5. Série 189697 Seite 56,57) sich vorher angesehen laätte. Aus derselben und ilren ausgezeichneten Abbildungen geht die typische Tierzelligkeit der Auriculariabasidie ebenfalls ganz zweifellos hervor. Mindestens hätte man doch erwarten dïrfen, dass er anch die "mbedingte Unrichtigkeit" der SappinTrouffyschen Zeichnumgen nachwies, ehe er das Ergebniss seiner eigenen „unbedingt unrichtigen" Beobachtungen in so lochtrabender Weise verkündete.

Holtermaun fährt daun in seiner Besprechung fort:

"Auch meine Kulturversuche ergaben ein ron Brefelds und Möllers Ansichten" (soll wolıl heissen Ergebnissen), ,abweichendes Resultat. Brefeld giebt an, dass die Sporen im Wasser, wie auch in der Nährlösung leicht anskeimen, indem sie Keimfäden austreiben, die sich zumeist nahe hinter der Ursprungsstelle unregelmässig verzweigen. An den Enden der Seitenäste bilden sie seiner Darstellung zu Folge äusserst winzige Conidien. Im Uebrigen rerweise ich auf seine eigenen Untersuchungen ïber diese Frage. Nur bemerke ich, dass bei Anwendung von reichlicher Nährlösung nach Brefeld besondere Zweige nnd Zweigsysteme als Conidienträger angelegt werden. Möller bestätigt die Brefeldschen Angabeu und hat auch eine spärlicher oder ïppiger eintretende Fruktifikation in den charakteristischen Häkchenconidien gefundeu. Leider giebt er hierzu lieine Zeichnung."

Der Ausdruck „leider“, den Herr Holtermann hier für zulässig hält, ist der einzige Grund, der mich zwingt, auf seine Bemerknngen, deren Ungenauigkeit sonst in der Länge der Zeit durch weitere Untersuchungen anderer Forscher ganz ron selbst sich herausgestellt haben würde, einzugehen. Ich liabe ansdrücklich betont, dass ich (cf. Protobasidiomyceten S. 42) durch sehr zahlreiche; oft wiederholte und mamigfach abgewandelte Kulturen mich von der Uebereinstimmung des Terhaltens der brasilischen Auricularia mit dem von Brefeld geschilderten der europäischen bis in alle Einzelheiten überzengte, so dass die von Brefeld gegebenen zablreichen vortrefflichen Abbildungen ohne jede Einsclıränknng auch für die iu Brasilien gemachten Kulturen gelten können. Dieser meiner Angabe gegenüber muss ich den Ausdruck "leider" in dem oben angegebenen Zusammenlıang als durchaus ungehörig entschieden zurïckweisen. Deu sonstigen Aensserungen des Herrn Holtermann über das Fehlen der Auricnlariaconidien bei der jaranischen Form muss ich aber entgegenhalten, dass die 
von Herm Raciborski ïbersandten Auriculariafruchtkörper ans Java, in Eberswalde durch Anfeuchten zum Leben erweckt, dort reichlich Sporen warfen, welche alsbald. keimten, und dass auch diese sich bezüglich der Conidienfruktifikation in Wasser und in Nährlösung in ïppiger oder schwächerer Entwickelung ganz genau so verhielterı, wie Brefeld es beschreibt und abbildet für die europäische Form und wie ich es in Brasilieu bestätigte. Die Conidien sind, wie schon Brefeld schreibt, wegen ihrer Kleinheit und Durchsichtigkeit leicht zu uibersehen, und es gehört dazu, dass man sie beobachtet, allerdings "die volle Beherrschung der Kulturmethoden". Damit Herr Holtermamn nicht wieder seinem Bedanern Ausdruck giebt darüber, dass ich auch jetzt darauf verzichte, die Entwickelungszustände der javanischen Auricularia abzubilden. weil auch für diese die Brefeldschen Abbildungen bis ins einzelnste zutreffen, so will ich noch hinzufügen, dass Herr Professor Ramann (jetzt in München) die Kulturen, die nachweislich von den javanischen Auricularien abgeleitet waren, mehrere Tage nach einander bei mir besichtigt hat, und dass ich ihm die Conidien, wie sie unmittelbar an den keimenden sporen. und demnächst an verzweigten Trägern sich bilden, wiederholt gezeigt habe.

Es ist wirklich ein Glück zu nemen, dass in diesem Falle Holtermanns Oberflächlichkeiten und Unrichtigkeiten sich auf einen Pilz bezogen, den man bei einiger Vorsicht rings um die ganze Erde schicken kamn, ohne dass seine Lebensfähigkeit und die Keimfähigkeit seiner Sporen darunter leiden. Sonst hätte es wohl zum Schaden der Wissenschaft noch länger gedauert, ehe derartige Verdunkelnngen sicherer und zweifellos erwiesener wissenschaftlicher Thatsachen in angemessener Weise zurïckgewiesen werden komnten. Die Probe aber genügt, um gegenüber den sonstigen Entdeckungen des Herm Holtermann die äussersten Zweifel jedem Hykologen zur Pflicht zu machen.

Wer sich etwa für die von Herrn Holtermann als zulässig erachtete Art der "Literaturbenutzung" interessirt, den wïrde ich bitten, seine „Schlussbetrachtung "Seite 109 nebst den Bildern Taf. VI Fig. 1a u. c zu vergleichen nit meinen drei Jahr früher erschienenen Ausführungen: Protobasidiomyceten Seite $40 \mathrm{ff} ., 153 \mathrm{ff}$. und Taf. I Fig. 1 ebendaselbst.

Der Herr Ab. J. Bresatola hat in der Hedwigia 1896 Seite $276 \mathrm{ff}$. eine ganze Reilıe der von mir in Brasilien gesammelten Pilze beschrieben und benannt, wie in meiner Arbeit bereits wiederholt erwähnt wurde. Er beschränkt sich aber nicht auf die einfache Beschreibung, sondern giebt an jener Stelle mir und anderen Mykologen aus Anlass der Beschreibung von Auricularia Auricula Judae eine längere Belehrung in lateinischer Sprache. Nach Herm Bresadola muss die Gattung Hirneola von Auricularia getremnt werden, wofür ein irgend gewichtiger Grund nicht vorgebracht wird. Sodann soll der von mir als Auricularia Auricula Judae bezeichnete Pilz mit der Laschia delicata Fries nicht identisch sein, wie ich auf Grund sorgsamer Untersuchung behauptet habe. Für seine gegentheilige Ansicht beruft sich Bresadola anf gewisse makroskopische Merkmale, deren Berechtigung nicht anzuerkennen ist, und über die weiter kein Wort zu verlieren ist. Darauf schliesst die lange Bemerkung mit den Worten: „Notis micrologicis ergo affinitates nobis magis innotescumt, ita ut species olim dis- 
junctae, sto naturali loco nunc systematice ordinantur" (ordinentur?), „at ex hoc notae macrologicae" (notas macrologicas?) ..negligere non debemus cum istae quoque ad perfectam rerum natnralinm cognitionem acquirendam et ad species generaque affinia distinguenda optime inserviant. Vitemus ergo ne extrema se tangant. Veteres enim notae microscopicae" (notas microscopicas?) "negligebant. Neoterici, e contra, notae macrologicae" (notas macrologicas?) "non tantum neglignnt, sed sperumut. An hoc verum scientiae progressum constituit?" Der Torwurf mit dem grossartig klingenden „non tantum negligunt, sed spermunt," ist so abgeschmackt, dass der Neotericus dem Vertreter der Veteres ruhig das letzte Wort lassen künnte. Er thut es nicht, weil der alte Herr es ihm gar zu leicht und rerlockend macht, auf die Philippica zu erwidern. Offenbar hat Herr Bresadola unter den vielen Druckfehlern noch einen letzten ïbersehen. An Stelle des Fragezeichens nämlich am Ende seiner Rede sollte ein Doppelpunkt stehen. Setzen wir ihn, so lesen wir a. a. 0. in der Hedwigia Folgendes:

An hoc verum scientiae progressum constituit:

106. Hirneola? lancicula Mont. Guj. n. 439 Sacc. Syll. VI p. 770.

Hab. ad ligna „Blnmenan“ Brasiliae (n. 25d). Obs.: Specimina observata sterilia, at, ex modo, quo basidia(?) sese gernnt, suspicor quod potins hic Orbilia" (sic) "vel Ombrophila" (sic!) „sp. pronti jam cl. Patonillard monuit, habemus." Und hier hinter würde ich das Fragezeichen setzen. Ein steriler Pilz, und aus der Art seiner Basidien, die er doch nicht haben kann, wenn er steril ist, argwöhnt Herr Bresadola, es sei ein Ascomscet, der doch erst recht keine Basidien haben dürfte. Und er benennt ihn mit Hirneola! Und nun will ich ihm als Neotericus sagen: Veterum ille clarissimns patronus notas microscopicas non tantum neglexit, sed sprerit. Die Specimina, die er untersucht hat, sind ebensowenig steril, wie die, welche ich noch unter derselben Nummer bewahre, man muss sie nur mikroskopisch untersnchen, daun sieht man ihre sehr kleinen (15 $\mu$ langen, $3 \mu$ breiten) Schläuche, die mit zahlreichen winzigen stäbchenförmigen Sporen gefüllt sind, und man findet auch Paraphyseu dazwischen, die ein Epithecinm bilden. Also ein Discomycet ist als "Hirneola?" beschrieben, auf derselben Seite, anf der Herr Bresadola sich zum Lehrer der Neoterici anfwirft. Ja ob solche Leistung den wahren Fortschritt der Wissenschaft ausmacht? "Vitemus ergo ne extrema se tangant" oder anch: "Wer im Glashanse sitzt, soll nicht mit Steinen werfen."

In der Nr. 24 der botanischen Zeitung vom Jahre 1900 befindet sich ein Bericht des Herm Grafen zu Solms-Laubach über jene Harpersche Arbeit, die ich Seite 44 nnd 48 ff. dieses Heftes zu erwähnen Gelegenheit fand. Meine Ansichten über jene Arbeit weichen allerdings von denen des Herrn Referenten nicht nur $a b$, sonderu sind ihnen gerade entgegengesetzt. Die Zeit wird lehren, wer Recht hat, und die Geschichte der Wissenschaft wird darüber befinden, ob jene Arbeit "so vortreff lich", ihre Worte so ,golden" sind, wie der begeisterte Vertreter de Baryscher Pilzsexualität behauptet. Referent schreibt dann weiter: „Durch des Verf." (sc. Harpers) „und Thaxters Angaben ist also die Geschlecht- 
lichkeit der Asconyceten, im landläufigen Sinne des Wortes, für jeden der sehen will, nachgewiesen, und wemn das E. Fischer auch hente noch nicht zugeben will, und als Hauptargument dagegen Möllers Spermatienkeimungen anführt, so hat dieses Beweismittel in des Ref. Augen nicht den allergeringsten Werth. Denn die Gameten von Ulothix und Ectocarpus, die gewiss sexuell differenzirt sind, keimen doch eventuell ohne Copula zu normalen Pflanzen aus." Hierzu muss num bemerkt werden, dass es die Frage verdunkeln heisst, wenn meine wenigen keimenden "Spermatien" flechtenbildender Ascomyceten abgetremnt angefiihrt werden von hunderten keimender "Spermatien“ anderer Ascomyceten, die Brefeld bekannt gemacht hat. Die Gegner müssen sich klar darüber sein, dass sie nicht mit den neun ron mir festgestellten Fällen, sondern mit mehr als $200 \mathrm{zu}$ thun haben, in denen die sogenannten "Spermatien" sich selbstständig "ohne Copula" zu normalen Pflanzen entwickeln. Und diese "Spermatien" sind nach der Ansicht der Gegner offenbar eminent sexuell differenzirt, sie haben gar keine Aehnlichkeit mehr mit dem für sie erdachten weiblichen Organ, der berïhnten Schraube mit ihrer Trichogyne. Dagegen stehen jene copulirenden Algenschwärmer, welche zu Zeugen angerufen werden. auf der niedersten Stufe sexueller Differenzirung, die man kennt. Die männlichen sind den weiblichen noch vollkommen gleich, und beide gleichen fast völlig den ungeschlechtlichen Schwärmern. Daran kanı der Relativsatz „die doch gewiss sexuell differenzirt sind" nichts ändern.

So hat demn die Argumentation des Referenten der botanischen Zeitung für mich bei der unbefangensten Würdigung, deren ich fähig bin, ,nicht den allergeringsten Werth." Noch ist kein Fall bekannt, das" echte Spermatozoiden, die den Ort ihrer Bestimunng rerfehlten, zu normalen Ptlanzen ausgewachsen sind. Ja wem die Florideenspermatien zu selbstständiger Entwickelung gebracht würden, da liesse sich doch mit einer gewissen Berechtigung über den Fall sprechen, da wäre doch eine Analogie zwischen den fraglichen Gebilden zu findeu, die zwischen den einander gleichartigen copulirenden Schwärmem ron Ulothtrix ete. und den sogenannten "Spermatien" der Ascomyceten der Unbefangene sicher nicht entdecken wird. 


\section{Zusammenstellung \\ der durch die vorliegende Arbeit veränderten und der Beschreibungen neuer Gattungen und Arten.}

\section{Phycomyceten.}

1. Cloanephora americana nov. spec. (Taf. I Fig. 1-14).

Sporangien schwarz, auf gebogenen violett schimmernden Stielen, mit kugliger Columella, bis 170 " Durchmesser. Sporangiensporen braunröthlich, eiförmig, mit glattem Epispor und je einem hyalinen Haarbüschel an den Enden der Sporen. 27-31 $\mu \times 12-15 \mu$.

Conidienträger bis $5 \mathrm{~mm}$ lang, nach oben wenig verdickt, einfach kopfig oder einfach, anch doppelt zusammengesetzt, mit ein bis vielen Capitellen, welche nach der Reifung der Conidien zusammenschrumpfen, doch nicht trichterförmig. Conidien braunröthlich, eiförmig mit längsgestreiftem Epispor und hyaliner polsterförmiger Ansatzstelle; 19-22 $\times 9-11 \mu$, ohne Haarbüschel. Chlamydosporen häufig, Zygosporen nicht beobachtet.

Blumenau, Brasilien; von Februar bis Mai auf noch ansitzenden Blumenblättern von Hibiscus und auf verschiedenen verwesenden Pflanzentheilen am Boden.

\section{Ascomyceten.}

1. Perisporiaceen.

2. Penicilliopsis brasiliensis nov. spec. (Taf. IX Fig. 1-2, Taf. II Fig. 40).

Conidienfrüchte gelbgrünlich, bis $5 \mathrm{~cm}$ hoch, mit kurzen, unregelmässig angeordneten annähernd gleichlangen Seitenverzweigungen be- 
setzt; bedeckt mit keulig angeschwollenen Hyphenenden, welche auf länglich flaschenförmigen, kopfförmig zusammengeordneten Sterigmen Conidien in Ketten erzeugen. Conidien von zweierlei Form an demselben Träger, lange mit glatter Membran von $15 \times 5 \mu$, runde mit feinstachlich punktirter Membran, $6-7 \mu$ Durchmesser. In Innern der befallenen Früchte bis $2 \mathrm{~mm}$ starke, kastanienbraune rhizomorphaartige Stränge, an denen ausser den Conidienfrüchten auch die $3-4 \mathrm{~mm}$ dicken kugligen honiggelben geschlossenen Ascusfrüchte sitzen. Asci kuglig, $12 \mu$ Durchmesser, mit je 8 Sporen von $9 \times 5 \mu$ mit netzleistenartig skulpirter Membran.

Auf Samen von Mucuna und Strychnos triplinervia. Blumenau, Brasilien.

\section{Pyrenomyceten.}

a. Hy ростасе en.

3. Melanospora erythraea nov. spec. (Taf. II Fig. 31).

Pcrithecien schwarz, glatt, fast kuglig, mit kurzer stumpfkegelförmiger Mündung, etwa 1/: $\mathrm{mm}$ Durchmesser, freistehend, Schläuche 250 "l lang, oben stumpf abgestntzt; Sporen oval, schwarzgrünlich, in einer Reihe, entweder zu vieren $36 \times 16$, oder zu achten $25 \times 14 \mu$ im Schlauche. Oidien in faustgrossen zerstäubenden orangerothen Polstern und Lagern.

Blumenar, Brasilien, anf verkohltem Holz der Roças.

4. Hypomyces Möllerianus Bres. in Hedwigia 1896 Seite 299.

In der dort gegebenen Diagnose muss die Dicke des filzigen Stromas anstatt mit $1 \frac{1}{2}-2 \mathrm{~mm}$ mit $-5 \mathrm{~mm}$ angegeben werden. Das Stroma zeigt einen mehrschichtigen Bau; die Länge der Sporen beträgt bis $21 \mu$. Zu dem Pilz gehören eiförmige, an einer Seite abgestutzte Conidien ron $6 \mu$ Durchmesser. Der Pilz ist auf Fomes fulvo-umbrinus Bres. gefunden worden.

5. Hypomyces Bresadoliauus nor. spec. (Taf. IX Fig. 3).

Perithecien weissgelblich, halb cingesenkt, flaschenförmig, $200 \mu$ Durchmesser mit einem 100 "langen Halse. Schläuche cylindrisch, achtsporig, $120 \mu$ lang, 4-5 $\mu$ breit, Sporen hyalin, ungleich zweizellig, 10-13 $\mu$ lang, 3,5-4 $\mu$ breit. Acrostalagmusartige Conidienträger mit ovalen hyalinen einzelligen Conidien von $6 \mu$ Durchmesser. Chlamydosporen (deren Zugehörigkeit nicht ganz sicher nachgewiescn ist), gelbbraun, kuglig, fein stachlig rauh, $6 \mu$ Durchmesser. 
Auf einer von dem Parasiten vollständig durchwucherten und deformirten nicht mehr bestimmbaren Agaricine. Blumenau, Brasilien.

6. Hypocrea succinea Bres. in Hedwigia 1896 Seite 300.

Der Diagnose ist zuzusetzen: Conidienbildung rom Typus der Hypocrea rufa (Bref. X Taf. V Fig. 57). Conidien oval, einzellig, $9 \Perp$ lang, 4 « breit.

7. Hypocrea pezizoidea nov. spec. (Taf II Fig. $37 \mathrm{c}$ ).

Fruclitkörper helllederfarben, gestielt, mit unregelmässig geformter bis $3 \mathrm{~cm}$ Durchmesser erreichender fleischiger Scheibe. Perithecien auf der Oberseite der Scheibe eingesenkt, 200-250 $\mu$ Durchmesser. Schläuche 75 "1 lang, Sporentheilzellen 4 " Durchmesser.

Blumenau, Brasilien, auf morschem Holz am Waldboden.

8. Hypocrea sphaeroidea nov. spec. (Taf. II Fig. 37 b).

Fruchtkörper gestielt, kuglig, ziegelfarbig (Sacc. 19), bis $1 \mathrm{~cm}$ Durchmesser, ringsum perithecientragend. Perithecien 200-250 $\mu$ Durchmesser, Schläuche $75 \mu$ lang, Sporentheilzellen $4 \mu$ Durchmesser.

Blumenau, Brasilien, auf morschem durchnässtem Holze in einem Waldbache.

9. Hypocrea poronioidea nov. spec. (Taf. II Fig. 37 a).

Fruchtkörper bis $1 \mathrm{~cm}$ lang gestielt, umbrabraun (Sacc. $9 \times 39$ ), mit runder flacher, in der Mitte etwas eingedrückter hellederfarbener Fruchtscheibe, welche die dicht stehenden eingesenkten Perithecien trägt. Perithecien $180 \mu$ Durchmesser, Schlauchlänge $70 \mu$, Sporentheilzellen 2,8 $\mu$ Durchmesser.

Blumenau, Brasilien; auf morschem Holz am Waldboden.

10. Hypocrea alutacea Pers.

Gefunden zu Blumenau, Brasilien, auf morschem Holz am Waldboden.

Podocrea Sacc. ist einzuziehen, oder nur als Untergattung von Hypocrea beizubehalten.

11. Corallomyces Jatrophae nov. spec. (Taf. I Fig. 21-28 rund 30. Taf. II Fig. 31-32. Taf. IX Fig. 5).

Stroma korallenroth, bisweilen nur kissenförmig, dann säulenförmig, und auch korallenartig reich verzweigt, trägt an seinen Enden runde muldenförmige Conidienlager, auf denen die Conidien in weissschleimigem Kugeltropfen stehen. Perithecien seitwärts an denselben Stromaten von gleicher Farbe wie diese, fast völlig frei, eiförmig, $1 \mathrm{~mm}$ lang, mit 
deckelartiger Spitze. Conidien lang, bananenförmig, farblos 4 bis 8 zellig, 40-100 $\mu$ lang, 8-10 $\mu$ breit. Sporen eilänglich bis spindelförmig gelbbräunlich, zweizellig, 30-40 $\mu$ lang, 7-9 9 breit.

Verwandt mit Cor. berolinensis P. Hemn. und Cor. novo-pommeranus P. Henn.

Blumenau, Brasilien; saprophytisch an nassem morschem Holze im Walde, und parasitisch auf den Wurzeln von Jatropha Aipi.

12. Nectria capitata Bres. in Hedwigia 1896 Seite 299. (Taf. I Fig. 29. Taf. II Fig. 39).

In der Diagnose sind die Sporen als hyalin bezeichmet, während sie hellgelbbräunlich sind. Der Diagnose ist zuzusetzen: Conidien vom Typus der N. Stilbosporae Tul. Carp. III Tarf. XI Fig. 15. 70-90 lang, 4--12 zellig, Theilzellen oftmals gemmenartig anschwellend.

13. Nectria Euterpes nov. spec. (Taf. IT Fig. 35).

Perithecien leuchtend roth, stromalos (Sace. Chrom. 14-15), frei, einzeln oder truppweise, kuglig, ${ }^{1 / 2}$ mm Durchmesser mit kurzer stumpfer Mündung, gemischt mit den Conidienlagern in kleinen weissen unregelmässig umgrenzten Sclıleimpolstern. Sporen hyalin oval, 14 "/ lang; 5 " breit, zweizellig. Conidien vom Typus der Nectria Stilbosporae (Tul. Carp. IIT Taf. XI Fig. 15), bananenförmig, 60-70 „l lang, $10-$ 12 " breit, durch drei Scheidewände in zwei kleine äussere und zwei grössere mittlere Zellen zerlegt.

Blumenau, Brasilien, auf abgefallenen Früchten der Euterpe oleracea.

14. Nectria miniata (P. Henn.) = Nectriella miniata P. Henn. in Hedwigia 1897 Seite 219.

15. Nectria Mölleri (P. Hem.) = Nectriella Mölleri P. Hem. ebenda.

16. Nectria farinosa ( P. Henn.) = Nectriella farinosa P. Henn. ebenda.

Sphaerostilbe 'Tul. 1865.

Die Gattungsdiagnose auf Seite 99100 Band III der Carpologie ist dahin zu erweitern, dass die Perithecien, welche dort als „nuda“" bezeichnet sind, auch fein behaart, und die Ascen, welche "quasi sessiles" genanut sind, auch lang gestielt sein können. Endlich müsste man zu dem Charakter "sporae pallidae" noch "aut olivascentes" hinzusetzen.

17. Sphaerostilbe longiascus nov. spec. (Taf. II Fig. 36).

Perithecien zusanmen mit den Conidienfrüchten auf unregelmässigem polsterförmigem Stroma, lebhaft roth, länglich tonnentörmig, schwach be- 
lıart, mit glatter deckelförmiger Spitze. Schläuche lang gestielt, 300 " lang. Sporen gelbbraun, spindelförmig, 28-38 $\mu$ lang, $10 \mu$ breit, schwach längsgestreift, an der Qnerwand schwach eingeschnürt. Conidienfrüchte bis $7 \mathrm{~mm}$ hoch, an der Spitze mit schleimigem Tröpfchen von $1 \frac{1}{2} \mathrm{~mm}$ Durchmesser. Zwischen sterilen haarartigen Fäden eiförmige Conidien, 44-50 $\mu$ lang, $15 \mu$ breit, vierzellig, mit zwei grösseren mittleren gelbbraunen und zwei kleineren hyalinen Endzellen.

Blumenau, Brasilien, auf morschem Holze an einem Bach im Walde.

Mycocitrus nov. gen.

Fruchtkörper festfleischig knollig, ringsum mit halbeingesenkten bis ganz freien Perithecien besetzt. Perithecien bisweilen nach Ueberwachsen der älteren in mehrfacher Schicht über einander. Sporen zweizellig.

18. Nycocitrus aurantium nov. spec. (Taf. II Fig. 38, Taf. III Fig. 45).

Fruchtkörper orangeroth, kuglig, bis $11,5 \mathrm{~cm}$ Durchmesser. Perithecien kuglig mit kurzer Nündung 170-250 $\mu$ Durchmesser. Schläuche $48 \mu$ lang, $4 \mu$ breit, Sporen zu acht in einer Reihe, hyalin, oval, zweizellig, $6-9 \mu$ lang, $3-4 \mu$ breit.

Conidien auf kurzen zugespitzten meist unverzweigten Trägern succedan abgeschniirt und zu Köpfchen verklebend, lıyalin, einzellig, etwa von der Grösse der Sporen, doch schwankend.

Bhmenar, Brasilien, anf dïnnen meist abgestorbenen Zwweigen verschiedener Bambusen (Guadua, Microstachys), den tragenden Zweig als Achse nmschliessend, oft mehrere Meter hoch n̈ber dem Boden.

19. Calonectria Balansiae nov. spec. Rundliche Perithecien von $150 \mu$ Durchmesser parasitiseh in den entleerten grösseren Perithecien der Balansia redundans nov. spec. (vgl. S. 196-197). Asci $65 \mu$ lang; $4 \mu$ breit. Sporen zu acht, braun, vierzellig, länglich, schwach gekrümmt, $13 \mu \times 3-4 \mu$.

Peloronectria nov. gen. Parallelgattung zu Myeocitrus unter den phragmosporischen Hypocreaceen. Grosses knolliges Stroma, das ringsum mit Perithecien besetzt ist.

20. Peloronectria vinosa nov. spec. (Taf. IX Fig. 4, Taf. IV Fig. 54).

Stroma knollig, den tragenden Bambuszweig rings umschliessend, braun mit zähem Fleisch, welches aus dicht verflochtenen, doch nicht plectenchymatisch zusammenschliessenden Hyphen gebildet wird. Peri- 
thecien in gleicher Vertheilung ringsum anf dem Stroma, kuglig, 250 " Durchmesser, je frei auf einem kugligen Fusse von gleicher Grösse. Schläuche $60 \mu$ lang, achtsporig. Sporen gelbbraun $16 \mu$ lang, $5 \mu$ breit, vierzellig. An den Mycelfäden in Culturen ovale Conidien, $6-18 \mu$ lang, hefeartige Sprossung, die bald in Nycelbildung übergeht. Blumenau, Brasilien, auf abgestorbenem Bambusstengel.

21. Megalonectria verrucosa nov. spec. (Taf. IV Fig. 55).

Perithecien roth, 1/2 mm Durchmesser, warzig rauh, gruppenweise gedrängt. Schläuche $70 \mu$ lang, achtsporig. Sporen 28-38 " lang. 10-12 $\mu$ breit, mauerförmig in viele Zellen getheilt, keimen mit rundlichen hyalinen Conidien von 3 « Durchmesser, welche hefeartig weitersprossen. Conidienfruchtkörper zwischen den Perithecien von gleicher Farbe, nach oben abblassend, $1 \mathrm{~mm}$ hoch; an der Spitze mit dichtem Haarbüschel steriler Fäden, zwischen denen längliche Conidien von $5-6 \mu$ Länge, 2-3 $\mu$ Breite gebildet werden.

Blumenan, Brasilien, auf trocknen Zweigen am Waldboden im Velhathale.

Mölleriella Bres. gehört zu Hypocrella (eventuell als Untergattung).

Dussiella Pat. ist zu streichen.

Echinodothis Atk, ist zu streichen.

Dothichloë Atk. ist zu streichen.

22. Oomyces monocarpus nov. spec. (Taf. IV Fig. 56).

Stromata 1,5 mm hocl, hellgelblich bis röthlich, weichfleischig, einzeln oder in büschelig verwachsenen Gruppen gedrängt, mit nur je einem Perithecium. Schlänche $500 \times 7--8 \mu$, mit je zwei oder vier fadenförmigen Sporen; Sporentheilzellen $9 \times 2 \mu$, im Schlauche nicht zerfallend.

Blumenau, Brasilien, auf Zweigen ron Mlicrostachys speciosa Spr.

Hypocrella Sacc. Der Diagnose der Gattung ist zuzufügen, dass das Stroma auch kuglig knollenförmig ausgebildet sein kann, und dass es eine Differenzirung in bestimmt begrenzte, Perithecien tragende, und andere, sterile Oberflächentheile nicht erkennen lässt. Die Schlänche sind vier- oder achtsporig. Die Sporen zerfallen bisweilen schon im Schlauche in zallleiche Theilzellen (Untergattung Mölleriella Bres.).

23. Hypocrella ochracea Mass. = Hyp. Edwalliana P. Henn. = Mölleriella sulphurea Bres. (Taf. IV Fig. 64a-f).

Stromata gelbroth, halbkuglig, glatt, später zottig rauh, bis $8 \mathrm{~mm}$ Durchmesser, auf Dikotyledonenblättern, befestigt durch einen concentrisch 
um das Stroma ausgebreiteten, der Epidermis des Blattes angeschmiegten Hypothallus. Zuerst erscheinen grubig vertiefte unregelmässige Conidienlager. Conidien in grossen Massen gebildet, zu schleimigen zinnoberrothen Massen verklebt, $16-18 \times 2-3 \mu$, nach den Enden scharf zugespitzt. Später auf denselben Stromaten zerstreute, tief eingesenkte Perithecien. Schläuche $250-300 \times 10-16 \mu$. Je acht fadenförmige Sporen, welche schon im Schlauche in unzählbare Theilsporen zerfallen. Theilsporen 11-14 $\times 3 \mu$, in der Mitte etwas geschwollen, an den Enden abgerundet.

Blumenan, Brasilien, auf verschiedenen Dikotyledonenblättern, sehr häufig.

24. Hypocrella cavemosa nov. spec. (Taf. IV Fig. 63).

Stroma kuglig; hellbraunroth, etwa $1 \mathrm{~cm}$ Durchmesser, fest fleischig. Conidien in labyrinthartigen mannigfach gestalteten, doch stets mit einer Ausführungsmündung in Verbindung stehenden Höllungen des Stroma gebildet, länglich spindelförmig $20 \times 6$ ", treten in röthlich gefärbten wurmförmigen Strängen ins Freie. Perithecien verstreut, tief eingesenkt, lang flaschenförmig, $425 \mu$ lang, wovon $200 "$ auf den Ausführungskanal entfallen, 125 " breit. Schläuche 170 " lang. Die fadenförmigen Sporen zerfallen schon im Schlauche. Theilsporen oval $10-12 \times 4 \mu$.

Blumenau, Brasilien, anf Zweigen von Microstachys speciosa Spr., bisweilen den tragenden Zweig völlig einschliessend.

25. Hypocrella verruculosa nov. spec. (Taf. IV Fig. 61).

Stroma gelbbraun, halbkuglig, warzig körnelig rauh, wenige $\mathrm{mm}$ Durchmesser. Conidien nicht beobachtet. Perithecien verstreut, vollkommen eingesenkt, langflaschenförmig $(600 \mu)$ mit langem Halse, Schläuche 270-300 " lang. Je vier fadentörmige Sporen, die schon im Schlauche zerfallen. Theilsporen $12-15 \times 3-5 \mu$, oval.

Blumenau. Brasilien, auf Stengeln von Bambusen und Olyra, meist halbseitig den tragenden Zweig umgebend.

26. Hypocrella Gärtneriana nov. spec. (Taf. III Fig. 51. Taf. IV Fig. 62). Stroma kuglig, knollig, blassgelblich, fleischig, mehrere cm Durchmesser, mit dicht gedrängten einzelnen polsterförmigen Hervorragungen, auf denen allein die verstreuten, halb bis ganz eingesenkten rundlich kurzhalsigen Perithecien von $350 \mu$ Durchmesser sitzen. Schläuche 190 « lang, je vier Fadensporen, Theilzellen stäbchenförmig, $4-6 \times 1,5 !$, im Schlauche sich nicht trennend. 
Blumenau, am Cederfluss, Brasilien. Auf einer Bambuse (Carí). E. Gärtner leg. 1894.

Mycomalus nor. gen.

Stroma kuglig, knollig, fleischig, mit einer gürtelartig angeordneten scharf begrenzten fertilen Zone, und zwei sterilen Endflächen; die fadenförmigen Sporen zerfallen sehr früh in unzählbare Theilsporen.

27. Hycomalus bambusinus nov. spec. ('Taf. III Fig. 47, 50. Taf. IV Fig. 60).

Stroma bis $6 \mathrm{~cm}$ Durchmesser, festfleischig aus starkwandigen, sclerotienartig zusammenschliessenden Hyphen; oben und unten mit je einer kastanienbraunen, unregelmässig runden, sterilen Fläche. Fertile Zone erhöht, honiggelb, an der belichteten Seite dunkler, punktirt von den gleichmässig weitläufig vertheilten Perithecienmüudungen. Perithecien völlig eingesenkt, $2 \mathrm{~mm}$ lang, flaschenförmig, Schläuche bis $1 \mathrm{~mm}$ lang, in der Jugend mit Fadensporen, die sehr früh zerfallen. Zahllose Theilsporen, länglich spindelförmig, 30-50 "l; zux Keimung je drei Scheidewände, Keimschläuche aus jeder Theilzelle, bilden unmittelbar runde Conidien in traubenartiger (sympodialer) Anordnung.

Blumenau, Brasilien, auf Guadua Taguara Kth.

Ascopolyporus nov, gen.

Stroma kmollig oder hufförmig, fleischig oder gallertig, mit steriler Ober- und fertiler Unterseite. Fadensporige Schläuche. Conidien in Ketten oder verklebten Köpfchen.

28. Ascopolyporus polychrous nov. spec. (Taf. III Fig. 41. 42. 44. Taf. IV Fig. 57).

Stroma knollig, kuglig, bis etwa $4 \mathrm{~cm}$ Durchmesser, zäh gallertig, fleischig, in der Jugend rosa, dann weiss oder gelblich, braun oder rostroth, auf einem zarten, dem tragenden Bambusstengel dicht aufliegenden kreistunden strahligen weissen Hypothallus nur im Mittelpunkt angeheftet.

Perithecien bei gut entwickelten Fruchtkörpern nur auf deutlich begrenzter Fläche der Unter'seite, dicht gedrängt, 750 " lang; Schläuche $500 \times 4 \mu$; je acht Fadensporen, $300 \times 1 \mu$, in frischen Schläuchen ohne Querwände. Nach der Aussaat Theilzellen von 6 " Länge, die auf $4 \mu$ Dicke anschwellen, und nur theilweise sich von einander trennen. Conidien auf dem Hypothallus und an den Mycelien der künstlichen Cultur auf zugespitzten Mycelenden naclı einander abgeschnürt, oft ver- 
klebend, 7-12 × 4-6 ", bald mit einer Querwand, welche jedenfalls vor ihrer Keimung deutlich ist.

Blumenau, Brasilien, auf lebenden und absterbenden Zweigen verschiedener Bambusen, besonders Guadua Taguara Kth.

29. Ascopolyporus villosus nov. spec. (Taf. III Fig. 46).

Stroma knollig kuglig oft hufförmig, bis etwa $4 \mathrm{~cm}$ Durchmesser, zäh gallertig fleischig, in der Jugend rosa, dann weiss, zuletzt braun auf der mit einem mehrere $\mathrm{mm}$ dicken zottigen Haarfilz bekleideten sterilen Oberseite, lehmgelb auf der fertilen Unterseite. Hypothallus wie bei voriger Form, im Alter verschwindend. Perithecien und Sporen wie bei voriger Form. Keimung nicht beobachtet.

An der Seeseite der Serra Geral, Sa. Catharina, Brasilien, auf Bambusstengeln.

30. Ascopolyporus polyporoïdes nov. spec. (Taf. III Fig. 52. 53 Taf. IV Fig. 59).

Stroma hufförmig, polyporusartig, gallertig fleischig, bis $7 \mathrm{~cm}$ Durchmesser, mit gewölbter brauner, oft runzliger steriler Oberseite, und scharf umgrenzter flacher, gelblichweisser Hymenialunterfläche. Perithecien dicht gedrängt, bis über $1 \mathrm{~mm}$ lang, Schläuche $500-600 \times 4 \mu$, je acht fadenförmige Sporen, $500 \times 1 \mu$. Nach der Aussaat Theilzellen von 8-15 "Länge, die nur theilweise sich trennen. Luftconidien an Fadenenden der Mycelien kettenweise alggeschü̈rt, $9-20 \times 2 \mu$ mit ein bis vier zarten Querwänden, nie zu Köpfchen verklebend.

Blumenau, Brasilien, an Zweigen verschiedener Bambusen, besonders der rankenden dünnen, nicht hohlen Taguari.

31. Ascopolyporus Möllerianus (P. Henn.) in Hedwigia 1897 S. 222 (Taf. III Fig. 48. 49. Taf. IV Fig. 65).

Stromata unregelmässig, kuglig, knollig, fleischig fest, in der Jugend weiss, fein wollig, dicht mit Conidienträgern besetzt, später mit dunkelbrauner steriler Oberseite und gelbweisser fertiler Unterseite, bis $2 \mathrm{~cm}$ Durchmesser; meist kleiner. Perithecien dicht gedrängt auf der sclıarf umgrenzten Hymenialfläche, 500 « lang, im oberen Drittel kappenförmig zusammengezogen, fadenförmige Sporen $360 \times 1 \mu$. Scheidewände erst nach der Aussaat sichtbar. Conidien auf den jungen Fruchtkörpern und an Mycelenden in künstlicher Cultur nach einander abgeschnürt, zu Köpfchen verklebend, oval, 4 " lang, ohne Theilwände.

Blumenau, Brasilien, auf Philodendron sp., den tragenden Zweig manchmal umschliessend, benachbarte oft verwachsend. 
Epichlö̈ Fries. Die Begrenzung der Gattung in dem ursprünglichen Sinne durch ein flach ausgebreitetes, die befallenen Pflanzentheile umkleidendes fleischiges, zuerst Conidien, dann aber Perithecien a uf der ganzen Oberfläche in gleichmässiger Vertheilung tragendes Stroma ist strenge festzuhalten.

Ophiodotis Sacc. Die Gattung gehört in die nächste Nähe von Epichloë und Balansia und ist nicht, wie bisher durch das dothideaceenartige Stroma und die angeblich mangelnde Perithecienwandung charakterisirt, sondern es gilt für sie die Diagnose von Epichloë; von dieser Gattung ist Ophiodotis dadurch unterschieden, dass bei ihr die Perithecien nicht auf der ganzen Stromaoberfläche gleichmässig vertheilt, sondern nur auf besonders ausgebildeten jeweils verschieden und unregelmässig gestalteten Theilen des Stromas auftreten.

32. Ophiodotis rhaphidospora Rehm in Hedwigia 1897 S. 380. (Taf. V Fig. 69a-e).

Stroma in gleichmässiger dünner Schicht aus gewebeartig zusammenschliessenden Hyphen zwischen dem durch den Pilz an der Entfaltung gehinderten spiralig zusammengerollten Olyra- oder Microstachysblatte, weiss. Unter der äussersten Blattschicht streifenweise verdickt und in Crestalt mehrere $\mathrm{cm}$ langer, $1-2 \mathrm{~mm}$ breiter mit schwarzer Rinde versehener Streifen vorbrechend. Perithecien auf den vorbrechenden Streifen in zwei parallelen Reihen, ganz eingesenkt, mit sehr dünner Wandung, von fast rechteckigem Längsschnitt, mit kurzer sehr feiner Nündung. Schläuche $200-250 \times 6$, hyaline Kappe eckig. Fadenförmige Sporen von beinahe der Länge des Schlauches; 'Theilzellen 20 bis 27 ॥ lang, zerfallen erst nach dem Verlassen des Schlauches.

Blumenau, Brasilien, auf Blättern von Olyra sp. und Microstachys speciosa Spr.

33. Ophiodotis Henningsiana nov. spec. (Taf. V Fig. 70).

Stroma ${ }^{1 / 10} \mathrm{~mm}$ stark, in gleichmässiger Schicht auf Blattscheiden von Andropogon, schwarz, stellenweise unregelmässig höckerig oder fleckweise verdickt bis zu $1 / 2 \mathrm{~mm}$ Stärke. Perithecien nur in den verdickten Stromatheilen, $300 \mu$ lang, flaschenförmig, tief eingesenkt mit sehr dünner Wandung. Schläuche $200 \times 6 \mu$, hyaline Kappe gerundet. Vier bis acht Fadensporen von beinahe Schlauchlänge, die im Schlauche nicht zerfallen.

Blumenau, Brasilien, auf Blattscheiden eines Andropogon. 
Iyriogenospora Atkins. gehört in die nächste Nähe von Epichloë bezw. Ophiodotis und unterscheidet sich von jenen Gattungen nur dadurch, dass die Schläuche schon sehr früh mit unzähligen länglich spindelförmigen Sporen erfüllt sind, deren Entstelıung aus ursprünglich wenigen Fadensporen zu vermuthen ist, aber noch nicht nacligewiesen werden konnte.

Balansia Speg. Die Gattungsdiagnose von Spegazzini : Fungi Guar. Pug. 1 n. 253, bei Saccardo Bd. IX S. 997, bedarf mit Rücksicht auf die neuen Funde einiger Ergänzung:

Stroma in einen sterilen und einen fertilen Theil geschieden; der sterile umgiebt scheidenartig die verschiedensten Theile, Stengel, Blätter, Blüthen von Gräsern, oder lebt auch im Innern der Gewebe, bildet aber keine bestimmt geformten Sclerotien oder Pilzpseudomorphosen; der fertile Theil besteht aus bestimmt geformten, kugligen oder scheibenförmigen oftmals gestielten Köpfchen, denen die Perithecien eingesenkt sind.

34. Balansia ambiens nov. spec. ('laf. V Fig. $66 \mathrm{a}-\mathrm{b}$ ).

Stroma in geschlossener glatter $1 / 10 \mathrm{~mm}$ starker, aus dicht gefügtem Plectenchym bestehender Scheide die Stengel einer Olyra unter der Blattscheide umschliessend, in $1 \mathrm{~mm}$ breitem Längsriss die Scheide aufsprengend, und auf den zu Tage tretenden Längsstreifen besetzt mit kugligen kaum gestielten Köpfchen, bis $2 \mathrm{~mm}$ Durchmesser. Die freiliegenden Theile sämmtlich schwarz berindet. Flaschenförmige Perithecien in die Köpfchen tief eingesenkt, mit dünner Wandung. Schläuche 225 "lang. Fadenförmige Sporen zu 4-8 im Schlauch, zerfallen erst ausserhalb des Schlauches bei der Keimung in $18 \mu$ lange Theilsporen.

Blumenau, Brasilien, auf Stengeln von Olyra sp.

34. Balansia regularis nov. spec. (Taf. V Fig. 68 a u. b).

Stroma parasitisch im Gewebe der Stengel von Guadua Taguara Kth., charakteristische Hexenbesenform hervorrufend. Je ein kugliges schwarzes kurz gestieltes Köpfchen bis $3 \mathrm{~mm}$ Durchmesser an jedem Knoten des befallenen Zweiges auf der offenen Seite der Blattscheide. Perithecien 350-400 $\mu$ lang, flaschenförmig, Schläuche $200 \mu$ lang. Vier fadenförmige Sporen; Theilsporen $25 \mu$ lang, zerfallen erst ausserhalb der Schläuche.

Blumenau, Brasilien. 
36. Balansia redundans nov. spec. (Taf. V Fig. 67 a, b).

Stroma in geschlossener glatter $1 / 10 \mathrm{~mm}$ starker, aus dicht gefügtem Plectenchym bestehender Scheide die Stengel eines wollig behaarten Grases unter der Blattscheide umschliessend, in einem mehrere $\mathrm{cm}$ langen Längsriss die Scheide sprengend und auf dem zu Tage tretenden schmalen Streifen besetzt mit den $5 \mathrm{~mm}$ lang gestielten, vom Stiel abgesetzteu kugligen Köpfchen. Alle freiliegenden Theile schwarz, Köpfchenstiel schuppigrauh. Perithecien nur auf der Oberseite des Köpfchens, mit den Mündungen vorragend, 400 "lang, flaschenförmig. Schläuche $200 \mu$ lang mit acht fadenförmigen Sporen.

Die ausgestossenen Sporen haften auf der Spitze der Perithecien und an der rauhen Rinde der Köpfchenstiele, keimen und bilden dort verzweigte Mycelien, an deren Fadenspitzen hyaline $4 \mu$ lange Conidien, welche zu Köpfchen verkleben.

Blumenau, Brasilien.

37. Balansia diadema nor. spec. (Taf. V Fig. 74 ; Taf. X Fig. 1).

Stroma die Aehrchen eines Panicum dicht umschliessend und einhüllend, besetzt mit meist $4-6$ in der Ebene der Spelzen stehenden, 3-4 $\mathrm{mm}$ lang gestielten Perithecienköpfen. Alle freien Theile hellgelb. Stiele der Perithecienköpfe oft flachgedrïckt. Perithecien auf der Oberseite des Köpfchens, 250 « lang, nur mit der Mündung vorragend. Schläuche 130 « lang. Die Fadensporen zerfallen nach dem Austritt in Theilsporen, keimen, und bilden feinfädige Mycelien, an deren Fadenenden hyaline, $7-9 \mu$ lange ovale später zweizellige nicht in Köpfchen verklebende Conidien stehen.

Blumenau. Brasilien, auf einem locker rispigen Panicum. Balansia pallida Wint. nahe verwandt, doch mit ganz anderen Conidien.

Clav: 'eps Tul. Es muss nach wie vor festgehalten werden, dass bei dieser Cattung das sterile Stroma ein bestimmt geformtes, einer Ruheperiode angepasstes Sclerotium bildet, während der fertile, aus gestielten Köpfchen bestehende Theil uur für kurze Dauer bestimmt, von dem sterilen ganz verschieden gebildet ist. und nicht wie bei Balansia in ibu ohne scharfe Grenze übergeht.

38. Claviceps balansioides nov. spec. (Taf. Y Fig. $73 \mathrm{a}-\mathrm{f}$ ).

Sclerotien mit hlauschwarzer Rinde, von unregehmässiger Gestalt, den von ihnen befallenen, durch- und umwachsenen Aehrchen einer Echinochloa sp. in der Form folgend, im Mai und Juni reifend. Keinung im September bis Januar mit je $1-5$ bis $8 \mathrm{~cm}$ lang gestielten 
kugligen Köpfcheu. Stiele und Köpfchen hellgelb. Perithecien rings auf der Oberfläche des Köpfchens $300 \mu$ lang, mit 1/4-1/3 der Länge vorragend. Schläuche $150-180 \times 3 \mu$. Fadeusporen von beinahe Schlauchlänge, theilen sich zur Keimung in viele aufschwellende Theilzellen. Auf kurzen Mycelzweigen hyaline Conidien $12 \times 5 \mu$, uicht zu Köpfchen verklebend. Sphacelialager mit ähulichen Conidien auf der Bliithe, vor Ausbildung des Sclerotiums.

Blumenau, Brasilien, auf Echinochloa spec.

39. Claviceps lutea nov. spec. (Taf. V Fig. 71).

Sclerotien hellgelb, schwach körnelig rauh, länglich, gekrümmt, bis $3 \mathrm{~mm}$ dick, im Mai urd Juni auf Paspalum spec, keimen im Dezember ınit je 1-2, bis $4 \mathrm{~cm}$ langen gestielten hellgelben Perithecienköpfchen. Perithecien wie bei voriger Art. Schläuche $250 \mu$ lang. Fadensporen $180 \mu$, theilen sich zur Keimung in viele aufschwellende Theilzellen. Auf den Mycelenden hyaline Conidien $9 \times 2 \mu$. Aehnliche Conidien in Sphacelialagern auf den befallenen Blüthen vor der Sclerotienbildung.

Blumenau, Brasilien, auf Paspalum spec.

40. Claviceps ranunculoides nov. spec. (Taf. V Fig. $72 \mathrm{a}-\mathrm{c}$ ).

Sclerotien mutterkornartig, hornartig gekrümmt, blauschwarz, auf Setariaähren im Mai; keimen im Jannar mit $1-2$ bis $3 \mathrm{~cm}$ langen gestielten hellgelben Perithecienköpfchın. Perithecien 400-500 $\mu$ lang, bouquetartig geordnet, eingesenkt; gemeinsame Rinde sehr dünn, so dass die Perithecien einzeln sichtbar werden und das Köpfchen an Ranunkelfrüchte erinnert. Schläuche $300 \times 4 \mu$. Fadensporen 160 " lang. Zur Keimung zerfallen sie in 5 " lauge anschwellende Theilzellen. An den Mycelenden der Kultur zahlreiche, ovale, hyaline Conidien 8 bis $12 \times 2$ ", zu Köpfchen verklebend. Sphaceliaconidien in der Masse orangeroth, $7-8 \times 3-4$ ॥, auf den befallenen Blïthen vor der Sclerotienanlage.

Blumenan, Brasilien, auf Setaria spec.

Cordyceps Fries. Die Gattung umfasst in dem hier angenommenen sinne alle auf Insekten parasitirenden fadensporigen Hypocreaceen. Die Diagnosen der einzelnen Arten müssen unter Beachtnng der Abbildungen der Arbeit entnommen werden, da eine Zusammenstellung hier beinahe eine vollständige Wiederholung des früher gesagten erfordern wïrde.

41. Cordyceps flavo-viridis nov. spec. (Taf. VII Fig. 97 a-d) s. S. 208. 


\section{- $306-$}

42. Cord. gonylepticida nor. spec. (Taf. VI Fig. 89) s. S. 210.

43. Cord. rhyuchoticola nov. spec. (Taf. VI Fig. 87) s. S. 211.

44. Cord. cristata nov. spec. (Taf. VI Fig. 81) s. S. 212.

45. Cord. polyarthra nov. spec. (Taf. VI Fig. 83) s. S. 213.

46. Cord. Mölleri P. Henn. (Taf. VI Fig. 79. 80. 84; Taf. XI Fig. 3 b u. c), s. S. 215.

47. Cord. corallomyces nor. spec. (Taf. VI Fig. 85 u. 86) s. S. 217.

48. Cord. australis Speg. (Taf. VI Fig. 92-93) s. S. 218.

49. Cord. thyrsoides nov. spec. (Taf. VI Fig. 90. 91) s. S. 221.

50. Cord. muscicola nov. spec. (Taf. VI Fig. 88) s. S. 221.

51. Cord. rubra nov. spec, (Taf. VII Fig. 102. 103) s. S. 223.

52. Cord. submilitaris P. Henn. (Taf. VII Fig. 95. 96) s. S. 224.

53. Cord. ainictos nov. spec. (Taf. VII Fig. 105) s. S. 226.

54. Cord. incarnata nor. spec. (Taf. VI Fig. 94) s. S. 228.

55. Cord. entomorrhiza (Dicks.) Fries (Taf. VII Fig. 101 a b c) s. S. 229 .

56. Cord. hormospora nov. spec. (Taf. VII Fig. 100) s. S. 230.

57. Cord. rhizomorpha nov, spec. (Taf. VII Fig. 104) s. S. 231.

58. Cord. Volkiana nor. spec. (Taf. VII Fig. 98. 99 b u, c; Taf. XI Fig. 4) s. S. 233.

\section{b. Spha er i a c en (Xylarieen).}

Entonaema nov. gen.

Fruchtkörper hohl, weichfleischig, innen gallertig, unregelmässig geformte, oft mehrere cm grosse Knollen oder Blasen mit verhältniss. mässig dünner Wandung darstellend. Perithecien auf der ganzen Oberfläche eingesenkt. Schlauchsporen einzellig, dunkel.

59. Entonaema mesenterica nor, spec. (Taf. VIII Fig. 109 a-c).

Fruchtkörper mattschwarz, gallertig, weich, hohl. unregelmässig kuglig, nach der Anheftungsstelle zusammengezogen, bis $8 \mathrm{~cm}$ Durchmesser. Oherfläche mit gekröseartiger Linienzeichnung. Wandung $4 \mathrm{~mm}$ dick, aus radial gerichteten Prosoplectenchym, in dem bündelweise wurzelartige dunkler gefärbte Adern sich abheben. Perithecien mit sehr feiner Mündung, eingesenkt, kughg, dunkehwandig, ${ }^{6} / 10 \mathrm{~mm}$ Durchmesser, in der Fruchtkörperwandung gleichmässig vertheilt, einander nicht berührend. Sporen zu acht, einreihig, schwarzbraun, oval, einseitig wenig gedrückt, $10-11 \times 5 \mu$. 
Seeseite der Serra Geral, Sa. Catharina, $400 \mathrm{~m}$ Meereshöhe, auf morschem Holze.

60. Entonaema liquescens nov. spec. (Abbildung S. 248 und Taf. VIII Fig. 108).

Stroma leellgelb, später fast schwarz, weich, fleischig, gallertig, hohl, unregelmässig blasige, an Tremella erinnernde, vielfach mit einander verwachsene blasige Gebilde bis zu $40 \mathrm{~cm}$ Ausdehnung bildend, im Alter zerfliessend.

Wandung $4 \mathrm{~mm}$ stark, aus radial gerichtetem Prosoplectenchym, in dem bündelweise wurzelartige dunkler gefärbte Adern sich abheben, nach innen gallertig zerfliessend. Perithecien mit feiner Nündung, eingesenkt, dunkelwandig, länglich, 6/10 $\mathrm{mm} \mathrm{lang,} \mathrm{in} \mathrm{der} \mathrm{Wandung}$ dicht gedrängt neben einander. Sporen zn acht, einreihig, $9-10 \times$ $5-6 \mu$, oval.

Blumenau, Brasilien, auf morschen Baumstämmen.

Glaziella Berk. ist zu streichen, weil man eine Ascomycetengattung nicht aufrecht erhalten kann, wenn man keine Schläuche bei ihr geselien hat.

Xylocrea nov. gen.

Fruchtkörper knollenförmig, fleischig, roll, mit einer auf die Unterseite beschränkten, deutlich begrenzten Perithecien tragenden Hymenialfläche. Sporen einzellig, dunkel.

61. Xylocrea piriformis nov. spec. (Taf. VIII Fig. 112).

Stroma gelblich, weichfleischig, voll, eine nach vorn dickere, oft birnenförmige, am Grunde kurz stielartig zusammengezogene Keule (bis $5 \mathrm{~cm}$ Durchmesser) darstellend, gebildet aus Paraplectenchym, in dem verstreut gefässartige grössere Zellen, bis $80 \mu$ Durchmesser vorkommen. Aschgraue kappenförmige, scharf umgrenzte Hymenialfläche auf dem vorderen unteren Theile des Stroma, von den Mündungen der dunkelwandigen $1 \mathrm{~mm}$ hohen, $6 / 10 \mathrm{~mm}$ dicken, eingesenkten, dicht, doch niclit gedrängt stehenden Perithecien dunkel punktirt. Sporen zu acht, einreihig, schwarzbraun, $10-13 \times 6 \mu$, oval.

Blumenau, Brasilien, an totem Holze (Stäbe der Wildfallen).

62. Poronia fornicata nov. spec. (Taf. VIII Fig. 115).

Flachgewölbte, kuchenförmige, weichkorkige, hellrostrothe, von den tiefschwarzen Perithecienmïndungen dunkel punktirte Knöpfehen, bis $1 \mathrm{~cm}$ Durchmesser, in einen mehr oder weniger langen (bis $2 \mathrm{~cm}$ ) 
Stiel zusammengezogen. Perithecien eingesenkt, kuglig, 6/10 mm Durch • messer, mit schwarzer von dem weissen Stromafleisch scharf abgesetzter Wandung. Sporen zu acht, dunkelbraun bis schwarz, $16 \times 7-8 \mu$, länglich oval, einseitig etwas gedrückt, mit einer helleren Keimspalte.

Blumenan, Brasilien, auf verkohlten Holzresten.

Trachyxylaria nov. gen. wie Xylaria aber mit zweizelligen Sporen.

63. Trachyxylaria phaeodidyma nov. spec. (Taf. VIII Fig. 114).

Schlanke, weichfleischige, aussen und innen schwarze, bis $7 \mathrm{~cm}$ holıe, $1 / 2$ cm dicke Keulen, mit lockerem Markcylinder, der bisweilen hohl ist, dicht besetzt von deu scheinbar freien, doch durch eine gemeinsame eng angeschmiegte Stromarinde umschlossenen Perithecien von 0,6 mm Höhe, 0,5 mm Breite. Perithecienwandung dunkel, deutlich al)gesetzt. Sporen zu acht, zweireihig oder unregelmässig gelagert, 8-11 $\times 3-4 \mu$, schwarzbraun, zweizellig.

Blumenau, Brasilien, auf morschem Holze.

64. Penzigia actinomorpha nov. spec. (Taf. VIII Fig. 110). Diagnose s. S. 257.

65. Hypoxylon magnum nov. spec. (Taf. VIII Fig. 111).

Stroma unregelmässig kuglig, nach der Ansatzstelle zusammengezogen, bis $7 \mathrm{~cm}$ Durchmesser, mit dünner röthlich schwarzer kohlig brïchiger, fein rissig gefelderter Rinde, und gelbem weichen, das ganze Innere erfüllenden Fleisch ans locker maschigem Plectenchym. Perithecien anf der oberen Seite des Fruchtkörpers eingesenkt, dunkelwandig, länglich oval, bis $1,7 \mathrm{~mm}$ lang. mit feiner Mündung. Sporen zu acht, einreihig, tieflraun $13-16 \times 6-7 \mu$.

Seeseite der Serra Cieral, Sa. Catharina, am Pombasfluss. $450 \mathrm{~m}$ Meereshöhe.

66. Hypoxylon symphyon nov. spec. (Taf. VIII Fig. 113).

Regelmässig runde, kreiselförmige, central gestielte Stromata bis $2 \mathrm{~cm}$ Durchmesser, mit flach gewölbter dunkelröthlicher Perithecien tragender Scheibe, und kastanienbrauner gezonter, dem Substrat zugewendeter steriler Oberseite, aus dunkelbramn bis schwarzem radial gebauten, von tiefsclıwarzen radialen Streifen durchzogenen, kohlig brüchigen P'rosoplectenchym. Perithecien länglich $1,3 \mathrm{~mm}$ lang, $0.3-0,4 \mathrm{~mm}$ breit, dicht gedrängt. Sporen zu acht. eimreihig, tiefbraun $10 \times$ $4,5 \mu$, oval. 
Benachbarte Fruchtkörper verwachsen oft zu melireren mit einander.

Blumenau, Brasilicn, an morschen Banmstämmen.

Henningsinia nov. gen.

Stromata mit einer urnenartigen Vertiefung, in welcher die lang eylindrischen Perithecien dicht gedrängt stehen. Ueber ihnen liegt eine nicht durchbohrte feste Deckelscheibe, nach deren Verwitternng erst die Sporen frei werden könnel. Sporen einzellig, dunkel.

67. Henningsinia durissima nov. spec. (Taf. VIII Fig. 116).

Stromata von regelmässig runder Kreiselform, bis $1.7 \mathrm{~cm}$ Durchmesser und 1,5 cm Höhe, mit einem umgekehrt kegelförmigen Fuss und einem kuchenartigen abgeflachten, in der Mitte etwas eingedıückten Aufsatz, durchweg schwarz, kohlig in der Mitte, nach anssen glasig; sehr hart, nicht schneidbar. Im oberen kuchenförmigen Theil eine kreisrunde $4 \mathrm{~mm}$ tiefe Höhlnng, in welcher die $3 \mathrm{~mm}$ langen, $1 / 3 \mathrm{~mm}$ breiten röhrenförmigen Perithecien dicht gedrängt stehen. Ueber der Hölılung die glasige feste schwarze Deckelscheibe, welche leicht abbricht und den Sporenraum frei macht. Schlänche länglich elliptisch $35 \times 12 \mu$ mit acht unregelmässig gelagerten ovalen dunkelbraunen, in grösserer Masse grïnlichschwarzen Sporen $12 \times 5 \mu$.

Seeseite der Serra Geral, an Pombasflnsse, Sa. Catharina, Brasilien, $150 \mathrm{~m}$ Meereshöhe. Gesellig auf morschem Holze.

\section{Discomyceten.}

Phycoascus nov, gen.

Hypothallus weit ausgebreitet, ans locker verflochtenen sehr dicken Fäden. Apothecien verstreut auf dem Hypothallus, der in das Hypothecinm olıne Grenze übergeht, unberandet, weich. Sporen hyalin einzellig. Pyronema verwandt?

68. Phycoascus tremellosus nov. spec.

Hypothallıs über mehrere $\mathrm{cm}$ weit ausgebreitet, ans locker verflochtenen $10 \mu$ starken, mit vakuolenreichem Protoplasma schaumig erfiillten Hyphen. Im Hypothecium dieselben Hyphen dicht verflochten, bis 15 " stark, kurzzellig. Apothecien weiss, weich, wachsartig, unberandet, bis $2 \mathrm{~cm}$ Durchmesser, nuregelmässig rundlich oder lappig faltig, im Alter convex, hohl über dem Hypothallns aufgewölbt. Schläuche $200 \times 10 \mu$, Sporen oval, hyalin, einzellig, einreihig $17 \times 8 \mu$. Sie schwellen zur Keimung auf das doppelte ihres Durchmessers, dann tritt 
das Endospor aus der geplatzten Spore mit $7 \boldsymbol{\mu}$ dickem Keimschlauch aus. Diekfädige Mycelien in Kulturen, wie im Hypothallus.

Blumenau, Brasilien, auf feuchten Rinden.

69. Peziza catlıarinensis nov. spec. (Taf. V Fig. 77).

S. die Diagnose anf S. 274.

Peltigeromyces nov. gen.

Apothecien knorpelig, dünn, mit grosser mannigfaltig gelappter ausgebreiteter Scheibe. Sporen hyalin einzellig.

70. Peltigeromyces microsporus nov. spec.

S. die Diagnose S. 276, 277.

71. Cordierites fasciculata nov. spec.

S. die Diagnose S. 278,279.

72. Cordierites umbilicarioides nov. spec.

S. die Diagnose S. 279. 


\section{Erklärung der Abbildungen.}

\section{Tafel 1.}

Fig. 1 bis 14. Choaneplrora americana nov. spec.

Fig. 1. Sporangium und Conidienträger an demselben Irycel; in kïnstlicher Kultur erzogen. Vergr. $1: 150$.

Fig. 2. Ans einer Conidie in diuftiger Nährlösung erwachsenes Mycel, welches ein Sporangium trägt; das Sporangium ist umgefallen und geplatzt. Vergr. $1: 150$.

Fig. 3. Conienträger der dürftigsten Form, einfach, kultivirt. Vergr. 1 : 100. algefallen, kultivirt. Vergr. $1: 100$.

Fig. 5. Conidienträger mit melıreren Capitellen, nach dem Abfall der Conidien, kultivirt. Vergr. 1:100.

Fig. 6. Conidienträger mit zahl leichen Capitellen, kurz vor dem Anssprossen der Conidien; kultivirt. Vergr. $1: 220$.

Fig. 7. Reifender Conidientrïger; kultivirt. Vergr. 1: 150.

Fig. 8. Reife Conidien; eine davon nach einstïndigem Liegen in Nährlösung. Begimn der Keimung. Vergr. $1: 6 \check{0}$.

Fig. 9. Sporangienspore mit den Haarbüscheln. Vergx. $1: 650$.

Fig. 10. Sporangienspore, vier Stunden nach der Aussaat. Vergr. 1: 320.

Fig. 11. Gekeimte Conidien. Vergr. $1: 320$.

Fig. 12. Bildung einer Chlamydospore. Vergr. $1: 350$.

Fig. 13. An einem ans einer Conidie gekeimten Farlen sind zwei Chlamydosporen gebildet. Vergr. $1: 350$.

Fig. 14. Anskeimmg einer Chlamydospore. Vergr. $1: 350$.

Fig. 15. Monoblepharis insignis Thaxter. Ein leeres Antheridium und ein Oogonium, in welches 4 Antherozoiden eingedrungen sint. Cop i e n a ch Thaxter. Botanical Gazette 1895, Plate XXIX. Fig: 6.

Fig. 16. Basidiobolus ranarum Eidam: Copulation. Die Figur zeigt die Schnabelfortsätze nicht wie sonst in gegenseitiger Berührus, sondern ansmahms- 
weise ein Stück weit von einander gerückt. Copie nach Eidam in Coln's Beiträgen zur Biologie, Banr IV. Tafel XI. Fig. 6. Tergr. $1: 500$.

Fig. 17. Conidiobolus utrieulosus Bref. Copulationsstadium, bei dem eine Endanschwellung schon als Spore hervortritt. Copie nach Brefelı, Heft VI. Tafel IV. Fig. 24. Vergr. 1 : 150.

Fig. 18. Syncephalis notosa van Tieghem. Copulirende Fädlen. Der äussere, welcher die Oospore trägt, hat ansserdem sterile Answiichse. Copie nacl Thaxter. Botanical Gazette, XXIT. Plate I. Fig. 20.

Fig. 19. Syncephalis comu. Copulation zweier ungleich grosser Zellen um Bildung der Oospore. Copie nach ran Tieglem. Ann, d. sc. nat., 6 Série, Bot. Tome 1, Pl. 3, Fig. 89 11. 90. Vergr. $1: 300$.

Fig. 20. Bildme der Zygospore von Piptocephalis Freseniana, von cler Seite gesehen, im optischen Durchschnitt. C'opie nach Brefeld. Band I. Tafel VI. Fig. 18. Vergr. $1: 630$.

Fig. 21. a-e) ('ouidienfrnchtliörper des Corallomyres Jatrophae nov. spec. von erkrankten Aipimwurzeln. Vergr. $1: 3$.

Fig. 22. a) Desgl. wie vor., mit höherer korallenartiger Stromaausbildung. Tergl. hierzu Tafel IX, Fig. 5; auf der dort photographiseh abgebildeten von dem Pilze befallenen Aipinwurel befindet sich das Original der hier besprochenen Figmr. Vergr. 1:4. b) Corallomyces Jatrophae, Stroma mit Conidienfucht und Perithecien, anf befallener Aipimwurel entwickelt. Vergr. 1:4.

Fig. 23. Corallomyces Jatrophae, Conidienfruchtkörper auf Aipimwurzehn unter der Erde gebildet. Nach einer Photographie gezeichnet ron Professor 1. Möbius, Frankfurt a/M. Vergr. $1: \mathbf{1 , 5}$.

Fig. 24. Ascusspore von Corallomyces Jatrophae aus einem saprophytisch im Walde gefumlenen Perithecium, mel Conilir ans einem parasitisch anf Aipinwurel gewarhs'nen Conidlienfruchtlö̈per. Beitle keimen, und die rntstehenden Mycelien fusioniren mit einander. Vergr. 1 :320.

Fig. 25. Conirlie ron Corallonyces Jatrophae gekeimt, Fusionen zwischen den Keimschlänchen. Vergr. 1: 500 .

Fig. 26. Ascus und einzelne Sporen von Corallomyces Jatroplae. Vergr. 1 : 270.

Fig. 27. Conielienbildnug von Corallomyces Jatrophae an Farlenenten in hïnstlicher Kultur. Verers. 1:320.

Fig. 28. Theilung der Conidion durch Querwände. Vergr. 1 : $: 320$.

Fig. 29. Ascussporen von Nectria rapitata Bres., gekeimt mul fusionirend. Veror. $1: 320$.

Fig. 30. Bildumg der comidien rom c'orallonyces . Tatrophar in them Lager der Conidienfurelatkirper. Tergr. 1:690.

\section{Tafel II.}

Fig. 31. Längssehnitt durch den entwickelten Conidienfonchthörper des Corallemyces Jatrophae; mit eine Perithecienanlage. Vergr. 1:36.

Fig. 32. Lüngssednitt durb einen jungen in Nïhrlïsung gezogenen Conidienfruchtkörper dessedben Pilzes. Terer. $1: 36$. 
Fig. 3:3. Längsschnitt durch einen jungen, doch sporenreifen, auf dem Objehtträger kïnstlich gezogenen Basidienfruchtkörper ron Schizophylhum commune nebst zwei stärker rergrösserten Basillien. Vergr. 1: う0.

Fig. 34. a) bis g) Melanospora erythraea nov. spec. a) Viersporiger Ascus. Vergr, $1: 220$, b) Achtsporiger Ascus. Vergr. 1: 220. (c) Mycelzweig aus künstlicher Konltur kurz ror dem Zerfall der Oirlien. Tergr. 1: 500. d) Descleichen, der Zerfall der Oidien lrat begomen. Vergr. 1: 506. e) f) Anlage der Perithecien in künstlicher Kultur. Veror. 1:500. g) Anskeimmug der Oidien. Tergr. 1; う00.

Fị. 3ó. Xectria Euterpes nor. sper. Ascus, keimende Schlauchspore, Conidienbildung in kïnstlicher Kultur, reife Conidie. Tergr, 1:500.

Fig. 36. a) bis d) Sphaerostilbe longiasens nor. spec. a Habitus; anf norseher

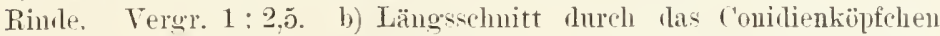
mit sterilen Hüllfäden, zwischen denen die Conidien gebildet werden. Vergr. 1:220. c) Langgestielter Ascus. Vergr. 1:220. d) Einzehne Conirlie. Teror, $1: 220$.

Fig. 37. a) Hypocrea poronioidea nor. spec. Längsschnitt durch einen reifen und einen jungen Fruchtkörper. Tergr. $1: 2$. b) Hypocrea sphaeroirlea nov. spec. Längsschnitt durch einen reifen Fruchtkörper. Vergr. 1:2. c) Hypocrea pezizoidea nor. spec. Längsichnitt durch einen reifen Fruchtiörner. Verg. 1:2.

Fig. 38. a) bis f) Mycocitrus aurantium nov, gen. et nov, spec. at Theil der Oberfläche des Fruchthörpers mit Perithecien in Längsschmitt. Tergr. 1:33, b) Desgleichen, die Perithecien sind ron deu fortwachsenden Frnchthörper ïberwachsen nur versenkt. Die Fruchtkörperoberfläche ist wierler steril. Vergr. $1: 33$. c) Desqleichen wie vor.. dloch ist eine nene sporenreife Peritheciensthicht anf der Oberfläche gebillet. Vergr. 1:33. 1) Iycel mit conidienabschüirenden Enden in künstlicher Kultur erzogen, Die Mycelfäden sint ron einer röthlichen Gallertscheide umbïllt. Vergr, 1:500. e) Sucessive Bildung der Conidien an den in Luft ragenden Farlenenden, und Verkleben der Conirlien zn Köpfchen. Vergr, 1:500. f) Ascussporen, anf trockener Glasplatte aufgefangen, zu acht zusammen liegend. Vergr. $1: 500$.

Fig. 39. a) bis e) Nectria capitata Bres. a) Conidienbildung an einem in kïnstlicher Kultur erwachsenen Irycelfaden, der sich durch kïrzere nach rorn verdickte Zellen und Aulage reicherer Verzweigmu zur Erzengung eines Conidienlagers anschickt. Vergr. 1; 35̃o. b) Beginn der Conidienbildung an beliebigen Iycelfäden. Ver@r. $1: 350$, c) Theilung der abgefallenen Conidien durch Theilwände. Vergr. 1:35̃o. d) e) Gemmenartige Ansbildung einzehner Conidientheilzellen mol Zerfall rler Conirlie. Tergr. $1: 270$.

Fig. 40. a) bis i) Penicilliopsis brasiliensis nor. spec. a) mal b) Conidienab. schnürtung in unbestimmer Form an Iycelfäden in kïnstlichen Kulturen. Vergr. 1: 500 , c) Eine Conirlie in diurfitiger Nährlösung gekeimt, bildet Conidien am Ende res kurzen Keimschlanches, Vergr. $1: 500$, d) Höchsteutwickelte Conidienträg(r mit zweierlei Conidien 
rom Fruchtkörper auf dem natïrlichen Standort. Vergr. 1:500. e) Wie bei 40 a) und b). Vergr. 1:500. f) Besonders lange Conidienreilıe, in kïnstlicher Kultn gebildet. Vergr. 1:220. g) Läugsschnitt durch die Ascusfrucht. Vergr. 1:2. h) Gezupfte Fäden ans dem Innern einer reifenden Ascusfrucht mit einem reifen Ascus. Vergr. 1:500. i) Ascussporen. Vergr. 1:900. k) Wie 40, a), b) nut e). Vergr. 1:500.

\section{Tafel 111.}

Alle Bilder in natürlicher Grösse und farbe.

Fig. 41, 42, 44. Ascopolyporus polychrous nor. gent. et nov. spec.

Fig. 43, 46. Ascopolyporns villosus nov. gene et nov. spec. 43: A. Giltsch fec. 46: R. Volk fec.

Fig. 45. Mycocitrus aurautium nov. gent. et nov. spec.

Fig. 47, 50. Mycomalns hambusinns nor. gen. et nov. spec. Beide Bilder stellen denselben Fruchtkörper dar. R. Volk fec.

Fì. 48, 49. Ascopolyporns Möllerianns (P. Hem.) nov. gen. R. Volk fec.

Fig. 51. Hypocrella Gärtneriana nov. spec. R. Volk fec.

Fig. 52, 53. Ascopolyporns polyporoides nov. gen. et nor. sper.

\section{Tafel IY.}

Fig. 5f. a) his f) Peloronectria vinosa nor. gent. et nov. spec. a) Längsschnitt durch die Perithecien und das Stroma. Vergr. 1:50. b) Ascus mit reifen sporen. Vergr. 1:500. (c) Keimung der Ascusspore. Vergr. 1:500. 1) Keimung der Conidie. Vergr, 1:500. e) Hefeartige Sprossung der Conidien. Vergr. $1: 500$. f) Bildnng der Conidien an Mycelfäden der kiüstlichen Kultur. Vergr. 1 : 220.

Fiø. 5̃. Megalonectria rerrucosa nov. spece. Längssehnitt durch die Spitze des conidienfruchtkörpers. Reife Aseuspore. Keimung der Ascussporen mit Sprossconidien, dic hefeartig weiter sprosscu. Tergr. $1: 500$.

Fig. 26. a) bis e) Oomyces monocarms nur. spec. a) Habitn.. Fruchthörper hiischelig rereint auf Bambuszweig. Vergr. 1:j. b) Quersehnitt durch das einfriichtige Stroma. Vergr. 1:50, e) Längsselmitt durch dasselbr. Verer. 1:7. d) Reifer Schlanch mit zwei Fadensporen. Vergr. $1: 900$. e) (S. bei Figur 58!) Spitze des mreifen Schlanches vor Anlage der sporen. Vergr. 1:900.

Fig. 57. a) bis h) Ascopolyporus polychrous nov. gen. et nov. spec. a) Querschnitt durch jumge Perithecicuanlagen und das Stroma. Vergr. 1:50. b) Desgreichen, reifende Perithecien. Vergr. 1:50. c) Schnitt durch einen jungen an Bambnsstengel ansitzenden Frnchthörper. Nat. Gr. i) Ausgeschleuderte Ascnssporen, auf einer trockuen Glasplatte anfgefangen. Vergr, 1:70. o) Theilstick einer ausgeworfenen Spore in Nährlösmg kurz vor der Keimung. Vergr. 1:500. f) Conidienrasen anf dem Hypothallus. Vergr. 1:200. g) Keimende Conidien. Tergr. $1: 560$. h) 'Theilstiick eint' in Nährlösung keimenden 
Ascusspore mit einem in die Luft ragenden Conirlienträger. Vergr. $1: 600$.

Fig. 58. a) Ascopolyporns rillosus nor. gen. et nov. spec. Längsschnitt durch einen Fruchtkörper. Nat. Gr. b) Der Haarfilz anf der sterilen Oberseite desselben Frnchtkürpers. Vergr. 1:12.

Fig. 59. a) his f) Ascopolyporns polyporoirles nov. gen. et nov. spec. a) Schnitt durch die entleerte Perithecienschicht eines iiberreifen Fruchtkörpers. Vergr. 1:7. b) bis e) Conidienbildnng in künstlicher Knltur. Vergr. 1:560. f) Auskeimung einer Conilie. Vergr. 1:560. «) Junge, eben abgefallene Conidien mit der gekriimmten Ansatzstelle. Vergr. 1: 1300 .

Fig. 60. a) bis h) Mycomalus bambusinus nov. gen. et nov. spec. a) Oberer Theil eines noch unreifen Schlanches mit fadenförmigen Sporenanlagen. Vergr. $1: 500$. b) Desgleichen eines reifen Schlauches mit mnzählharen Theilsporen. Vergr. 1:500. c) Ausgeschleuderte Theilsporen und Bildung der Qnerwände in ilmen. Vergr. $1: 500$. d) Gekeinte Conidie mit nener Conidienfruktifikation an allen Mycelenden. Vergr. 1:500. e) Gekeiute Conidie mit unmittelbarer Nenbildung rou Conidien. Vergr. 1:500. f) g) h) Keimmg der Ascussporen und Conidienbildung. Vergr. 1 : 500.

Fig. 61. a) bis e) Hypocrella reruculosa nov. spec. a) Der Pilz auf einem Bambusstengel. Nat. Gr. b) Querschnitt durch deu Frnchtküryer und neu tragenden Zweig. Vergr. $1: 3$. c) Unreifer Ascus mit Fadensporen. Vergr. $1: 500$. d) Die Theilsporen sehwellen an und tremen -ich ron einander schon im Ascus. Vergr. 1:500. e) Bruchstiick einer Spore vor dem Zerfall in Theilsporen. Vergr. $1: 850$.

Fig. 62. Hypocrella Gärtneriana nor. spec. Schnitt durch den Fruchtkörper. Wenig rerkleinert.

Fig. 63. a) lis d) Hypocrella cavemosa nov. spee. a) Der Fruchtkörper an einem Microstachyszweige. Nat. Gr. lo) Querschnitt durch einen Frnchtkörper mit einem Perithecinm links oben, und zalulreichen Höhlungen, deren Tände mit dem Conidienlager bekleidet sind. Vergr. $1: 2$. c) Theil des Conidienlagers. Die Conidien haben keine echten Scheidewände. Vergr. $1:$ j00. d) Die Theilsporen schwellen an und brechen schon im Schlauche von einander. Vergr. 1:500.

Fig. 64. a) bis f) Hypocrella ochracea Mass. a) Schnitt durch ein conidienerzengendes Stroma. Vergr. 1:7, b) Desgleichen durch ein Perithecien tragendes Stroma. Vergr. 1:7. e) Theil des Conidienlagers and einzelne Conidien. Vergr. 1:500. d) Einzelne Theilsporen ans dem Ascus. Vergr. 1:500. e) Ascus, welcher im oberen Theile noch zusammenhängende, im unteren vou einander getrennte und etwas angeschwollene Theilsporen enthält. Vergr, $1:$ j60. f) Bruchstiicke der Ascussporen mit noch zusammen hängenden Theilsporen. Vergr. 1:1200. @) Schnitt dureh das Stroma einer der vorigen verwandten Hypocrella mit Perithecien und Conidienlagern in Höhlungert. Vergr. 1: $\mathbf{7}$. 
Fig. (55. a) bis e) Ascopolyporus Mö̈llerianus (P. Henm.). a) Sclmitt dureh die Perithecien mud die Stromarinde. Vergr. 1:50. ly) Conidien. Vergr. 1:500. d) Conidienbildemtes Fadenende. Tergr. 1:500.

\section{Tafel Y.}

Fig. 66. a) b) Balansia ambiens nor. spec. a) Habitns. Xat. (ir. ly) Querschnitt durch den Grasstengel und den Pilzfruchtkörper. Vergr. 1: 20.

Fig: 67. a) b) Balansia redundans nor. spee. a) Habitns. Nat. Gr. b) Querschnitt durch den Grasstengel mul den Pilzfruchtkörper. Vergr. 1:15).

Fig. 68. a) b) Balansia regnlaris nor. spec. a) Ein Zweig des Bambushexenbesens (vergl. Tafel X Figur 2). Tat. (ir. b) Querschnitt durch den Grasstengel und den Pilzfruchtkörper. Veror. 1:15.

Fig. 69. a) bis e) Ophiorlotis rhaphidospora Rehm. a) Habitus. Nat. Gr. b) Querschitt durch das befallene zusammengerollte Blatt mit den (granschattirten) Stroma des Pilzes. Vergr. 1: 22. (c) Längsschnitt durch tine der beiden parallel angeorineten Perithecienreilıen. Vergr. 1:15. d) Oberes Enle eines reifen Ascus. Vergr. 1:850, e) Ein ganzer Ascons. Veror. 1:220.

Fig. 70. Ophiodotis Henningsiana nor. spec. Querschnitt dnrel eine befallene Blattscheide. Vergr. $1: 20$.

Fig. 71. Claviceps lutea nor. spec, links ein Sclerotimm anf dem PaspalumAehrchen; rechts aligefallenes nud auscekeintes Selerotium. Nat. Gr.

Fig. 72. a) b) c) Claviceps ranmenloides nor. spec. R. Volk fee. a) Ansgekeintes sclerotium. Nat Gr. h) Das perithecientrageme Kö̈pfehen. Vergr. 1:3. c) Dasselle in anderer Ansicht. Vergr. 1:2.

Fig. 73. a) his f) ('lariceps balansioides nor. spec. a) Fin Sclerotiun, welchemit fünf Fruchtträgern gekeimt hat. Nat. (ir. b) Ein sehr kleines Sclerotium mit nur einem Fruchtträger. Terer. $1: 2$. c) Längssehnitt dureh das perithecientragende Köpfchen. Vergr. 1:20. d) Ein reifer Ascus. Vergr. 1:70. (2) Brnehstiitek einer Ascusspore, welche keint, unl an den Keimfäden Conidien erzengt. Terær. 1:500. f) Keimende conidie. Vergr: 1:500.

Fig. 74. Balansia diadema nor. spee. Unten ein befallenes dehrchen des Panicum mit den Prithecienköpfehen des Pilzes. Nat. Gr. Darïher Längsschnitt durch das Köpfchen. Veror. 1 : 10. Rechts daneben: Bildung einer Conidie an einem Mrcelzweig; die Conidie keint um bildet eine Secunläreonilie, diese ilnerseits in gleicher Weise eine Tertiäreonidie. Vergr. 1: 500 (rgl. Taf. X Fig. 1).

Fig. 75. a.) b) Daldinia coneentrica (Bolt.) Ces. et de Yot. a) Conidienbildenter Mycelzweig. Vergr. 1 : 220. b) Desgleiehen. Veror. $1: 900$.

Fig: 76. Thamnomyces Chamissonis Elubg. Keimmy der Sporen. Vergr. 1 : 900. (Vergl. Tafel X Fignu :3.)

Fig. 77 und 78. Sporenkeinum zweier groser Peziza-Formen. Ver@r. 1 : 700. 


\section{Tafel VI.}

Fig. 79. Cordyceps Mölleri P. Heun. Habitus. Vergr. 1:1,5. R. Volk fec.

Fig. 80. Eine perithecientragende henle des rorigen. Vergr. $1: 3$. R. Volk fee. Fig. 81. Cordyceps cristata nov. spec. Vergr. 1:2. R. Volk fee.

Fig. 82. Conidienbildung ron Cordreeps polyarthra nor. spec. Vergr. 1:50\%. Fig. 83. Corlyceps polyarthra uor. spec. Vergr. 1:1,4. R. Volk fee.

Fig. 84. Conidienbildung von Cordyceps Mölleri. Vergr. 1 : 500.

Fig. 85. Cordyceps corallonyces nov. spec. Vergr. 1:2.

Fig. 86. Längxchnitt durch ein perithecientragendes Köpfehen des rorigen. Vergr. $1: 10$.

Fig. 87. Cordyceps rliyuchoticola nor. spec. Vergr. 1:3. R. Volk fec.

Fig. 88. Cordyceps muscicola nor. spec. Vergr. 1:2. R. Volk fec.

Fig. 89. Cordyceps gonylepticida nov. spec. Vergr. 1:2. R. Volk fec.

Fig. 90. Perithecientragendes Köpfchen von Cordyceps thyrsoides nor. spec. Vergr. 1:8. R. Volk fee.

Fig. 91. Cordyceps thyrsoides nov. spec. Vergr. $1: 2$. R. Volk fec.

Fig. 92. Perithecientragendes Köpfchen ron Cordyceps australis Speg. Tergr. $1:$ j. R. Volk fee.

Fig. 93. Cordyceps australis speg. Nat. Gr. R. Volk fec.

Fig. 94. Cordyceps incarnata nor. spec. Nat. Gr. R. Volk fec.

\section{Tafel VII.}

Fig. 95 und 96. Cordycess submilitaris P. Hem. Nat. Gr. R. Volk fec.

Fig. 97. a bis d) Cordyceps flavo-riridis nor. spec. a) Habitus. Nat. Gr. R. Volk fec. b) Anordnung der Perithecien auf den Hyphensträngen. Vergr. 1:10. c) Couidientragende Luftfäden des Iycels. Vergr. $1: 500$. d) Bruchstück der Ascusspore keimend, mit Conidien. Vergr. $1: 500$.

Fig. 98. Conidienlager auf den Stromafortsätzen rou Cord. Volkiana nor. spec. Veror. $1: 500$.

Fig. 99. a) Eripus hetrogaster Latr. Nat. (ir. R. Volk fec. b) c) Cordyceps Volkiana nor. spec. Nat. Gr. R. Volk fec.

Fig. 100. Cordyceps hormospora nov. spec. Vergr. $1: 1,2$. R. Volk fec. Daneben ein Theilstiick einer Ascusspore. Vergr' 1 : 900.

Fig. 101. a) bis e) (orlyceps entonorrhiza (Dicks.) Fries. a) Theilstiock der Ascusspore. Vergr. 1: 1200. b) c) Habitus. Nat. Gr.

Fir. 102. a) Conidienbildung an der keimenden Ascusspore ron Cordyceps rubra nov. spec. Vergr' $1: 500$. b) Desgleichen an Luftfäden des Mrcels. Veror. $1: 500$.

Fig. 103. Cordyceps rubra nor. spec. Nat. Gr. R. Volk fec.

Fig. 104. Cordyceps rhizomorpha nov. spec. Nat. Gr.

Fig. 105. Cordyceps ainictos nov. spec. Tat. Gr.

Fir. 106. a) bis c) Isaria. a) Conidienkettenbildung an einen Mycelzweig in künstlicher Kultur. Vergr. $1: 220$. b) Mycel aus einer noch keunt- 
lichen Conidie künstlich gezogen, mit Luftconidien fructificirend. Tergr. 1:220. c) Ein Stielchen aus dem anf Tafel XI Figm 2 abgebildeten Isariawalde anf einer haarigen Raupe. Nat. Gr.

\section{Tafel VIII.}

Fig, 107. a) bis c) Eine nach dem Typus von Sphaerostilbe gebildete Xylariee. a) Habitus. Nat. Gr. b) Stroma mit Perithecienanlagen mur Conidienfruchtkörper. Vergr. 1:15. c) Spitze zweier Conirlienfruchtkörper. Vergr. $1: 30$.

Fig. 108. Entonaema liquescens nor. gen. et nov. spec. (Tergl. Abbildumg auf Seite 248.) Schnitt dmeh die Wand des Fruchtkörpers mit den Perithecien. Tergr. $1: 8$.

Fig. 109. a) bis c) Entonaema mesenterica nor. gen. et nor. spec. a) Schnitt durch den hohlen Fruchtkörper. Nat. Gr. b) Aeussere Ansicht desselben Fruchtkörpers. Nat. Gr. c) Schnitt durch die Wand des Frnchtkörpers mit den Peritherien. Vergr. $1: 8$.

Fig. 110. Penzigia actinomorpha nov. spec. Lüngssehnitt durch den Fruchtkörper. Nat. Gr.

Fig. 111. Hypoxylon magmum nov. spec. Längsschnitt durch den Fruchtkörper. Nat. Gir.

Fig. 112. Xylocrea piriformis nov. gell. et. nor. spec. Aeussere Allicht des Fruchtkörpers. Nat. Gr. Daneben Schnitt durch das Fleisch des Fruchtkörpers. Vergr. $1: 160$.

Fig. 113. Hypoxylon symphyon nov. spee. Oben ein einfacher, darunter ein aus mehreren rerwachsener znsammengesetzter Fruchtkörper von der Unterseite; darunter derselbe von oben gesehen. Nat. Gr.

Fig: 114. Trachyxylaria phaeodidyma nor. gen. et nor. spec. Links Habitus. Nat. (ir. Rechts cin Aseus. Tergr. 1: 850. Darüber Theil eines Quersehnitts durch die Keule mit Perithecieu. Tergr. 1: 15.

Fig. 115. Poronia fornicata now. spec, '/wei Fruchtkörper in Lüngsschnitt. Vergr: 1:2.

Fig. 116. Henninesinia durissima nov. gen. et nor. spec. Links Ansicht eines Fruchtkörpers. Nat. Gr. Danehen Längsschnitt desselben. Nat. Gr. Darüber ein Ascus. Vergr. $1: 850$.

\section{Tafel IX.}

Fig. 1 und 2. Peniciliopsis brasiliensis nor. spee. Fig. 1. Conidienträger auf einer Frncht von Strychnos triplinervia. Fig. 2. Conidientrïger und Ascusfriichte auf einem Samen von Mucuna sp. Nat. Gr.

Fig. 3. Hypoynces Bresadolianus nor. spec. Etwa nat. Gr.

Fig. 4. Peloronectria rinosa nov. genl. ef nor. spec. Nat. Gr.

Fig. 5. Corallomyces Jatrophae nov. spec. Conidienfrüchte auf einem Stück Aipimwurel. Wenig verkleinert.

\section{Tafel $\mathrm{X}$.}

Fig. 1. Balansia dialema nor. spec. Auf Paspalum spec. Nat. Gr. 
Fig. 2. Balansia regularis now. spec. auf Guadua Taguara Kth. Die Photographie ist nach einem für das Herbarium gepressten Exemplar gemacht. Etwa. $1 / 3$ nat. Gr:

Fig. 3. Thamnomyees Chamissonis Elrbg. 1/2 nat. Gr.

\section{Tafel X1.}

Hig. 1. Isaria anf einer Morpho-l’uppe. Ein wenig über nat. Gr.

Fig. 2. Isaria auf einer haarigen Raupe. Ein wenig unter nat. Gr.

Fig. 3. a) Isaria anf einer haarigen Raupe. Die aufstrebenden Conidienträger durchbohren ein welkes Blatt, einer kriecht an der Unterseite des Blattes bis zum Rande, um dort zu fructificiren. Etwa uat. Gr. b) c) Cordyceps Mölleri P. Henu. Etwa nat. Gr. Vergl. Taf. IT Fig. 79.

Fig. 4. Cordyceps Tolkiana nov. spee. aus Lamellicornierlarven. Etwa nat. Gr. Vergl. Taf. VII Fig. 99 b c. 
Lippert \& Co. (G. Pätz'sche Bucbdr.), Naumburg a. S. 



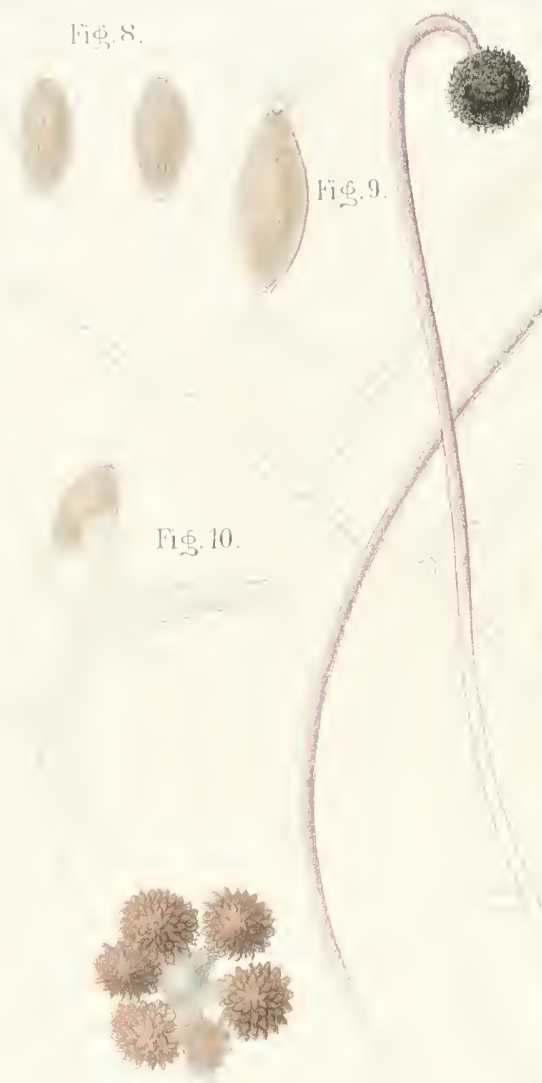

Fịg 11 .
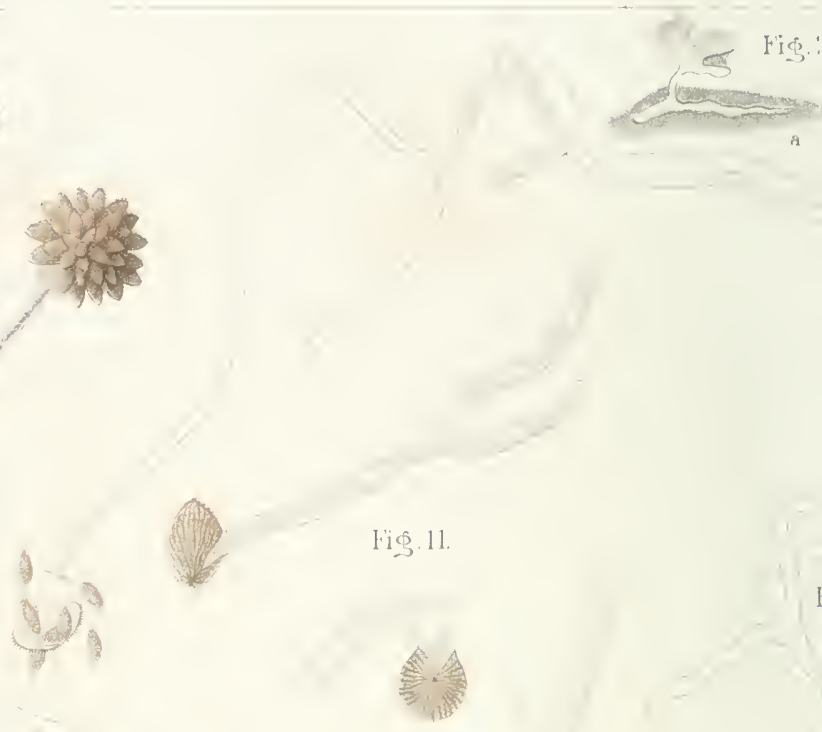

(n) 6 -

3 , Fis.

Fiф 12

liv $\$$

$$
\text { 3 }
$$

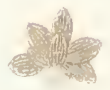

$\operatorname{ligs} 3$

Fì. 5.

Fis, 6

Fio 13

Fi $\underline{3}, 1$

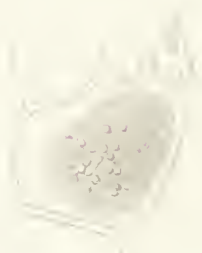

Fing 15.

$11 \%, 16$ 


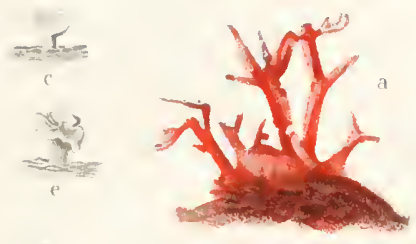

a

Fis. 24

Fis,:7.

Fis. 25

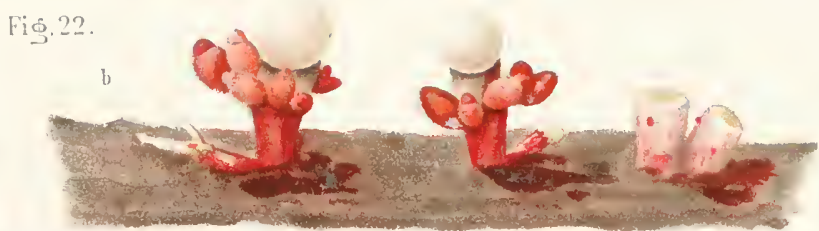

Fig. 23.

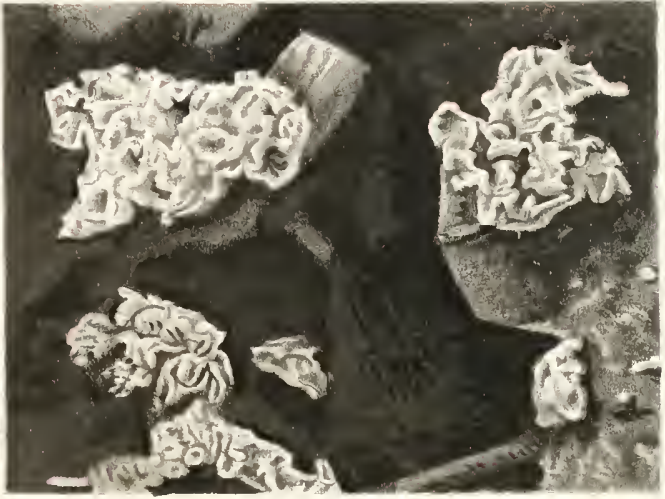

Fis 28

Fi\$ 30 .

Fìs 29

Fig 17

Fig.19.

Fig. 20.

Fig. 18 


Fis, 3 . 3is

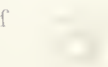

Fis 38 
Figु. 22.

510.39

d

Fig 40
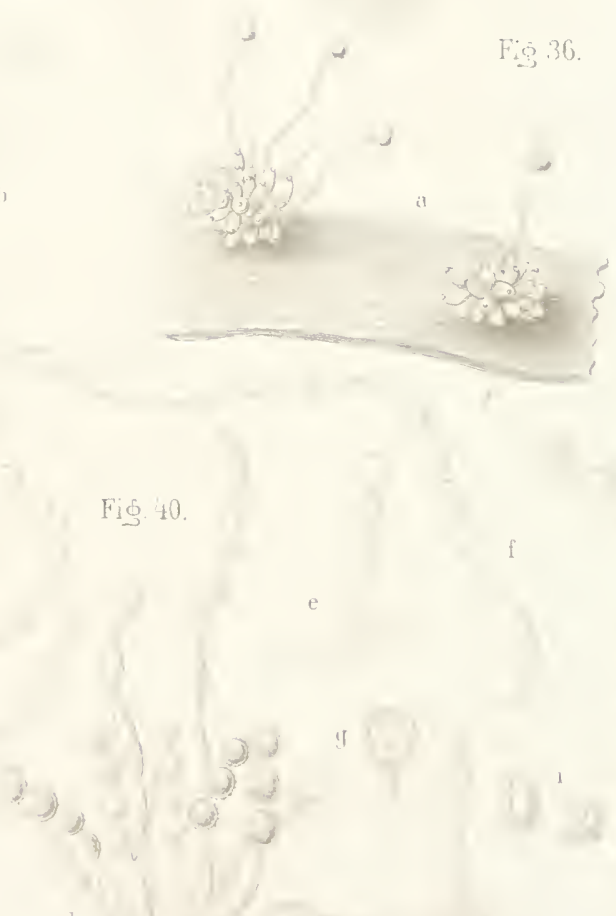




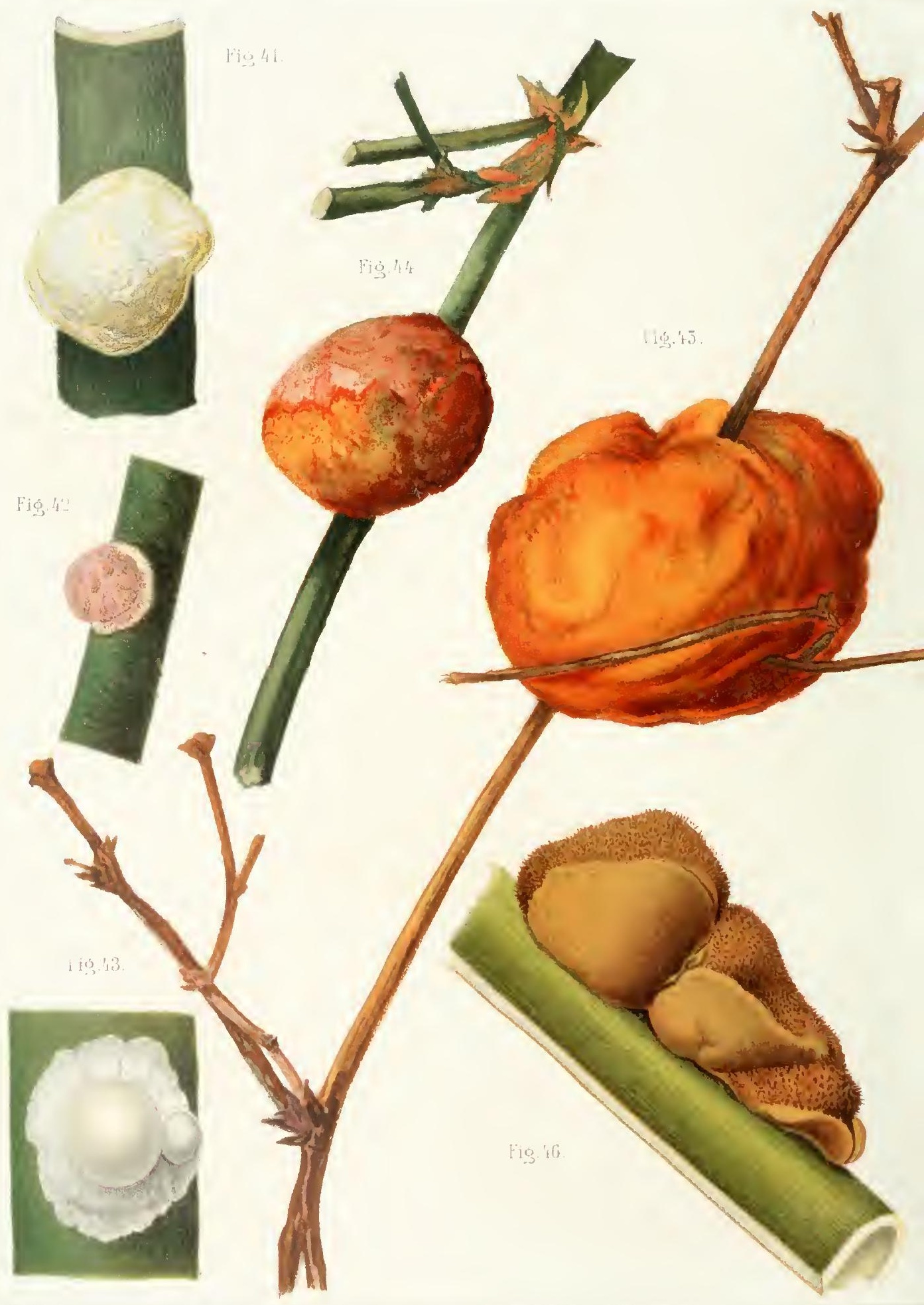




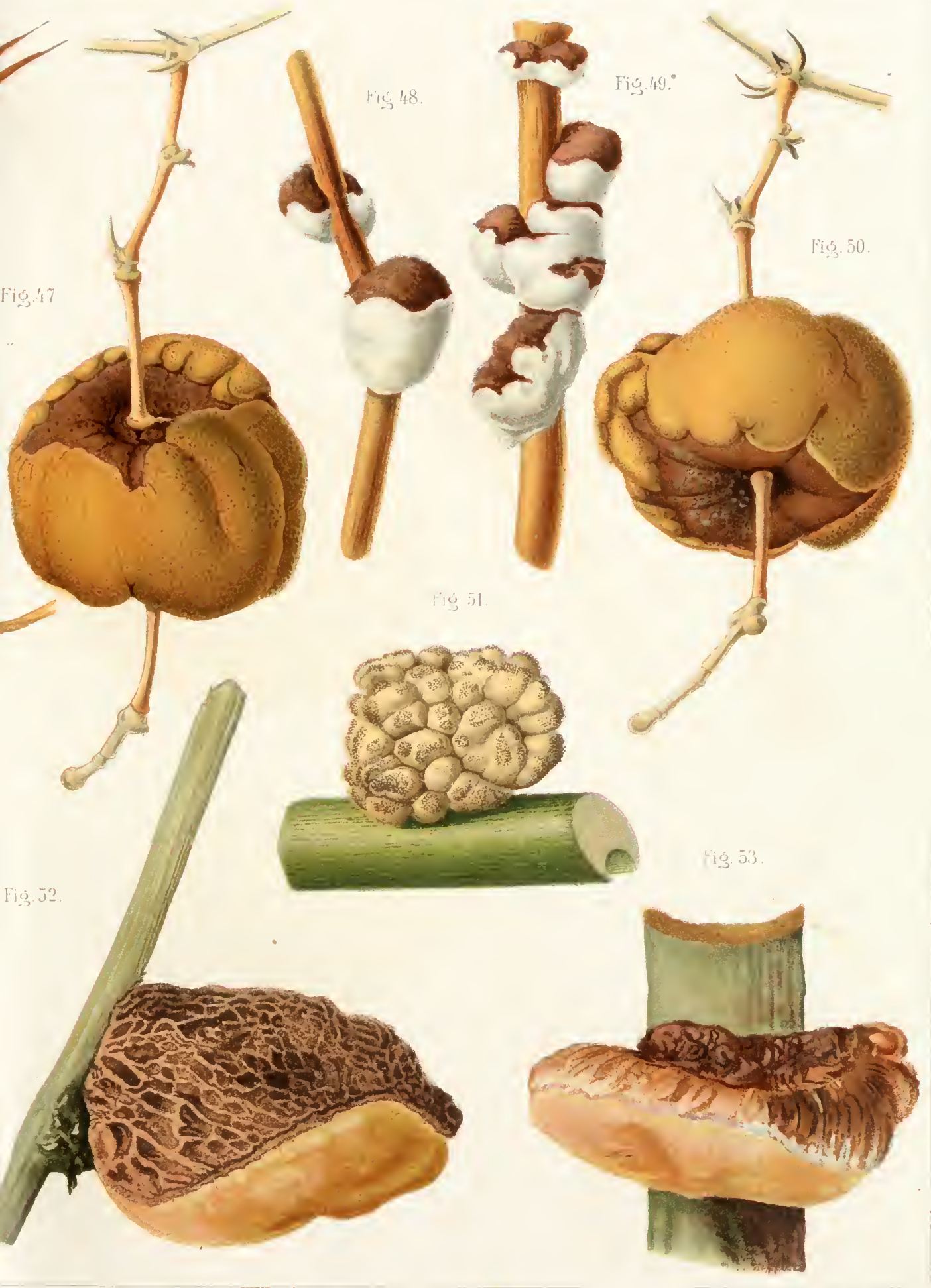






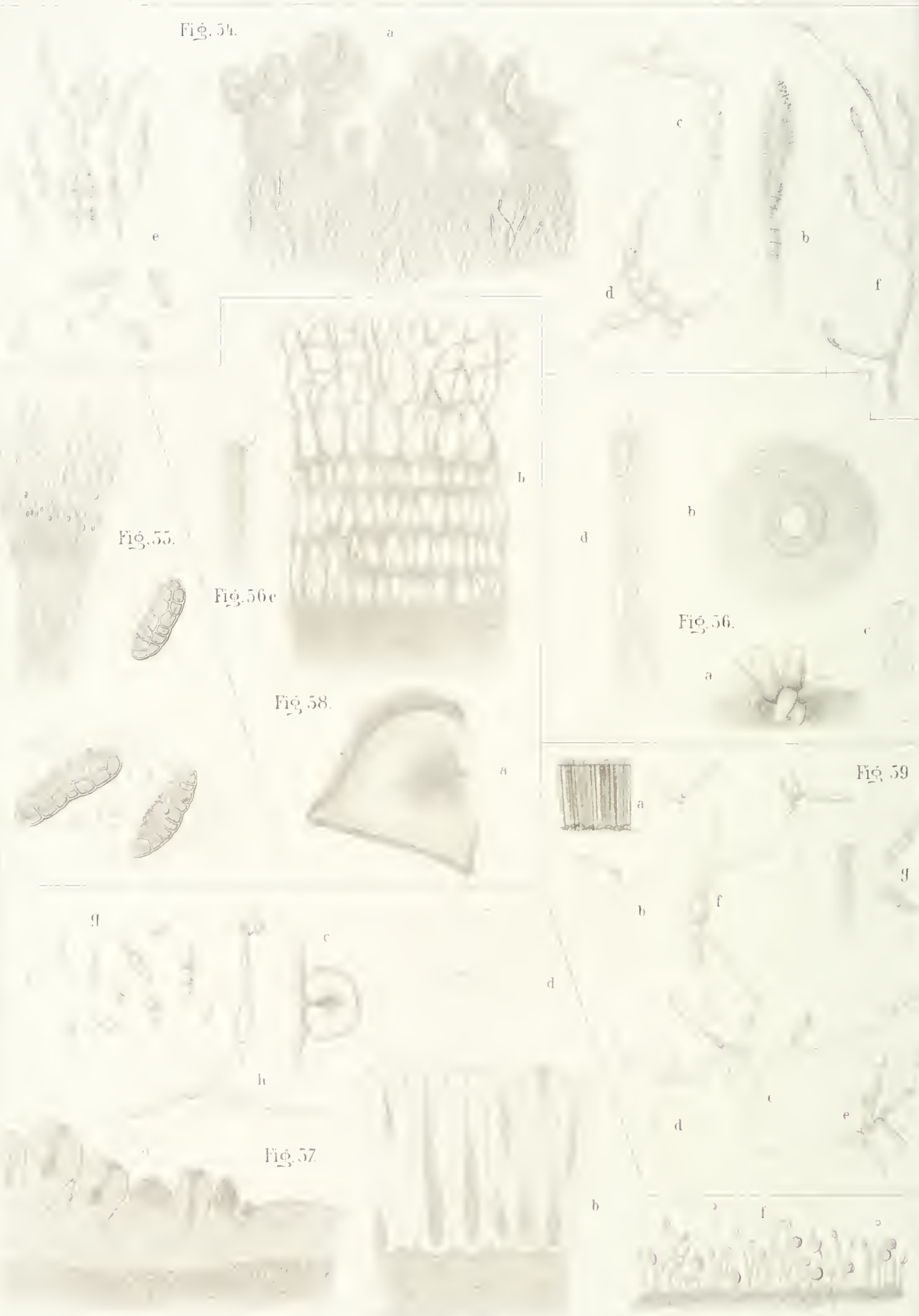


Tief. It

h

Fis 60

and

e

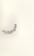

f

$$
\text { ! }
$$

Fiọ. 62.

c

$\int_{1}^{1}+1$

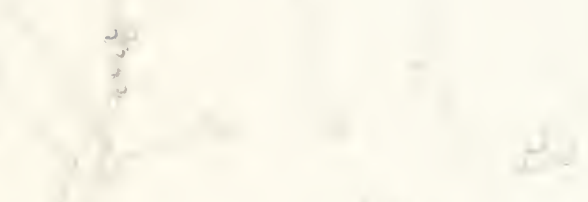

d h

$$
\text { Fis. } 61 .
$$

$$
\text { . }
$$

.

118.

c

b

g

Fịg 63.

Fig 6't.

i.

b

Fis 65.

b

d.

f

.

a

c

4
2
$=1$<smiles></smiles> 



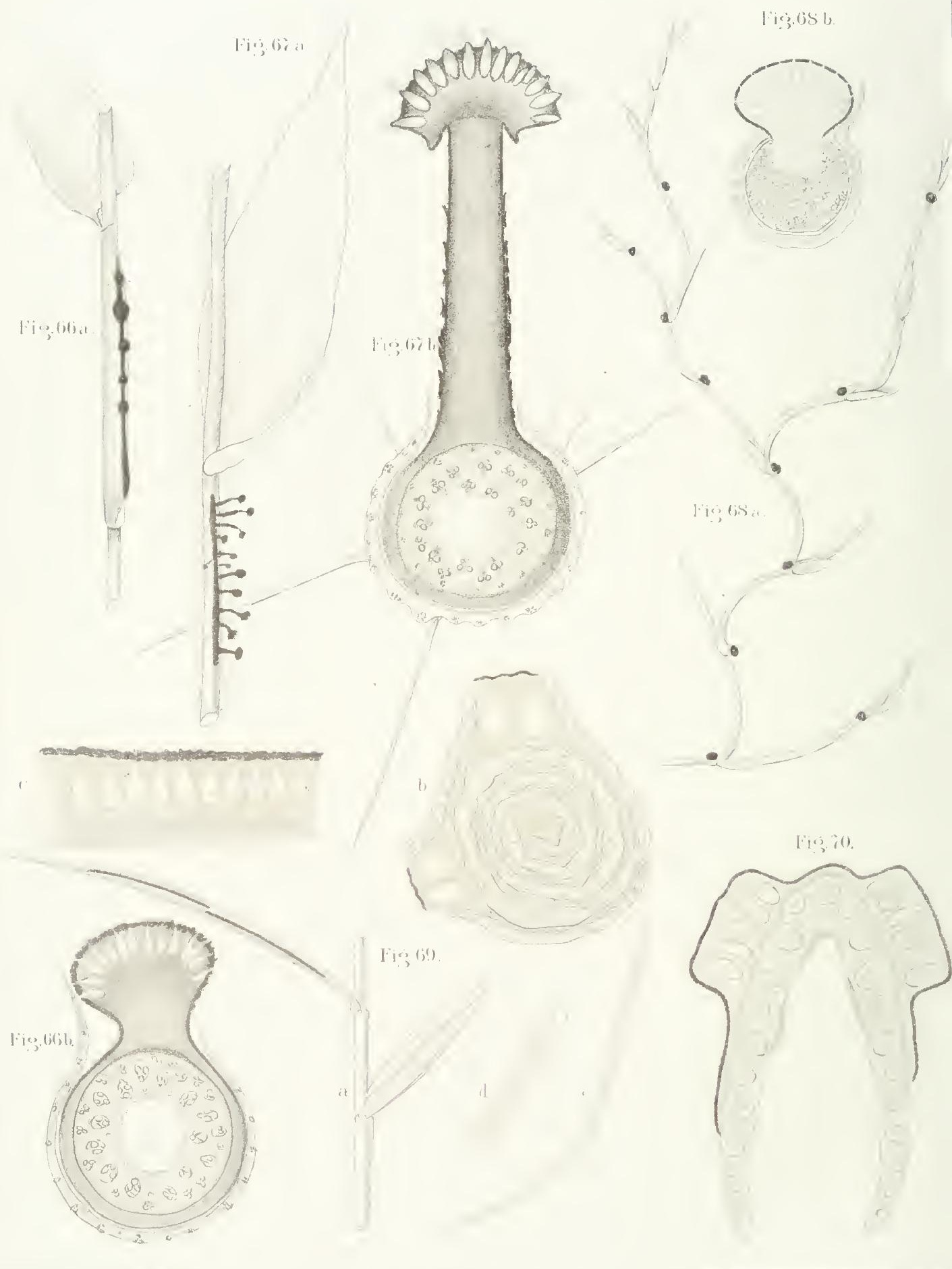


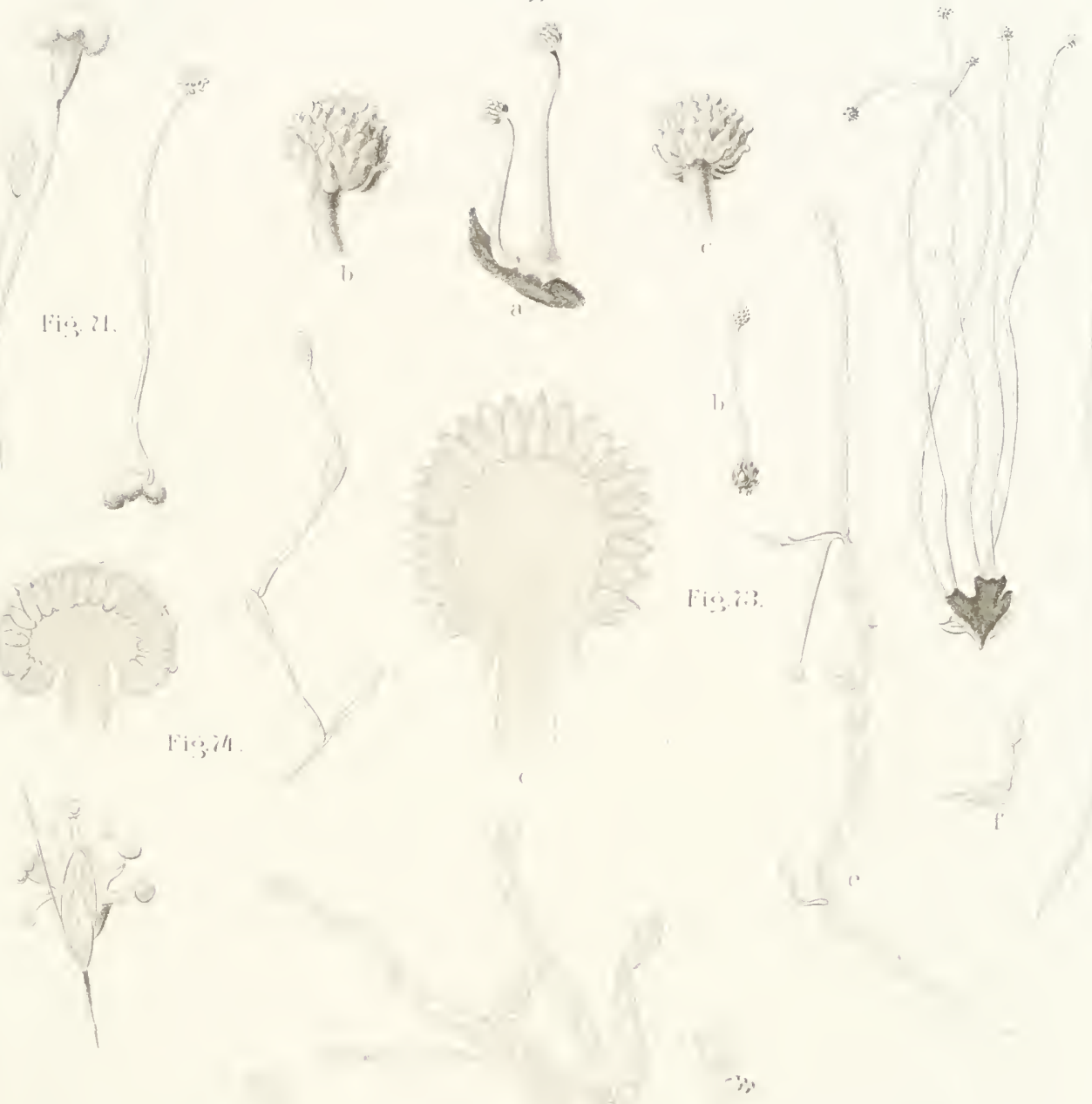

Fiv, is

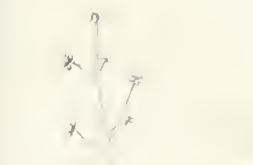

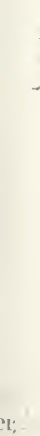

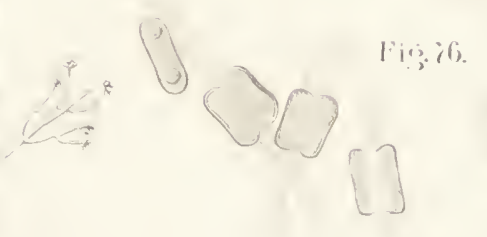




Fis, 80

$[i \because .7$

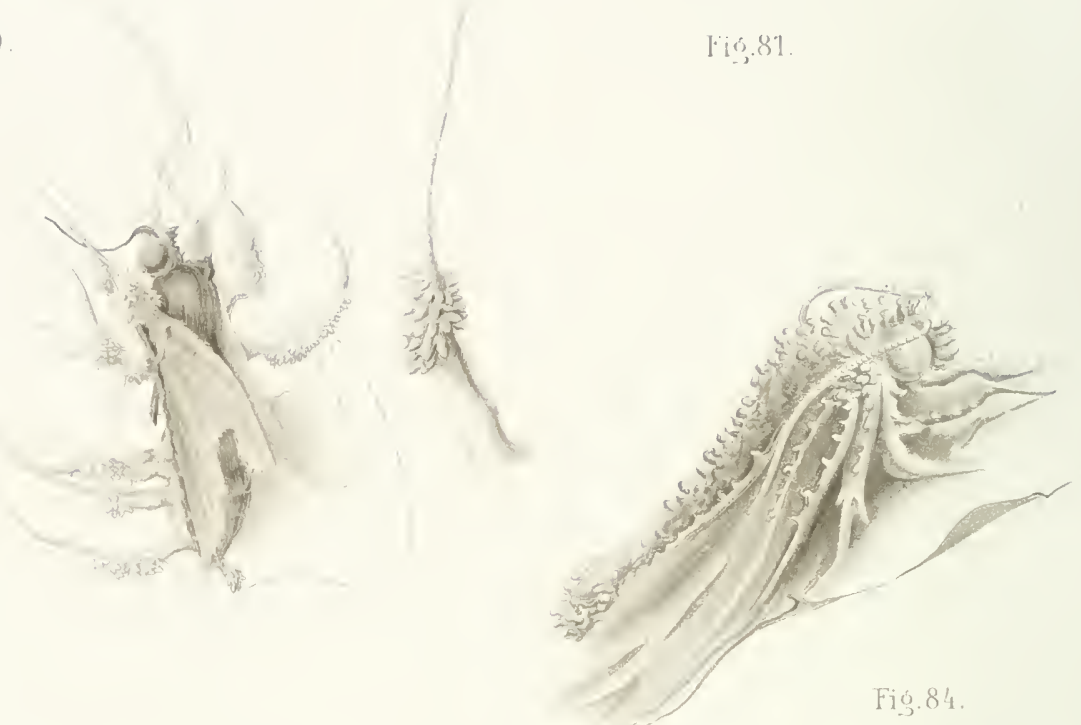

Fig. 84.
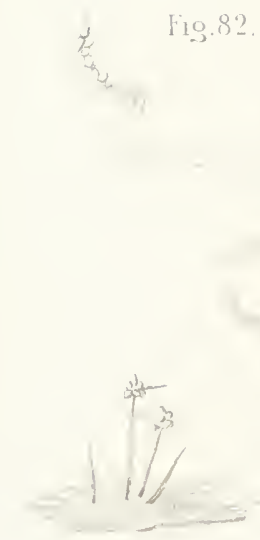

Iis, 8.5.
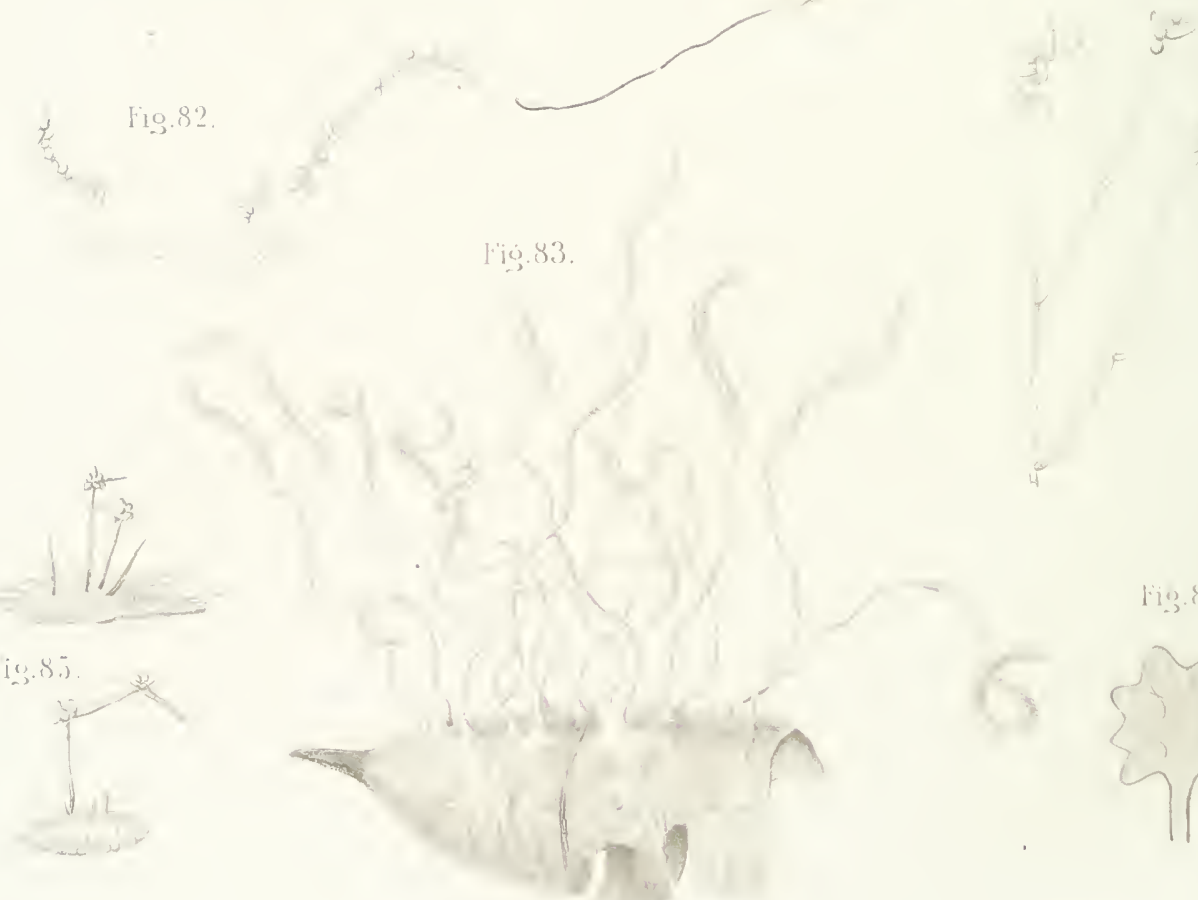

1"jo 83.

Fin 86.

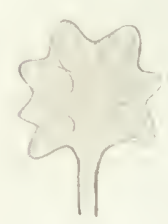




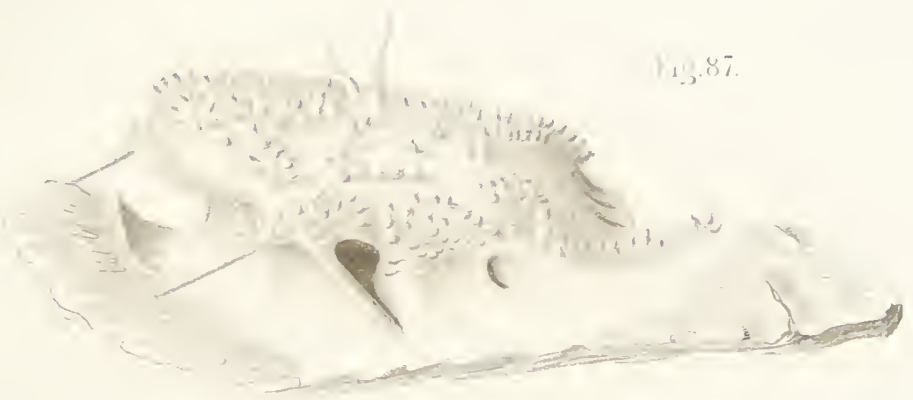

Fin. 88
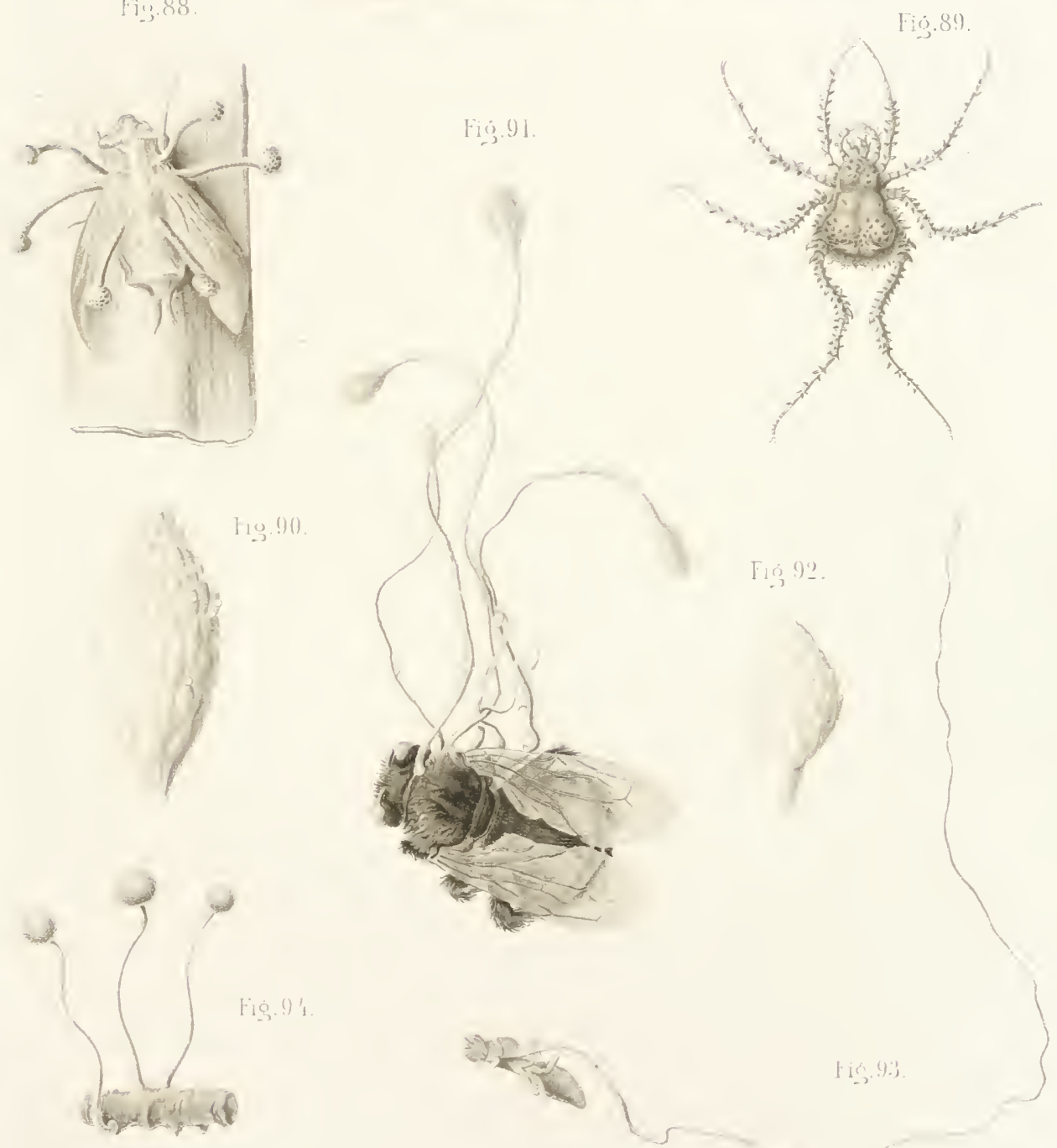




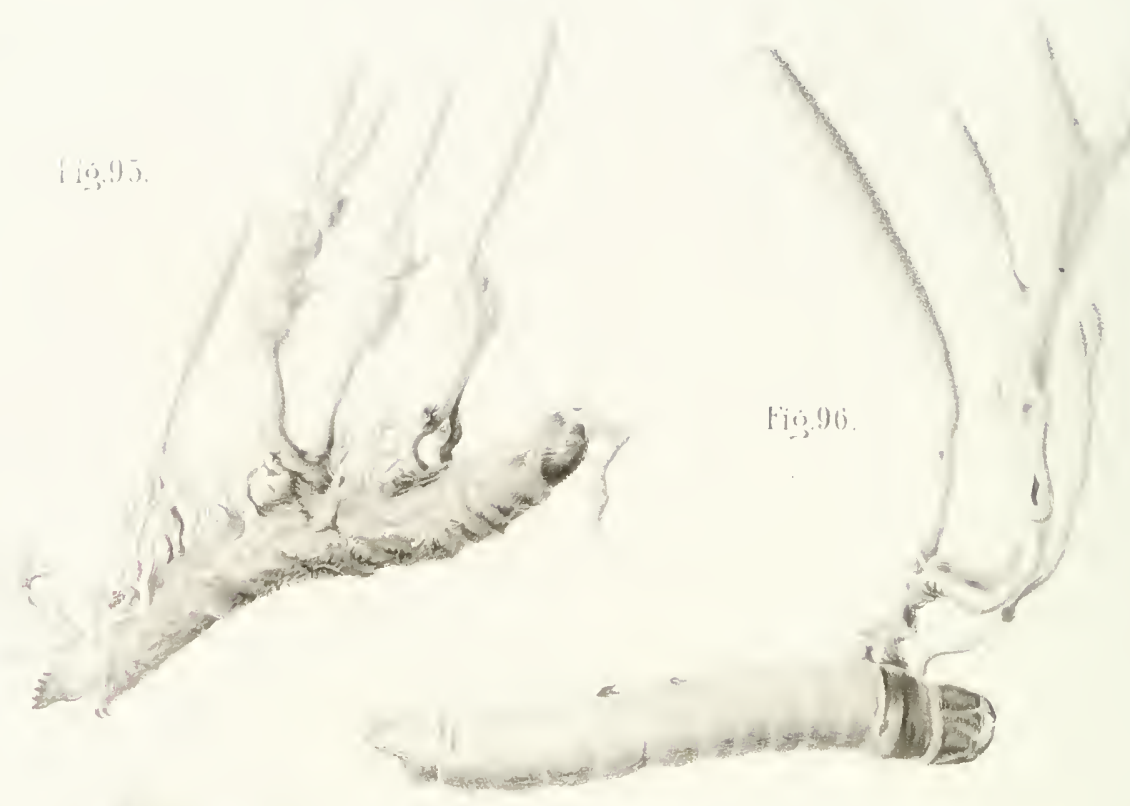

$\operatorname{lig} 9 \%$
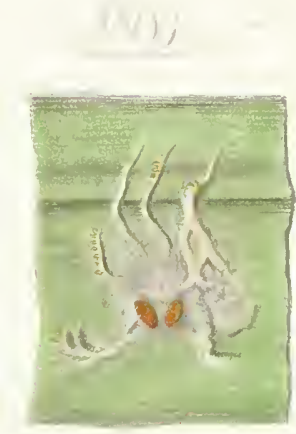

Fis. 98
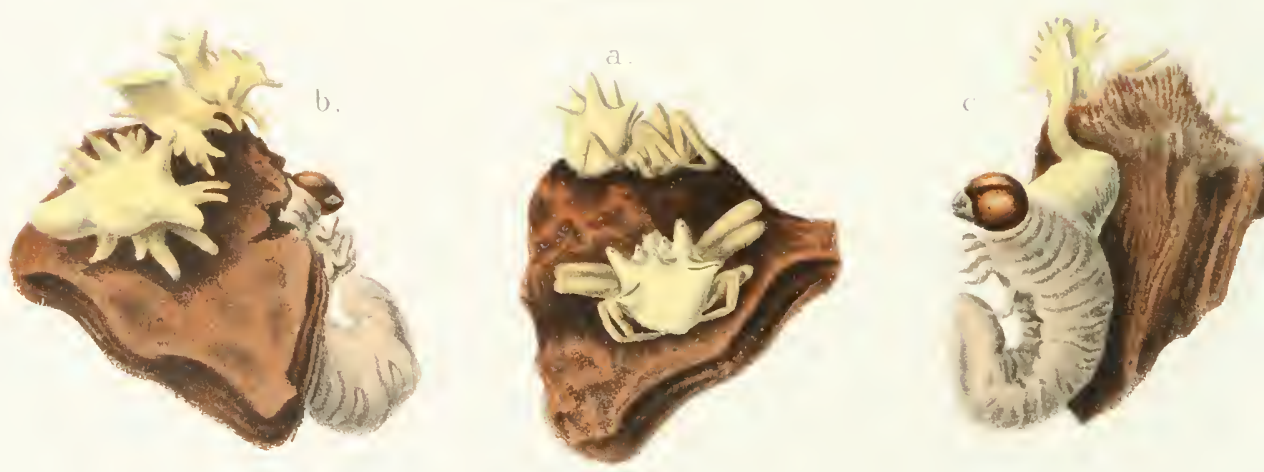

ए'icis!!!). 
Fio. 100 .

[10.101.

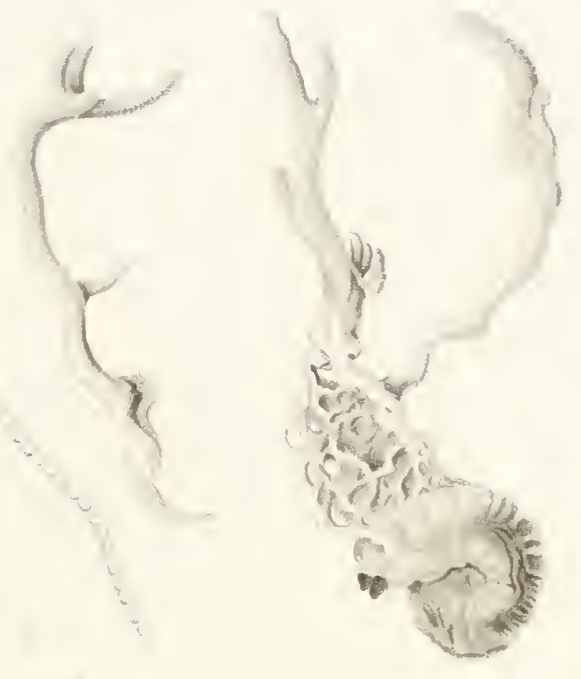

Fis. 10.3.

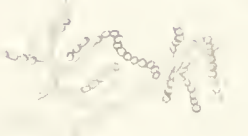

150.106

Fig. 10?. 3

a

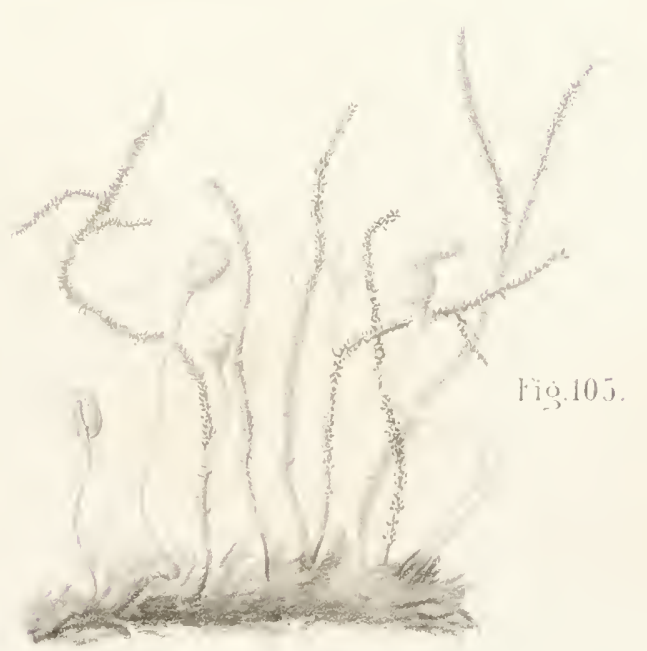

1 iog. 104. 


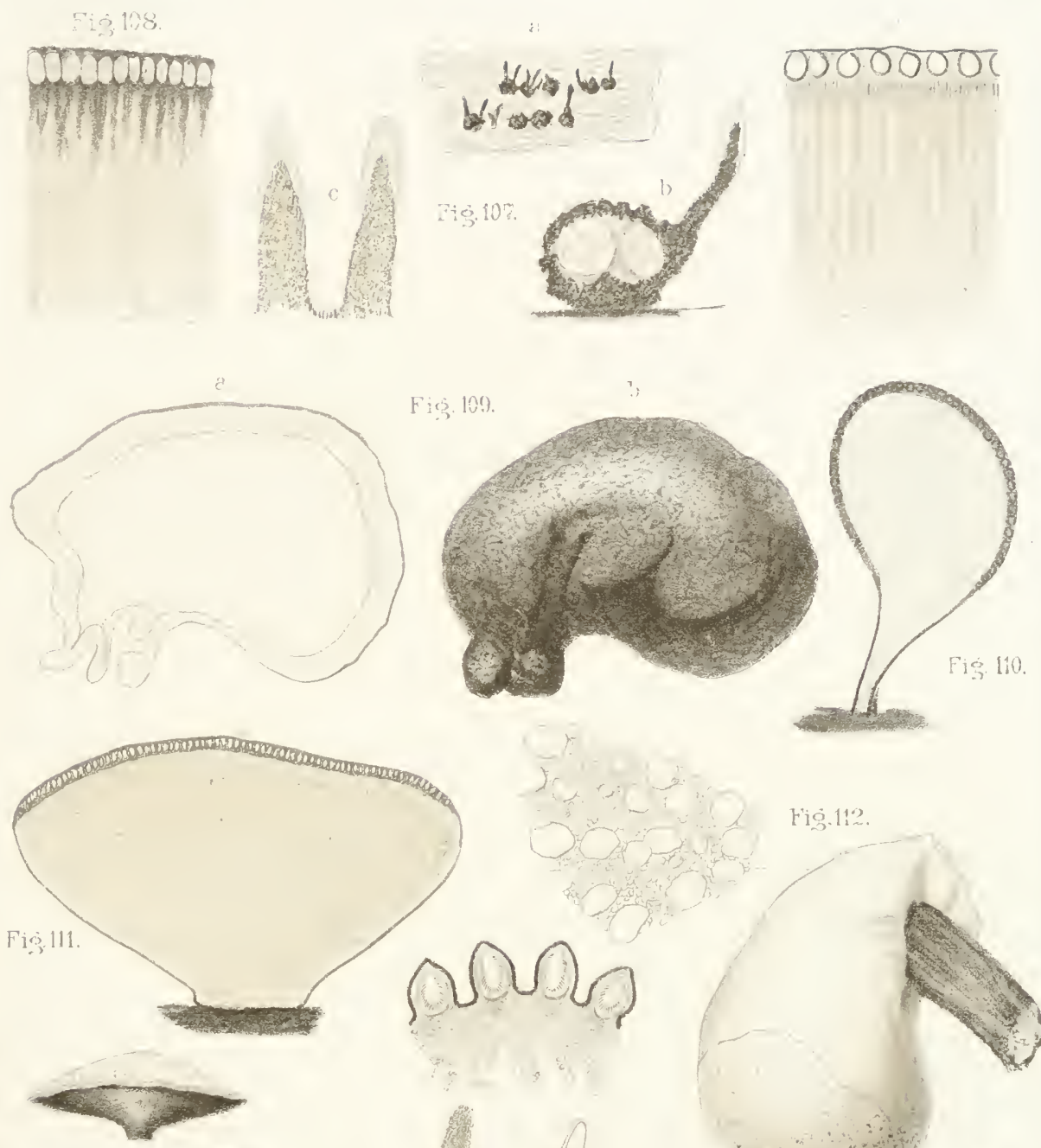

Fis. 113.

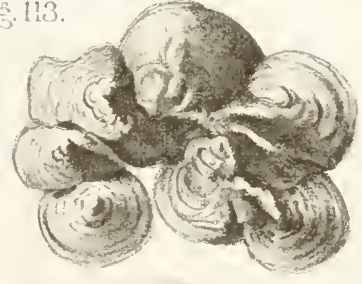

$$
\text { pors }
$$
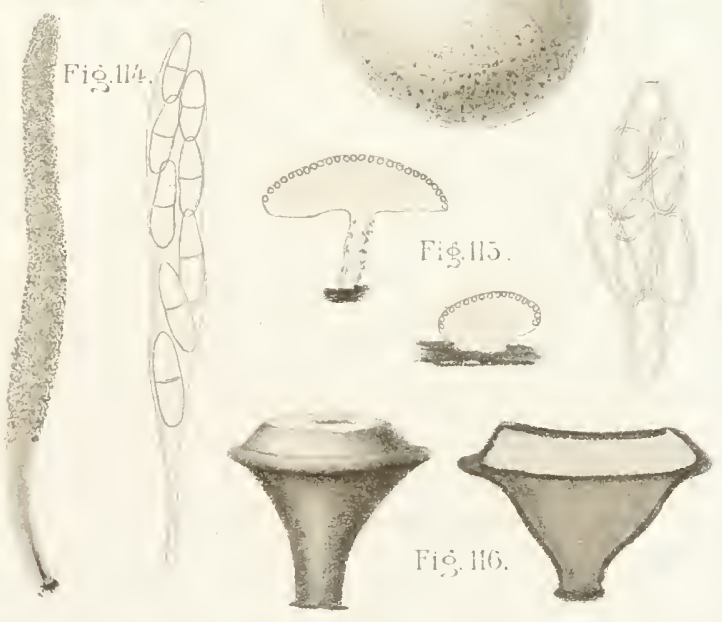



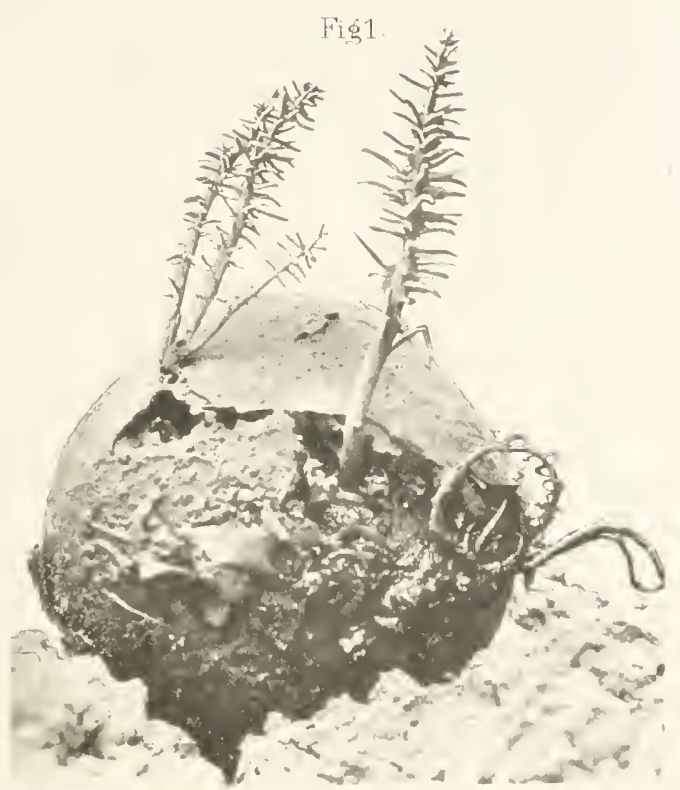

Fig 2

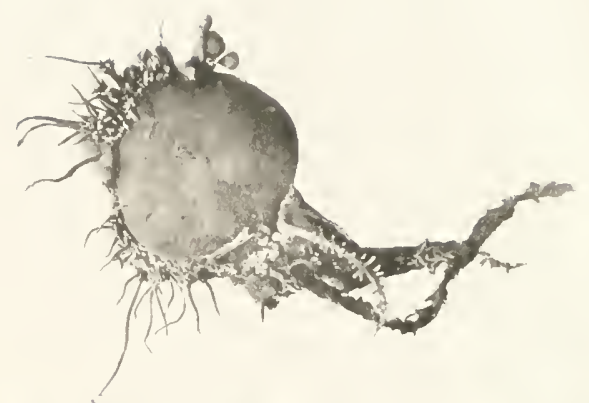

Figs 3

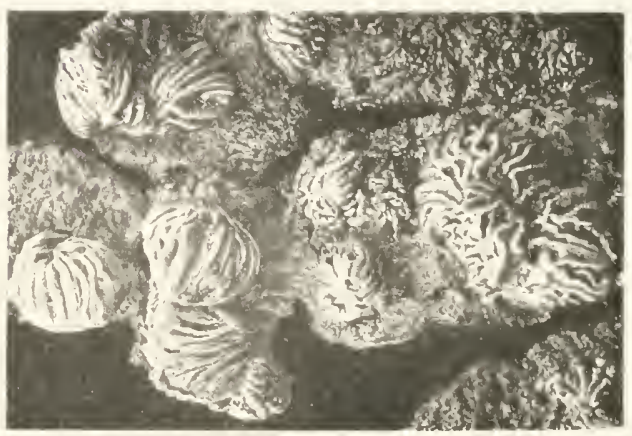

Fight.

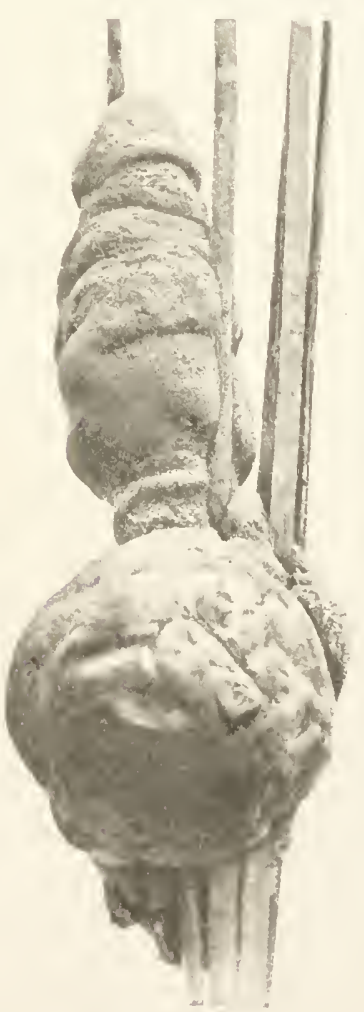

Fig 5

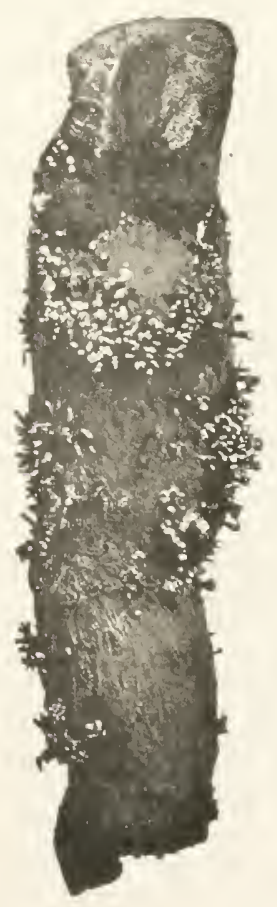

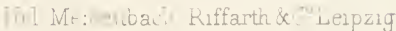

Iu 2 P'encilhopsis brasiliensis nou spec. 3 Hypomyces Bresadolumum now spec. 

Fig.1.

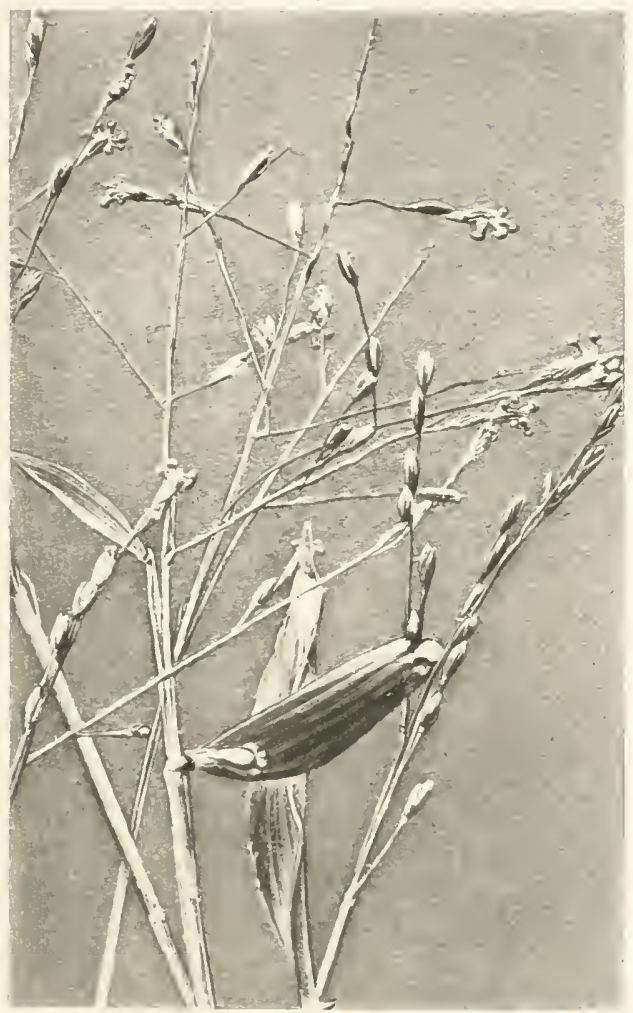

Fig.2.

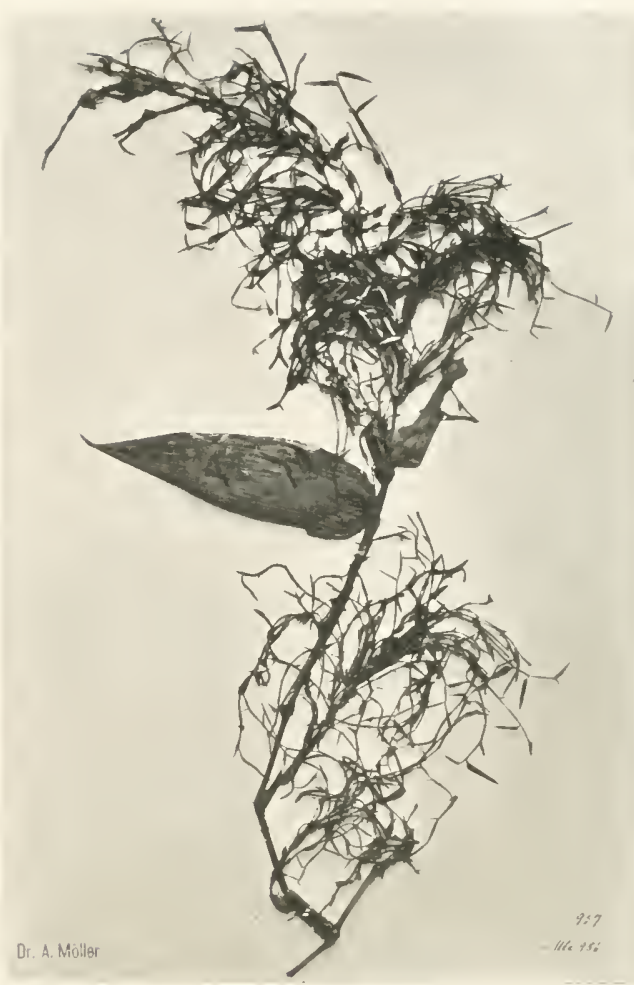

Fig. 3.

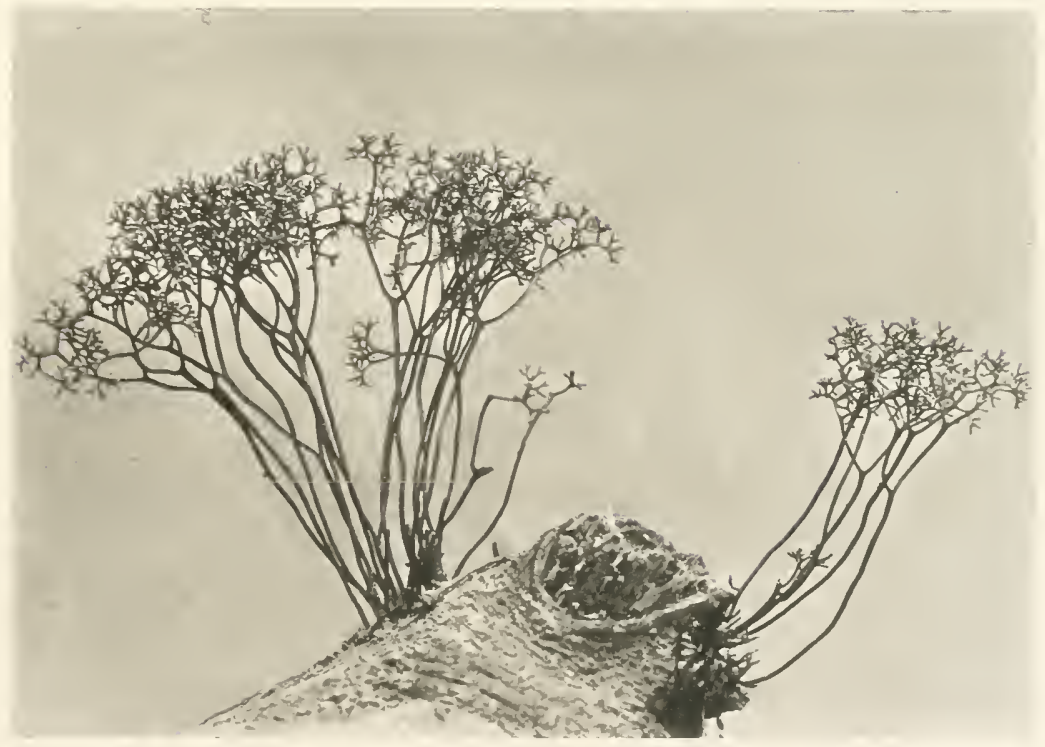




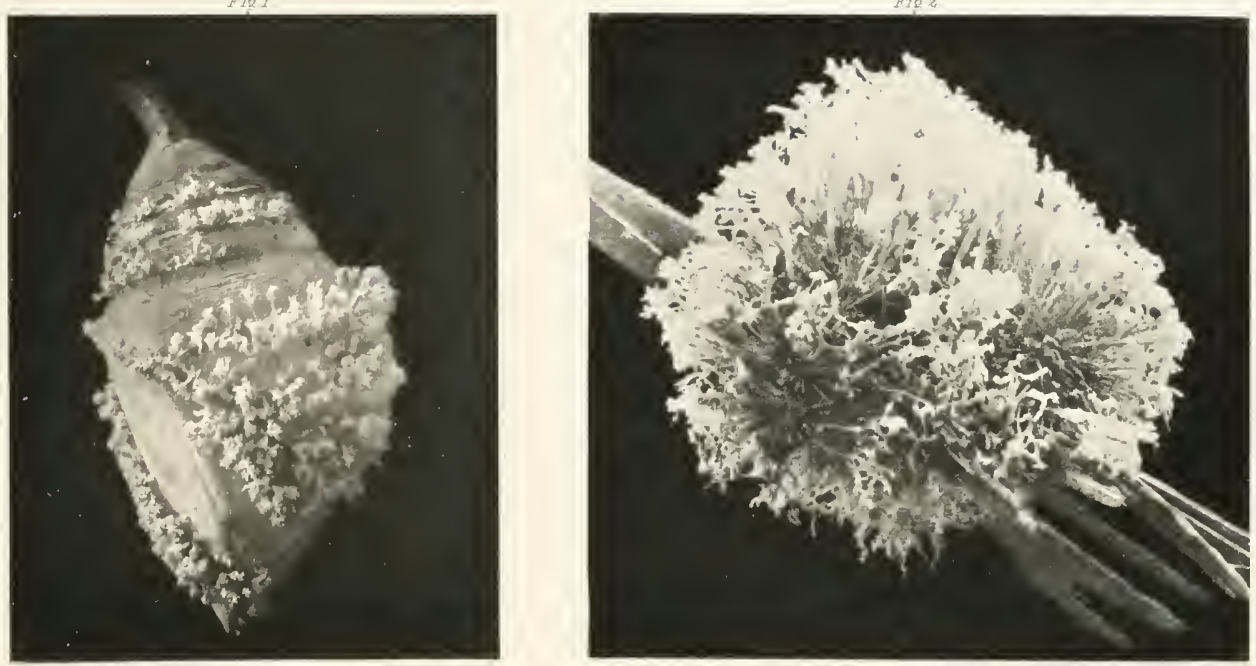

Fig.5a

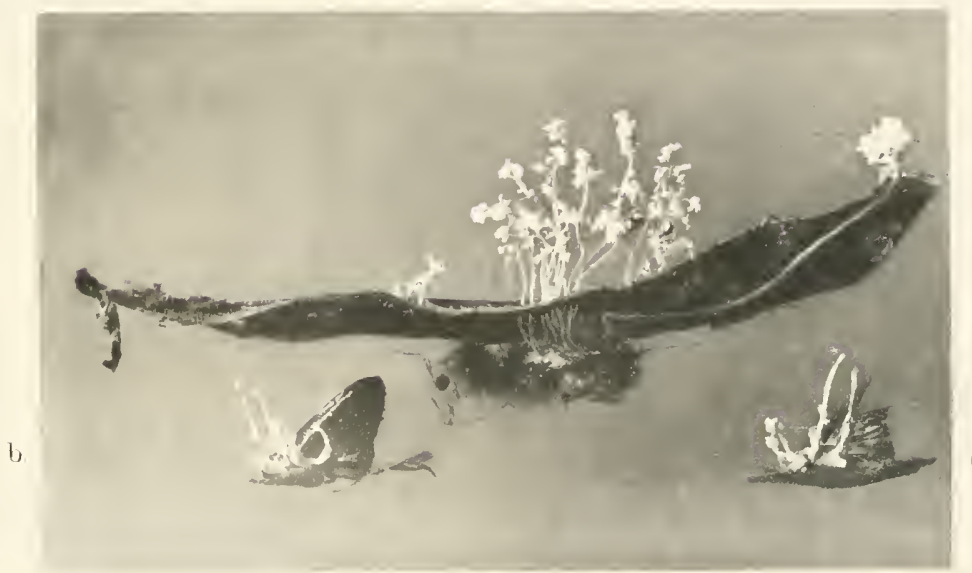

Fig.4

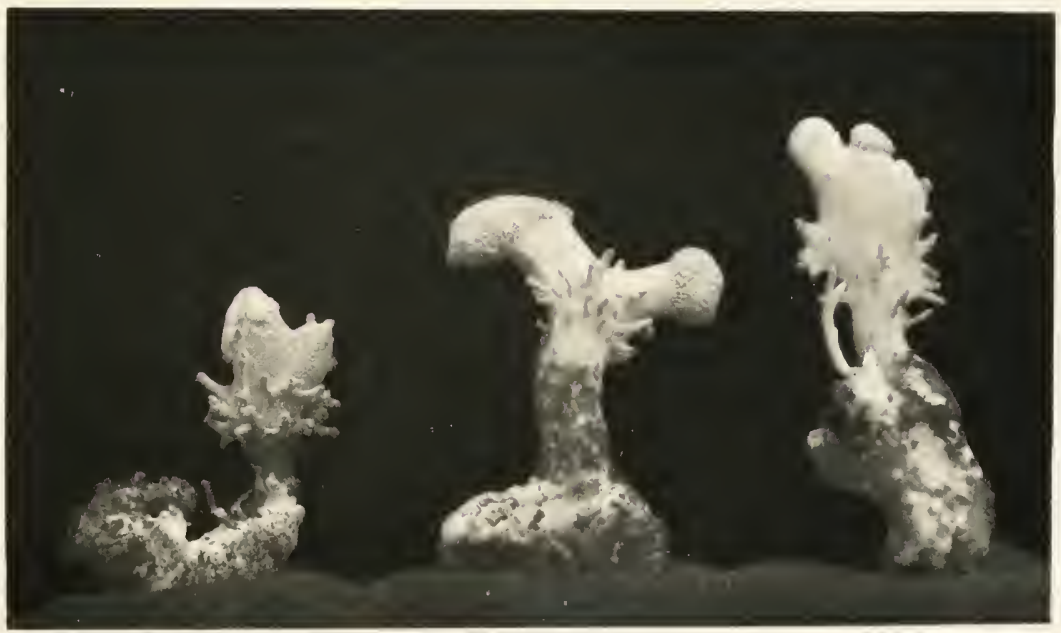

Hel. Moisenbach Riffarth \& Co Ioivo:

123 a Soura Formen 36 u. Cordyceps Molleri P.Henn 





New York Botanical Garden Library
OK606.4.b7 M66

Moller, Alfred/Phycomyceten und Ascomyce

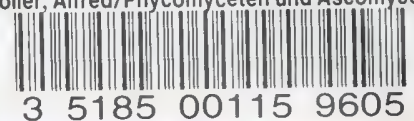


